\title{
EXPERIMENT DATA REPORT FOR SEMISCALE MOD-1 TEST S-06-1 (LOFT COUNTERPART TEST)
}

\author{
BRENT L. COLLINS MORRIS L. PATTON, JR. \\ KENNETH E. SACKETT
}

MASTER

July 1977

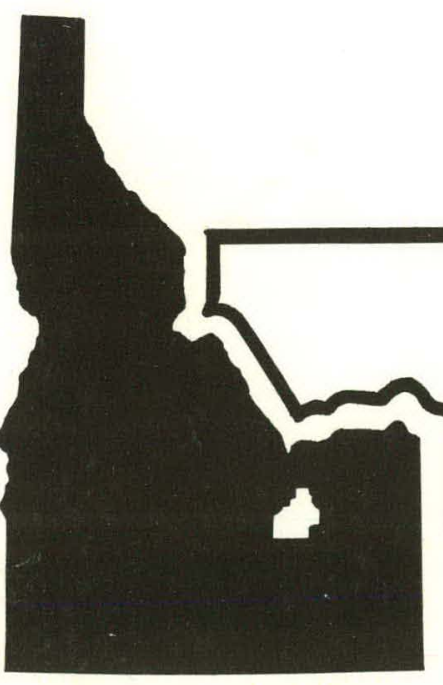

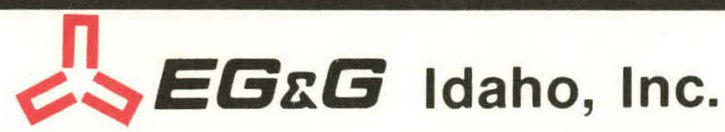

IDAHO NATIONAL ENGINEERING LABORATORY

ENERGY RESEARCH AND DEVELOPMENT ADMINISTRATION 


\section{DISCLAIMER}

This report was prepared as an account of work sponsored by an agency of the United States Government. Neither the United States Government nor any agency Thereof, nor any of their employees, makes any warranty, express or implied, or assumes any legal liability or responsibility for the accuracy, completeness, or usefulness of any information, apparatus, product, or process disclosed, or represents that its use would not infringe privately owned rights. Reference herein to any specific commercial product, process, or service by trade name, trademark, manufacturer, or otherwise does not necessarily constitute or imply its endorsement, recommendation, or favoring by the United States Government or any agency thereof. The views and opinions of authors expressed herein do not necessarily state or reflect those of the United States Government or any agency thereof. 


\section{DISCLAIMER}

Portions of this document may be illegible in electronic image products. Images are produced from the best available original document. 
Printed in the United States of America Available from

Natiunal Technical Information Service

U.S. Department of Commerce

5285 Port Royal Road

Springfield, Virginia 22161

Price: Printed Copy $\$ 9.25$; Microfiche $\$ 3.00$

"The NRC will make available data tapes and operational computer codes on research programs dealing with postulated loss-of-coolant accidents in light water reactors. Persons requesting this information must reimburse the NRC contractors for their expenses in preparing copies of the data tapes and the operational computer codes. Requests should be submitted to the Research Applications Branch, Office of Nuclear Regulatory Research, Nuclear Regulatory Commission, Washington, D.C. 20555."

\section{NOTICE}

This report was prepared as an account of work sponsored by the United States Government. Neither the United States nor the Energy Research and Development Administration, nor the Nuclear Regulatory Commission, nor any of their employees, nor any of their contractors, subcontractors, or their employees, makes any warranty, express or implied, or assumes any legal liability or responsibility for the accuracy, completeness or usefulness of any information, apparatus, product or process disclosed, or represents that its use would not infringe privately owned rights. 
TREE-NUREG-1121

\section{EXPERIMENT DATA REPORT FOR SEMISCALE MOD-1}

TEST S-06-1

\section{(LOFT COUNTERPART TEST)}

Approved:

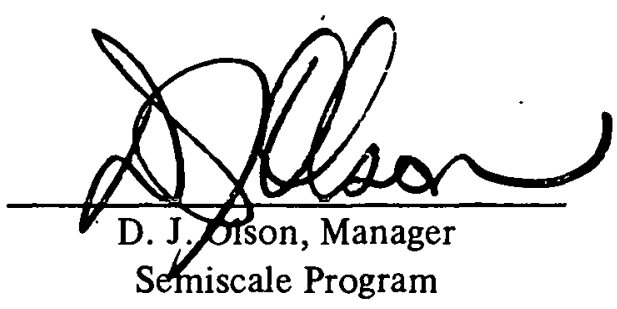

Semiscale Program
This report was protice sponsored by the Urepared as an account of work the United States nor the United Stotes. Eeither Rexearhed States nor the United States Energy their employevelopment Administation, nor any of subcontractors, or their warranty, exptess or implied, or assumes ony lega Liability; or responsibility for the accuncy completega or usecuines of any information, apparatus, product or process disclosed, or represents that its use would not infringe privately owned tights.

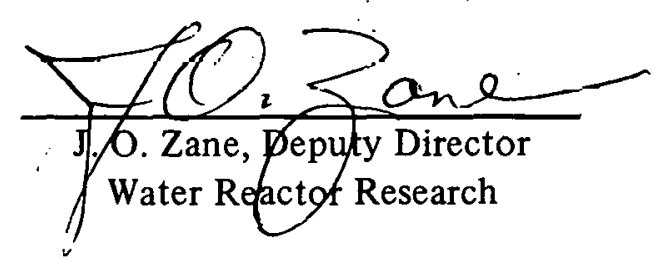




\section{EXPERIMENT DATA REPORT FOR SEMISCALE MOD-1}

TEST S-06-1

\section{(LOFT COUNTERPART TEST)}

By

Brent L. Collins Morris L. Patton, Jr.

Kenneth E. Sackett

EG\&G IDAHO, INC.

July 1977

PREPARED FOR THE

U.S. NUCLEAR REGULATORY COMMISSION

AND

ENERGY RESEARCH AND DEVELOPMENT ADMINISTRATION

IDAHO OPERATIONS OFFICE

UNDER CONTRACT NO. EY-76-C-07-1570 


\begin{abstract}
,
Recorded test data are presented for Test 'S-06-1 of the Semiscale Mod-1 LOFT counterpart test series. These tests are among several Semiscale Mod-1 experiments conducted to investigate the thermal and hydraulic phenomena accompanying an hypothesized loss-of-coolant accident in a pressurized water reactor (PWR) system.

Test S-06-1 was conducted from initial conditions of $15568 \mathrm{kPa}$ and $564 \mathrm{~K}$ to investigate the response of the Semiscale Mod-1 system to a depressurization and reflood transient following a simulated double-ended offset shear of the broken loop cold leg piping. During the test, cooling water was injected into the cold leg of the intact loop to simulate emergency core coolant injection in a PWR. The heater rods in the electrically heated core were operated at an axial peak power density which was $30 \%$ of the maximum peak power density $(52.5 \mathrm{~kW} / \mathrm{m})$.

The purpose of this report is to make available the uninterpreted data from Test S-06-1 for future data analysis and test results reporting activities. The data, presented in the form of graphs in engineering units, have been analyzed only to the extent necessary to ensure that they are reasonable and consistent.
\end{abstract}




\section{SUMMARY}

Test S-06-1 was performed as part of the Semiscale Mod-1 portion of the Semiscale Program conducted by EG\&G Idaho, Inc. for the United States Government. This test was part of the LOFT counterpart test series (Test Series 6) performed to investigate the response of the Mod-1 system to specific variations in the peak power densities of the heater rods to assist the LOFT Program in the planning of the first LOFT nuclear test series. The test objective specific to Test S-06-1 was to determine whether an axial peak power density which was $30 \%$ of the maximum peak power density $(52.5 \mathrm{~kW} / \mathrm{m})$ will cause the heater rod high power zones to experience departure from nucleate boiling and then return immediately to nucleate boiling. Hardware configuration and test parameters were selected to yield a system response that simulates the response of the LOFT nuclear facility during the first nuclear test series.

Test S-06-1 utilized the Semiscale Mod-1 system equipped with a pressure vessel with a 40-rod electrically heated core; an intact loop with pump, steam generator, and pressurizer; a broken loop with simulated pump, simulated steam generator, simulated reflood bypass lines, LOFT counterpart nozzles, and rupture assemblies; and a pressure suppression system with header, pressure suppression tank, and heated steam supply system. High and low pressure coolant injection pumps and a coolant injection accumulator were provided for the intact loop. For Test S-06-1, four heater rods were intentionally unpowered to simulate LOFT passive rod locations, and the power in four heater rods was increased to produce a peaked power profile.

The test was conducted from initial conditions of $15568 \mathrm{kPa}$ and $564 \mathrm{~K}$ (at the intact loop cold leg vessel inlet) with a simulated full size (200\%) double-ended offset shear of the broken loop cold leg piping at an initial core power level of $405 \mathrm{~kW}$, and an initial core inlet flow rate of $7.1 \mathrm{l} / \mathrm{s}$. The instantaneous offset shear of the broken loop cold leg piping was simulated by simultaneous (within $10 \mathrm{~ms}$ ) actuation of the rupture assemblies. After initiation of blowdown, power to the heated core was reduced to simulate the predicted heat flux response of nuclear fuel rods during a loss-of-coolant accident. Blowdown was accompanied by simulated emergency core coolant injection into the cold leg piping of the intact loop.

Test S-06-1 was generally conducted as specified. Conditions which did not conform to the specified test configuration were considered acceptable for analysis purposes within the test objectives. The instrumentation used generally functioned as intended. Of 222 measurements taken, 215 produced usable data. 
CONTENTS

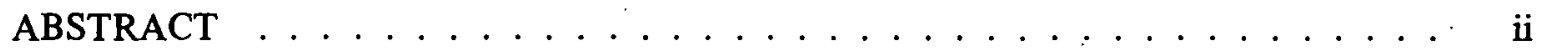

SUMMARY $\ldots \ldots \ldots \ldots \ldots \ldots \ldots \ldots \ldots \ldots \ldots \ldots \ldots$

I $\ldots$ INTRODUCTION $\ldots \ldots \ldots \ldots \ldots \ldots \ldots \ldots \ldots \ldots$

II: : SYSTEM, PROCEDURES, CONDITIONS, AND

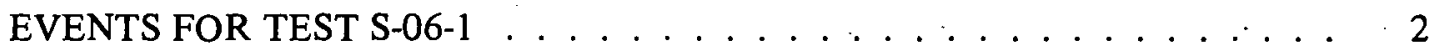

1. SYSTEM CONFIGURATION AND

TEST PROCEDURES $\ldots \ldots \ldots \ldots \ldots \ldots \ldots \ldots \ldots$

2. INITIAL TEST CONDITIONS AND

SEQUENCE OF EVENTS ................. . . 5

III. DATA PRESENTATION $\ldots \ldots \ldots \ldots \ldots \ldots \ldots \ldots$

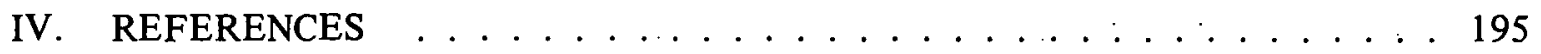

APPENDIX A - POSTTEST ADJUSTMENTS TO DATA FROM

SEMISCALE MOD-1 TEST S-06-1 . . . . . . . . . . . . . . . . . . . 197

1. PRESSURE MEASUREMENTS . . . . . . . . . . . . . . . . . . . 199

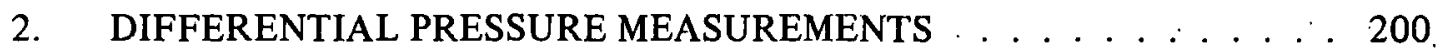

3. MOMENTUM FLUX MEASUREMENTS . . . . . . . . . . 202

4. DENSITY MEASUREMENTS . . . . . . . . . . . . . . . . . 204

5. VOLUMETRIC FLOW MEASUREMENTS . . . . . . . . . . . 209

6. CORE POWER MEASUREMENTS . . . . . . . . . . . . . 209

APPENDIX B - SELECTED DATA WITH ESTIMATED TOTAL

ERROR BANDS FROM SEMISCALE MOD-1 TEST S-06-1 . . . . . . . . 211 


\section{FIGURES}

1. Semiscale Mod-1 system for cold leg break configuration - isometric . . . . . . . . . . . . . . . 3

2. Semiscale Mod-1 system for cold leg break configuration - schematic . . . . . . . . . . . . . . 4

3. Semiscale Mod-1 system and instrumentation

for cold leg break configuration - isometric . . . . . . . . . . . . . . . . 11

4. Semiscale Mod-1 system and instrumentation for cold leg break configuration - schematic . . . . . . . . . . . . 12

5. Semiscale Mod-1 pressure vessel - cross section showing instrumentation . . . . . . . . . . . . . . . . 13

6. Semiscale Mod-1 pressure vessel - isometric showing instrumentation . . . . . . . . . . . . . . . . . 14

7. Semiscale Mod-1 pressure vessel - penetrations and instrumentation ...................... 15

8. Semiscale Mod-1 heated core - plan view . . . . . . . . . . . . 16

9. Fluid temperature in intact loop hot lcg

(TFU-1 and RBU-2), from -20 to $200 \mathrm{~s} \ldots \ldots \ldots \ldots$. . . . . . . . 28

10. Fluid temperature in intact loop hot leg

(TFU-1 and RBU-2), from -6 to $42 \mathrm{~s} \ldots \ldots \ldots$

11. Fluid temperature in intact loop cold leg

(TFU-7 and TFU-10), from -20 to $200 \mathrm{~s} \ldots \ldots$. . . . . . . . . . . . . 29

12. Fluid temperature in intact loop cold leg (TFU-7 and TFU-10), from -6 to $42 \mathrm{~s}$

13. Fluid temperature in intact lonp cold leg

(RBU-14A, TFU-14B, and TFU-15), from -20 to $200 \mathrm{~s}$

14. Fluid temperature in intact loop cold leg (RBU-14A, TFU-14B, and TFU-15), from -6 to $42 \mathrm{~s} \ldots \ldots . . . . . . .30$

15. Fluid temperature in broken loop, vessel side (TFB-20 and TFB-23), from-20 to $200 \mathrm{~s}$ 
16. Fluid temperature in broken loop, vessel side

(TFB-20 and TFB-23), from -6 to $42 \mathrm{~s} \ldots \ldots \ldots . \ldots \ldots$

17. Fluid temperature in broken loop, pump side (TFB-30, TFB-37, and TFB-42), from -20 to $200 \mathrm{~s} \ldots \ldots . \ldots . . \ldots 32$

18. Fluid temperature in broken loop, pump side (TFB-30, TFB-37, and TFB-42), from -6 to $42 \mathrm{~s} \ldots \ldots . \ldots . \ldots 32$

19. Fluid temperature in broken loop, reflood bypass simulators (TFB-RFB-C and TFB-RFB-H), from -20 to $200 \mathrm{~s} \ldots \ldots . \ldots 33$

20. Fluid temperature in broken loop, reflood bypass simulators (TFB-RFB-C and TFB-RFB-H), from -6 to $42 \mathrm{~s} \ldots \ldots . \ldots 33$

21. Fluid temperature in inlet annulus (TFV-ANN-4A and TFV-ANN-4M), from -20 to $200 \mathrm{~s} \ldots \ldots \ldots 34$

22. Fluid temperature in inlet annulus (TFV-ANN-4A and TFV-ANN-4M), from -6 to $42 \mathrm{~s} \ldots \ldots . \ldots 34$

23. Fluid temperature in downcomer annulus (TFV-ANN-15T, TFV-ANN-35A, TFV-ANN-35T, and TFV-ANN-70A), from -20 to $200 \mathrm{~s} \ldots \ldots \ldots \ldots \ldots$

24. Fluid temperature in downcomer annulus (TFV-ANN-15T, TFV-ANN-35A, TFV-ANN-35T, and TFV-ANN-70A), from -6 to $42 \mathrm{~s} \ldots \ldots \ldots \ldots \ldots$

25. Fluid temperature in downcomer annulus (TFV-ANN-115A, TFV-ANN-1 15M, and TFV-ANN-156A), from -20 to $200 \mathrm{~s} \ldots \ldots$

26. Fluid temperature in downcomer annulus (TFV-ANN-115A, TFV-ANN-1 15M, and TFV-ANN-156A), from -6 to $42 \mathrm{~s}$

27. Fluid temperature in upper plenum (TFV-UP+13), from -20 to $200 \mathrm{~s} \ldots \ldots \ldots \ldots \ldots$

28. Fluid temperature in upper plenum (TFV-UP+13), from -6 to $42 \mathrm{~s} \ldots \ldots \ldots \ldots \ldots$

29. Fluid temperature in lower plenum (TFV-LP-8, TFV-LP-15, and TFV-LP-22), from -20 to $200 \mathrm{~s}$

30. Fluid temperature in lower plenum (TFV-LP-8, TFV-LP-15, and TFV-LP-22), from -6 to $42 \mathrm{~s}$ 
31. Fluid temperature in core inlet (TFV-CORE-IN),

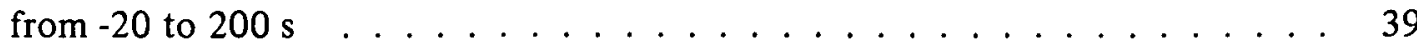

32. Fluid temperature in core inlet (TFV-CORE-IN),

from -6 to $42 \mathrm{~s} \ldots \ldots \ldots \ldots$. . . . . . . . . . . . . . . . . . . .

33. Fluid temperature in core, Grid Spacer 5

(TFG-5CD-45), from -20 to $200 \mathrm{~s} \ldots \ldots$. . . . . . . . . . 40

34. Fluid temperature in core, Grid Spacer 5

(TFG-5CD-45), from -6 to $42 \mathrm{~s} \ldots \ldots . \ldots 40$

35. Fluid temperature in core, Grid Spacer 6 (TFG-6CD-45

and TFG-6DE-67), from -20 to $200 \mathrm{~s} \ldots \ldots . \ldots . \ldots . . \ldots 41$

36. Fluid temperature in core, Grid Spacer 6 (TFG-6CD-45

and TFG-6DE-67), from -6 to $42 \mathrm{~s} \ldots \ldots \ldots 41$

37. Fluid temperature in core, Grid Spacer 10

(TFG-10GH-45), from -20 to $200 \mathrm{~s} \ldots \ldots \ldots$. . . . . . . . . . 42

38. Fluid temperature in core, Grid Spacer 10

(TFG-10GH-45), from -6 to $42 \mathrm{~s} \ldots \ldots \ldots \ldots$. . . . . . . . . 42

39. Fluid temperature in intact loop coolant injection

line (TFU-ECC-14), from -20 to $200 \mathrm{~s} \ldots \ldots . \ldots 43$

40. Fluid temperature in intact loop coolant injection

line (TFU-ECC-14), from -6 to $42 \mathrm{~s} \ldots \ldots . \ldots 43$

41. Fluid temperature in steam generator, feedwater

line (TFU-SGFW), from -20 to $200 \mathrm{~s} \ldots \ldots$. . . . . . . . . . . 44

42. Fluid temperature in steam generator, feedwater

line (TFU-SGFW), from -6 to $42 \mathrm{~s} \ldots \ldots . \ldots . \ldots 44$

43. Fluid temperature in steam generator, secondary

side (TFU-SGSD), from -20 to $200 \mathrm{~s} \ldots \ldots$. . . . . . . . . . 45

44. Fluid temperature in steam generator, secondary

side (TFU-SGSD), from -6 to $42 \mathrm{~s} \ldots \ldots \ldots$

45. Fluid temperature in steam generator, secondary side

(TFU-SG1, TFU-SG3, and TFU-SG4), from -20 to $200 \mathrm{~s}$ 
46. Fluid temperature in steam generator, secondary side (TFU-SG1, TFU-SG3, and TFU-SG4), from -6 to $42 \mathrm{~s} \ldots \ldots$. . . . . . . . . 46

47. Fluid temperature in pressurizer surge line (TFU-PRIZE), from -20 to $200 \mathrm{~s} \ldots \ldots \ldots$. . . . . . . . . . . . . . . 47

48. Fluid temperature in pressurizer surge line (TFU-PRIZE), from -6 to $42 \mathrm{~s} \ldots \ldots \ldots \ldots \ldots$. . . . . . . . . . . . . 47

49. Fluid temperature in pressure suppression tank (TF-PSS-33, TF-PSS-48, TF-PSS-63, and TF-PSS-130), from -20 to $200 \mathrm{~s}$

50. Fluid temperature in pressure suppression tank (TF-PSS-33, TF-PSS-48, TF-PSS-63, and TF-PSS-1.3()), from -6 tn 4 \% $s$

51. Material temperature in intact loop (TMU-1T16 and TMU-15T16), from -20 to $200 \mathrm{~s}$

52. Material temperature in intact loop (TMU-1T16 and TMU-15T16), from -6 to $42 \mathrm{~s} \ldots \ldots \ldots$

53. Material temperature in broken loop (TMB-20B 16 and TMB-30B 16), from -20 to $200 \mathrm{~s} \ldots \ldots \ldots 50$

54. Material temperature in broken loop (TMB-20B 16 and TMB-30B 16), from -6 to $12 \mathrm{E}$

55. Material temperature in vessel filler (TMV-FI-115A), from -20 to $200 \mathrm{~s}$

56. Material temperature in vessel filler (TMV-FI-115A), from -6 to $42 \mathrm{~s}$

57. Material temperature in core barrel inner diameter (TMV-CI-35A), from -20 to $200 \mathrm{~s}$

58. Material temperature in core barrel inner diameter (TMV-Cl-35A), from -6 to $42 \mathrm{~s} \ldots \ldots \ldots$

59. Core heàter temperature, Rod D-4 (TH-D4-14 and TH-D4-29), from -20 to $200 \mathrm{~s} \ldots \ldots \ldots$

60. Core heater temperature, Rod D-4 (TH-D4-14 and TH-D4-29), from -6 to $42 \mathrm{~s}$ 
61. Core heater temperature, Rod D-5 (TH-D5-09,

TH-D5-29, and TH-D5-39), from -20 to $200 \mathrm{~s} \ldots \ldots . \ldots 54$

62. Core heater temperature, Rod D-5 (TH-D5-09, TH-D5-29, and TH-D5-39), from -6 to $42 \mathrm{~s} \ldots \ldots \ldots 54$

63. Core heater temperature, Rod E-4 (TH-E4-09, TH-E4-27, and TH-E4-55), from -20 to $200 \mathrm{~s} \ldots \ldots$. . . . . . . . . 55

64. Core heater temperature, Rod E-4 (TH-E4-09, TH-E4-27, and TH-E4-55), from -6 to $42 \mathrm{~s}$

65. Core heater temperature, Rod E-5 (TH-E5-21), from -20 to $200 \mathrm{~s} \ldots \ldots \ldots \ldots$. . . . . . . . . . . . . . . . . .

66. Core heater temperature, Rod E-5 (TH-E5-21), from -6 to $42 \mathrm{~s} \ldots \ldots \ldots \ldots$. . . . . . . . . . . . . . 56

67. Core heater temperature, Rod A-4 (TH-A4-09 and TH-A4-29), from -20 to $200 \mathrm{~s} \ldots \ldots \ldots$. . . . . . . . . . . .

68. Core heater temperature, Rod A-4 (TH-A4-09 and TH-A4-29), from -6 to $42 \mathrm{~s}$

69. Core heater temperature, Rod A-5 (TH-A5-29 and TH-A5-45), from -20 to $200 \mathrm{~s} \ldots \ldots \ldots 5$

70. Core heater temperature, Rod A-5 (TH-A5-29 and TH-A5-45), from -6 to $42 \mathrm{~s} \ldots \ldots \ldots 5$

71. Core heater temperature, Rod B-3 (TH-B3-32), from -20 to $200 \mathrm{~s}$

72. Core heater temperature, Rod B-3 (TH-B3-32), from -6 to $42 \mathrm{~s}$

73. Core heater temperature, Rod B-5 (TH-B5-29 and TH-B5-33), from -20 to $200 \mathrm{~s}$

74. Core heater temperature, Rod B-5 (TH-B5-29 and TH-B5-33), from -6 to $42 \mathrm{~s}$

75. Core heater temperature, Rod B-6 (TH-B6-14 and TH-B6-29), from -20 to $200 \mathrm{~s}$ 
76. Core heater temperature, Rod B-6 (TH-B6-14

and TH-B5-29), from -6 to $42 \mathrm{~s}$

77. Core heater temperature, Rod C-2

(TH-C2-38), from -20 to $200 \mathrm{~s}$

78. Core heater temperature, Rod C-2

(TH-C2-38), from -6 to $42 \mathrm{~s}$

79. Core heater temperature, Rod C-3 (TH-C3-28

and TH-C3-60), from -20 to $200 \mathrm{~s}$

80. Core heater temperature, Rod C-3 (TH-C3-28

and $\mathrm{TH}-\mathrm{C} 3-60$ ), from -6 to $42 \mathrm{~s}$

81. Core heater temperature, Rod $\mathrm{C}-4$

(TH-C4-26), from -20 to $200 \mathrm{~s}$

82. Core heater temperature, Rod $\mathrm{C}-4$

(TH-C4-26), from -6 to $42 \mathrm{~s}$

83. Core heater temperature, Rod C-5

(TH-C5-28), from -20 to $200 \mathrm{~s}$

84. Core heater temperature, Rod C -5

(TH-C5-28), from -6 to $42 \mathrm{~s}$

85. Core heater temperature, Rod C-6 (TH-C6-32

and $\mathrm{TH}-(-6-53)$, from -20 to $200 \mathrm{~s}$

86. Core heater temperature, Rod C-6 (TH-C6-32

and TH-C6-53), from -6 to $42 \mathrm{~s}$

87. Core heater temperature, Rod C-7 (TH-C7-07 -

and TH-C7-15), from -20 to $200 \mathrm{~s}$

88. Core heater temperature, Rod C-7 (TH-C7-07

and TH-C7-15), from -6 to $42 \mathrm{~s}$

89. Core heater temperature, Rod D-1

(TH-D1-21), from -20 to $200 \mathrm{~s}$

90. Core heater temperature, Rod D-1

(TH-D1-21), from -6 to $42 \mathrm{~s}$ 
91. Core heater temperature, Rod D-2 (TH-D2-14

and TH-D2-61), from -20 to $200 \mathrm{~s} \ldots \ldots \ldots$. . . . . . . . 69

92. Core heater temperature, Rod D-2 (TH-D2-14

and TH-D2-61), from -6 to $42 \mathrm{~s} \ldots \ldots \ldots \ldots$

93. Core heater temperature, Rod D-3 (TH-D3-29

and TH-D3-39), from -20 to $200 \mathrm{~s} \ldots \ldots \ldots \ldots$

94. Core heater temperature, Rod D-3 (TH-D3-29

and TH-D3-39), from -6 to $42 \mathrm{~s} \ldots \ldots \ldots \ldots \ldots \ldots$

95. Core heater temperature, Rod D-7

(TH-D7-20), from -20 to $200 \mathrm{~s} \ldots \ldots \ldots \ldots \ldots$. . . . . . . . . 71

96. Core heater temperature, Rod D-7

(TH-D7-20), from -6 to $42 \mathrm{~s} \ldots \ldots \ldots \ldots \ldots \ldots \ldots \ldots \ldots$

97. Core heater temperature, Rod D-8

(TH-D8-57), from -20 to $200 \mathrm{~s} \ldots \ldots \ldots \ldots \ldots \ldots \ldots$. . . . . . . . 72

98. Core heater temperature, Rod D-8

(TH-D8-57), from -6 to $42 \mathrm{~s} \ldots \ldots \ldots \ldots \ldots \ldots \ldots . \ldots \ldots \ldots$

99. Core heater temperature, Rod E-1

(TH-E1-33), from -20 to $200 \mathrm{~s} \ldots \ldots \ldots \ldots$. . . . . . . . . . 73

100. Core heater temperature, Rod E-1

(TH-E1-33), from -6 to $42 \mathrm{~s}$

101. Core heater temperature, Rod E-2 (TH-E2-20

and TH-E2-33), from -20 to $200 \mathrm{~s} \ldots \ldots \ldots \ldots$. . . . . . . . 74

102. Core heater temperature, Rod E-2 (TH-E2-20

and TH-E2-33), from -6 to $42 \mathrm{~s} \ldots \ldots \ldots \ldots \ldots \ldots$

103. Core heater temperature, Rod E-3

(TH-E3-24), from -20 to $200 \mathrm{~s}$

104. Core heater temperature, Rod E-3

(TH-E3-24), from -6 to $42 \mathrm{~s}$

105. Core heater temperature, Rod E-6 (TH-E6-08,

TH-E6-28, and TH-E6-37), from -20 to $200 \mathrm{~s}$ 
106. Core heater temperature, Rod E-6 (TH-E6-08, TH-E6-28; and TH-E6-37), from -6 to $42 \mathrm{~s}$

107. Core heater temperature, Rod E-7 (TH-E7-13

and TH-E7-44), from -20 to $200 \mathrm{~s} \ldots \ldots \ldots$. . . . . . . . .

108. Core heater temperature, Rod E-7 (TH-E7-13 and TH-E7-44), from -6 to $42 \mathrm{~s}$

109. Core heater temperature, Rod E-8 (TH-E8-14, TH-E8-29, and TH-E8-45), from -20 to $200 \mathrm{~s}$

110. Core heater temperature, Rod E-8 (TH-E8-14, TH-E8-29, and TH-E8-45), from -6 to $42 \mathrm{~s}$

111. Core heater temperature, Rod F 2 (TH-F2-07, TH-F2-22, and TH-F2-25), from -20 to $200 \mathrm{~s} \ldots \ldots \ldots \ldots$

112. Core heater temperature, Rod F-2 (TH-F2-07, TH-F2-22, and TH-F2-25), from -6 to $42 \mathrm{~s}$

113. Core heater temperature, Rod F-3 (TH-F3-06, TH-F3-22, and TH-F3-25), from -20 to $200 \mathrm{~s}$

114. Core heater temperature, Rod F-3 (TH-F3-06, TH-F3-22, and.TH-F3-25), from -6 to $42 \mathrm{~s}$

115. Core heater temperature, Rod F-4 (TH-F4-14, TH-F4-29, and TH-F4-44), from -20 to $200 \mathrm{~s}$

116. Core heater temperature, Rod F-4 (TH-F4-14, TH-F4-29, and TH-F4-44), from -6 to $42 \mathrm{~s}$

117. Core heater temperature, Rod F-5 (TH-F5-20 and TH-F5-26), from -20 to $200 \mathrm{~s}$

118. Corc hcatcr tempcrature, Rod F-5 (TH-F5-20 and TH-F5-26), from -6 to $42 \mathrm{~s}$

119. Core heater temperature, Rod F-6 (TH-F6-08

120. Core heater temperature, Rod F-6 (TH-F6-08 and TH-F6-28), from -6 to $42 \mathrm{~s}$ 
121. Core heater temperature, Rod F-7 (TH-F7-39), from -20 to $200 \mathrm{~s}$

122. Core heater temperature, Rod F-7 (TH-F7-39), from -6 to $42 \mathrm{~s}$

123. Core heater temperature, Rod G-3 (TH-G3-13), from -20 to $200 \mathrm{~s}$

124. Core heatcr temperature, Rod G-3

(TH-G3-13), from -6 to $42 \mathrm{~s}$

125. Core heater temperature, Rod G-4 (TH-G4-29, TH-G4-33, and TH-G4-38), from -20 to $200 \mathrm{~s} \ldots \ldots \ldots$. . . . . . . 86

126. Core heater temperature, Rod G-4 (TH-G4-29, TH-G4-33, and TH-G4-38), from -6 to $42 \mathrm{~s}$.

127. Core heater temperature, Rod G-5 (TH-G5-14 and TH-G5-24), from -20 to $200 \mathrm{~s}$

128. Core heater temperature, Rod G-5 (TH-G5-14 and TH-G5-24), from -6 to $42 \mathrm{~s}$

129. Corc heater temperature, Rod H-5, (TH-H5-32), from -20 to $200 \mathrm{~s}$

130. Core heater temperature, Rod H-5, (TH-H5-32), from -6 to $42 \mathrm{~s}$

131. Pressure in intact loop (PU-13 and PU-I $3 \mathrm{~L}$ ), from -20 to $200 \mathrm{~s}$

132. Pressure in intact loop (PU-13 and PU-13L), from -6 to $42 \mathrm{~s}$

133. Pressure in broken loop, vessel side (PB-21 and PB-23), from -20 to $200 \mathrm{~s}$

134. Pressure in broken loop, vessel side (PB-21 and PB-23), from -6 to $42 \mathrm{~s}$

135. Pressure in broken loop, pump side (PB-30, $\mathrm{PB}-42$, and PB-43), from -20 to $200 \mathrm{~s}$ 
136. Pressure in broken loop, pump side (PB-30,

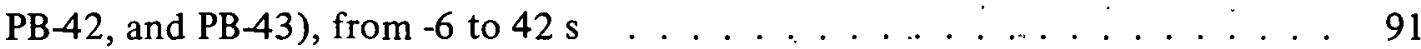

137. Pressure in vessel (PV-LP-1 80), from -20 to $200 \mathrm{~s} \ldots \ldots \ldots 2$

138. Pressure in vessel (PV-LP-180), from -6 to $42 \mathrm{~s} \ldots \ldots . \ldots 92$

139. Pressure in intact loop accumulator (PU-ACC), from -20 to $200 \mathrm{~s} \ldots \ldots \ldots$. . . . . . . . . 93

140. Pressure in intact loop accumulator (PU-ACC), from -6 to $42 \mathrm{~s} \ldots \ldots . \ldots 93$

141. Pressure in steam generator, secondary side (PU-SGSD), from -20 to $200 \mathrm{~s} \ldots \ldots$. . . . . . . . . . . . . 94

142. Pressure in steam generator, secondary side (PU-SGSD), from -6 to $42 \mathrm{~s} \ldots \ldots \ldots . \ldots \ldots 4$

143. Pressure in pressurizer (PU-PRIZE), from -20 to $200 \mathrm{~s} \ldots \ldots \ldots \ldots$

144. Pressure in pressurizer (PU-PRIZE),

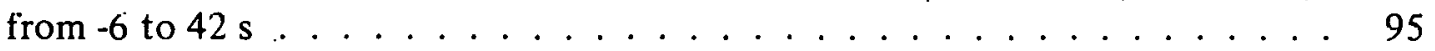

145. Pressure in pressure suppression tank

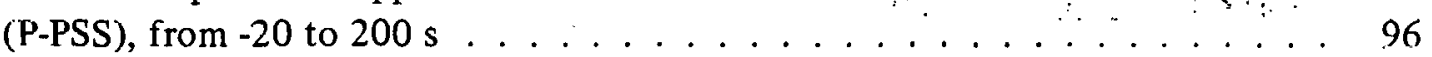

146. Pressure in pressure suppression tank (P-PSS), from -6 to $42 \mathrm{~s} \ldots \ldots \ldots 6$

147. Differential pressure in intact loop (DPU-UP-3), from -20 to $200 \mathrm{~s} \ldots \ldots \ldots$. . . . . . . . . . . 97

148. Differential pressure in intact loop (DPU-UP-3), from -6 to $42 \mathrm{~s} \ldots \ldots \ldots \ldots$

149. Differential pressure in intact loop (DPU-3-6), from -20 to $200 \mathrm{~s}$

150. Differential pressure in intact loop (DPU-3-6), from -6 to $42 \mathrm{~s} \ldots \ldots \ldots$. . . . . . . . . . . . 98

151. Differential pressure in intact loop (DPU-G-SGIP), from -20 to $200 \mathrm{~s}$ 
152. Differential pressure in intact loop

(DPU-6-SGIP), from -6 to $42 \mathrm{~s} \ldots \ldots . \ldots . \ldots$. . . . . . . . . . 99

153. Differential pressure in intact loop

(DPU-6-7), from -20 to $200 \mathrm{~s}$

154. Differential pressure in intact loop

(DPU-6-7), from -6 to $42 \mathrm{~s} \ldots \ldots \ldots 100$

155. Differential pressure in intact loop

(DPU-SGOP-7), from -20 to $200 \mathrm{~s} \ldots \ldots \ldots 10 \ldots 1$

156. Differential pressure in intact loop

(DPU-SGOP-7), from -6 to $42 \mathrm{~s}$

157. Differential pressure in intact loop

(DPU-7-10), from -20 to $200 \mathrm{~s} \ldots \ldots \ldots . \ldots \ldots 2$

158. Differential pressure in intact loop

(DPU-7-10), from -6 to $42 \mathrm{~s} \ldots \ldots \ldots 10 \ldots 2$

159. Differential pressure in intact loop

(DPU-12-10), from -20 to $200 \mathrm{~s} \ldots \ldots \ldots 103$

160. Differential pressure in intact loop

(DPU-12-10), from -6 to $42 \mathrm{~s}$

161. Differential pressure in intact loop, low

range (DPU-12-10L), from -20 to $200 \mathrm{~s} \ldots \ldots . . \ldots 104$

162. Differential pressure in intact loop, low

range (DPU-12-10L), frum -6 to $42 \mathrm{~s}$

163. Differential pressure in intact loop

(DPU-12-13), from -20 to $200 \mathrm{~s} \ldots \ldots \ldots$. . . . . . . . . . . . . . .

164. Differential pressure in intact loop

(DPU-12-13), from -6 to $42 \mathrm{~s} \ldots \ldots \ldots \ldots$. . . . . . . . . . . . . . . . .

165. Differential pressure in intact loop

(DPU-13-3), from -20 to $200 \mathrm{~s} \ldots \ldots \ldots 106$

166. Differential pressurc in intact loop

(DPU-13-3), from -6 to $42 \mathrm{~s}$ 
167. Differential pressure in intact loop, low range (DPU-13-3L), from -20 to $200 \mathrm{~s} \ldots \ldots \ldots \ldots$

168. Differential pressure in intact loop, low range (DPU-13-3L), from -6 to $42 \mathrm{~s} \ldots \ldots \ldots \ldots \ldots$

169. Differential pressure in intact loop (DPU-13-IANN), from -20 to $200 \mathrm{~s}$

170. Differential pressure in intact loop (DPU-13-IANN), from -6 to $42 \mathrm{~s} \ldots \ldots \ldots \ldots \ldots$

171. Differential pressure in intact loop (DPU-PRESLL), from -20 to $200 \mathrm{~s}$

172. Differential pressure in intact loop (DPU-PRESLL), from -6 to $42 \mathrm{~s} \ldots \ldots \ldots \ldots \ldots$. . . . . . . . 109

173. Differential pressure in intact loop (DPU-PR-4), from -20 to $200 \mathrm{~s}$

174. Differential pressure in intact loop (DPU-PR-4), from -6 to $42 \mathrm{~s}$

175. Differential pressure in broken loop (DPB-21-IANN), from -20 to $200 \mathrm{~s}$

176. Differential pressure in broken loop (DPB-21-IANN), from -6 to $42 \mathrm{~s}$

177. Differential pressure in broken loop (DPB-21-23), from -20 to $200 \mathrm{~s}$

178. Differential pressure in broken loop (DPB-21-23), from -6 to $42 \mathrm{~s}$

179. Differential pressure in broken loop (DPB-23-CN1), from -20 to $200 \mathrm{~s}$

180. Differential pressure in broken loop (DPR-23-CN1), from -6 to $42 \mathrm{~s}$

181. Differential pressure in broken loop (DPB-23-24), from -20 to $200 \mathrm{~s}$ 
182. Differential pressure in broken loop (DPB-23-24), from -6 to $42 \mathrm{~s}$

183. Differential pressure in broken loop (DPB-30-36L), from -20 to $200 \mathrm{~s}$

184. Differential pressure in broken loop (DPB-30-36L), from -6 to $42 \mathrm{~s}$.

185. Differential pressure in broken loop (DPB-30-38), from -20 to $200 \mathrm{~s}$

186. Differential pressure in broken loop (DPB-30-38), from -6 to $42 \mathrm{~s}$

187. Differential pressure in broken loop (DPB-32U-36L), from -20 to $200 \mathrm{~s}$

188: Differential pressure in broken loop (DPB-32U-36L), from -6 to $42 \mathrm{~s}$

189. Differential pressure in broken loop (DPB-38-40), from -20 to $200 \mathrm{~s}$

190. Differential pressure in broken loop (DPB-38-40), from -6 to $42 \mathrm{~s}$

191. Differential pressure in broken loop (DPB-40-42), from -20 to $200 \mathrm{~s}$

192. Differential pressure in broken loop (DPB-40-42), from -6 to $42 \mathrm{~s}$

193. Differential pressure in broken loop (DPB-42-43), from -20 to $200 \mathrm{~s}$

194. Differential pressure in broken loop (DPB-42-43), from -6 to $42 \mathrm{~s}$

195. Differential pressure in vessel (DPV-UP-IANN), from -20 to $200 \mathrm{~s}$

196. Differential pressure in vessel (DPV-UP-IANN), from -6 to $42 \mathrm{~s}$ 
197. Differential pressure in vessel

(DPV-0-9GQ), from -20 to $200 \mathrm{~s}$

198. Differential pressure in vessel

(DPV-0-9GQ), from -6 to $42 \mathrm{~s} \ldots \ldots \ldots \ldots . \ldots \ldots 22$

199. Differential pressure in vessel

(DPV-9-26QQ), from -20 to $200 \mathrm{~s} \ldots \ldots \ldots \ldots$

200. Differential pressure in vessel

(DPV-9-26QQ), from -6 to $42 \mathrm{~s} \ldots \ldots \ldots \ldots \ldots \ldots$

2001. Differential pressure in vessel

(DPV-9-180QQ), from -20 to $200 \mathrm{~s} \ldots \ldots \ldots 124$

202. Differeitial pressure in vessol

(DPV-9-1 80QQ), from -6 to $42 \mathrm{~s} \ldots \ldots \ldots 124$

203. Differential pressure in vessel

(DPV-26-55QM), from -20 to $200 \mathrm{~s} \ldots \ldots \ldots \ldots$. . . . . . . . . 125

204. Differential pressure in vessel

(DPV-26-55QM), from -6 to $42 \mathrm{~s} \ldots \ldots \ldots \ldots \ldots$

205. Differential pressure in vessel

(DPV-55-110MM), from -20 to $200 \mathrm{~s} \ldots \ldots \ldots 126$

206. Differential pressure in vessel

(DPV-55-110MM), from -6 to $42 \mathrm{~s} \ldots \ldots \ldots 126$

207. Differential pressure in vessel

(DPV-1 10-1 56MQ), from -20 to $200 \mathrm{~s} \ldots \ldots \ldots$. . . . . . . . 127

208. Differential pressure in vessel

(DPV-1 10-1 56MQ), from -6 to 42 s . . . . . . . . . . . 127

2.ก9. Differential pressure in vessel

(DPV-156-173QQ), from -20 to $200 \mathrm{~s} \ldots \ldots \ldots$. . . . . . . . . . . . .

210. Differential pressure in vessel

(DPV-156-1 73QQ), from -6 to $42 \mathrm{~s} \ldots \ldots \ldots \ldots . \ldots \ldots$

211. Differential pressure in vessel

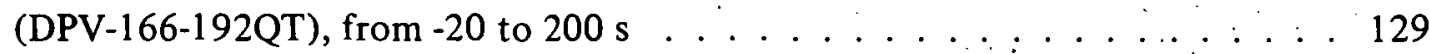


212. Differential pressure in vessel

(DPV-166-192QT), from -6 to $42 \mathrm{~s} \ldots \ldots \ldots$. . . . . . . . . 129

213. Differential pressure in vessel

(DPV-173-180QQ), from -20 to $200 \mathrm{~s} \ldots \ldots$. . . . . . . . . 130

214. Differential pressure in vessel

(DPV-173-180QQ), from -6 to $42 \mathrm{~s} \ldots \ldots \ldots$. . . . . . . . . 130

215. Differential pressure in vcssel

(DPV-LP-UP), from -20 to $200 \mathrm{~s} \ldots \ldots \ldots$. . . . . . . . . . 131

216. Differential pressure in vessel

(DPV-LP-UP), from -6 to $42 \mathrm{~s} \ldots \ldots \ldots 131$

217. Differential pressure in intact loop

accumulator (DPU-ACC-TB), from -20 to $200 \mathrm{~s} \ldots \ldots \ldots \ldots$

218. Differential pressure in intact loop

accumulator (DPU-ACC-TB), from -6 to $42 \mathrm{~s} \ldots \ldots \ldots \ldots$

219. Differential pressure across steam generator

feedwater orifice (DPU-SGFW), from -20 to $200 \mathrm{~s} \ldots \ldots$. . . . . . . . . . 133

220. Differential pressurc across steam generator

feedwater orifice (DPU-SGFW), from -6 to $42 \mathrm{~s} \ldots \ldots \ldots$

221. Differential pressure in steam generator

secondary (DPU-SG-SEC), from -20 to $200 \mathrm{~s}$

222. Differential pressure in steam generator

secondary (DPU-SG-SEC), trom -6 to $42 \mathrm{~s} \ldots \ldots \ldots 134$

223. Differential pressure across steam generator outlet orifice (DPU-SG-DISC), from -20 to $200 \mathrm{~s} \ldots \ldots \ldots 135$

224. Differential pressure across steam generator outlet orifice (DPU-SG-DISC), from -6 to $42 \mathrm{~s} \ldots \ldots \ldots \ldots$

225. Differential pressure in pressure suppression tank (DP-PSS-TB), from -20 to $200 \mathrm{~s} \ldots \ldots 136$

226. Differential pressure in pressure suppression tank (DP-PSS-TB), from -6 to $42 \mathrm{~s}$ 
227. Volumetric flow in intact loop (FTU-1

and FTU-9), from -20 to $200 \mathrm{~s}$

228. Volumetric flow in intact loop (FTU-1

and FTU-9), frorn -6 to $42 \mathrm{~s} \ldots \ldots \ldots \ldots \ldots$

229. Volumetric flow in intact loop (FTU-13

and FTU-15), from -20 to $200 \mathrm{~s} \ldots \ldots \ldots \ldots \ldots$

230. Volumetric flow in in tact loop (FTU-13

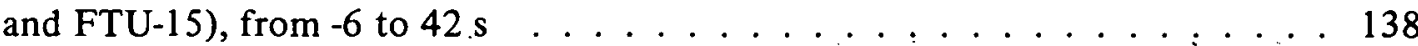

231. Volumetric flow in broken loop (FTB-21), from -20 to $200 \mathrm{~s} \ldots \ldots \ldots \ldots . \ldots \ldots$

232. Volumetric flow in broken loop (FIB-21), from -6 to $42 \mathrm{~s} \ldots \ldots \ldots \ldots \ldots \ldots \ldots$

233. Volumetric flow in broken loop (FTB-30 and FTB-37), from -20 to $200 \mathrm{~s} \ldots \ldots \ldots$. . . . . . . . . . . . . . . . .

234. Volumetric flow in broken loop (FTB-30 and FTB-37), from -6 to $42 \mathrm{~s}$

235. Volumetric tlow in core entrance (FTV-CORE-IN), from -20 to $200 \mathrm{~s}$

236. Volumetric flow in core entrance (FTV-CORE-IN), from -6 to $42 \mathrm{~s}$

237. Volumetric flow in intact loop high pressure injection line (FTU-HPIS), from -20 to $200 \mathrm{~s}$

238. Volumetric flow in intact loop high pressure injection line (FTU-HPIS), from -6 to $42 \mathrm{~s}$.

239. Volumetric flow in intact loop low pressure injection line (FTU-LPIS), from -20 to $200 \mathrm{~s}$

240. Volumetric flow in intact loop low pressure injection line (FTU-LPIS), from -6 to $42 \mathrm{~s}$

241. Volumetric flow in intact loop accumulator discharge line (FTU-ACC), from -20 to $200 \mathrm{~s}$ 
242. Volumetric flow in intact loop accumulator discharge

line (FTU-ACC), from -6 to $42 \mathrm{~s} \ldots \ldots \ldots \ldots$. . . . . . . . . 144

243. Volumetric flow from pressurizer

(FTU-PRIZE), from -20 to $200 \mathrm{~s}$

244. Volumetric flow from pressurizer

(FTU-PRIZE), from -6 to $42 \mathrm{~s} \ldots \ldots \ldots \ldots \ldots$

245. Fluid velocity in vessel (FTV-40A

and FTV-40M), from -20 to $200 \mathrm{~s}$

246. Fluid velocity in vessel (FTV-40A

and FTV-40M), from -6 to $42 \mathrm{~s} \ldots \ldots \ldots \ldots$

247. Momentum flux in intact loop (FDU-1),

from -20 to $200 \mathrm{~s} \ldots \ldots \ldots \ldots$. . . . . . . . . . . . . . . . . . . . . . .

248. Momentum flux in intact loop (FDU-1),

from -6 to $42 \mathrm{~s} \ldots \ldots \ldots \ldots \ldots$. . . . . . . . . . . . . . . . . . . . . . .

249. Momentum flux in intact loop (FDU-5),

from -20 to $200 \mathrm{~s}$

250. Momentum flux in intact loop (FDU-5),

from -6 to $42 \mathrm{~s}$

251. Momentum flux in intact loop (FDU-10),

from -20 to $200 \mathrm{~s}$

252. Momentum flux in intact loop (FDU-10),

from -6 to 123

253. Momentum flux in intact loop (FDU-13),

from -20 to $200 \mathrm{~s}$

254. Momentum flux in intact loop (FDU-13),

from -6 to $42 \mathrm{~s}$

255. Momentum flux in intact loop (FDU-15),

from -20 to $200 \mathrm{~s}$

256. Momentum flux in intact loop (FDU-15),

from -6 to $42 \mathrm{~s}$ 
25.7. Momentum flux in broken loop (FDB-21),

from -20 to 200

258. Momentum flux in broken loop (FDB-21),

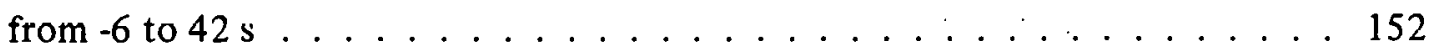

259. Momentum flux in broken loop (FDB-30),

from -20 to $200 \mathrm{~s}$

260. Momentum flux in broken loop (FDB-30),

from -6 to $42 \mathrm{~s}$

261. Momentum flux in broken loop (FDB-37),

from -20 to $200 \mathrm{~s}$

262. Momentum flux in broken loop (FDB-37),

from -6 to $42 \mathrm{~s}$

263. Momentum flux in broken loop (FDB-42);

from -20 to $200 \mathrm{~s}$

264. Momentum flux in broken loop (FDB-42),

265. Momentum flux in core entrance (FUV-CURE-IN),

from -20 to $200 \mathrm{~s}$

266. Momentum flux in core entrance (FUV-CORE-IN),

from -6 to $42 \mathrm{~s}$

267. Density in intact loop (GU-1T

and GU-1B), from -20 to $200 \mathrm{~s}$

268. Density in intact loop (GU-1T and GU-1B), from -6 to 42

269. Density in intact loop (GU-1C), from -20 to $200 \mathrm{~s}$

270. Density in intact loop (GU-1C), from -6 to $42 \mathrm{~s}$

271. Density in intact loop (GU-5VR and GU-10VR), from -20 to $200 \mathrm{~s}$

272. Density in intact loop (GU-5VR and GU-10VR), from -6 to $42 \mathrm{~s}$ 
273. Density in intact loop (GU-13VR), from -20 to $200 \mathrm{~s} \ldots \ldots$. . . . . . . 160

274. Density in intact loop (GU-13VR), from -6 to $42 \mathrm{~s} \ldots \ldots \ldots$

275. Density in intact loop (GU-15T

and GU-15B), from -20 to $200 \mathrm{~s} \ldots \ldots \ldots 16 \ldots \ldots$

276. Density in intact loop (GU-15T and GU-15B), from -6 to $42 \mathrm{~s} \ldots \ldots \ldots 161$

277. Density in intact loop (GU-15C), from -20 to $200 \mathrm{~s} \ldots \ldots . \ldots 162$

278. Density in intact loop (GU-15C), from -6 to $42 \mathrm{~s} \ldots \ldots \ldots 2$

279. Density in broken loop (GB-21T and GB-21B), from -20 to $200 \mathrm{~s} \ldots \ldots \ldots \ldots$

280. Density in broken loop (GB-21T and GB-21B), from -6 to $42 \mathrm{~s} \ldots \ldots \ldots \ldots$. . . . . . . . . . . . . . . .

281. Density in broken loop (GB-21C), from -20 to $200 \mathrm{~s} \ldots \ldots$. . . . . . . 164

282. Density in broken loop (GB-21C), from -6 to $42 \mathrm{~s} \ldots \ldots \ldots 4$

283. Density in broken loop (GB-23VR), from -20 to $200 \mathrm{~s} \ldots \ldots \ldots 5$

284. Density in broken loop (GB-23VR), from -6 to $42 \mathrm{~s} \ldots \ldots 165$

285. Density in broken loop (GB-30T and GV-30B), from -20 to $200 \mathrm{~s} \ldots \ldots \ldots 6$

286. Density in brưken lừu (GB-30T and GB-30B), from -6 to $42 \mathrm{~s} \ldots \ldots \ldots 6$

287. Density in broken loop (GB-30C), from -20 to $200 \mathrm{~s} \ldots \ldots \ldots$

288. Density in broken loop (GB-30C), from -6 to $42 \mathrm{~s} \ldots \ldots \ldots 7$

289. Density in broken loop (GB-42VR), from -20 to $200 \mathrm{~s} \ldots \ldots$. . . . . . 168

290. Density in broken loop (GB-42VR), from -6 to $42 \mathrm{~s} \ldots \ldots \ldots$

291. Density in vessel (GV-COR-150HZ), from -20 to $200 \mathrm{~s} \ldots \ldots$. . . . . . . 169

292. Density in vessel (GV-COR-150HZ), from -6 to 42 s . . . . . . . . . . . . 169 
293. Density in vessel (GV-162/192D), from -20 to $300 \mathrm{~s} \ldots \ldots . \ldots 170$

294. Density in vessel (GV-162/192D), from -6 to $42 \mathrm{~s} \ldots \ldots \ldots$

295. Density in vessel (GVLP-165HZ and

GVLP-172HZ), from -20 to $200 \mathrm{~s} \ldots \ldots \ldots \ldots 17$. . . . . . . . . . 171

296. Density in vessel (GVLP-165HZ and

GVLP-172HZ), from -6 to $42 \mathrm{~s} \ldots \ldots \ldots \ldots 171$

297. Density in pressurizer (GU-PRIZE), from -20 to $200 \mathrm{~s} \ldots \ldots$. . . . . . . 172

298. Density in pressurizer (GU-PRIZE), from -6 to $42 \mathrm{~s} \ldots \ldots \ldots$. . . . . . . 172

299. Mass flow in intact loop (FDU-1 and GU-1C), from -20 to $200 \mathrm{~s} \ldots \ldots \ldots \ldots$

300. Mass flow in intact loop (FDU-1 and

GU-1C), from -6 to $42 \mathrm{~s}$

301. Mass flow in intact loop (FTU-1 and

GU-1C), from -20 to $200 \mathrm{~s} \ldots \ldots \ldots \ldots$. . . . . . . . . . . . . . . . . . .

302. Mass flow in intact loop (FTU-1 and GU-1('), from -6 to $42 \mathrm{~s} \ldots \ldots \ldots \ldots \ldots \ldots$

303. Mass flow in intact loop (FDU-5 and GU-5VR), from -20 to $200 \mathrm{~s} \ldots \ldots \ldots \ldots$

304. Mass flow in intact loop (FDU-5 and GU-5VR), from -6 to $42 \mathrm{~s} \ldots \ldots \ldots \ldots$

305. Mass flow in intact loop (FTU-9 and GU-10VR), from -20 to $200 \mathrm{~s} \ldots \ldots \ldots \ldots$. . . . . . . . . . . . . . . . .

306. Mass flow in intact loop (FTU-9 and GU-10VR), from -6 to $42 \mathrm{~s} \ldots \ldots \ldots \ldots \ldots$

307. Mass flow in intact loop (FDU-10 and GU-10VR), from -20 to $200 \mathrm{~s} \ldots \ldots \ldots 177$

308. Mass flow in intact loop (FDU-10 and GU-10VR), from -6 to $42 \mathrm{~s} \ldots \ldots \ldots \ldots \ldots \ldots$

309. Mass flow in intact loop (FDU-13 and GU-13VR), from -20 to $200 \mathrm{~s}$ 
310. Mass flow in intact loop (FDU-13 and GU-13VR), from -6 to $42 \mathrm{~s} \ldots \ldots \ldots \ldots$. . . . . . . . . . . . . . . . . .

311. Mass flow in intact loop (FTU-13 and GU-13VR), from -20 to $200 \mathrm{~s}$

312. Mass flow in intact loop (FTU-13 and GU-13VR), from -6 to $42 \mathrm{~s} \ldots \ldots . \ldots . \ldots . . \ldots 179$

313. Mass flow in intact loop (FDU-1 5 and GU-15C), from -20 to $200 \mathrm{~s}$

314. Mass flow in intact loop (FDU- 15 and GU-15C), from -6 to $42 \mathrm{~s}$

315. Mass flow in intact loop (FTU-15 and GU-15C), from -20 to $200 \mathrm{~s}$

316. Mass flow in intact loop (FTU-15 and GU-15C), from -6 to $42 \mathrm{~s}$

317. Mass flow in intact loop (FDB-21 and GB-21C), from -20 to $200 \mathrm{~s}$

318. Mass flow in intact loop (FDB-21 and GB-21C), from -6 to $42 \mathrm{~s}$

319. Mass flow in broken loop (FTB-21 and GB-21C), from -20 to $200 \mathrm{~s} \ldots \ldots \ldots \ldots$

320. Mass flow in broken loop (FTB-21 and GD-21C), from $=6$ to $42 \mathrm{~s}$

321. Mass flow in broken loop (FDB-30 and GB-30C), from -20 to $200 \mathrm{~s} \ldots \ldots \ldots \ldots$

322. Mass flow in broken loop (FDB-30 and GB-30C), from $-61042 \mathrm{~s}$

323. Mass flow in broken loop (FTB-30 and GB-30C), from -20 to $200 \mathrm{~s} \ldots \ldots \ldots \ldots$

324. Mass flow in broken loop (FTB-30 and GB-30C), from -6 to $42 \mathrm{~s}$ 
325. Mass flow in broken loop (FDB-42 and

GB-42VR), from -20 to $200 \mathrm{~s}$

186

326. Mass flow in broken loop (FDB-42 and

GB-42VR), from -6 to $42 \mathrm{~s} \ldots \ldots \ldots \ldots$

327. Mass flow in vessel (FDV-CORE-IN and

GV-COR-150HZ), from -20 to $200 \mathrm{~s} \ldots \ldots \ldots$. . . . . . . . . 187

328. Mass flow in vessel (FDV-CORE-IN and

GV-COR-150HZ), from -6 to $42 \mathrm{~s} \ldots \ldots \ldots$. . . . . . . . . 187

329. Mass flow in vessel (F"l V-LUKE-IN and

GV-COR-150HZ), from -20 to $200 \mathrm{~s} \ldots \ldots \ldots$. . . . . . . . 188

330. Mass flow in vessel (FTV-CORE-IN and

GV-COR-150HZ), from -6 to $42 \mathrm{~s} \ldots \ldots \ldots$. . . . . . . . . . 188

331. Mass flow in pressurizer (FTU-PRIZE and GU-PRIZE), from -20 to $200 \mathrm{~s} \ldots \ldots \ldots \ldots$. . . . . . . . . . 189

332. Mass flow in pressurizer (FTU-PRIZE and

GU-PRIZE), from -6 to $42 \mathrm{~s} \ldots \ldots \ldots \ldots$. . . . . . . . . . . 189

333. Core heater rod total power (PWKCUK T-1 and

PWRCOR T-2), from -20 to $200 \mathrm{~s} \ldots \ldots \ldots$. . . . . . . . 190

334. Core heater rod total power (PWRCOR T-1 and

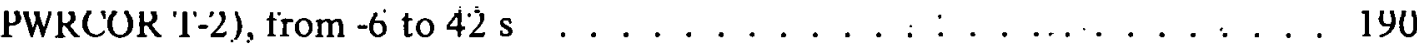

335. Core heater voltage (VOLTCOR-T), from -20 to $200 \mathrm{~s} \ldots \ldots 191$

336. Core heater voltage (VOLTCOR-T), from -6 to $42 \mathrm{~s} \ldots \ldots \ldots$. . . . . 191

337. Core heater total current (AMPCOR-T), from -20 to $200 \mathrm{~s} \ldots \ldots . \ldots 192$

338. Core heater total current (AMPCOR-T), from -6 to $42 \mathrm{~s} \ldots \ldots \ldots 2$

339. Primary pump current (PUMPU-CUR), from -20 to $200 \mathrm{~s} \ldots \ldots$. . . . . 193

340. Primary pump current (PUMPU-CUR), from -6 to $42 \mathrm{~s} \ldots \ldots \ldots \ldots$

341. Primary pump speed (PUMPU-RPM), from -20 to $200 \mathrm{~s} \ldots \ldots \ldots$

342. Primary pump speed (PUMPU-RPM), from -6 to $42 \mathrm{~s} \ldots \ldots$. . . . . . . . 194 
A-1. Geometry used for processing of density

data obtained from two-beam gamma densitometers . . . . . . . . . . 206

B-1. Fluid temperature in pressurizer surge line (TFU-PRIZE) . . . . . . . . 222

B-2. Fluid temperature in steam generator (TFU-SG1) . . . . . . . . . 223

B-3. Fluid temperature in steam generator (TFU-SG4) . . . . . . . . 223

B-4. Fluid temperature in broken loop, vessel side (TFB-23) . . . . . . . . . 224

B-5. Fluid temperature in downcomer annulus (TFV-ANN-35A) . . . . . . . . . 224

B-6. Fluid temperature in downcomer annulus (TFV-ANN-35T) . . . . . . . 225

B-7. Fluid temperature in lower plenum (TFV-LP-8) . . . . . . . . . 225

B-8. Fluid temperature in lower plenum (TFV-LP-15) . . . . . . . . 226

B-9. Fluid temperature in lower plenum (TFV-LP-22) . . . . . . . . . 226

B-10. Fluid temperature in core, Grid Spacer 6 (TFG-6DE-67) . . . . . . . . . 227

B-11. Material temperature in intact loop (TMU-15T16) . . . . . . . . . . 227

B-12. Material temperature in core barrel inner diameter (TMV-CI-35A) . . . . . . 228

B-13. Core heater temperature, Rod E-4 (TH-E4-09) . . . . . . . . . . . 228

B-14. Core heater temperature, Rod E-4 (TH-E4-27) . . . . . . . . . . . . . . 229

B-15. Core liealer temperature, Rod E-4 (TH-E4-55) . . . . . . . . . . . . . 229

B-16. Pressure in intact loop (PU-13) . . . . . . . . . . . . . . . 230

B-17. Pressure in broken loop, Spool 23 (PB-23) f . . . . . . . . . . . . 230

B-1 8. Differential pressure in intact loop (DPU-6-7) . . . . . . . . . . . . 231

B-19. Differential pressure in intact loop (DPU-7-10) . . . . . . . . 231

B-20. Differential pressure in intact loop (DPU-12-10) . . . . . . . . . 232

B-21. Differential pressure in intact loop (DPU-12-13) . . . . . . . . 232

B-22. Differential pressure in vessel (DPV-LP-UP) . . . . . . . . . . . 233 
B-23. Fluid velocity in vessel (FTV-40A) . . . . . . . . . . . 233

B-24. Fluid velocity in vessel (FTV-40M) . . . . . . . . . . . . . . . 234

B-25. Volumetric flow in intact loop accumulator

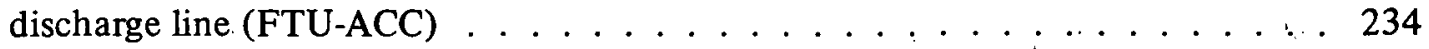

B-26. Volumetric flow in intact loop high pressure

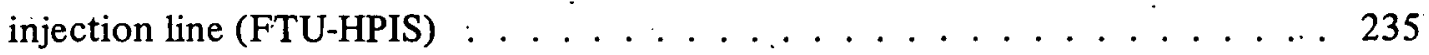

B-27. Volumetric flow in intact loop low pressure injection line (FTU-LPIS) . . . . . . . . . . . . 235

B-28. Density in intact loop (GU-1B) $\ldots \ldots \ldots \ldots \ldots$

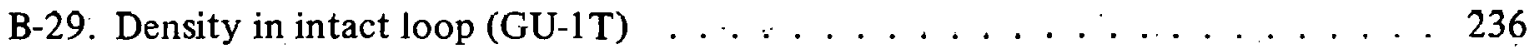

B-30. Density in intact loop (GU-1C) . . . . . . . . . . . . 237

B-31. Density in intact loop (GU-10VR) . . . . . . . . . . . . 237

B-32. Density in intact loop (GU-15B) . . . . . . . . . . . . . 238

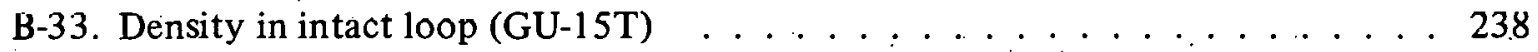

B-34. Density in intact loop (GU-15C) . . . . . . . . . . . . . . . 239

B-35. Density in broken loop (GV-23VR) $\ldots \ldots . \ldots \ldots$

B-36. Density in vessel $($ GV-COR-150HZ) . . . . . . . . . . . . . . . 240

B-37. Density in vessel (GVLP-165HZ) . . . . . . . . . . . . 240

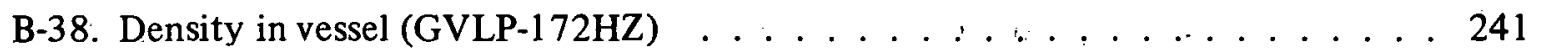

B-39. Mass flow in intact loop (FTU-13 and GU-13VR) . . . . . . . . . . . 241

B-40. Mass flow in intact loop (FTU-15 and GU-15C) . . . . . . . . . . . . 242

B-41. Mass flow in intact loop (F́TU-1 and GU-1C) . . . . . . . . . . . . . . . 241

B-42. Mass flow in vessel (FTV-CORE-IN and GV-COR-150HZ) . . . . . . . . 243

B-43. Mass flow in intact loop (FDU-1 and GU-1C) . . . . . . . . . . . . . . 243 
B-44. Mass flow in in tact loop (FDU-5 and GU-5VR) . . . . . . . . . . . . 244

B-45. Mass flow in broken loop (FTB-21 and GB-21C) . . . . . . . . . . . 244

\section{TABLES}

I. Conditions at Blowdown Initiation . . . . . . . . . . . . 6

II. Primary Coolant Temperature Distribution Prior to Rupture ... . . . . . . . . . . . . . . . . . 7

III. Water Chemistry Prior to Blowdown . . . . . . . . . . . . 8

IV. Sequence of Events During Test S-06-1 . . . . . . . . . . . 9

V. Data Presentation for Semiscale Mod-1 Test S-06-1 _ . . . . . . . . 17

A-I. Constants for Pressure Measurement Corrections (Test S-06-1) . . . . . . . . . . . . . . 200

A-II. Constants for Differential Pressure Measurement Corrections (Test S-06-1) _ . . . . . . . . . . . . 202

A-III. Constạnts for Momentum Flux Measurement Corrections (Test S-06-1) . . . . . . . . . . . . 203

A-IV. Constants for Density Measurement Corrections (Test S-06-1) . . . . . . . . . . . . . . 205

A-V. Constants for Density Measurcment Conversions

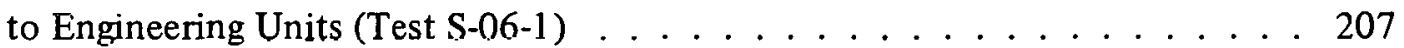

B-I. Random Error Variance . . . . . . . . . . . . . . . 214

B-II. General Measurement Engineering Error Sources and Error Values . . . . . . . . . . . . . . . . . . . . 245

B-III. Time Periods when Fluw Regime Errors were Applied . . . . . . . . . . . . . . . . . . . . 250 


\title{
EXPERIMENT DATA REPORT FOR SEMISCALE MOD-1
}

\author{
TEST S-06-1
}

\section{(LOFT COUNTERPART TEST)}

\section{INTRODUCTION}

The Semiscale Mod-1 experiments represent the current phase of the Semiscale Program conducted by EG\&G Idaho, Inc. for the United States Government. The program, which is sponsored by the Nuclear Regulatory Commission through the Energy Research and Development Administration, is part of the overall program designed to investigate the response of a pressurized water reactor system to an hypothesized loss-of-coolant accident (LOCA). The underlying objectives of the Semiscale Program are to quantify the physical processes controlling system behavior during a LOCA and to provide an experimental data base for assessing reactor safety evaluation models. The Semiscale Mod-1 program has the further objective of providing support to other experimental programs in the form of instrumentation assessment, optimization of test series, selection of test parameters, and evaluation of test results.

Test S-06-1 was conducted April 12, 1977, in the Semiscale Mod-1 system as part of the LOFT counterpart test series (Test Series 6), which was designed to obtain thermal-hydraulic response data from blowdown, refill, and reflood transients in a simulated nuclear reactor with a heated core to assist the LOFT Program in the planning of the first LOFT nuclear test series. Test S-06-1 was conducted specifically to determine whether an axial peak power density which was $30 \%$ of the maximum peak power density $(52.5 \mathrm{~kW} / \mathrm{m})$ will cause the heater rod high power zones to experience departure from nucleate boiling and then return immediately to nucleate boiling.

The purpose of this report is to present the test data in an uninterpreted but readily usable form for use by the nuclear community in advance of detailed analysis and interpretation. Section II briefly describes the system configuration, procedures, initial test conditions, and events that are applicable to Test S-06-1; Section III presents the data graphs and provides comments and supporting information necessary for interpretation of the data. A description of the overall Semiscale Program and test series, a more detailed description of the Semiscale Mod-1 system, and a description of the measurement and data processing techniques and uncertainties can be found in Reference 1. 


\section{SYSTEM, PROCEDURES, CONDITIONS, AND EVENTS FOR TEST S-06-1}

The following system configuration, procedures, initial test conditions, and events are specific to Test S-06-1 as indicated.

\section{SYSTEM CONFIGURATION AND TEST PROCEDURES}

The Semiscale Mod-1 system used for this test consisted of a pressure vessel with internals, including a 40-rod core with 36 electrically heated rods; an intact loop with steam generator, simulated pump, simulated reflood bypass lines, LOFT counterpart nozzles ${ }^{[a]}$, and two rupture assemblies; a coolant injection accumulator for the intact loop; high and low pressure coolant injection pumps for the intact loop; and a pressure suppression system with a suppression tank, header, and heated steam supply system. Semiscale Mod-1 experimental system configuration information is provided in Reference 1. Figures 1 and 2 provide the system configuration for Test S-06-1.

For Test S-06-1, the 40-rod electrically heated core was operated at an axial peak power density which was $30 \%$ of the maximum peak power density $(52.5 \mathrm{~kW} / \mathrm{m}$ ). Four rods (Rods D-4, D-5, E-4, and E-5) were operated at approximately $15.75 \mathrm{~kW} / \mathrm{m}, 32$ rods were operated at approximately $9.97 \mathrm{~kW} / \mathrm{m}$, and 4 rods (Rods C-4, D-6, E-3, and F-5) were unpowered to simulate LOFT passive rod locations. This configuration yielded a peaked power profile which simulates that of LOFT and provides a total core power of approximately $405 \mathrm{~kW}$.

In preparation for the test, the intact loop accumulator was filled with treated demineralized water, drained to the specified initial level, and pressurized with nitrogen to $4223 \mathrm{kPa}$. The system was filled with treated demineralized water and vented at strategic points to ensure a liquid full system. Prior to warmup the system was pressurized to check for leakage, system instrumentation was checked, and transducer readings were initialized. Warmup to initial test conditions was accomplished with the heaters in the vessel core. Heatup of the broken loop piping was accomplished with bypass lines which served to allow circulation through the broken loop. During warmup, the puritication and sampling systems were valved into the primary system to maintain water chemistry requirements and to provide a water sample at system conditions for subsequent analysis. At 180-K-temperature intervals during warmup, detector readings were sampled to allow the integrity of the measurement instrumentation and the operability of the data acquisition system to be checked.

[a] The Semiscale Mod-1 system normally utilizes a break nozzle of the converging-diverging type referred to as a Henry nozzle. Reference 2 provides an illustration of the LOFT counterpart break nozzle. 


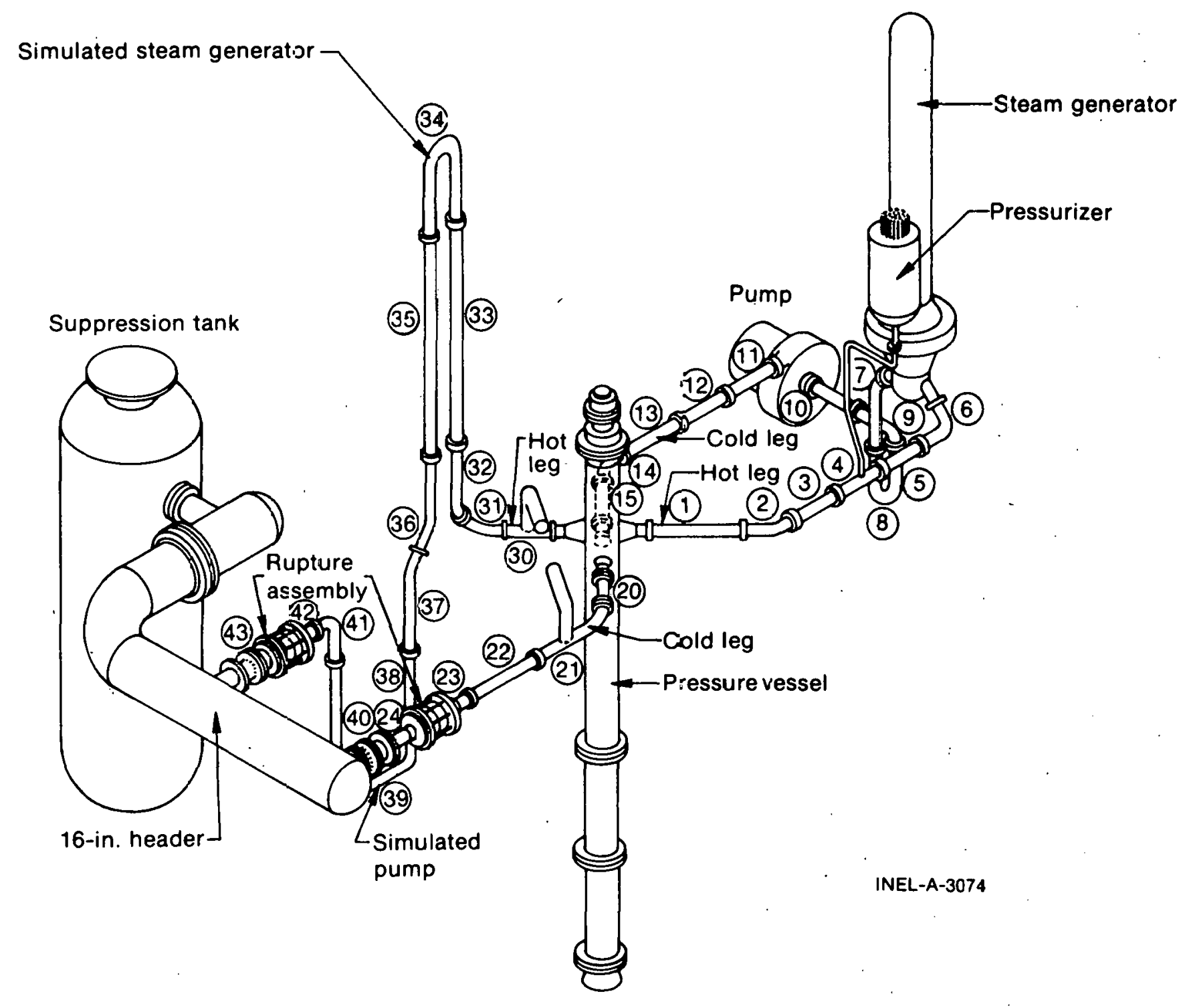

Fig. I Semiscale Mod-1 system for cold leg break configuration -- isometric. 


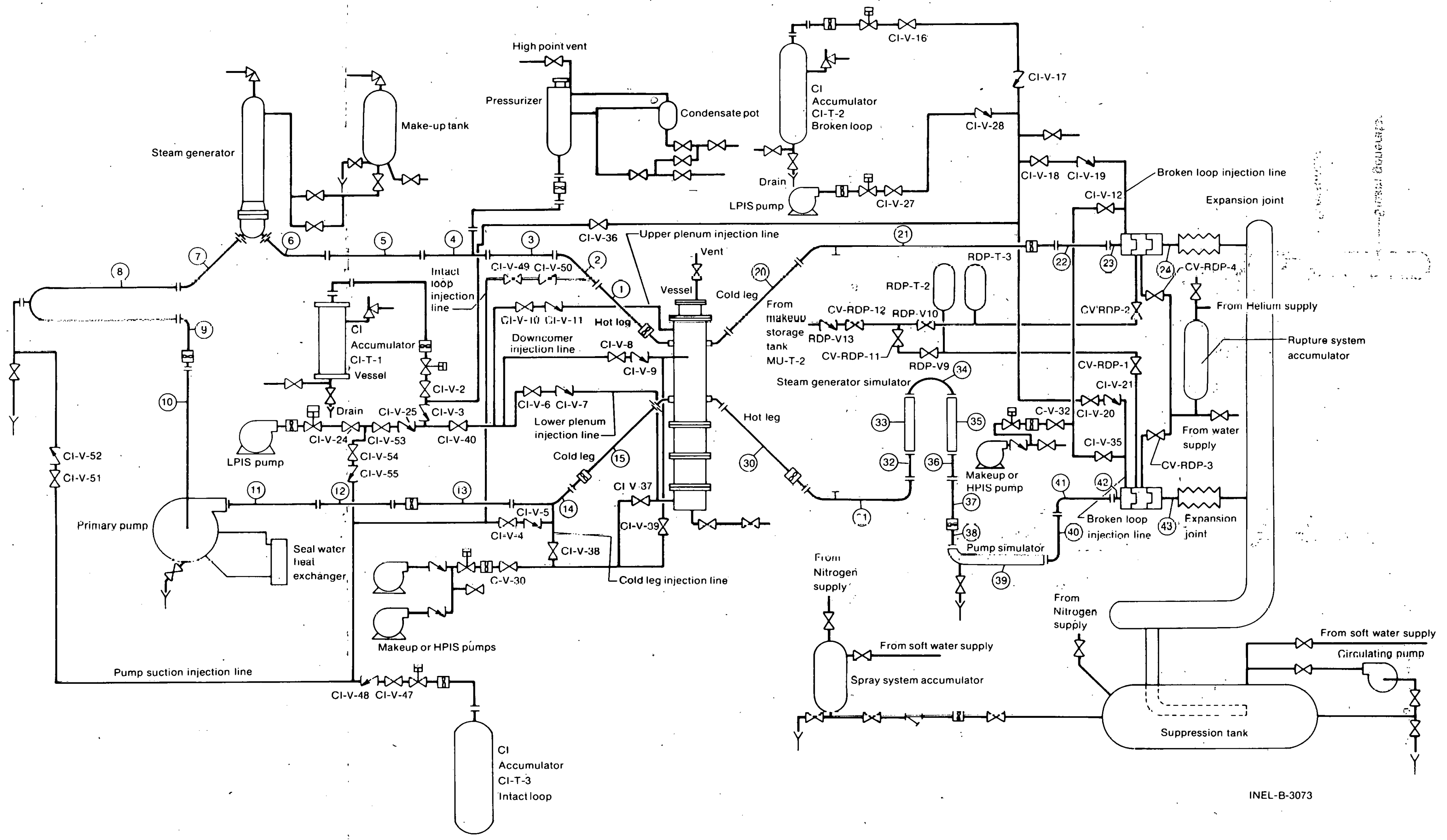

Fig. 2 Semiscale Mod-1 system for cold leg break configuration -- schematic. 
Prior to the initial core power level being established, the pressure suppression system was pressurized to $241 \mathrm{kPa}$ with saturated steam from the steam supply system. After the core power was increased to $405 \mathrm{~kW}$, initial test conditions were held for $1080 \mathrm{~s}$ to establish equilibrium in the system. At the end of this period all auxiliary systems including the bypass lines were isolated to prevent blowdown through those systems.

The system was successfully subjected to a simulated double-ended cold leg break through two rupture assemblies and two LOFT counterpart nozzles, each having a break area of $0.000243 \mathrm{~m}^{2}$. Pressure to operate the rupture assemblies and initiate blowdown was taken from an accumulator system filled with water and pressurized to $15600 \mathrm{kPa}$ with gaseous nitrogen. Immediately (within $0.02 \mathrm{~s}$ ) after initiation of blowdown, the lines to the accumulator were again isolated. The effluent from the primary system was ejected into the pressure suppression system which was vented to maintain a constant pressure of $241 \mathrm{kPa}$. During the blowdown transient, power to the electrically heated core was automatically controlled to simulate the thermal response of nuclear heated fuel rods. The steam generator feedwater flow and steam control valves were also automatically controlled to aid in the LOFT simulation. Throughout the test, the primary coolant circulation pump speed was held constant, at about $1760 \mathrm{rpm}$ :

For Test S-06-1, the coolant injection systems were arranged to discharge into the intact loop at the cold leg injection point (Spool 14). The high pressure coolant injection pump was started immediately after initiation of blowdown $(0 \mathrm{~s})$ and continued to the end of the test $(300 \mathrm{~s})$. Coolant injection from the intact loop accumulator started after the system was depressurized to $4226 \mathrm{kPa}$ at $20 \mathrm{~s}$ after blowdown, and nitrogen discharge began $56 \mathrm{~s}$ after rupture and was terminated $87 \mathrm{~s}$ after blowdown. Low pressure coolant injection was initiated $30.5 \mathrm{~s}$ after blowdown at a system pressure of $1551 \mathrm{kPa}$ and continued until test termination (300 s).

\section{INITIAL TEST CONDITIONS AND SEQUENCE OF EVENTS}

Conditions in the Semiscale Mod-1 system at initiation of blowdown are given in Tables I and II, the primary system water chemistry prior to blowdown is given in Table III, and the sequence of events relative to rupture is given in Table IV. 
TABLE I

CONDITIONS AT BLOWDOWN INITIATION

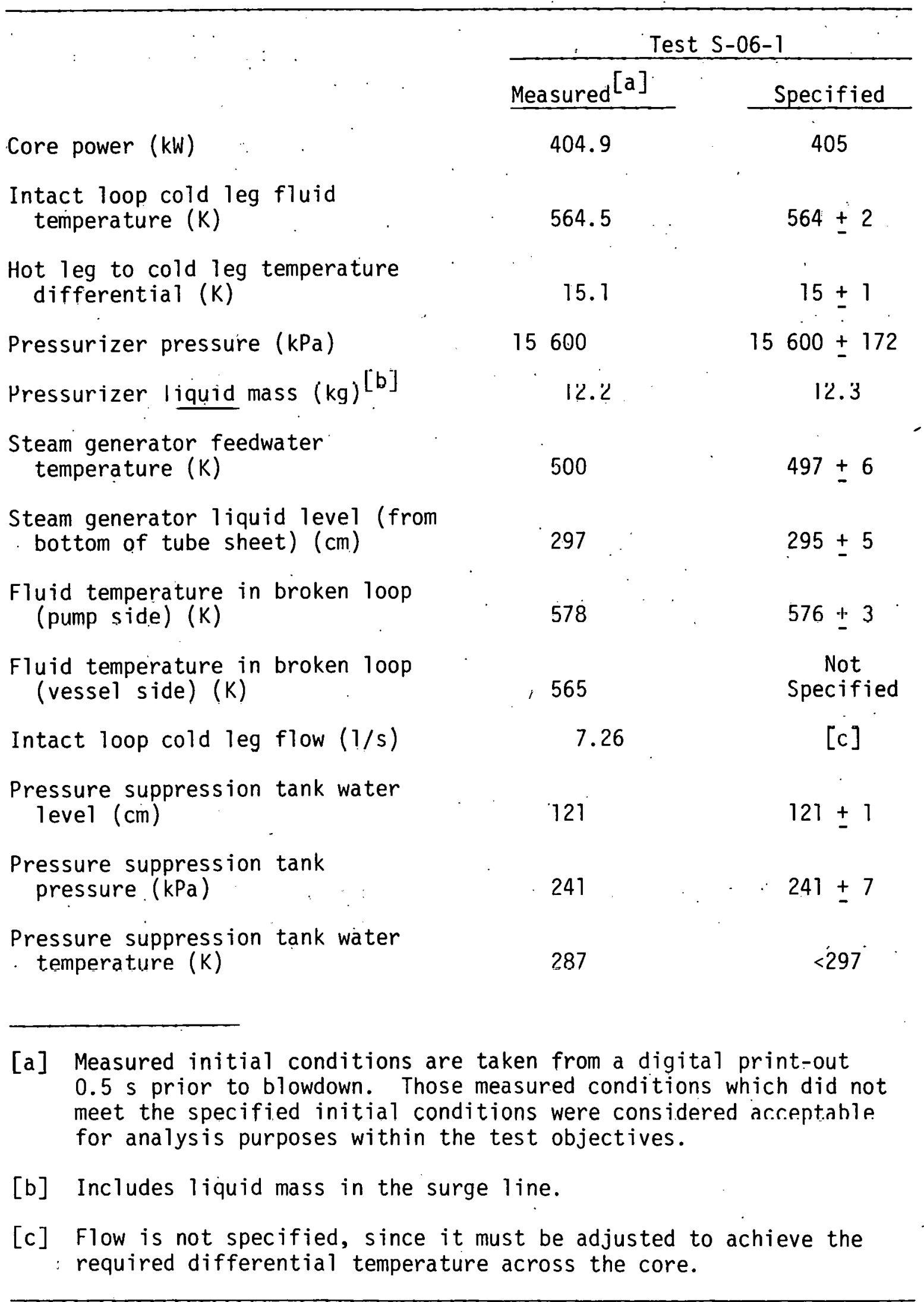


TABLE II

PRIMARY COOLANT TEMPERATURE DISTRIBUTION PRIOR TO RUPTURE[a]

\begin{tabular}{|c|c|c|}
\hline & \multicolumn{2}{|c|}{ Test S-06-1 } \\
\hline & Detector & Temperature (K) \\
\hline Vessel lower plenum & TFV-LP-22 & 564 \\
\hline Intact loop hot leg (near vessel) & RBU -2 & 580 \\
\hline Intact loop cold leg (near pump inlet) & TFU-10 & 565 \\
\hline Intact loop cold leg (near vessel) & RBU-14A & 564 \\
\hline Broken loop cold leg (near nozzle) & TFB-23 & 564 \\
\hline Broken loop hot leg (near vessel) & TFB -30 & 579 \\
\hline Broken loop cold leg (near nozzle) & TFB -42 & 574 \\
\hline $\begin{array}{l}\text { Reflood bypass line hot leg (near } \\
\text { end cap) }\end{array}$ & TFB-RFB-H & 570 \\
\hline $\begin{array}{l}\text { Reflood bypass line cold leg (near } \\
\text { end cap) }\end{array}$ & TFB-RFB-C & 563 \\
\hline
\end{tabular}




\section{TABLE III}

WATER CHEMISTRY PRIOR TO BLOWDOWN ${ }^{[a]}$

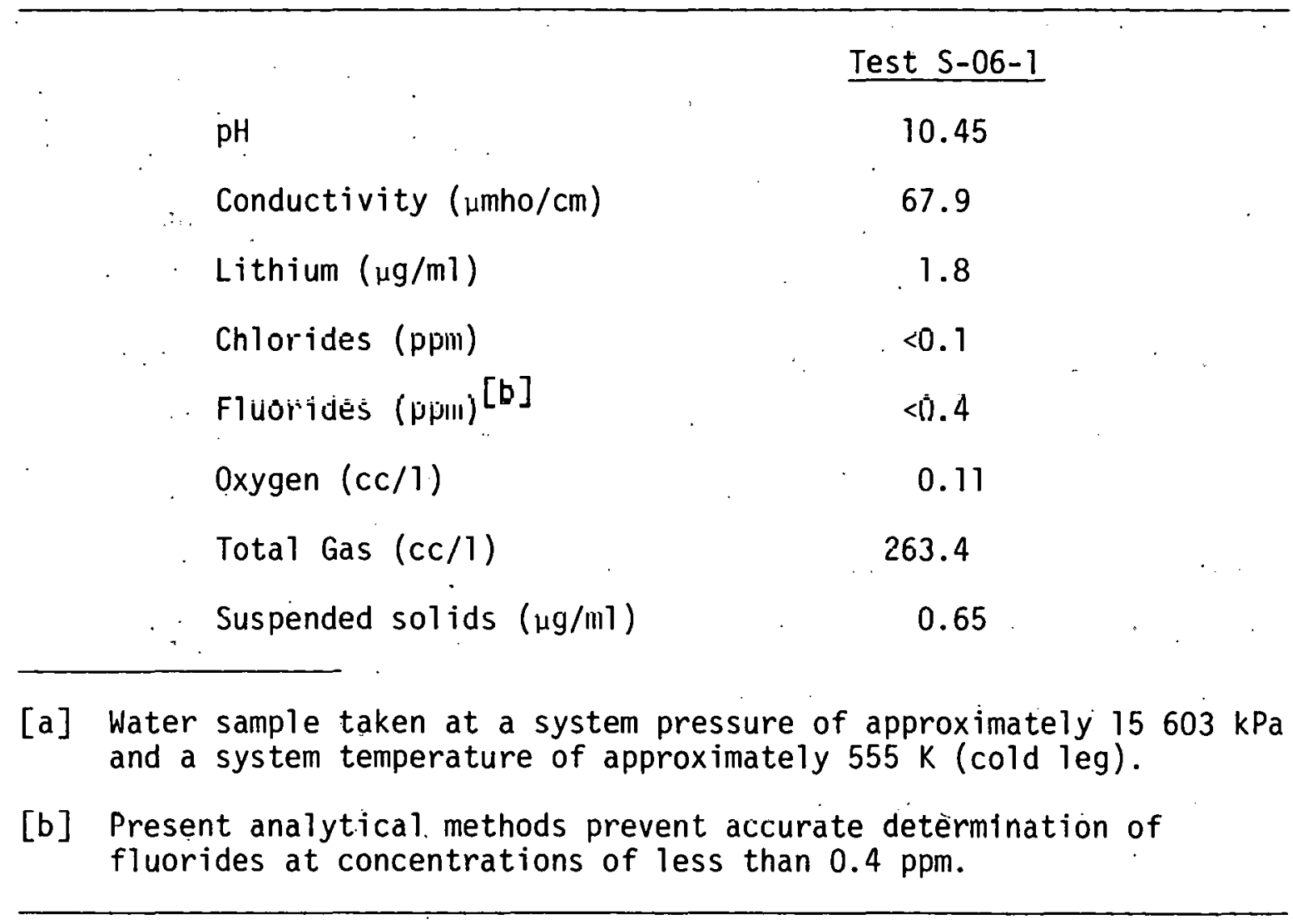


TABLE IV

SEQUENCE OF EVENTS DURING TEST S-06-1 [a]

Time Relative

Event

Core power level established

Bypass lines valved out of system

Blowdown initiated

High pressure injection system pumps

- started $[\mathrm{b}]$

ECC accumulators valved in ${ }^{[b]}$ switch to automatic flow control

Core power decay transient started

Low pressure injection system pumps started ${ }^{[\mathrm{b}]}$

Core power tripped off $[\mathrm{c}]$
Steam generator feedwater and discharge valves

To Rupture (s)

$-1080$

[a] A time-controlled sequencer was used to control critical events during the test.

[b]. Injection from ECC accumulators and high and low pressure injection system pumps does not start until system pressure drops below accumulator or pump pressure, respectively.

[c]. Core power tripped manually at termination of test. 


\section{DATA PRESENTATION}

The data from Semiscale Mod-1 Test S-06-1 are presented with brief comment. Processing analysis has been performed only to the extent necessary to obtain appropriate engineering units and to ensure that the data are reasonable and consistent. In all cases, in converting transducer output to engineering units, a homogeneous fluid was assumed. Further interpretation and analysis should consider that sudden decompression processes such as those occurring during blowdown may have subjected the measurement devices to nonhomogeneous fluid conditions.

The performance of the system during Test S-n6-1 was mnnitnred hy 222 detectors. The data obtained were recorded on both digital and analog data acquisition systems. The digital system was used to process the data presented in this repurt. The digital data were recorded at a sample rate of 57.5 points per second. Long term data ( -20 to $300 \mathrm{~s}$ ) were compressed at a 20 to 1 ratio giving an effective sample rate of 2.875 points per second. Long term plots are given for -20 to $200 \mathrm{~s}$ to provide better resolution of the plots. Short term data and plots ( -6 to $42 \mathrm{~s}$ ) were compressed at a 3 to 1 ratio giving an effective sample rate of 19.17 points per second. The analog system was used to provide better resolution capability (needed as input to various data analysis codes).

The data are presented in some instances in the form of composite graphs to facilitate comparison of the values of given variables at several locations. The scales selected for the graphs do not reflect the obtainable resolution of the data. (The data processing techniques are described further in Reference 1.)

Figures 3 through 8 and Table $\mathrm{V}$ provide supporting information for interpretation of the data graphs shown in Figures 9 through 342, and provide relative locations of all detectors used during Test S-06-1. Table V groups the measurements according to measurement type, identifies the specific measurement location and range of the detector and actual recording range of the data acquisition system, provides brief comments regarding the data, and references the measurements and comments to the corresponding figure. Figures 9 through 342 present all the blowdown and reflood data obtained. Time zero on the graphs is the time of rupture initiation. Appendix A provides information explaining posttest data processing for data conversion into engineering units and data adjustments. Presented in Appendix B is an analysis of selected data which provide a guide to the uncertainty associated with data measurements in the Semiscale Mod-1 system. 


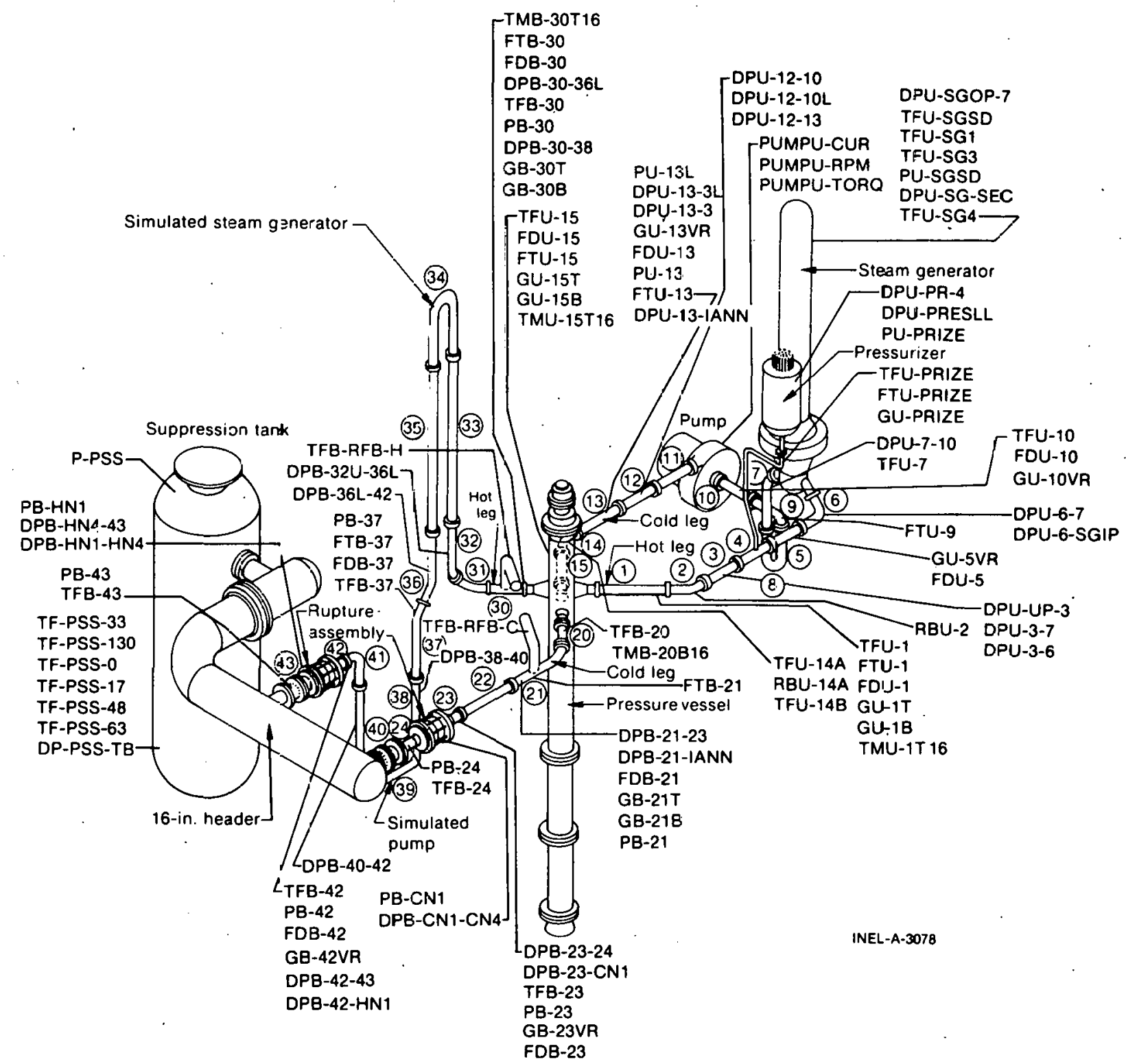

Fig: 3 Semiscàle Mod-1 system and instrumentation for cold leg break configuration -- isometric. 


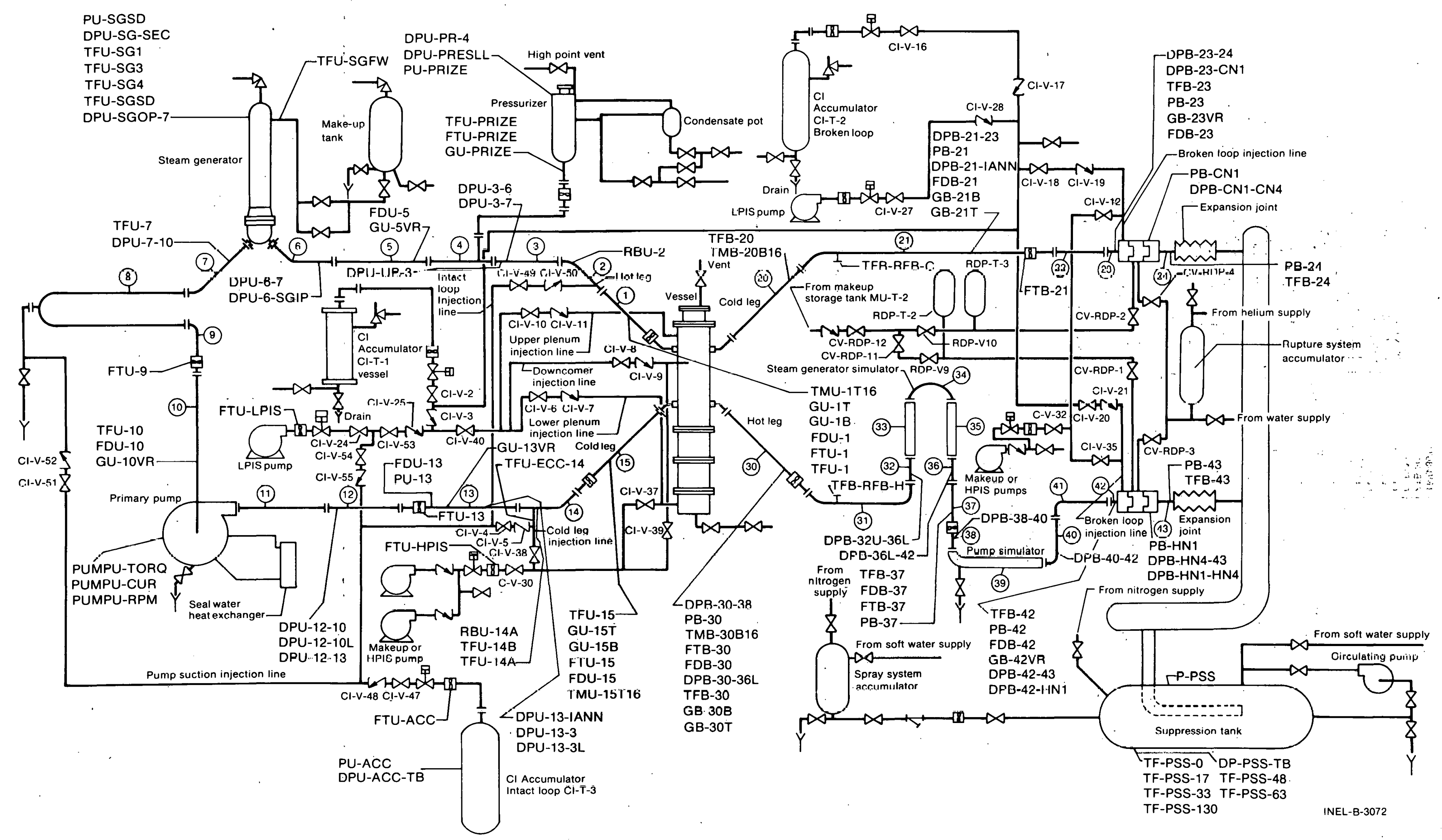

Fig. 4 Semiscale Mod-l system and instrumentation for cold leg break configuration -- schematic. 


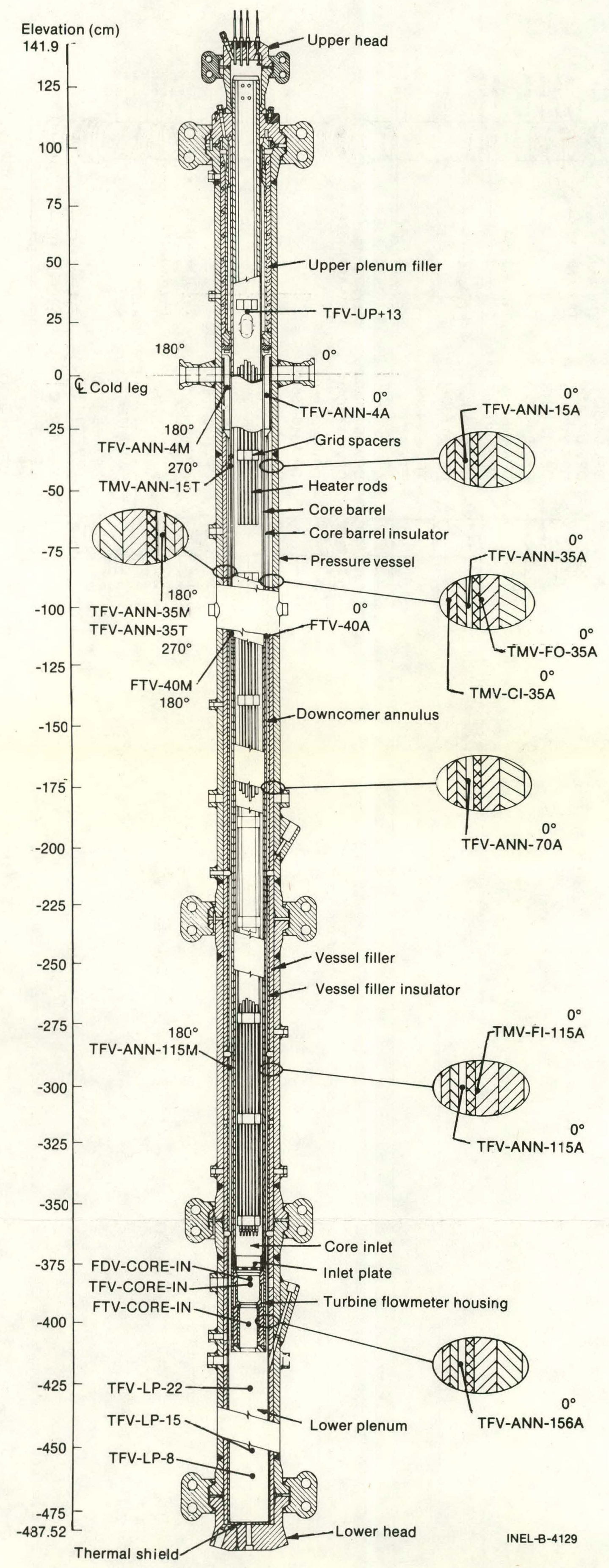

Fig. 5 Semiscale Mod-1 pressure vessel -- cross section showing instrumentation. 
Distance from cold leg \& $(\mathrm{cm})$

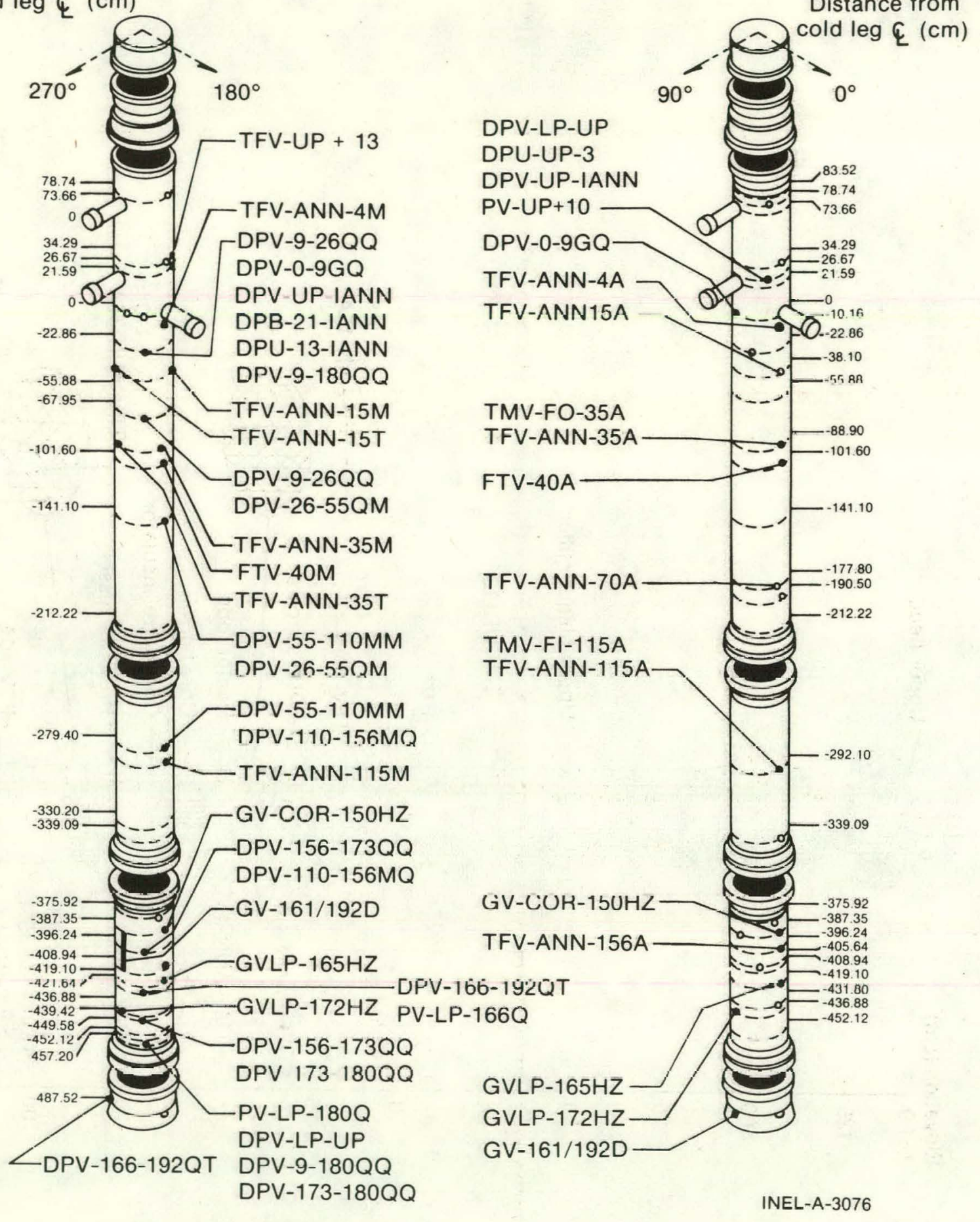

Fig. 6 Semiscale Mod-1 pressure vessel -- isometric showing instrumentation. 


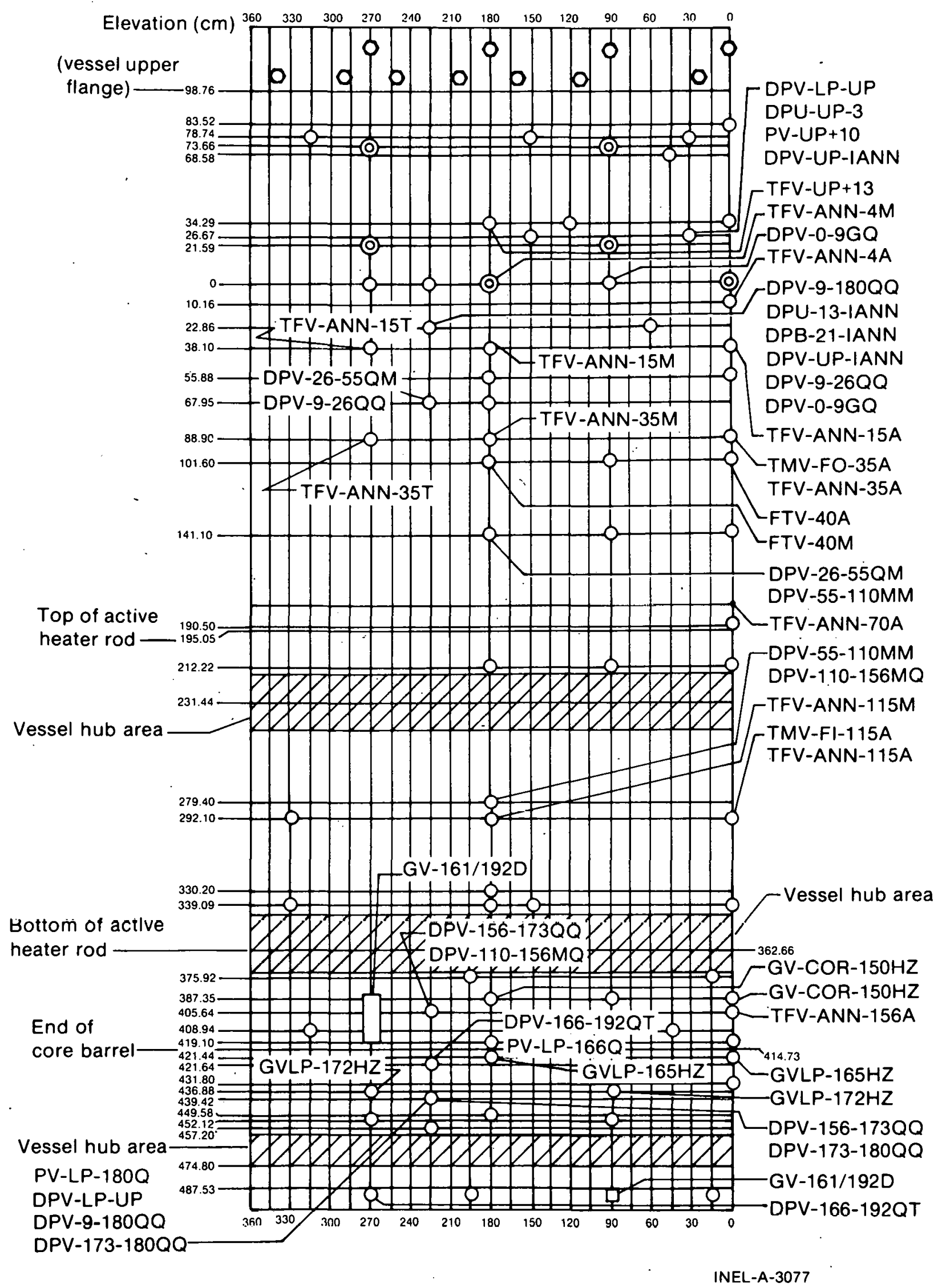

Fig. 7 Semiscale Mod-1 pressure vessel -- penetrations and instrumentation. 
$\begin{array}{lllllllllllllllll}A & B & C & D & E & F & G & H\end{array}$

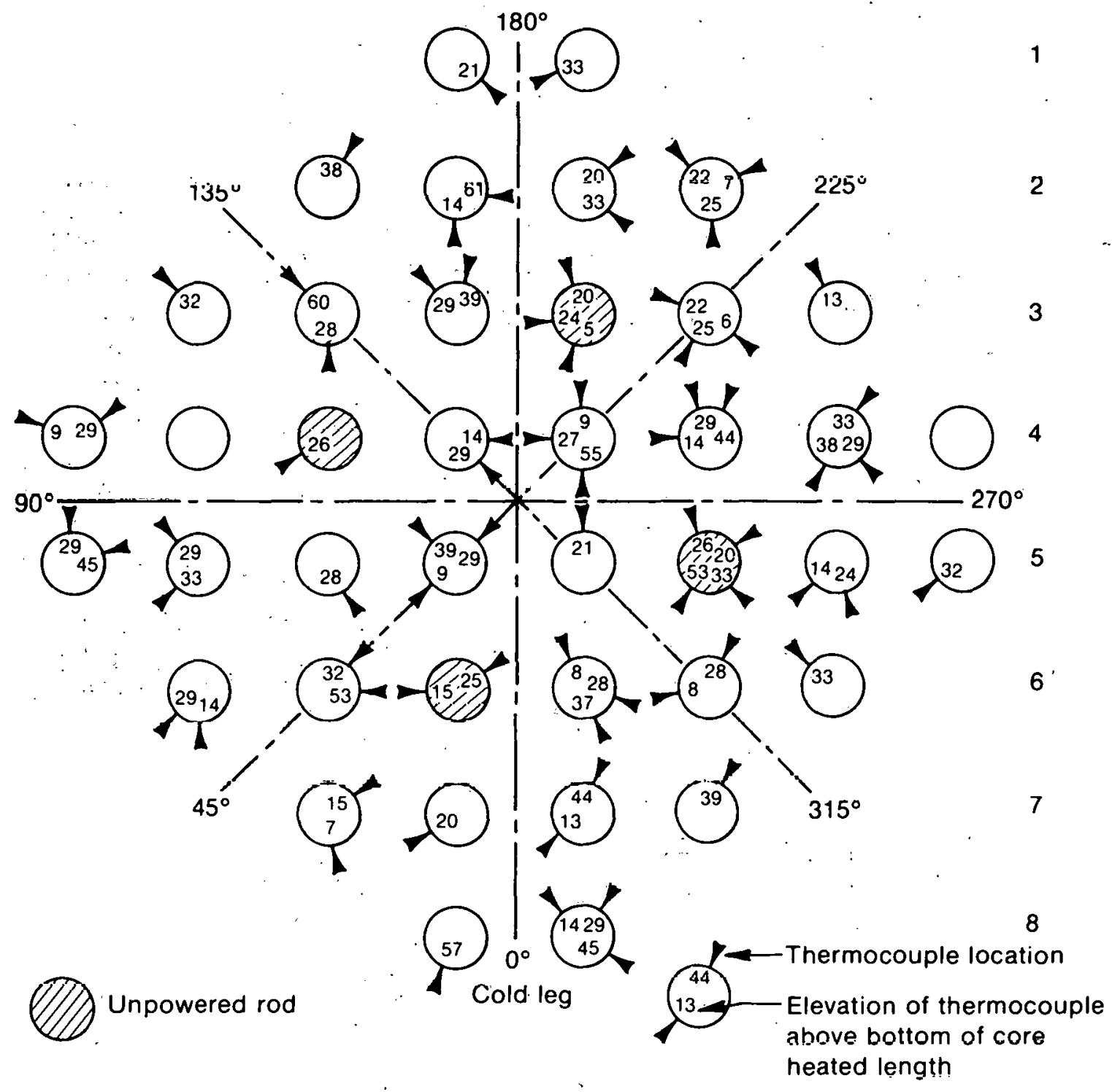

INEL-A-3075

Fig. 8 Semiscale Mod- $]$ heated core -- plan view. 
TABLE V

DATA PRESENTAJION FOR SEMISCALE MOD-1 TEST S-06-1

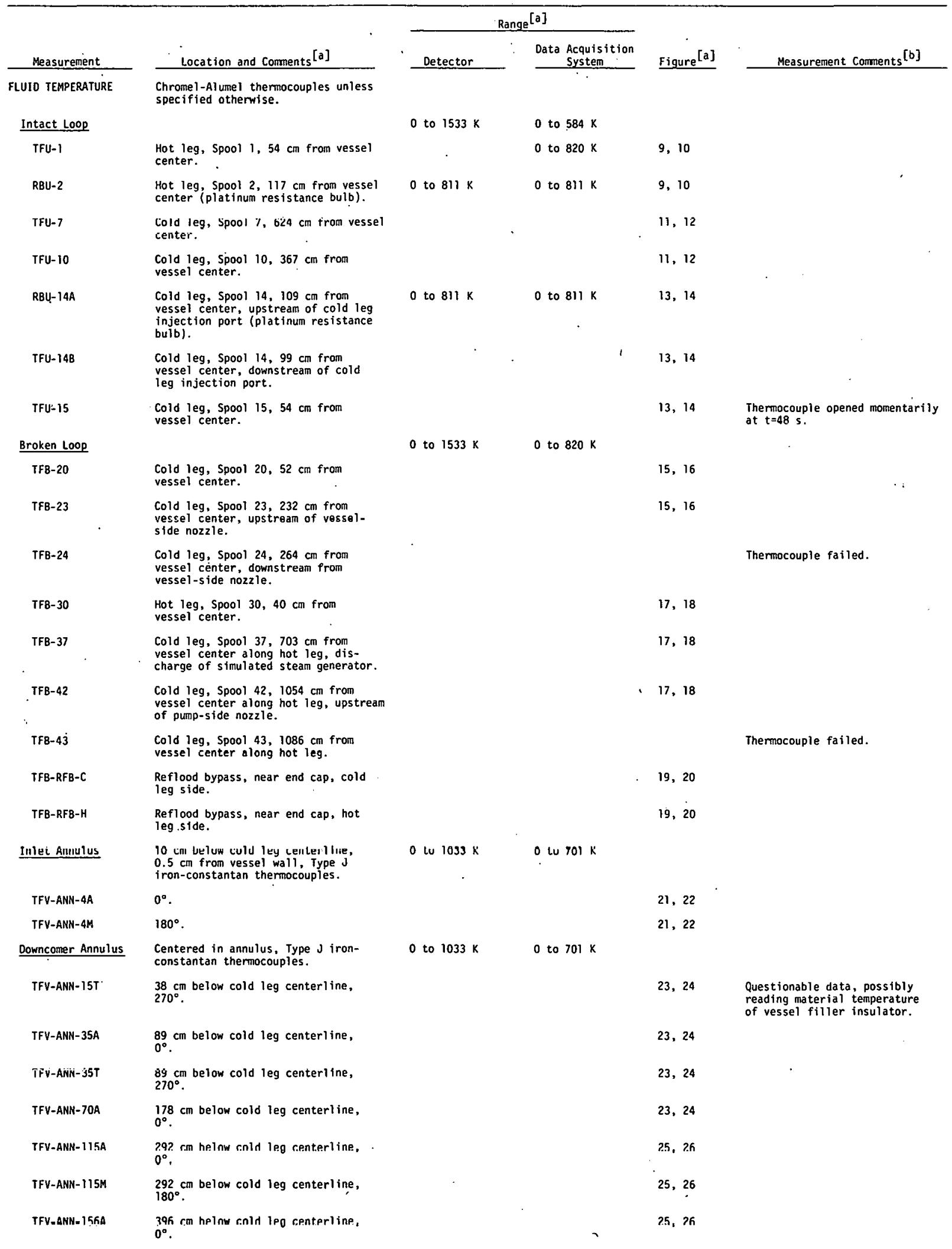


TADLC V (continued)

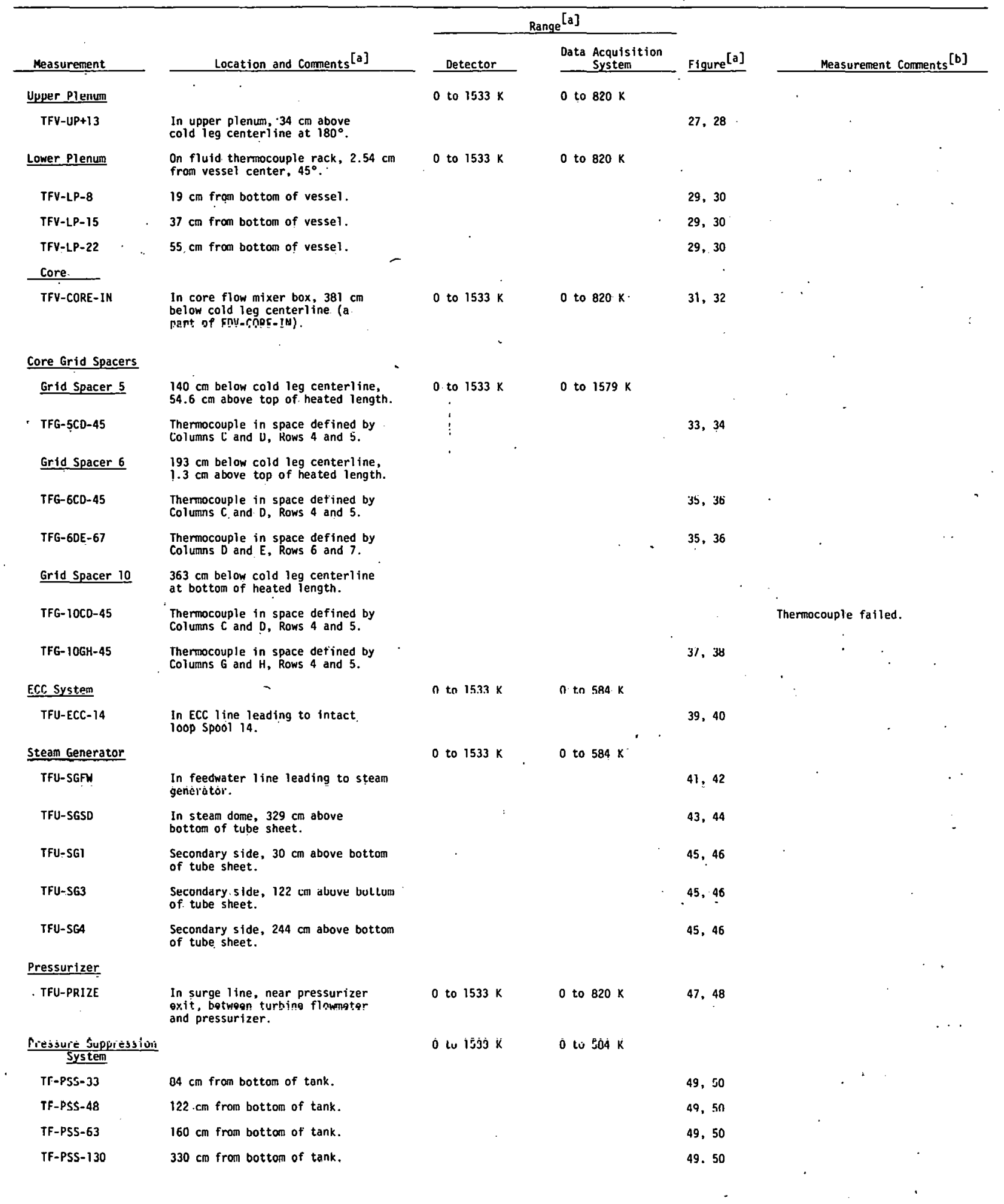


TABLE V (continued)

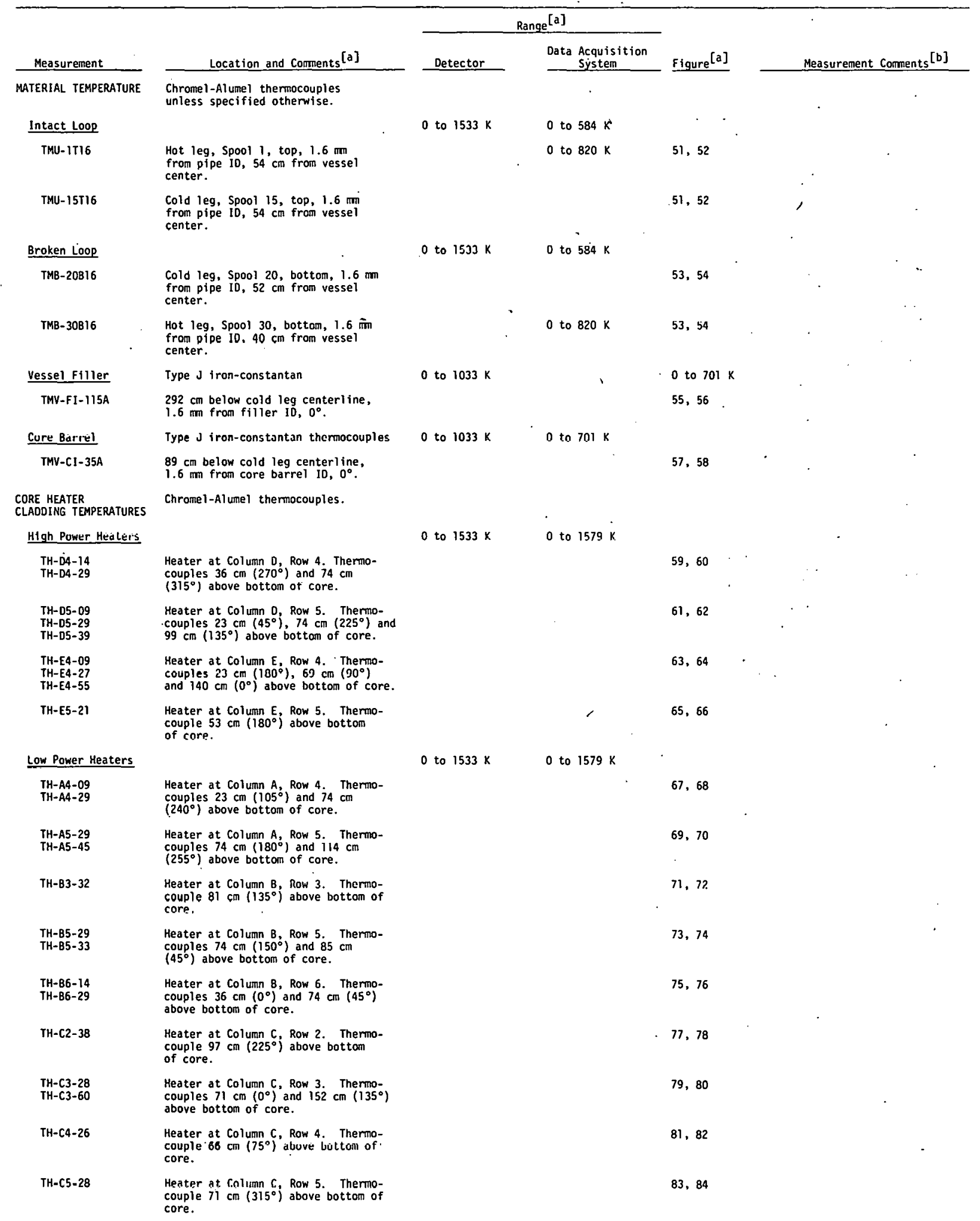




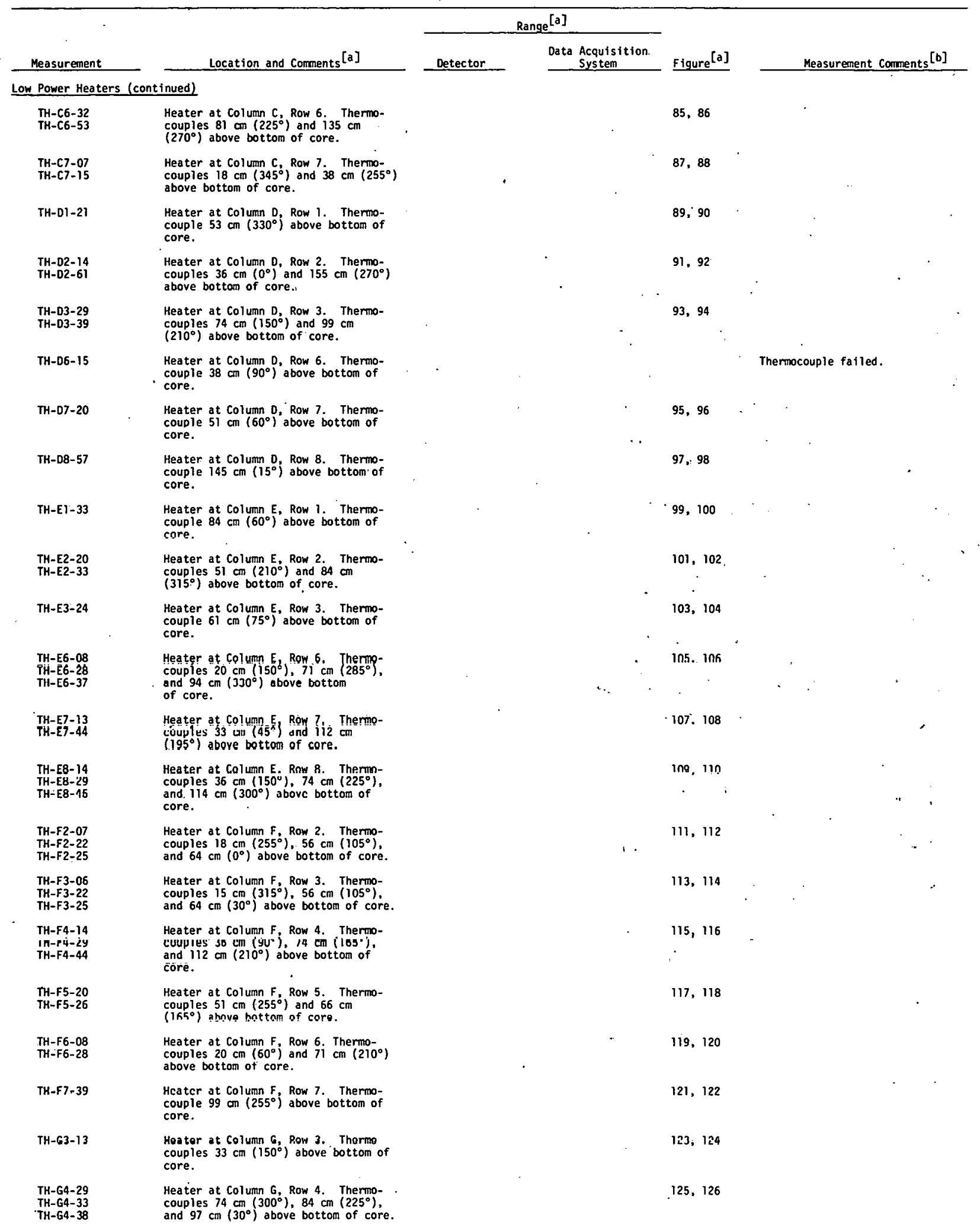


IABLE $\vee$ (cont inued)

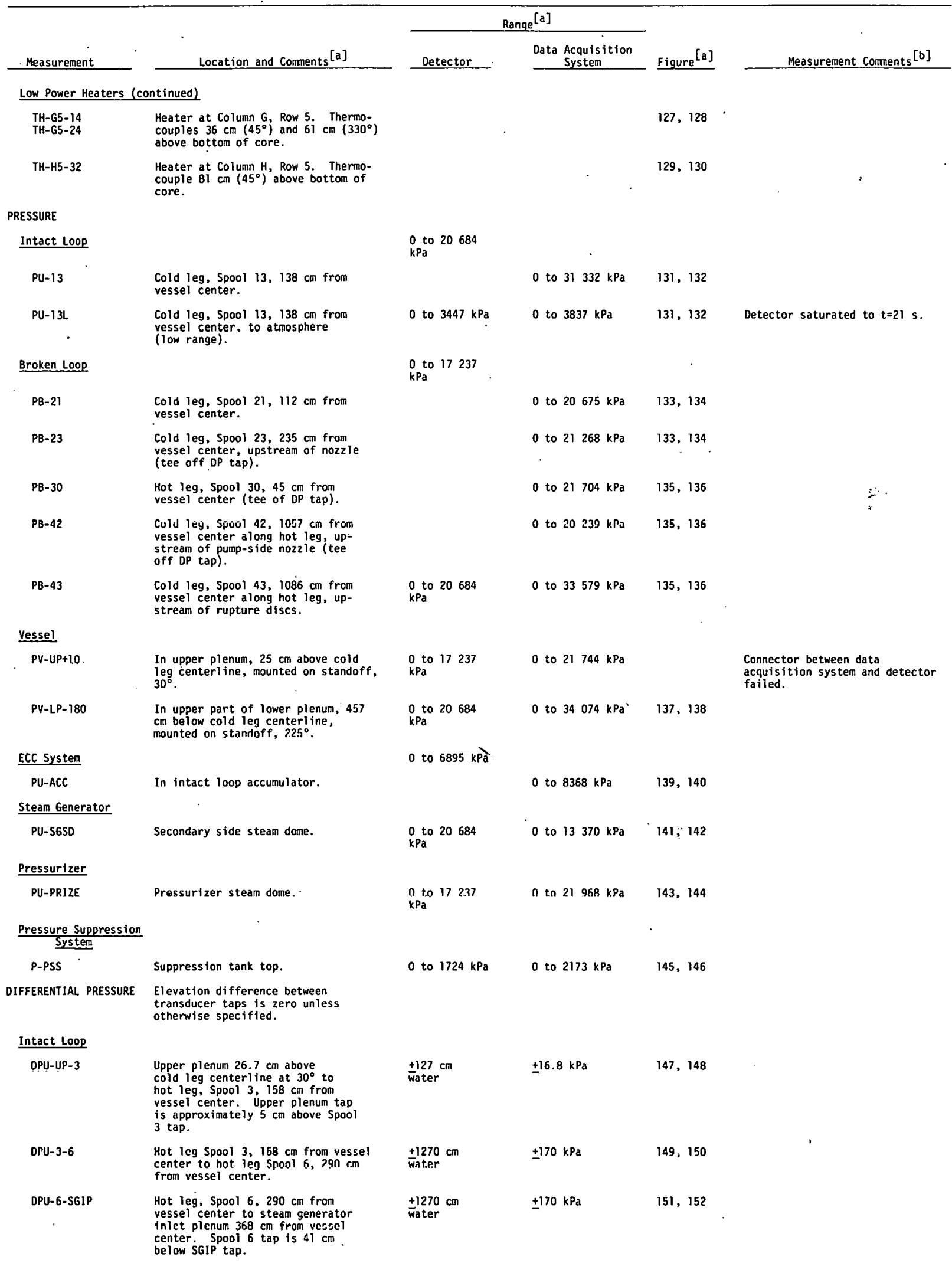


TABLE V (continued)

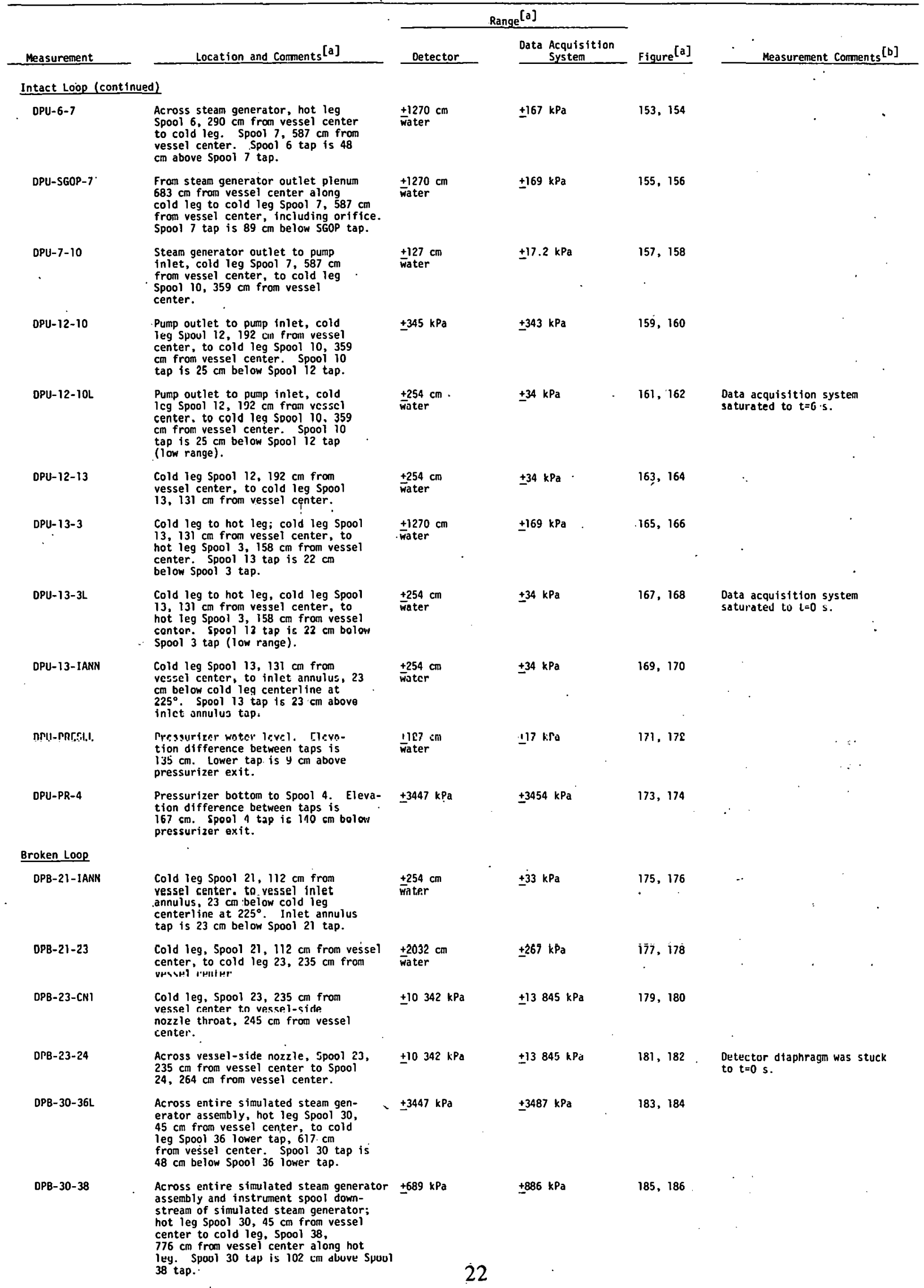


TABLE V_(continued)

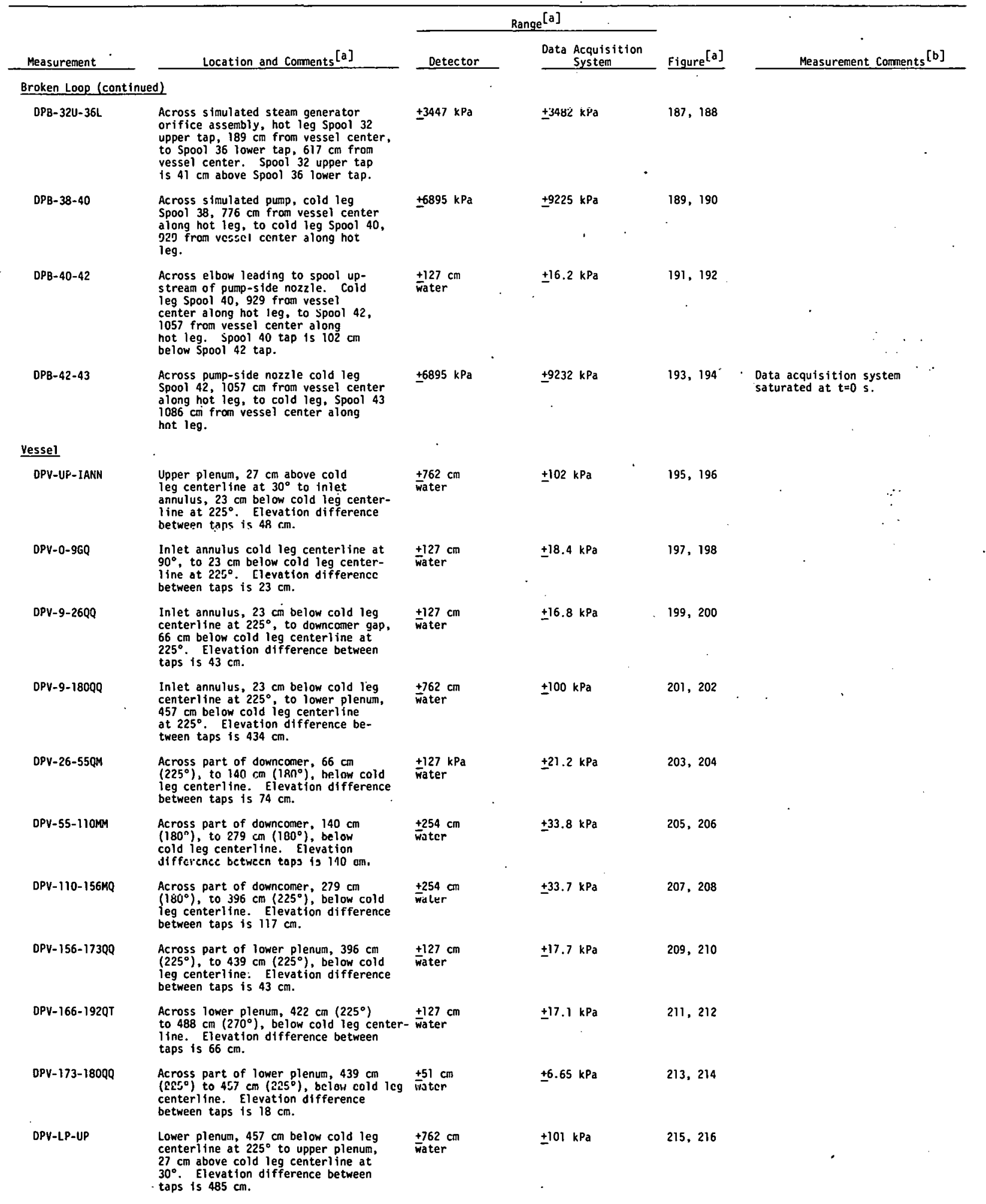


TABLE V (cont Inued)

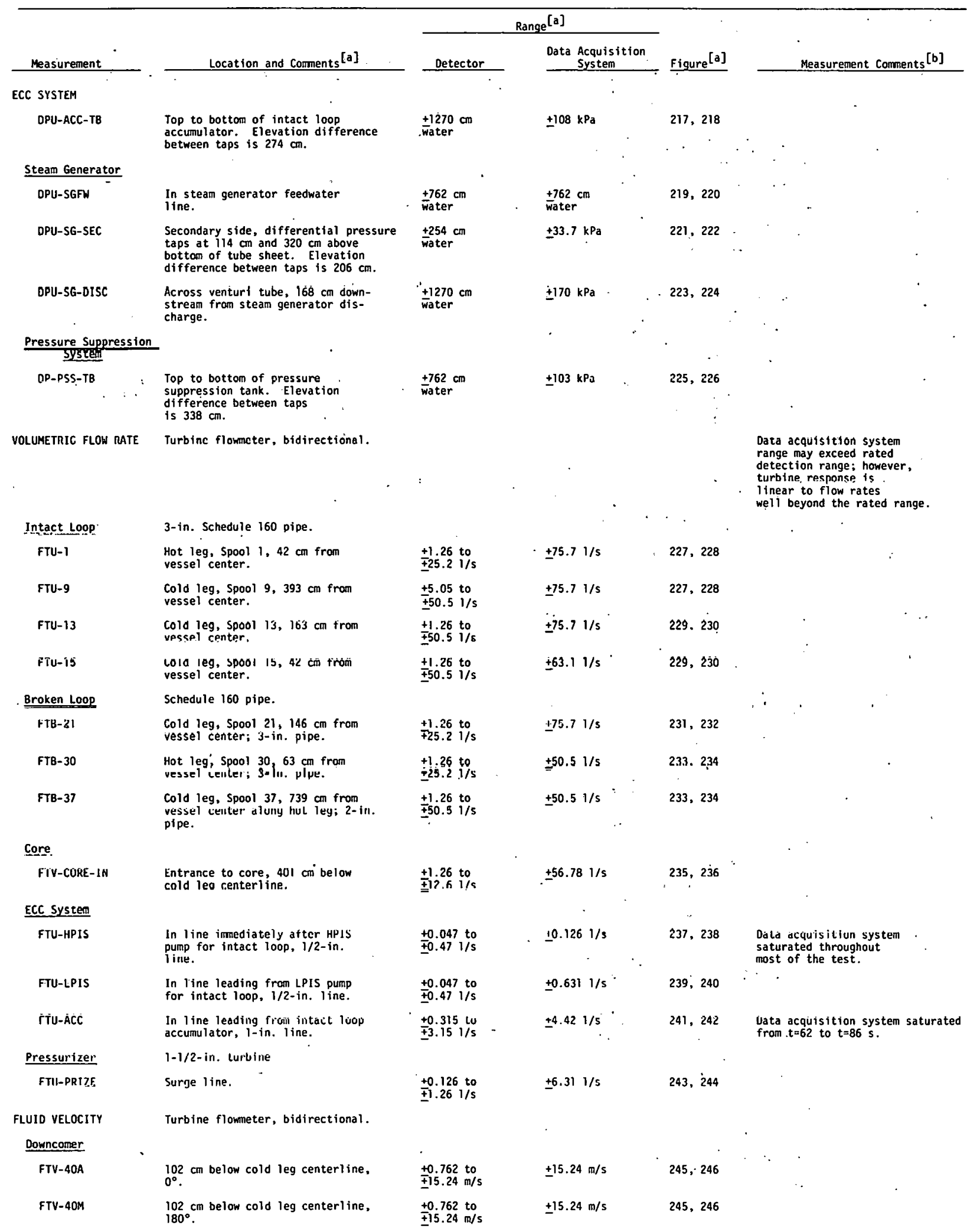


TABLE V (continued).

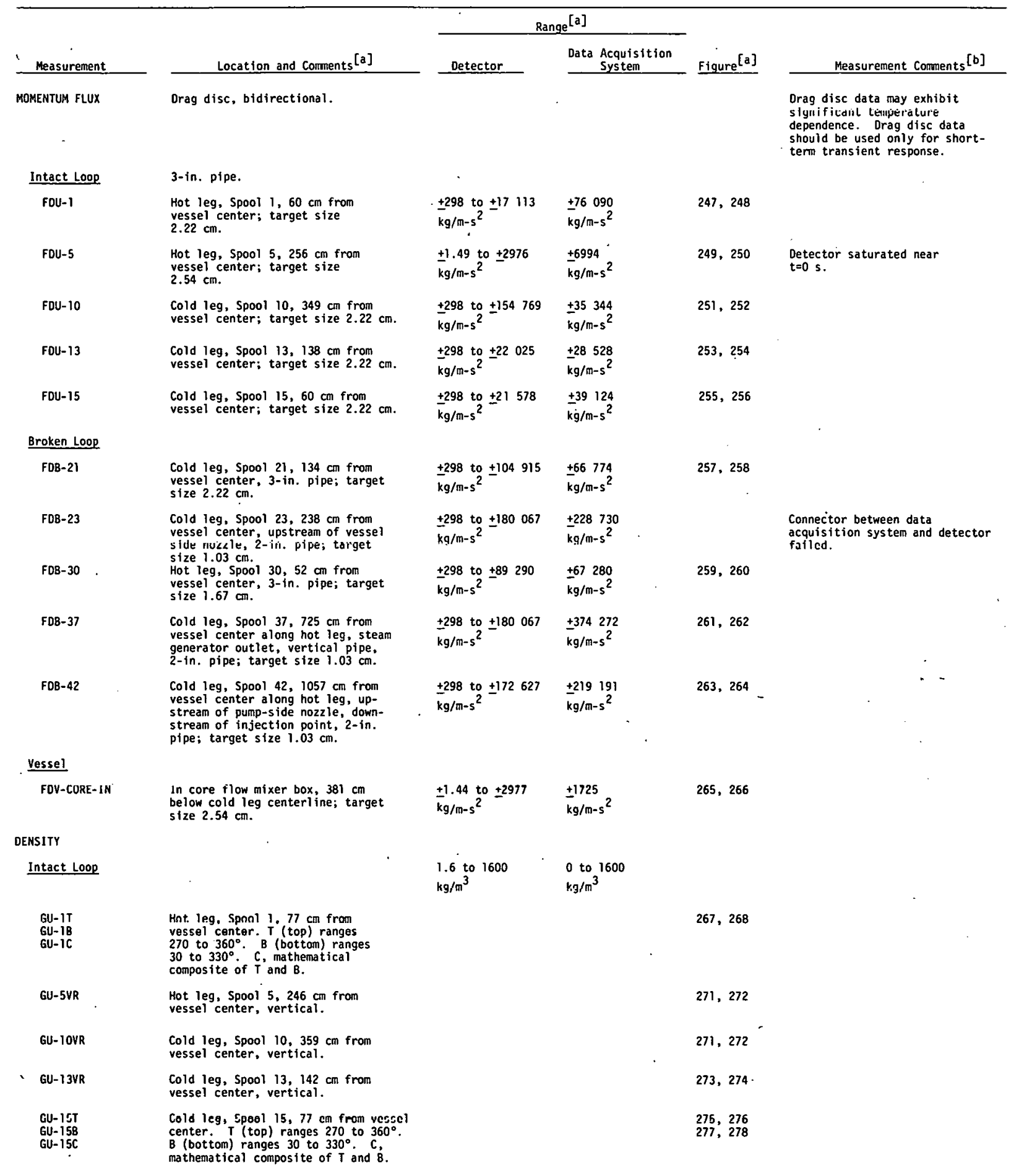


TABLC $\vee$ (continued)

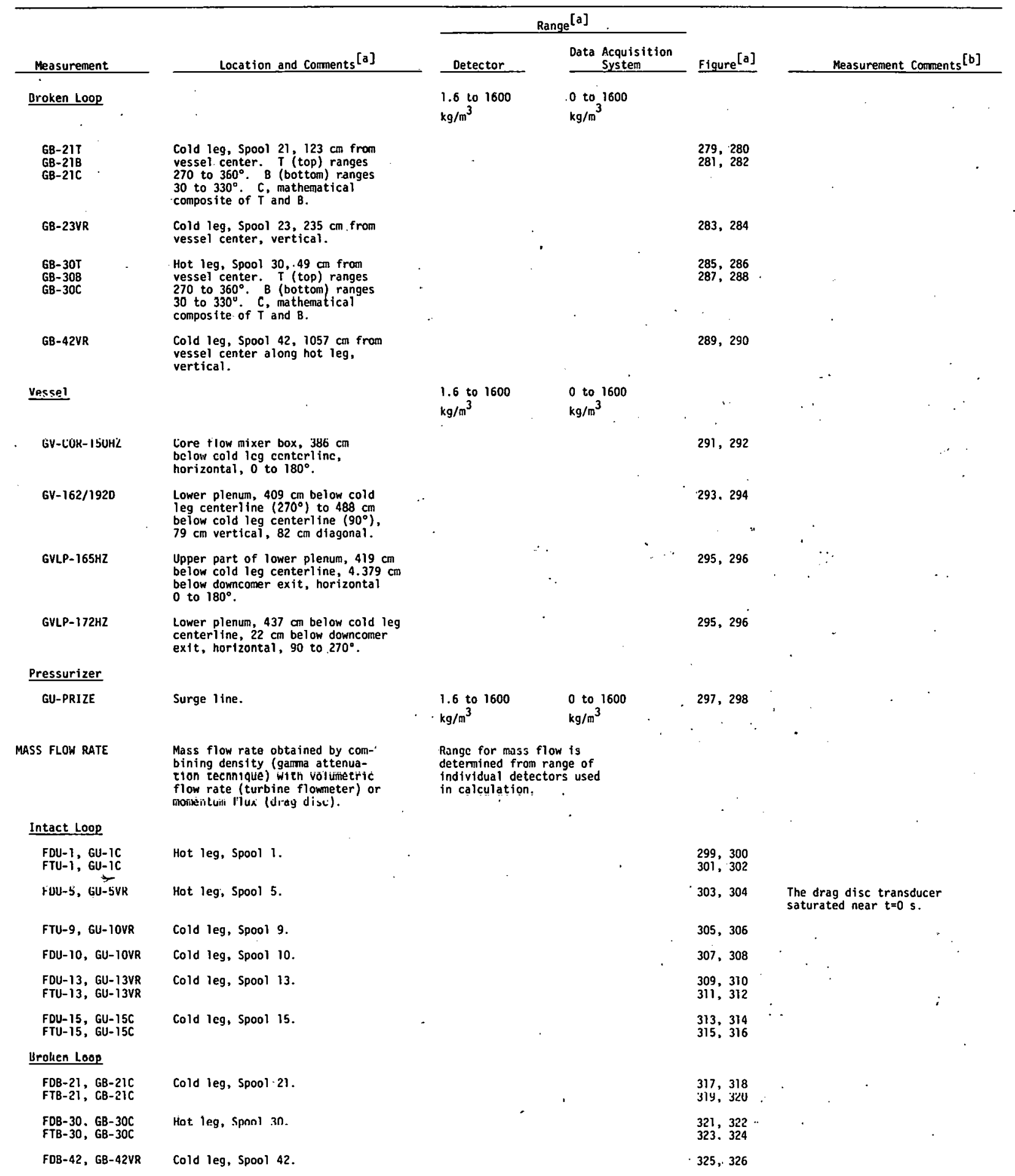


TABLE V (continued)

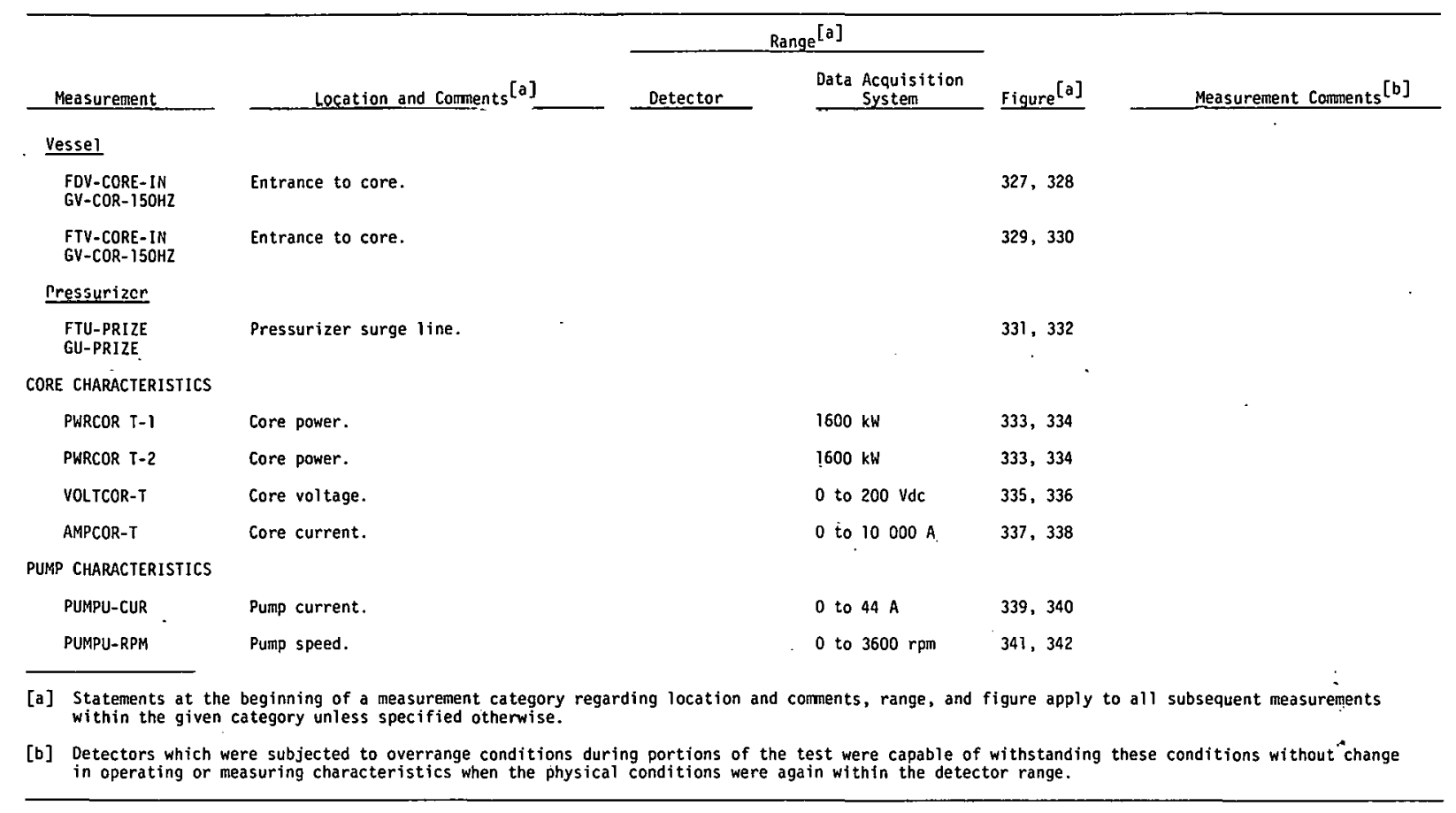




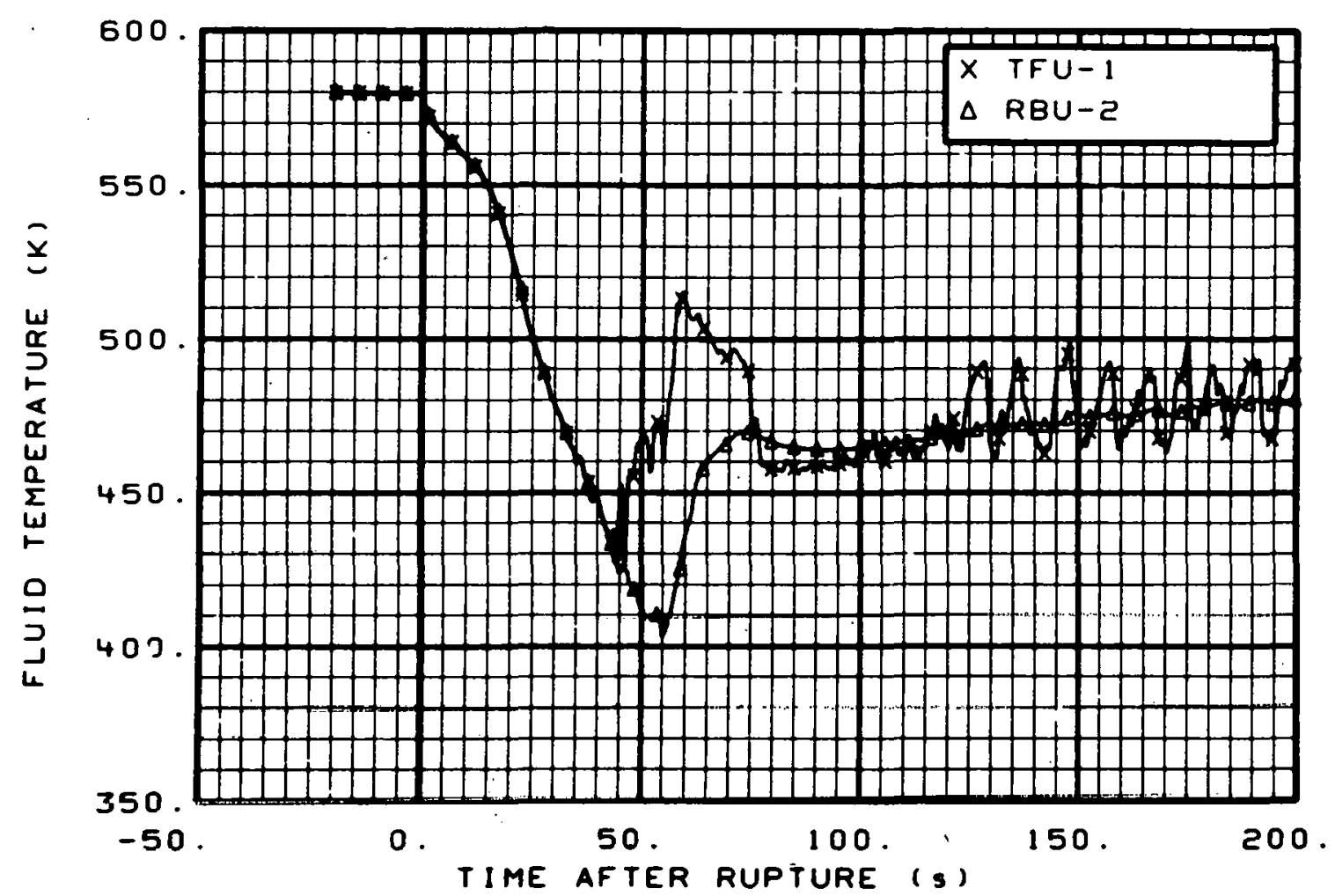

Fig. Y Fluid temperature in intact loop hot leg (TFU-1 and RBU-2), from -20 to $200 \mathrm{~s}$.

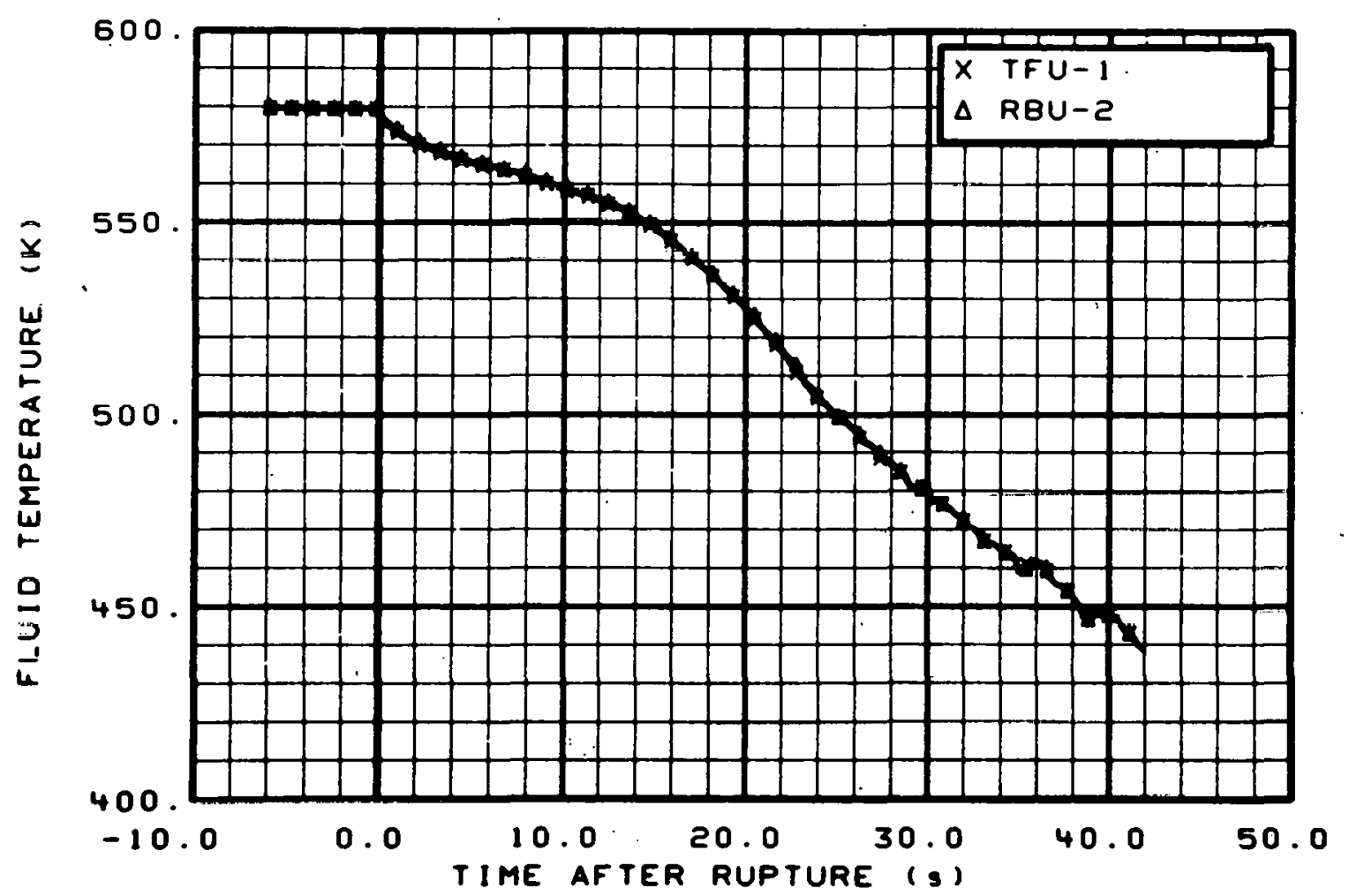

Fig. 10 Fluid temperature in intact loop hot leg (TFU-1 and RBU-2), from -6 to 42 s. 


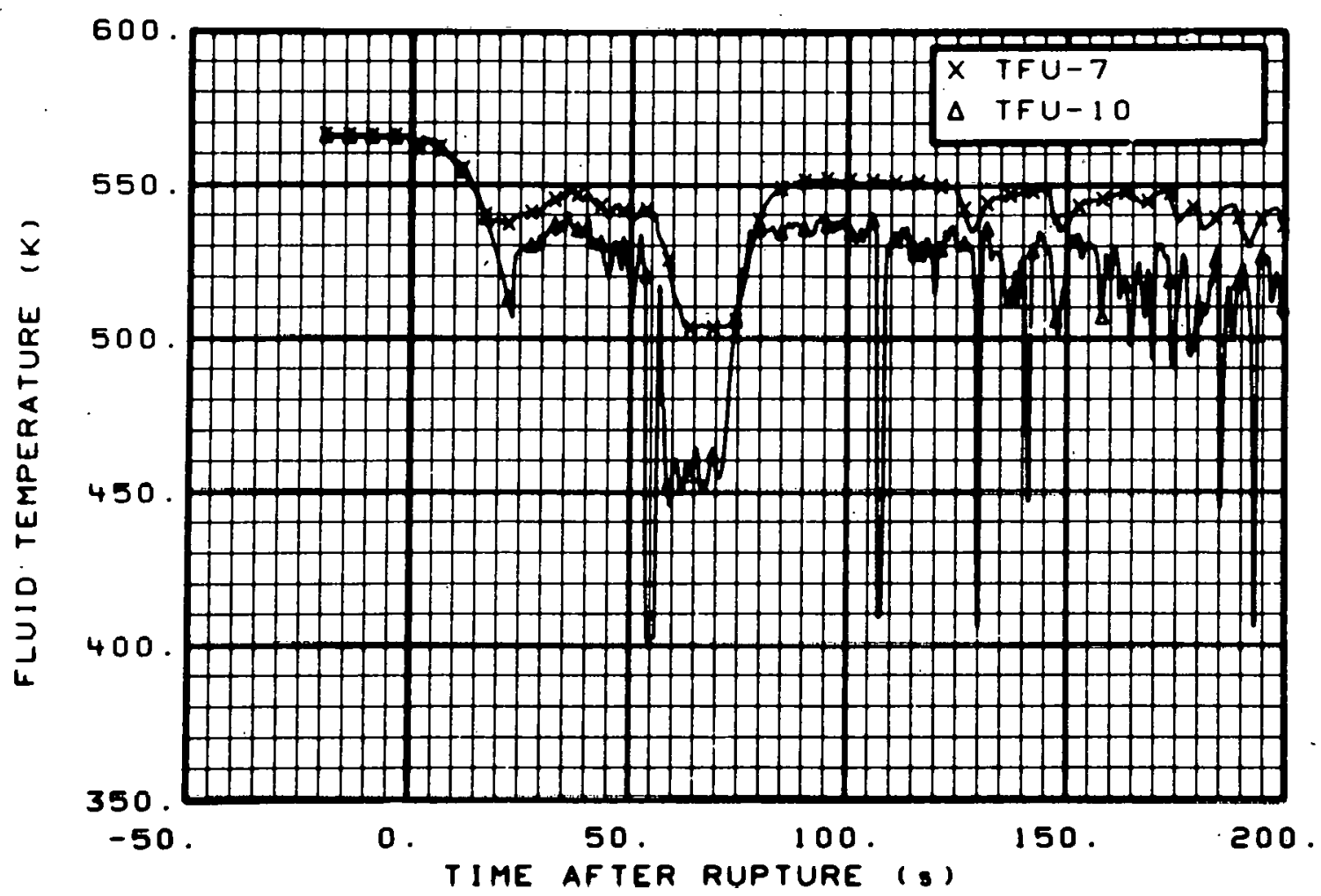

Fig. 11 Fluid temperature in intact loop cold leg (TFU-7 and TFU-10), from -20 to $200 \mathrm{~s}$.

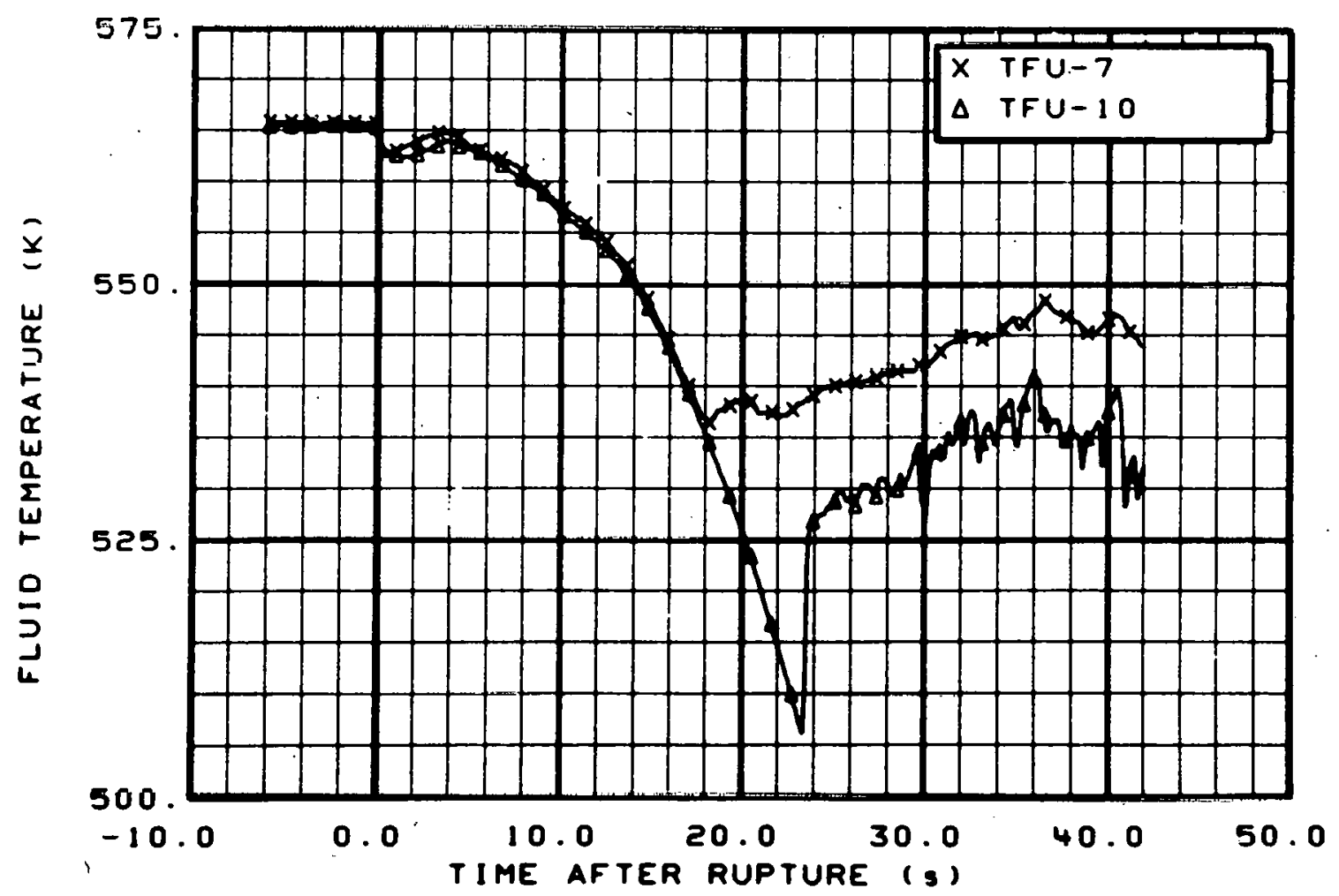

Fig. 12 Fluid temperature in intact 100p cold $1 \mathrm{cg}$ (TFU-7 and TFU-10), from -6 to $42 \mathrm{~s}$. 


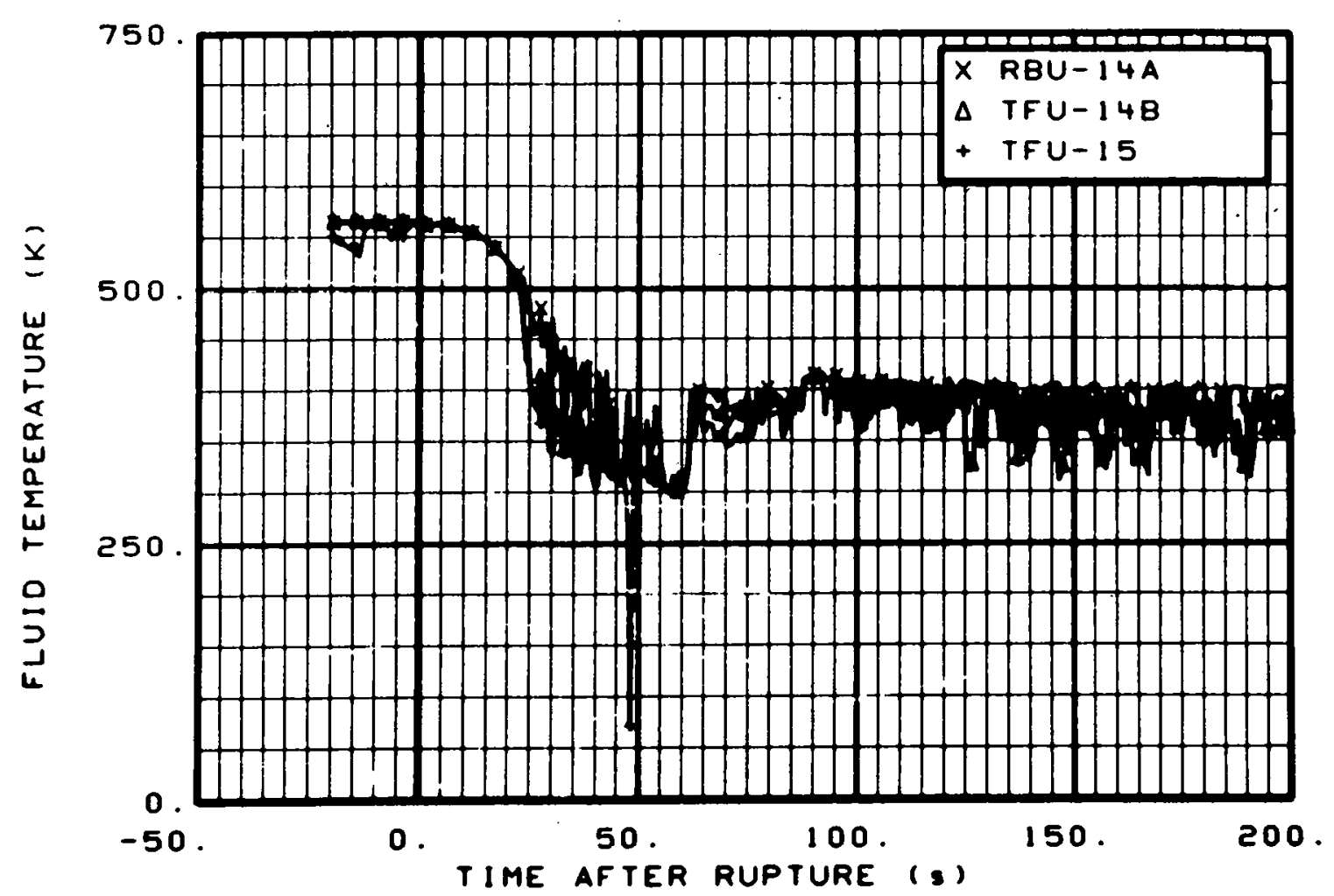

Fig. 13 Fluid temperature in intact loop cold leg (RBU-14A, TFU-14B, and TFU-15), from -20 to $200 \mathrm{~s}$.

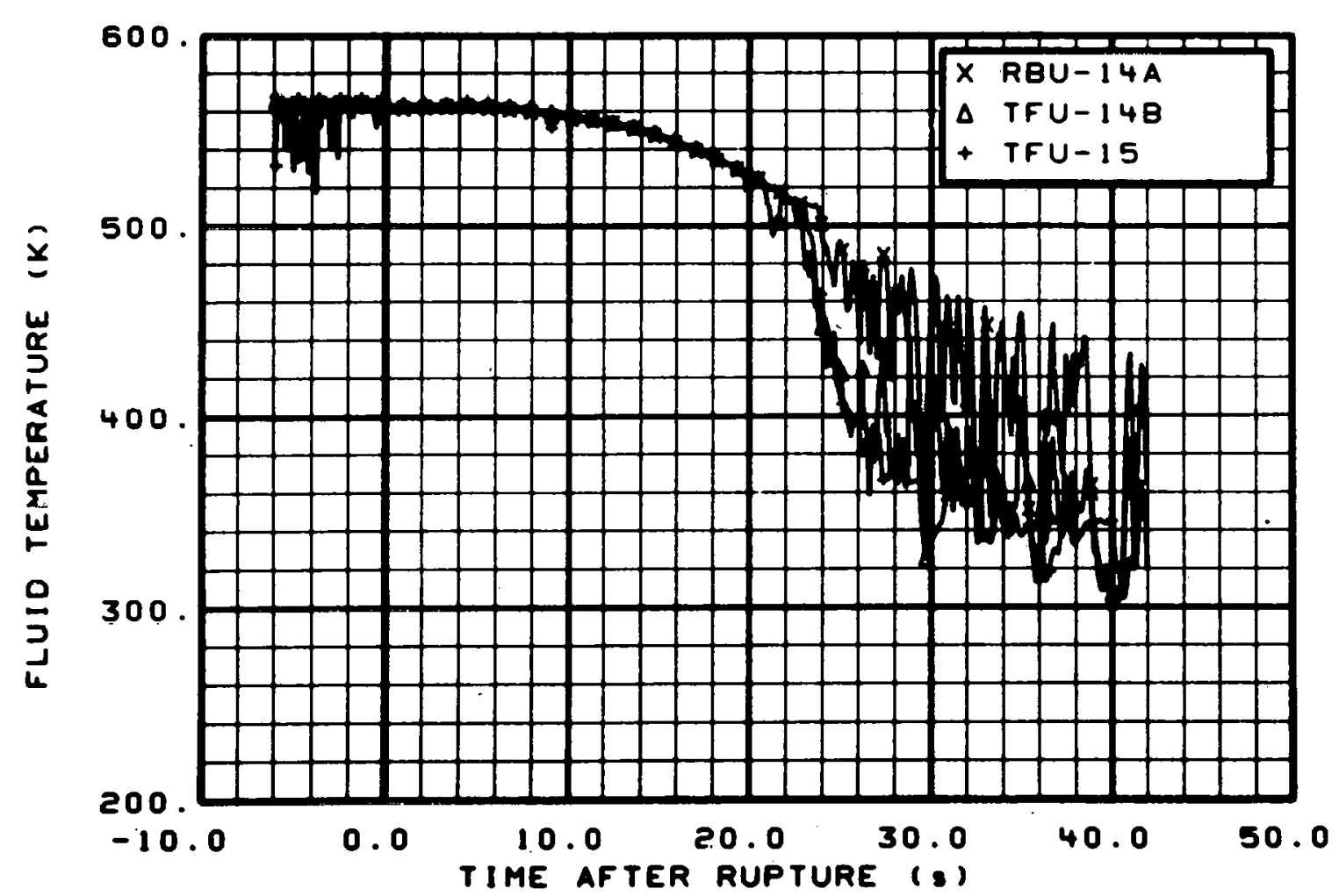

Fig. 14 Fluid temperature in intact loop cold leg (RBU-14A, TFU-14B, and TFU-15), from -6 to $42 \mathrm{~s}$. 


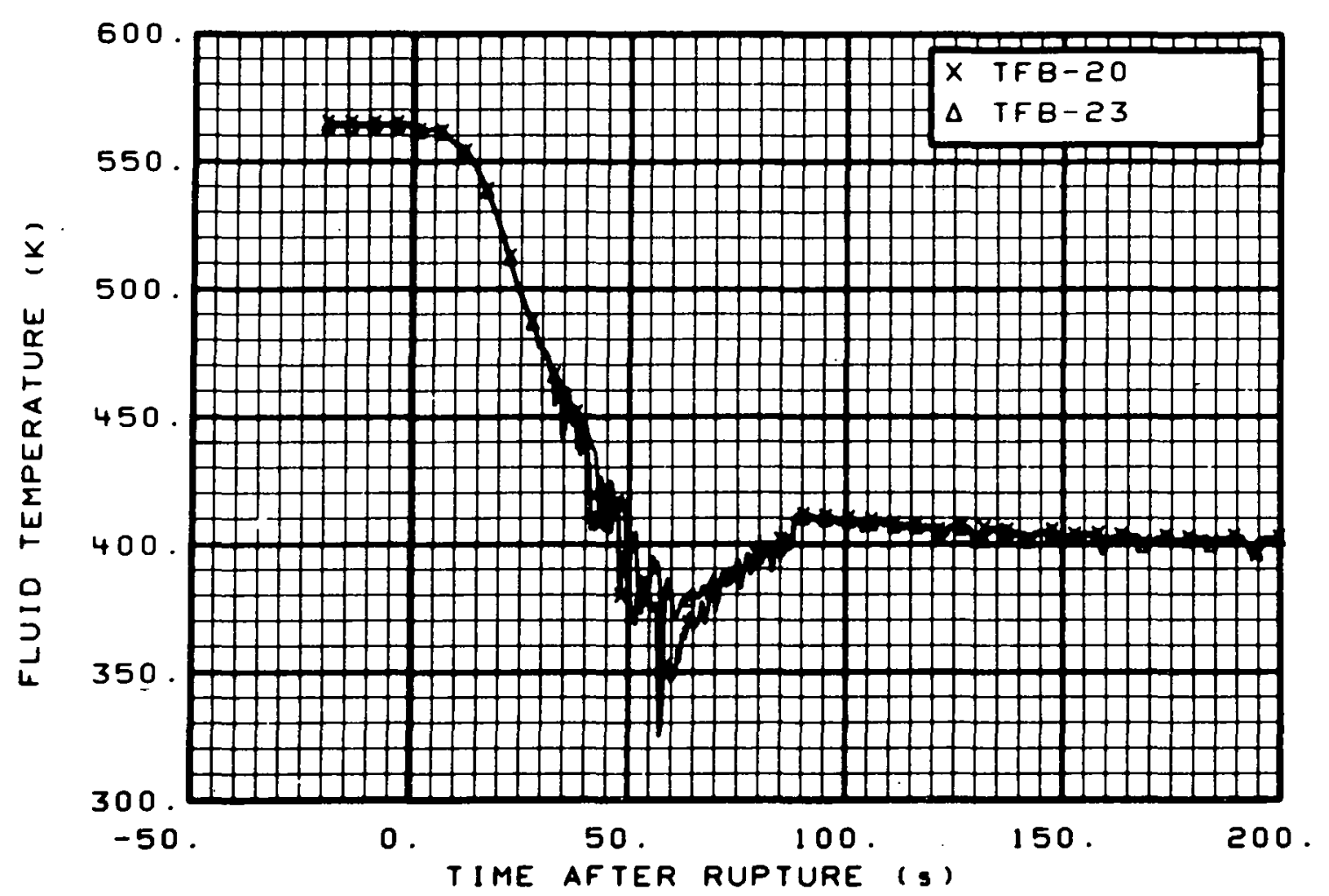

Fig. 15 Fluid temperature in broken loop, vessel side (TFB-20 and TFB-23), from -20 to $200 \mathrm{~s}$.

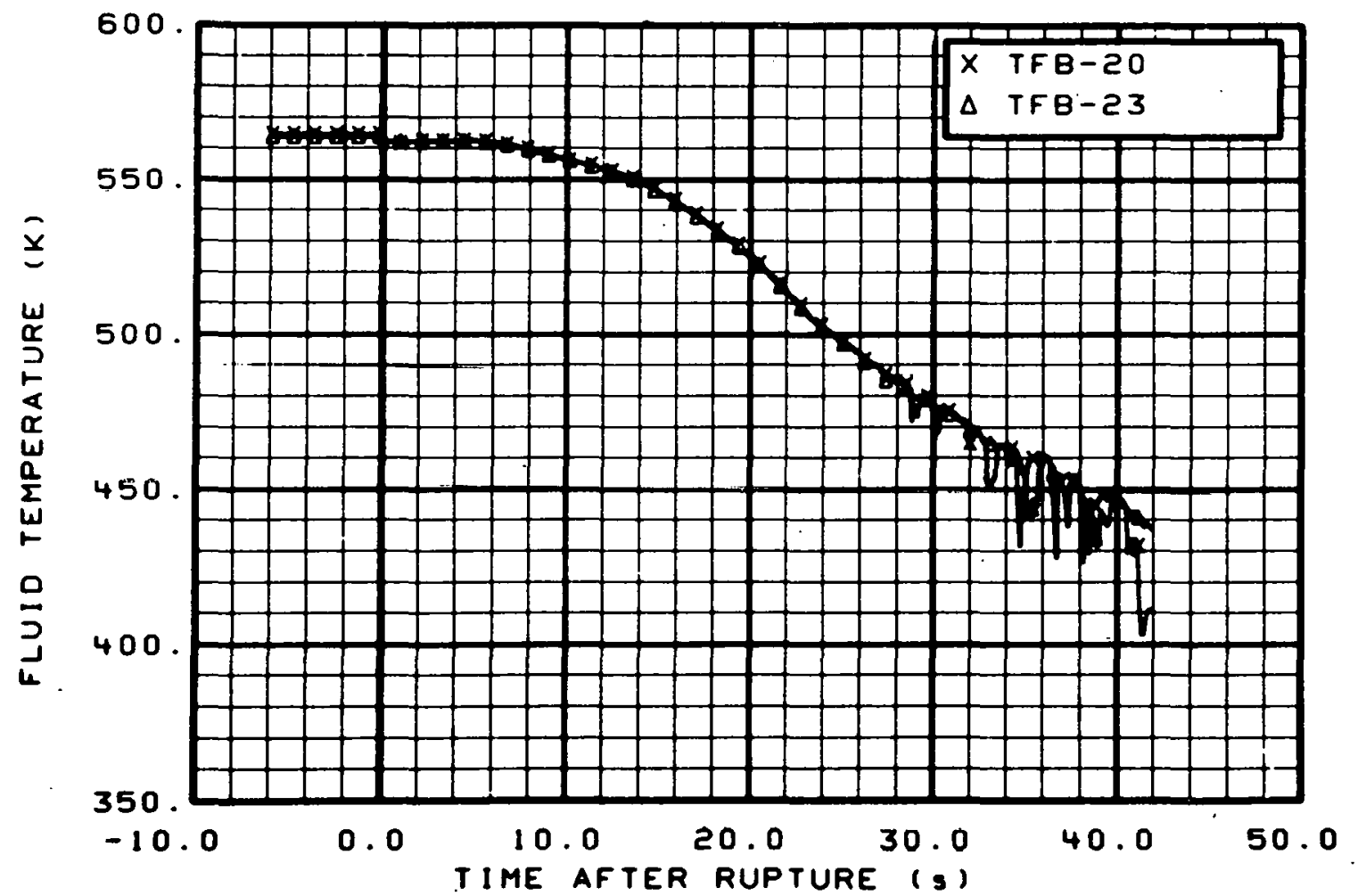

Fig. 16 Fluid temperature in broken loop, vessel side (TFB-20 and TFB-23), from -6 to $42 \mathrm{~s}$. 


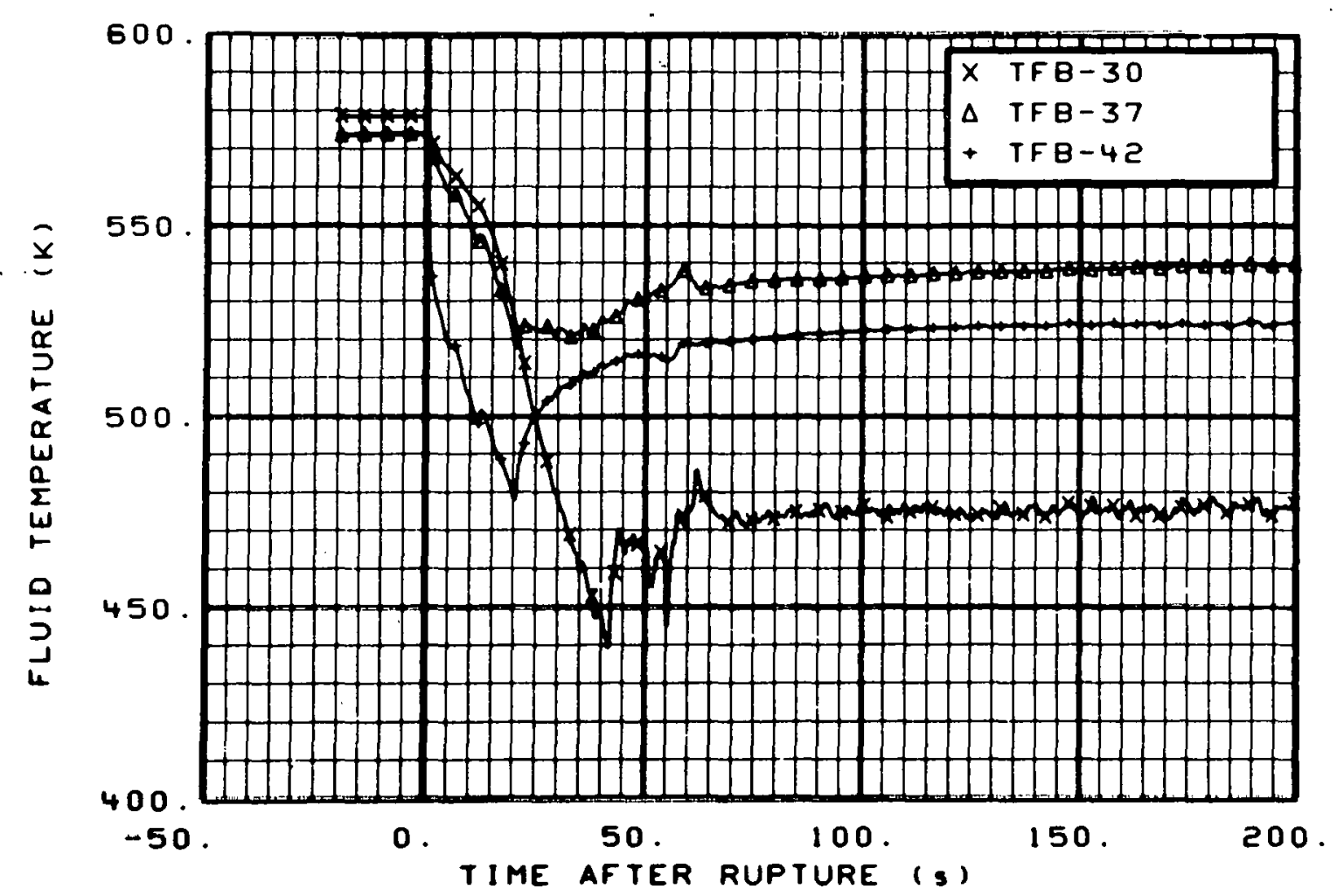

Fig. 17 Fluid temperature in broken loop, pump side (TFB-30, TFB-37, and TFB-42), from -20 to $200 \mathrm{~s}$.

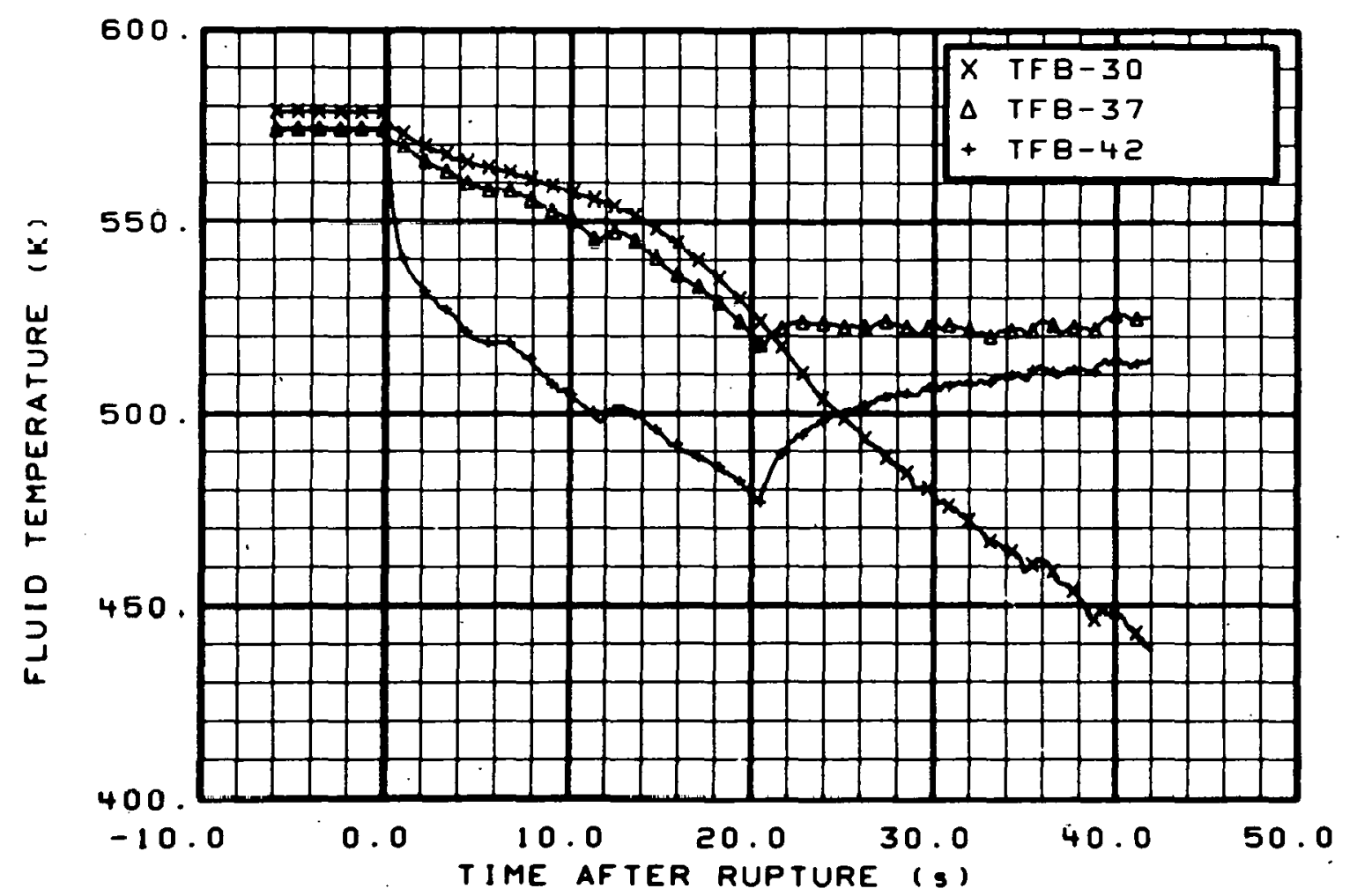

Fig. 18 Fluid temperature in broken loop, pump side (TFB-30, TFB-37, and TFB-42), from -6 to $42 \mathrm{~s}$. 


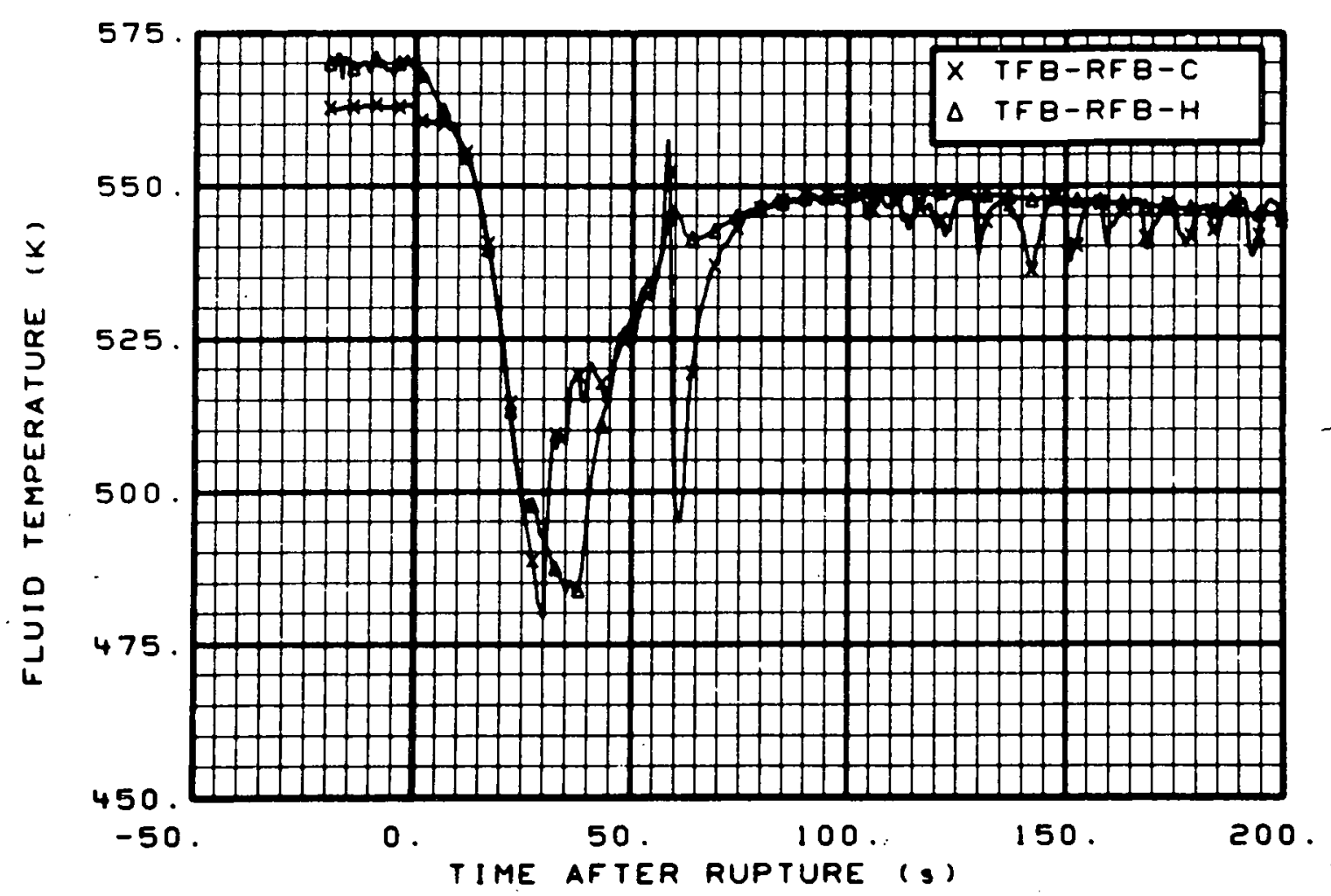

Fig. 19 Fluid temperature in broken loop, reflood bypass simulators (TFB-RFB-C and TFB-RFB-H), from -20 to $200 \mathrm{~s}$.

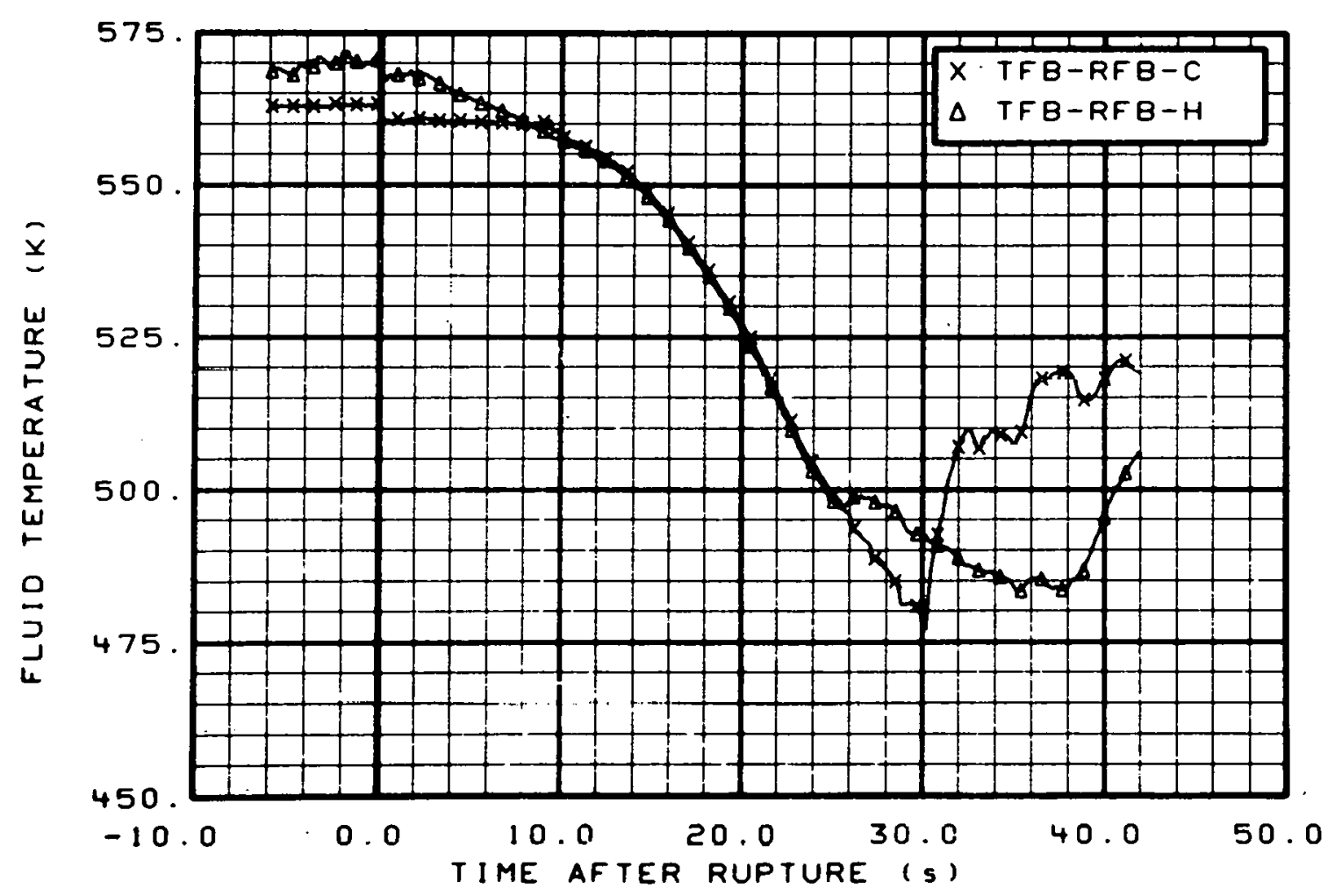

Fig. 20 Fluid temperature in broken loop, reflood bypass simulators (TFB-RFB-C and TFB-RFB-H), from -6 to $42 \mathrm{~s}$. 


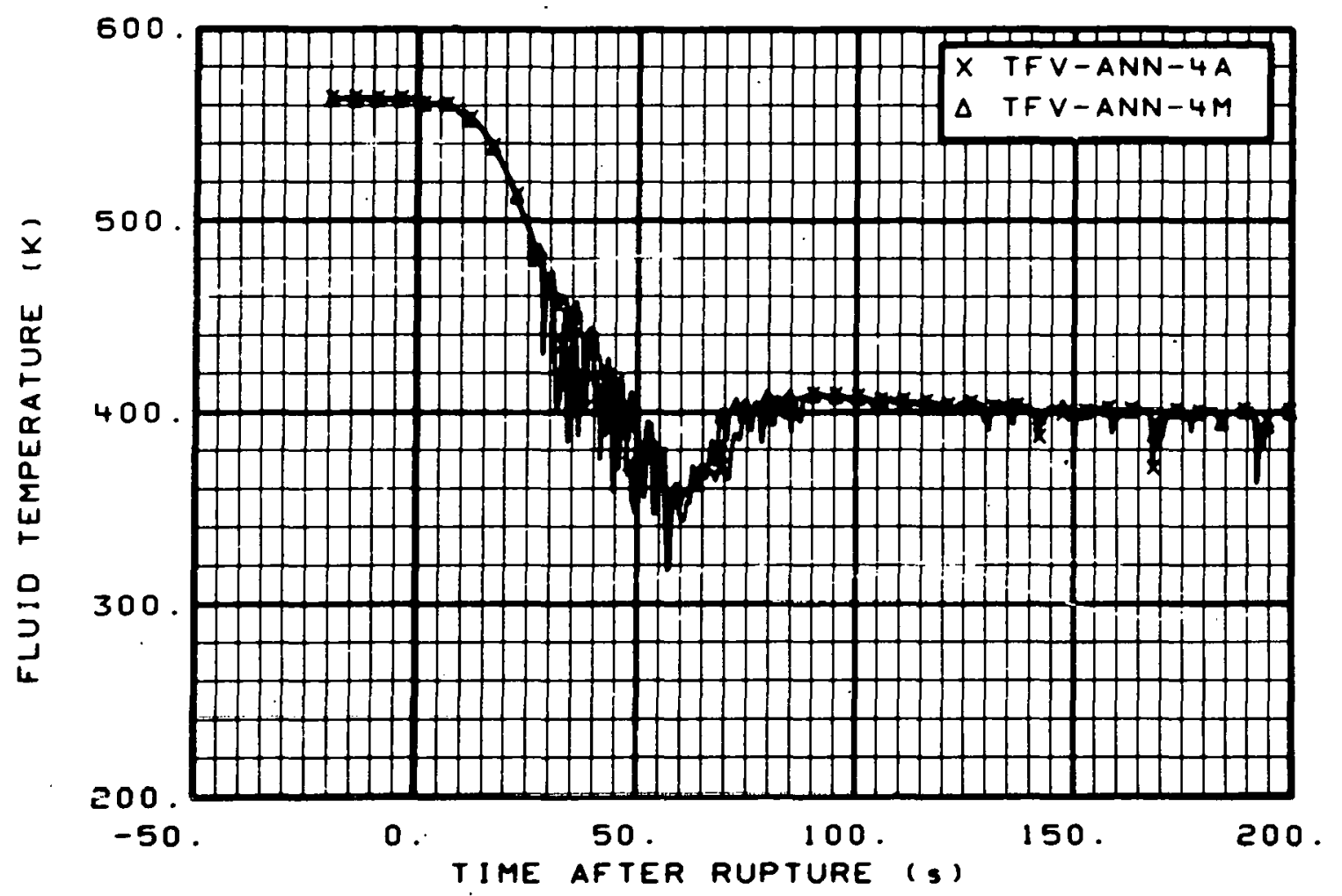

Fig. 21 Fluid temperature in inlet annulus (TFV-ANN-4A and TFV-ANN-4M), from -20 to $200 \mathrm{~s}$.

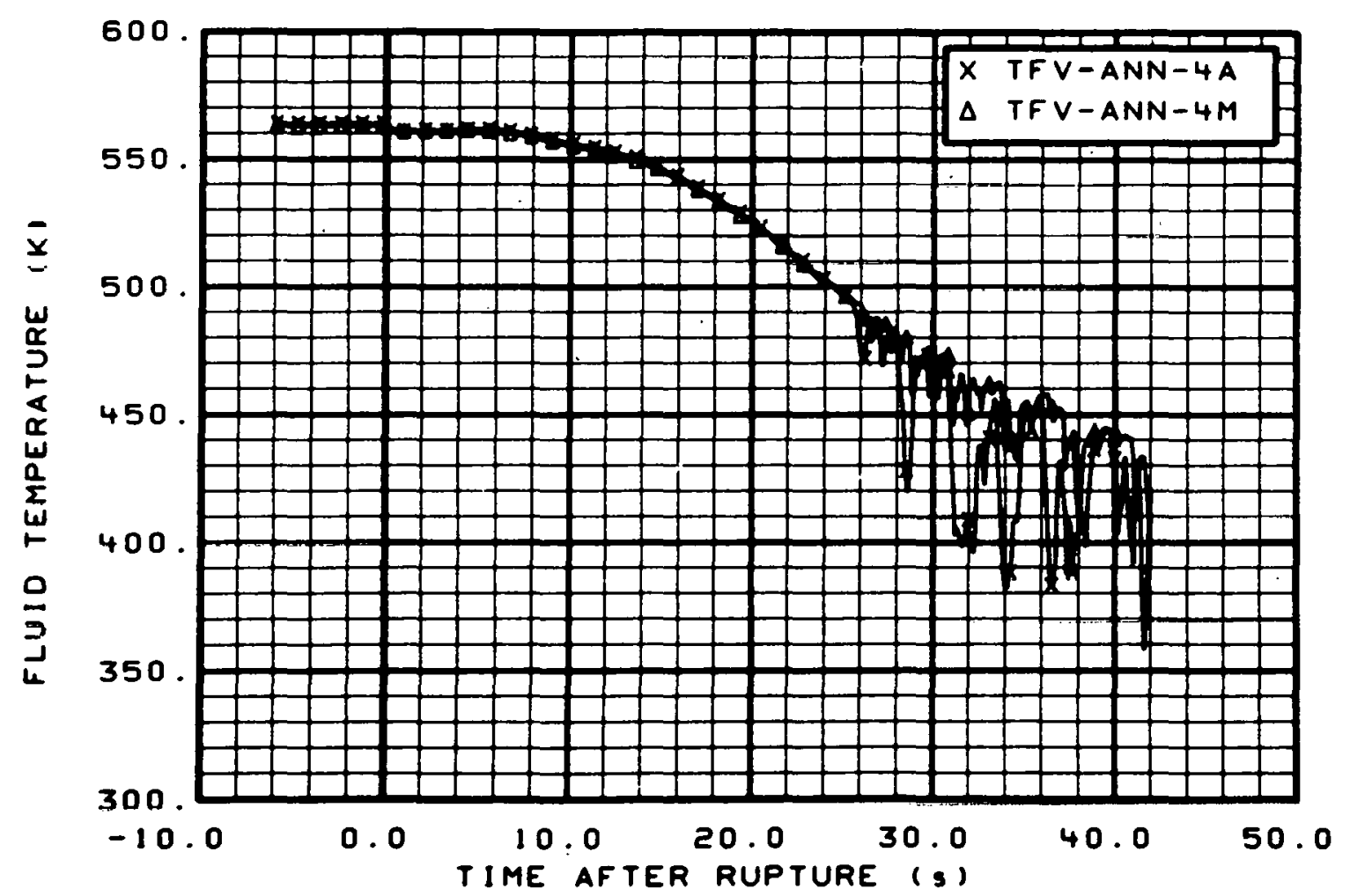

Fig. 22 Fluid temperature in inlet annulus (TFV-ANN-4A and TFV-ANN-4M), from -6 to $42 \mathrm{~s}$. 


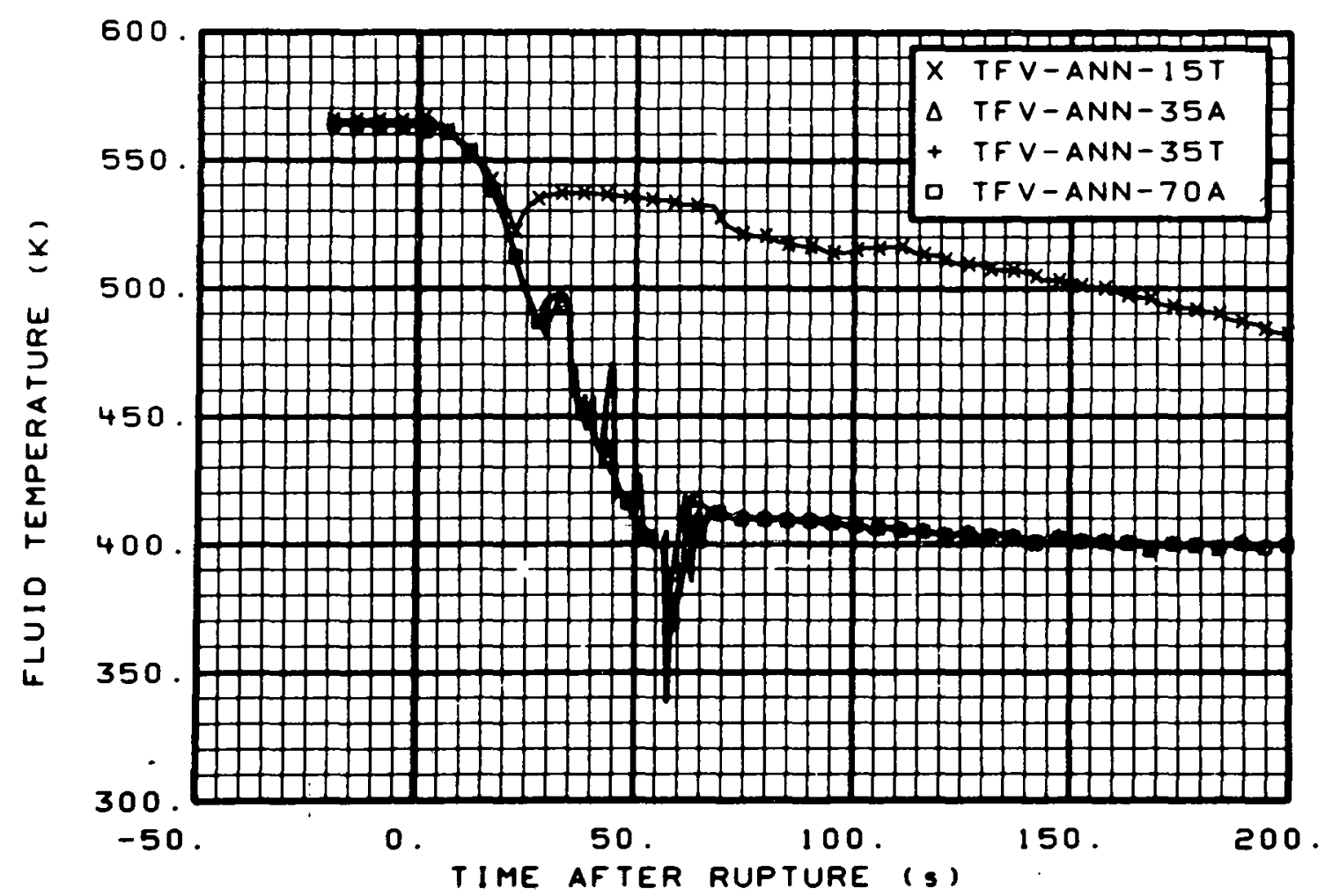

Fig. 23 Fluid temperature in downcomer annulus (TFV-ANN-15T, TFV-ANN-35A, TFV-ANN-35T, and TFV-ANN-70A), from -20 to $200 \mathrm{~s}$.

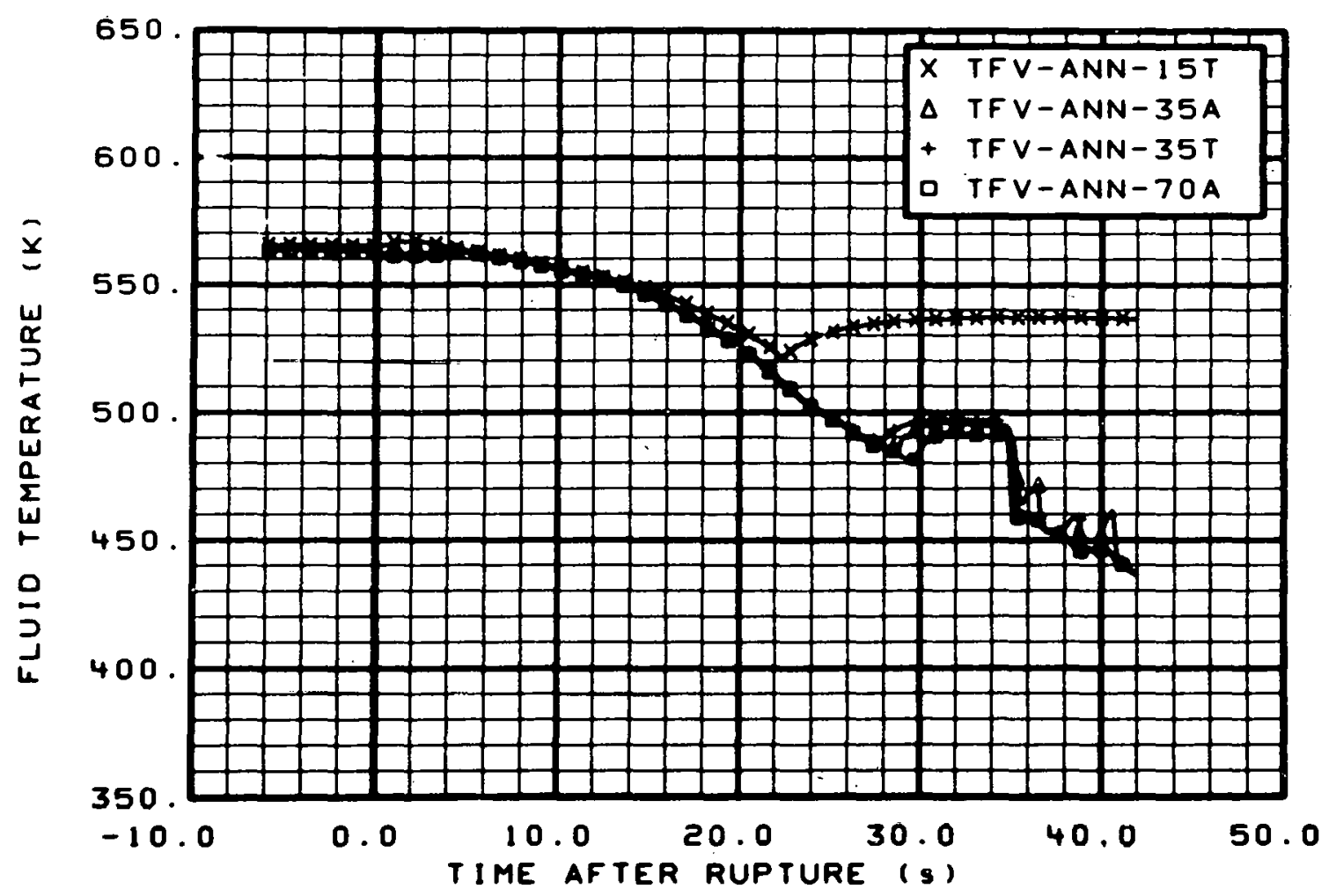

Fig. 24 Fluid temperature in downcomer annulus (TFV-ANN-15T, TFV-ANN-35A, TFV-ANN-35T, and TFV-ANN-70A), from -6 to $42 \mathrm{~s}$. 


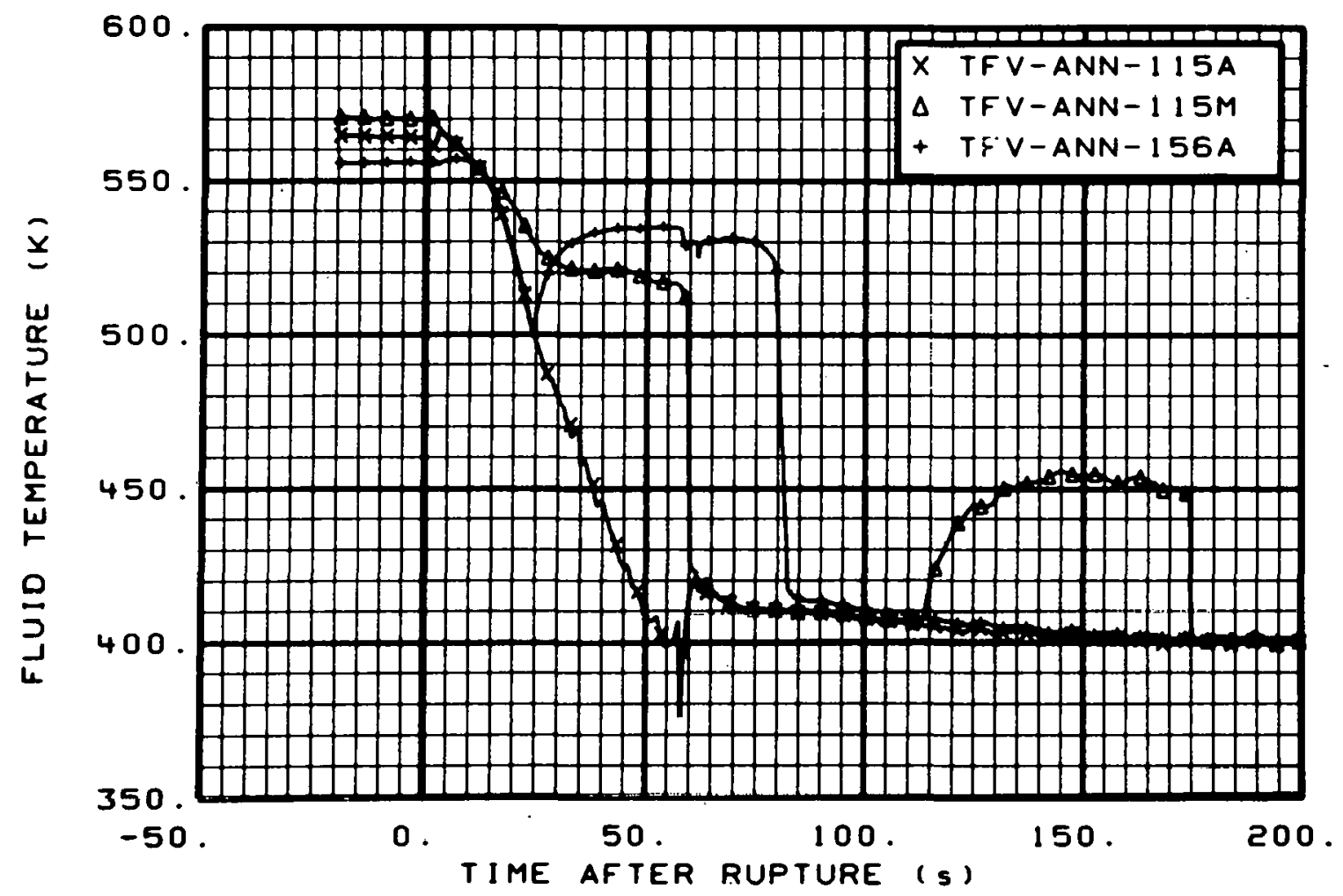

Fig. 25 Fluid temperature in downcomer annulus (TFV-ANN-115A, TFV-ANN-115M, and TFV-ANN-156A), from -20 to $200 \mathrm{~s}$.

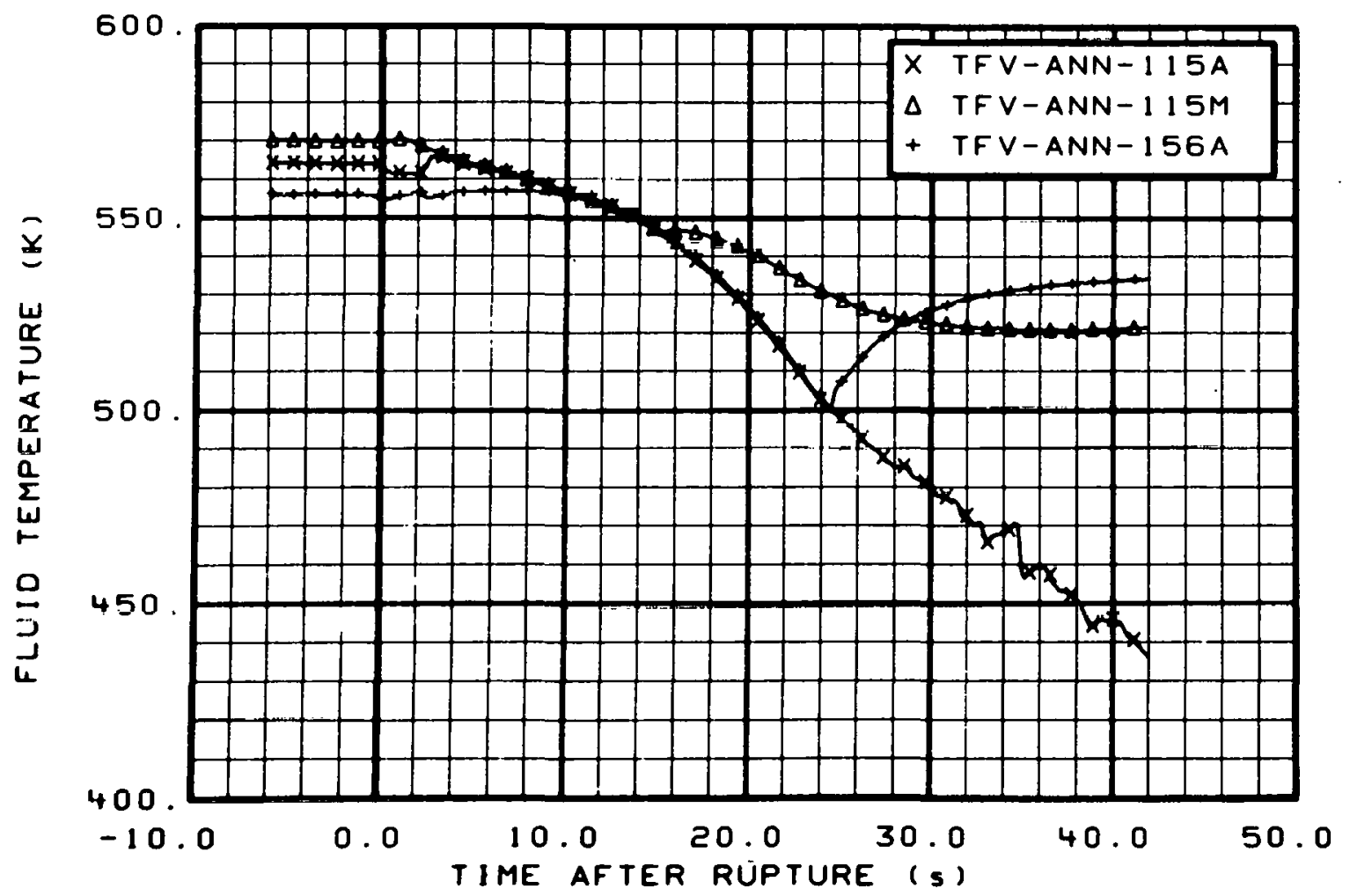

Fig. 26 Fluid temperature in downcomer annulus (TFV-ANN-115A, TFV-ANN-115M, and TFV-ANN-156A), from -6 to $42 \mathrm{~s}$. 


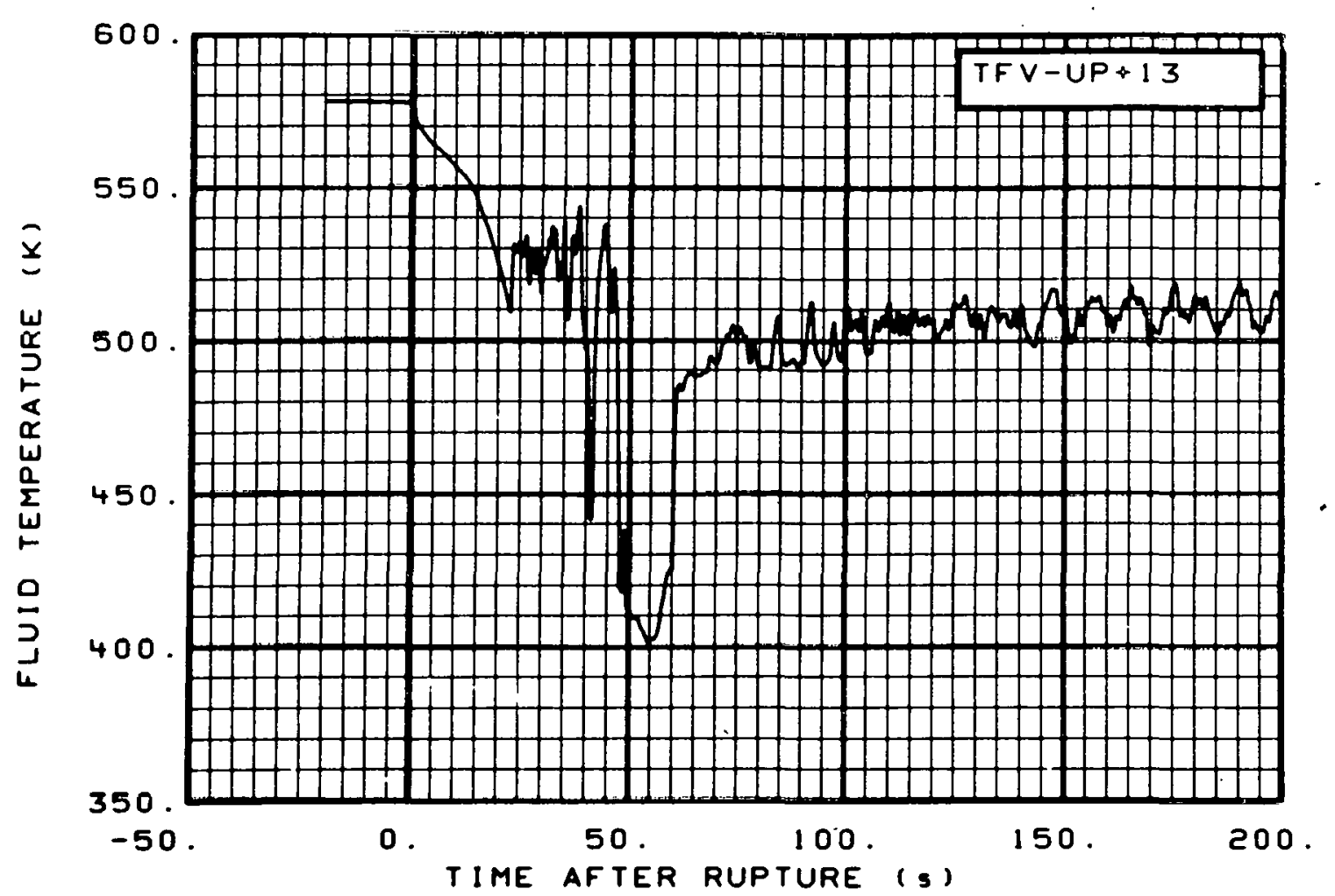

Fig. 27 Fluid temperature in upper plenum (TFV-UP+13), from -20 to $200 \mathrm{~s}$.

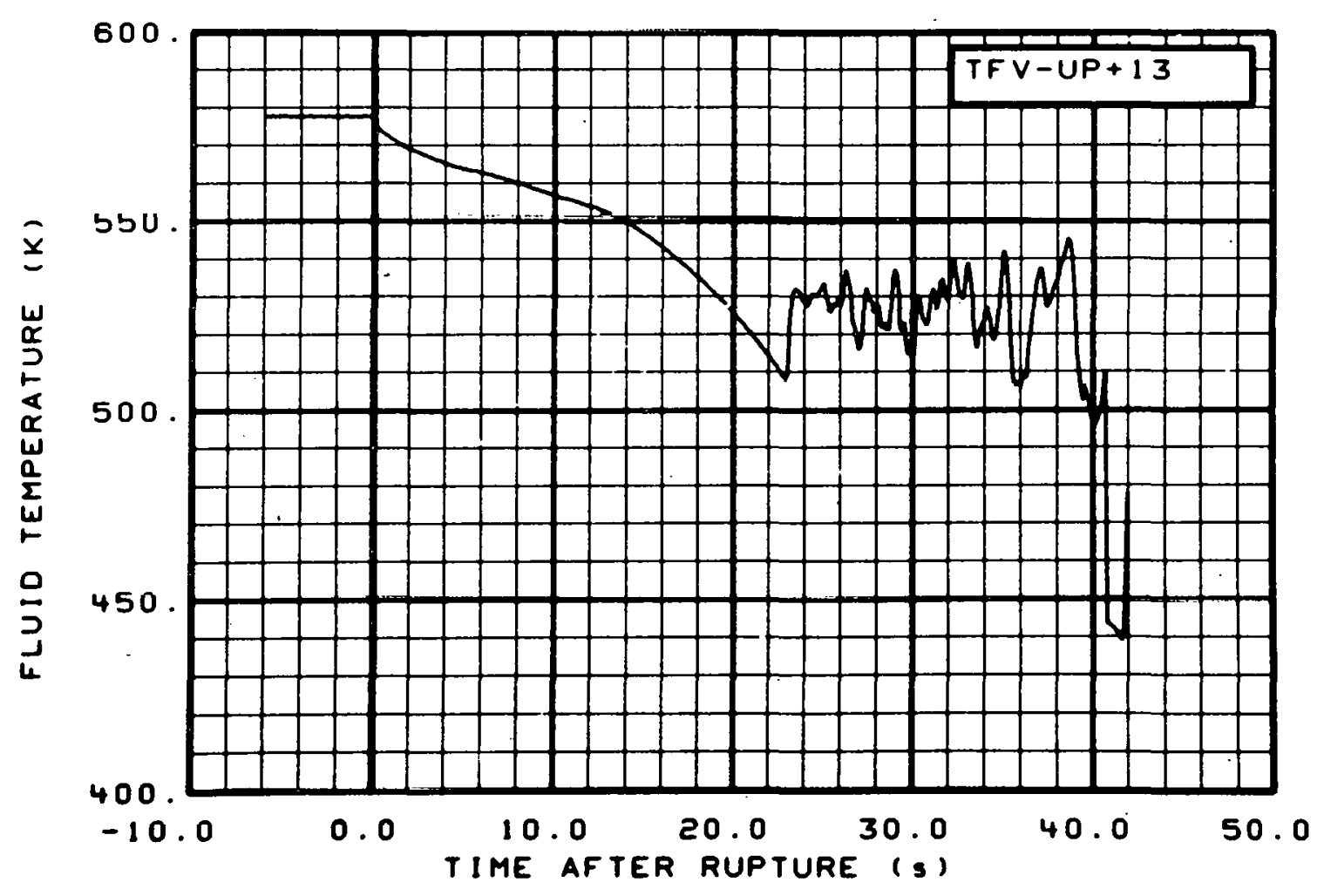

Fig. 28 Fluid temperature in upper plenum (TFV-UP+13), from -6 to $42 \mathrm{~s}$. 


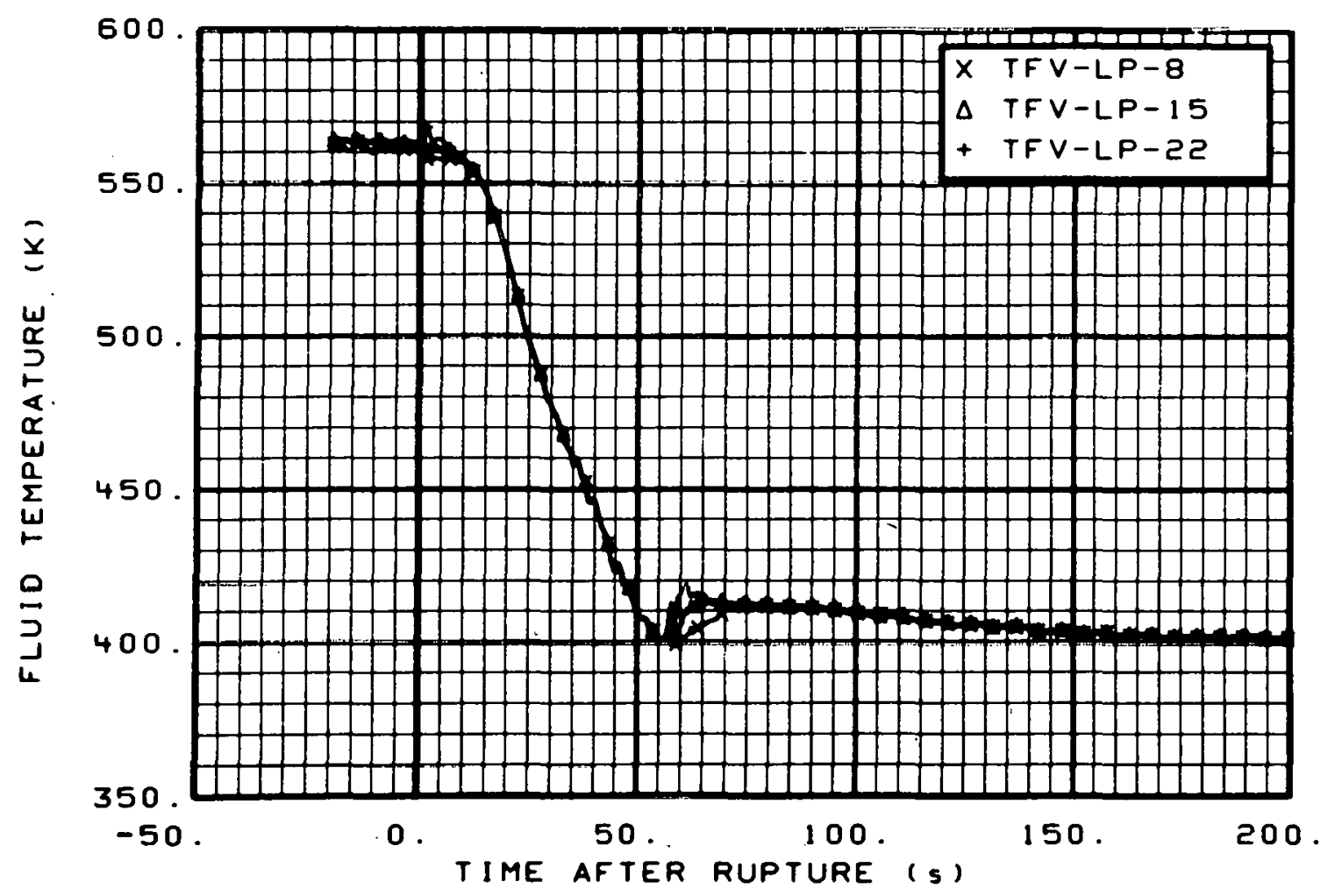

Fig. 29 Fluid temperature in lower. plenum (TFV-LP-8, TFV-LP-15, and TFV-LP-22), from -20 , to $200 \mathrm{~s}$.

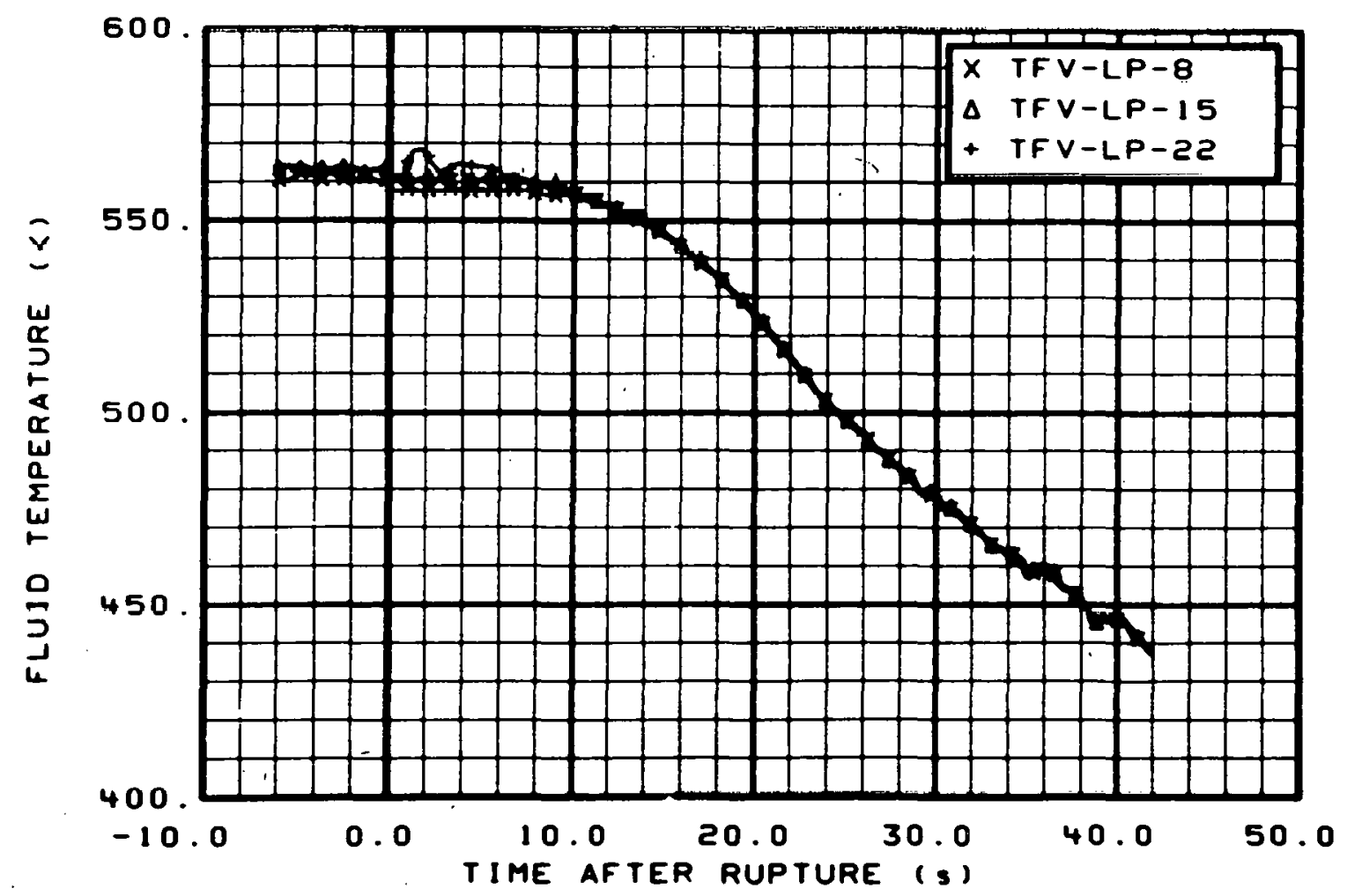

Fig. 30 Fluid temperature in lower plenum (TFV-LP-8, TFV-LP-15, and TFV-LP-22), from -6 to $42 \mathrm{~s}$. 


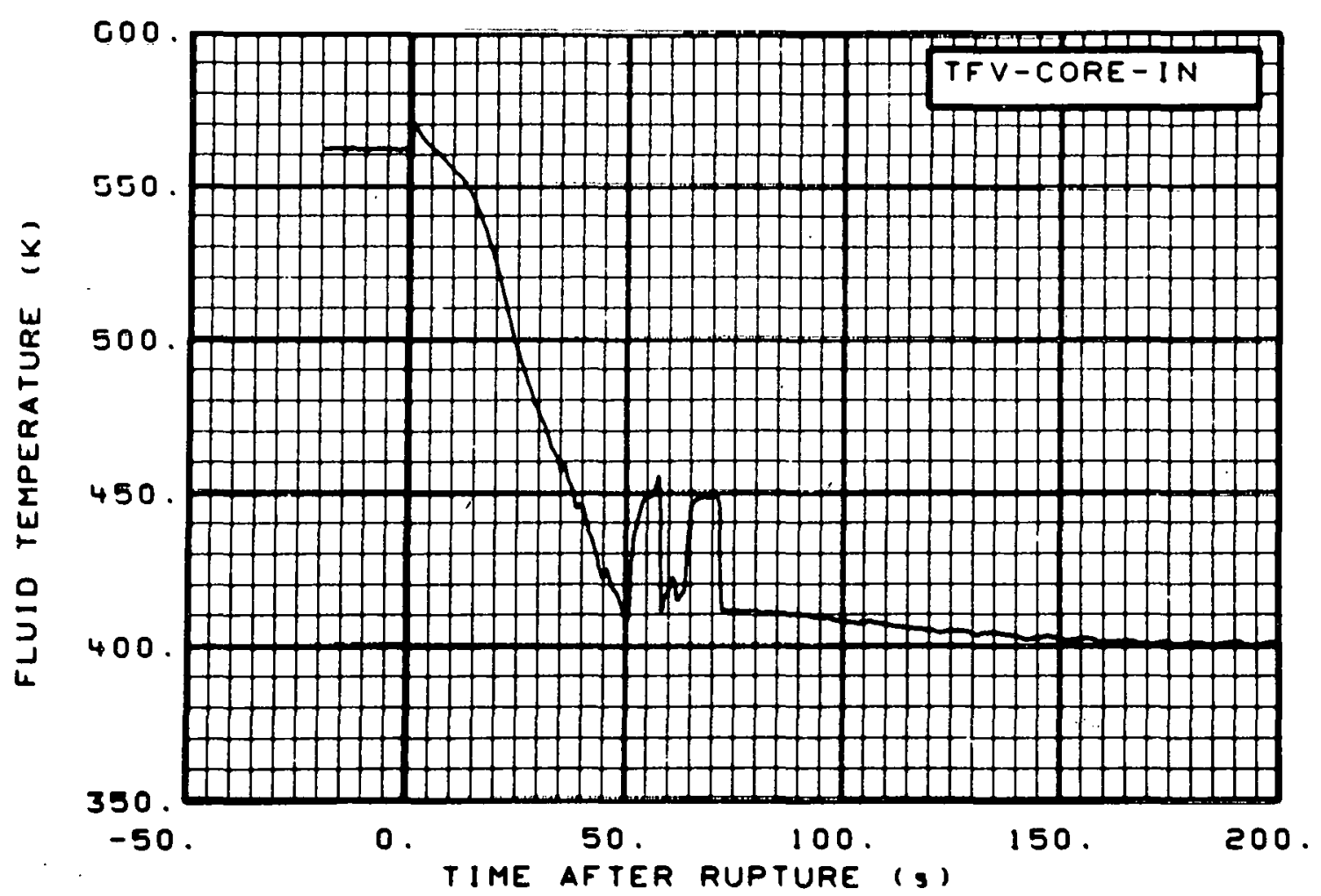

Fig. 31 Fluid temperature in core inlet (TFV-CORE-IN), from -20 to $200 \mathrm{~s}$.

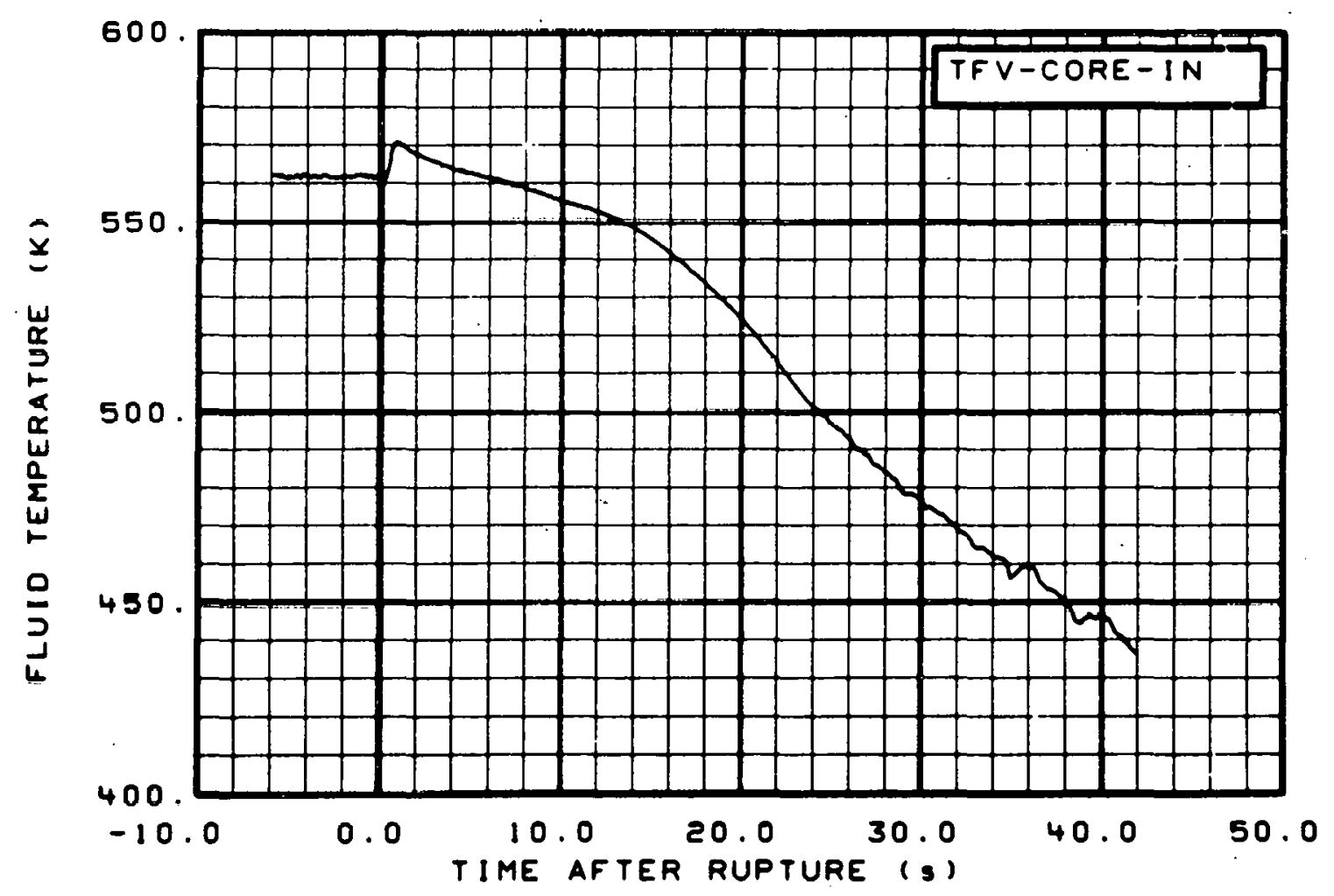

Fig. 32 Fluid temperature in core inlet (TFV-CORE-IN), from -6 to $42 \mathrm{~s}$. 


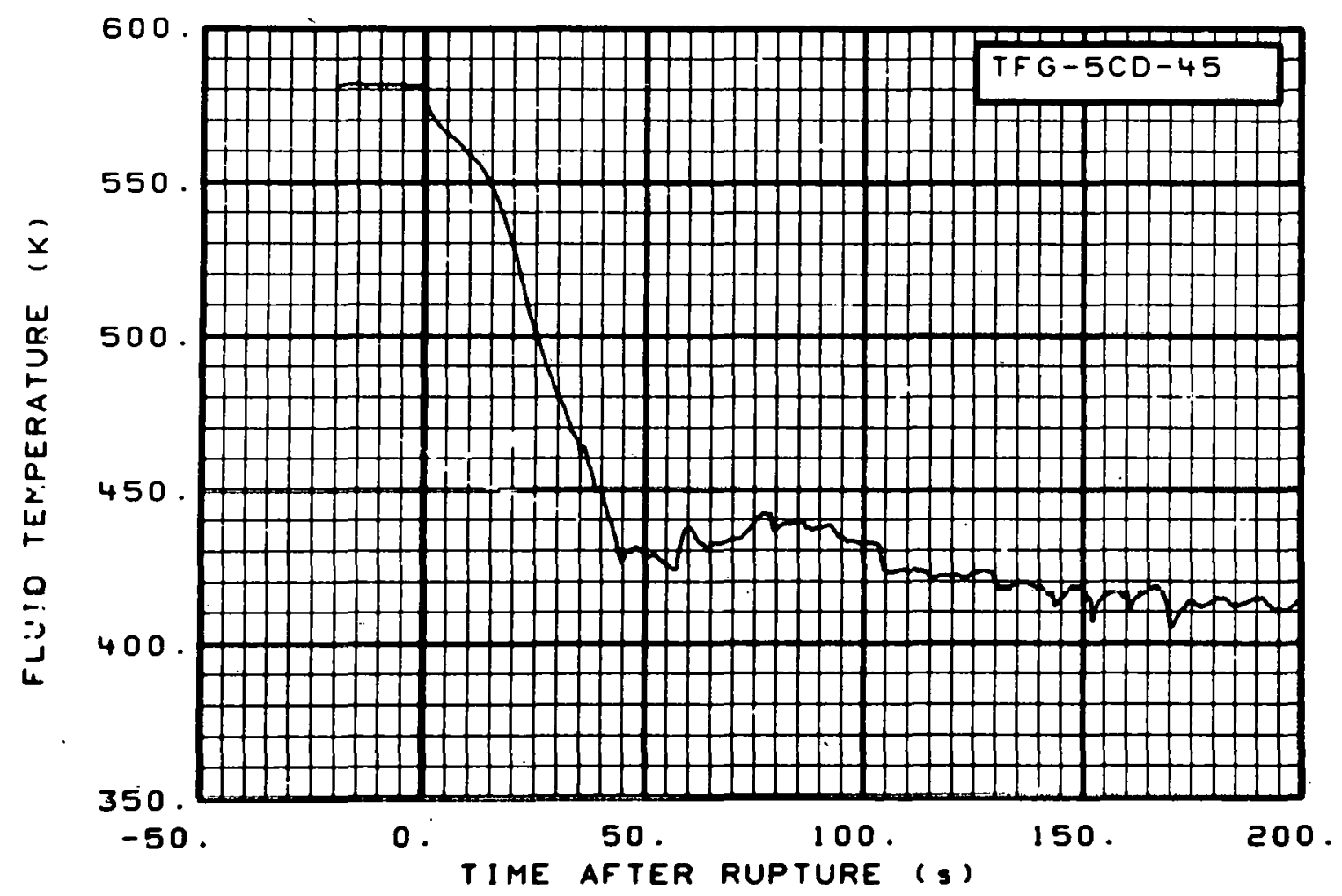

Fig. 33 Fluid temperature in core, Grid Spacer 5 (TFG-5CD-45), from -20 to $200 \mathrm{~s}$.

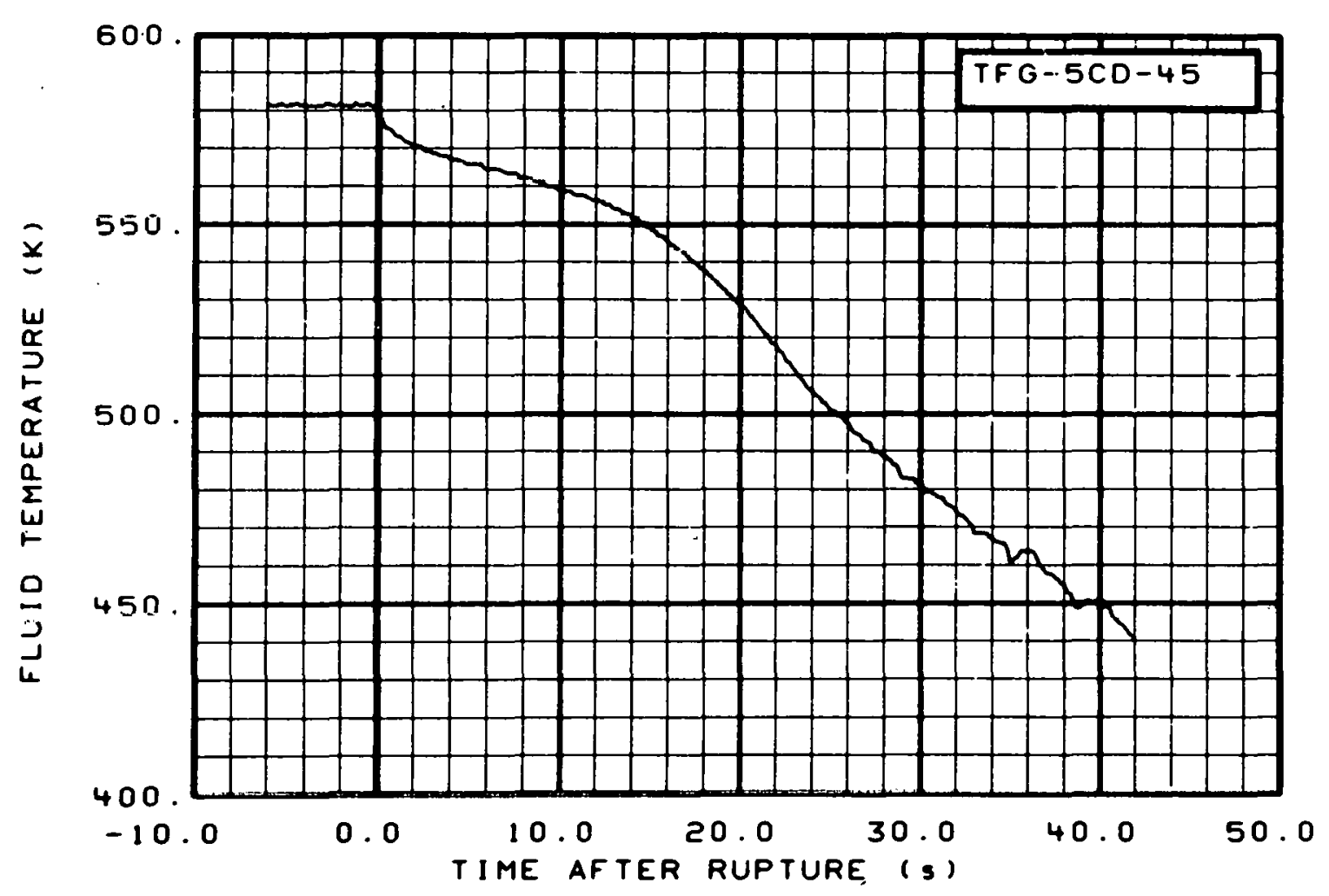

Fig. 34 Fluid temperature in core, Grid Spacer 5 (TFG-5CD-45), from -6 to $42 \mathrm{~s}$. 


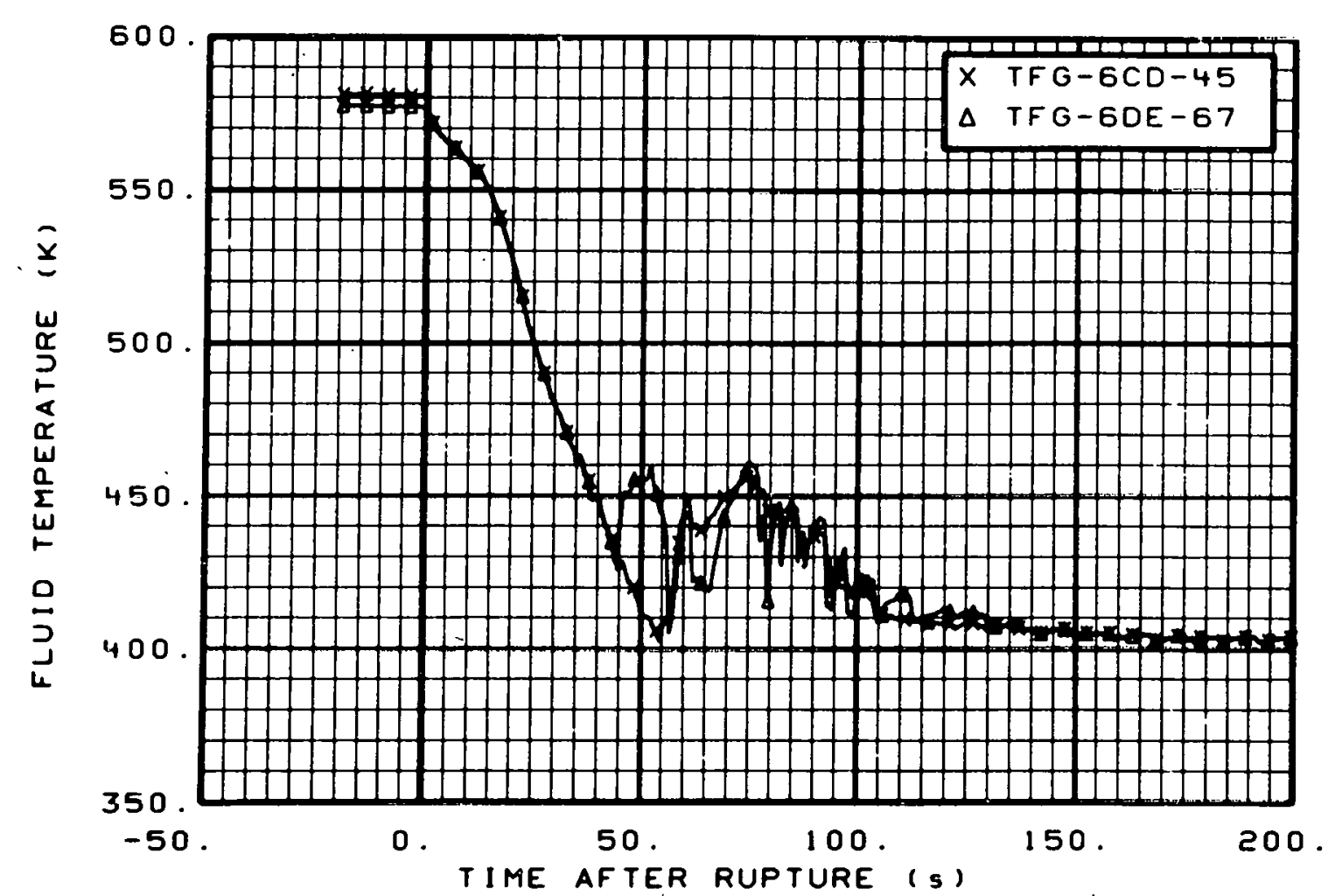

Fig. 35 Fluid temperature in core, Grid Spacer 6 (TFG-6CD-45 and TFG-6DE-67), from -20 to $200 \mathrm{~s}$.

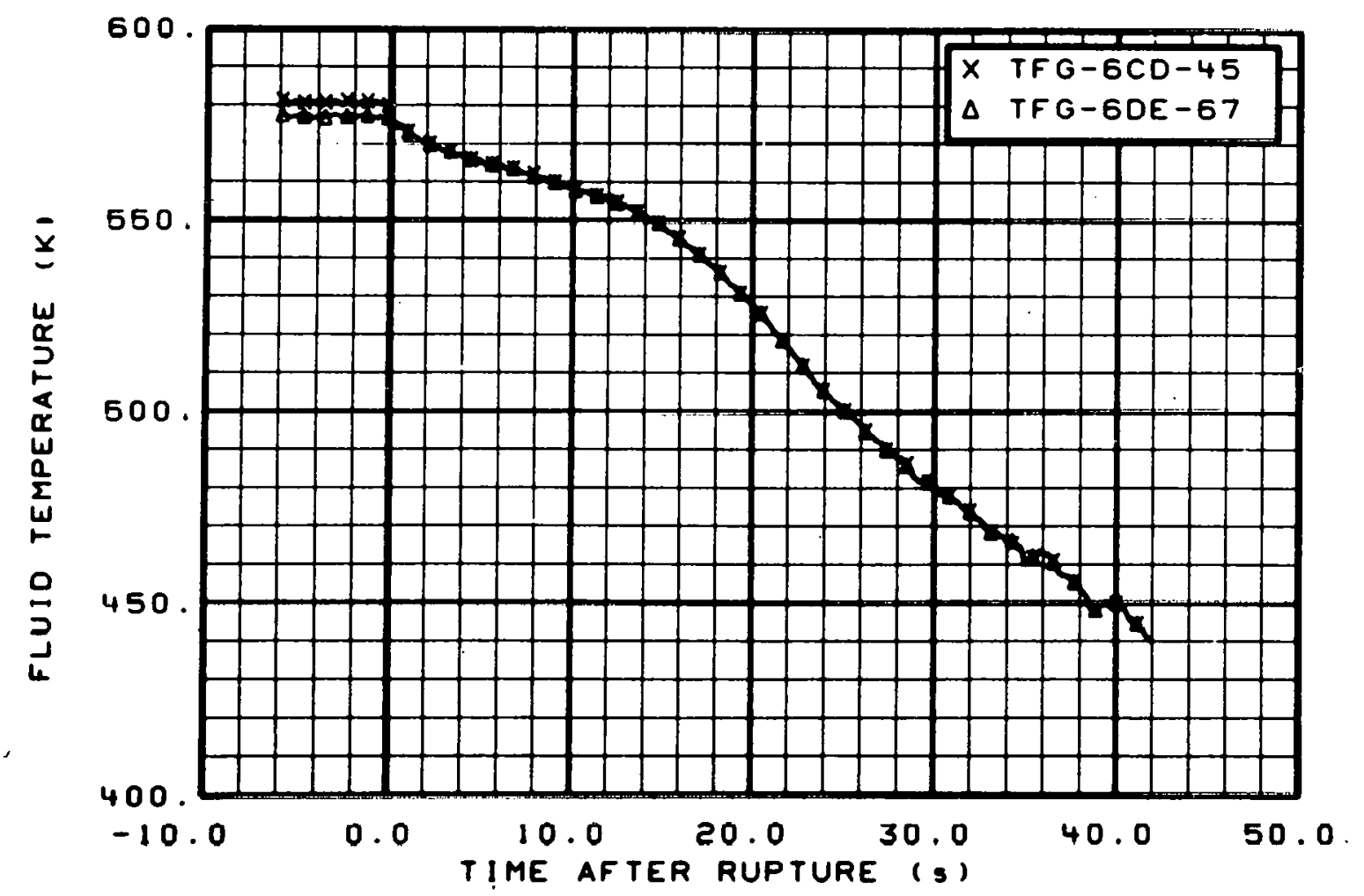

Fig. 36 Fluid temperature in core, Grid Spacer 6 (TFG-6CD-45 and TFG-6DE-67), from -6 to $42 \mathrm{~s}$. 


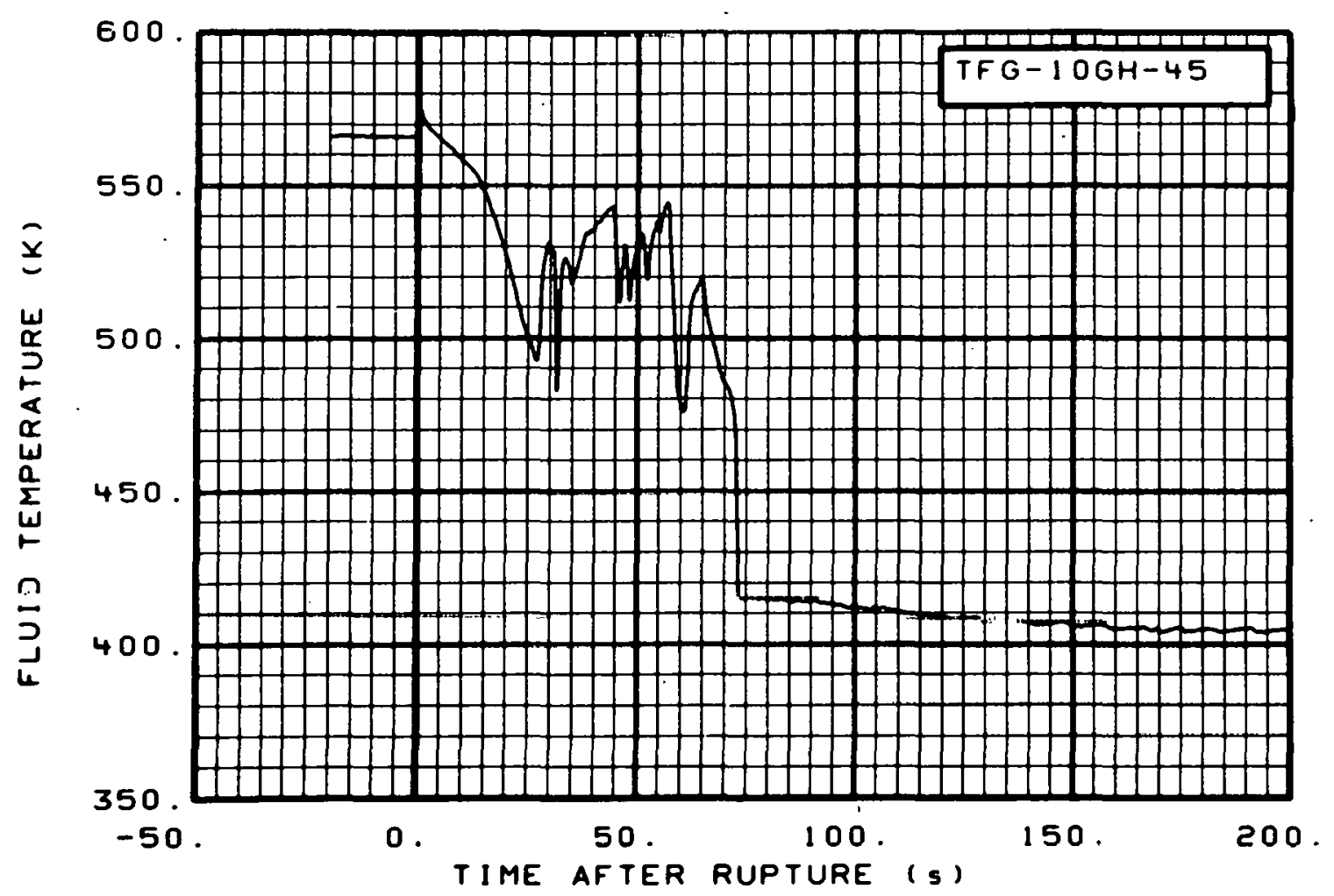

Fig. 37. Fluid temperature in core, Grid Spacer 10 (TFG-10GH-45), from -20 to $200 \mathrm{~s}$.

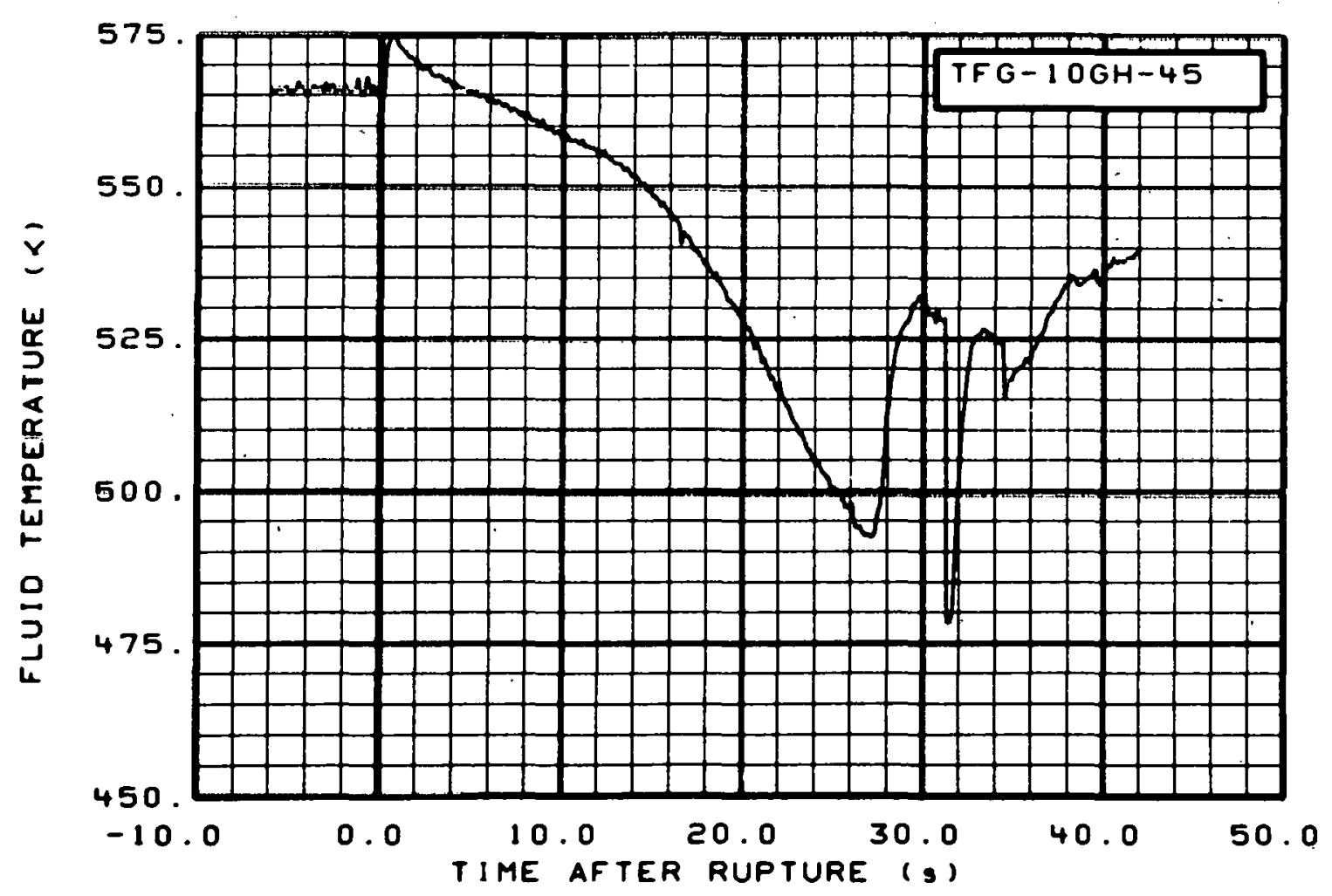

Fig. 38 Fluid temperature in core, Grid Spacer 10 (TFG-10GH-45), from -6 to $42 \mathrm{~s}$. 


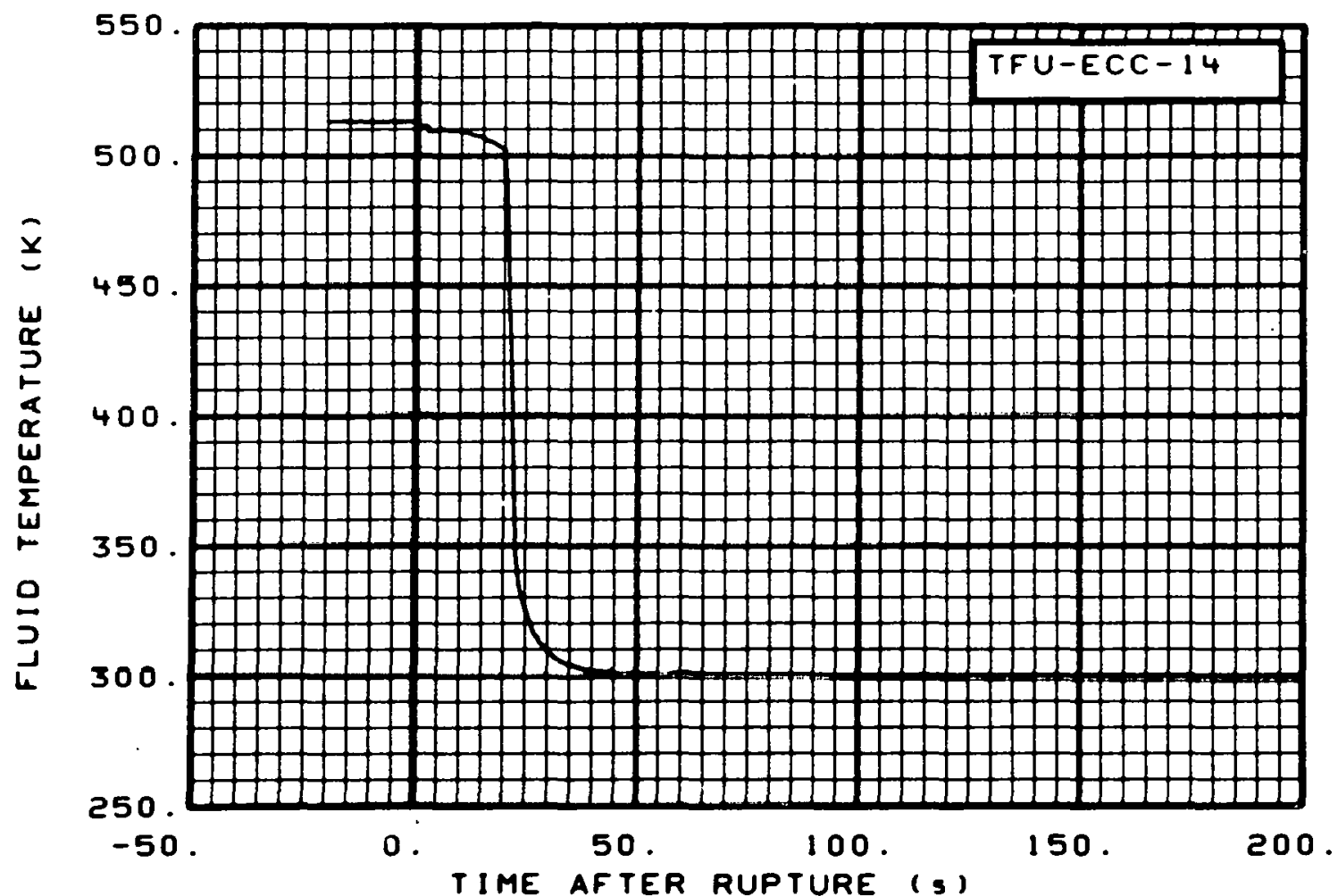

Fig. 39 Fluid temperature in intact loop coolant injection line (TFU-ECC-14), from -20 to $200 \mathrm{~s}$.

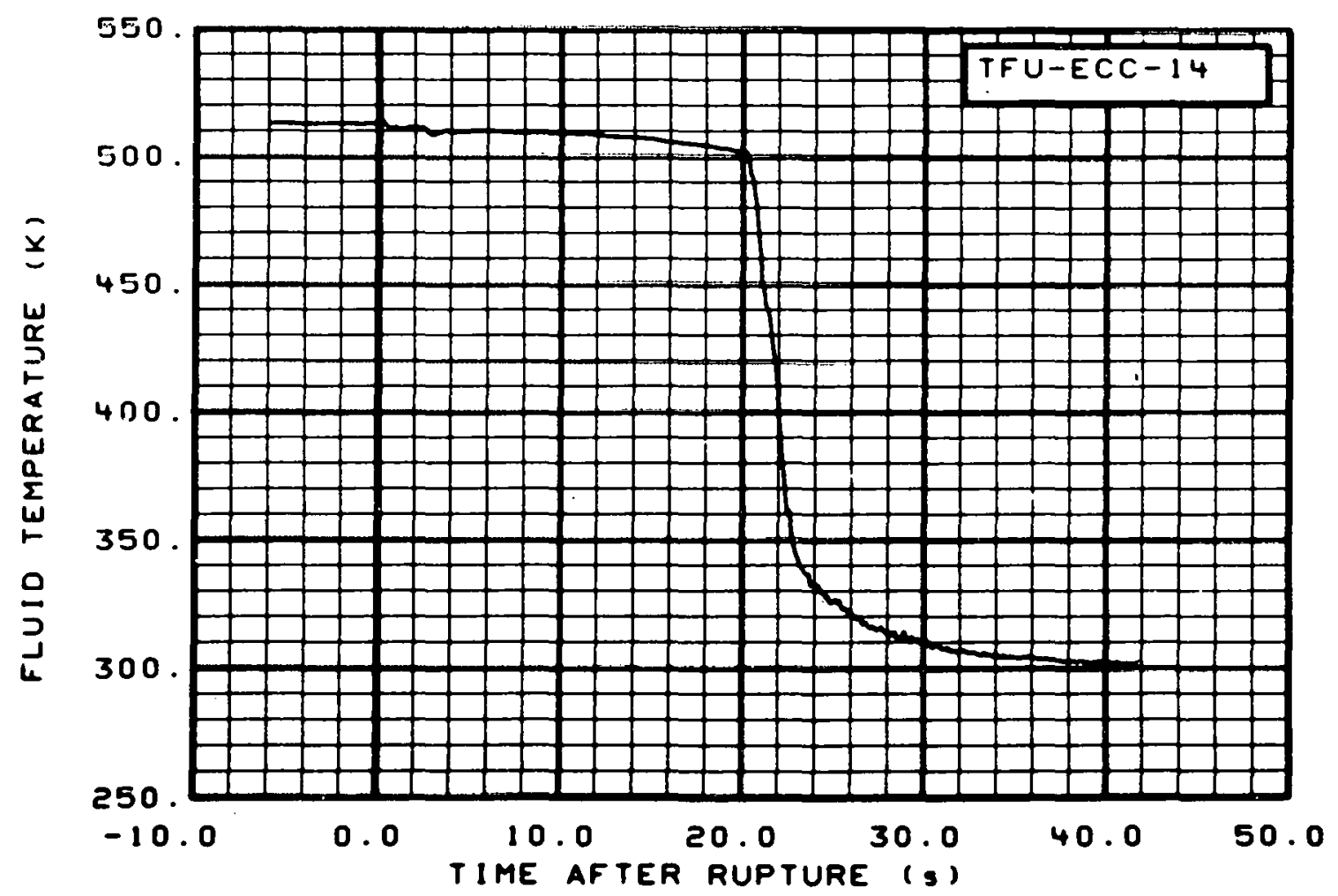

Fiy. 40 Fluid temperature in intact loop coolant injection line (TFU-ECC-14), from -6 to $42 \mathrm{~s}$. 


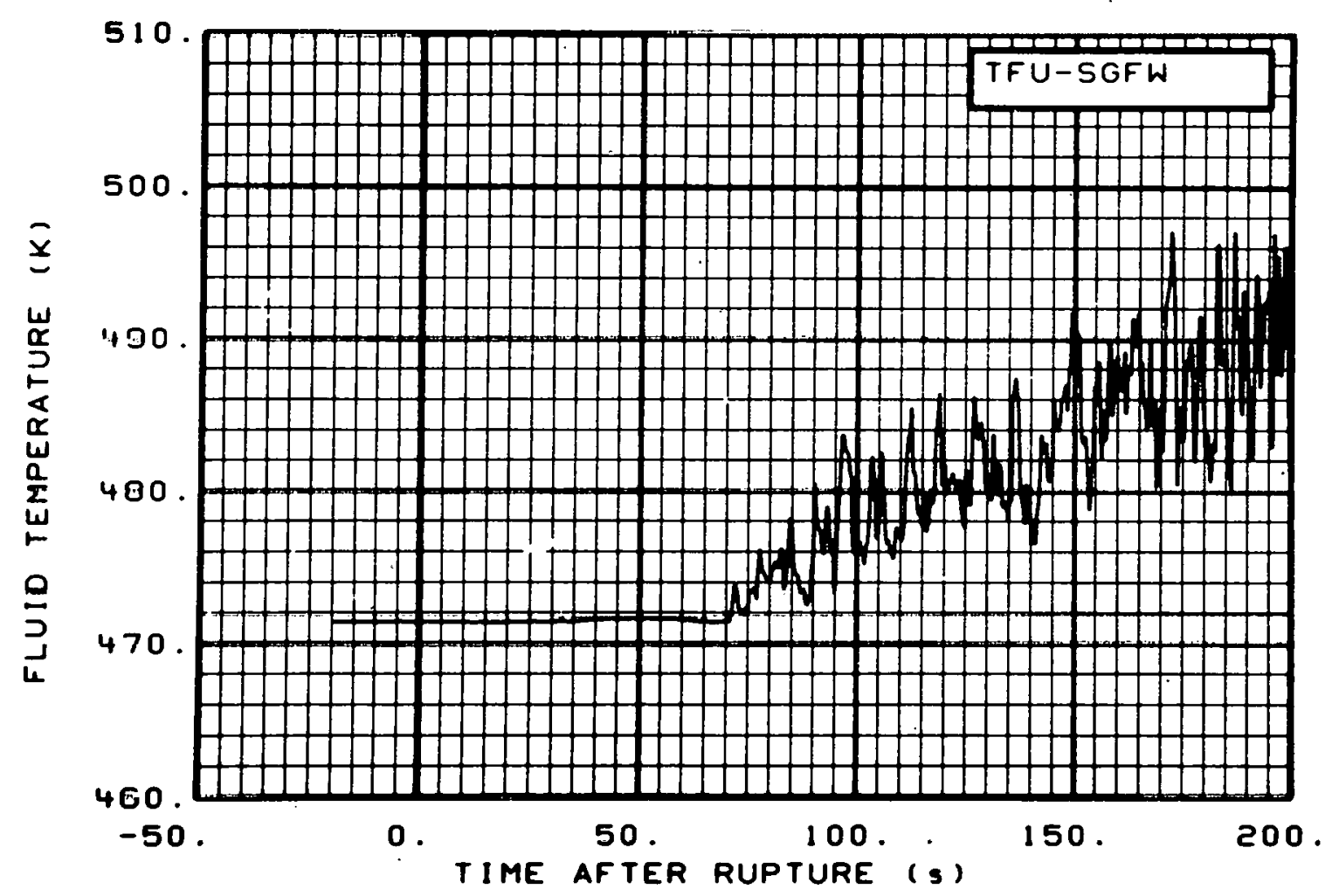

Fig. 41 Fluid temperature in steam generator, feedwater line (TFU-SGFW), from -20 to $200 \mathrm{~s}$.

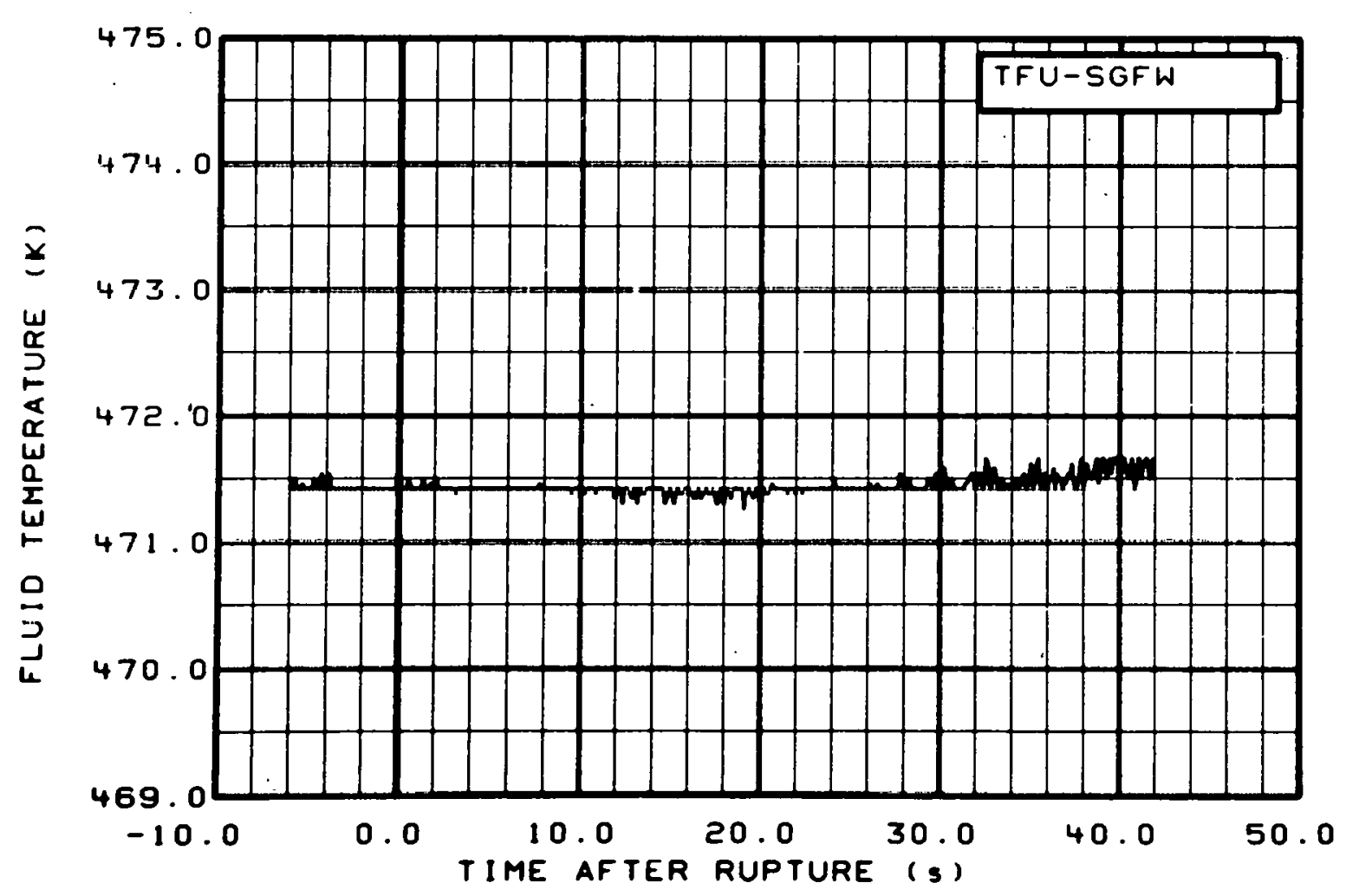

Fig. 42 Fluid temperature in steam generator, feedwater 1 ine (TFU-SGFW), from -6 .to $42 \mathrm{~s}$. 


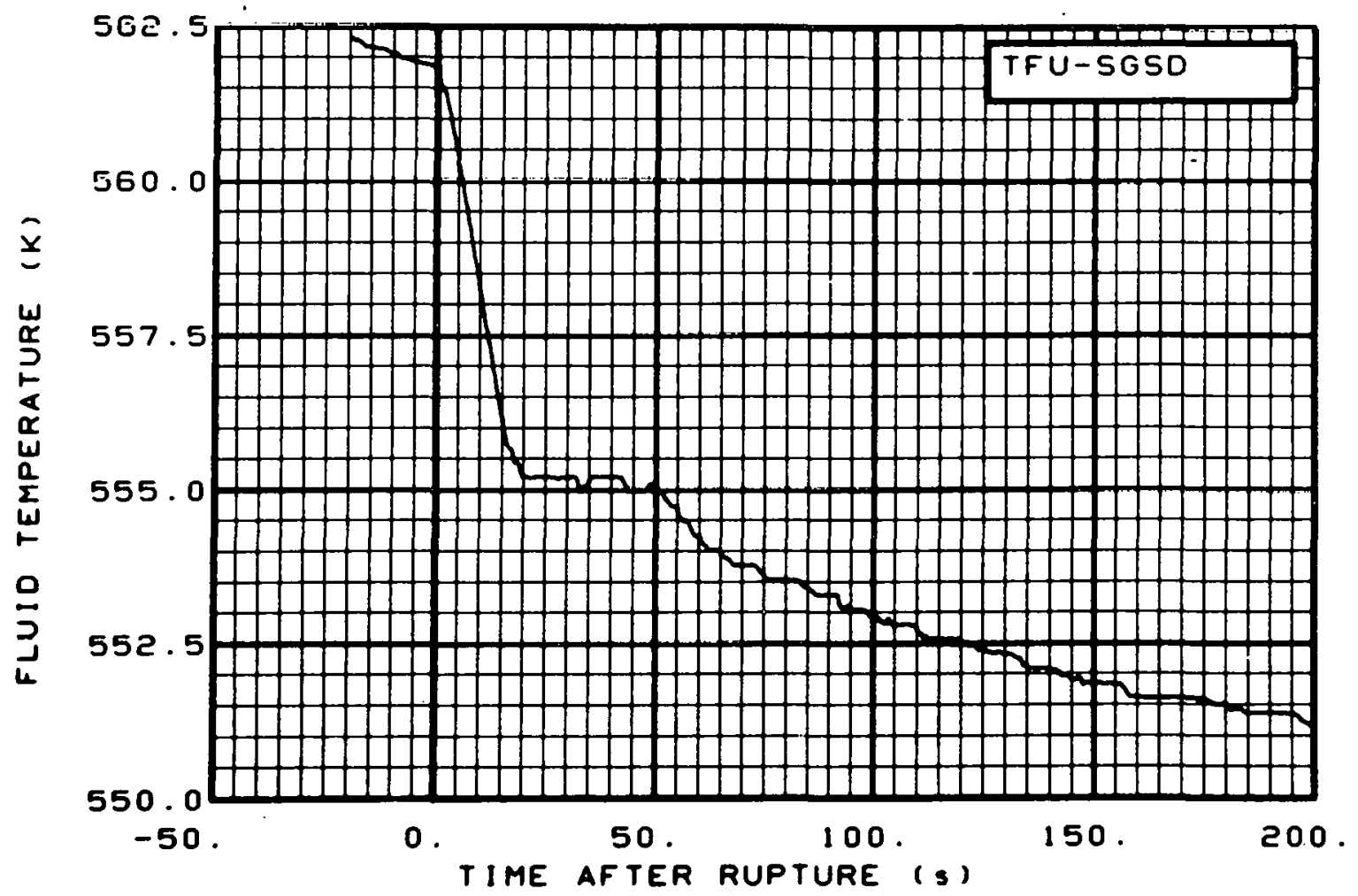

Fig. 43 Fluid temperature in steam generator, secondary side (TFU-SGSD), from -20 to $200 \mathrm{~s}$.

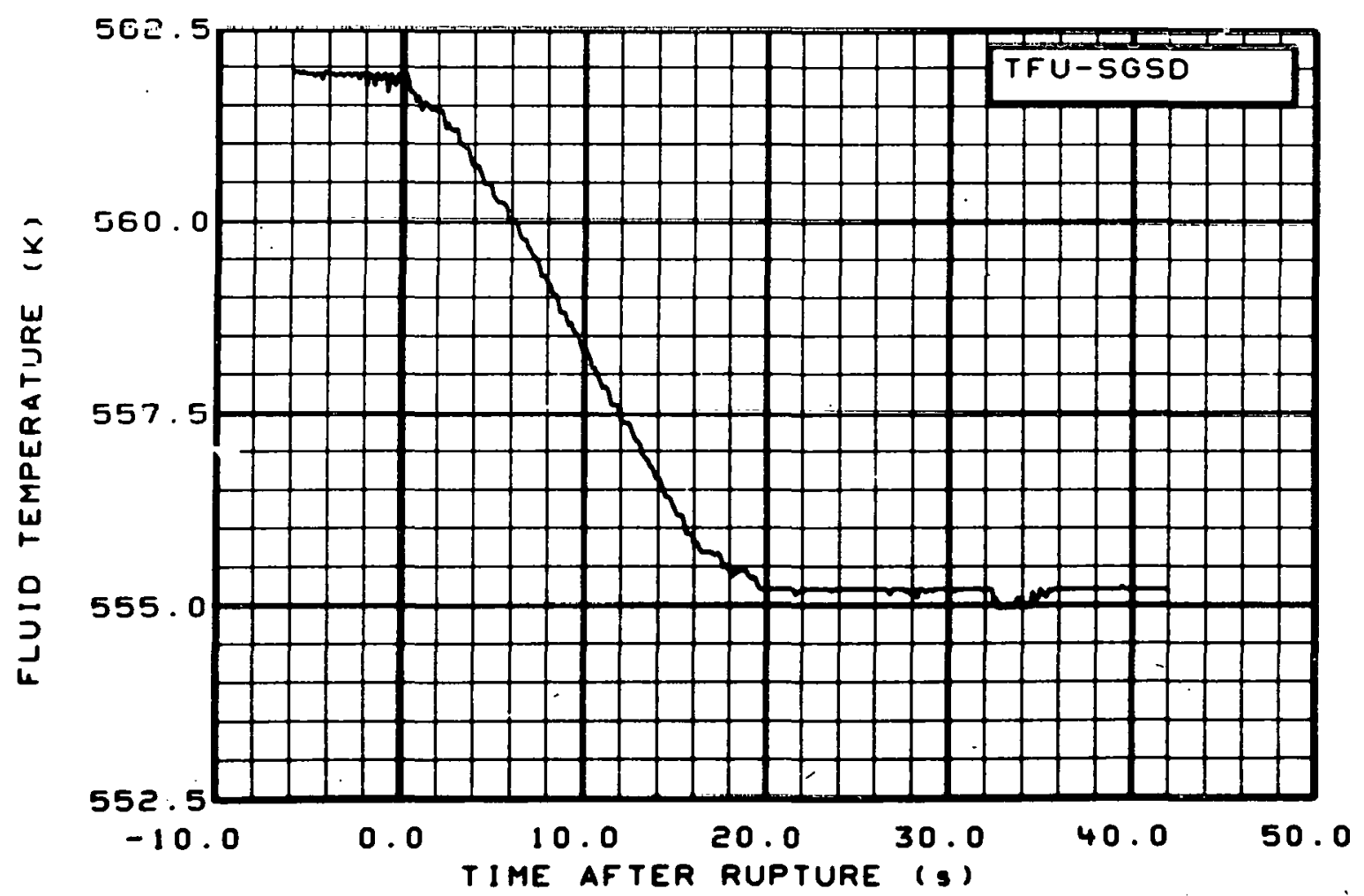

Fig. 44 Fluid temperature in steam generator, secondary side (TFU-SGSD), from -6 to $42 \mathrm{~s}$, 


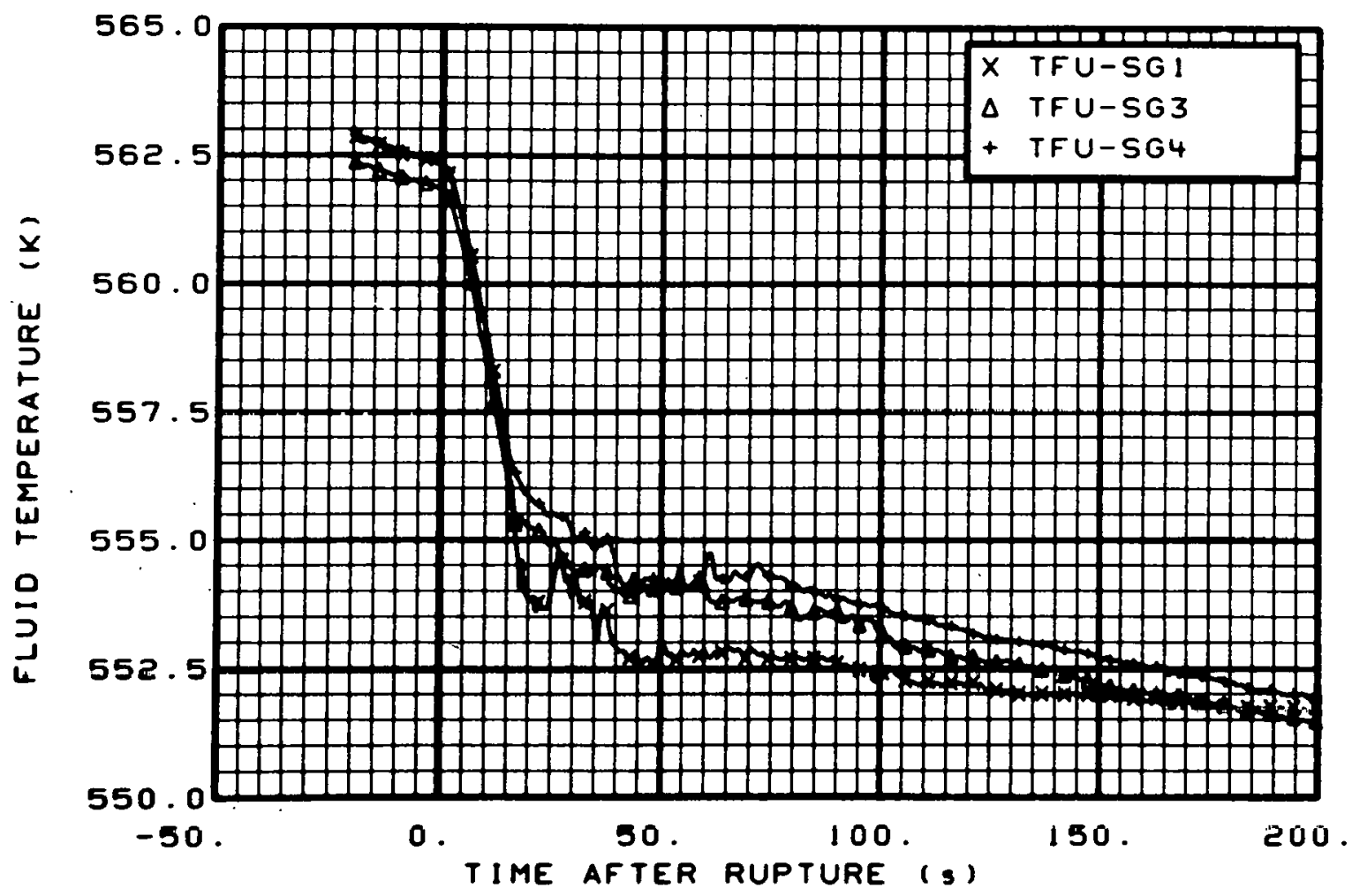

Fig. 45 Fluid temperature in steam generator, secondary side (TFU-SGl, TFU-SG3, and TFU-SG4), from -20 to $200 \mathrm{~s}$.

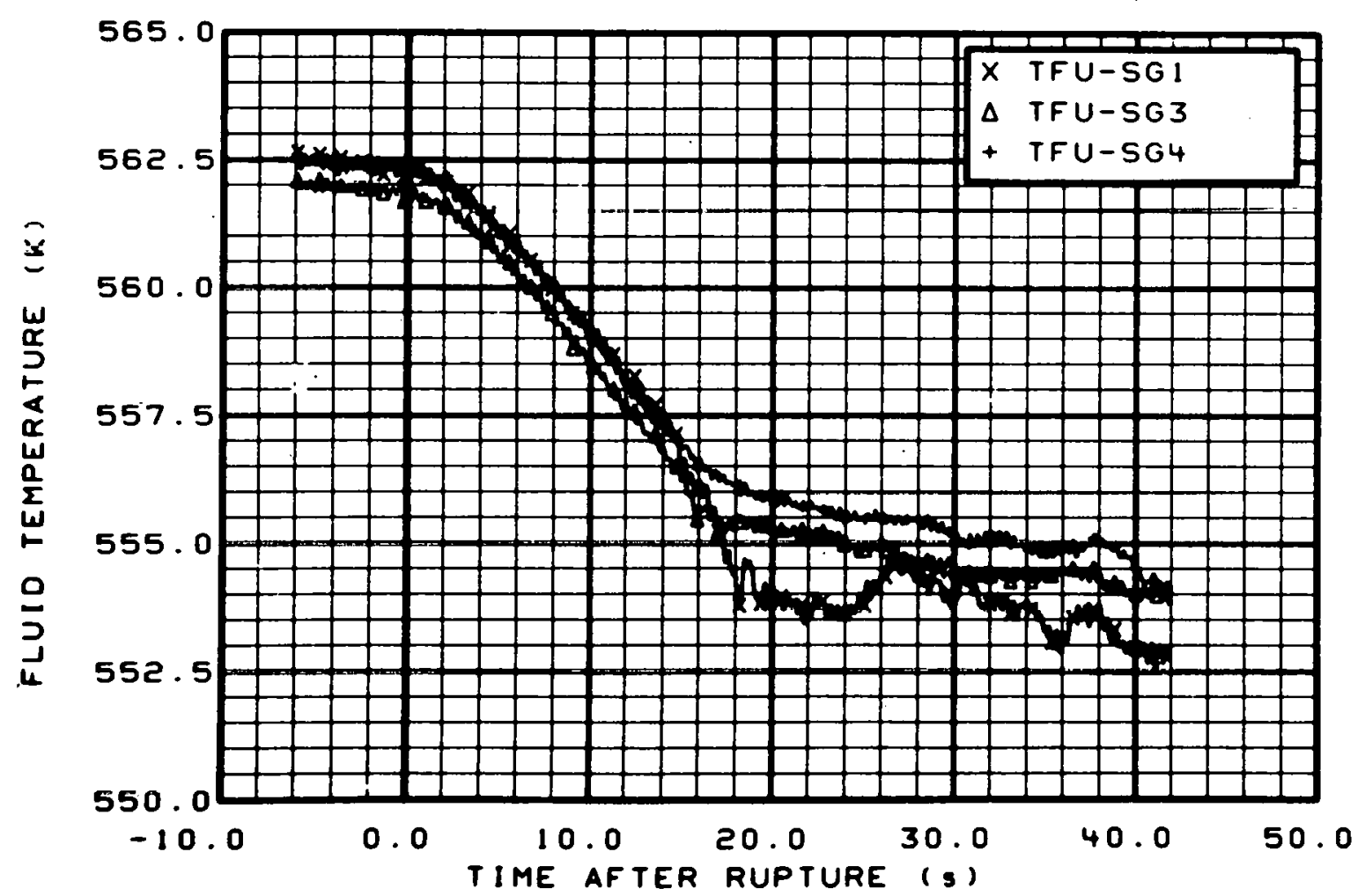

Fig. 46 Fluid temperature in steam generator, secondary side (TFU-SG TFU-SG3, and TFU-SG4), from -6 to $42 \mathrm{~s}$. 


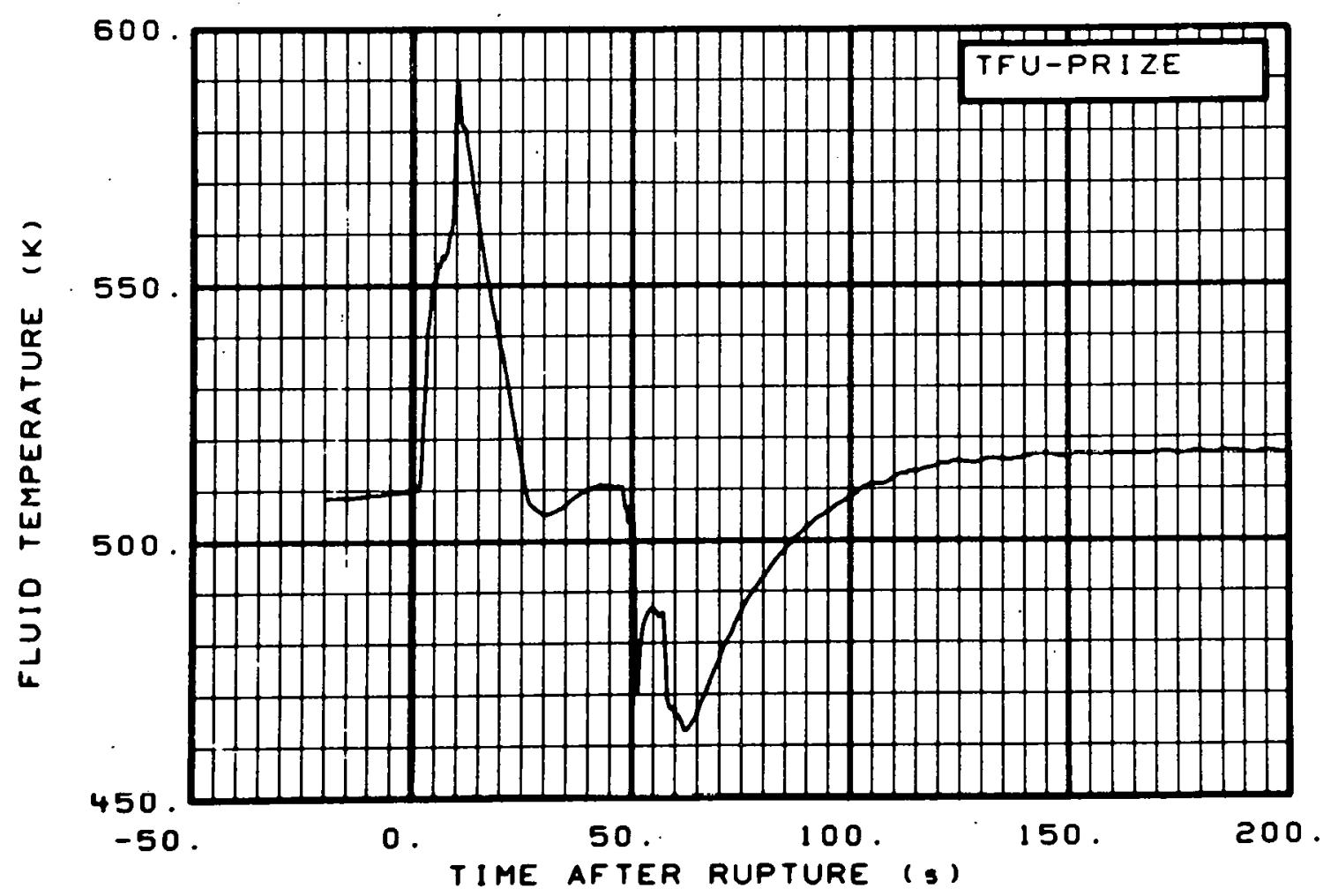

Fig. 47. Fluid temperature in pressurizer surge line (TFU-PRIZE), from -20 to $200 \mathrm{~s}$.

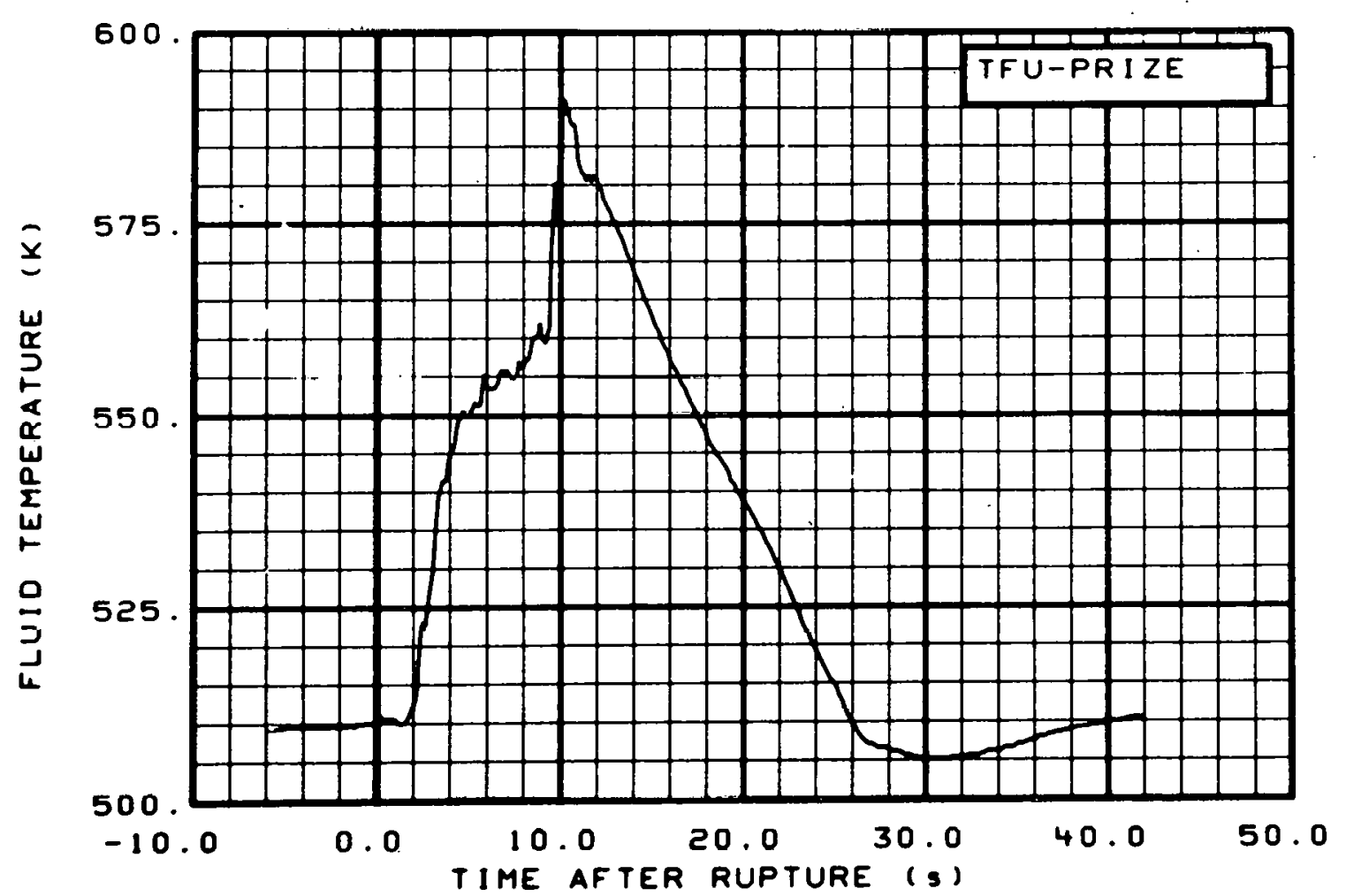

Fig. 48 Fluid temperature in pressurizer surge line (TFII-PRIZE), from -6 to $42 \mathrm{~s}$. 


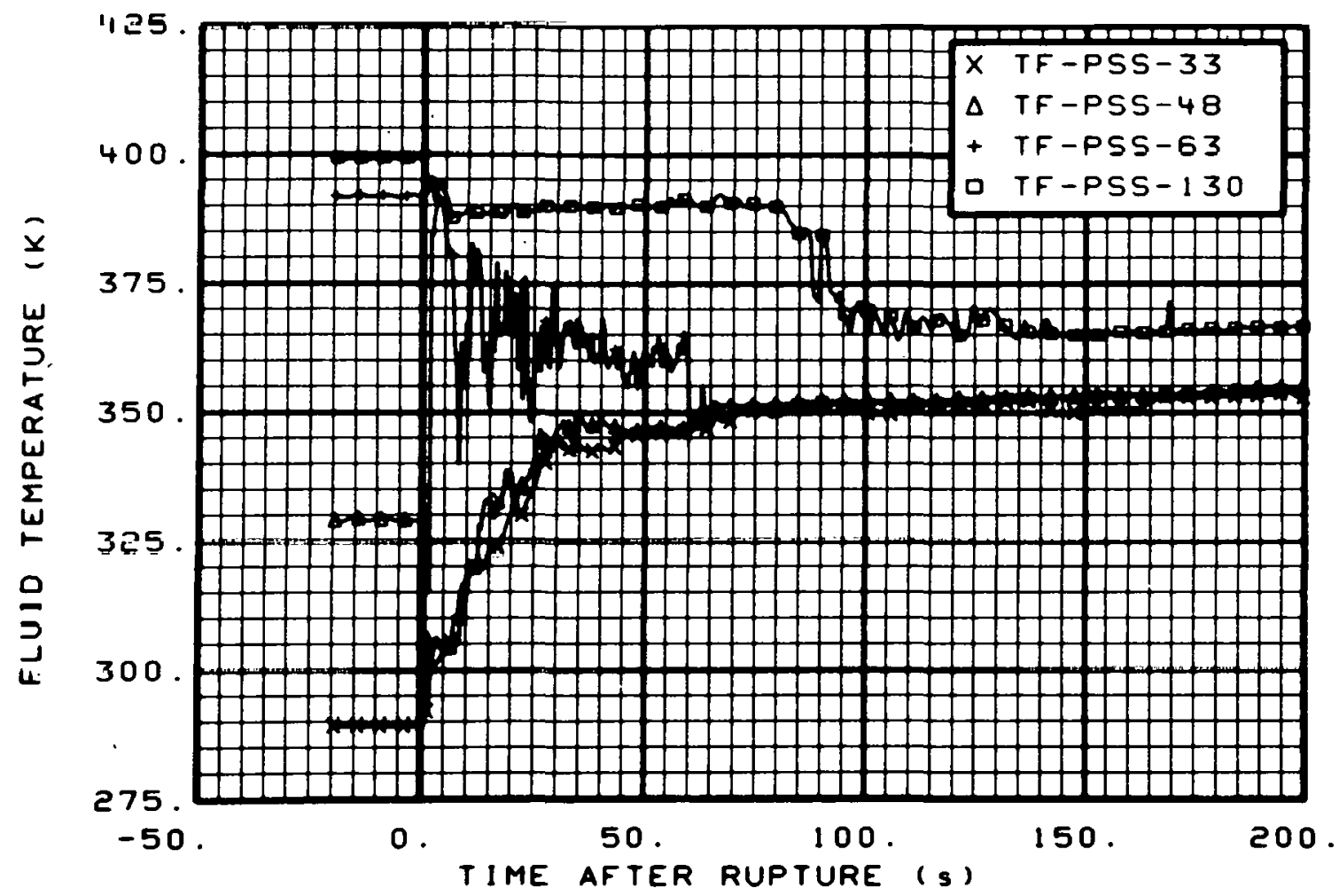

Fig. 49 Fluid temperature in pressure suppression tank (TF-PSS-33, TF-PSS-48, TF-PSS-63, and TF-PSS-130), from -20 to $200 \mathrm{~s}$.

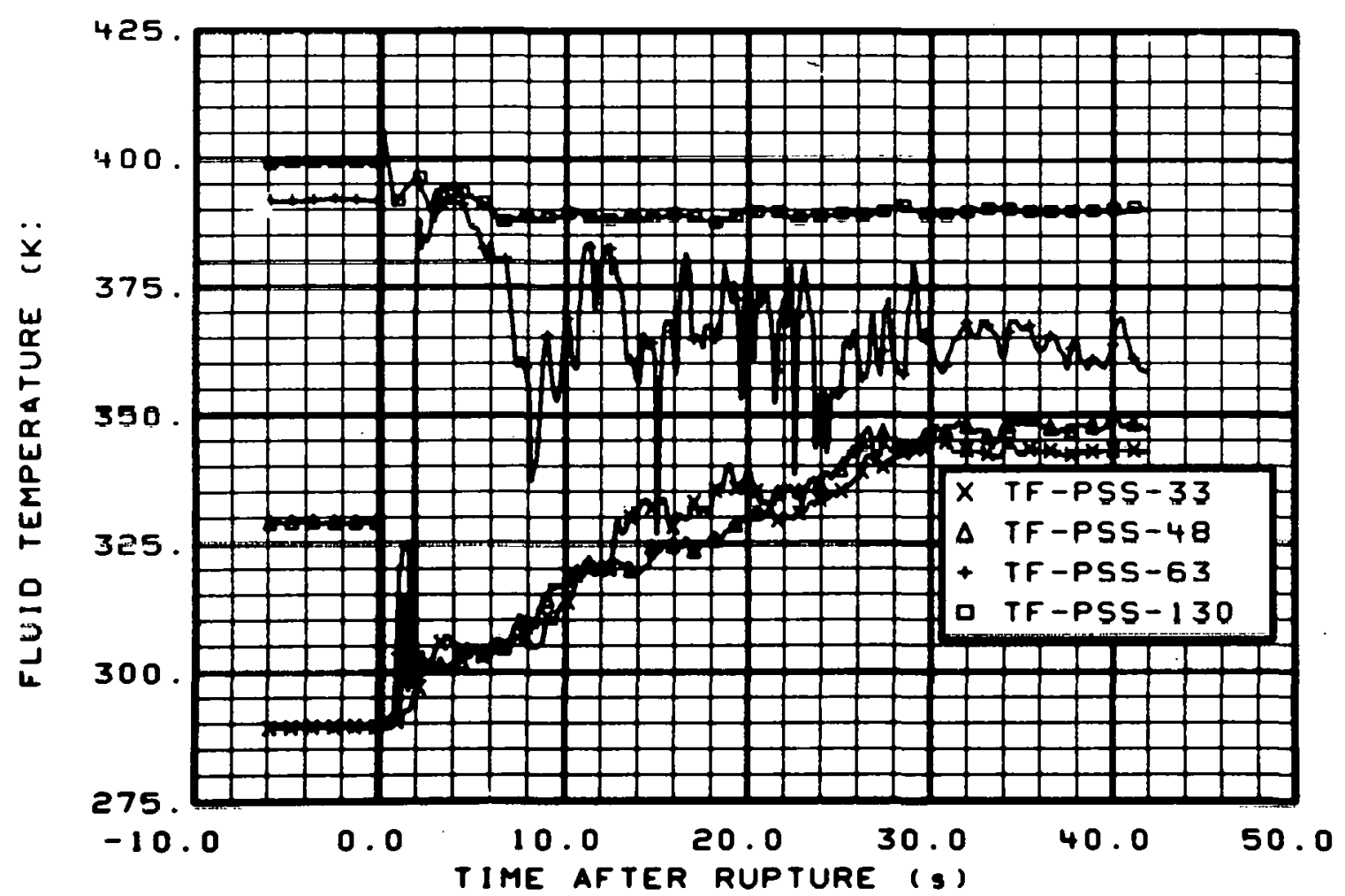

Fig. 50. Fluid temperature in pressure suppression tank (TF-PSS-33, TF-PSS-48, TF-PSS-63, and TF-PSS-130), from -6 to $42 \mathrm{~s}$. 


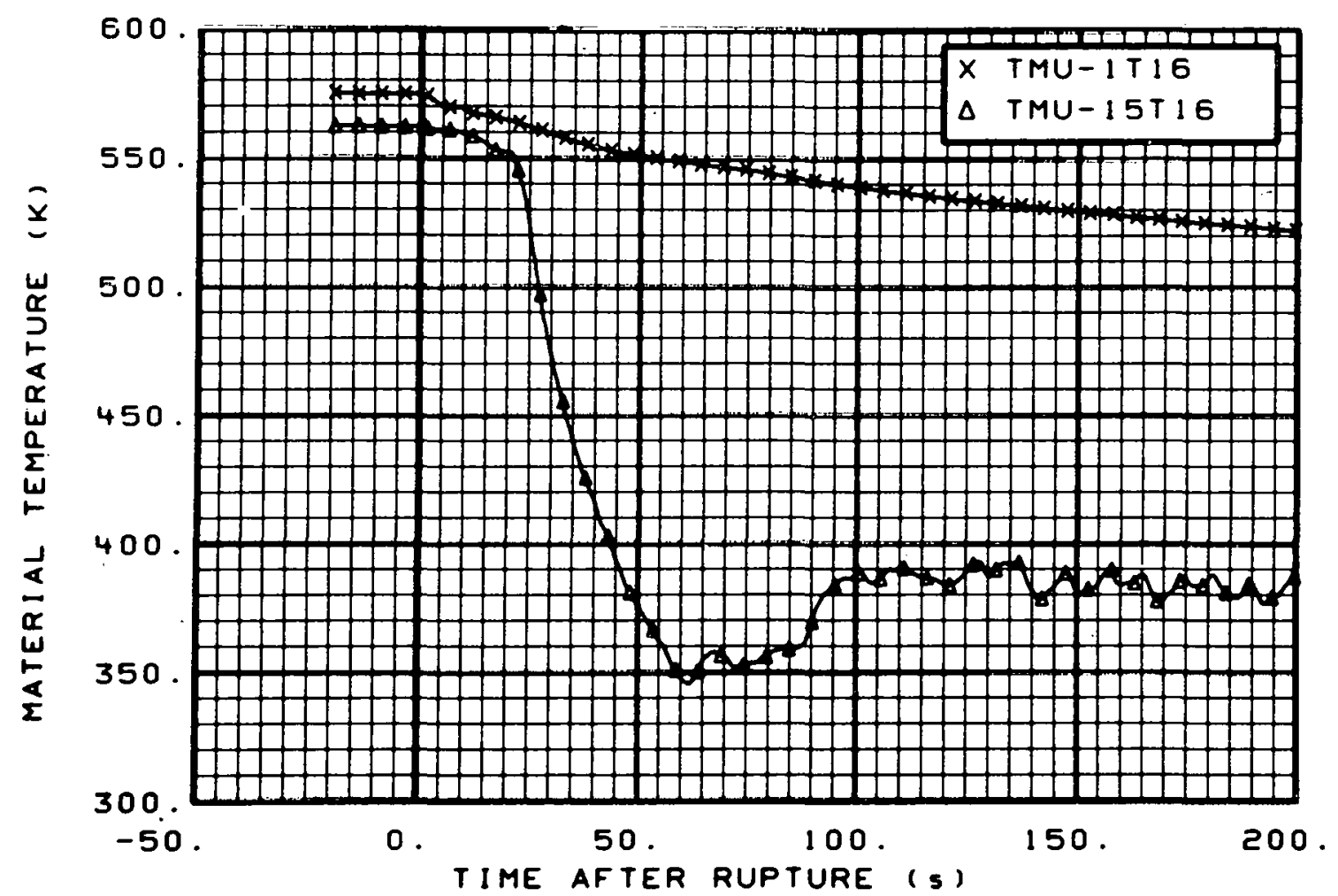

Fig. 51 Material temperature in intact 100p (TMU-1T16 and TMU-15T16), from -20 to $200 \mathrm{~s}$.

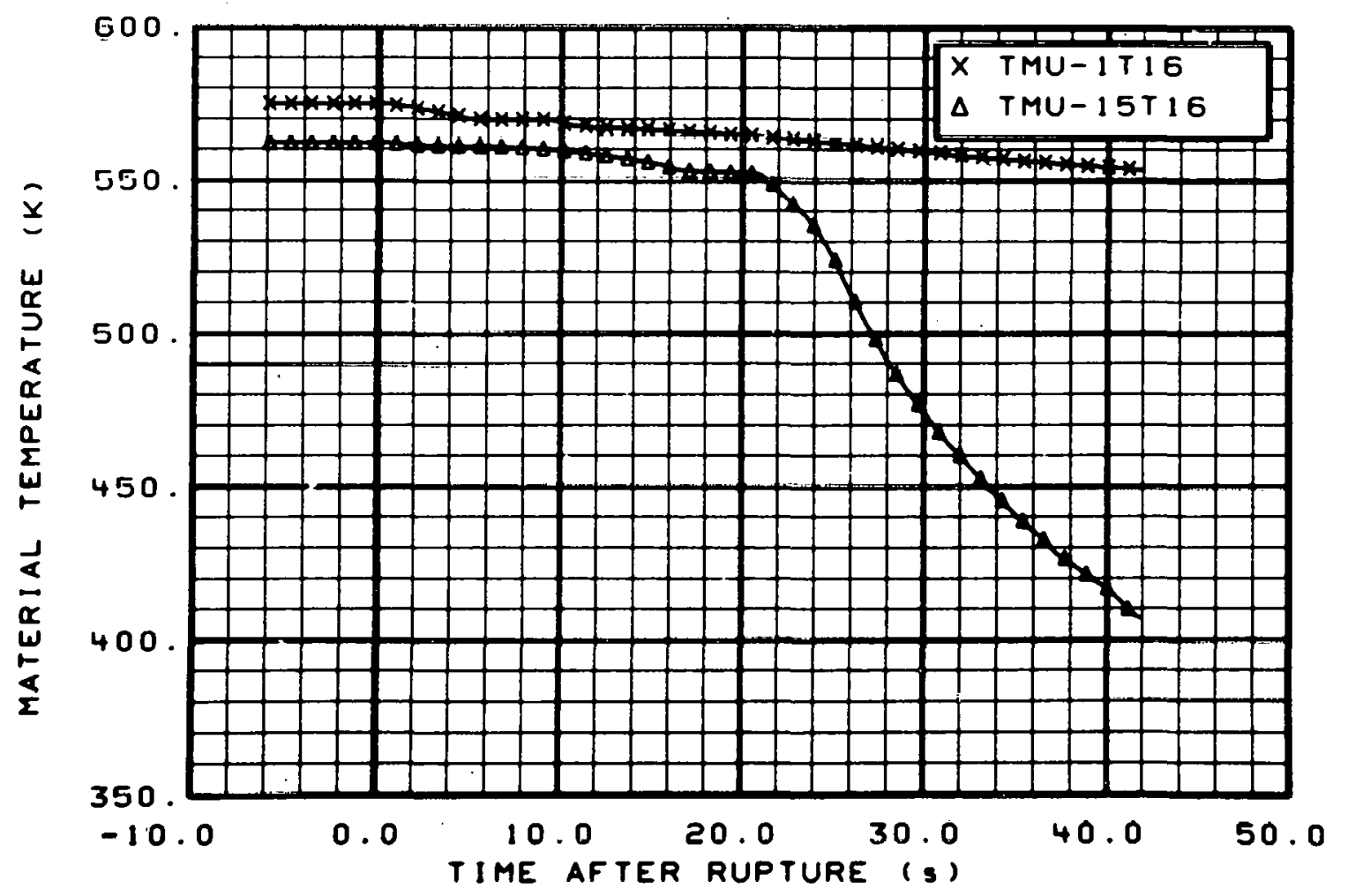

Fig. 52 Material temperature in intact loop (TMU-1T16 and TMU-15T16), from -6 to $42 \mathrm{~s}$. 


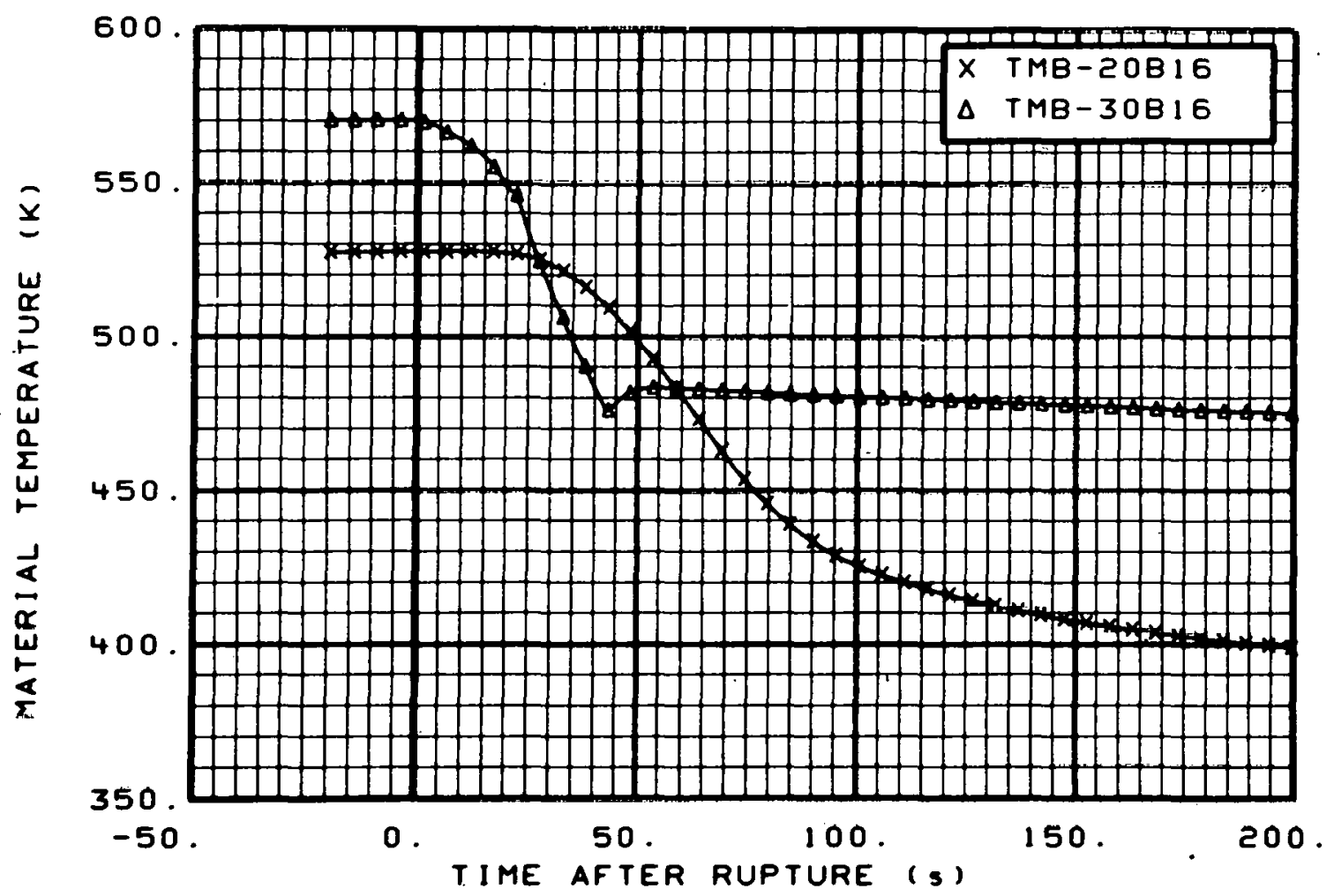

Fig. 53 Material temperature in broken loop (TMB-20B16 and TMB-30B16), from -20 to $200 \mathrm{~s}$.

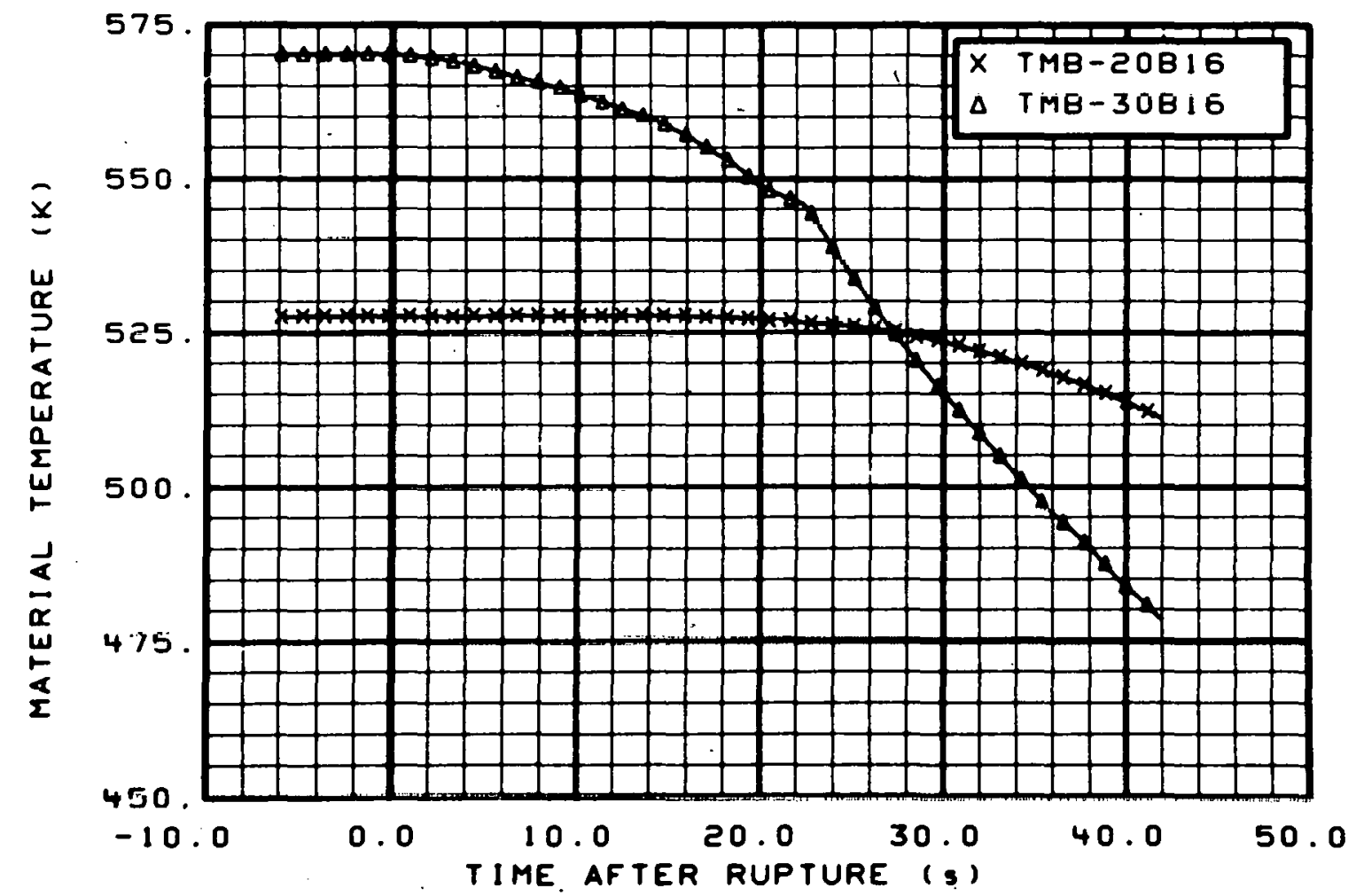

Fig. 54 Material temperature in broken loop (TMB-20B16 and TMB-30B16), from -6 to $42 \mathrm{~s}$. 


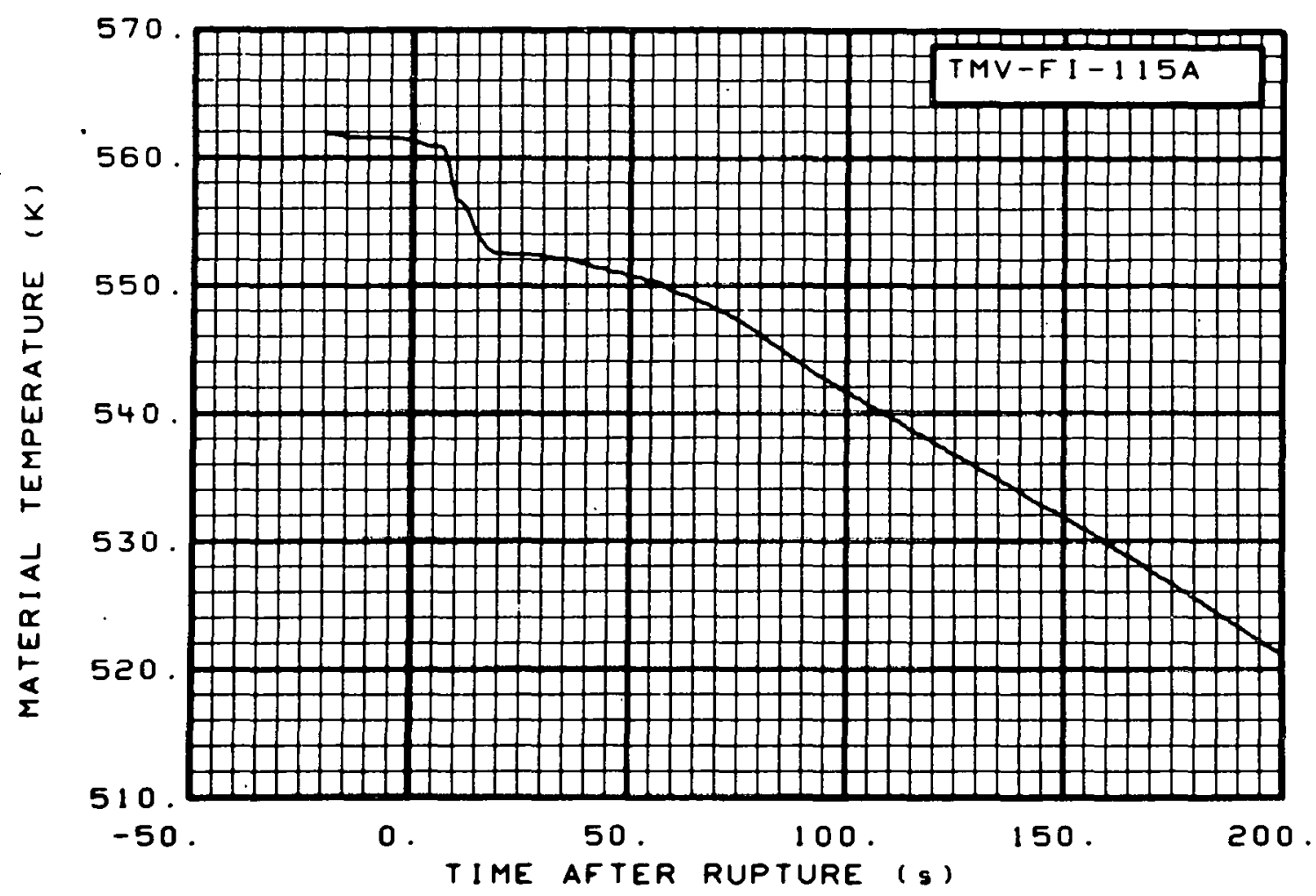

Fig. 55 Material temperature in vessel filler (TMV-FI-115A), from -20 to $200 \mathrm{~s}$.

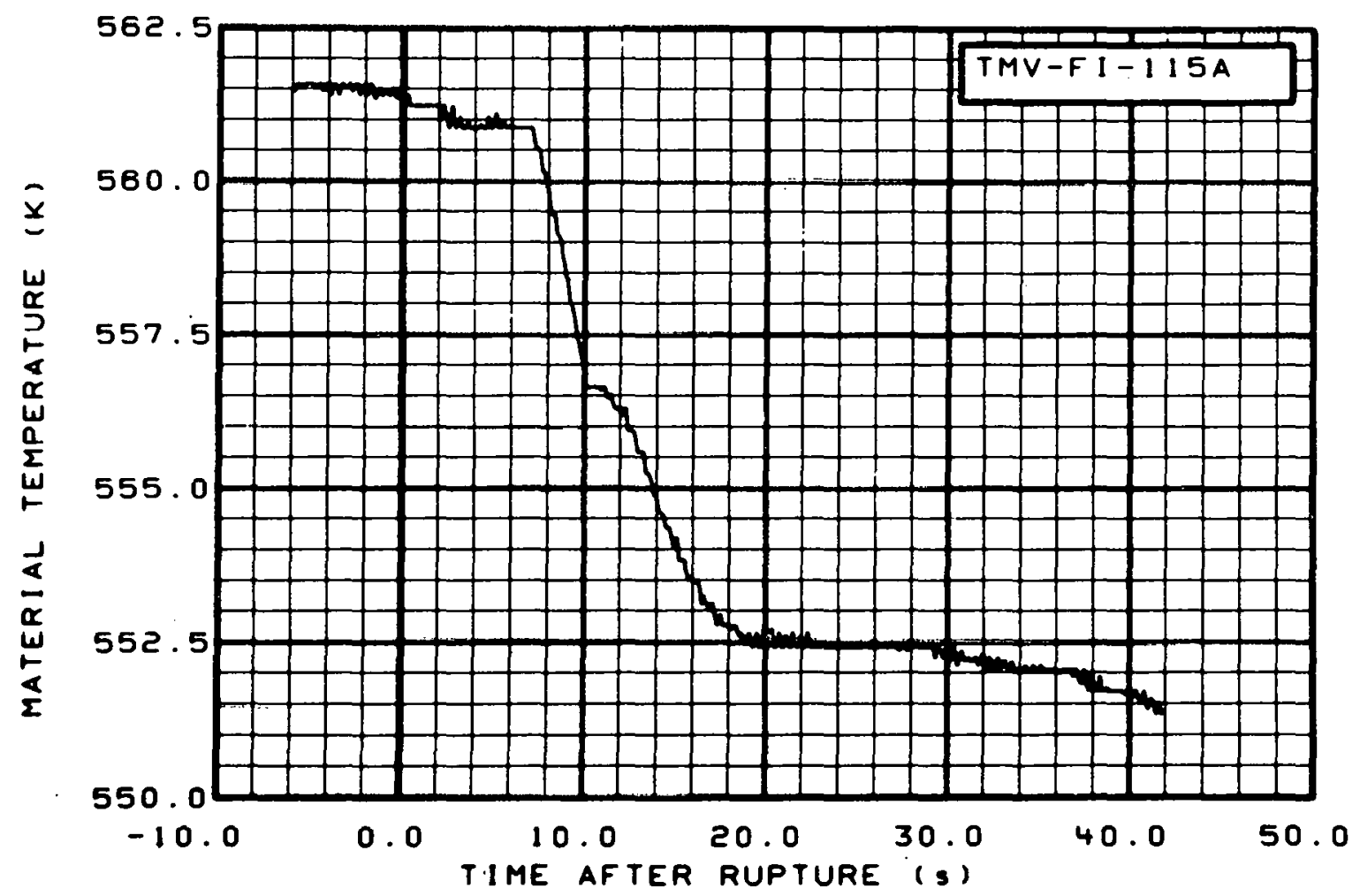

Fig. 56 Material temperature in vessel filler (TMV-FI-115A), from -6 to $42 \mathrm{~s}$. 


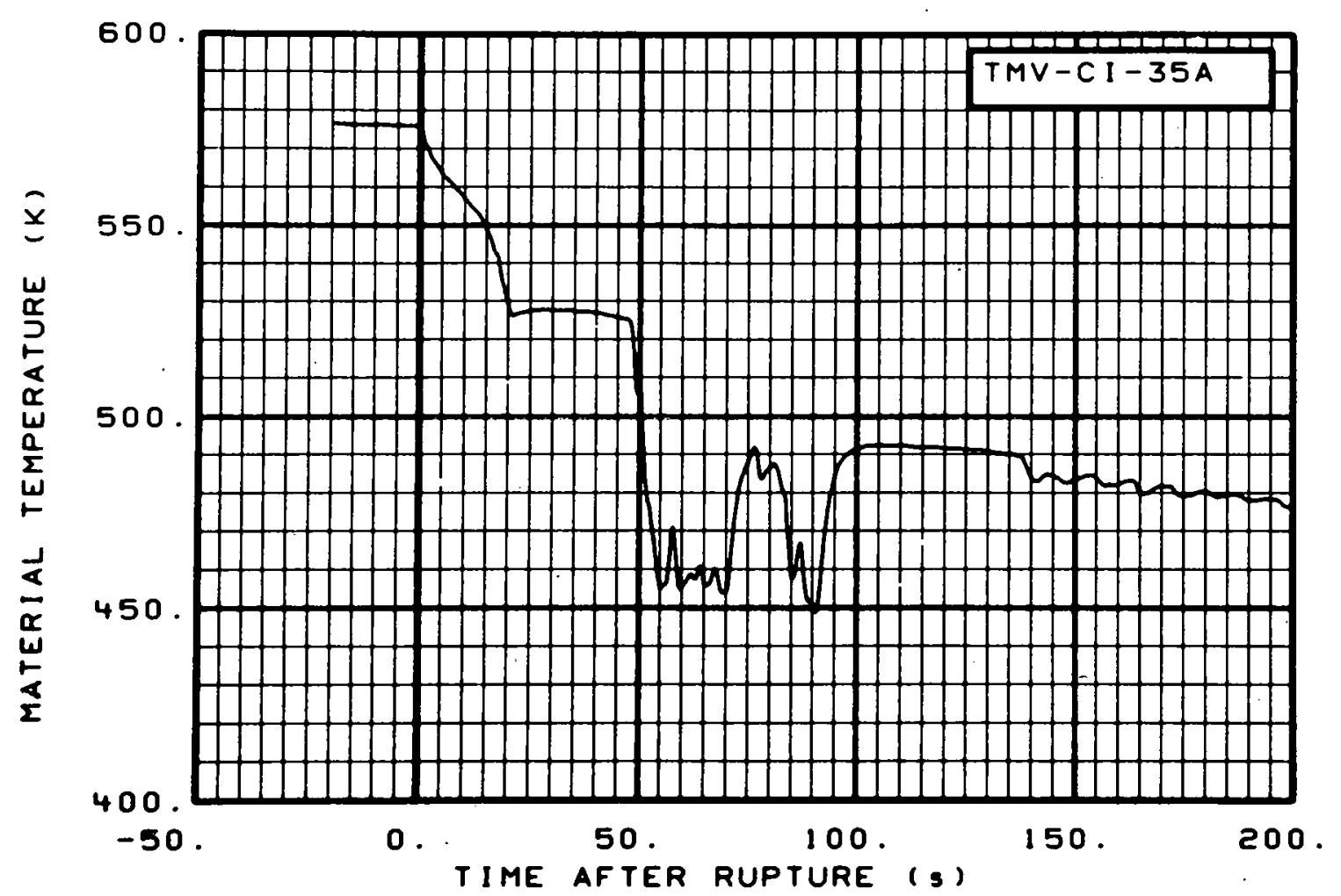

Fig. 57 Material temperature in core barrel inner diameter (TMV-CI-35A), from -20 to $200 \mathrm{~s}$.

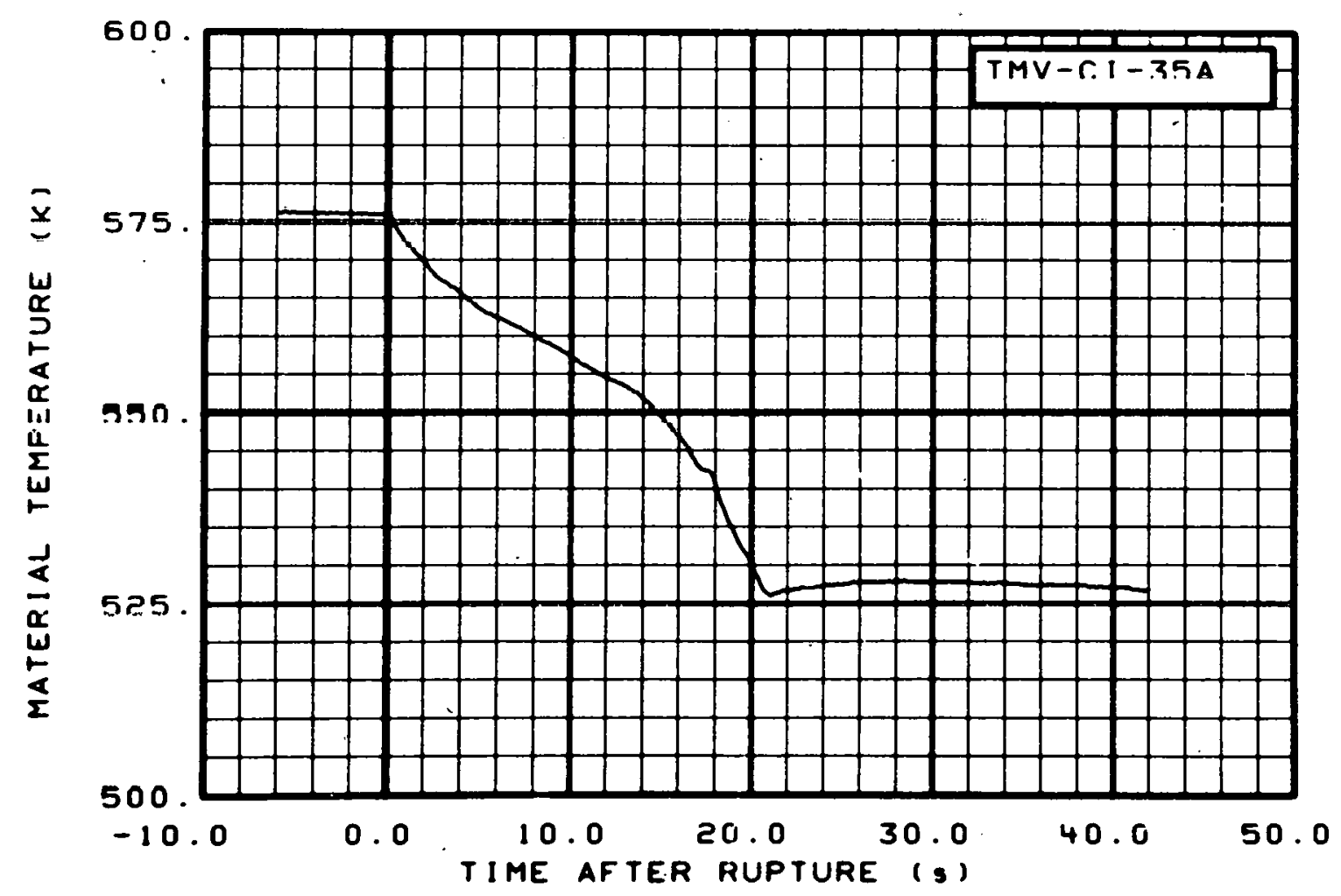

Fig. 58 Material temperature in core barrel inner diameter (TMV-CI-35A), from -6 to $42 \mathrm{~s}$. 


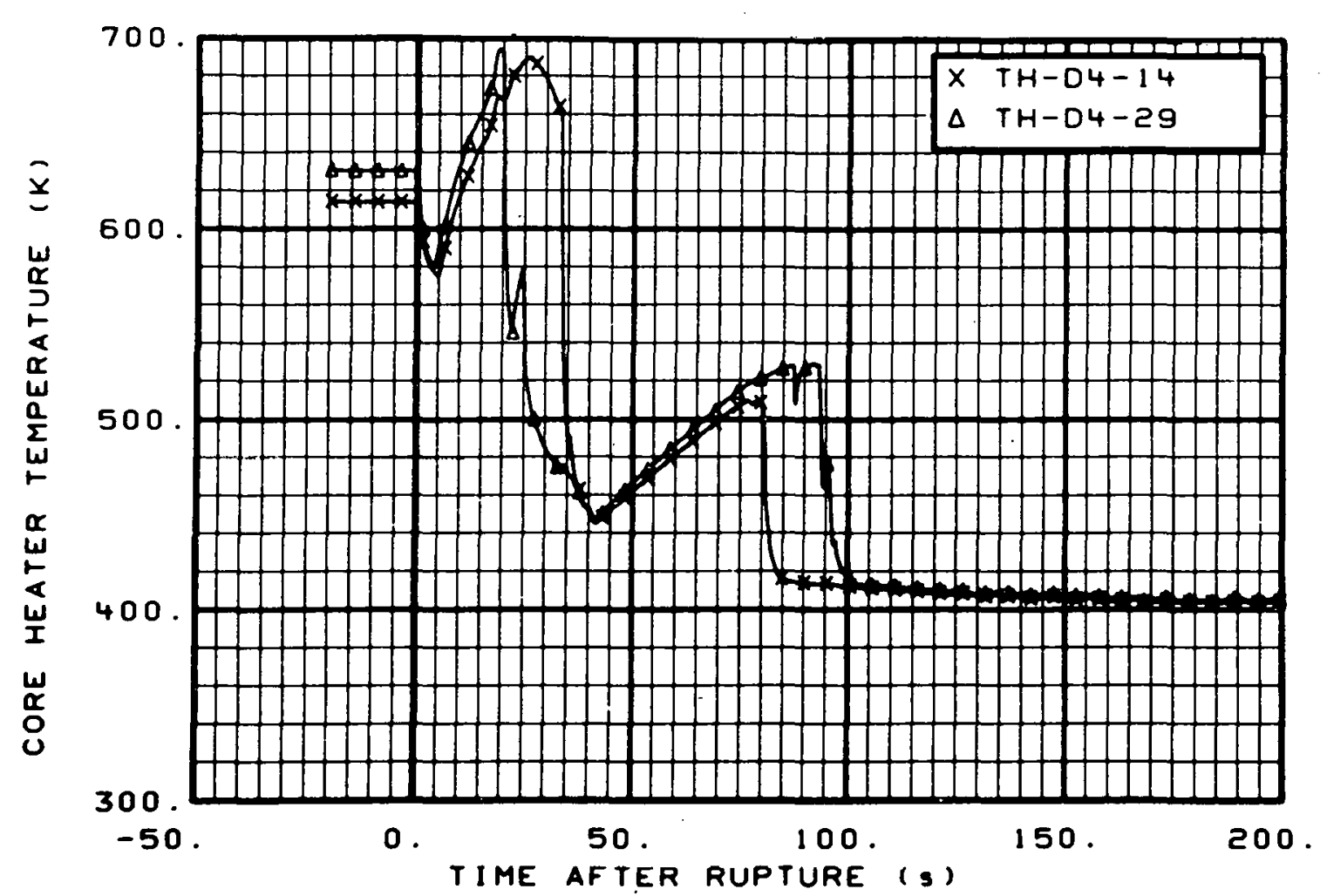

Fig. 59 Core heater temperature, Rod D-4 (TH-D4-14 and TH-D4-29), from -20 to $200 \mathrm{~s}$.

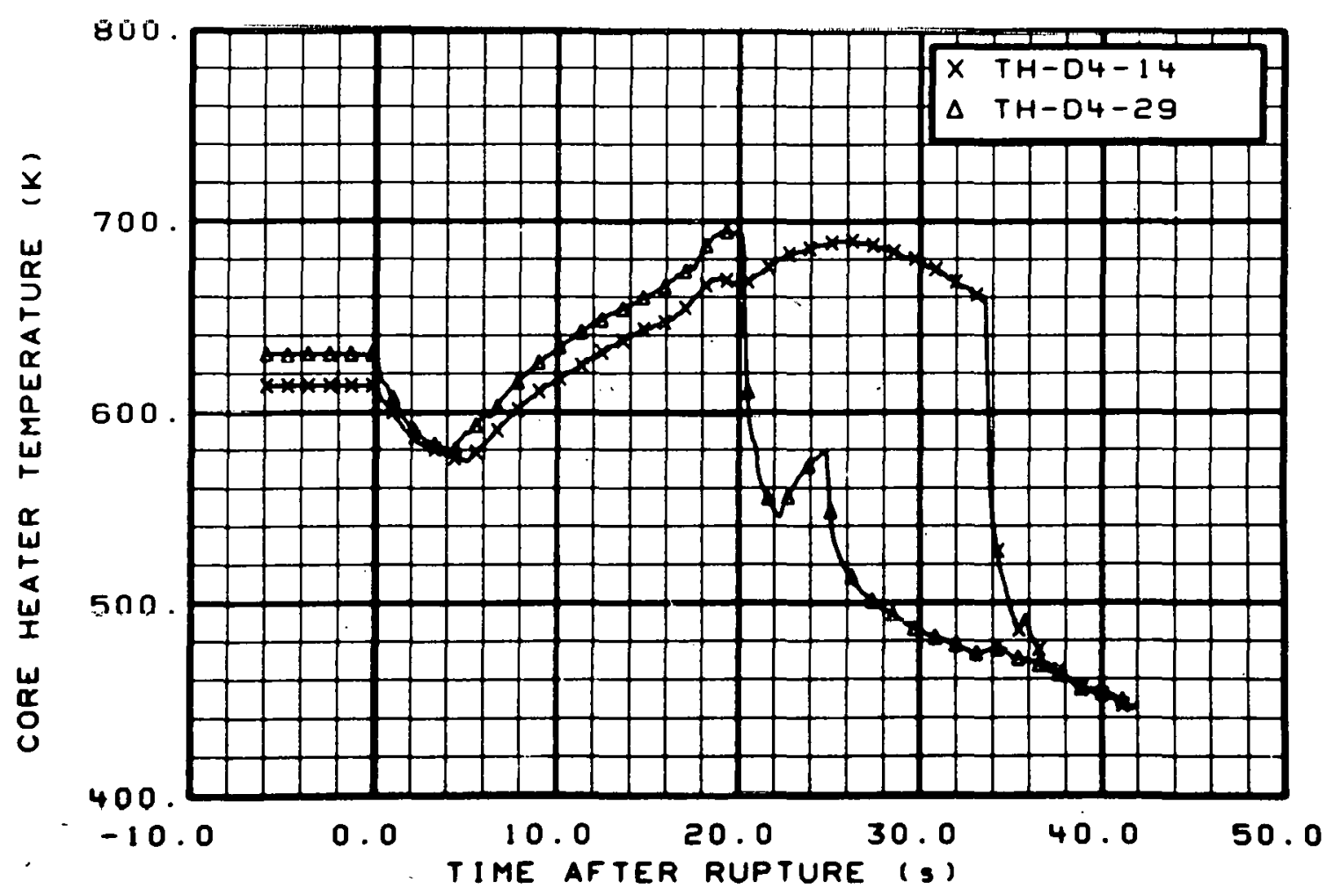

Fig. 60 Core heater temperature, Rod D-4 (TH-D4-14 and TH-D4-29), from -6 to $42 \mathrm{~s}$. 


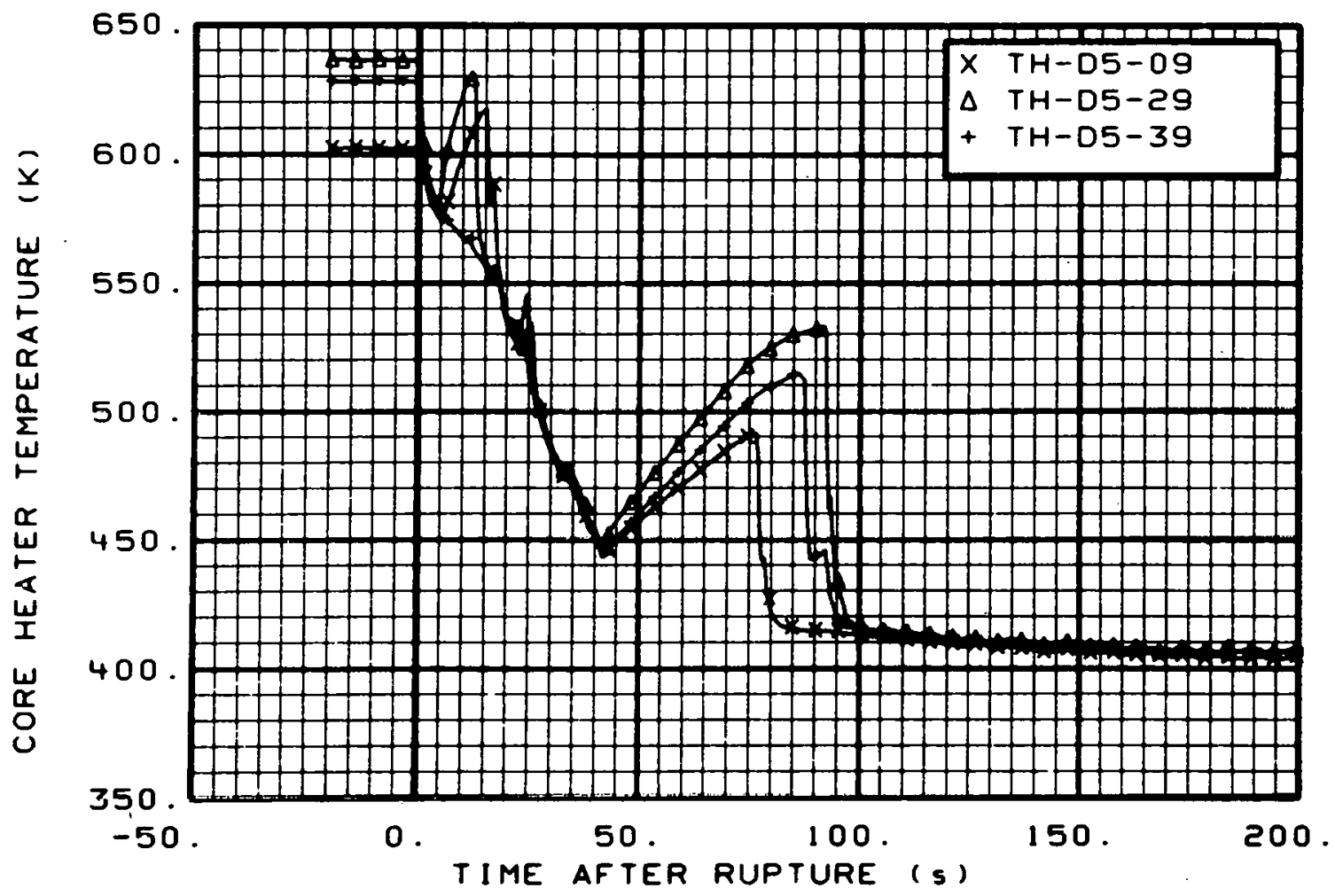

Fig. 61 Core heater temperature, Rod D-5 (TH-D5-09, TH-D5-29, and TH-D5-39), from -20 to $200 \mathrm{~s}$.

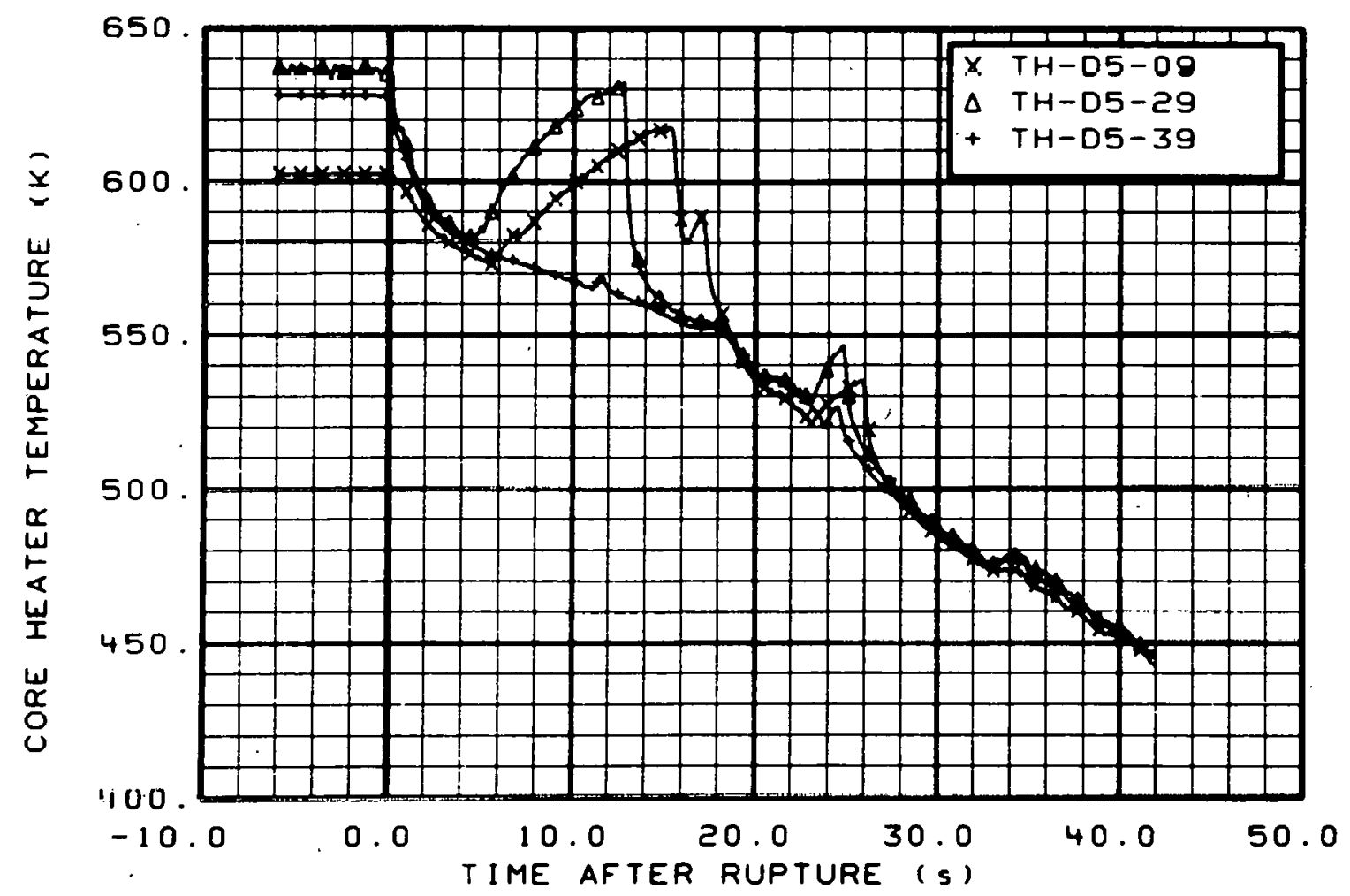

Fig. 62 Core heater temperature, Rod D-5 (TH-D5-09, TH-D5-29, and TH-D5-39), from -6 to $42 \mathrm{~s}$. 


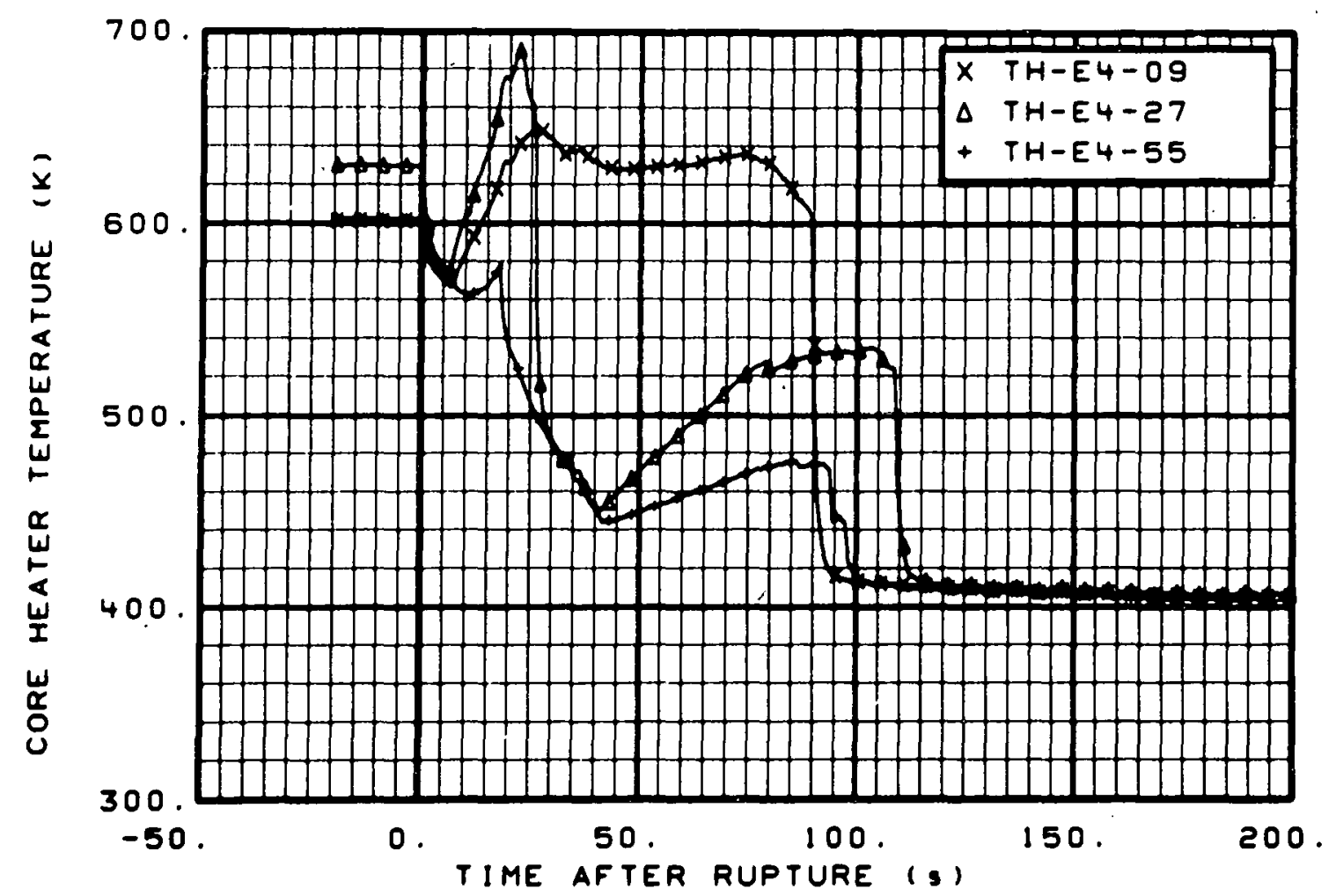

Fig. 63 Core heater temperature, Rod E-4 (TH-E4-09, TH-E4-27, and TH-E4-55), from -20 to $200 \mathrm{~s}$.

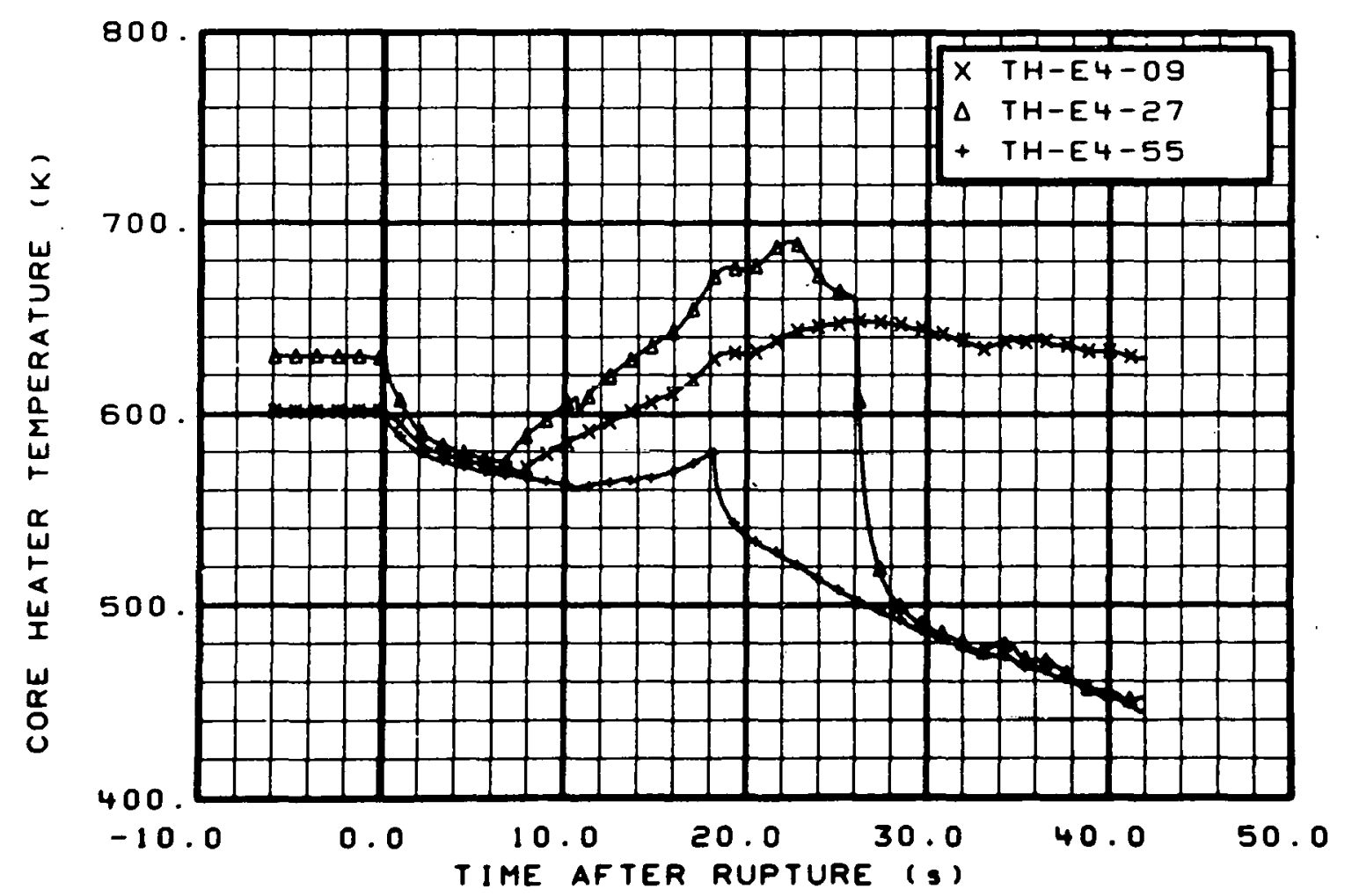

Fig. 64 Core heater temperature, Rod E-4 (TH-E4-09, TH-E4-27, and TH-E4-55), from -6 to $42 \mathrm{~s}$. 


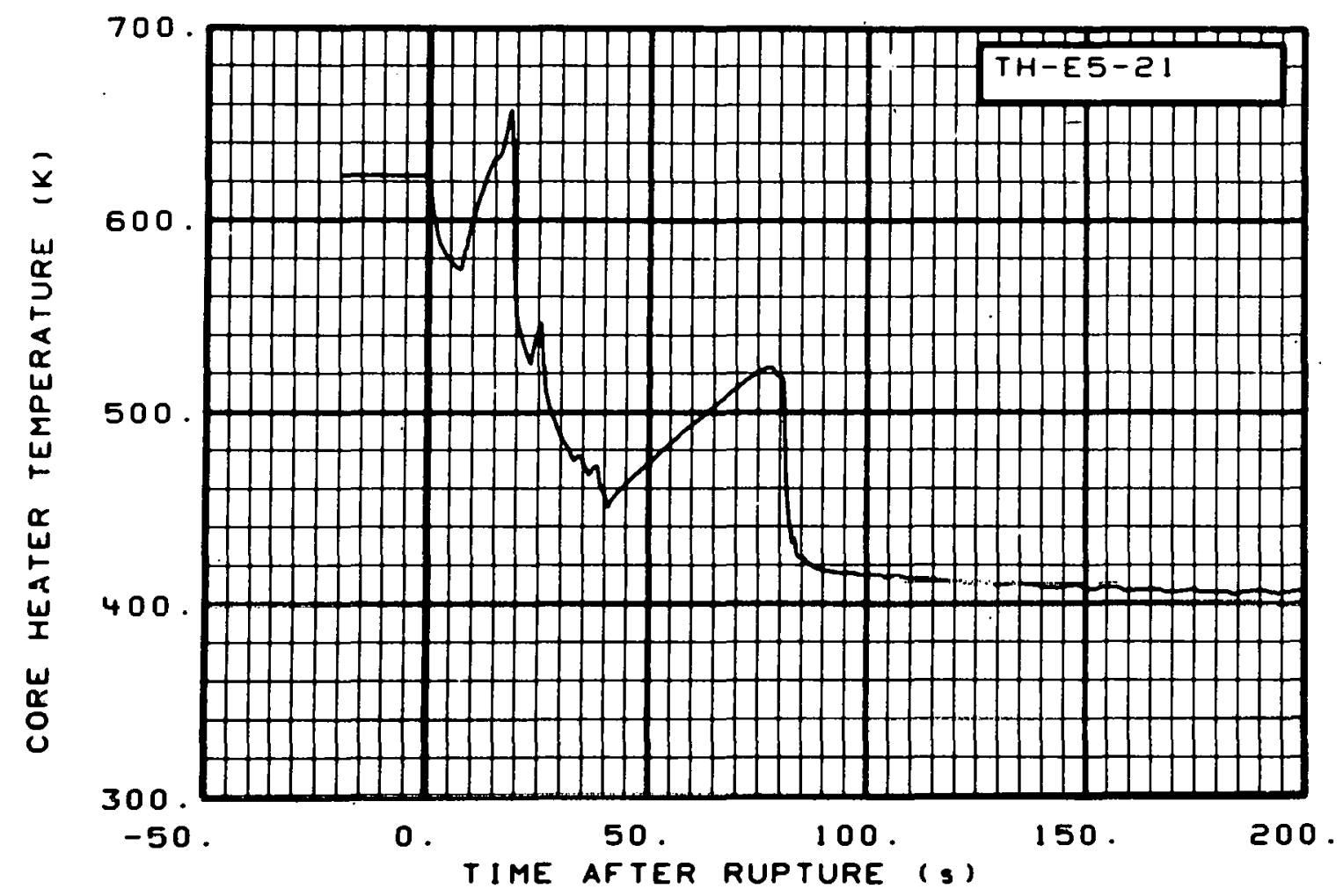

Fig. 65 Core heater temperature, Rod E-5 (TH-E5-21), from -20 to $200 \mathrm{~s}$.

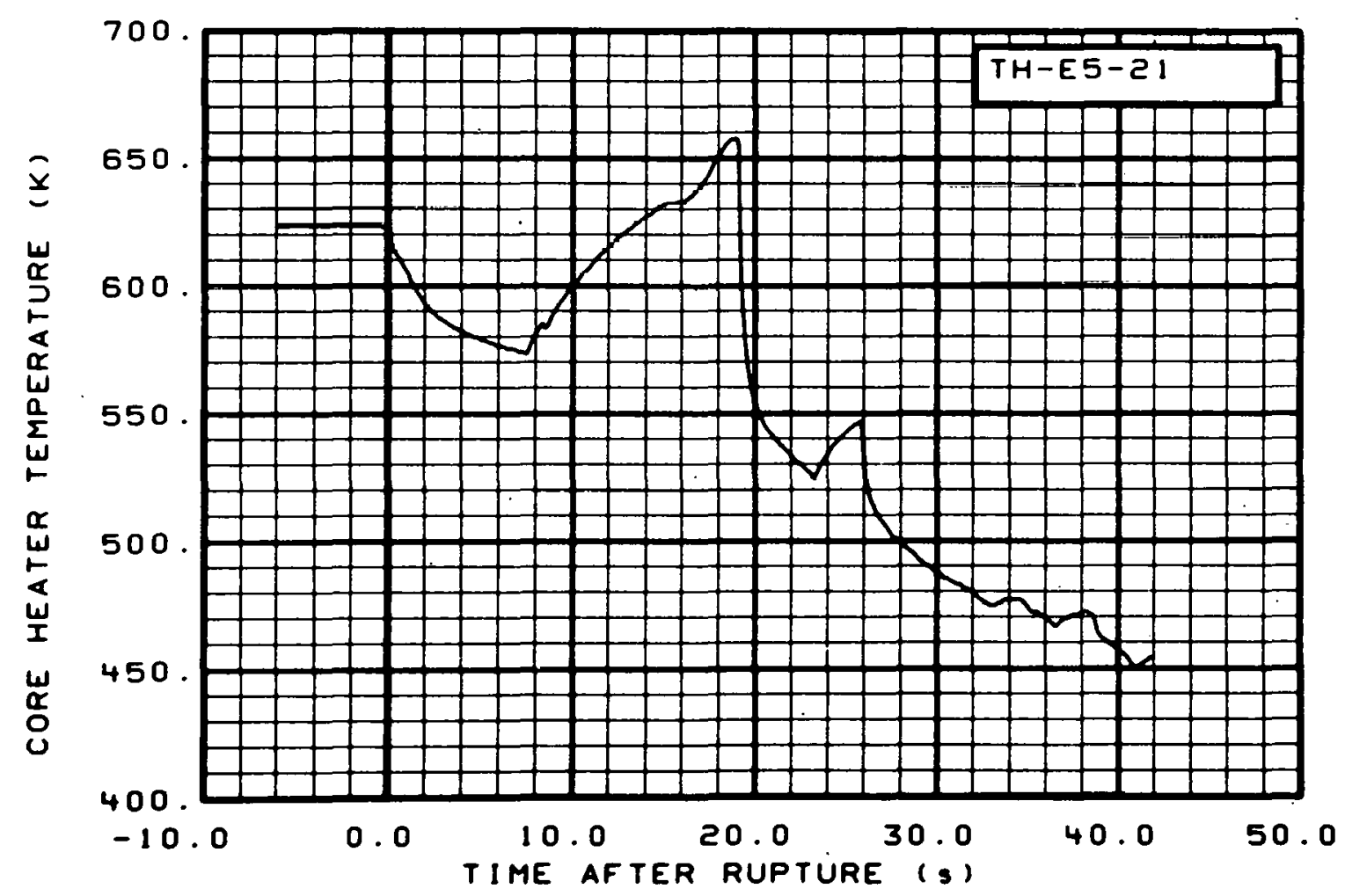

Fig. 66 Core heater temperature, Rod E-5 (TH-E5-21), from -6 to $42 \mathrm{~s}$. 


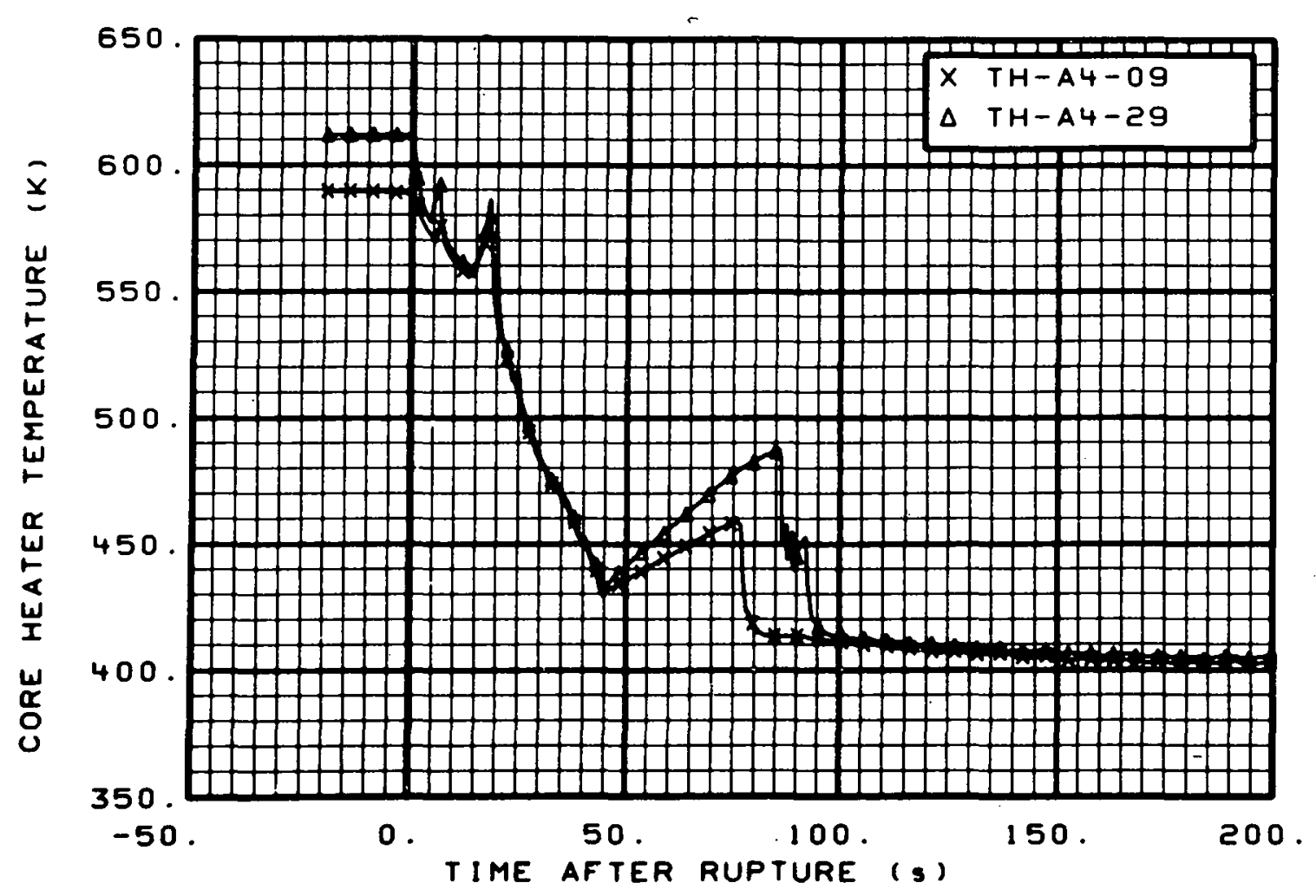

Fig. 67 Core heater temperature, Rod A-4 (TH-A4-09 and TH-A4-29), from -20 to $200 \mathrm{~s}$.

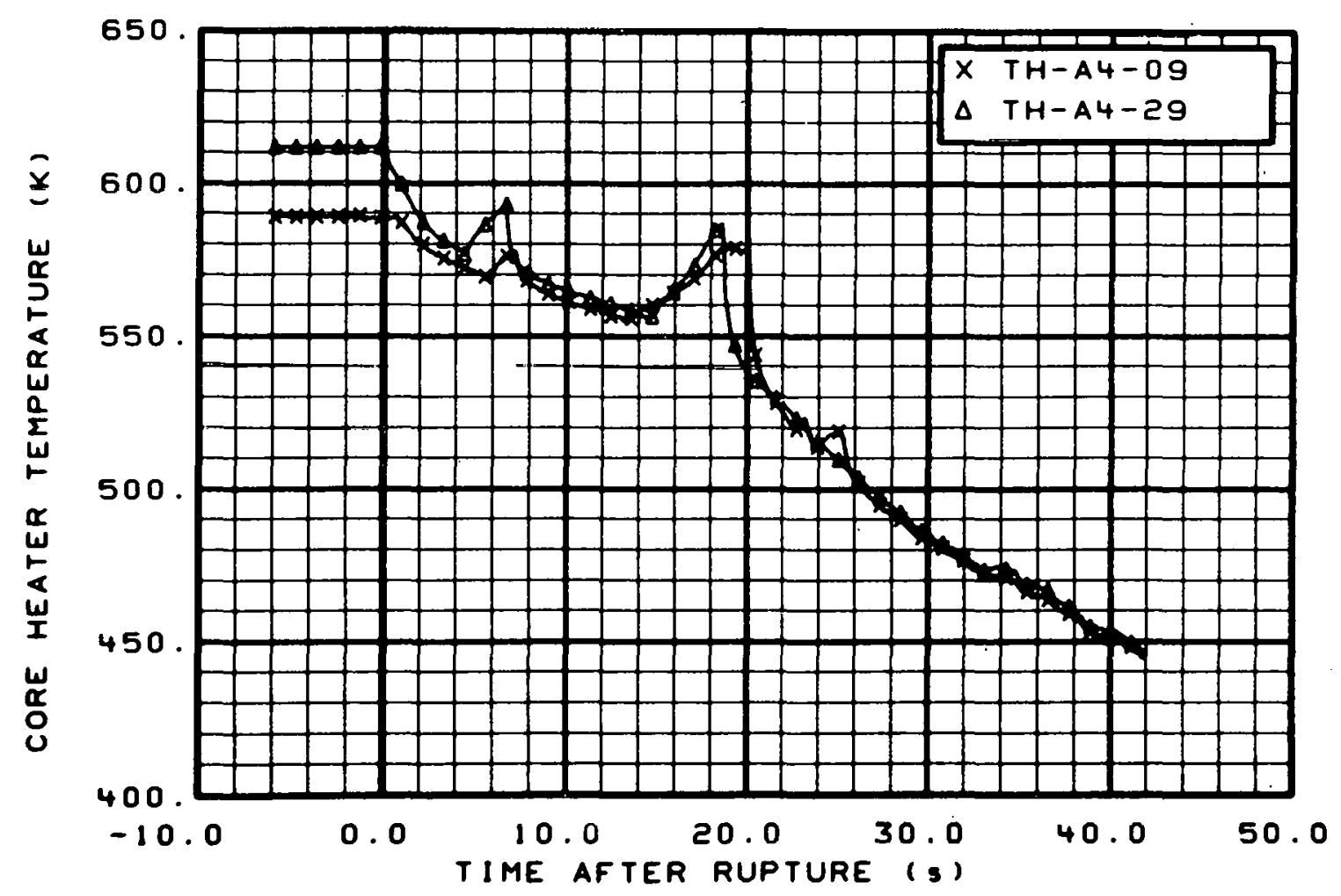

Fig. 68 core heater temperature, Rod A-4 (TII-A4-09 and TH.A1-29), from -6 to $42 \mathrm{~s}$. 


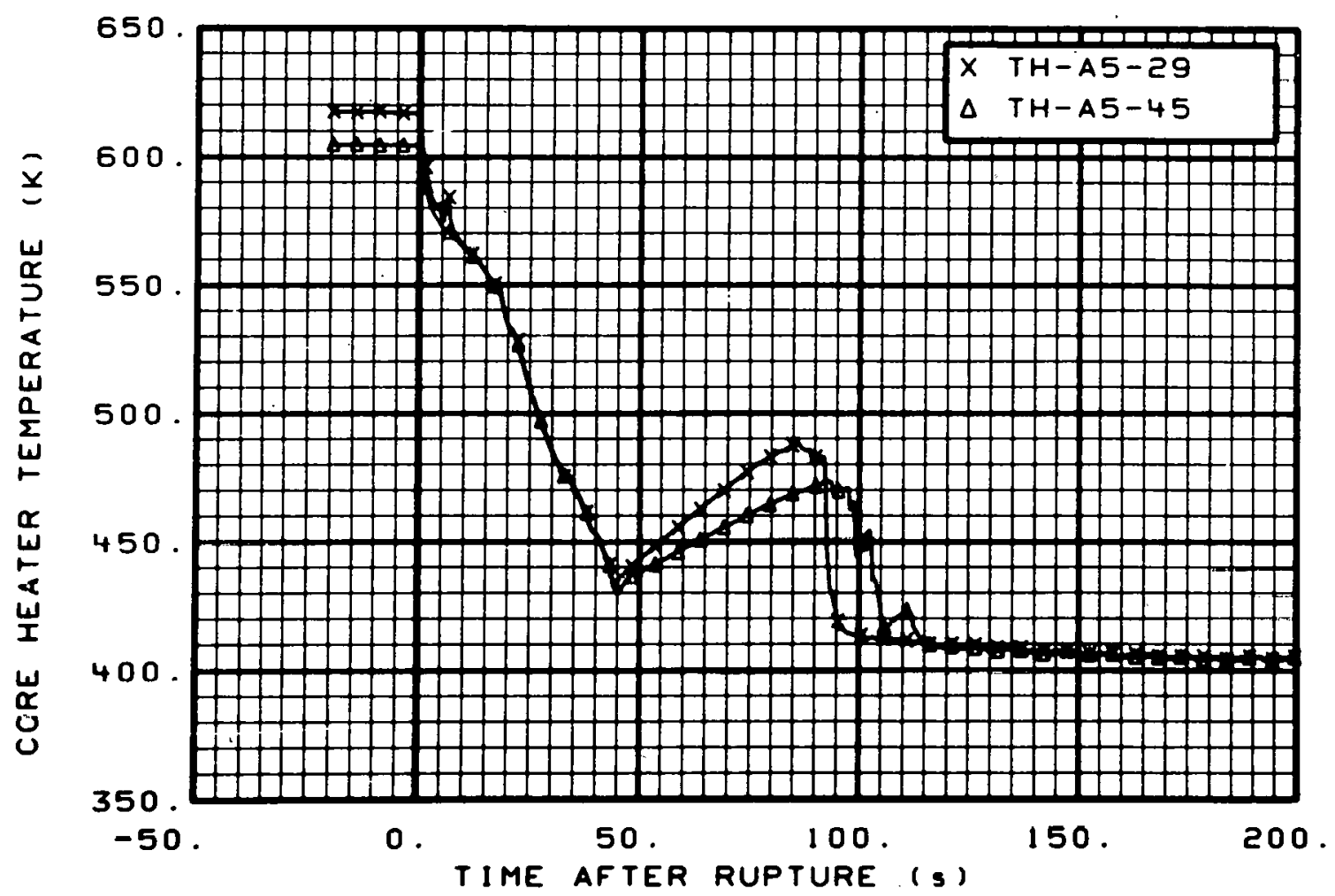

Fig. 69 Core heater temperature, Rod A-5 (TH-A5-29 and TH-A5-45), from -20 to $200 \mathrm{~s}$.

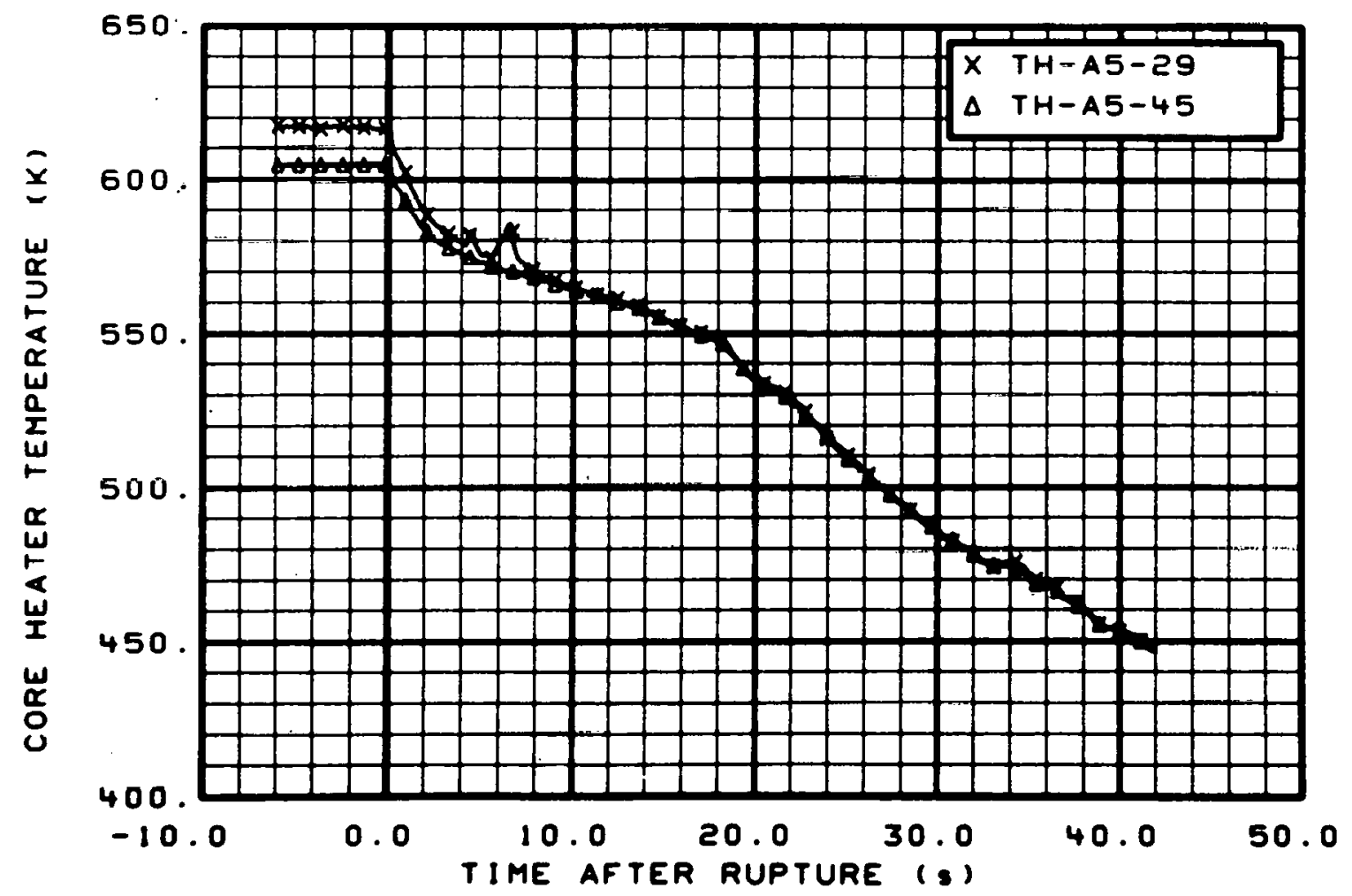

Fig. 70 Core heater temperature, Rod A-5 (TH-A5-29 and TH-A5-45), from -6 to $42 \mathrm{~s}$. 


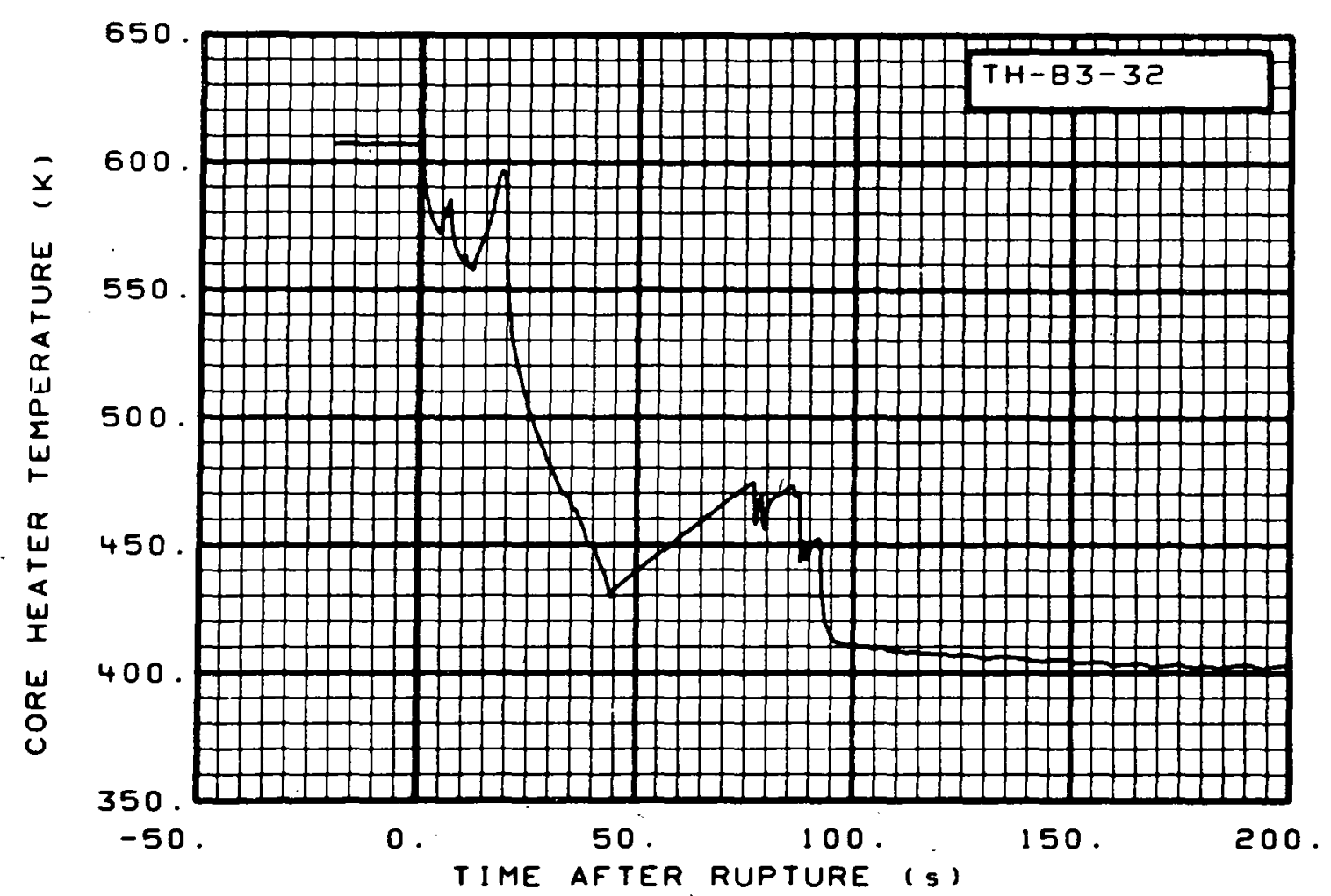

Fig. 71 Core heater temperature, Rod B-3 (TH-B3-32), from -20 to $200 \mathrm{~s}$.

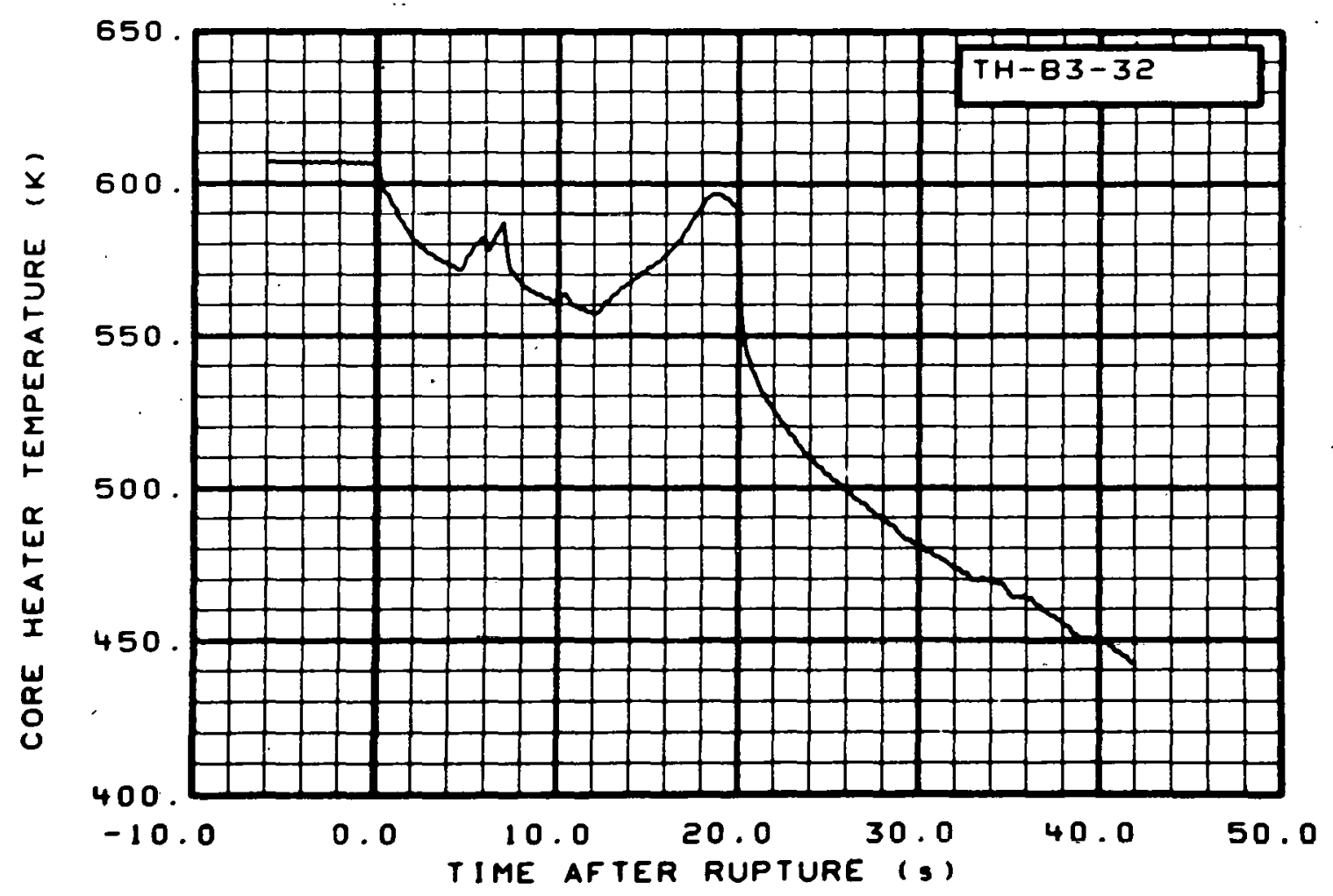

Fig. 72 Core heater temperature, Rod B-3 (TH-B3-32), from -6 to $42 \mathrm{~s}$. 


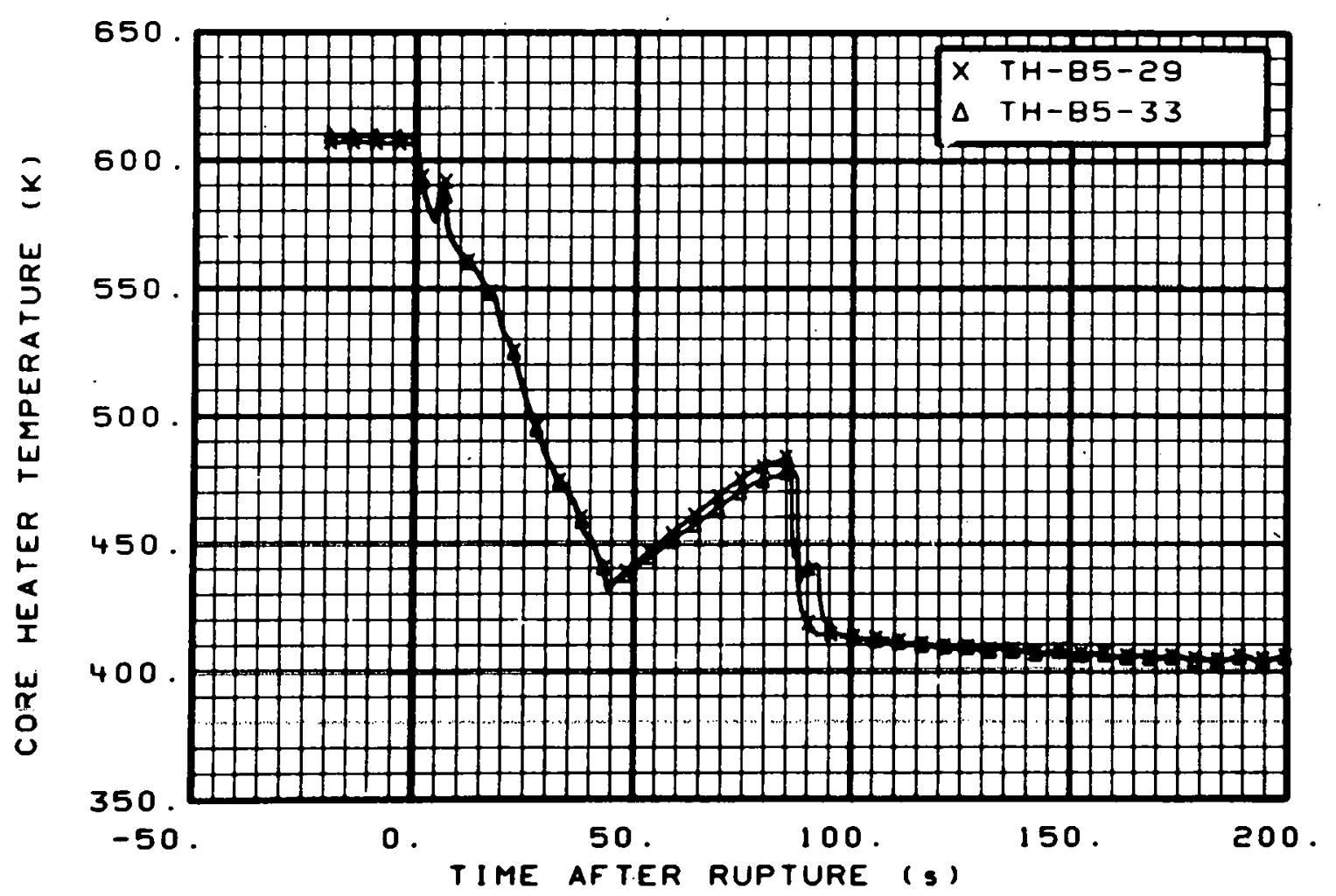

Fig. 73 Core heater temperature, Rod B-5 (TH-B5-29 and TH-B5-33), from -20 to $200 \mathrm{~s}$.

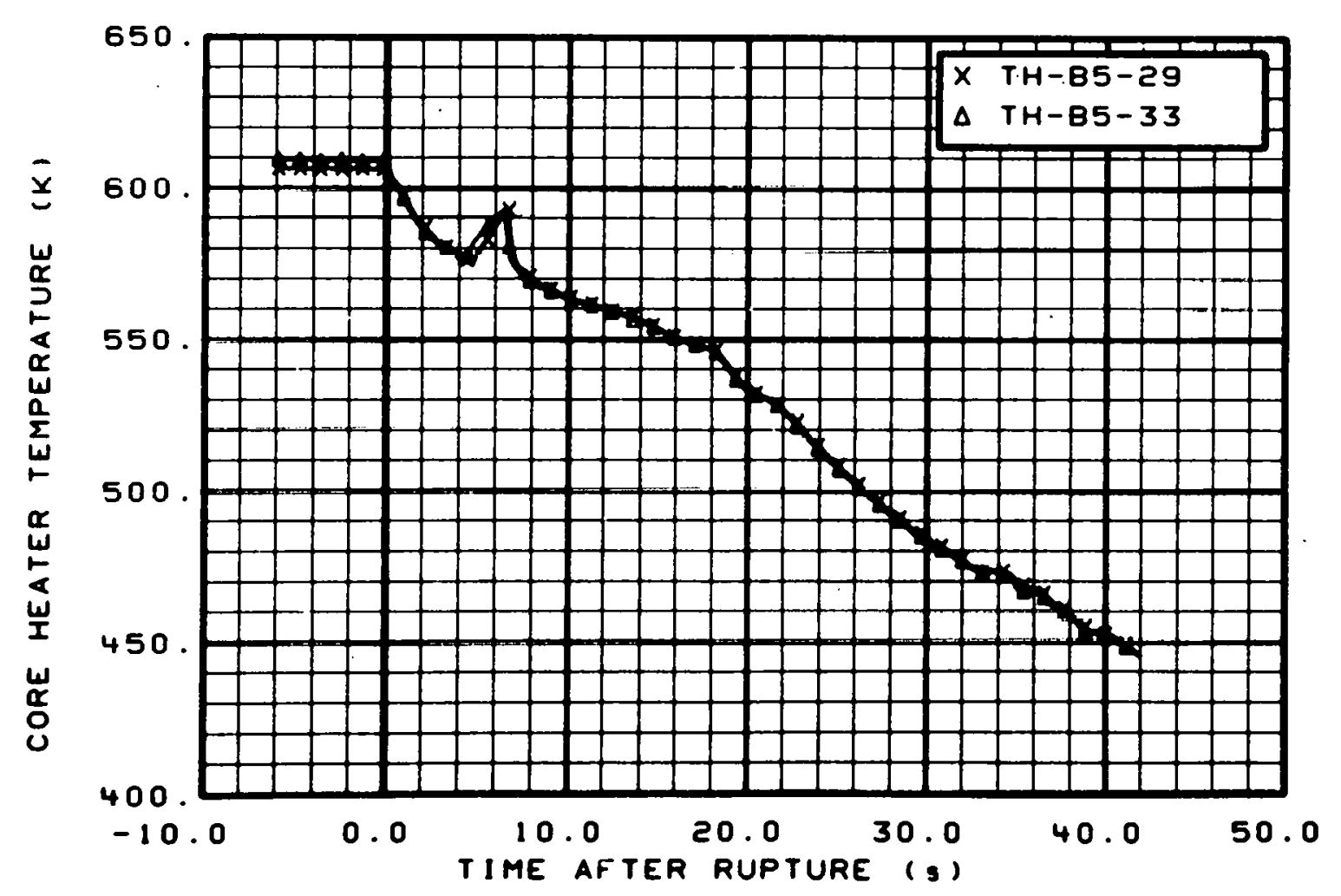

Fig. 74 Core heater temperature, Rod B-5 (TH-B5-29 and TH-B5-33), from -6 to $42 \mathrm{~s}$. 


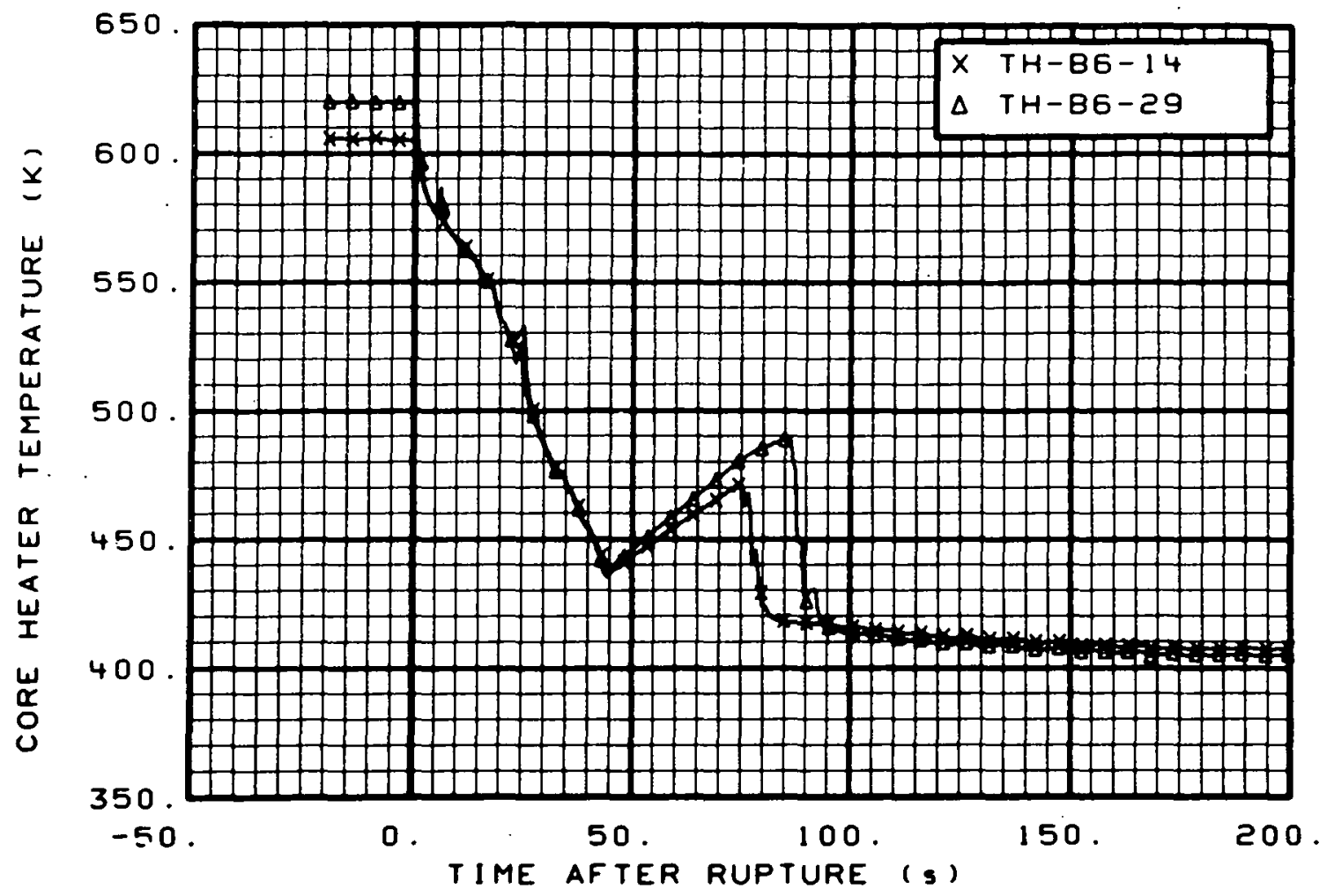

Fig. 75 Core heater temperature, Rod B-6 (TH-B6-14 and TH-B6-29), from -20 to $200 \mathrm{~s}$.

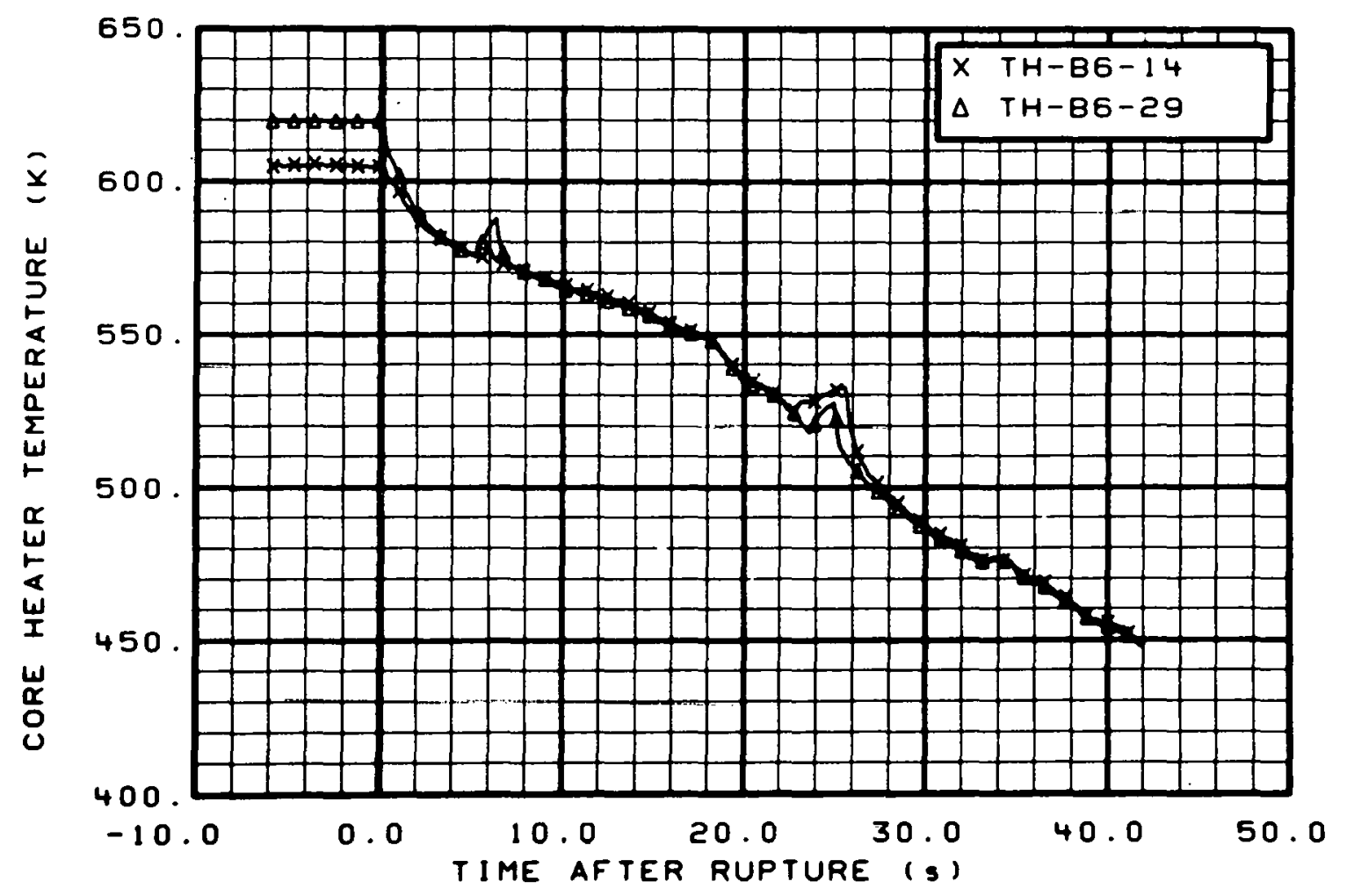

Fig. 76 Core heater temperature, Rod B $\cdots 6$ (TH-B6-14 and TH-B6-29), from -6 to 42 s: 


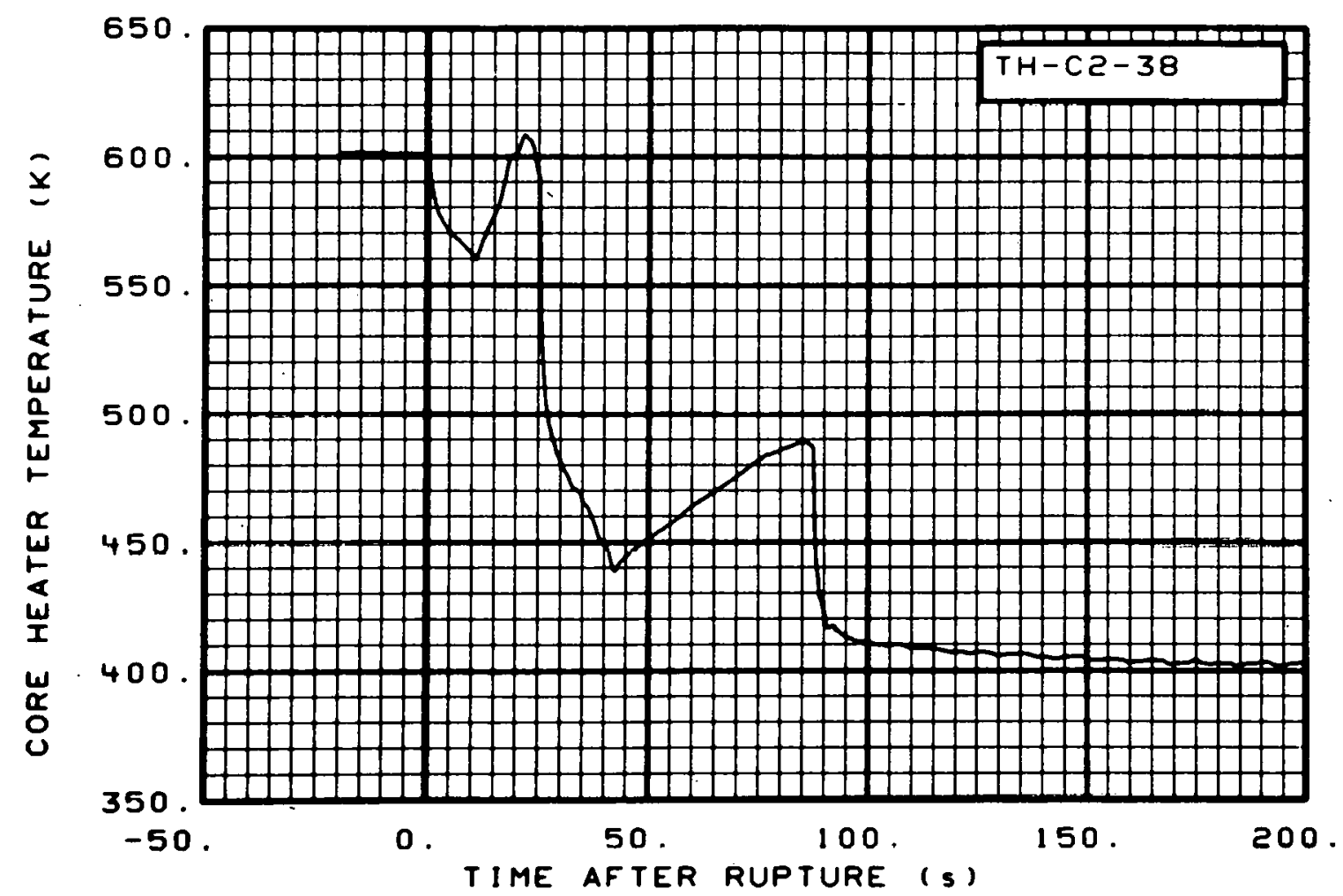

Fig. 77 Core heater temperature, Rod C-2 (TH-C2-38), from -20 to $200 \mathrm{~s}$.

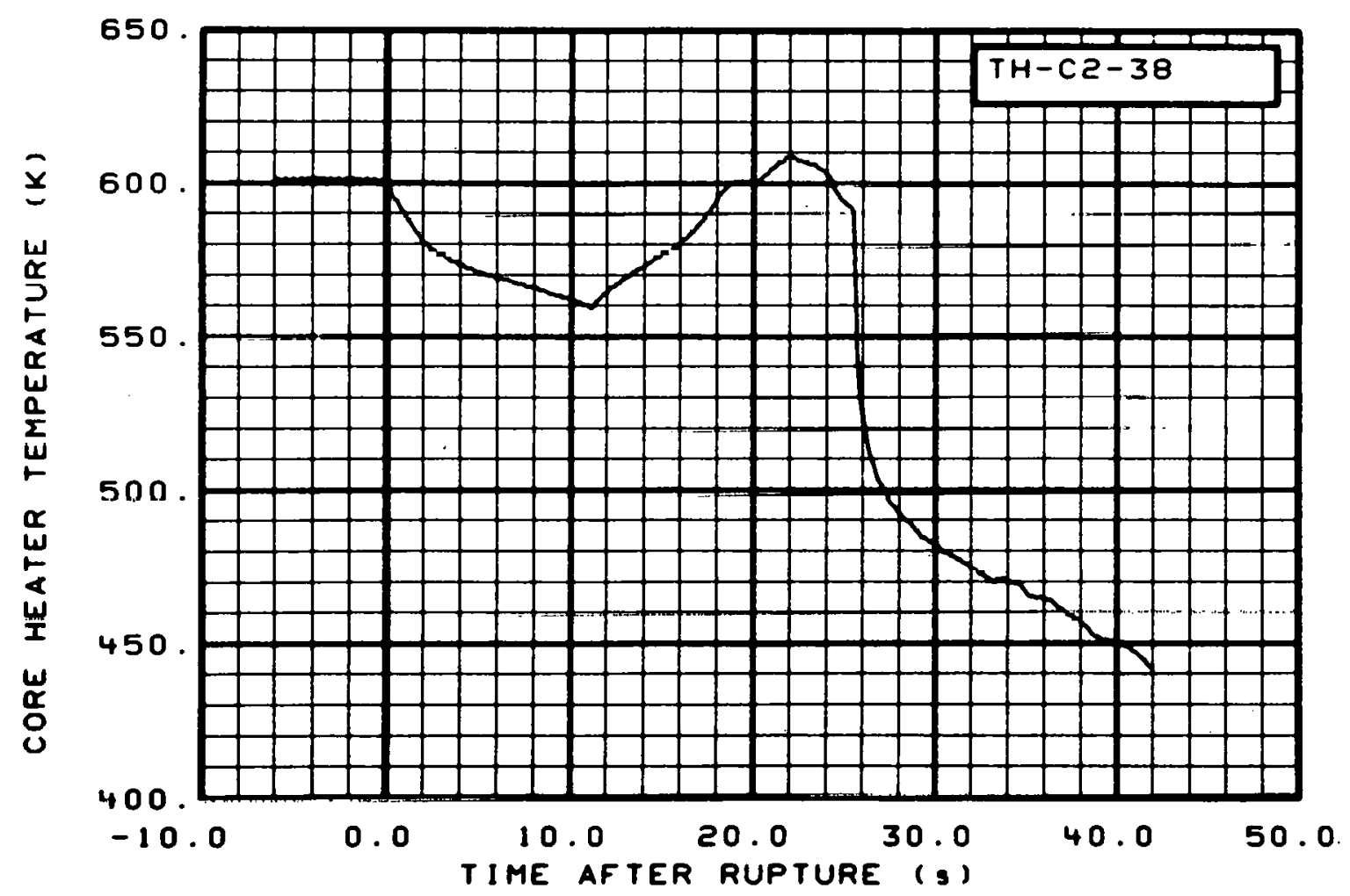

Fig. 78 Core heater temperature, Rod C-2 (TH-C2-38), from -6 to $42 \mathrm{~s}$. 


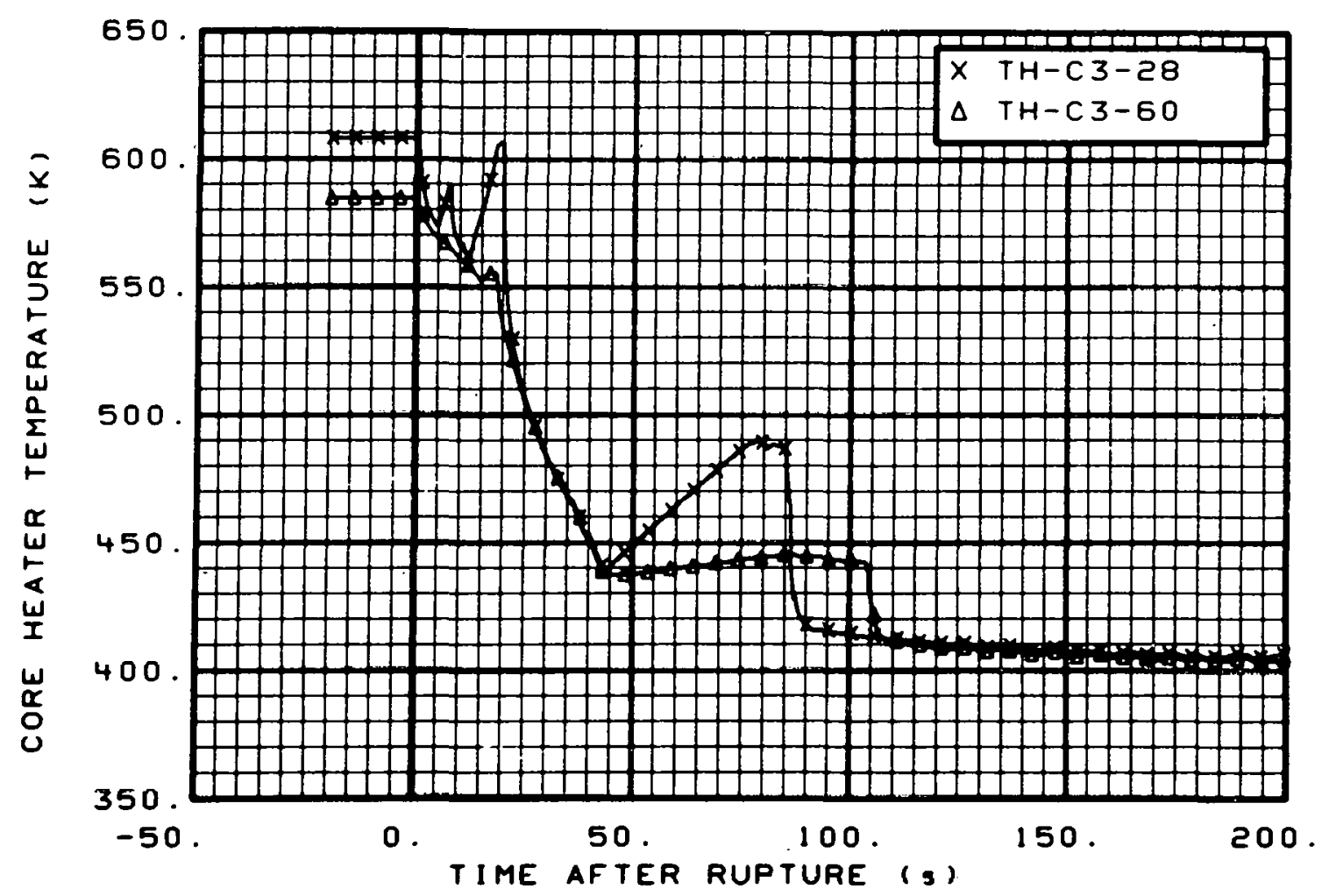

Fig. 79 Core heater temperature, Rod $\mathrm{C}-3$ (TH-C3-28 and TH-C3-60), from -20 to $200 \mathrm{~s}$.

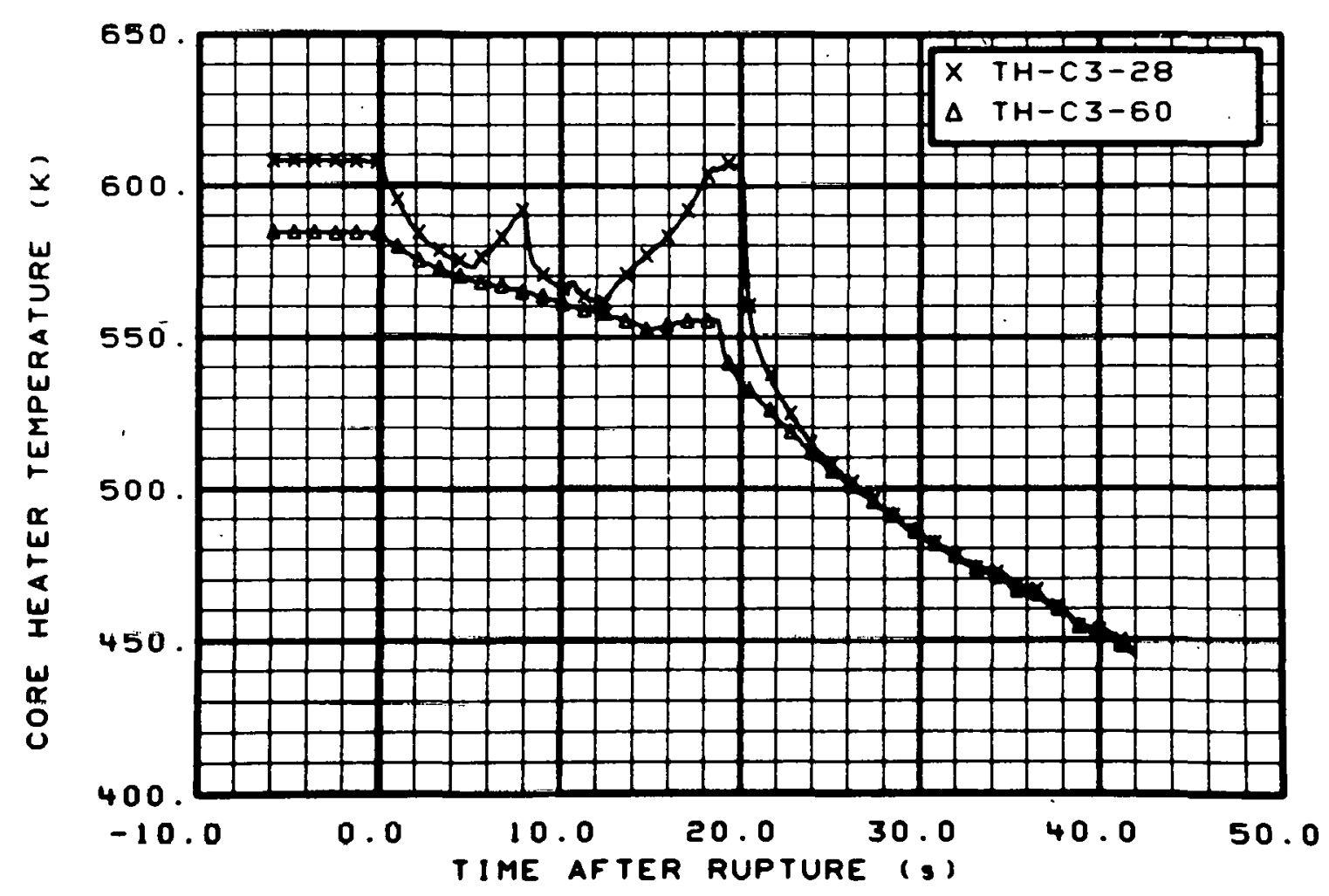

Fig. 80 Core heater temperature, Rod $\mathrm{C}-3$ (TH-C3-28 and $\mathrm{TH}-\mathrm{C} 3-60)$, from -6 to $42 \mathrm{~s}$. 


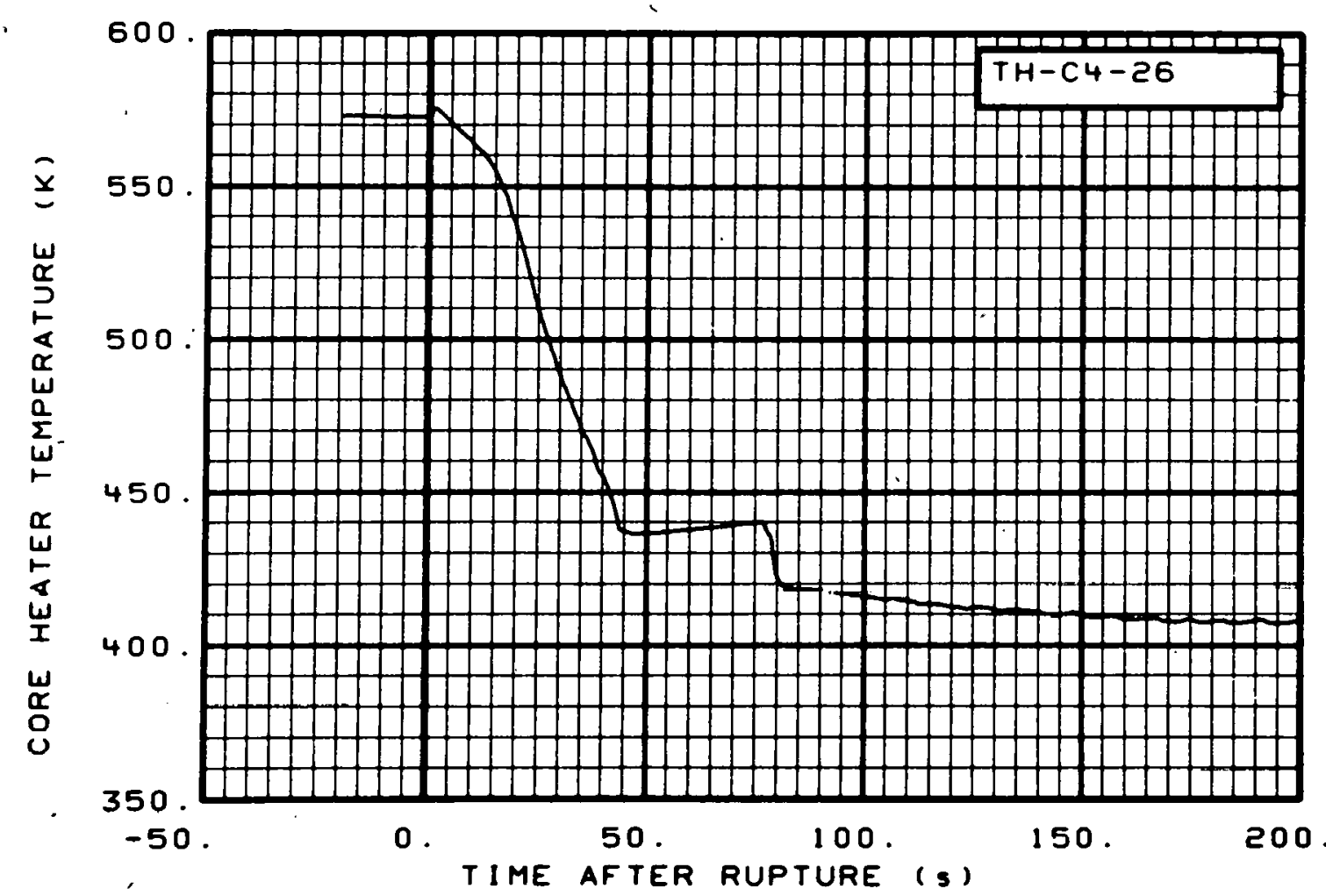

Fig. 81 Core heater temperature, Rod C-4 (TH-C4-26), from -20 to $200 \mathrm{~s}$.

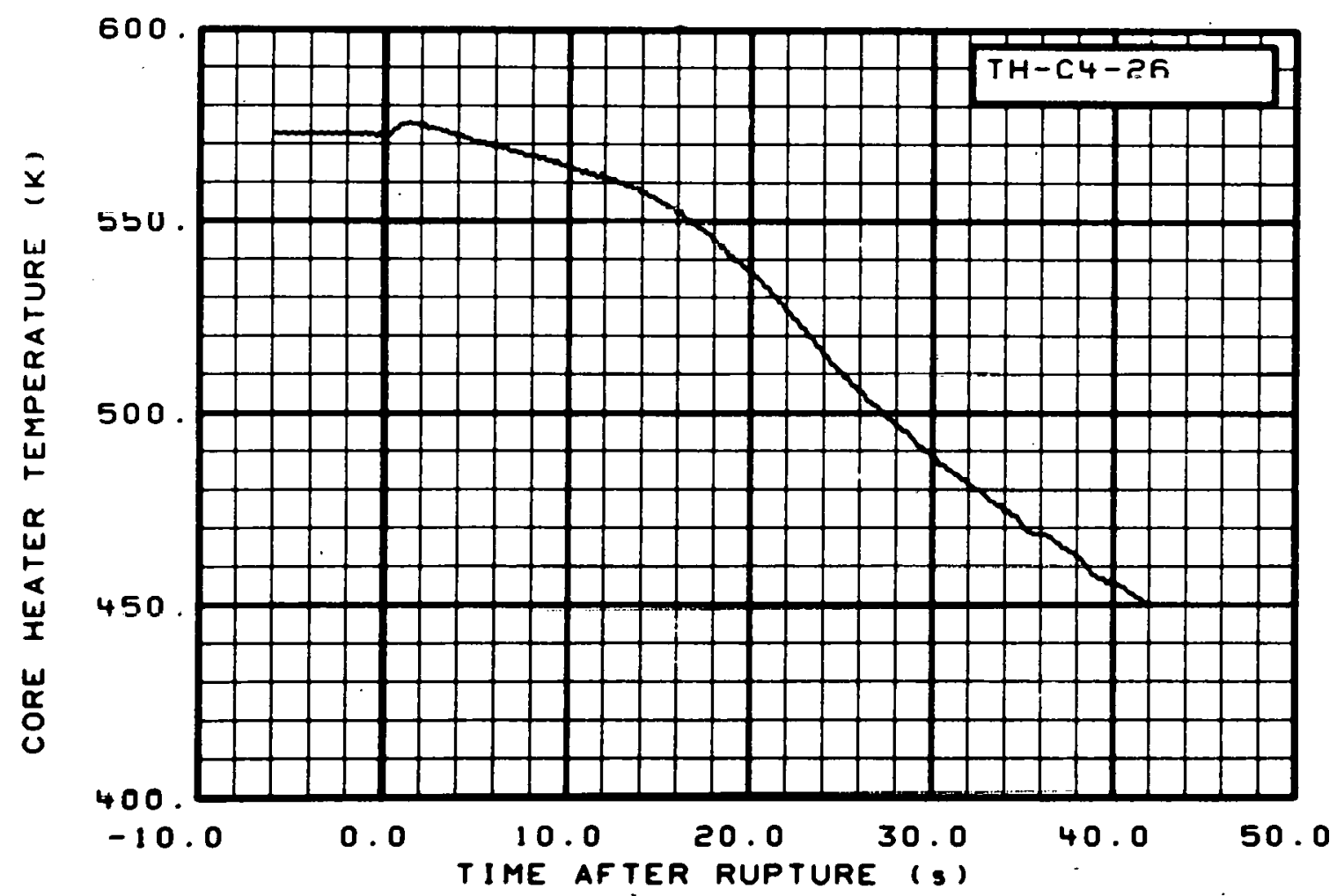

Fig. 82 Core heater temperature, Rod C-4 (TH-C4-26), from -6 to $42 \mathrm{~s}$. 


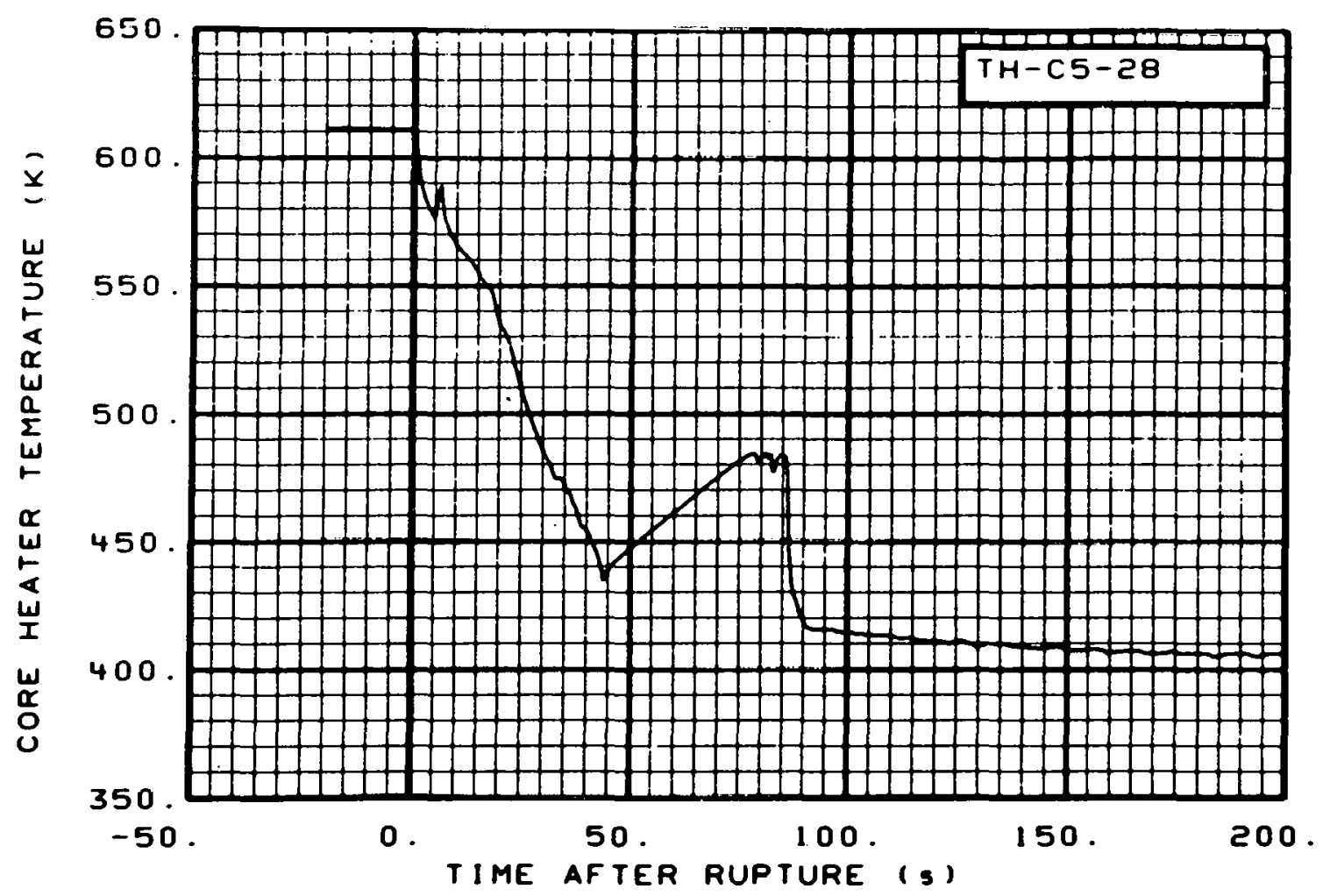

Fig. 83 Core heater temperature, Rod C-5 (TH-C5-28), from -20 to $200 \mathrm{~s}$.

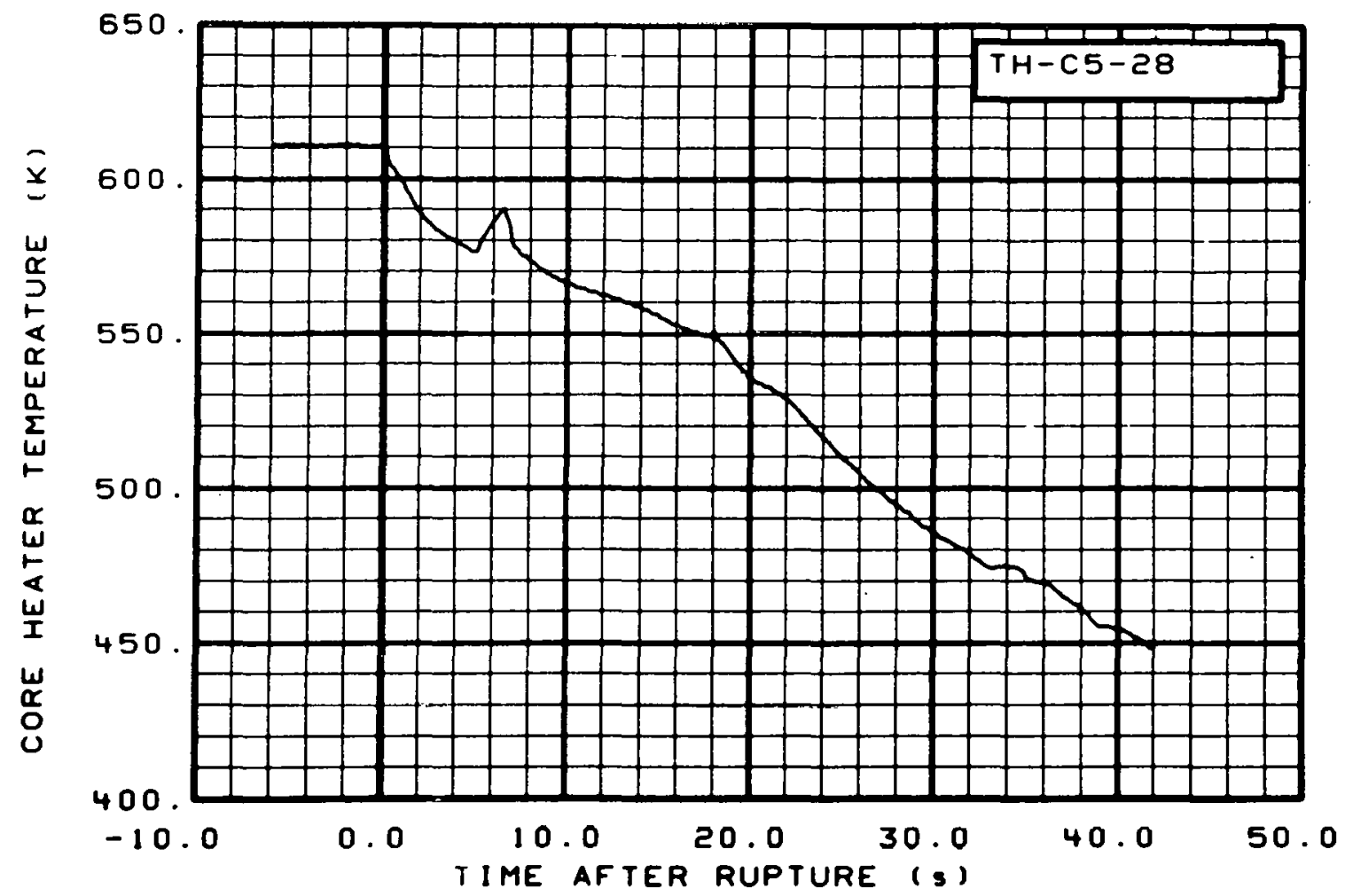

Fig. 84 Core heater temperature, Rod $\mathrm{C}-5$ (TH-C5-28), from -6 t.o $42 \mathrm{~s}$. 


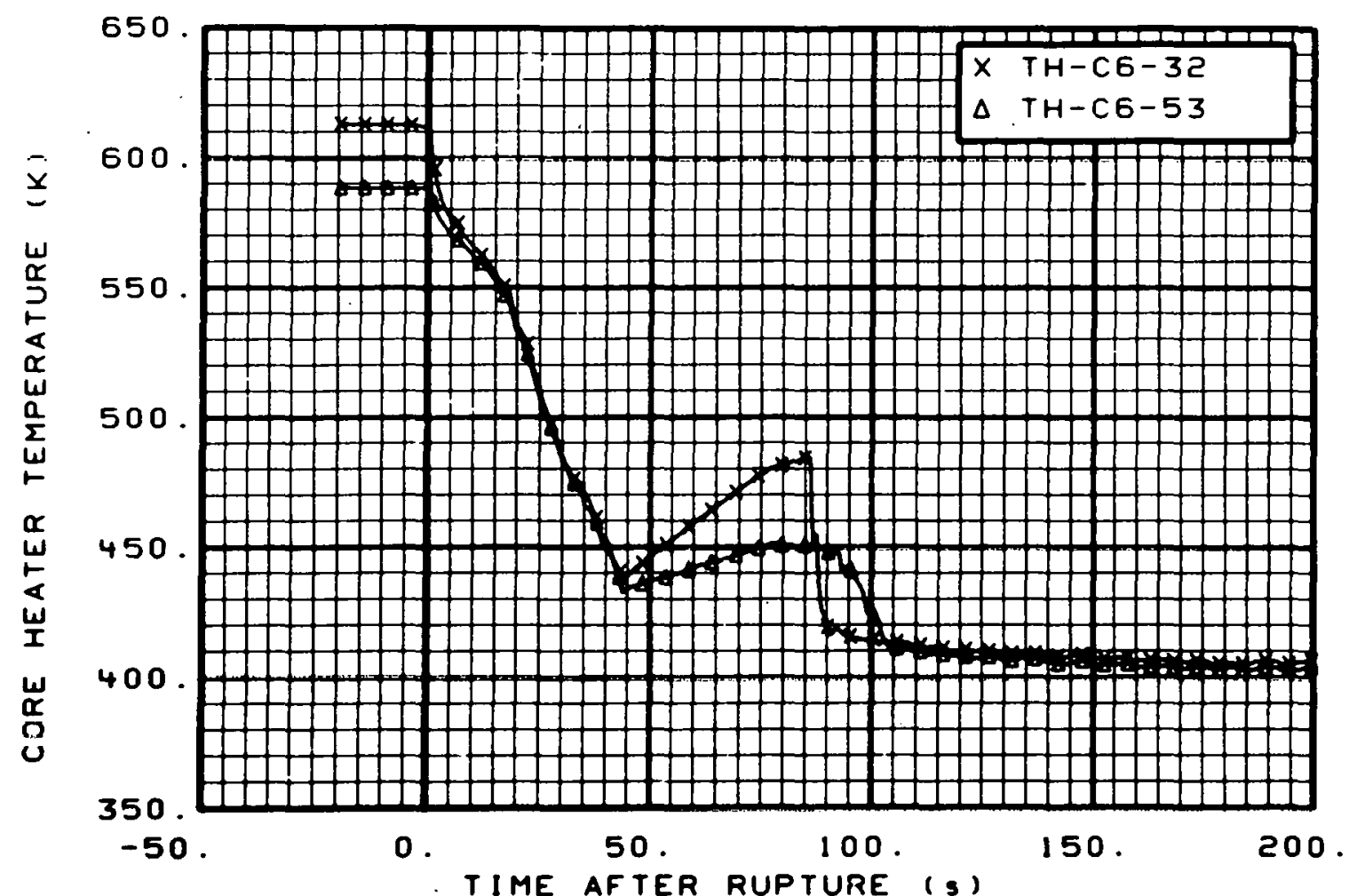

Fig. 85 Core heater temperature, Rod C-6 (TH-C6-32 and TH-C6-53), from -20 to $200 \mathrm{~s}$.

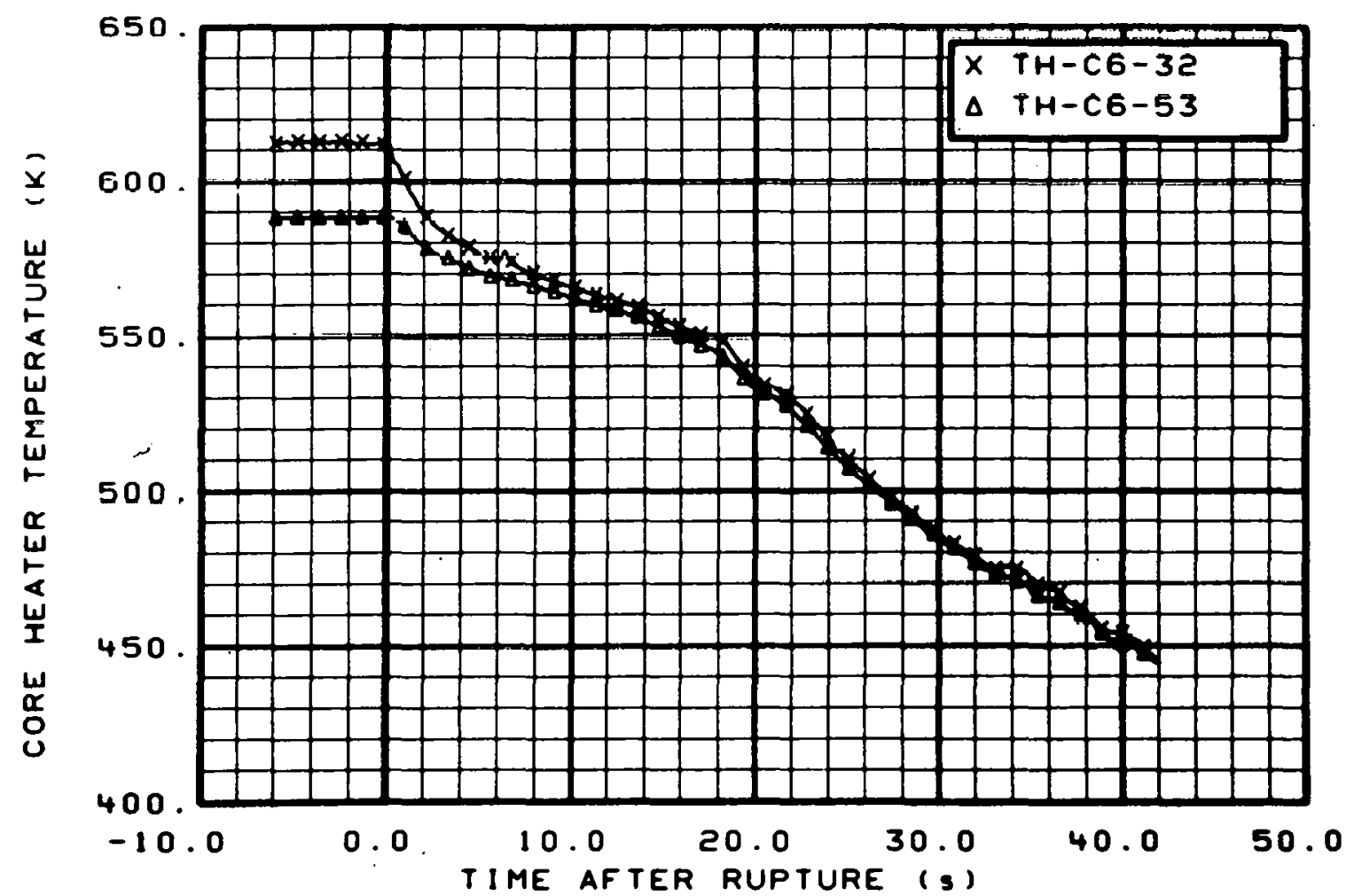

Fig. 86 Core heater temperature, Rod C-6 (TH-C6-32 and TH-C6-53), from -6 to $42 \mathrm{~s}$. 


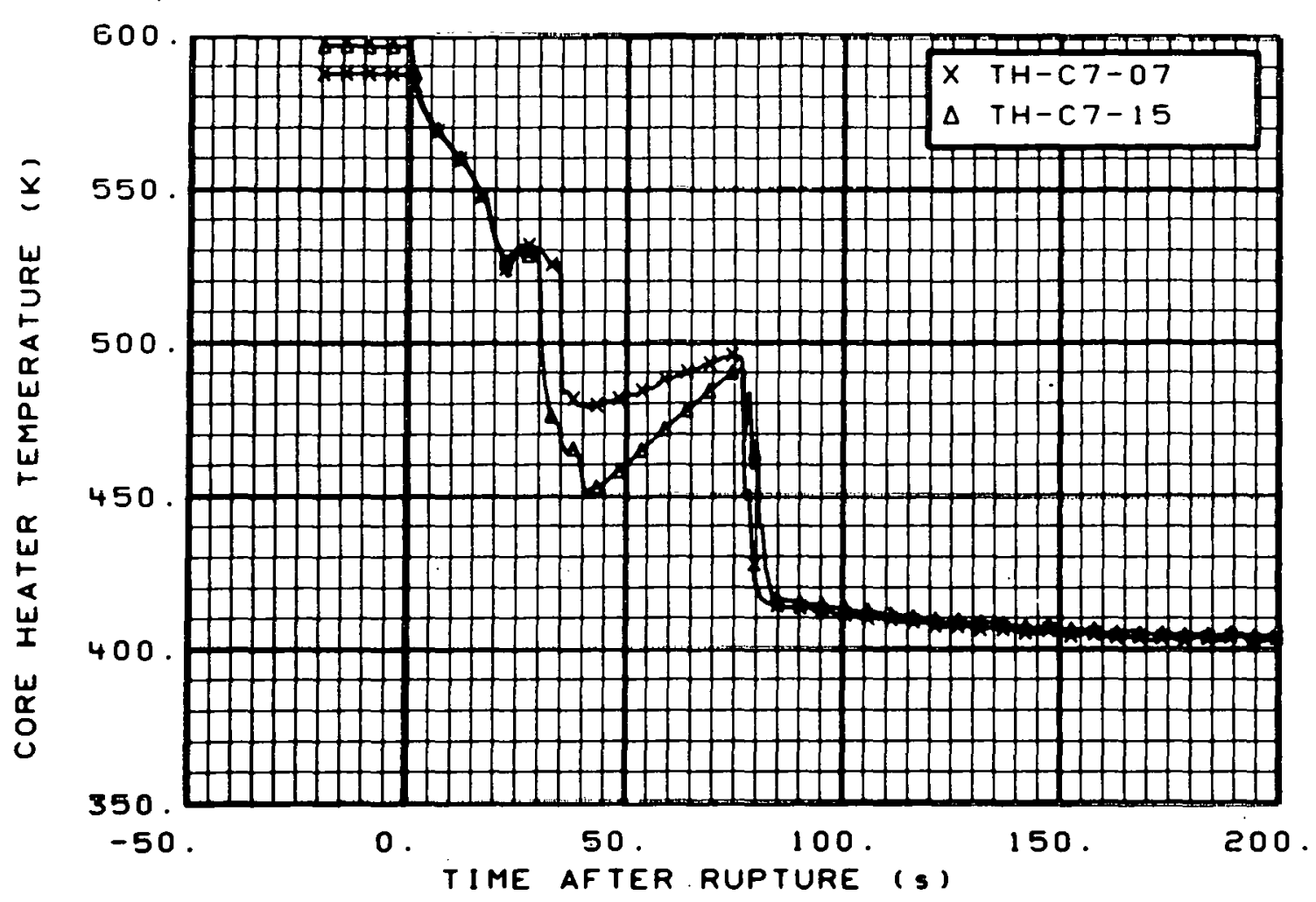

Fig. 87 Core heater temperature, Rod $\mathrm{C}-7$ (TH-C7-07 and TH-C7-15), from -20 to $200 \mathrm{~s}$.

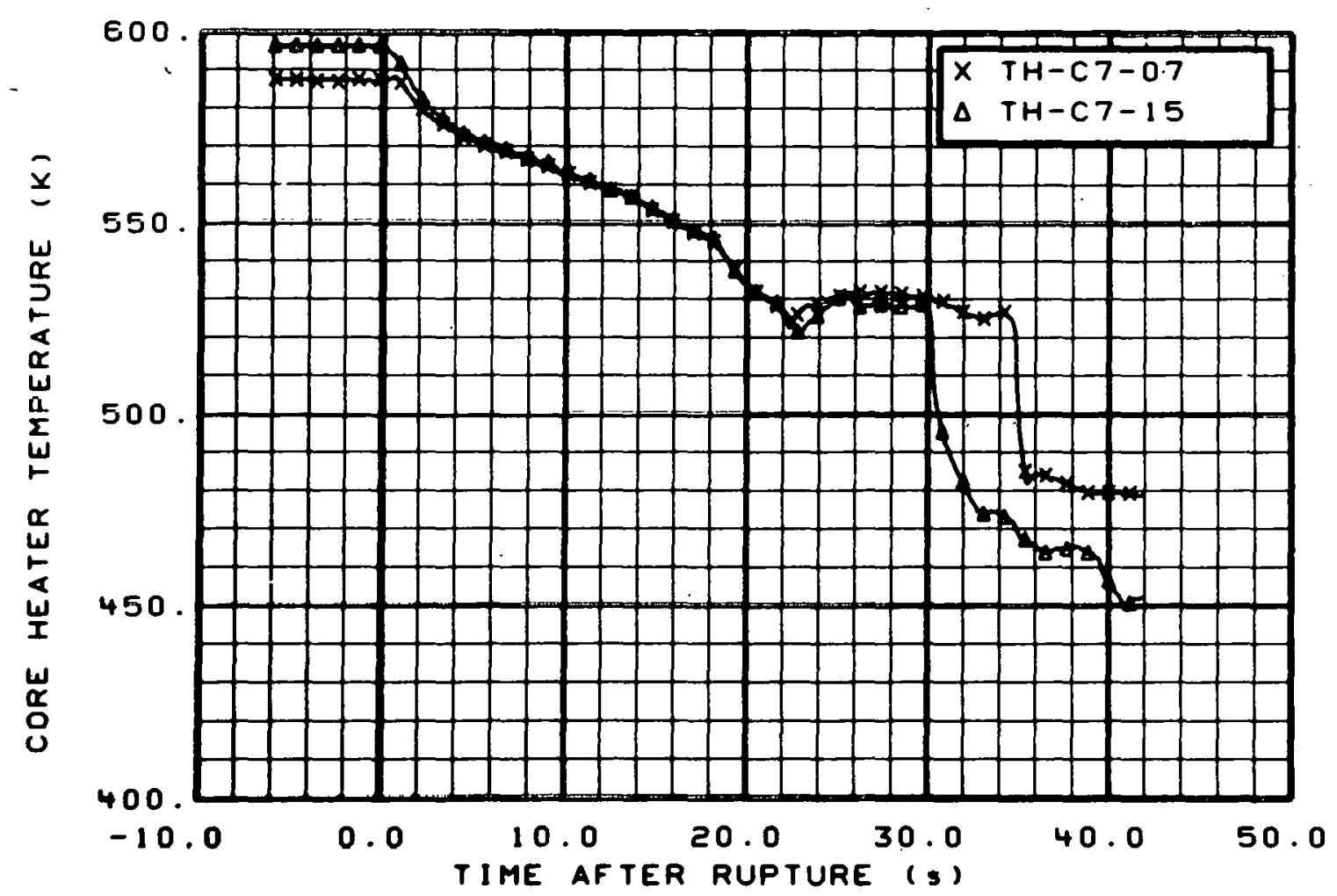

Fig. 88 Core heater temperature, Rod $\mathrm{C}-7$ (TH-C7-07 and TH-C7-15), from -6 to $42 \mathrm{~s}$. 


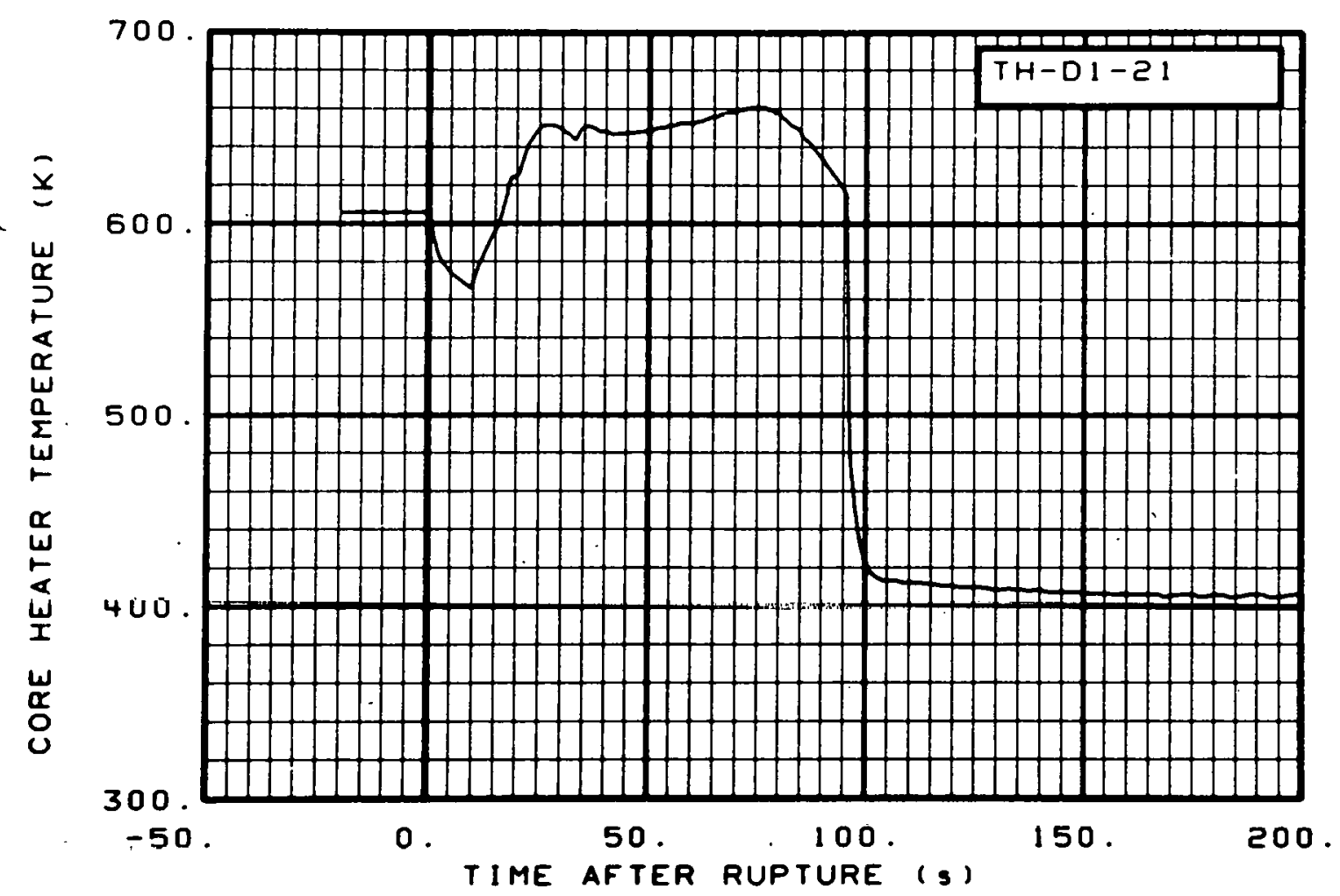

Fig. 89 Core heater temperature, Rod D-1 (TH-D1-21), from -20 to $200 \mathrm{~s}$.

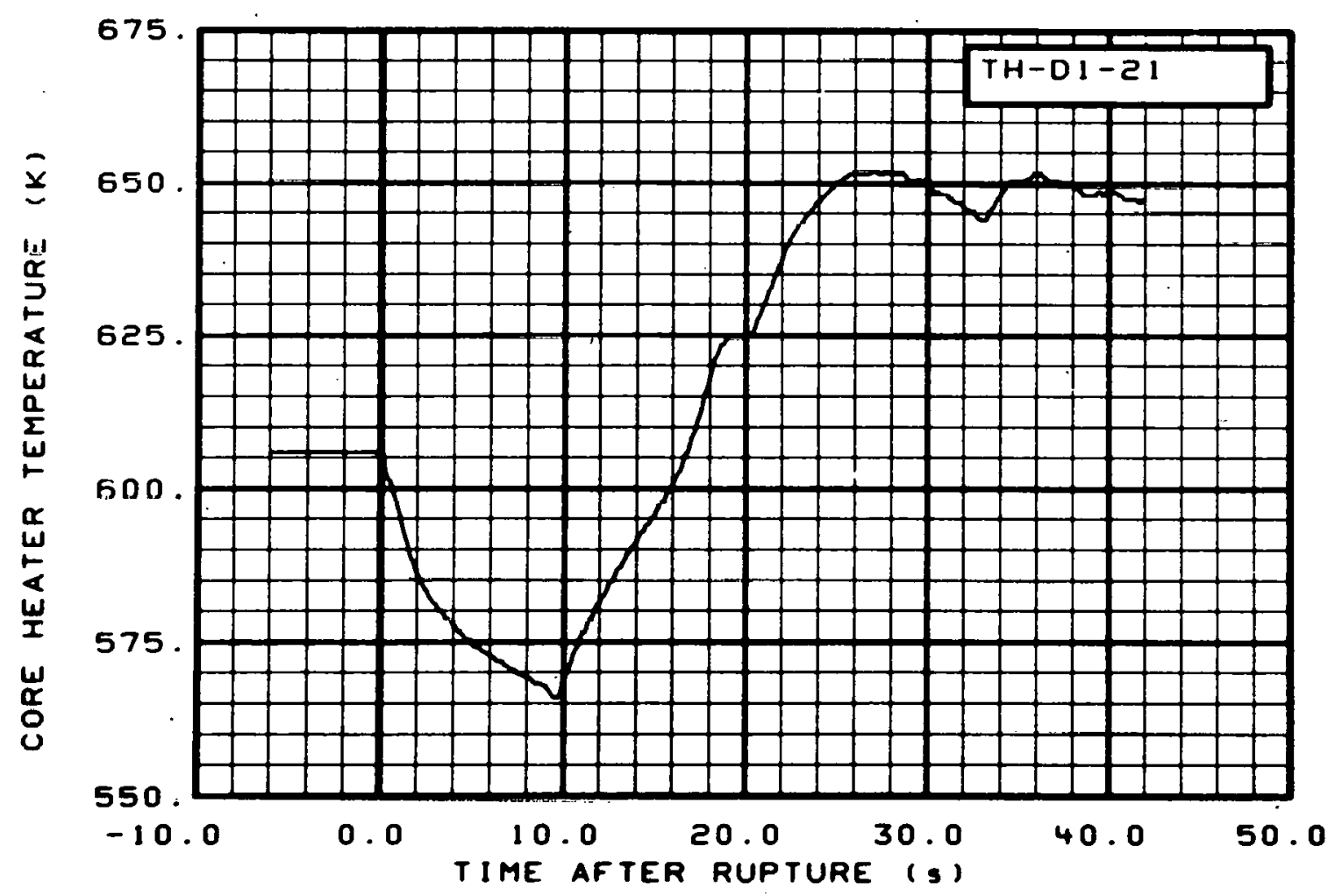

Fig. 90 Core heater temperature, Rod D-1 (TH-D1-21), from -6 to $42 \mathrm{~s}$. 


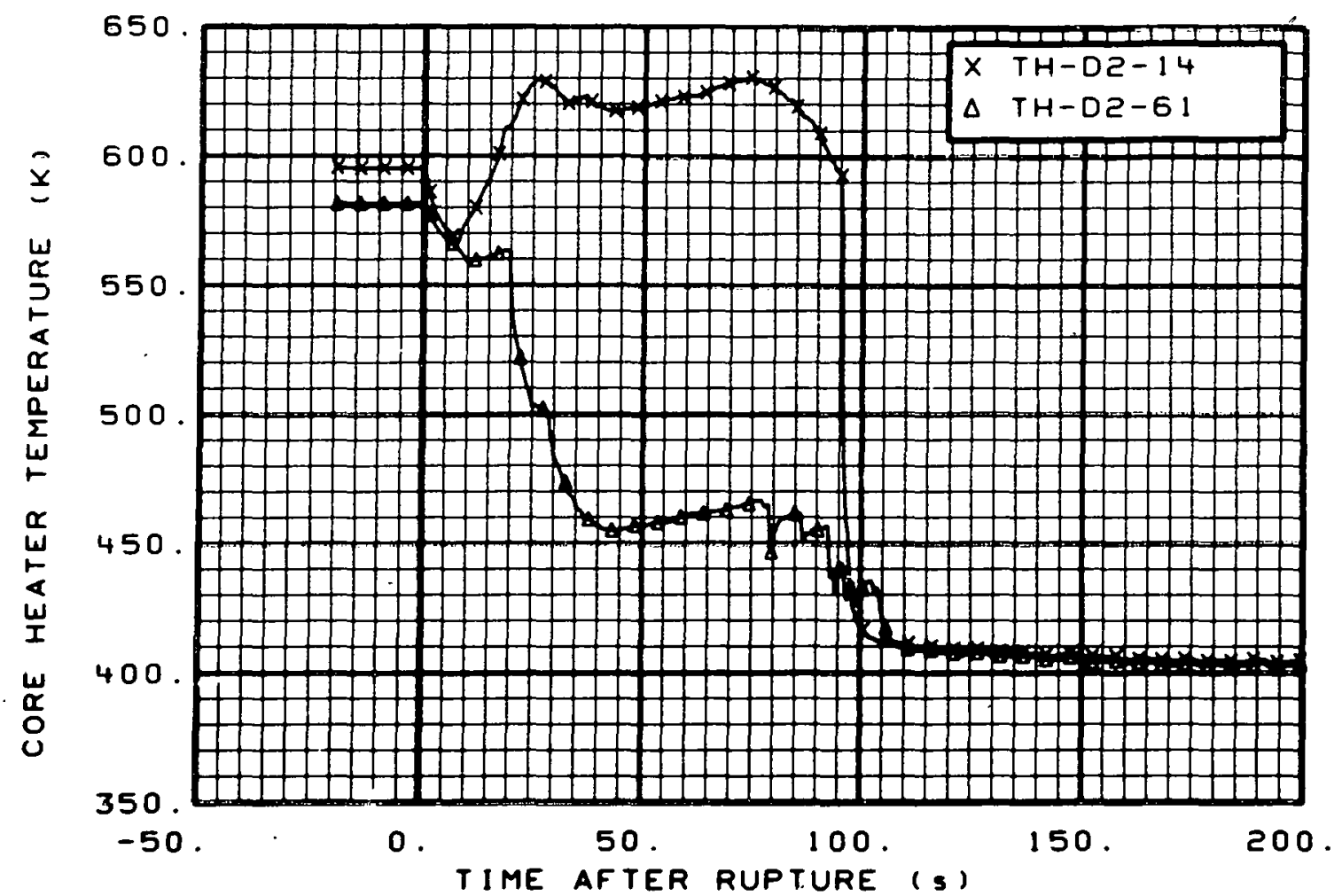

Fig. 91 Core heater temperature, Rod D-2 (TH-D2-14 and TH-D2-61), from -20 to $200 \mathrm{~s}$.

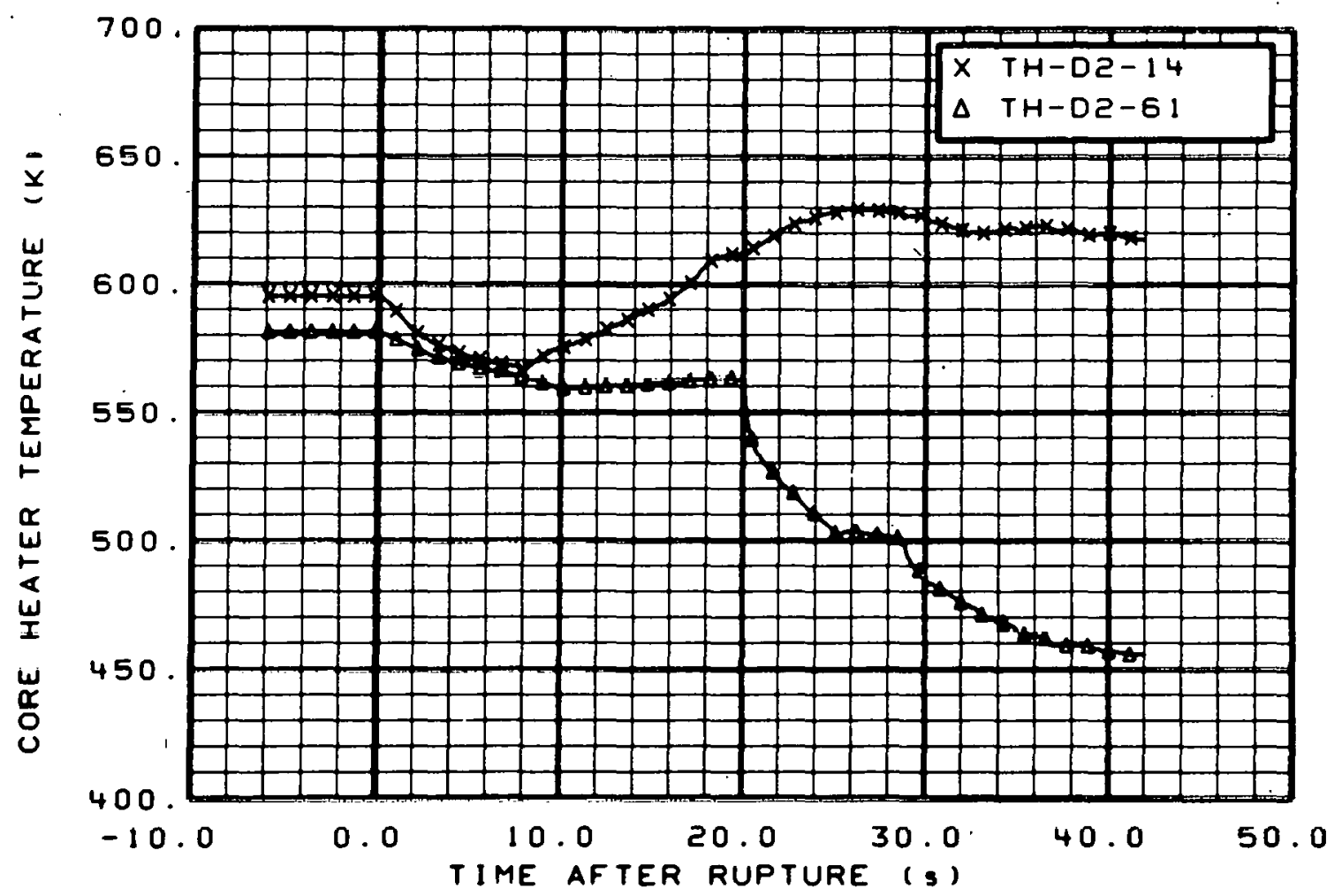

Fig. 92 Core heater temperature, Rod D-2 (TH-D2-14 and TH-D2-61), from -6 to $42 \mathrm{~s}$. 


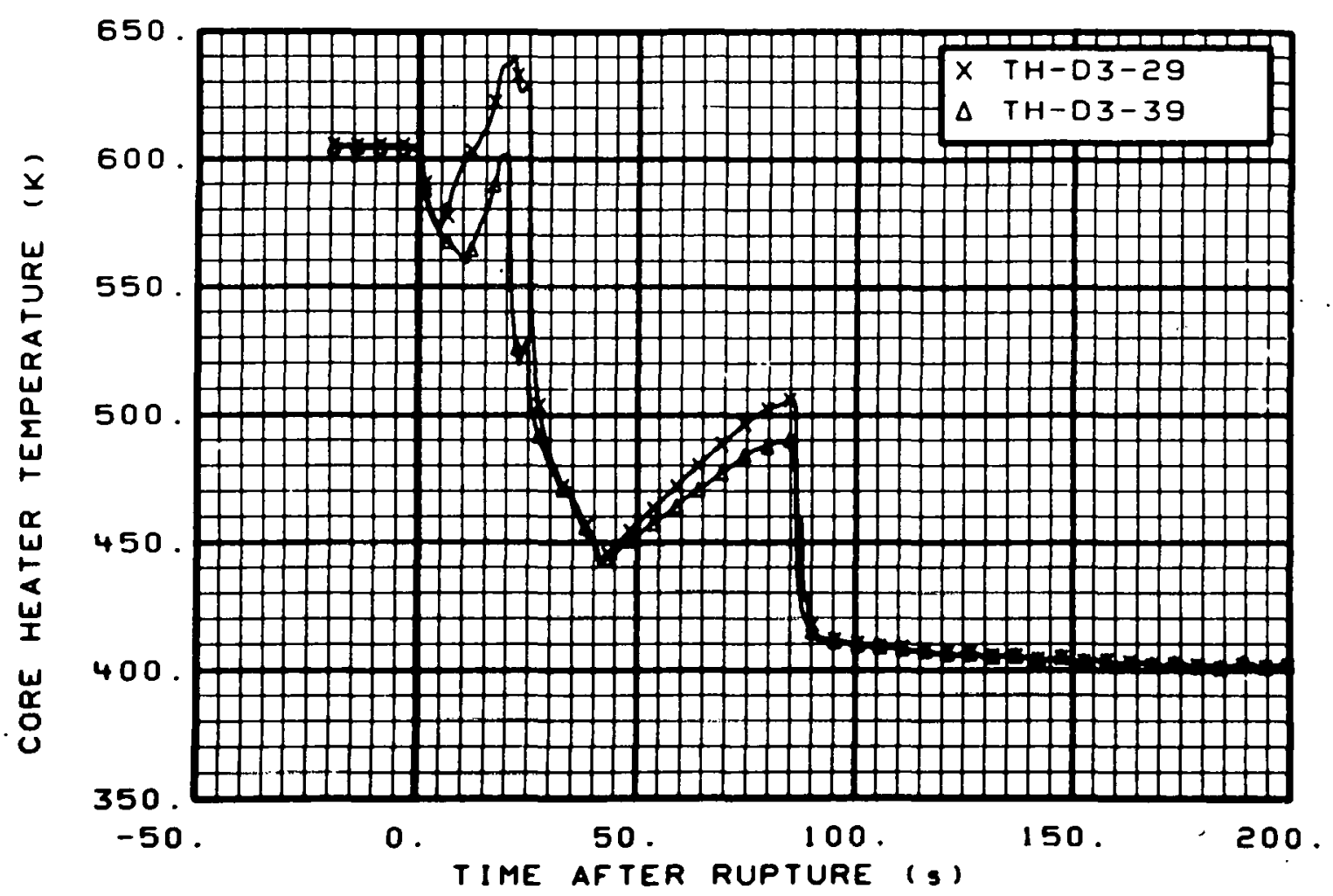

Fig. 93 Core heater temperature, Rod D-3 (TH-D3-29 and TH-D3-39), from -20 to $200 \mathrm{~s}$.

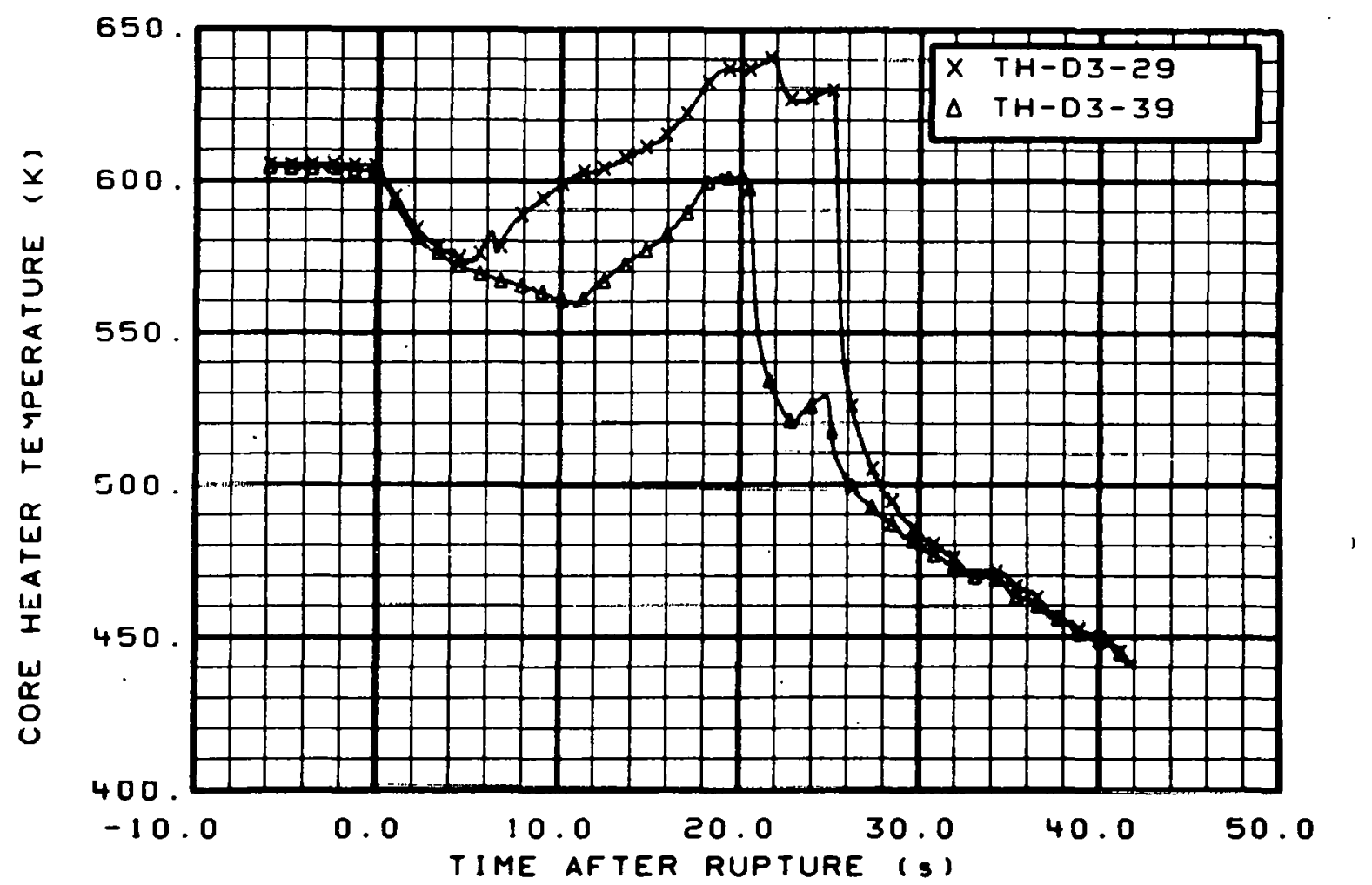

Fig. 94 Core heater temperature, Rod D-3 (TH-D3-29 and TH-D3-39), from -6 to $42 \mathrm{~s}$. 


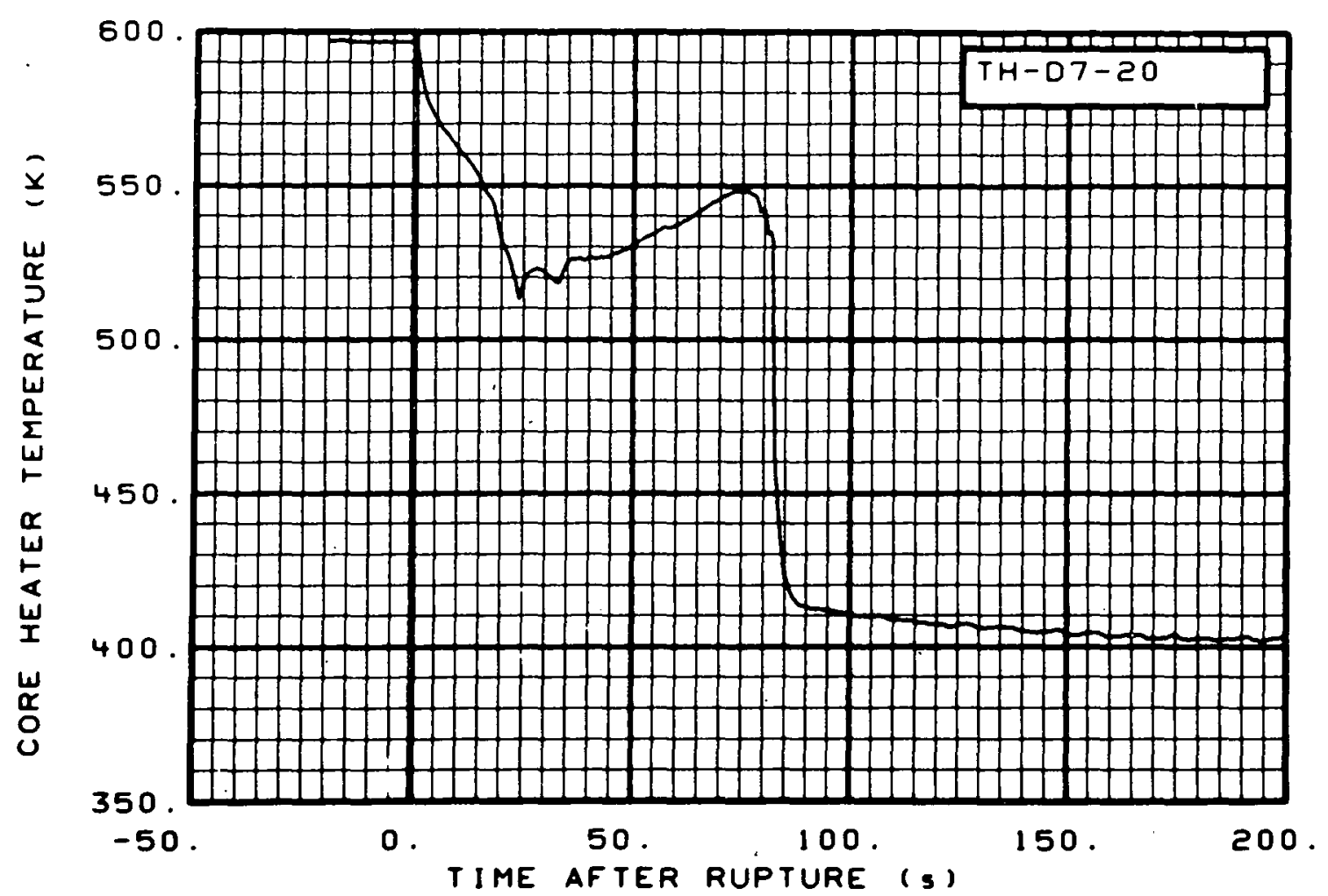

Fig. 95 Core heater temperature, Rod D-7 (TH-D7-20), from -20 to $200 \mathrm{~s}$.

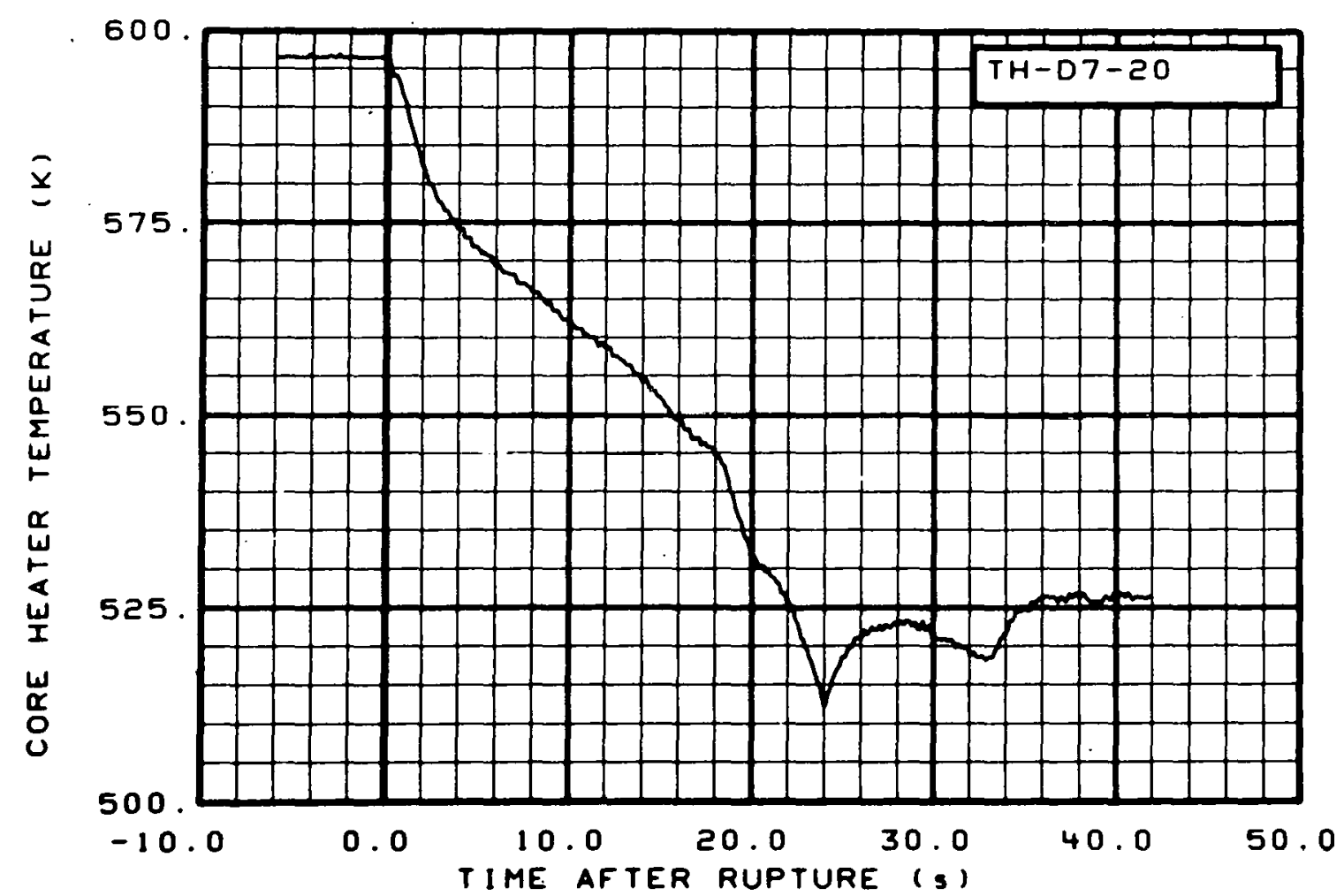

Fig. 96 Core heater temperature, Rod D-7 (TH-D7-20), from -6 to $42 \mathrm{~s}$. 


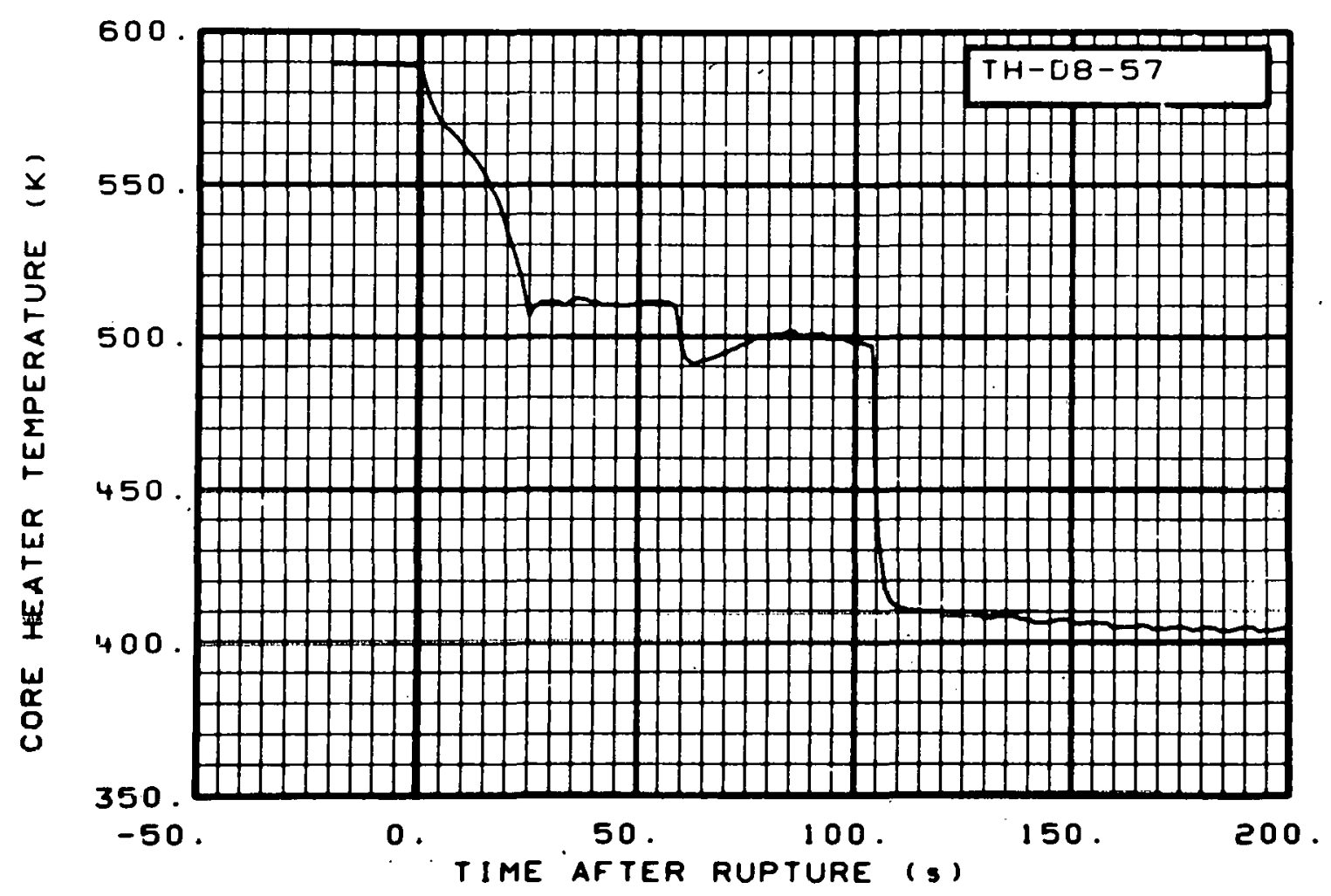

Fig. 97 Core heater temperature, Rod D-8 (TH-D8-57), from -20 to $200 \mathrm{~s}$.

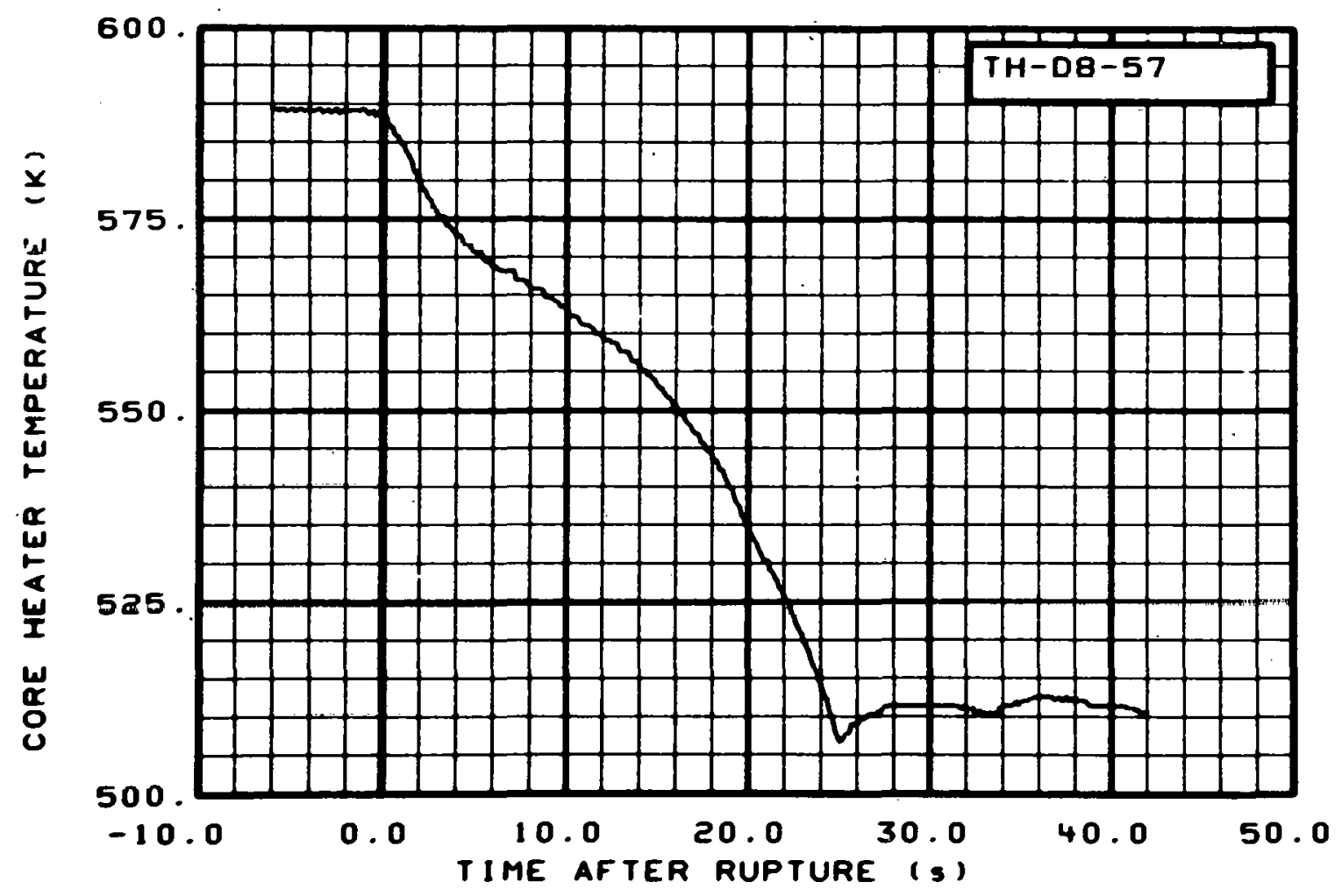

Fig: 98 Core heater temperature, Rod D-8 (TH-D8-57), from -6 to $42 \mathrm{~s}$. 


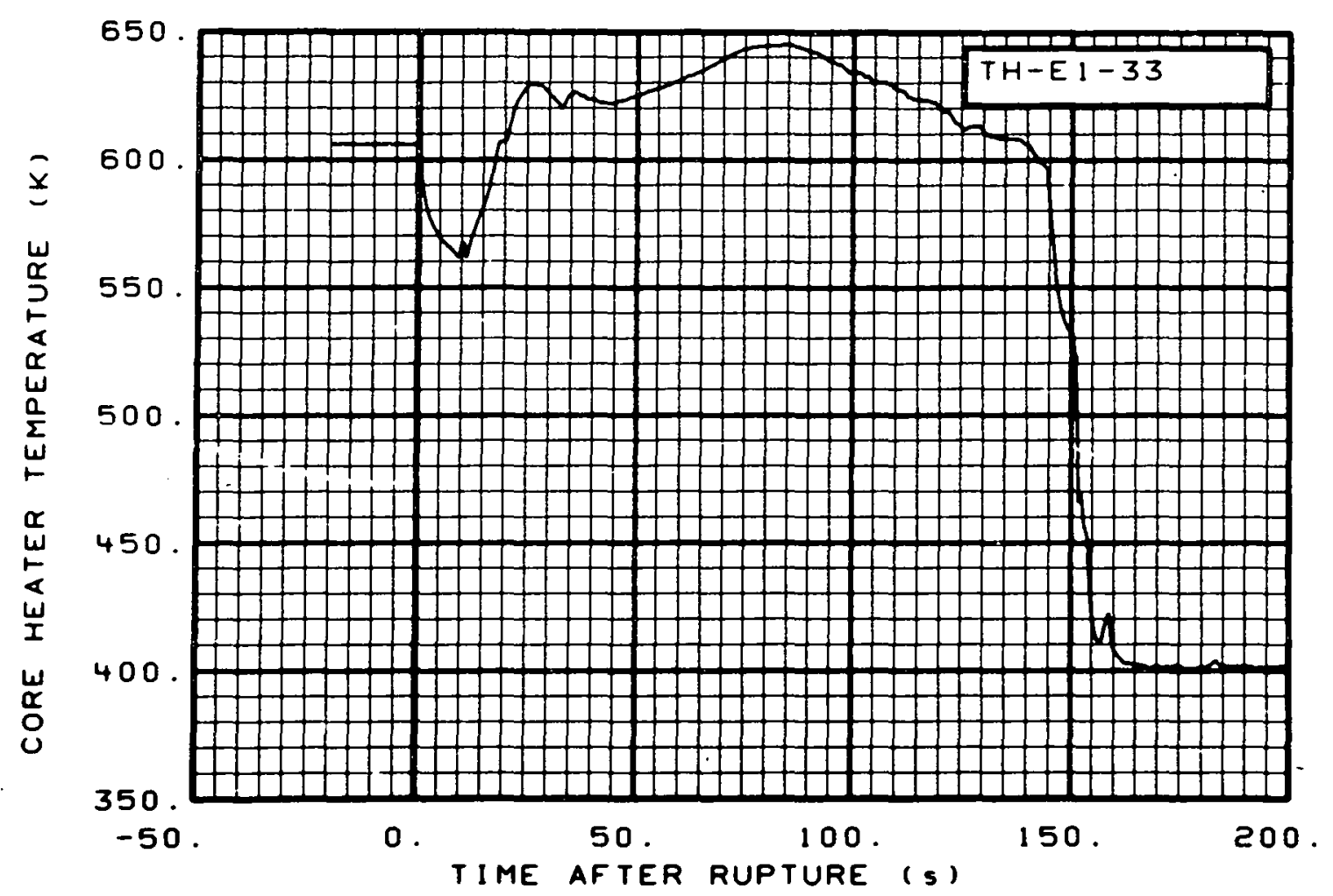

Fig. 99 Core heater temperature, Rod E-1 (TH-E $1-33$ ), from -20 to $200 \mathrm{~s}$ :

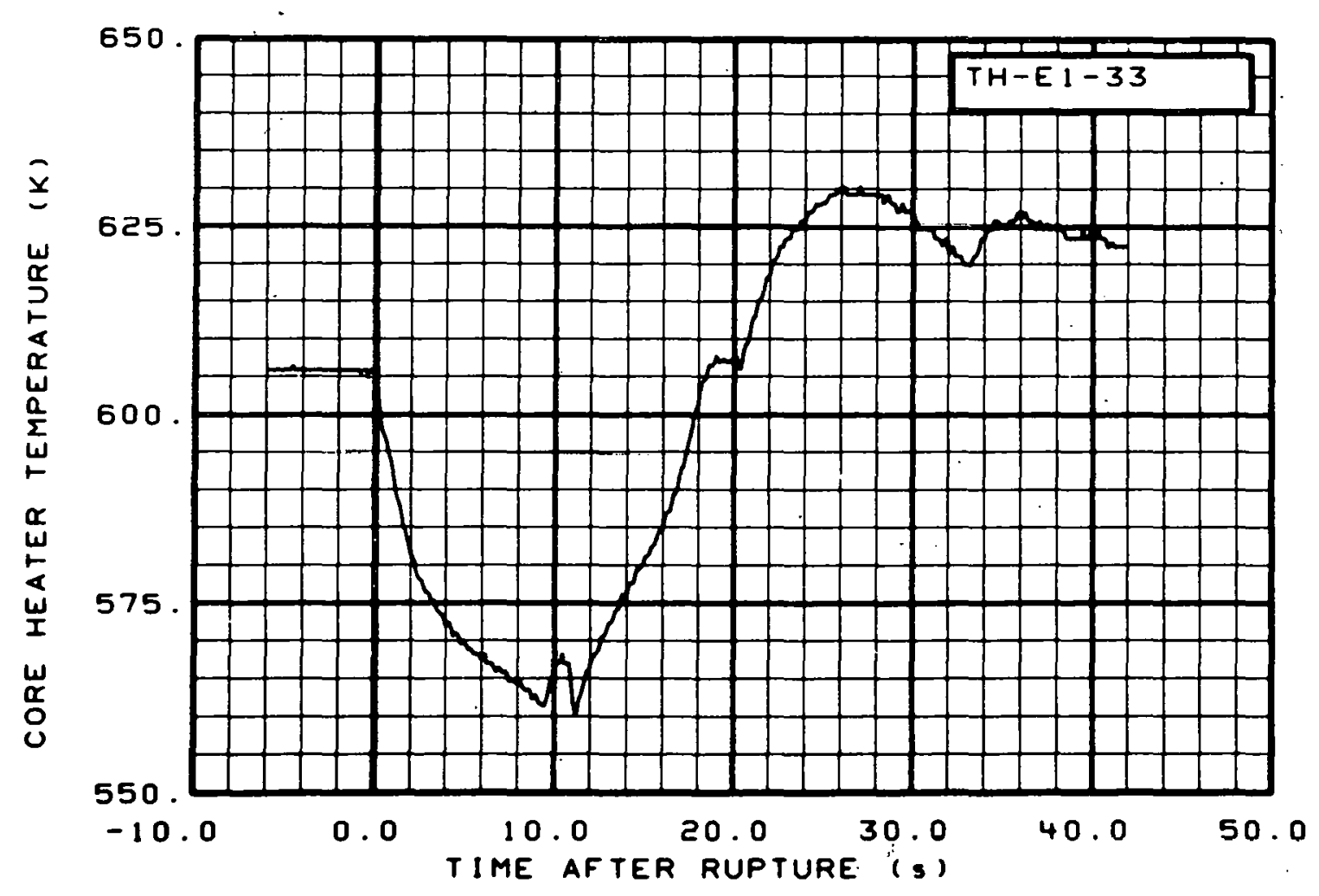

Fig. 100 Core heater temperature, Rod E-l (TH-El-33), from -6 to $42 \mathrm{~s}$. 


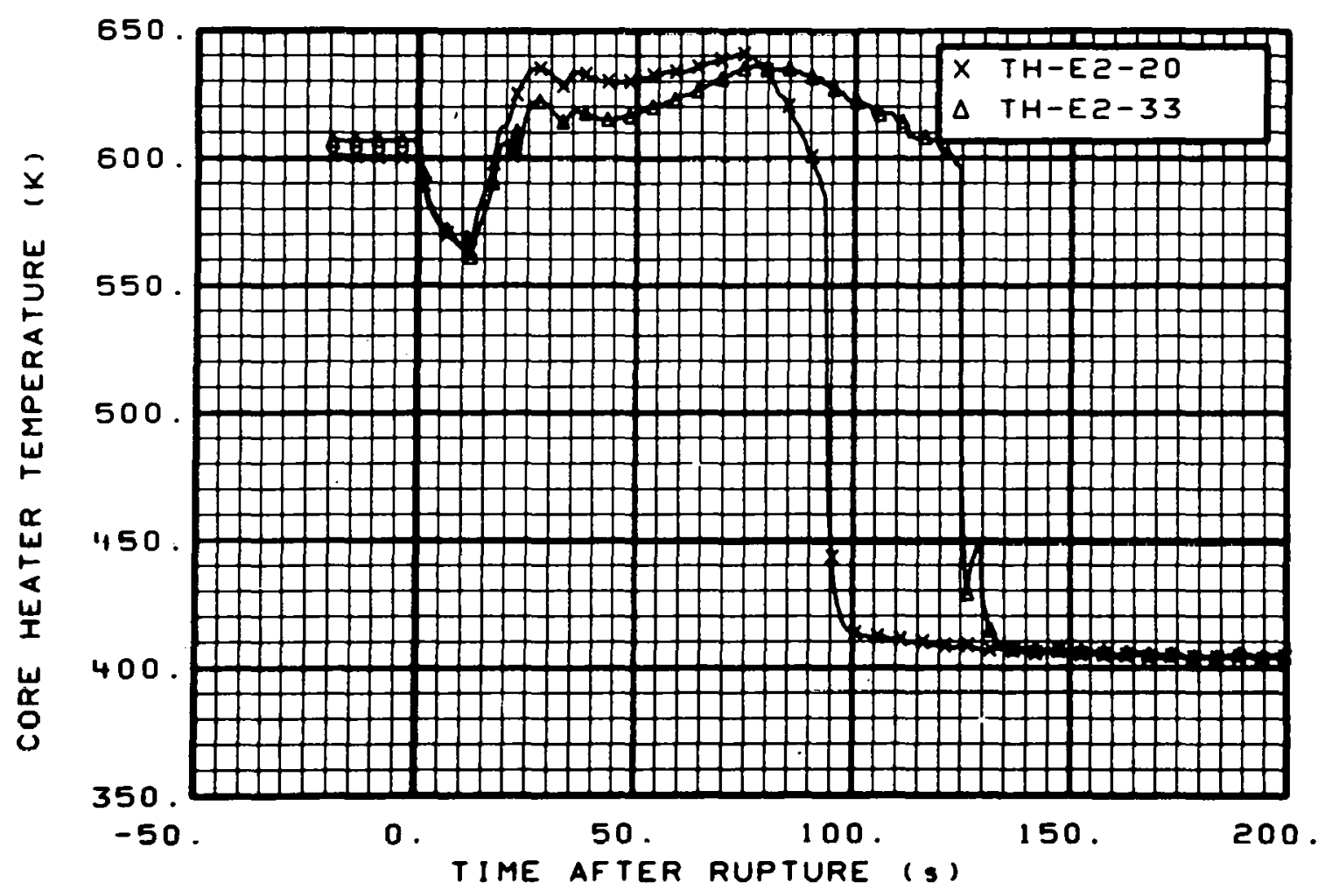

Fig. 101 Core heater temperature, Rod E-2 (TH-E2-20 and TH-E2-33), from -20 to $200 \mathrm{~s}$.

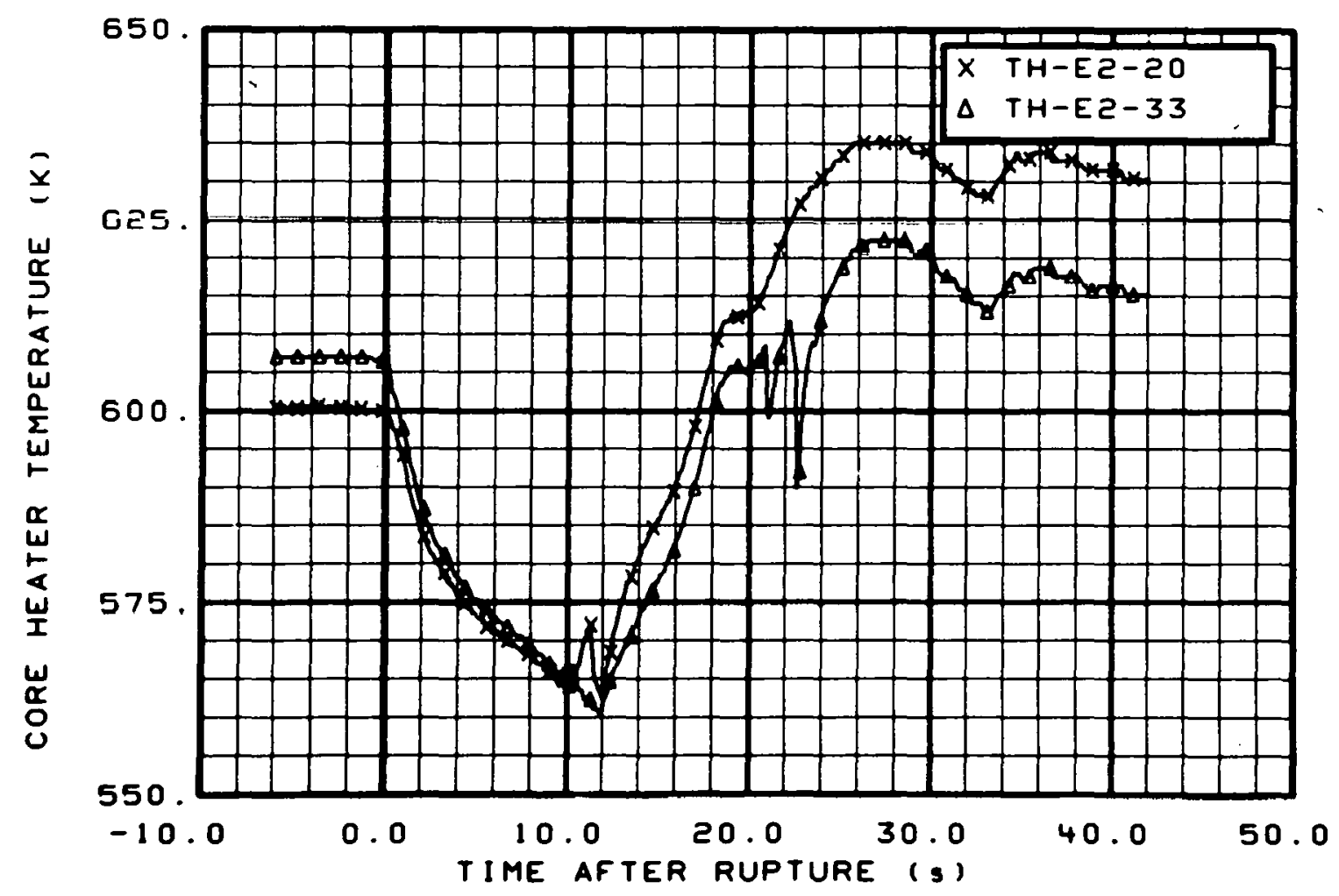

Fig. 102 Core heater temperature, Rod E-2 (TH-E2-20 and TH-E2-33), from -6 to $42 \mathrm{~s}$. 


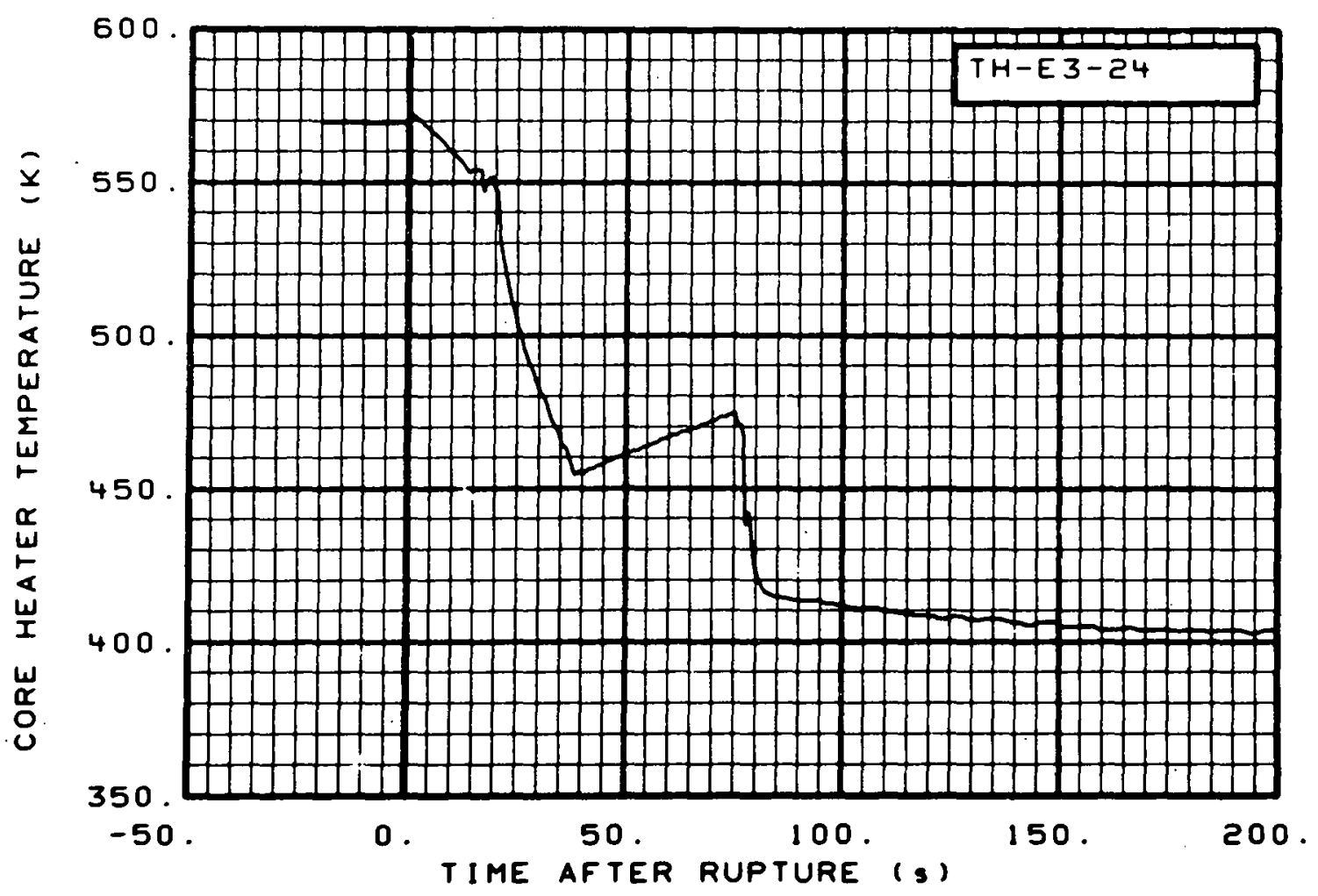

Fig. 103 Core heater temperature, Rod E-3 (TH-E3-24), from -20 to $200 \mathrm{~s}$.

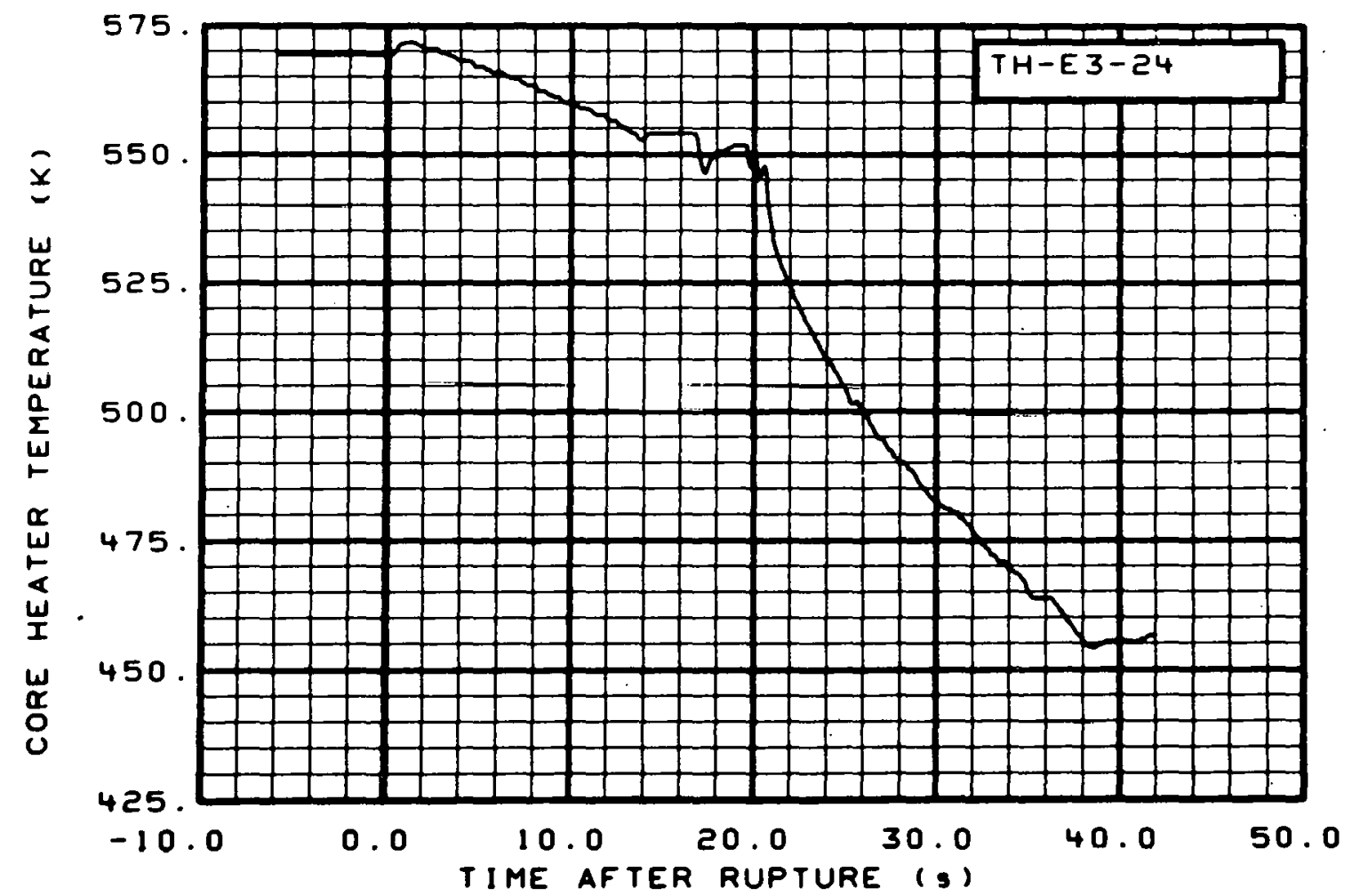

Fig. 104 Core heater temperature, Rod E-3 (TH-E3-24), from -6 to $42 \mathrm{~s}$. 


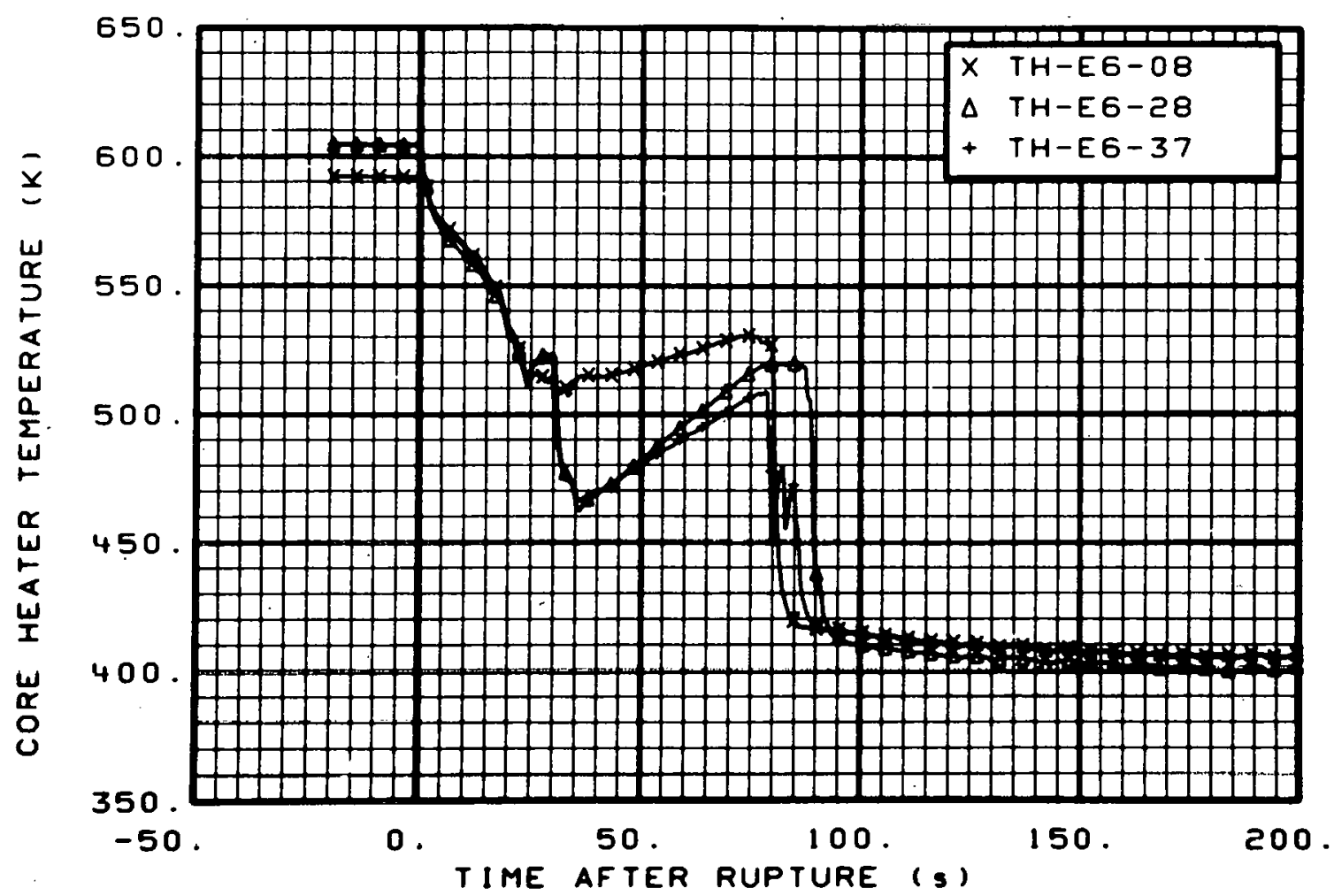

Fig. 105 Core heater temperature, Rod E-6 (IH-E6-U8, TH-E6-28, and. TH-E6-37), from -20 to $200 \mathrm{~s}$.

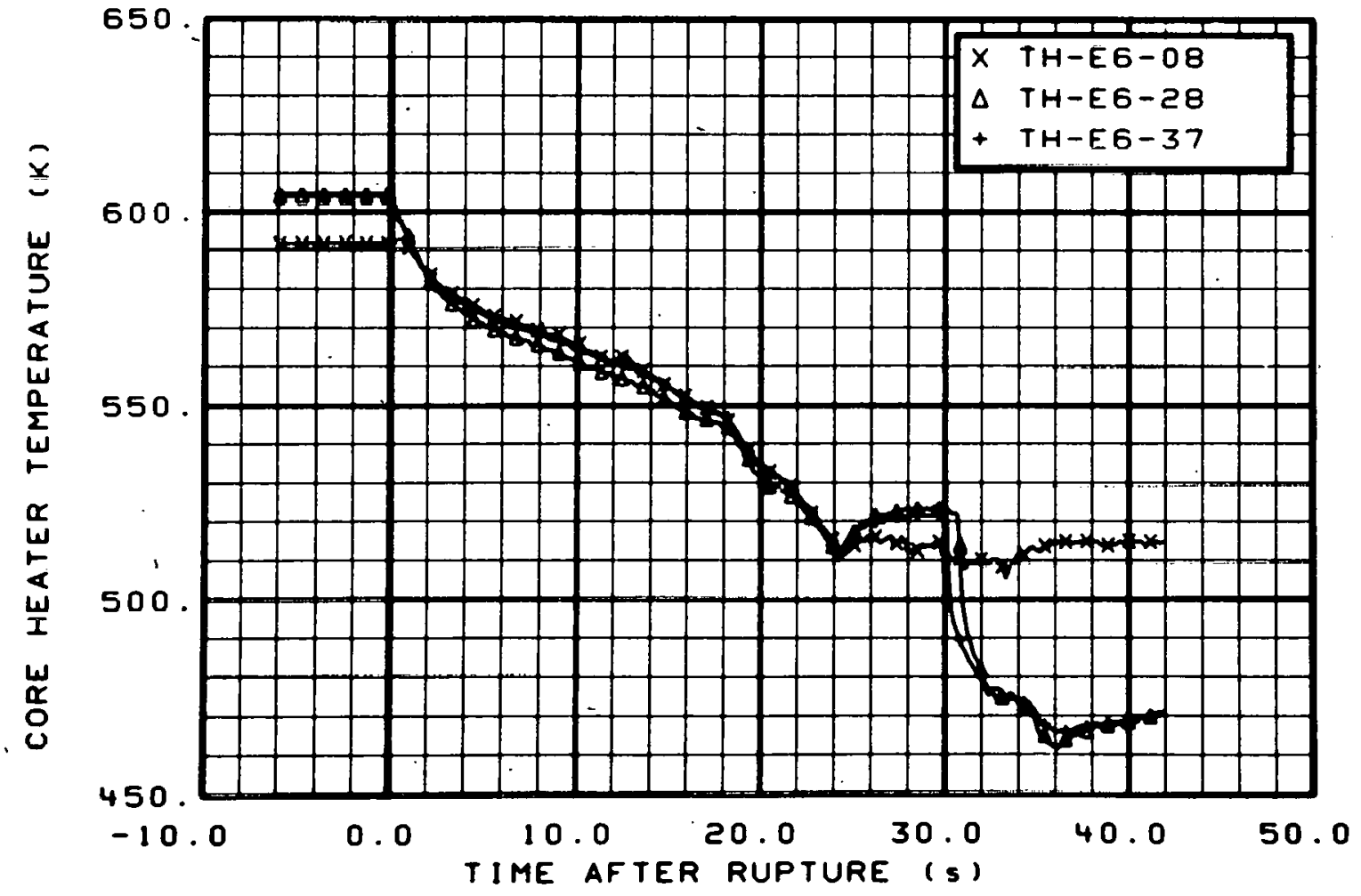

Fig. 106 Core heater temperature, Rod E-6 (TH-E6-08, TH-E6-28, and $\mathrm{TH}-\mathrm{E} 6-37$ ), from -6 to $42 \mathrm{~s}$. 


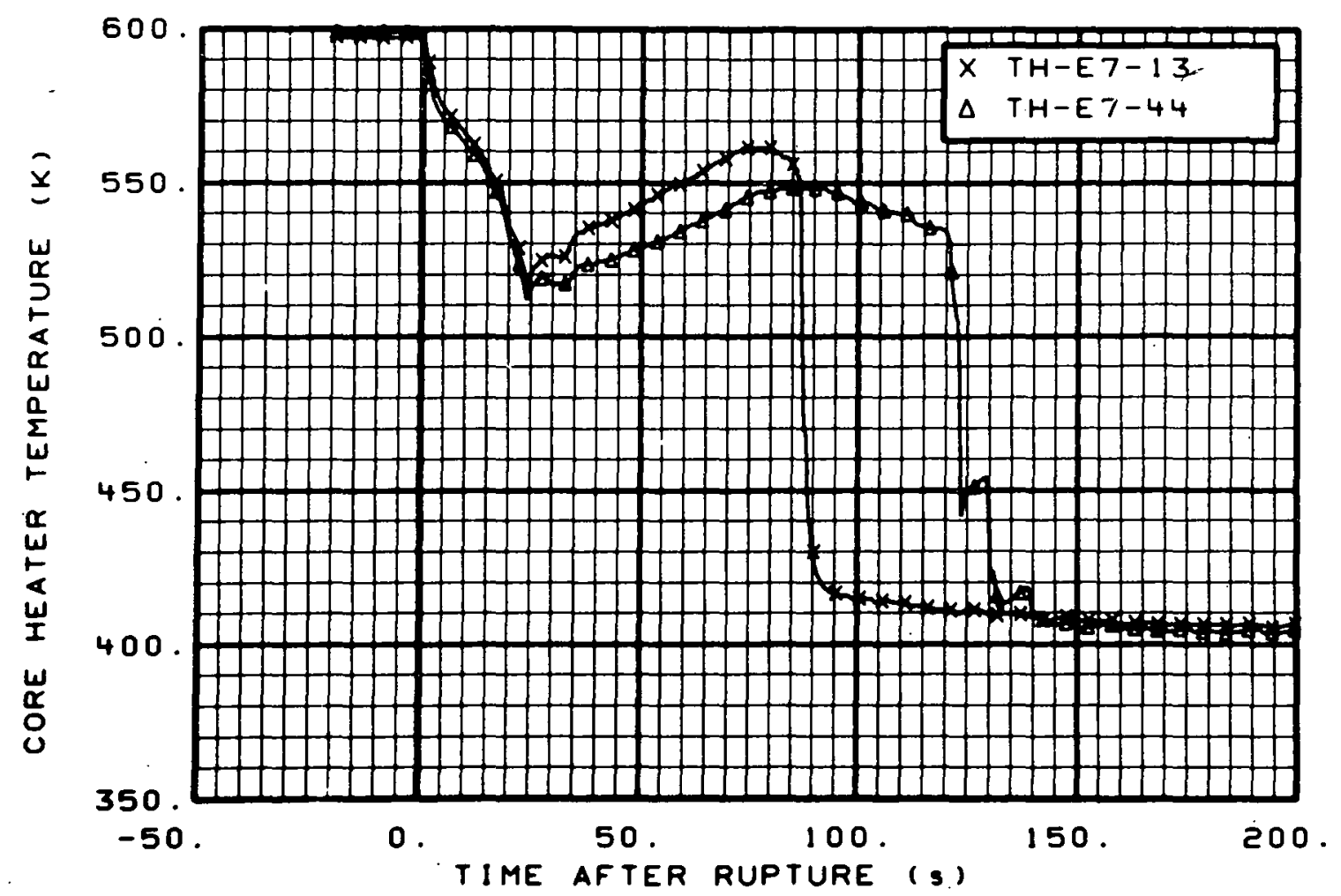

Fig. 107 Core heater temperature, Rod E-7 (TH-E7-13 and TH-E7-44), from -20 to $200 \mathrm{~s}$.

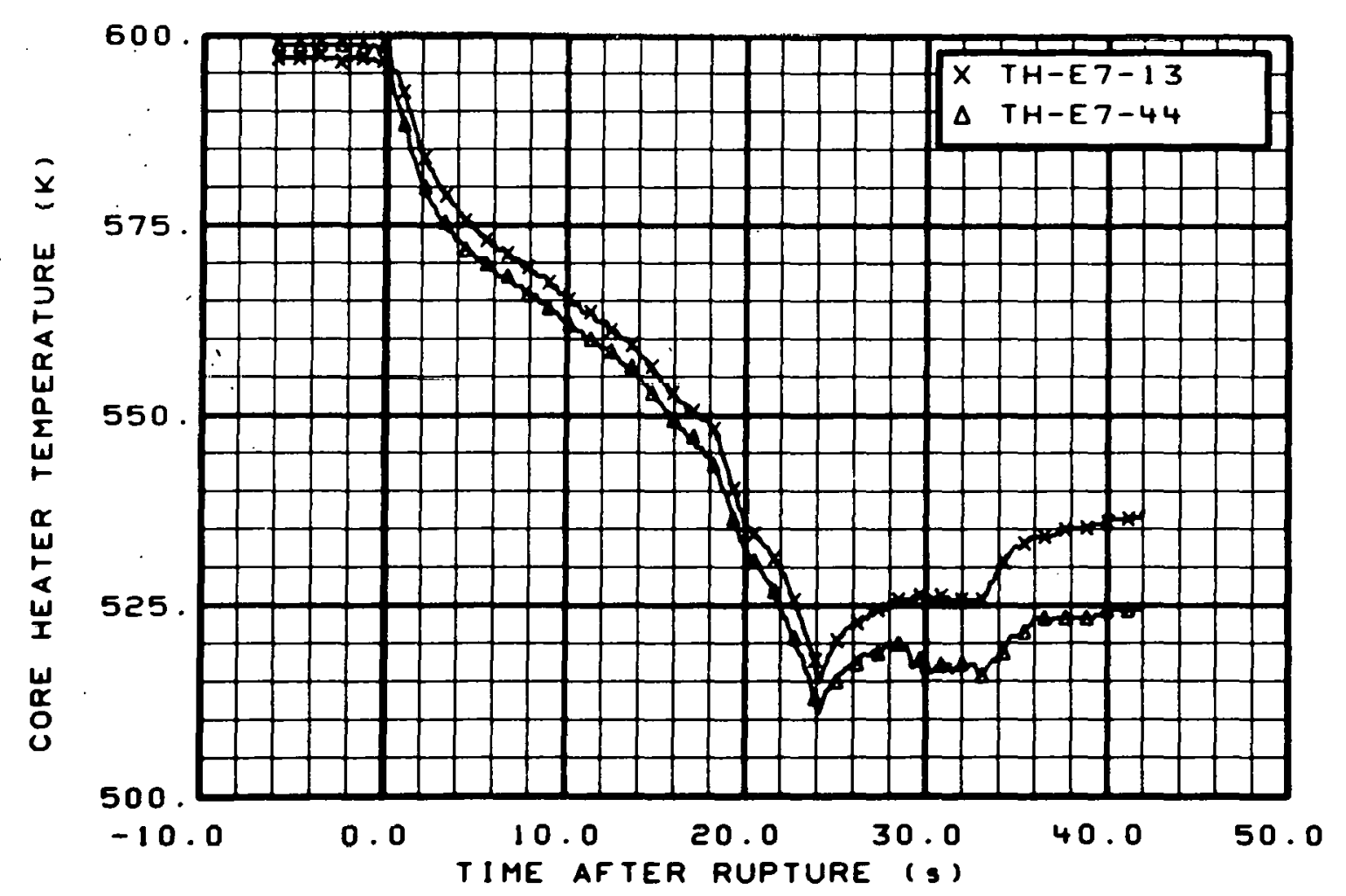

Fig. 108 Core heater temperature, Rod E-7 (TH-E7-13 and TH-E7-44), from -6 to $42 \mathrm{~s}$. 


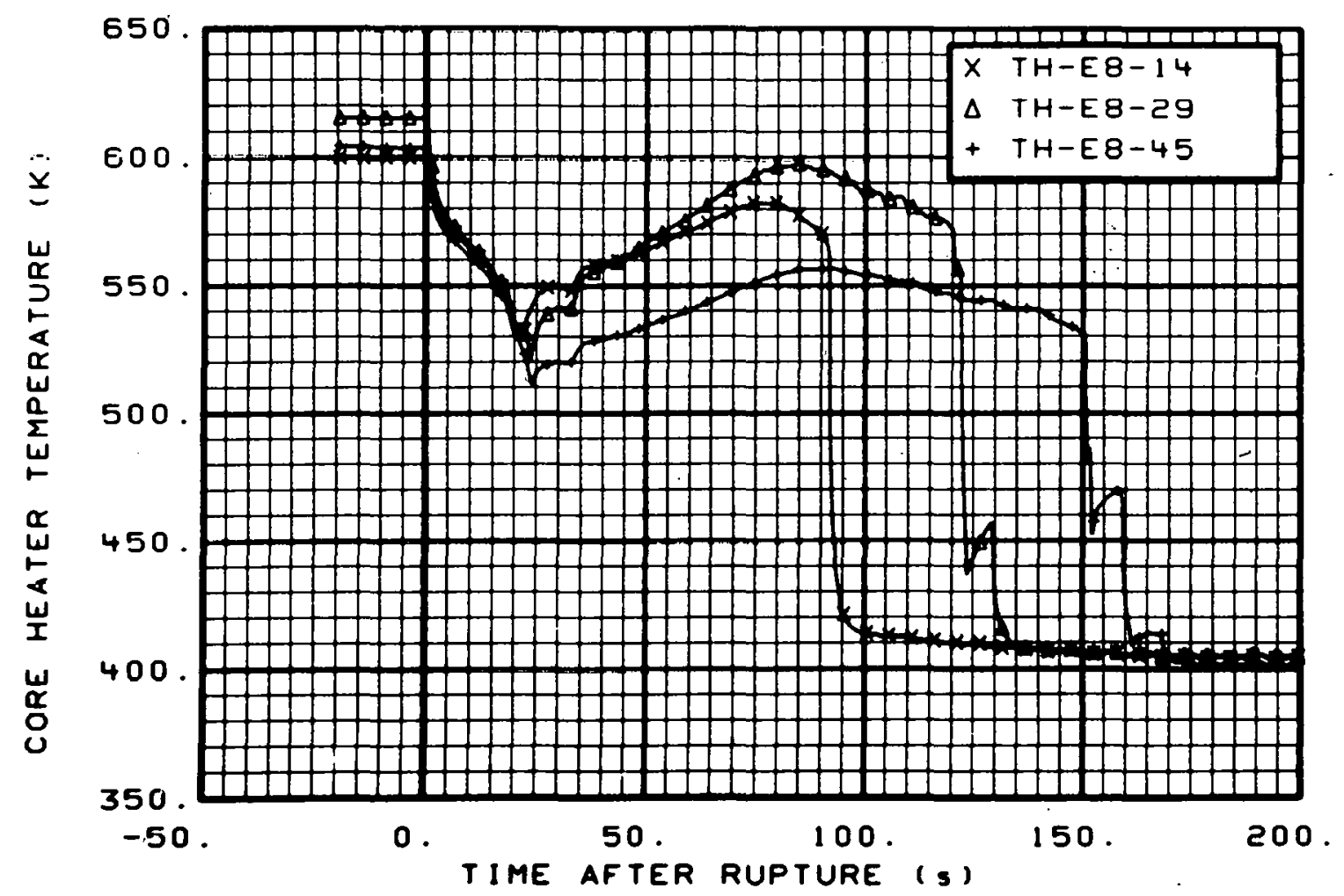

Fig. 109 Core heater temperature, Rod E-8 (TH-E8-14, TH-E8-29, and $\mathrm{TH}-\mathrm{E} 8-45$ ), from -20 to $200 \mathrm{~s}$.

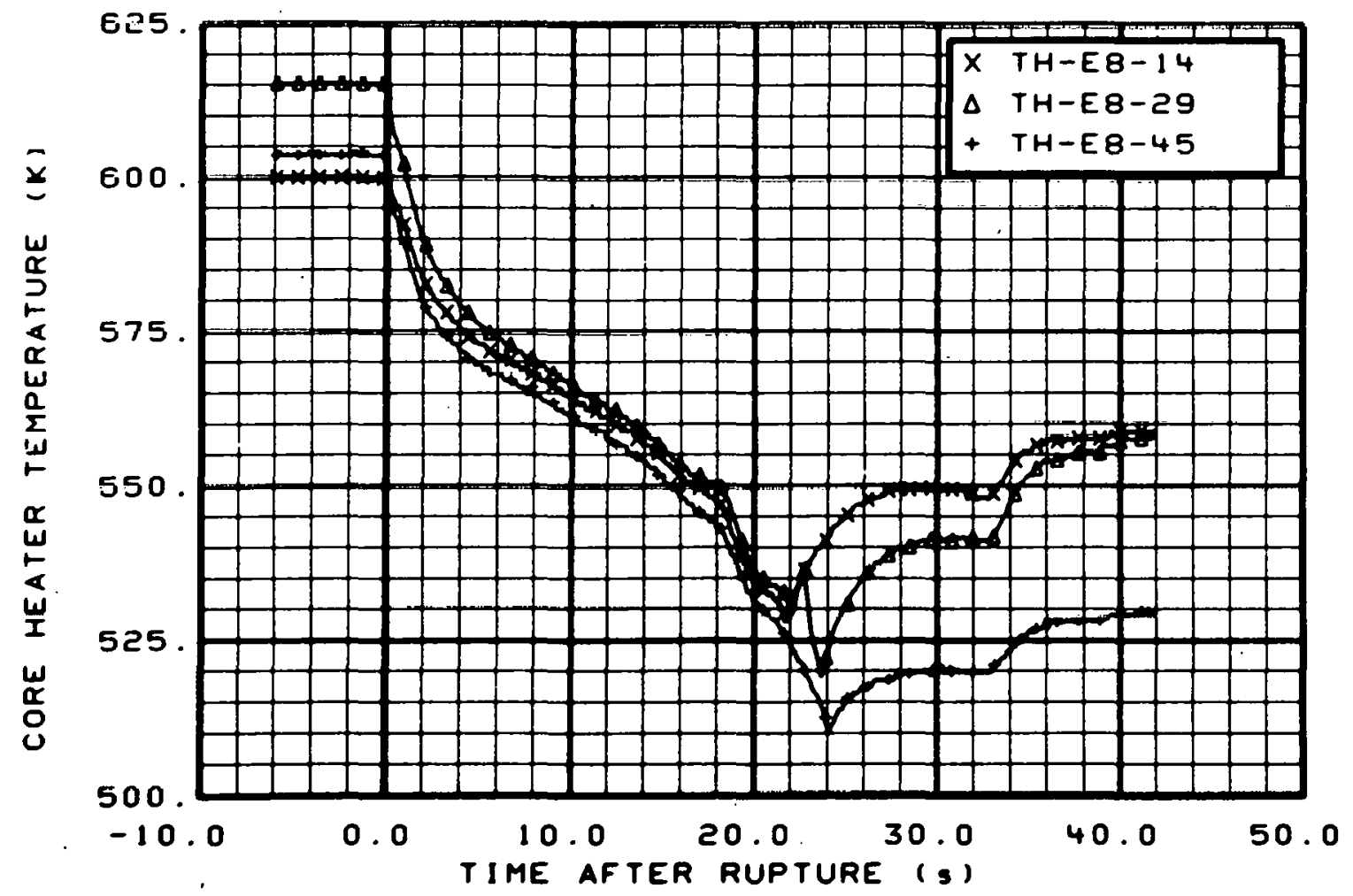

Fig. 110 Core heater temperature, Rod E-8 (TH-E8-14, TH-E8-29, and TH-E8-45), from -6 to $42 \mathrm{~s}$. 


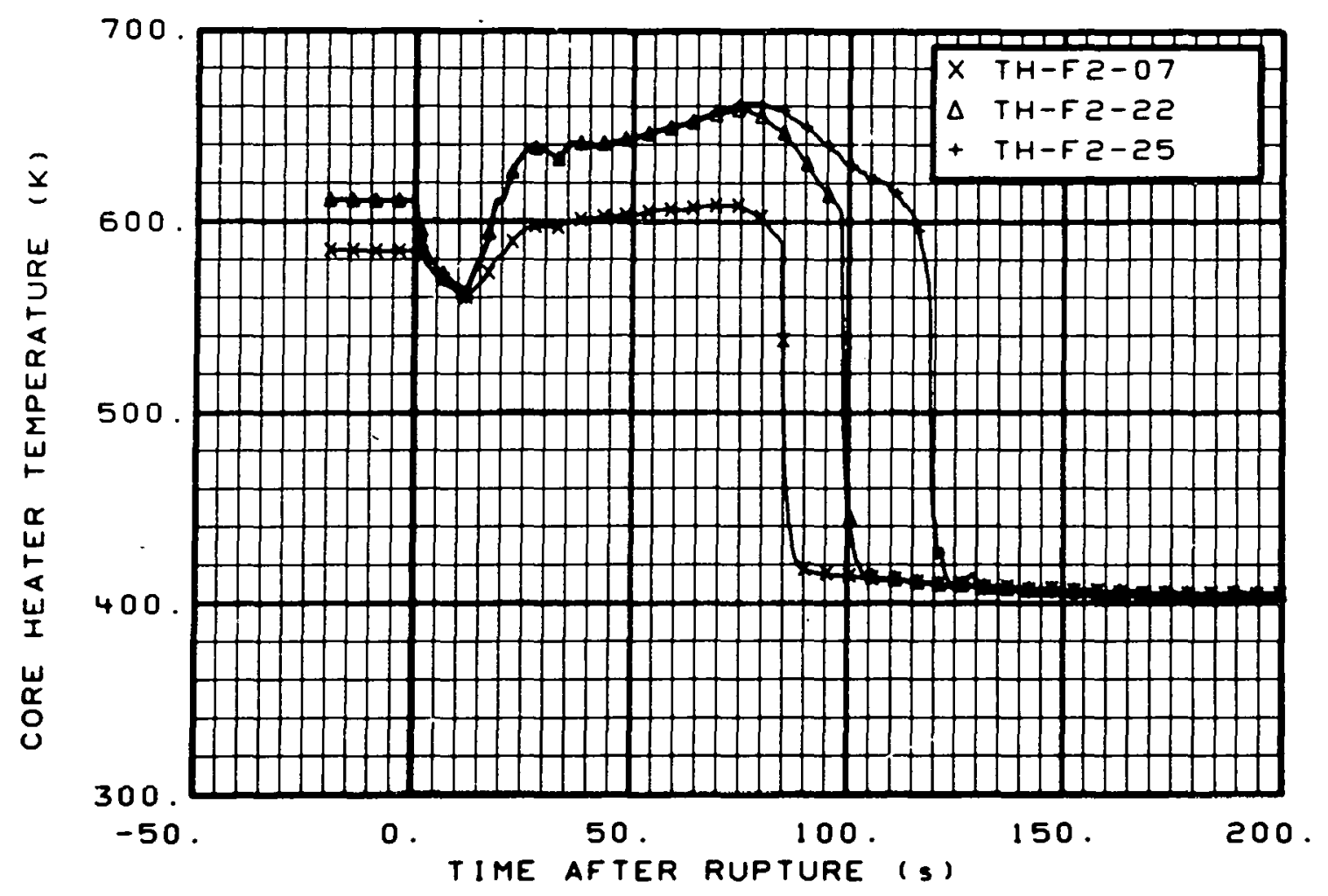

Fig. 111 Core heater temperature, Rod F-2 (TH-F2-07, TH-F2-22, and $\mathrm{TH}-\mathrm{F} 2-25$ ), from -20 to $200 \mathrm{~s}$.

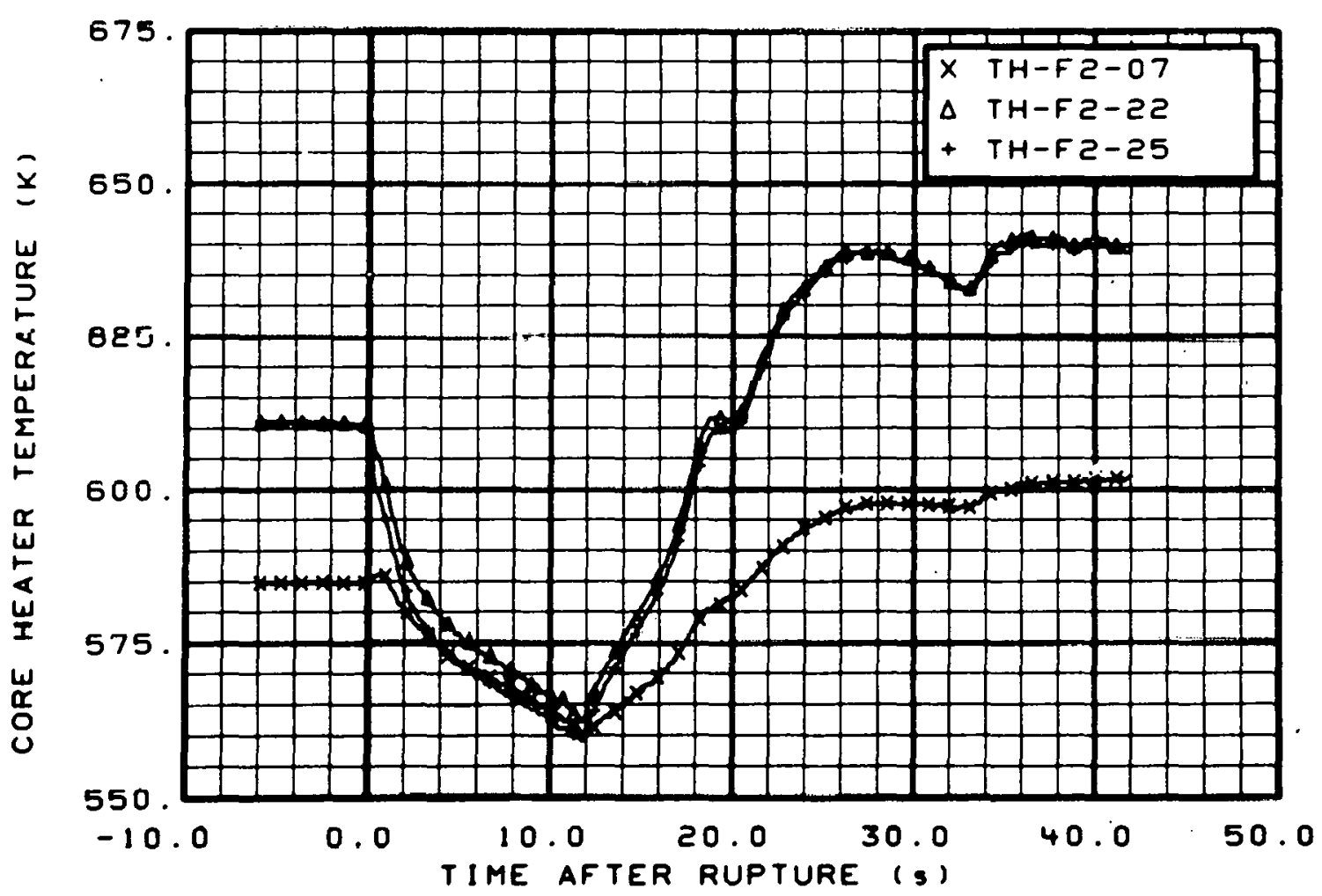

Fig. 112 Core heater temperature, Rod F-2 (TH-F2-07, TH-F2-22, and TH-F2-25), from -6 to $42 \mathrm{~s}$. 


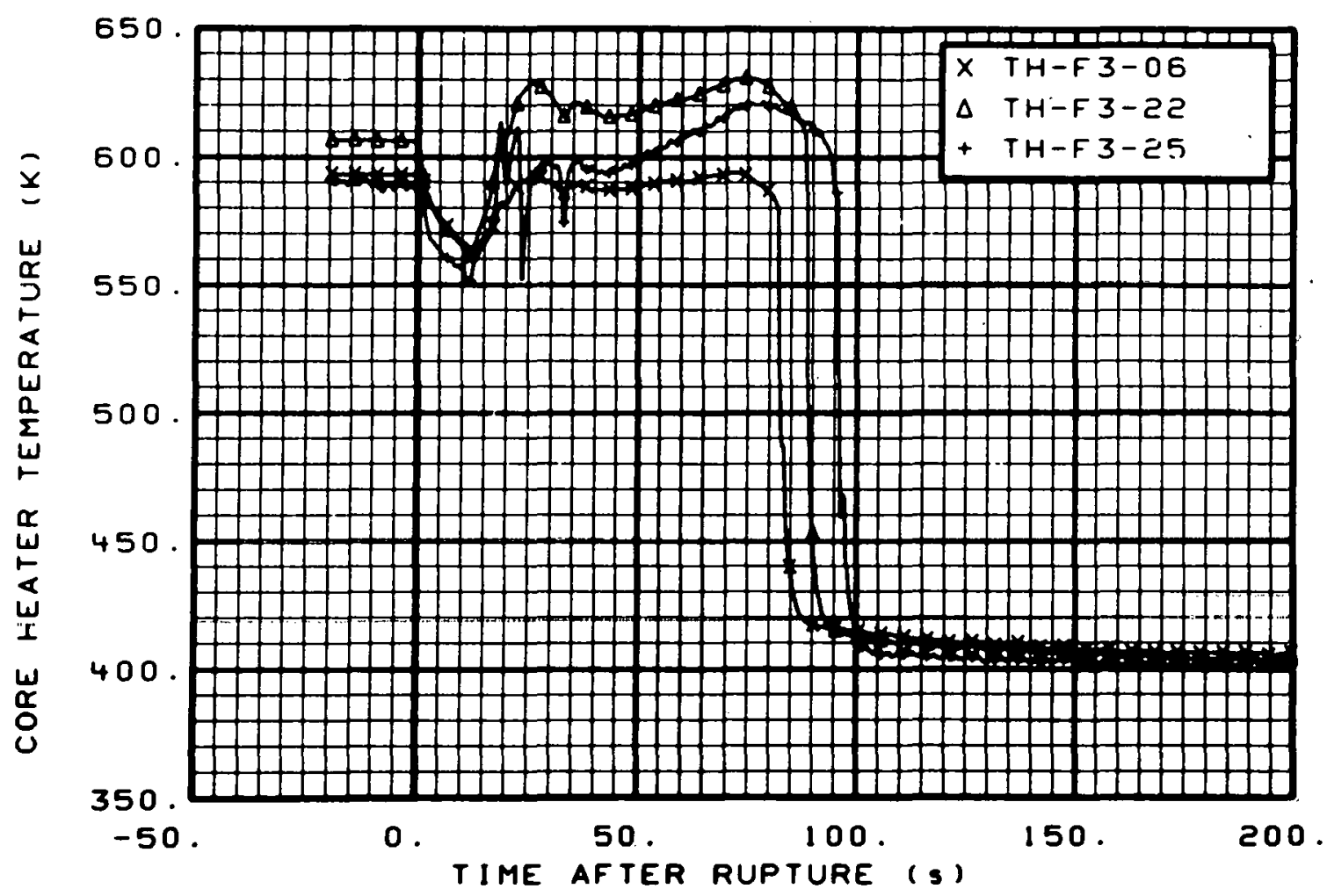

Fig. 113 Core heater temperature, Rod F-3 (TH-F3-06, TH-F3-22, and TH-F3-25), from -20 to $200 \mathrm{~s}$.

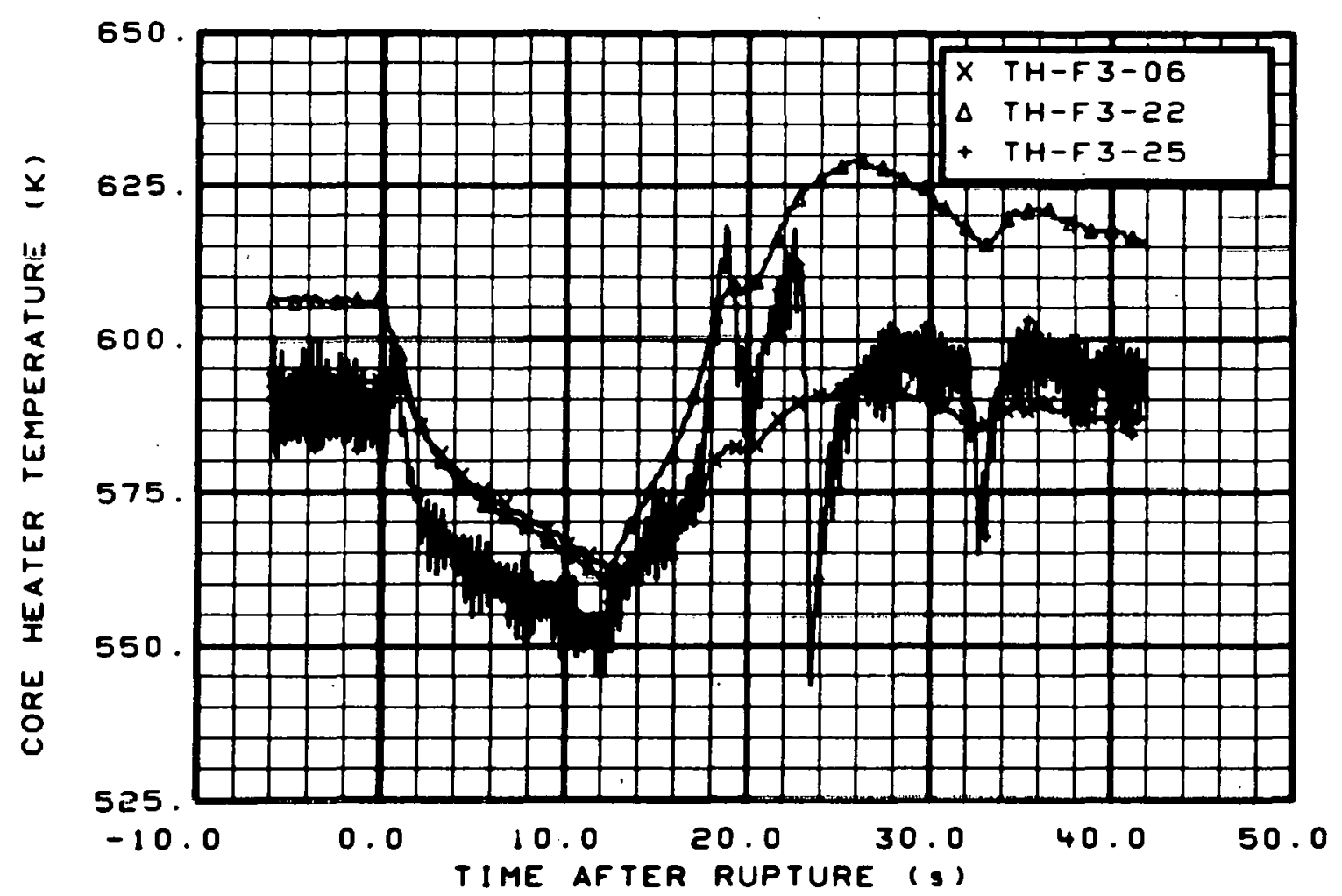

Fig. 114 Core heater temperature, Rod F-3 (TH-F3-06, TH-F3-22, and TH-F3-25), from -6 to $42 \mathrm{~s}$. 


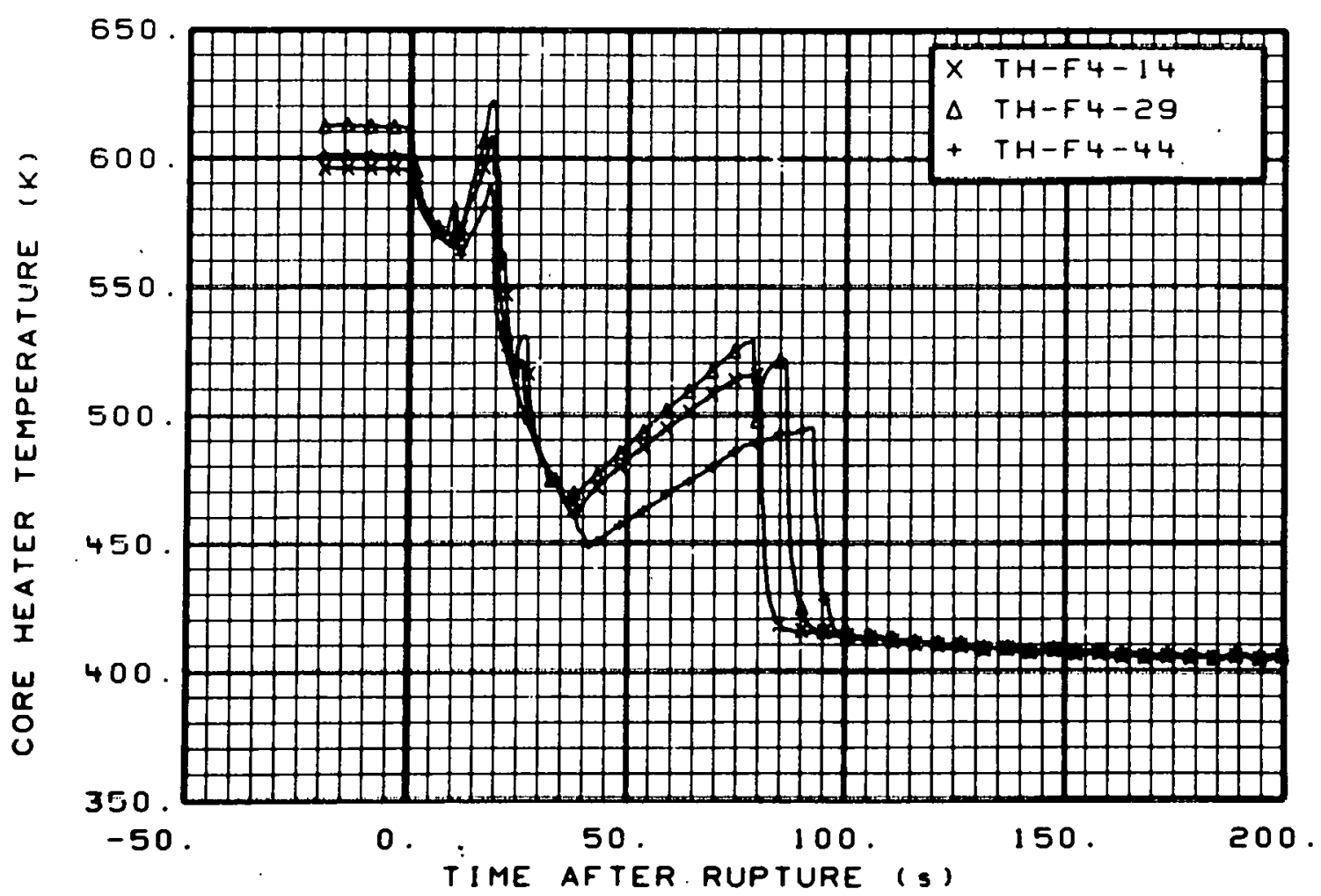

Fig. 115 Core heater temperature, Rod F-4 (TH-F4-14, TH-F4-29, and $\mathrm{TH}-\mathrm{F} 4-44$ ), from -20 to $200 \mathrm{~s}$.

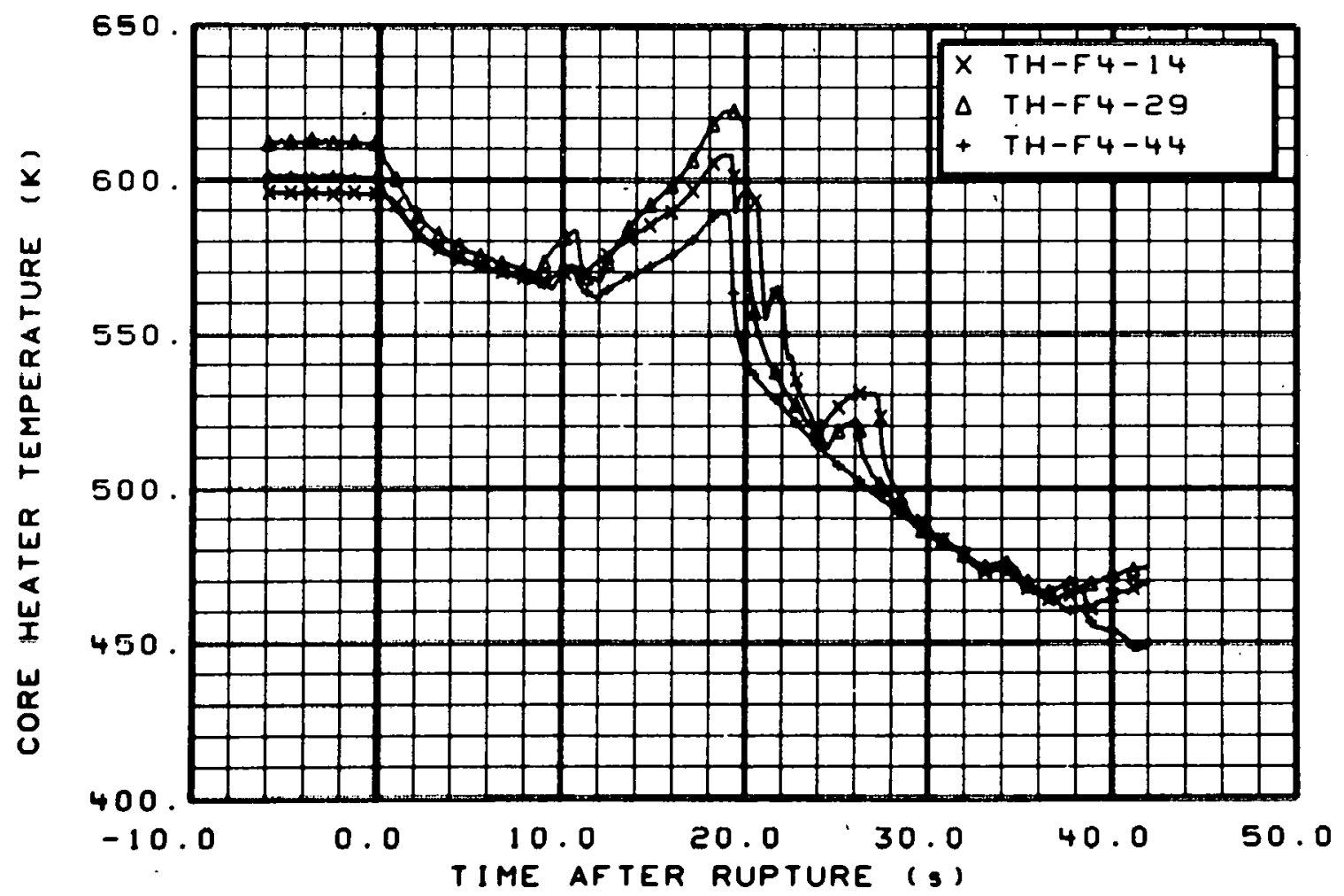

Fig. 116-Core heater temperature, Rod F-4 (TH-F4-14, TH-F4-29, and TH-F4-44), from -6 to $42 \mathrm{~s}$. 


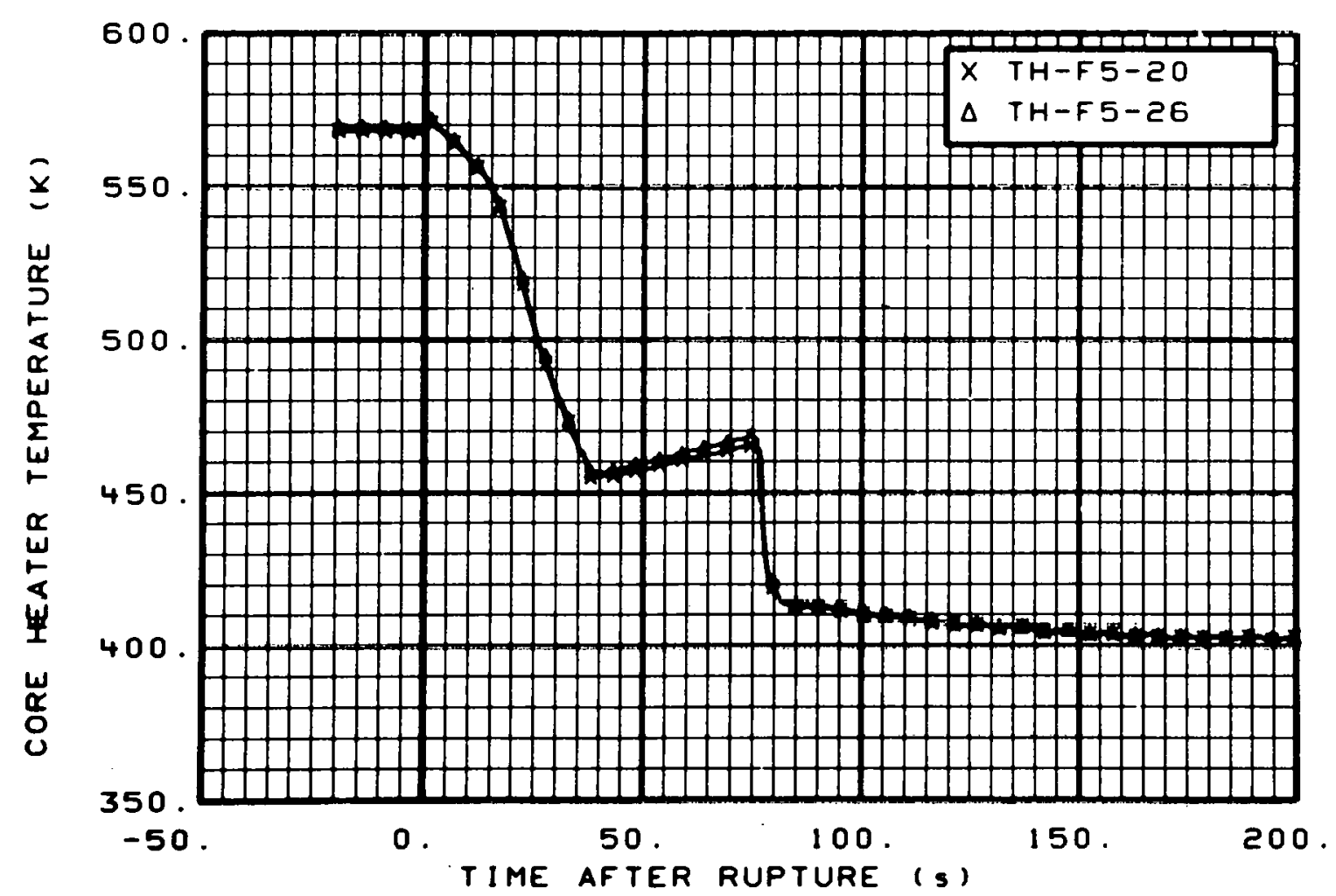

Fig. 117 Core heater temperature, Rod F-5 (TH-F5-20 and TH-F5-26), from -20 to $200 \mathrm{~s}$.

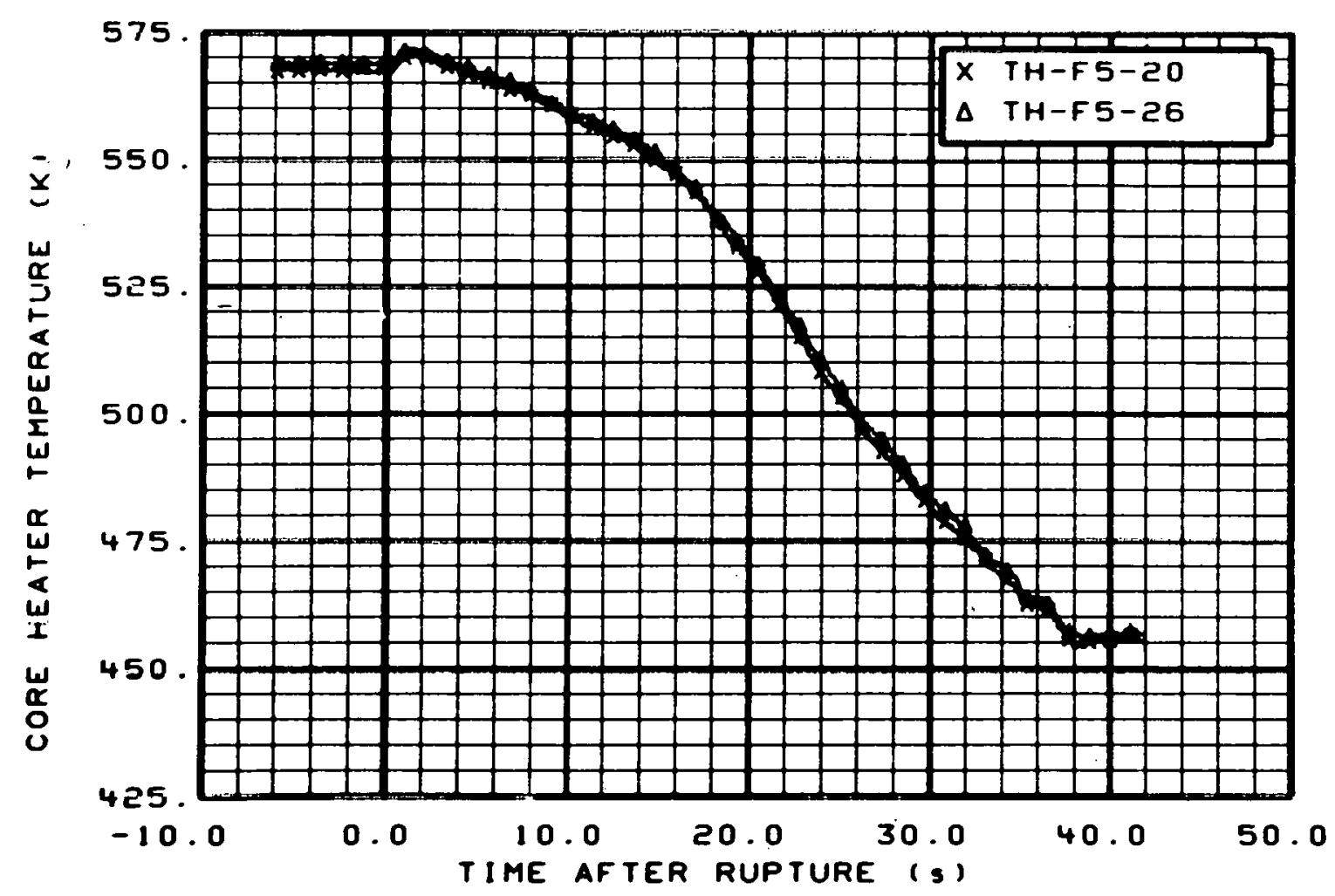

Fig. 118 Core heater temperature, Rod F-5 (TH-F5-20 and TH-F5-26), from -6 to $42 \mathrm{~s}$. 


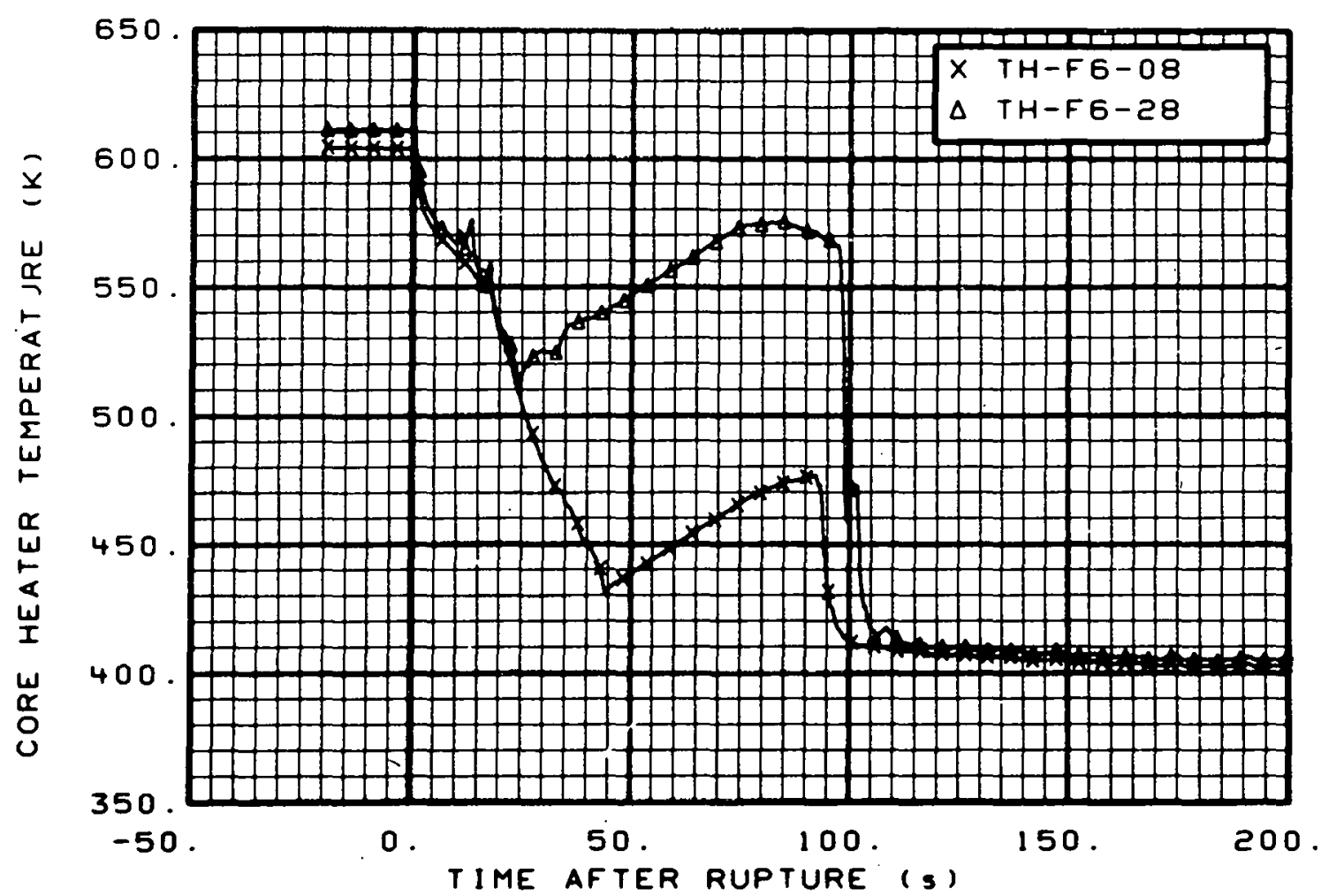

Fig. 119 Core heater temperature, Rod F-6 (TH-F6-08 and TH-F6-28), from -20 to $200 \mathrm{~s}$.

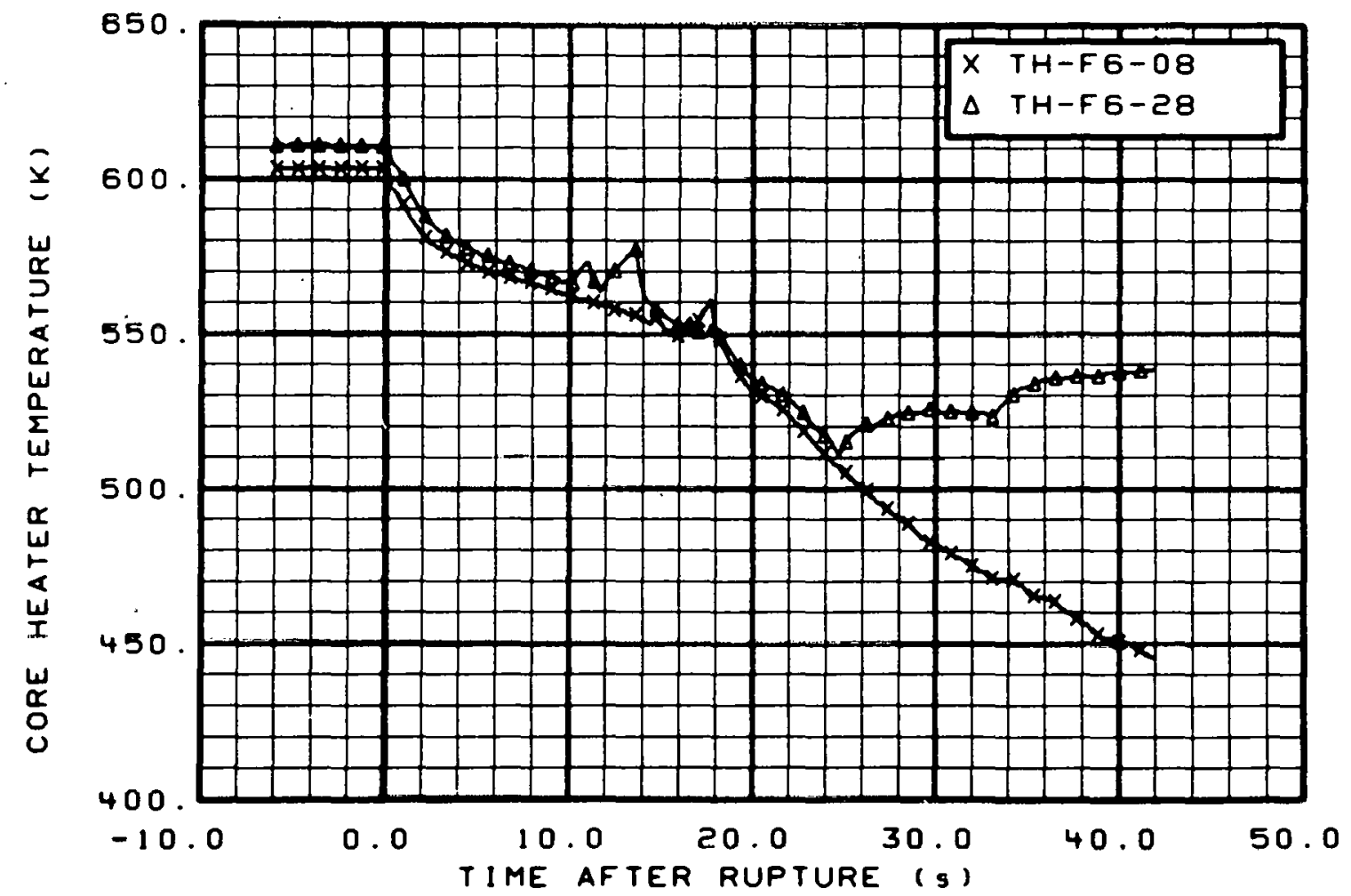

Fig. 120 Core heater temperature, Rod F-6 (TH-F6-08 and TH-F6-28), from -6 to $42 \mathrm{~s}$. 


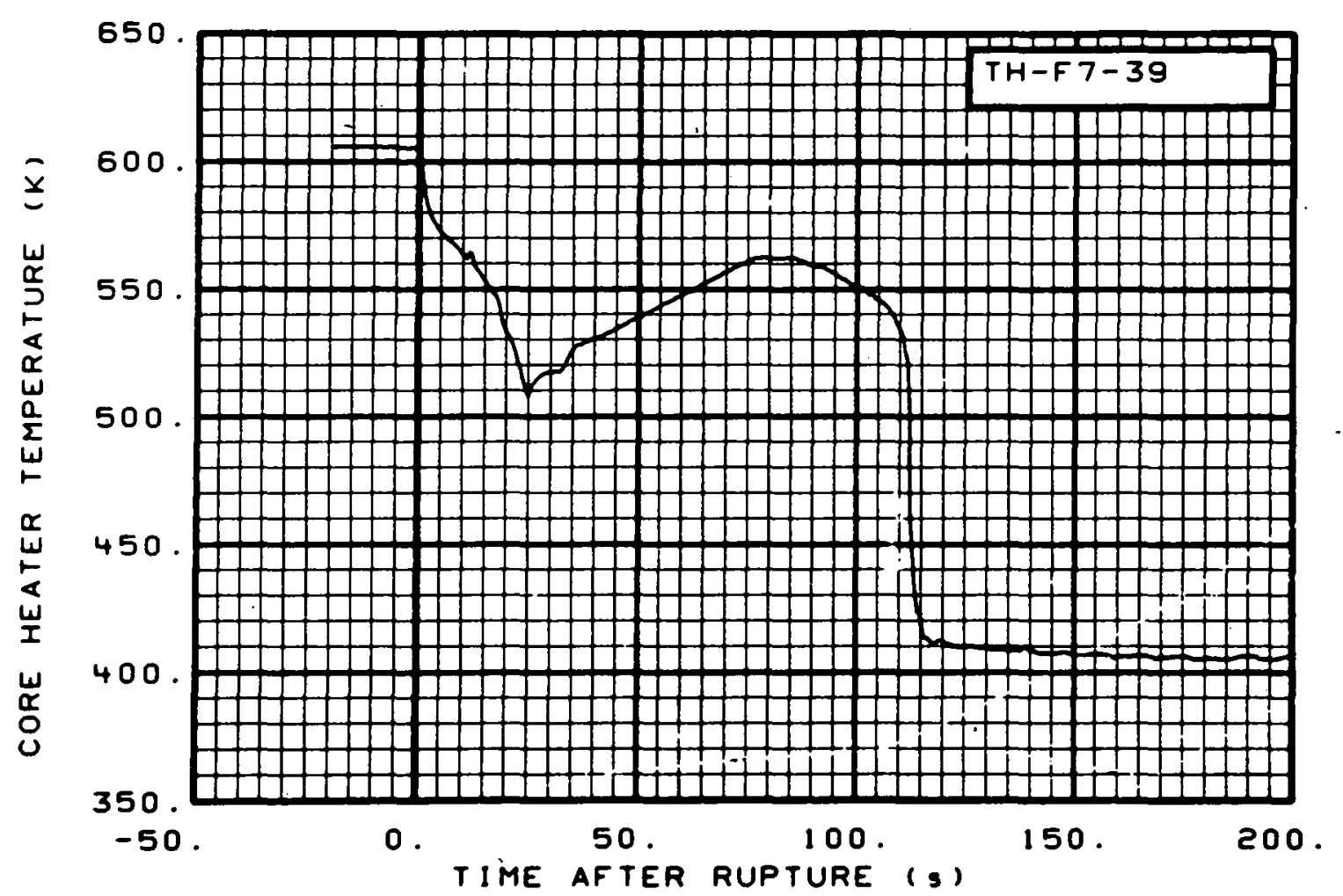

Fig. 121 Core heater temperature, Rod F-7 (TH-F7-39), from -20 to $200 \mathrm{~s}$.

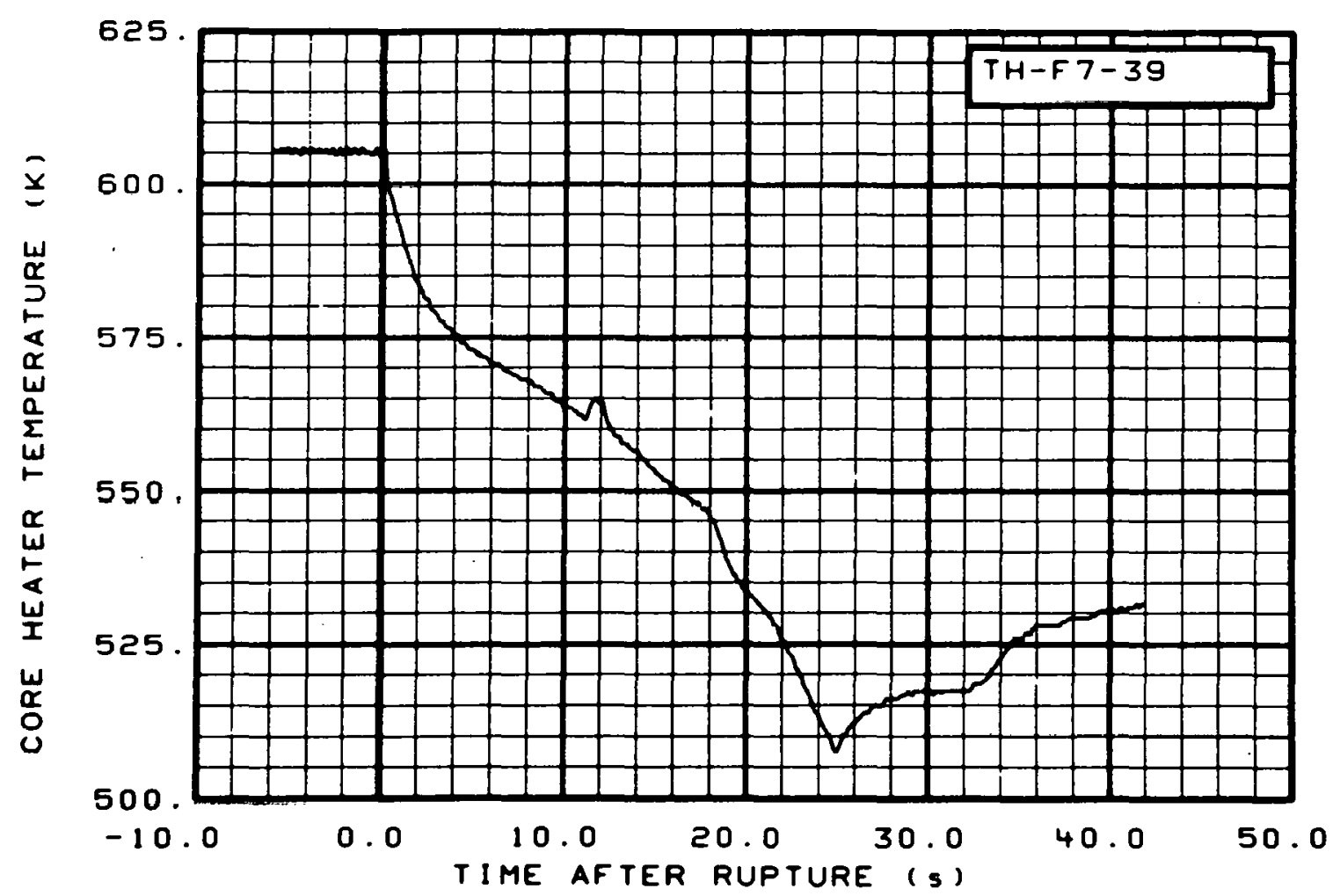

Fig. 122 Core heater temperature, Rod F-7 (TH-F7-39), from -6 to $42 \mathrm{~s}$. 


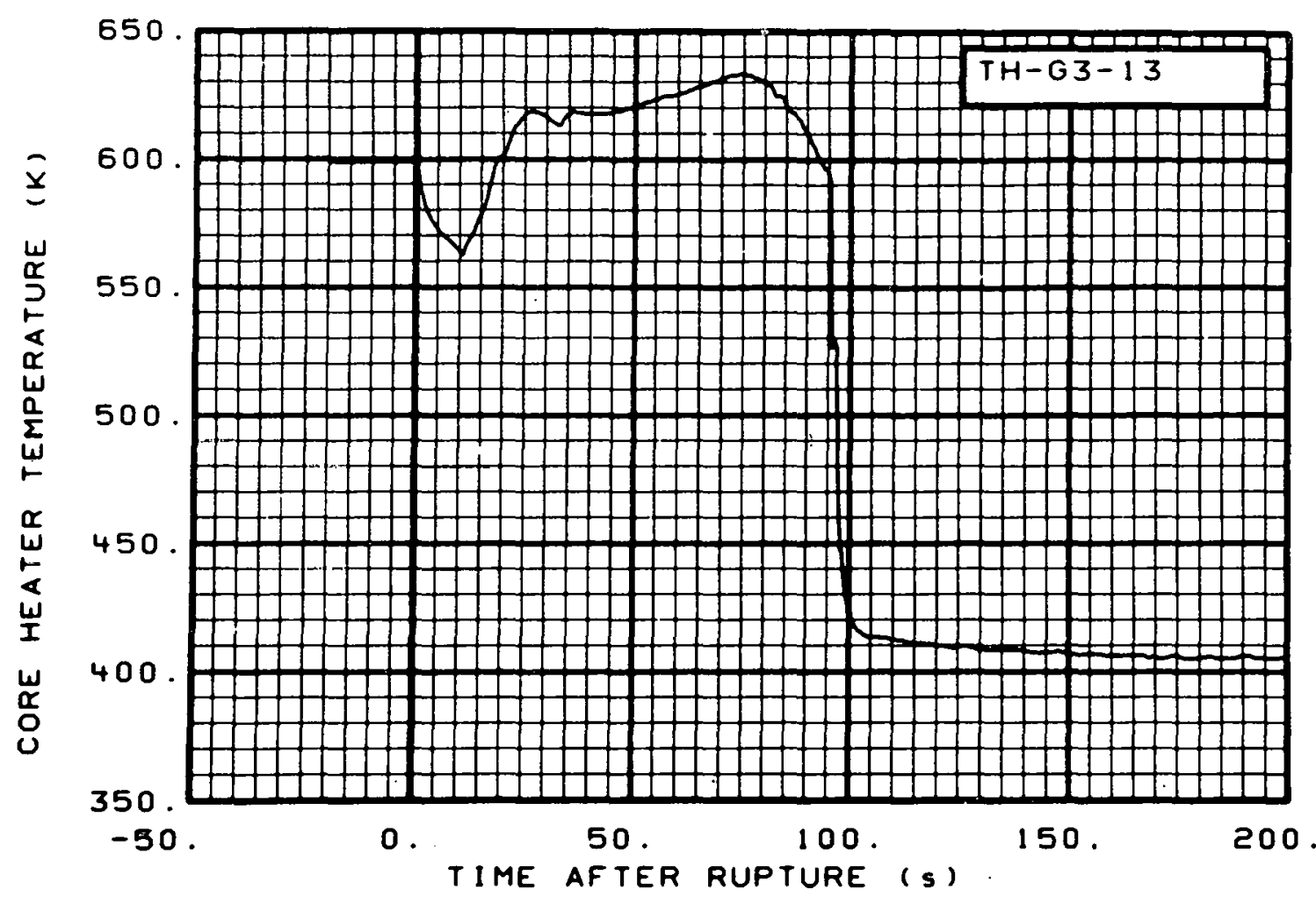

Fig. 123 Core heater temperature, Rod G-3 (TH-G3-13), from -20 to $200 \mathrm{~s}$.

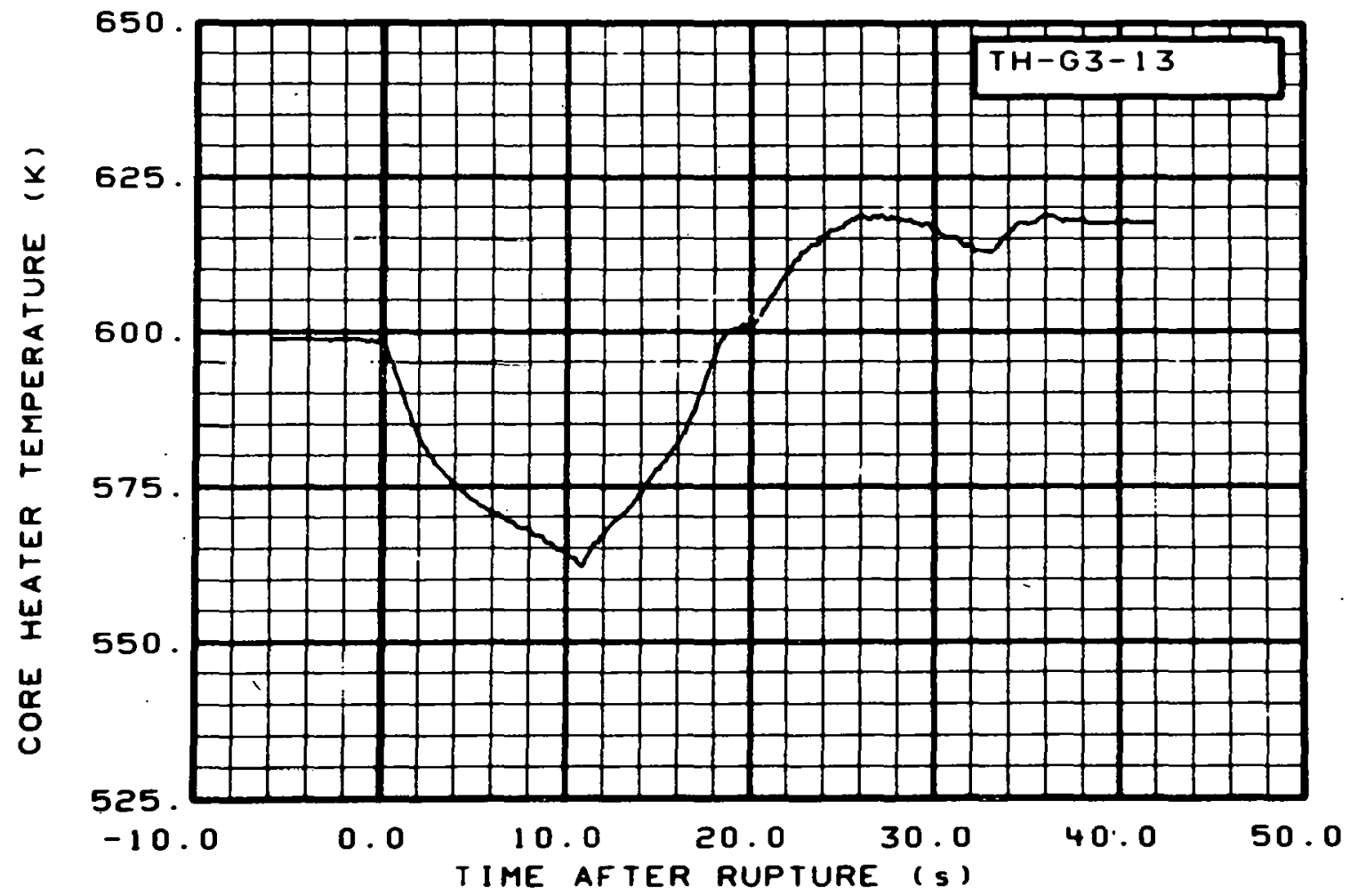

Fig. 124 Core heater temperature, Rod G-3 (TH-G3-13), from -6 to $42 \mathrm{~s}$. 


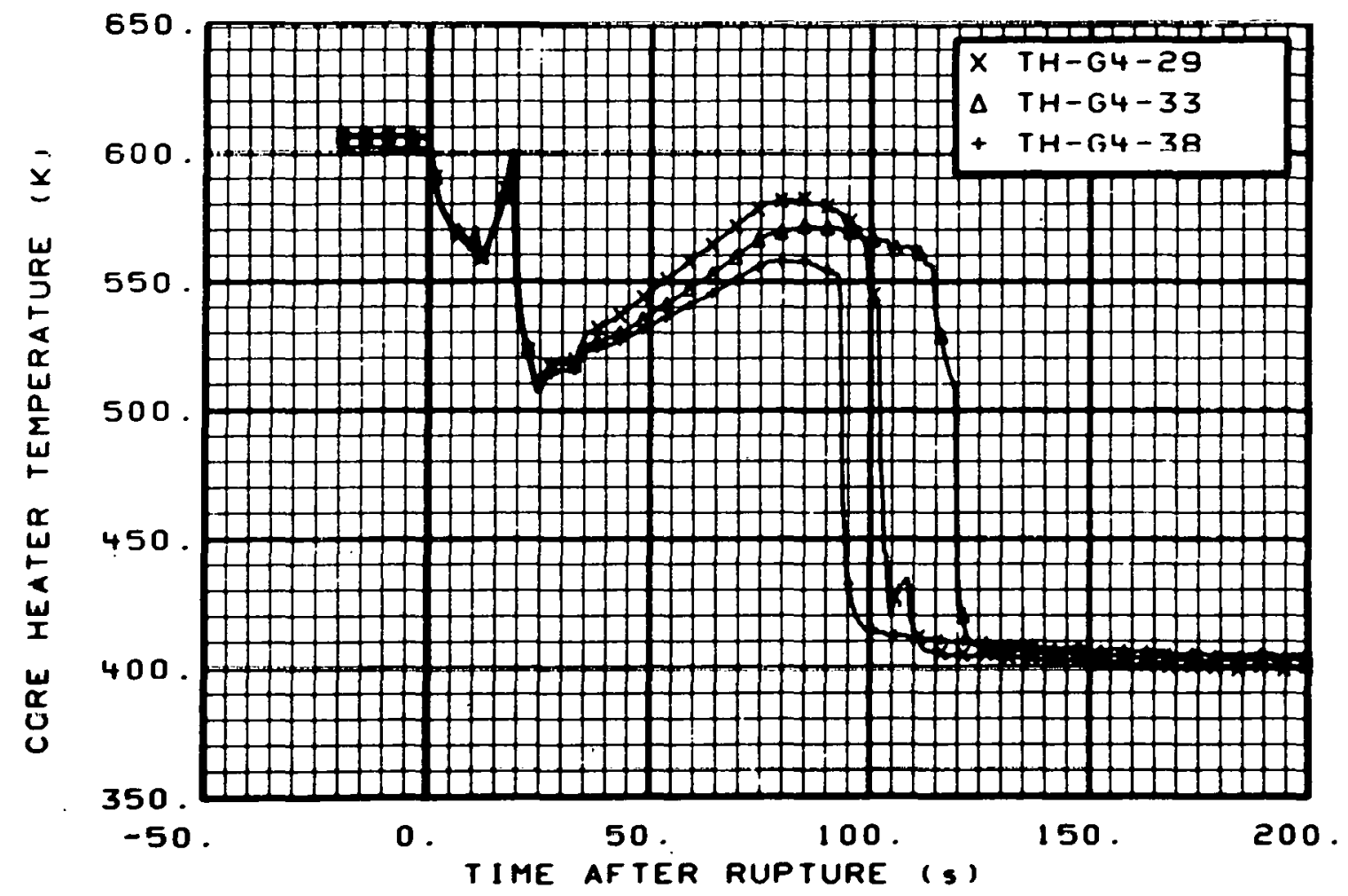

Fig. 125 Core heater temperature, Rod G-4 (TH-G4-29, TH-G4-33, and TH-G4-38), from -20 to $200 \mathrm{~s}$.

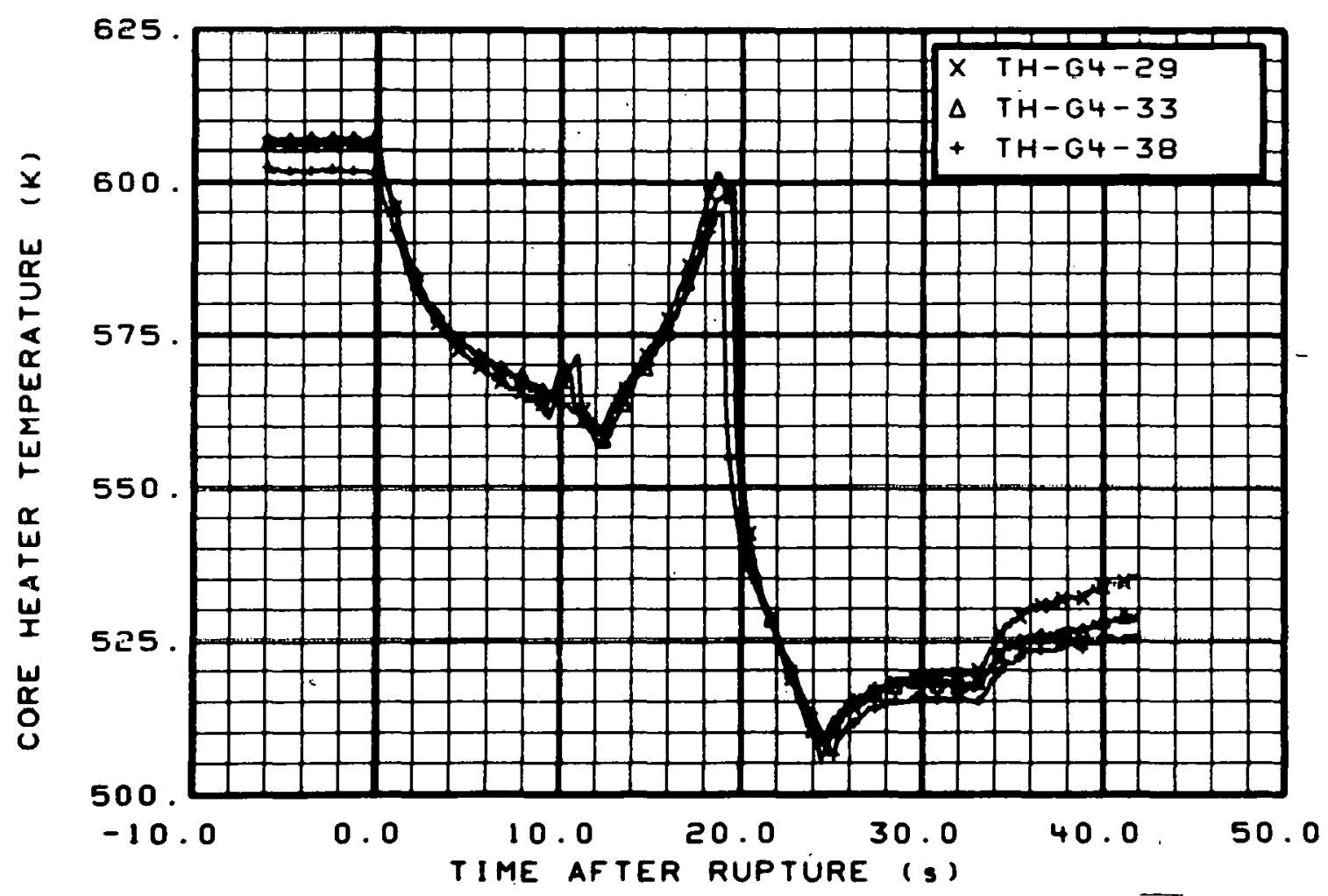

Fig. 126 core heater temperature, Rod G-4 (TH-G4-29, TH-G4-33, and $\mathrm{TH}-\mathrm{G} 4-38$ ), from -6 to $42 \mathrm{~s}$. 


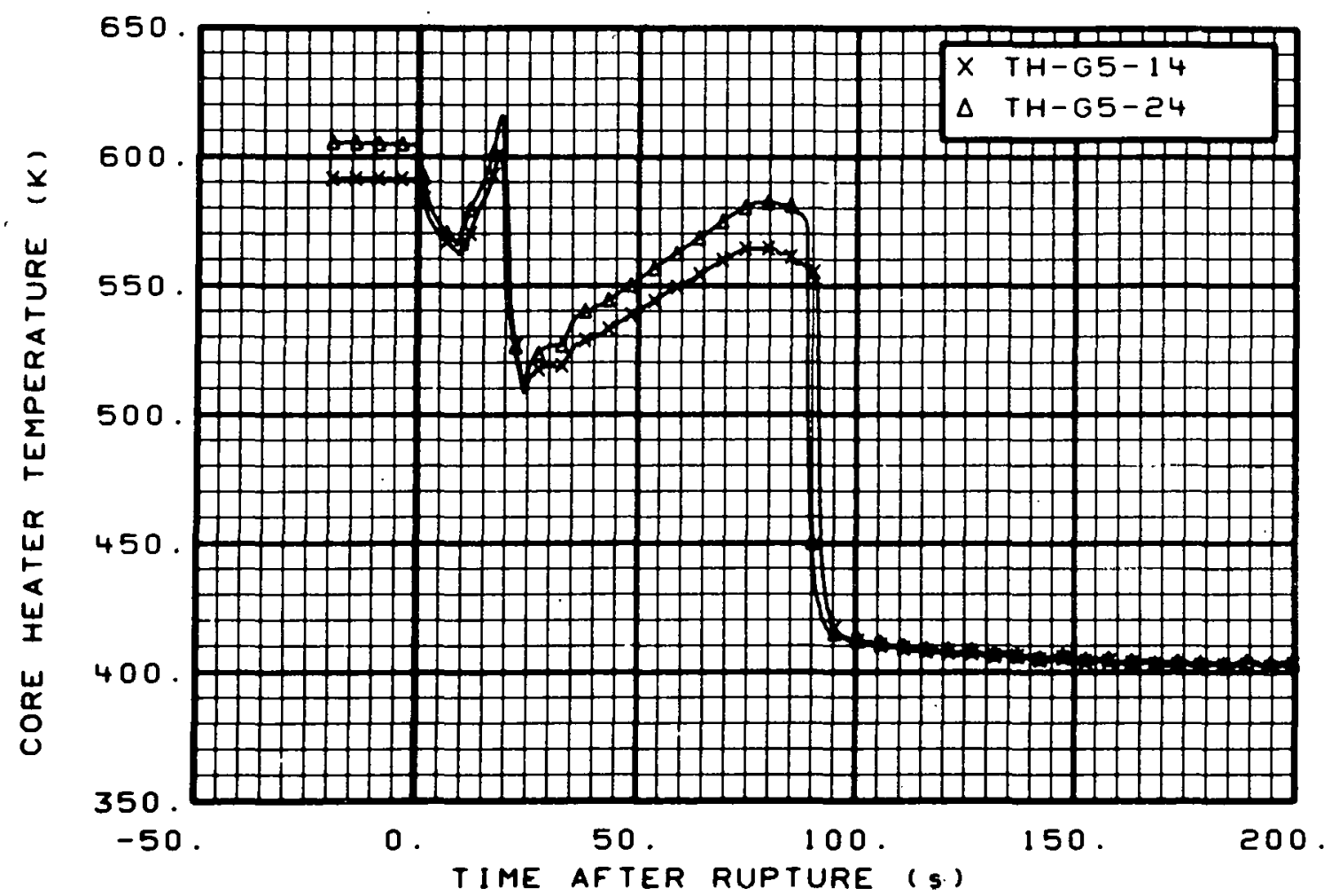

Fig. 127 Core heater temperature, Rod G-5 (TH-G5-14 and TH-G5-24), from -20 to $200 \mathrm{~s}$.

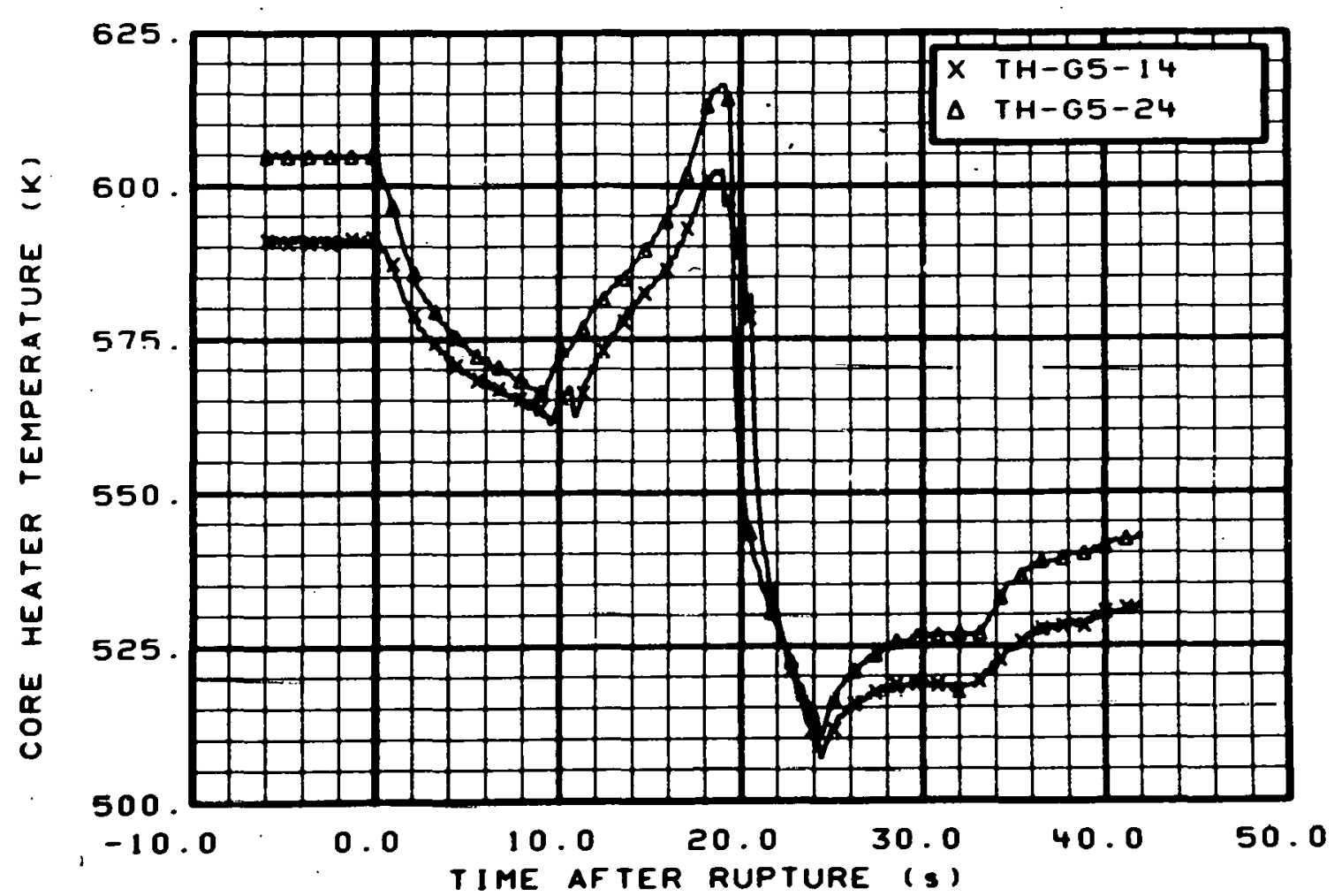

Fig. 128 Core heater temperature, Rod G-5 (TH-G5-14 and TH-G5-2A), from -6 to $42 \mathrm{~s}$. 


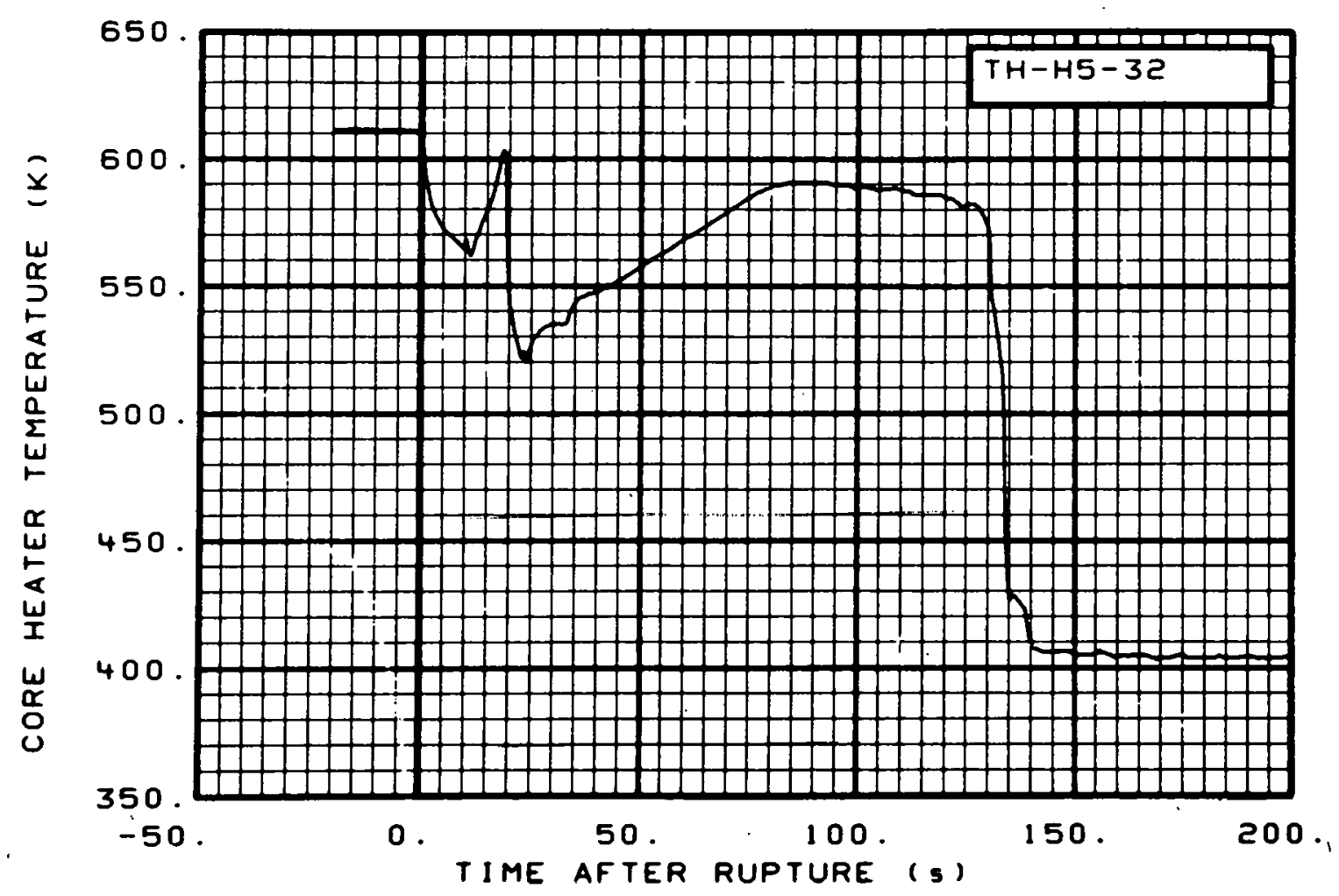

Fig. 129 Core heater temperature, Rod H-5, (TH-H5-32), from -20 to $200 \mathrm{~s}$.

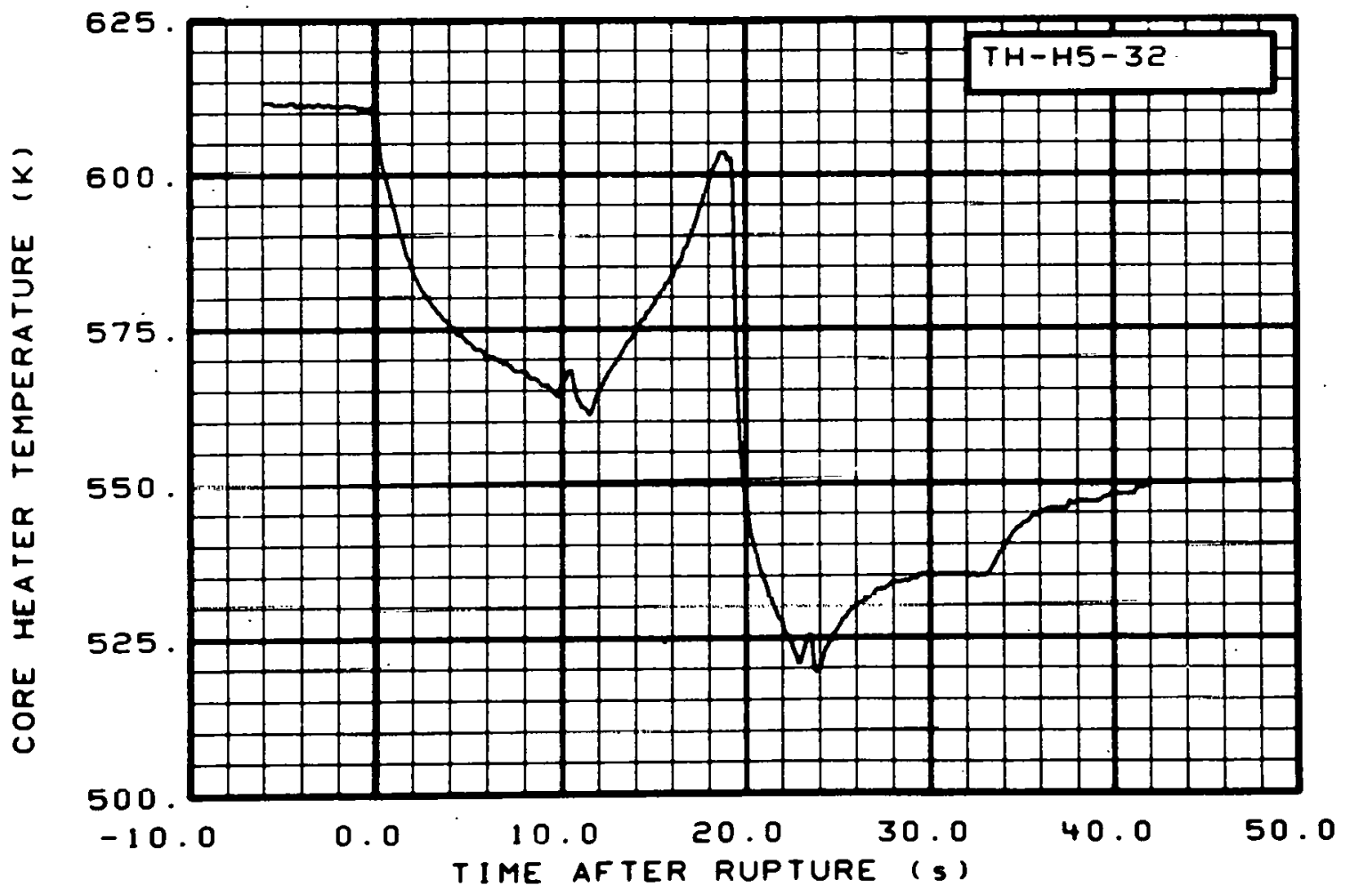

Fig. 130 Core heater temperature, Rod H-5, (TH-H5-32), from -6 to $42 \mathrm{~s}$. 


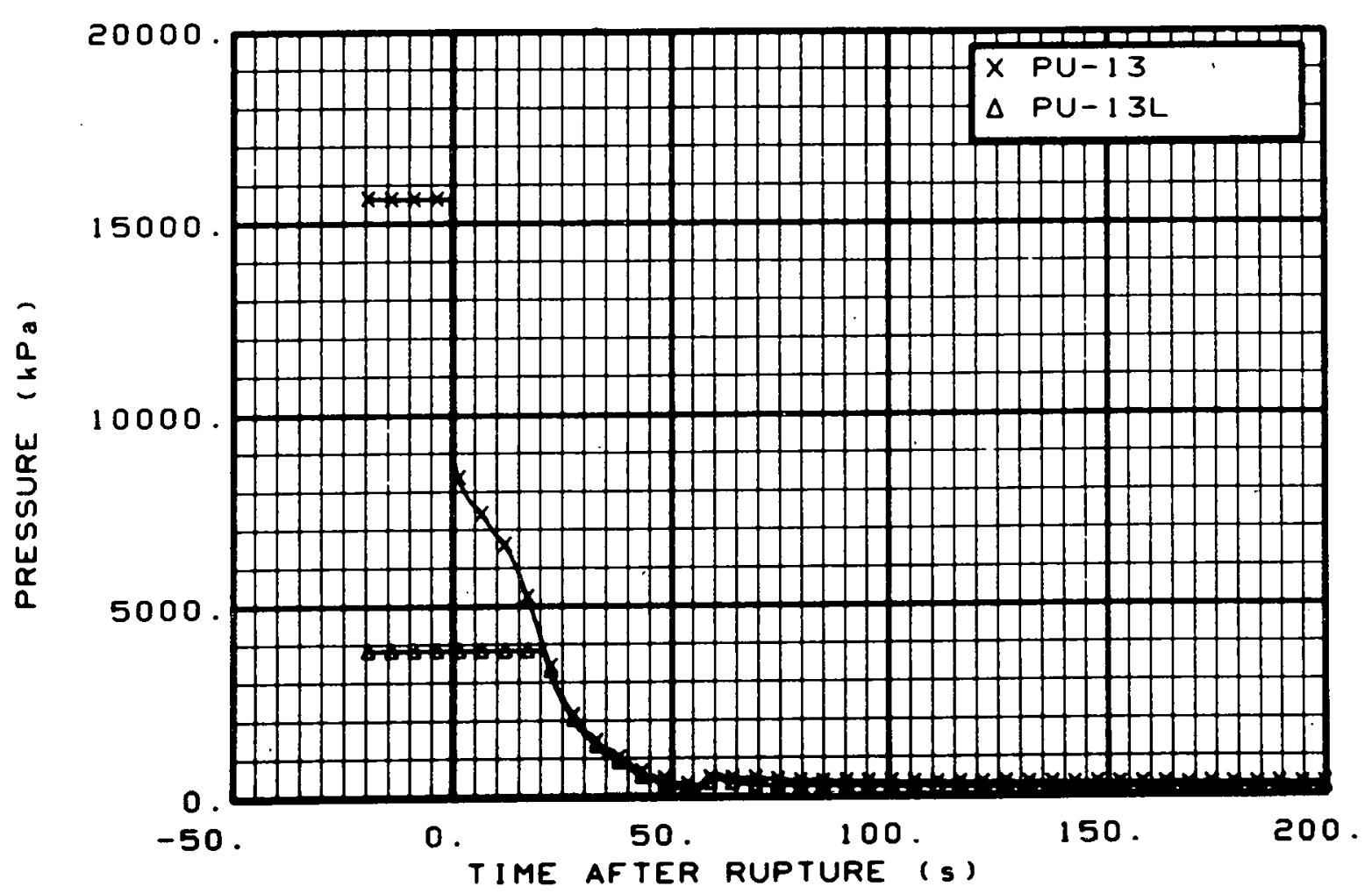

Fig. 131 Pressure in intact loop (PU-13 and PU-13L), from -20 to $200 \mathrm{~s}$.

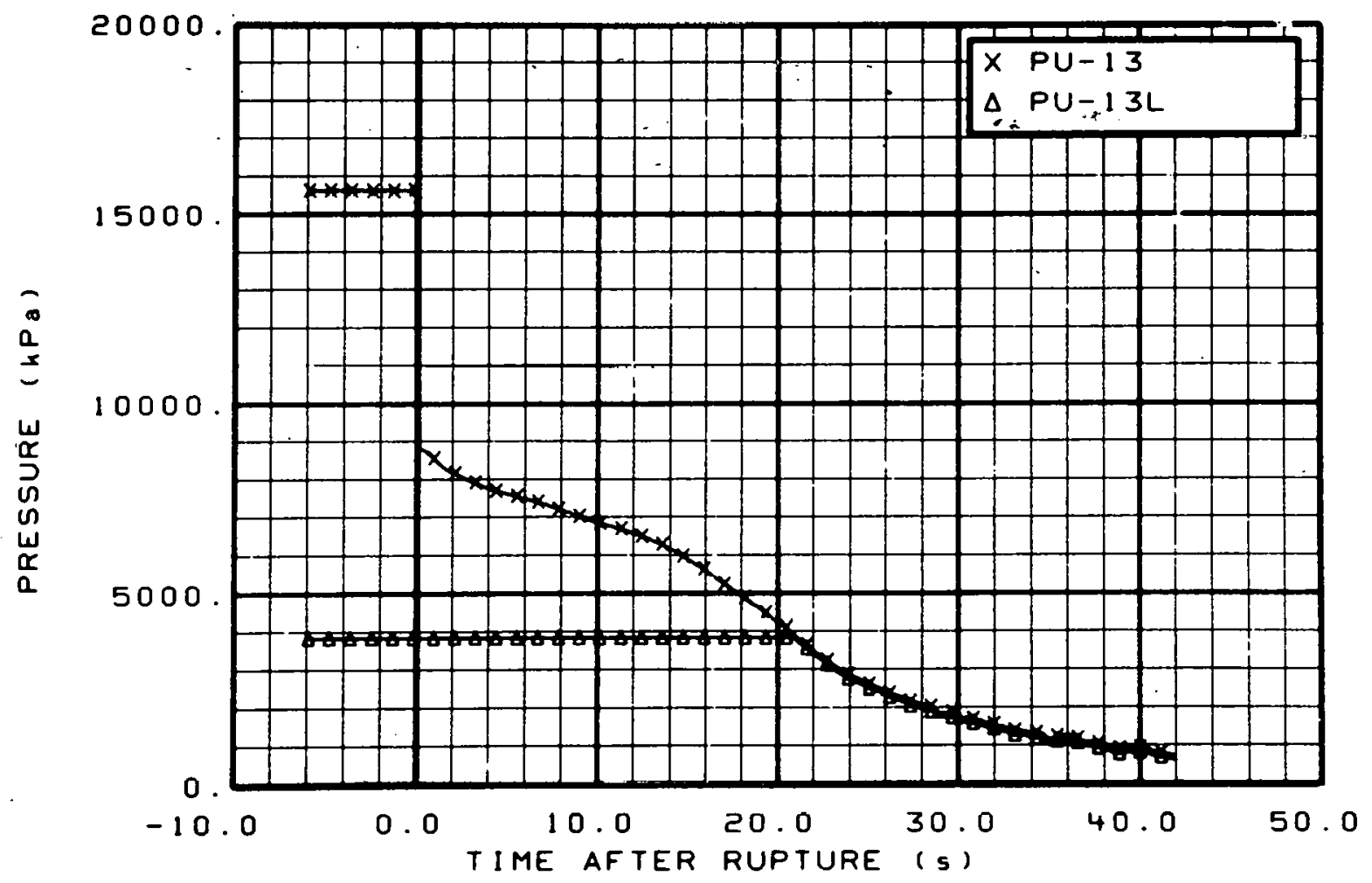

Fig. 132 Pressure in intact loop (PU-13 and PIJ-131.), from -6 to $42 \mathrm{~s}$. 


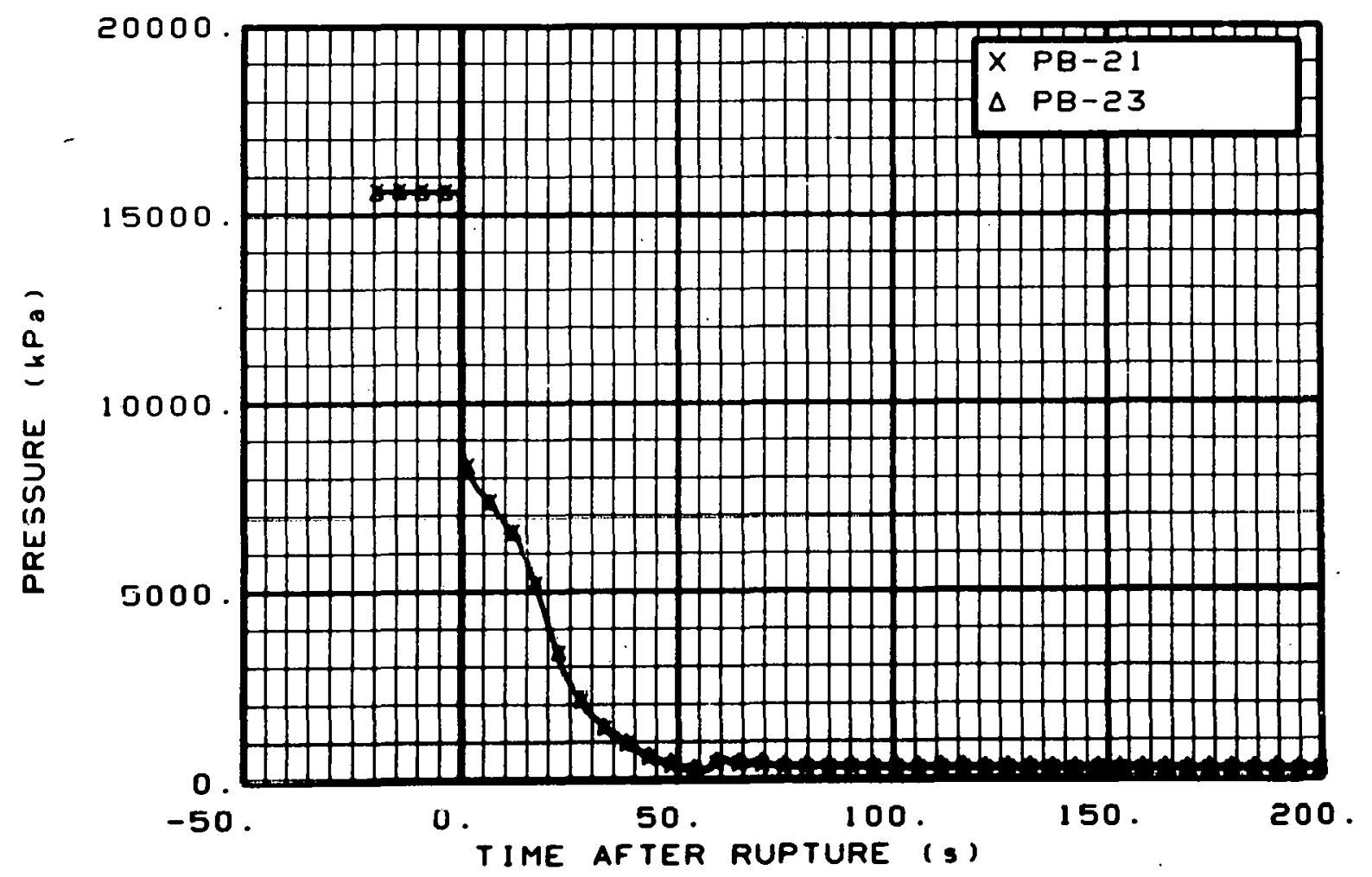

Fig. 133 Pressure in broken loop, vessel side (PB-21 and PB-23), from -20 to $200 \mathrm{~s}$.

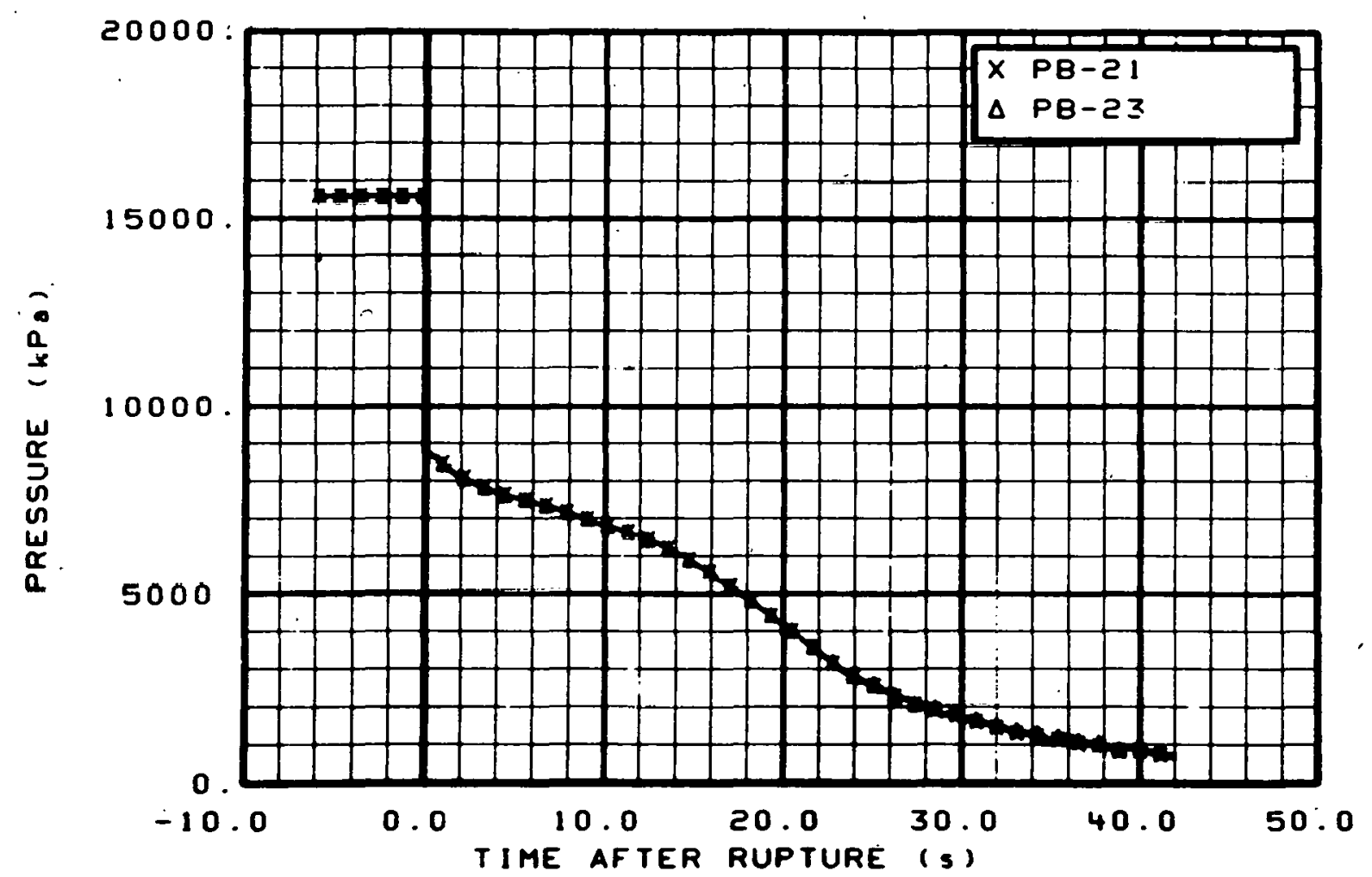

Fig. 134 Pressure in broken 10op, vessel side (PB-21 and PB-23), from -6 to $42 \mathrm{~s}$. 


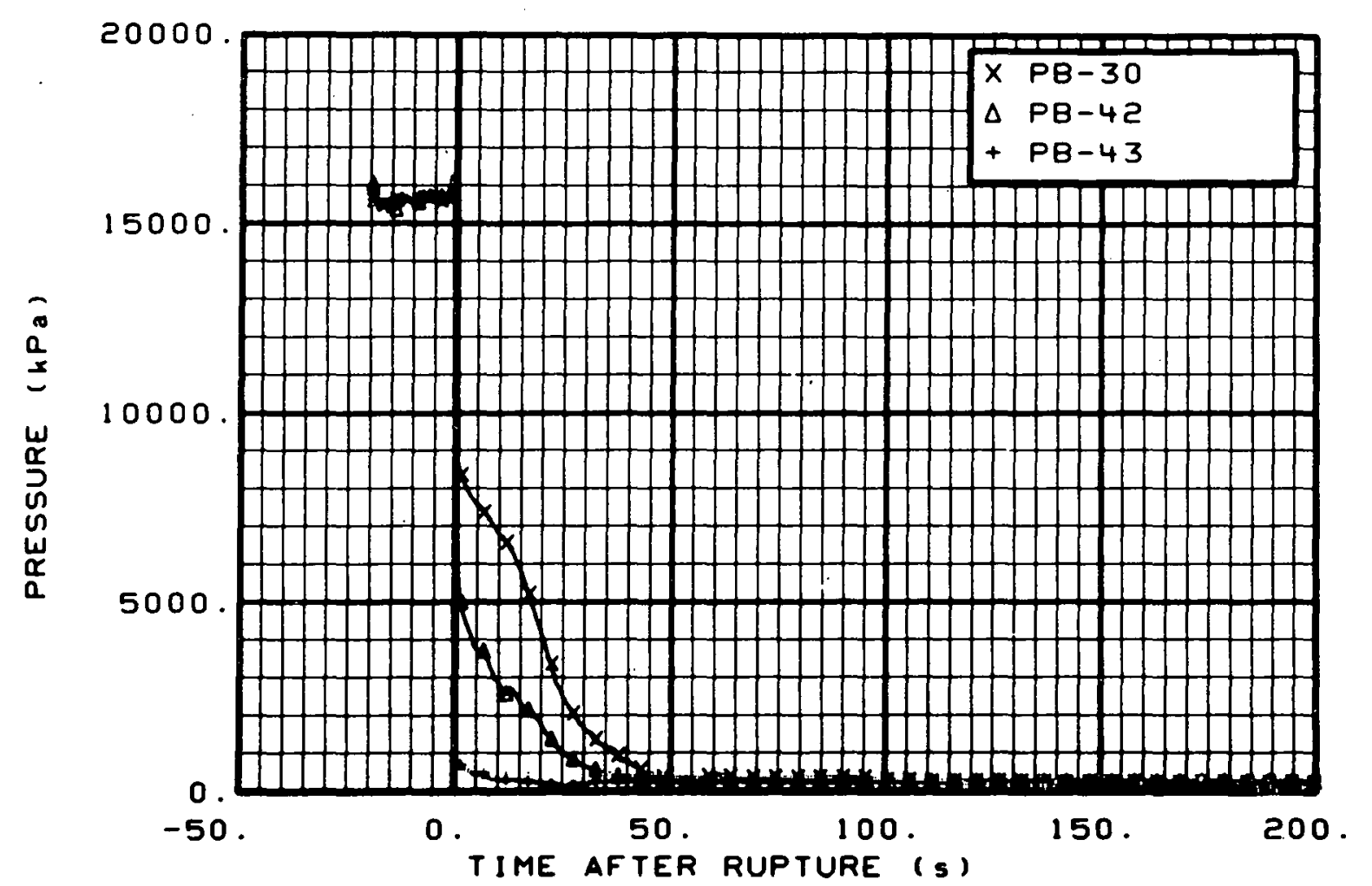

Fig. 135 Pressure in broken 10op, pump side (PB-30, PB-42, and $P B-43$ ), from -20 to $200 \mathrm{~s}$.

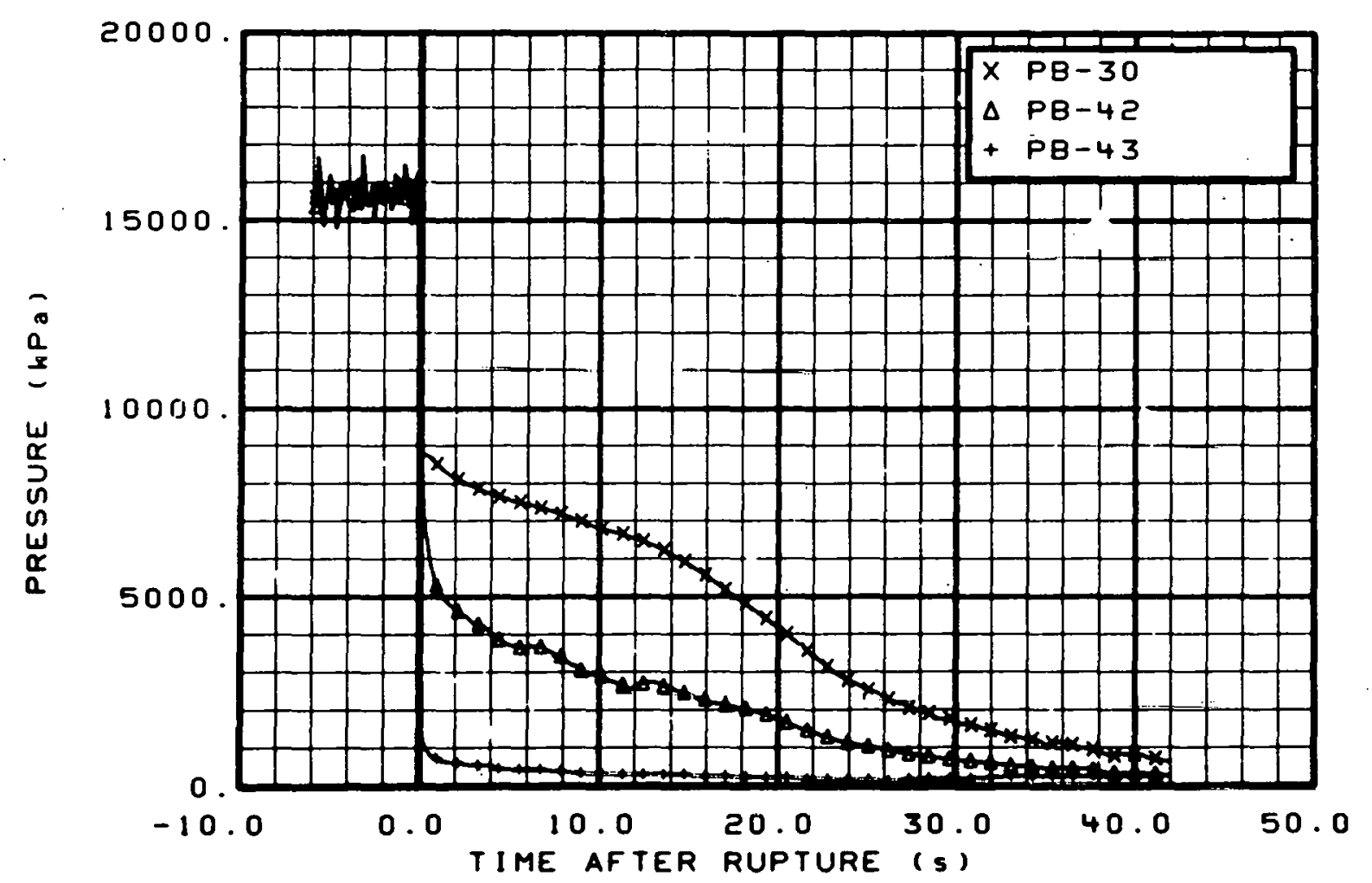

Fig. 136 Prcssure in broken loop, pump side (PB-30, PB-42, and PB-43), from -6 to $42 \mathrm{~s}$. 


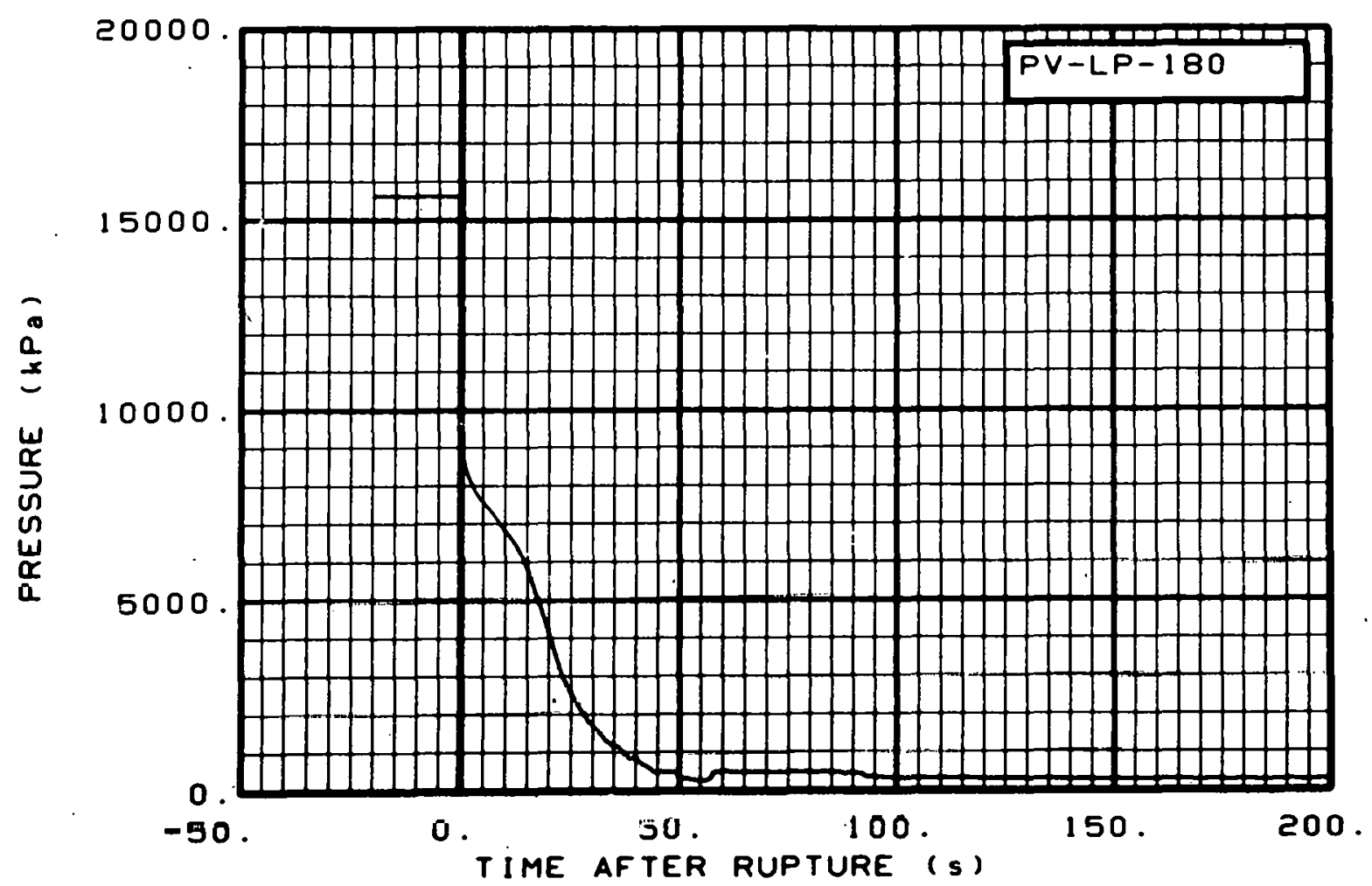

Fig. 137 Pressure in vessel (PV-LP-180), from -20 to $200 \mathrm{~s}$.

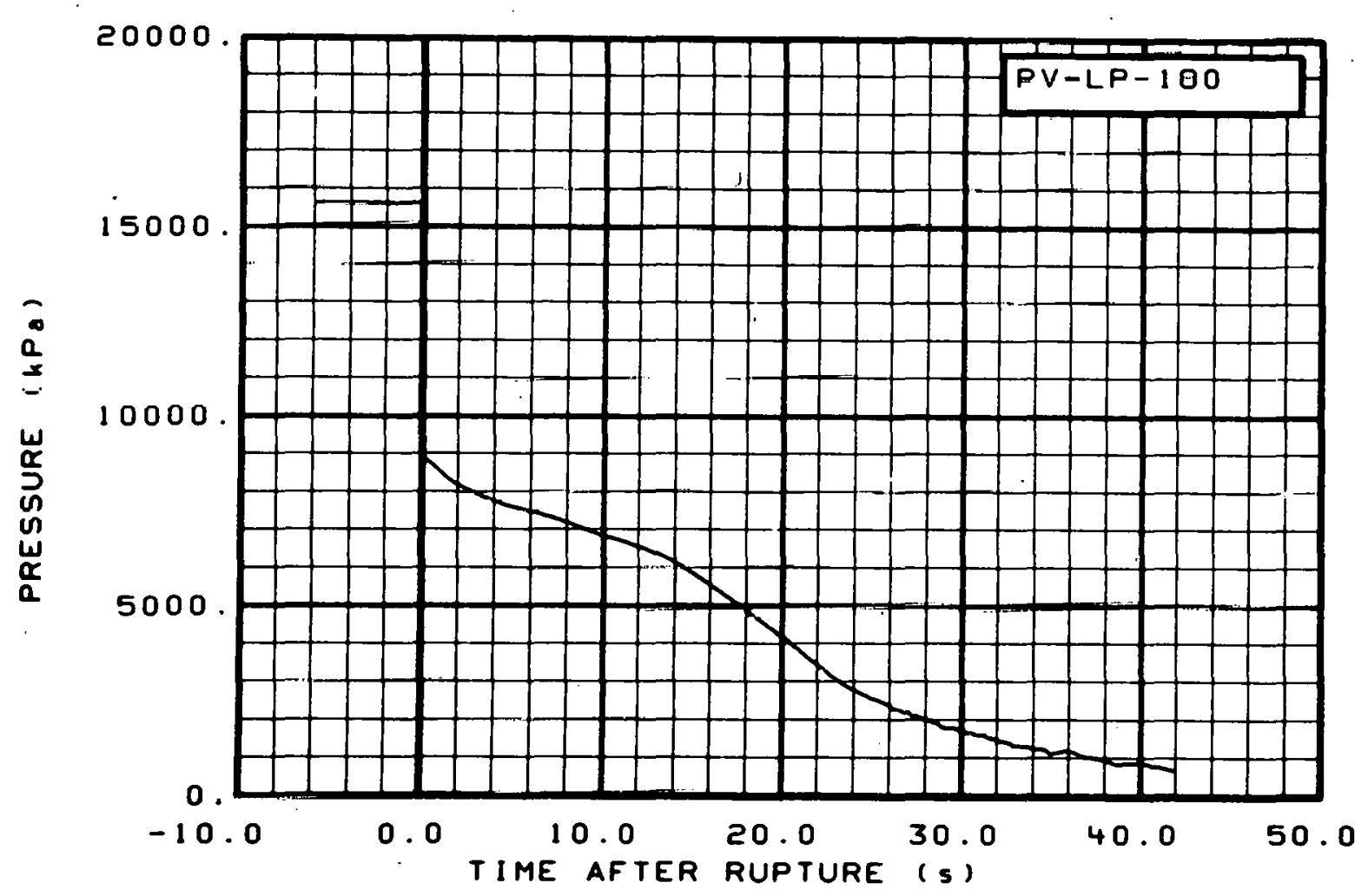

Fig. 138 Pressure in vessel (PV-LP-180), from -6 to $42 \mathrm{~s}$. 


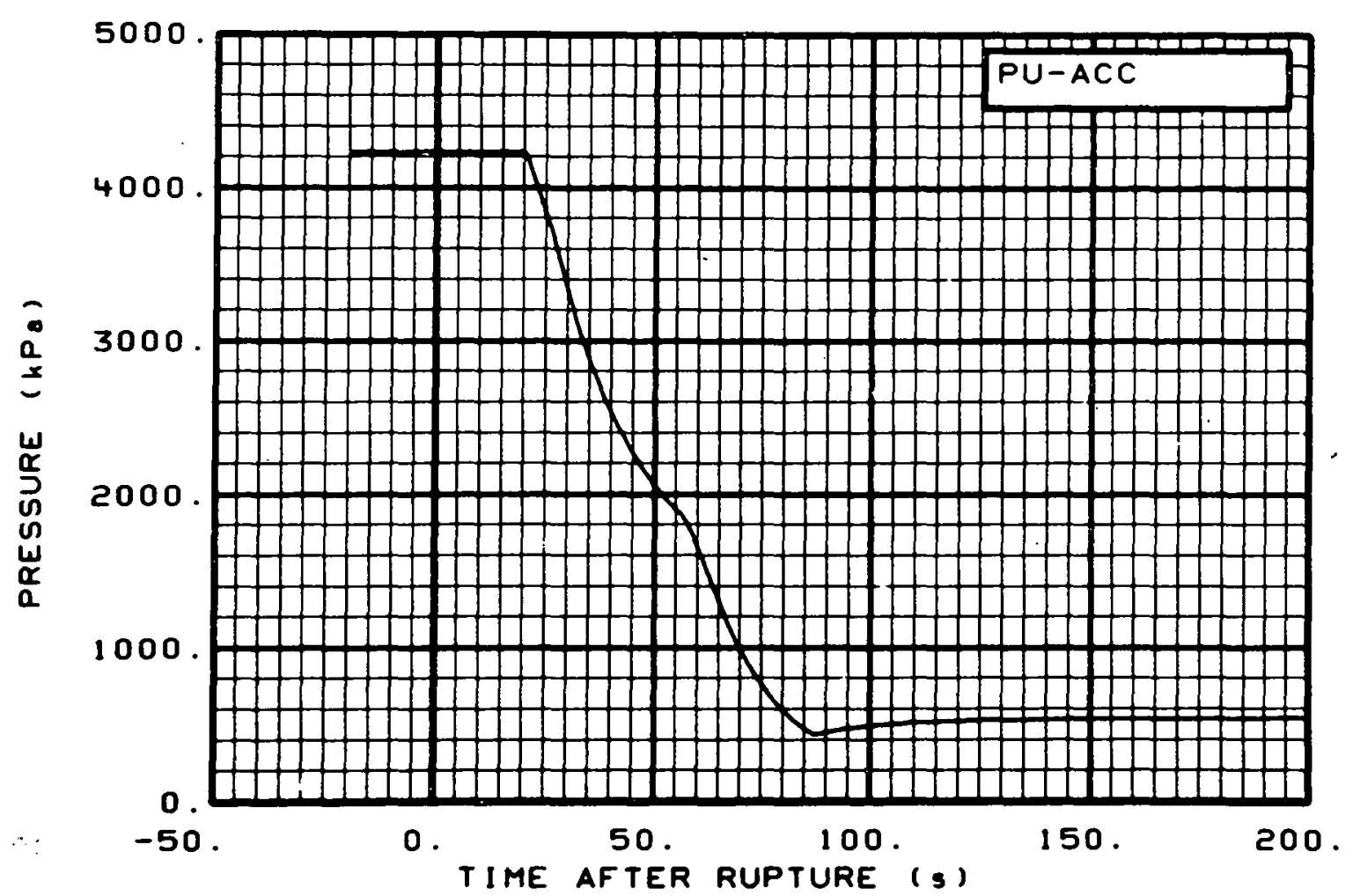

Fig. 139 Pressure in intact loop accumulator (PU-ACC), from -20 to $200 \mathrm{~s}$.

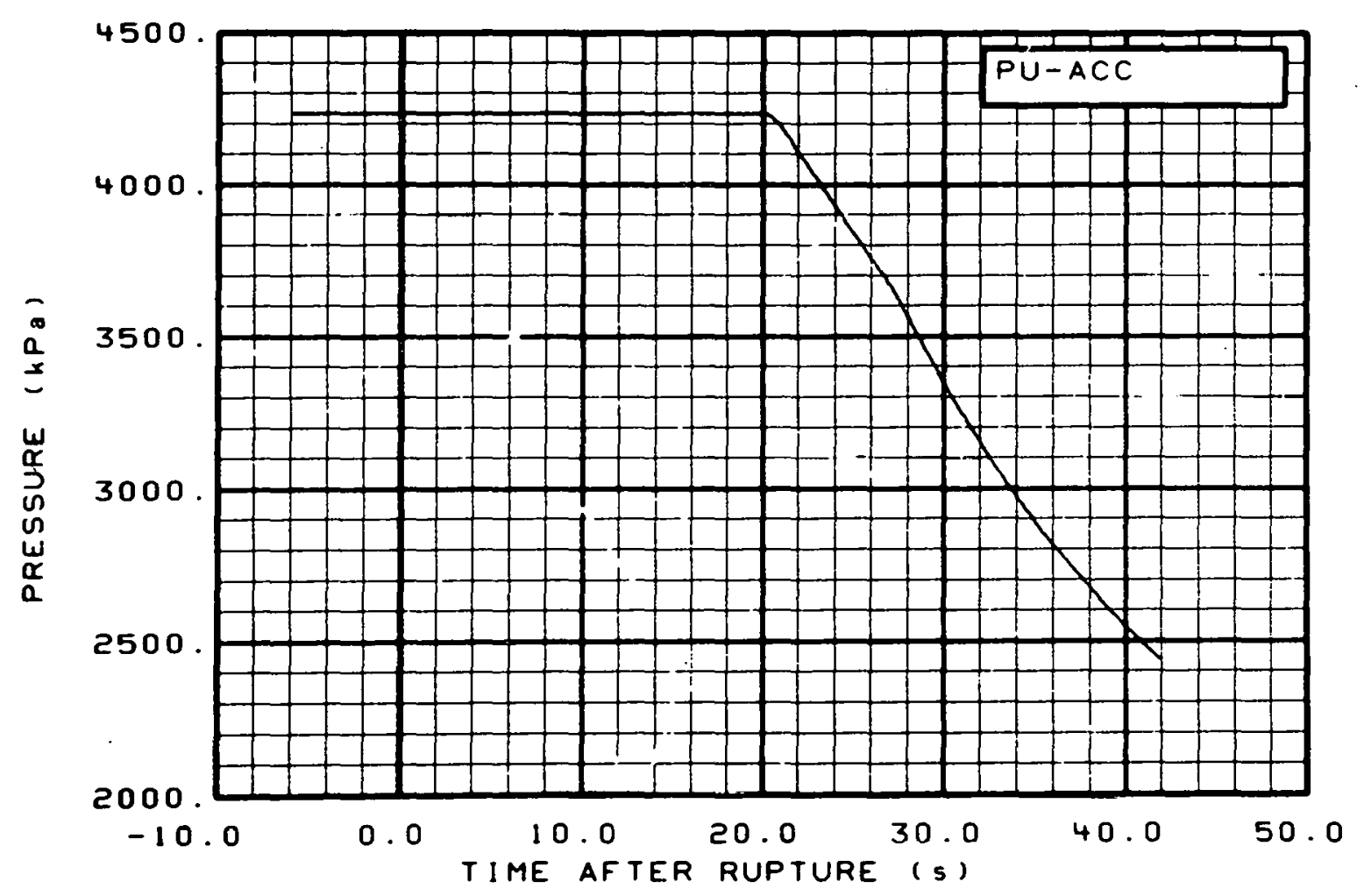

Fig. 140 Pressure in intact. loop accumulator (PU-ACC), from -6 to $42 \mathrm{~s}$. 


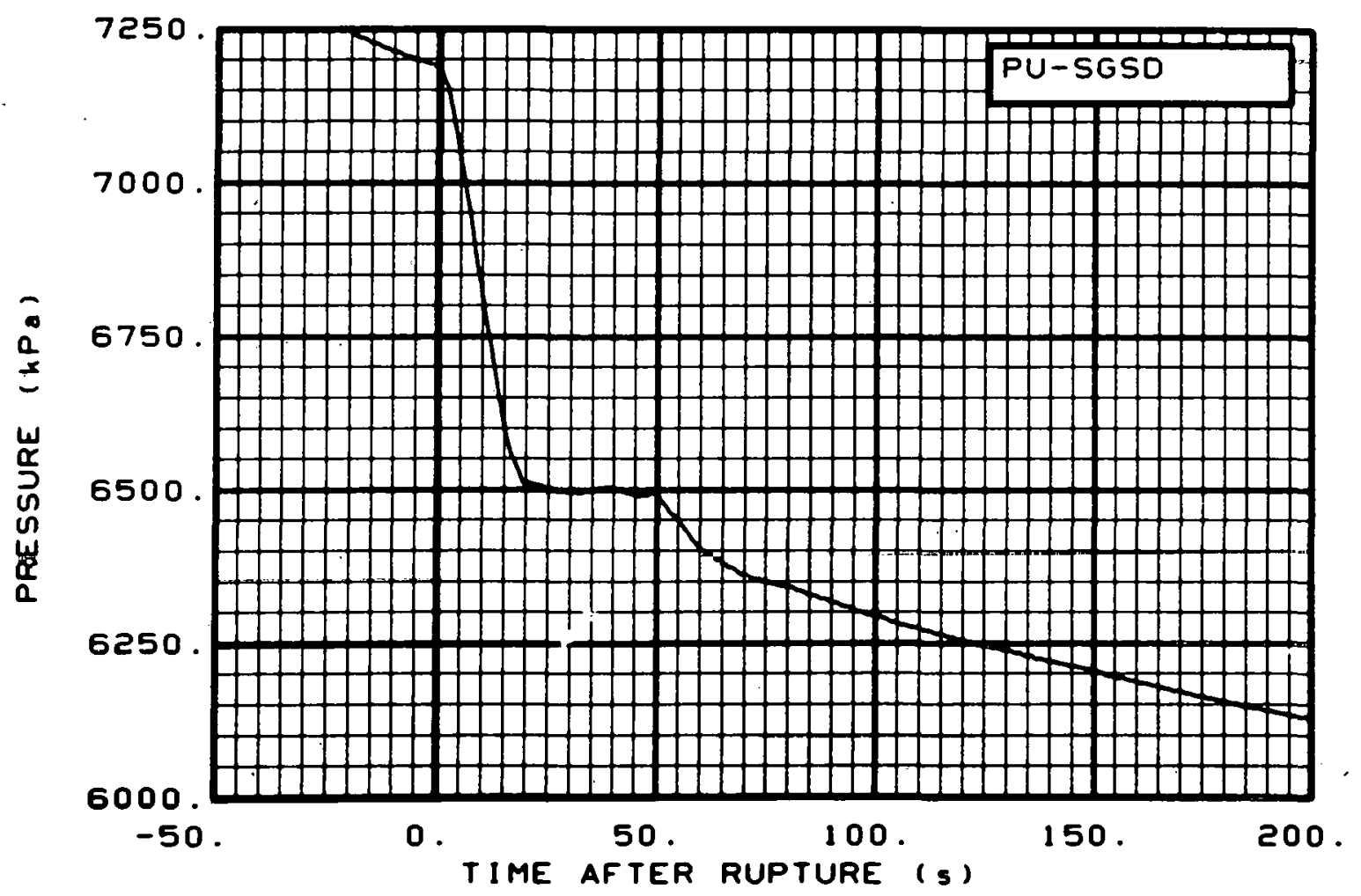

Fig. 141 Pressure in steam generator, secondary side (PU-SGSD), from -20 to $200 \mathrm{~s}$.

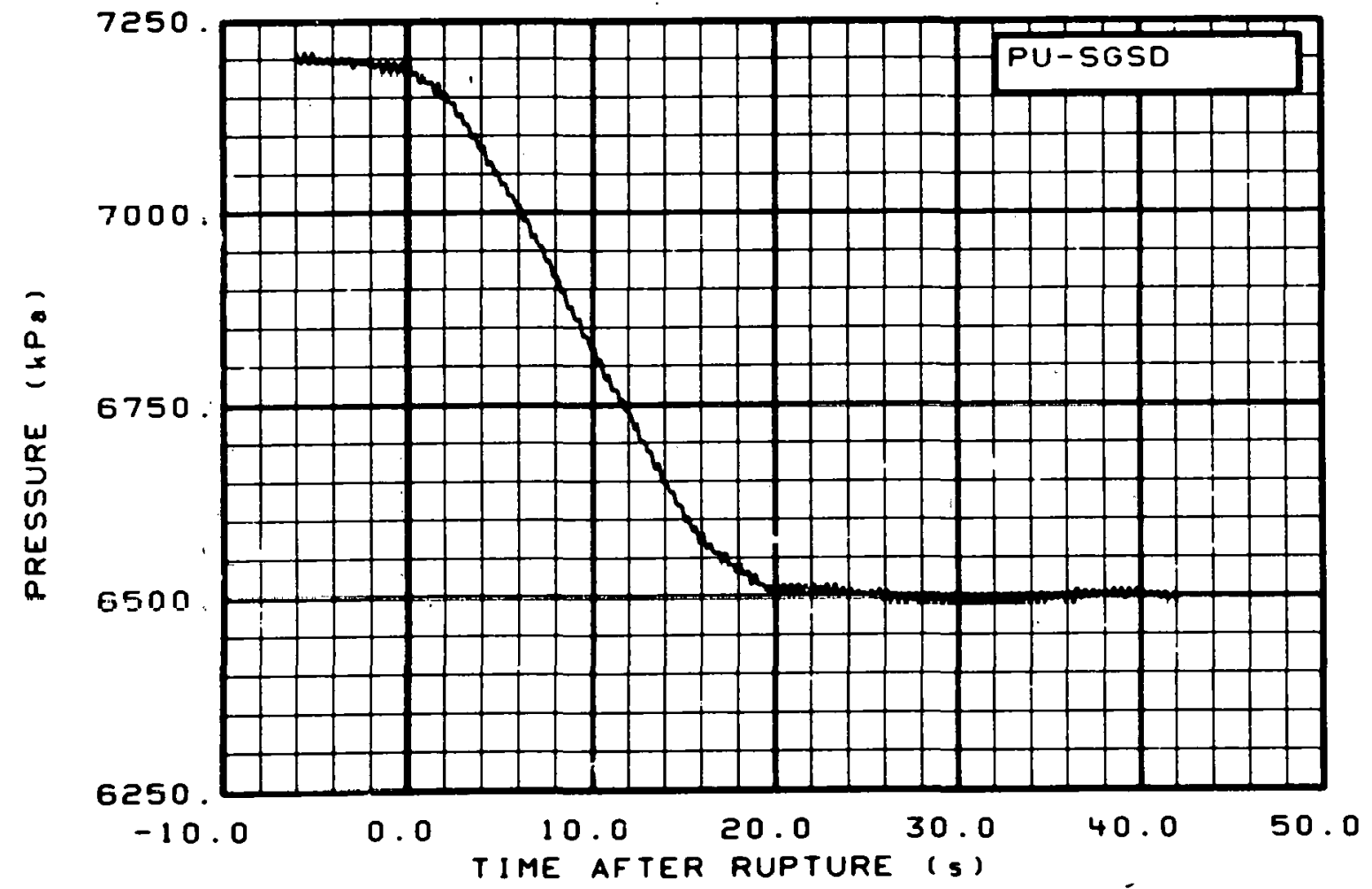

Fig. 142 Pressure in steam generator, secondary side (PU-SGSD), from -6 to $42 \mathrm{~s}$. 


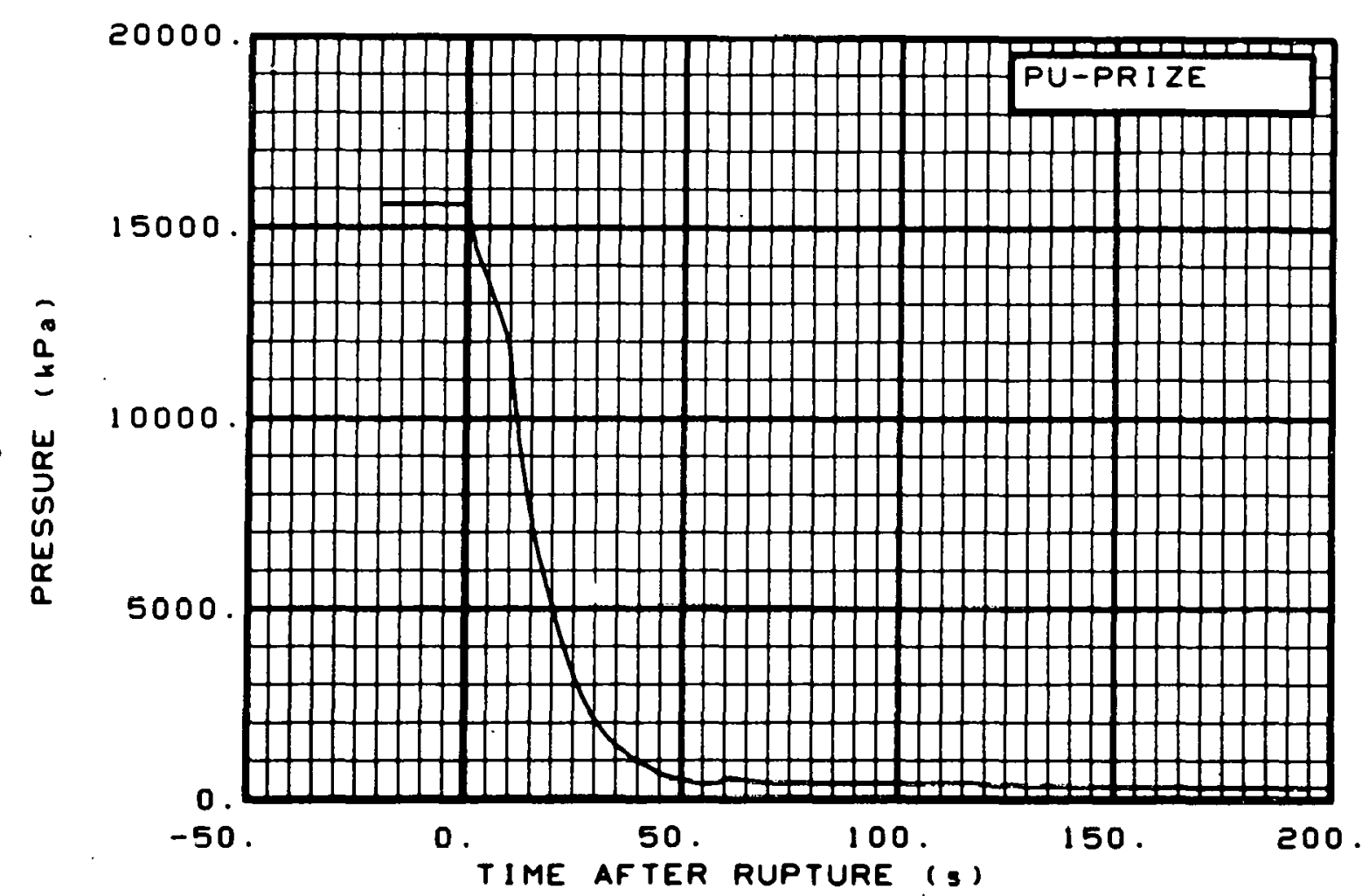

Fig. 143 Pressure in pressurizer (PU-PRIZE), from -20 to $200 \mathrm{~s}$.

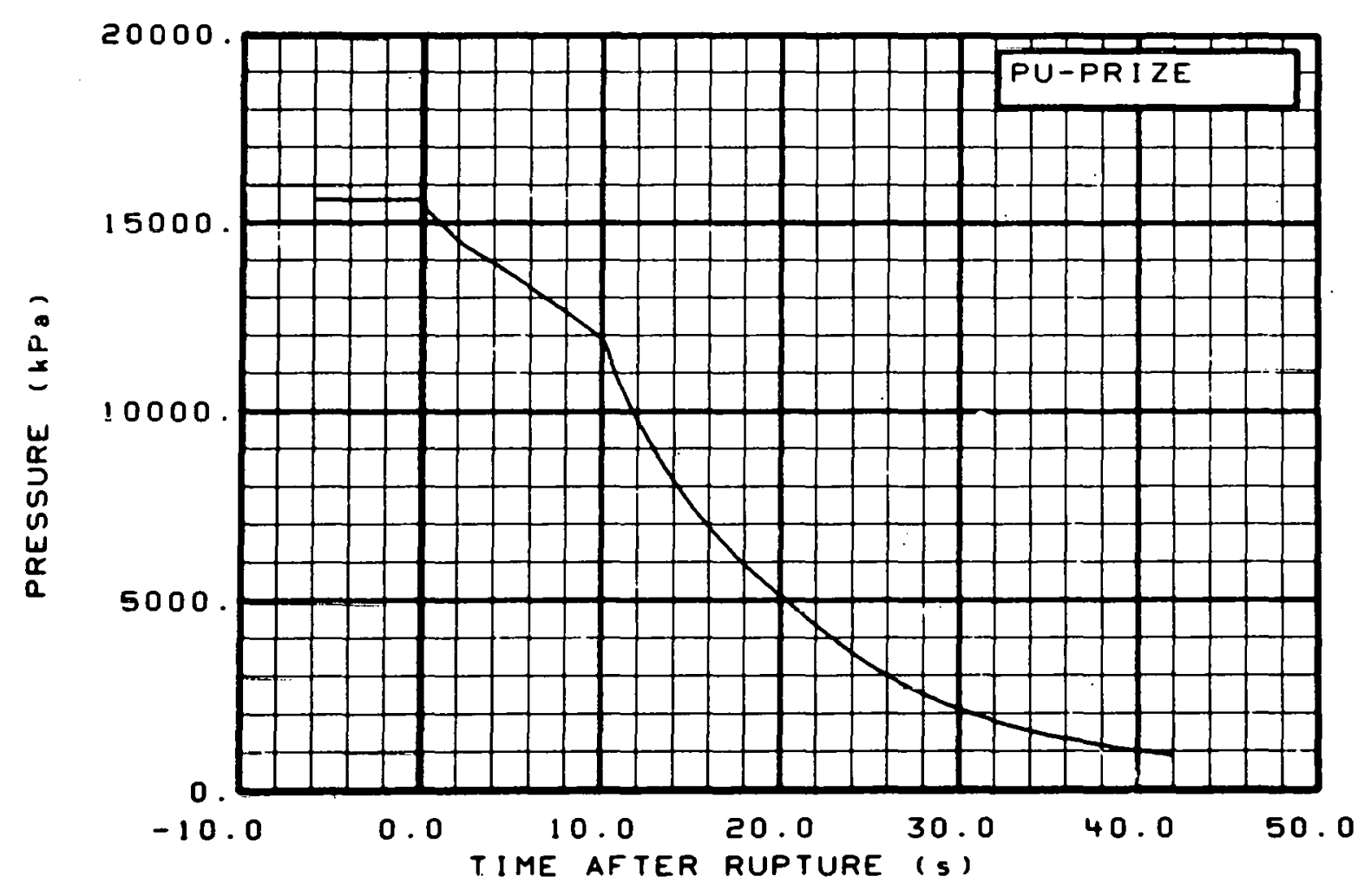

rig. 144 Pressure in pressurizer: (PU-PRIZL), from .6 to $42 \mathrm{~s}$. 


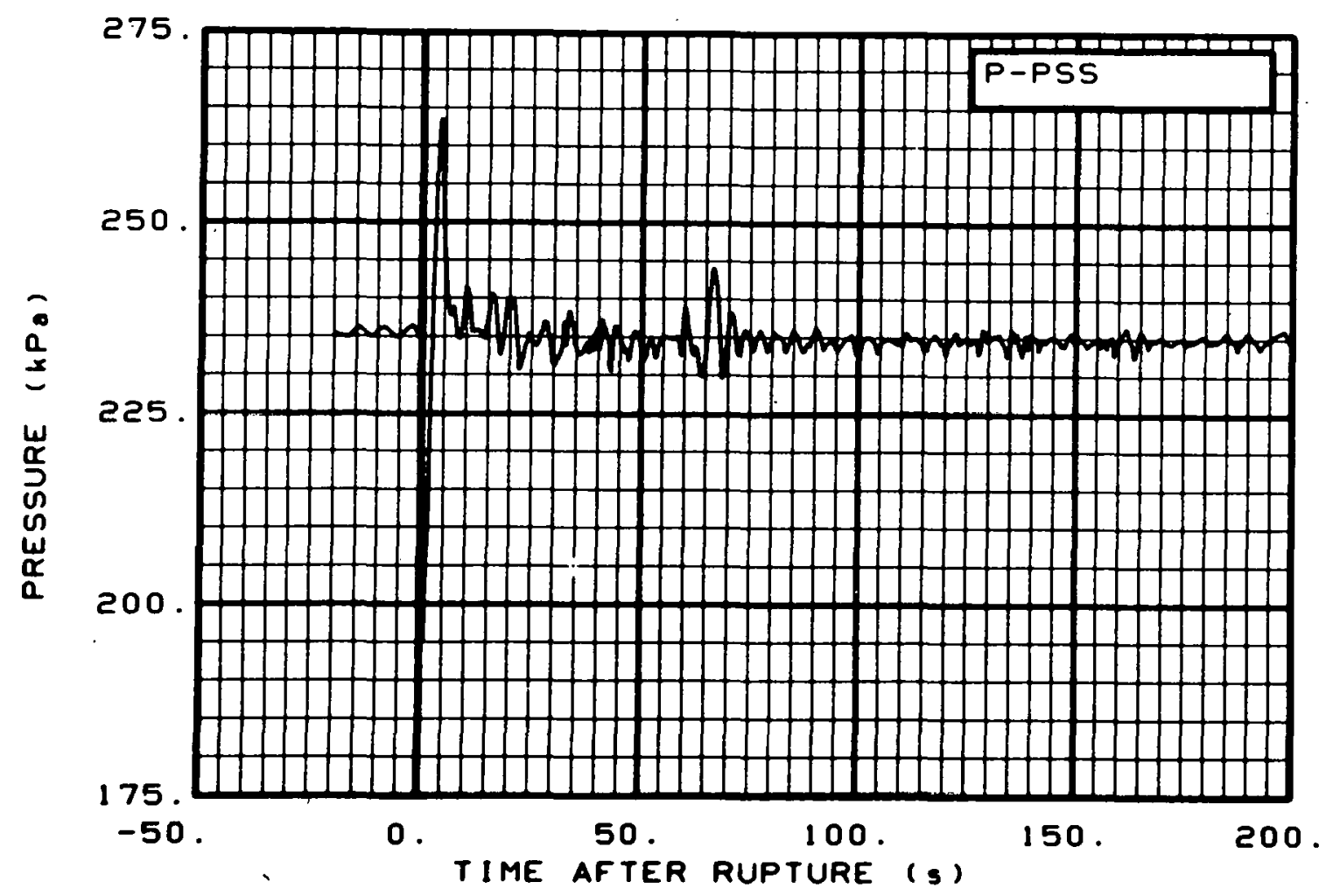

Fig. 145 Pressure in pressure suppression tank (P-PSS), from -20 to $200 \mathrm{~s}$.

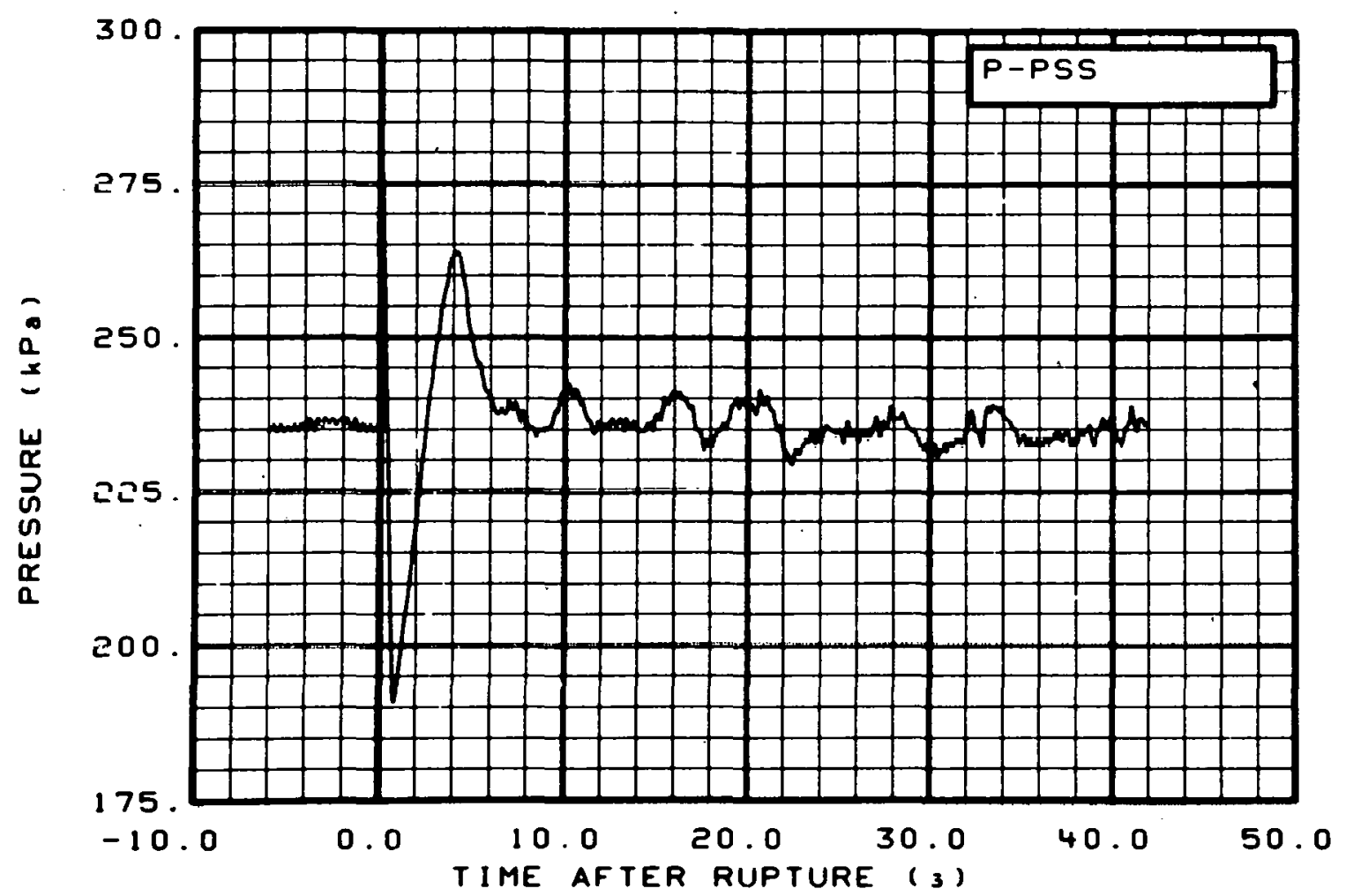

Fig. 146 Pressure in pressure suppression tank (P-PSS), from -6 to $42 \mathrm{~s}$. 


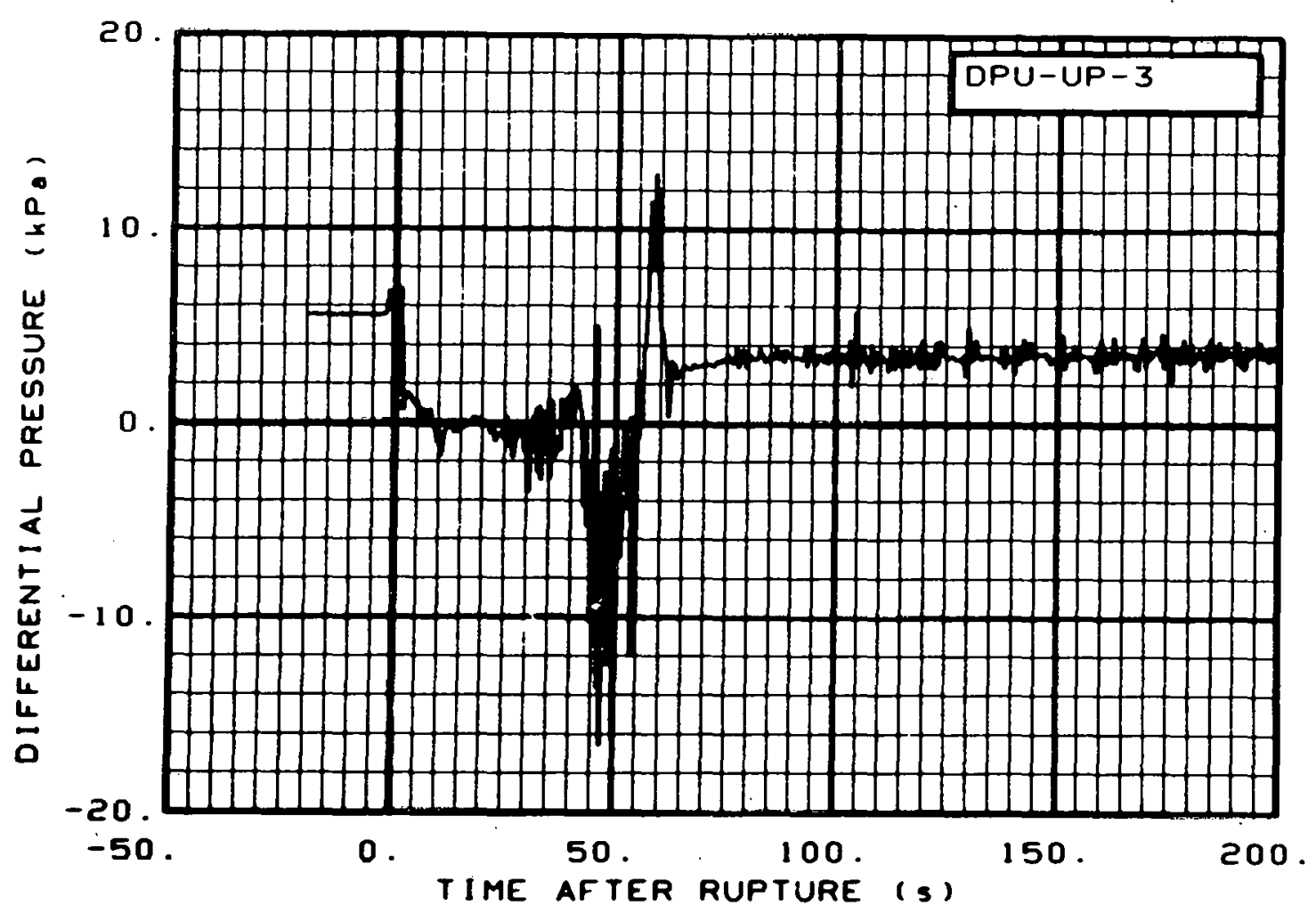

Fig. 147 Differential pressure in intact loop (DPU-UP-3), from -20 to $200 \mathrm{~s}$.

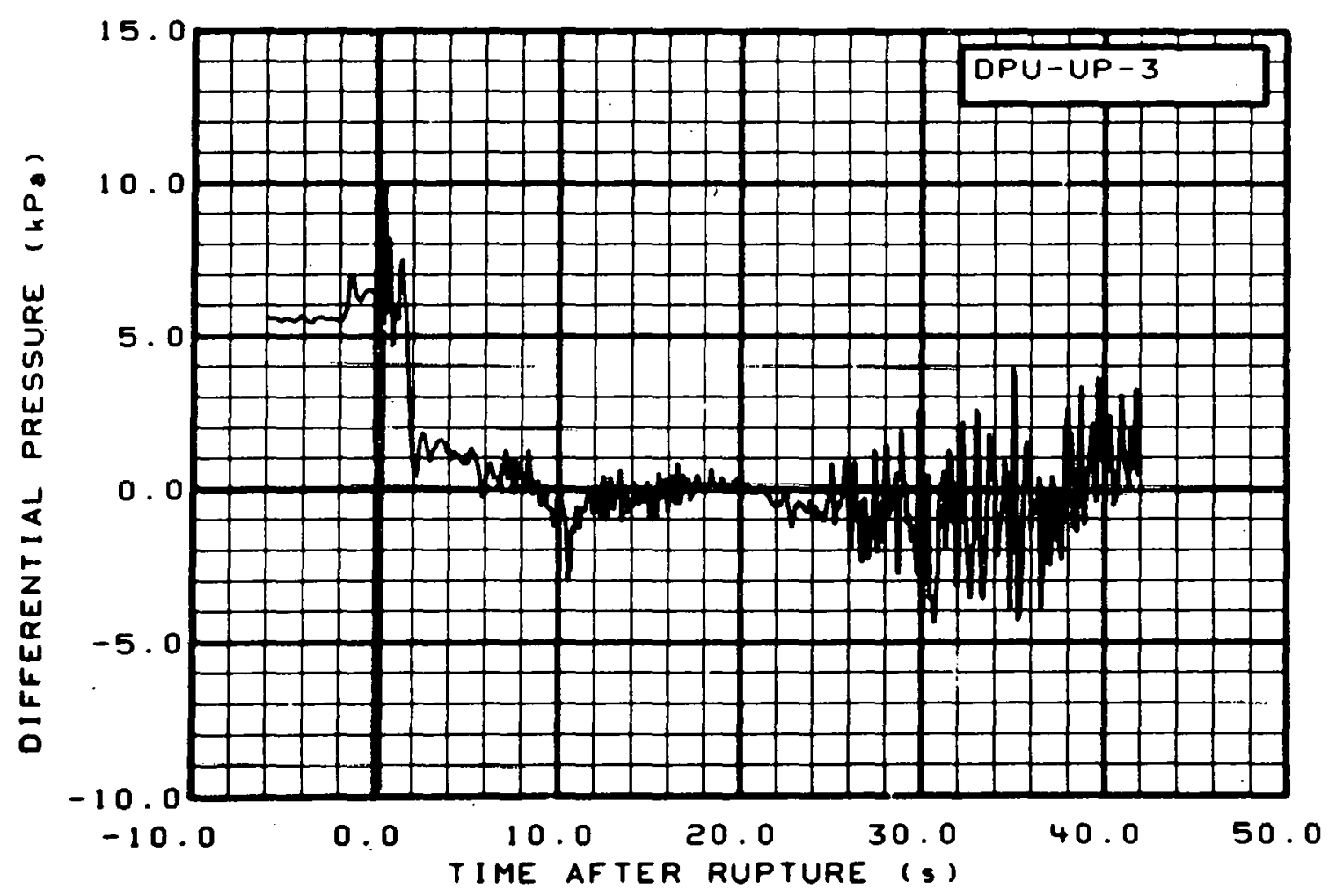

Fig. 148 Uifferentlal pressure in intact loop (DPU-UP-3), from -6 to $42 \mathrm{~s}$. 


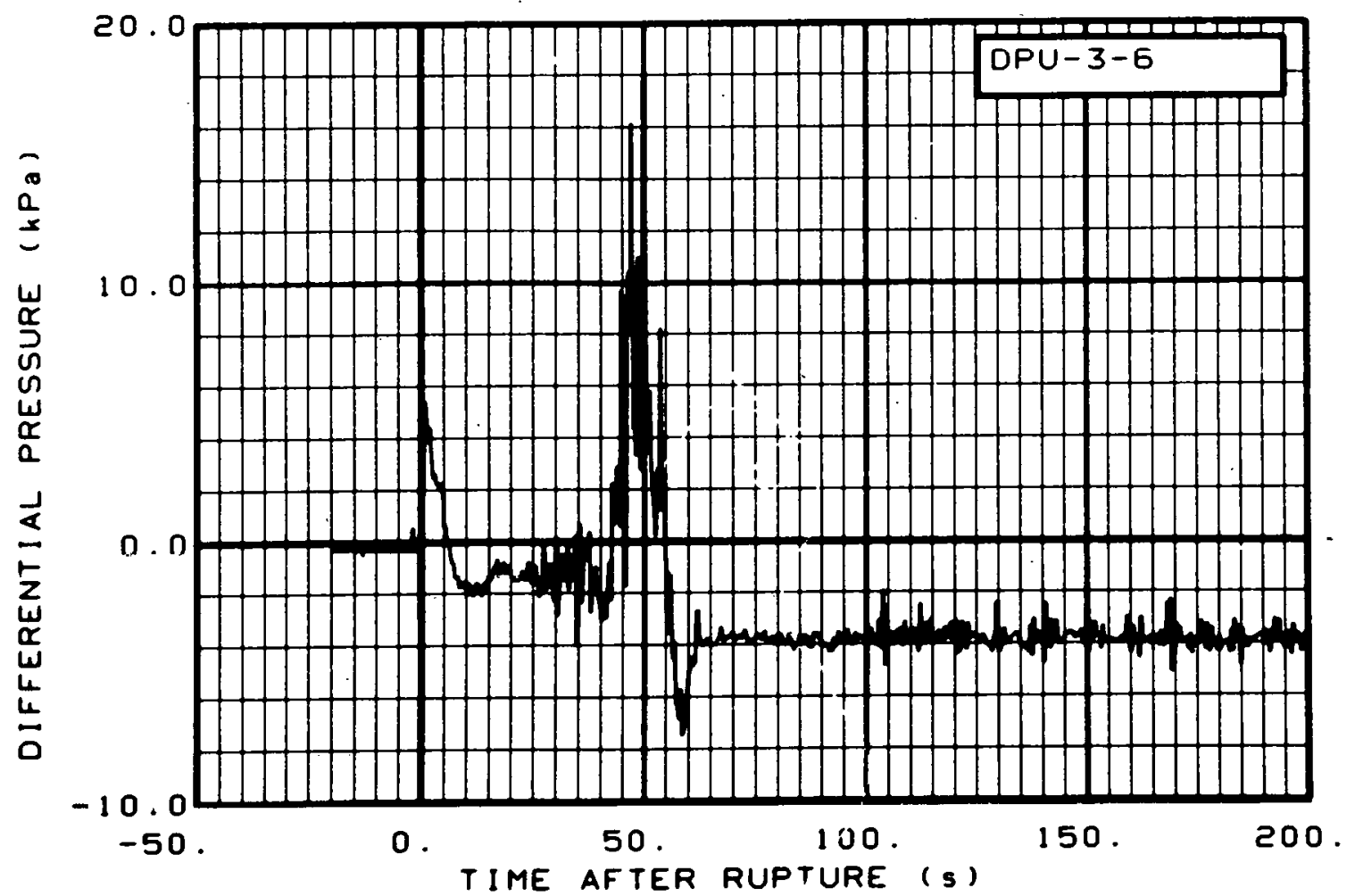

Fig. 149 Differential pressure in intact loop (DPU-3-6), from -20 to $200 \mathrm{~s}$.

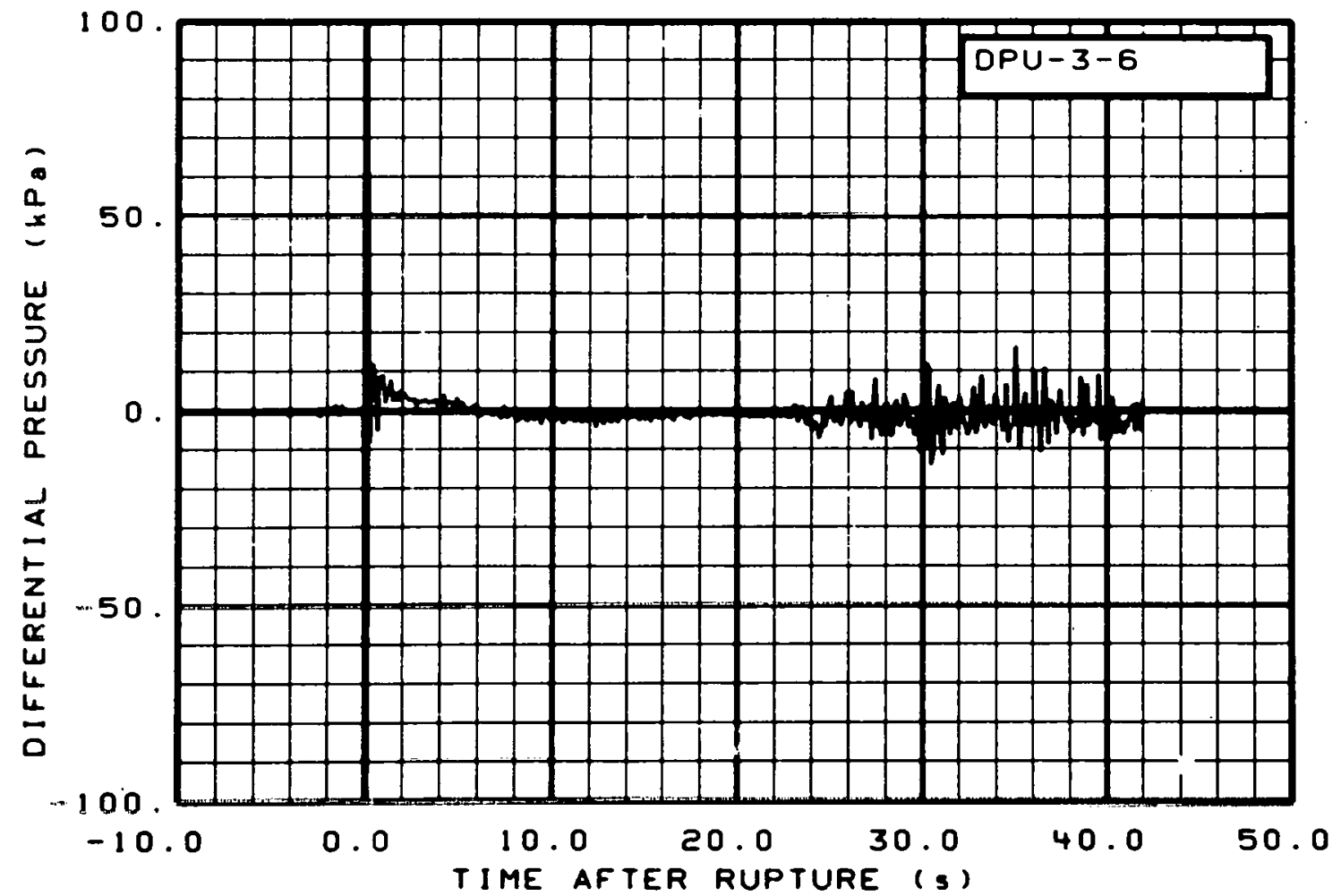

Fig. 150 Differential pressure in intact loop (DPU-3-6), from -6 to $42 \mathrm{~s}$. 


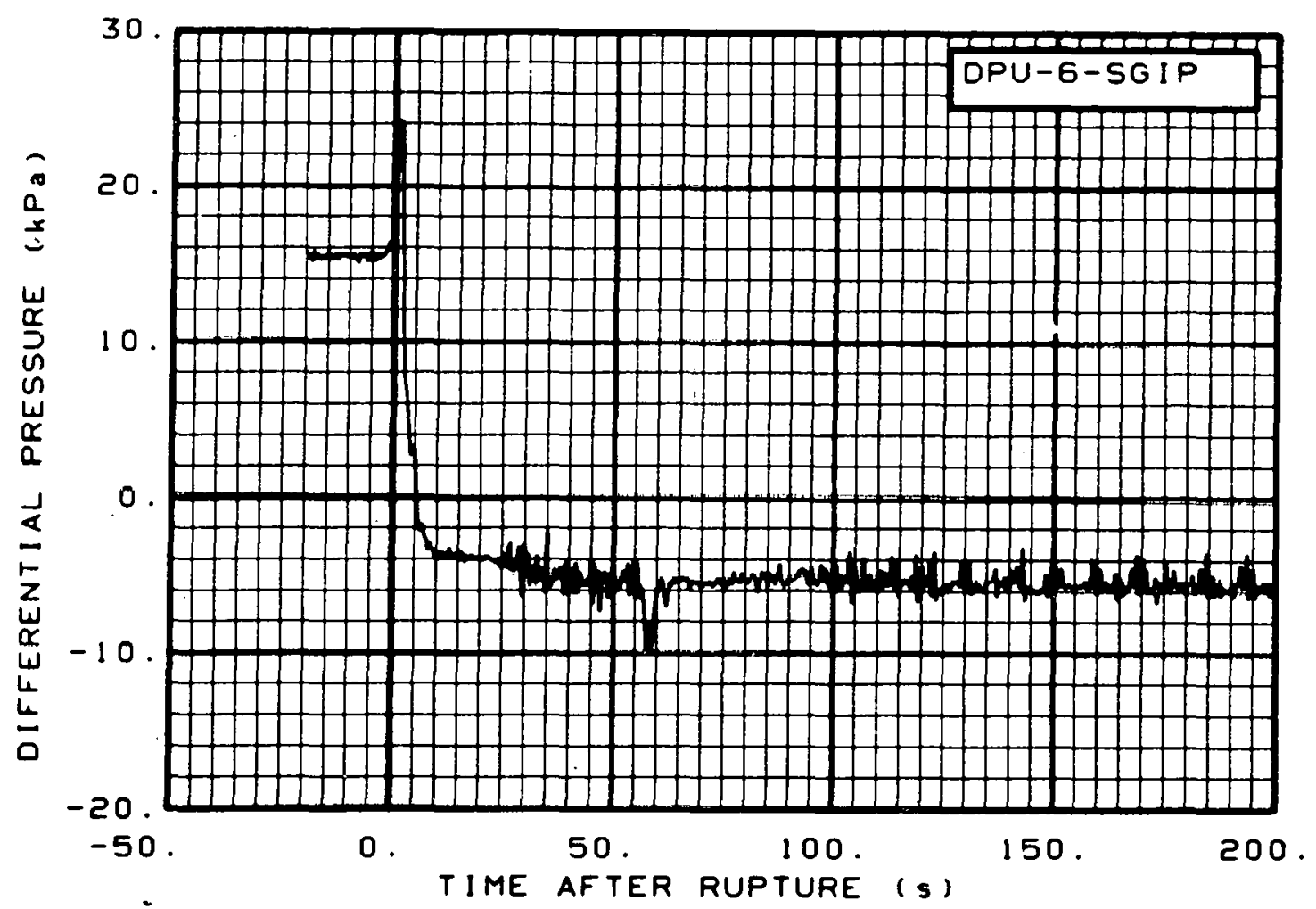

Fig. 151 Differential pressure in intact loop (DPU-6-SGIP), from -20 to $200 \mathrm{~s}$.

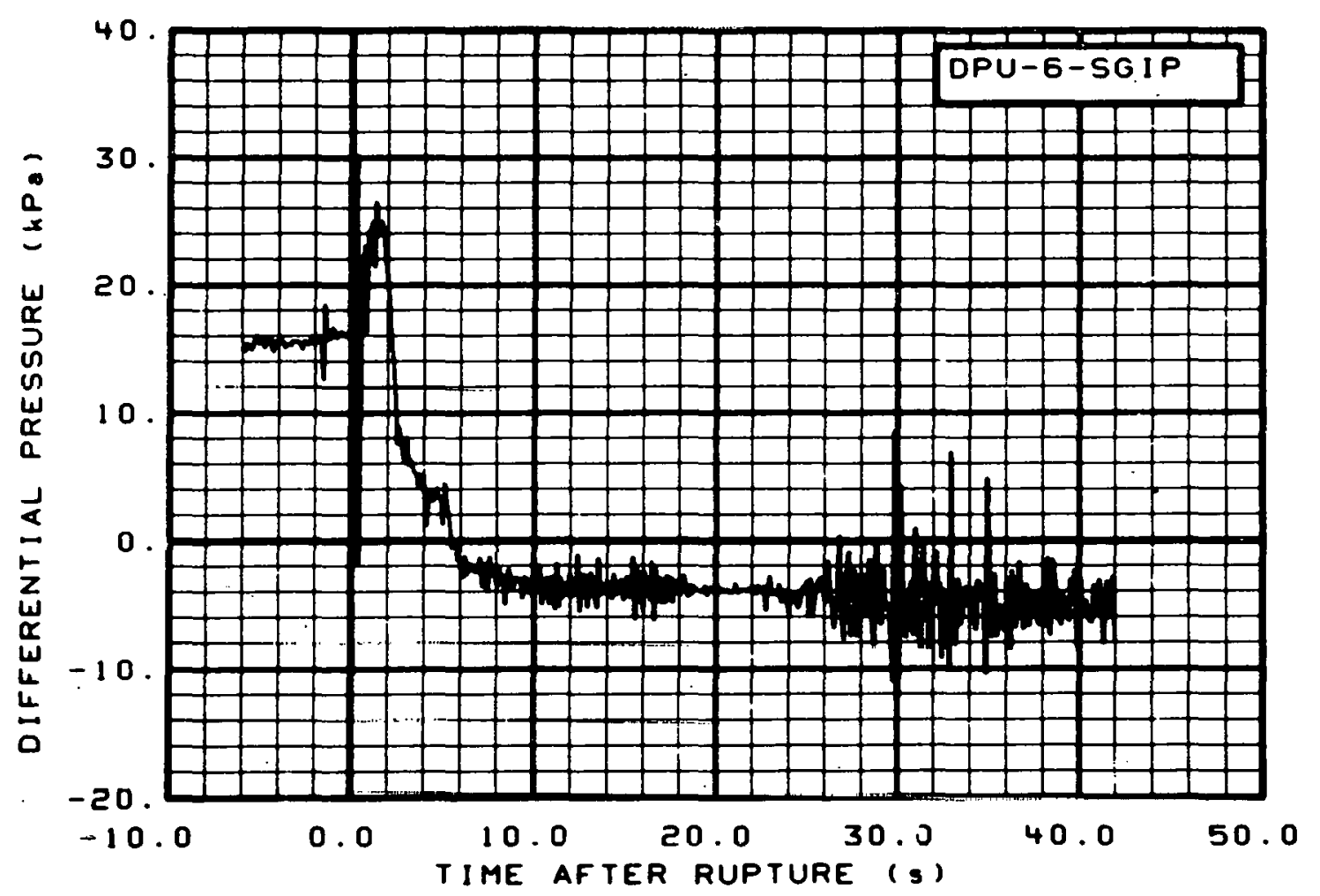

Fig. 152 Differential pressure in intact loop (DPU-6-SGIP), from -6 to $42 \mathrm{~s}$. 


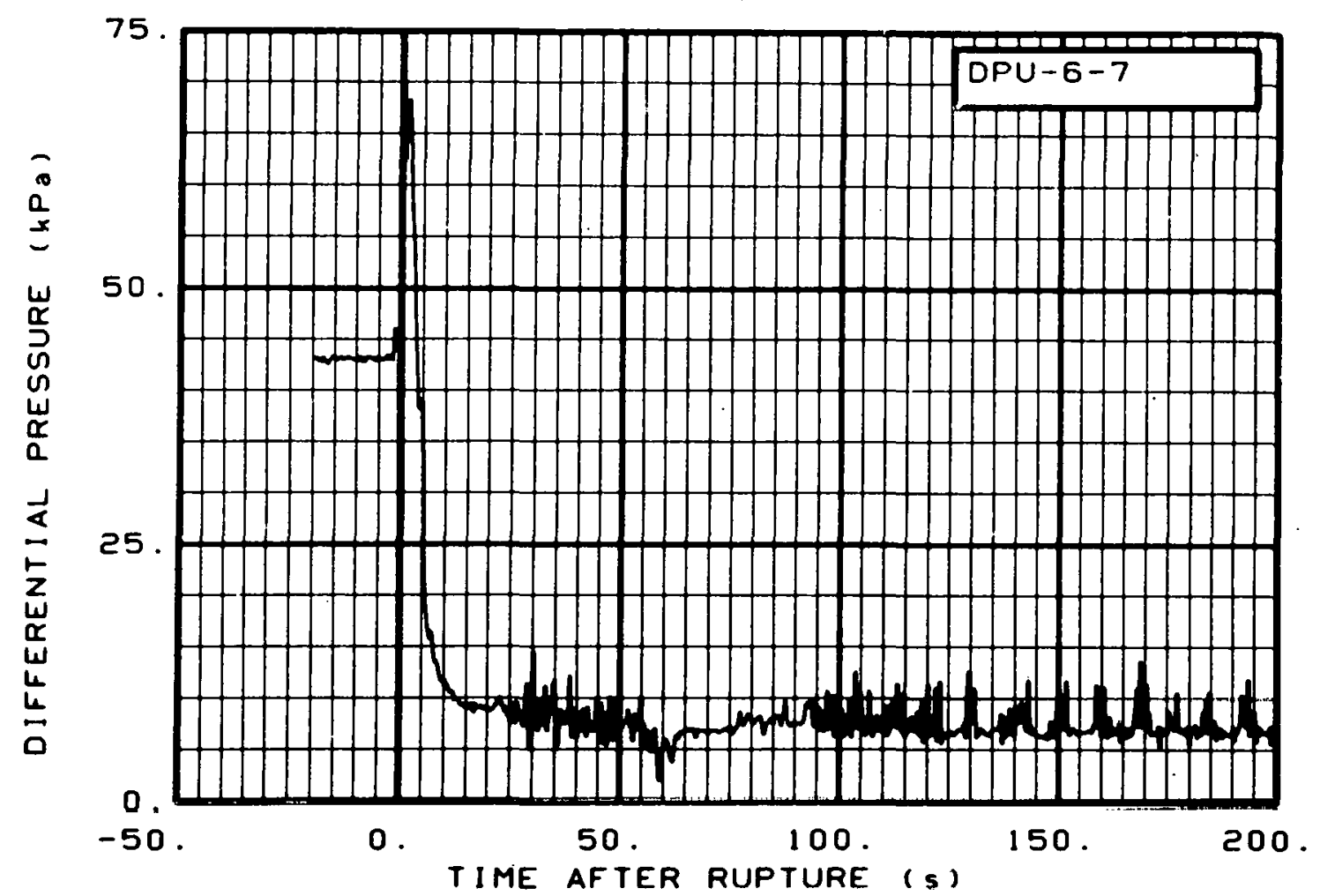

Fig. 153 Differential pressure in intact loop (DPU-6-7), from -20 to $200 \mathrm{~s}$.

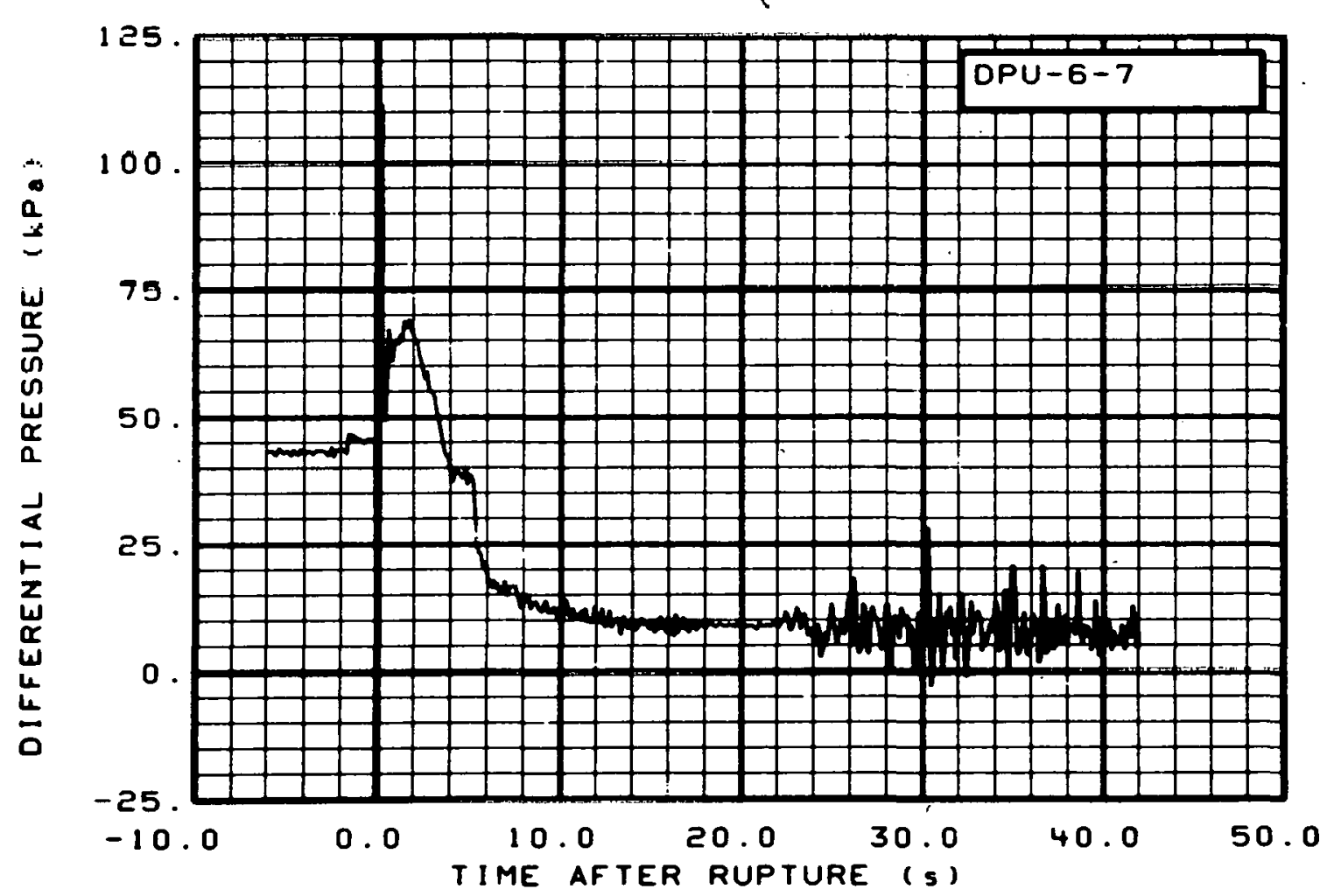

Fig. 154 Differential pressure in intact loop (DPU-6-7), from -6 to $42 \mathrm{~s}$. 


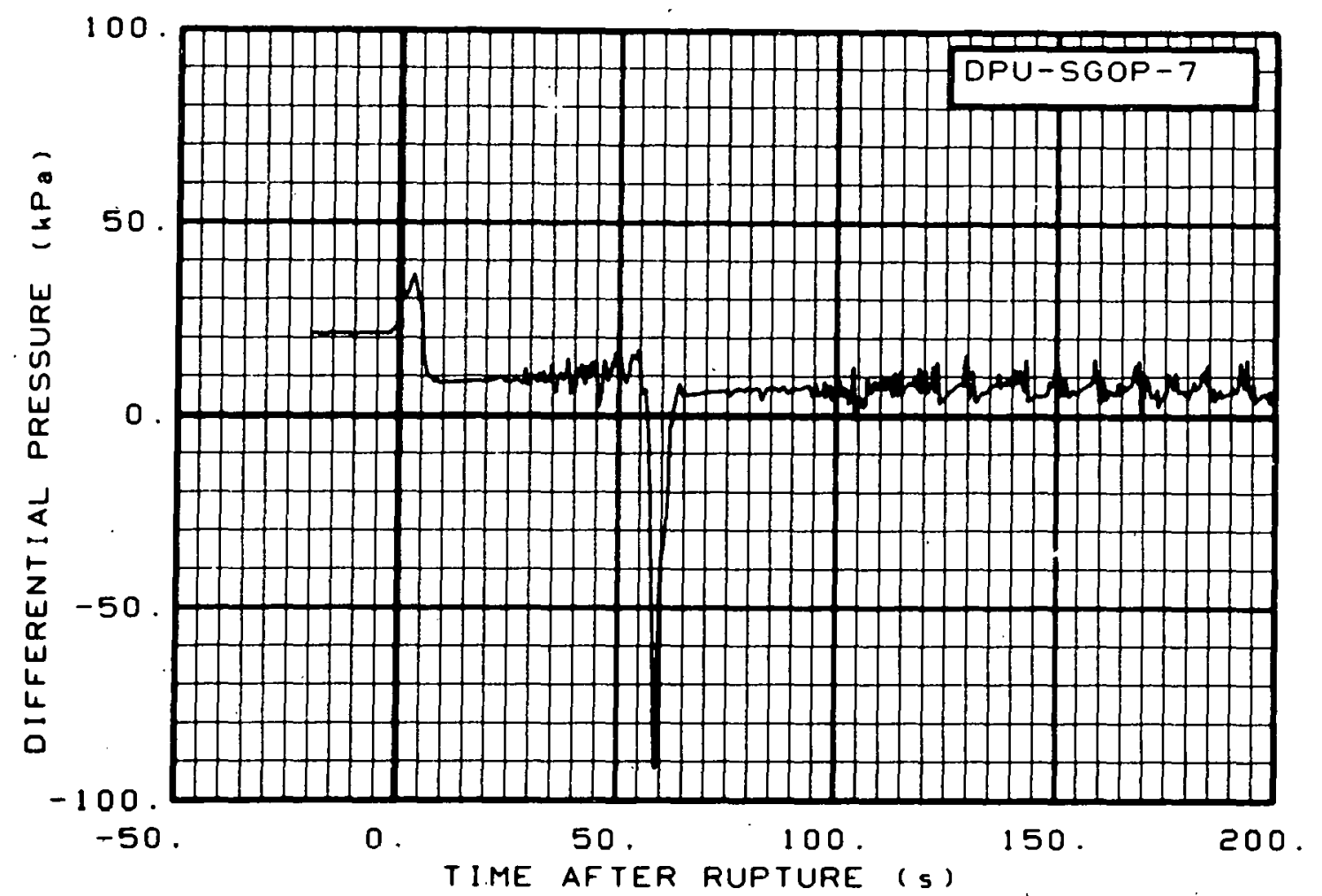

Fig. 155 Differential pressure in intact loop (DPU-SGOP-7), from -20 to $200 \mathrm{~s}$.

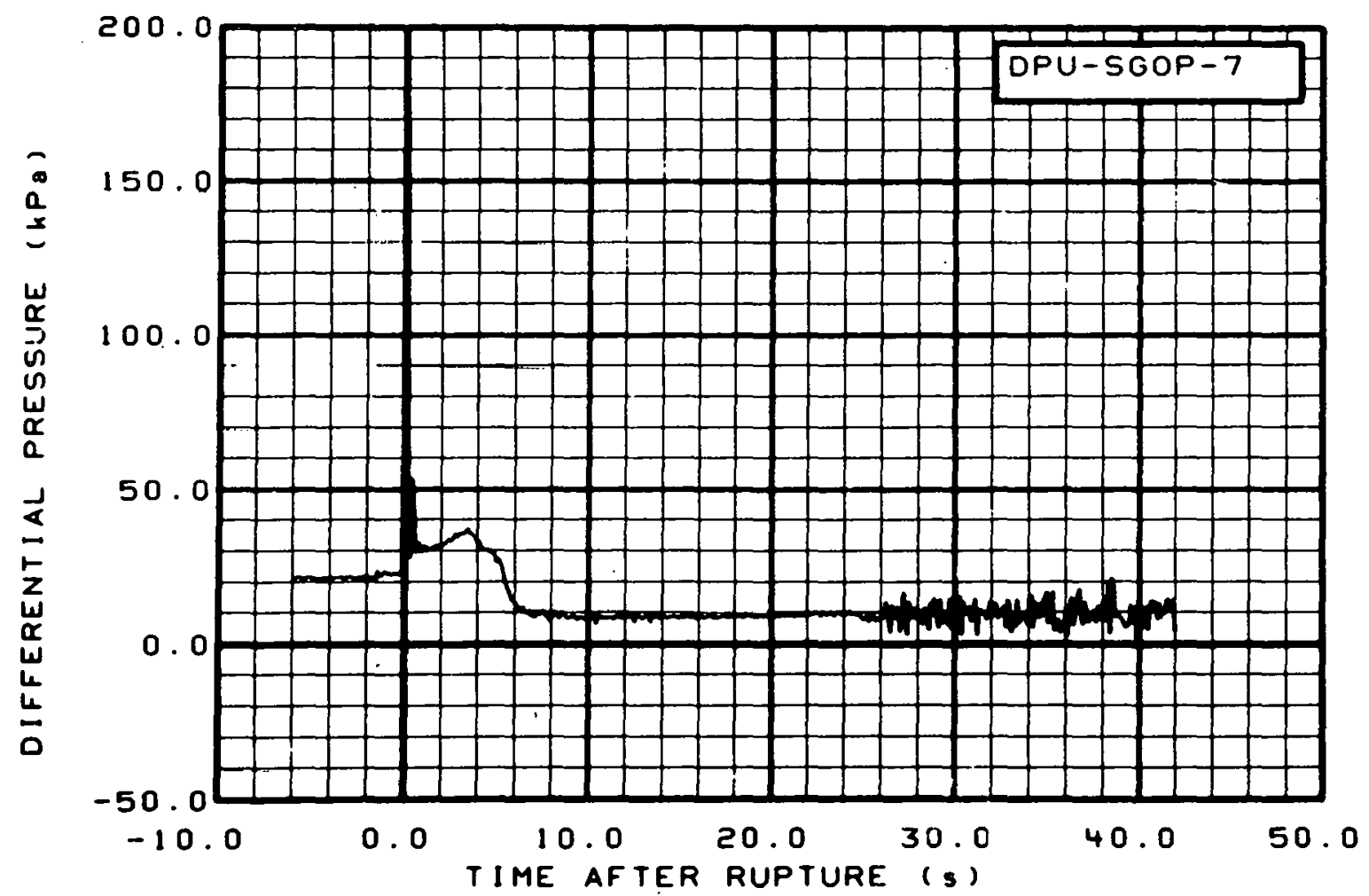

Fig. 156 Differential pressure in intact loop (DPU-SGOP-7), from -6 to $42 \mathrm{~s}$. 


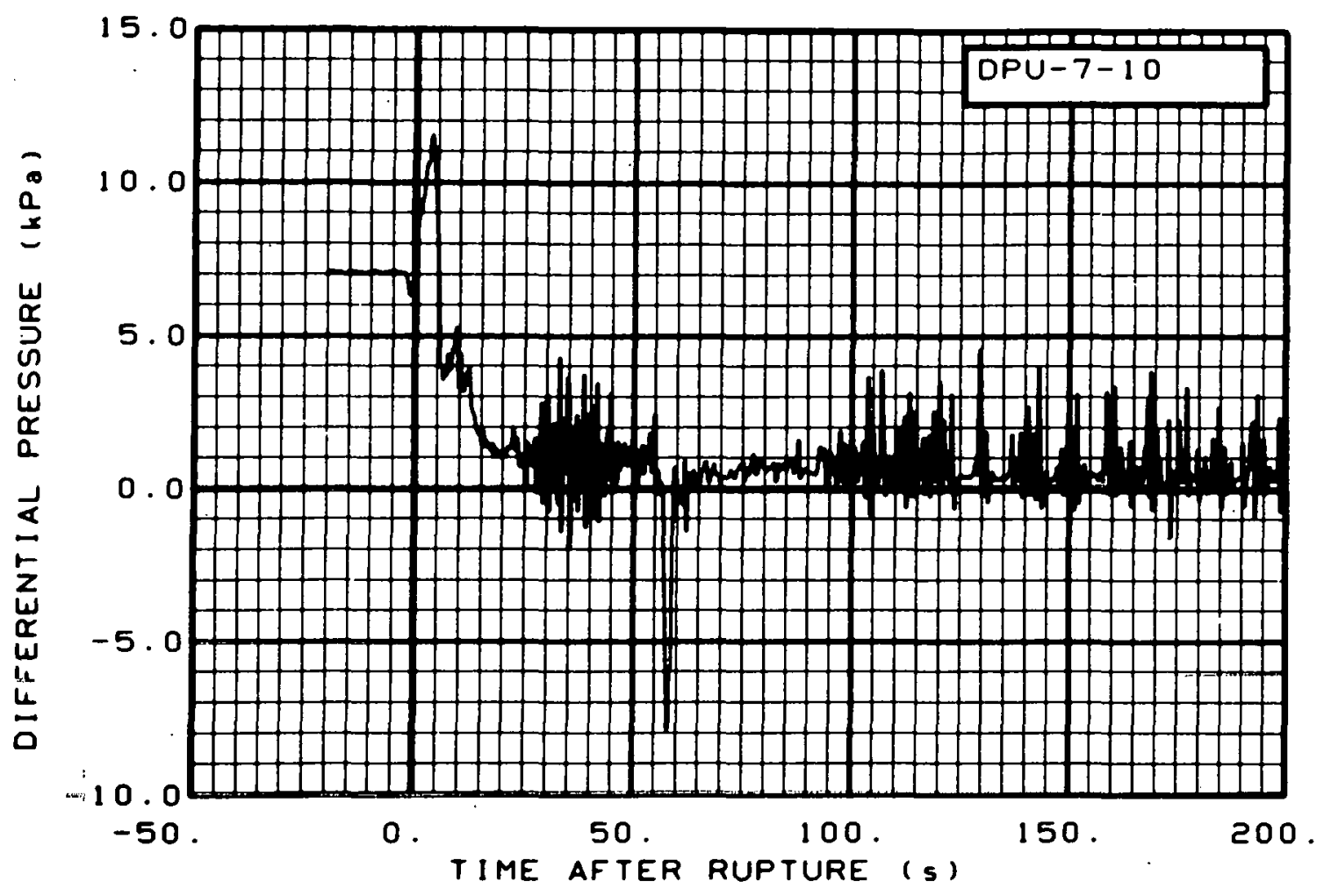

Fig. 157 Differential pressure in intact loop (DPU-7-10), from -20 to $200 \mathrm{~s}$.

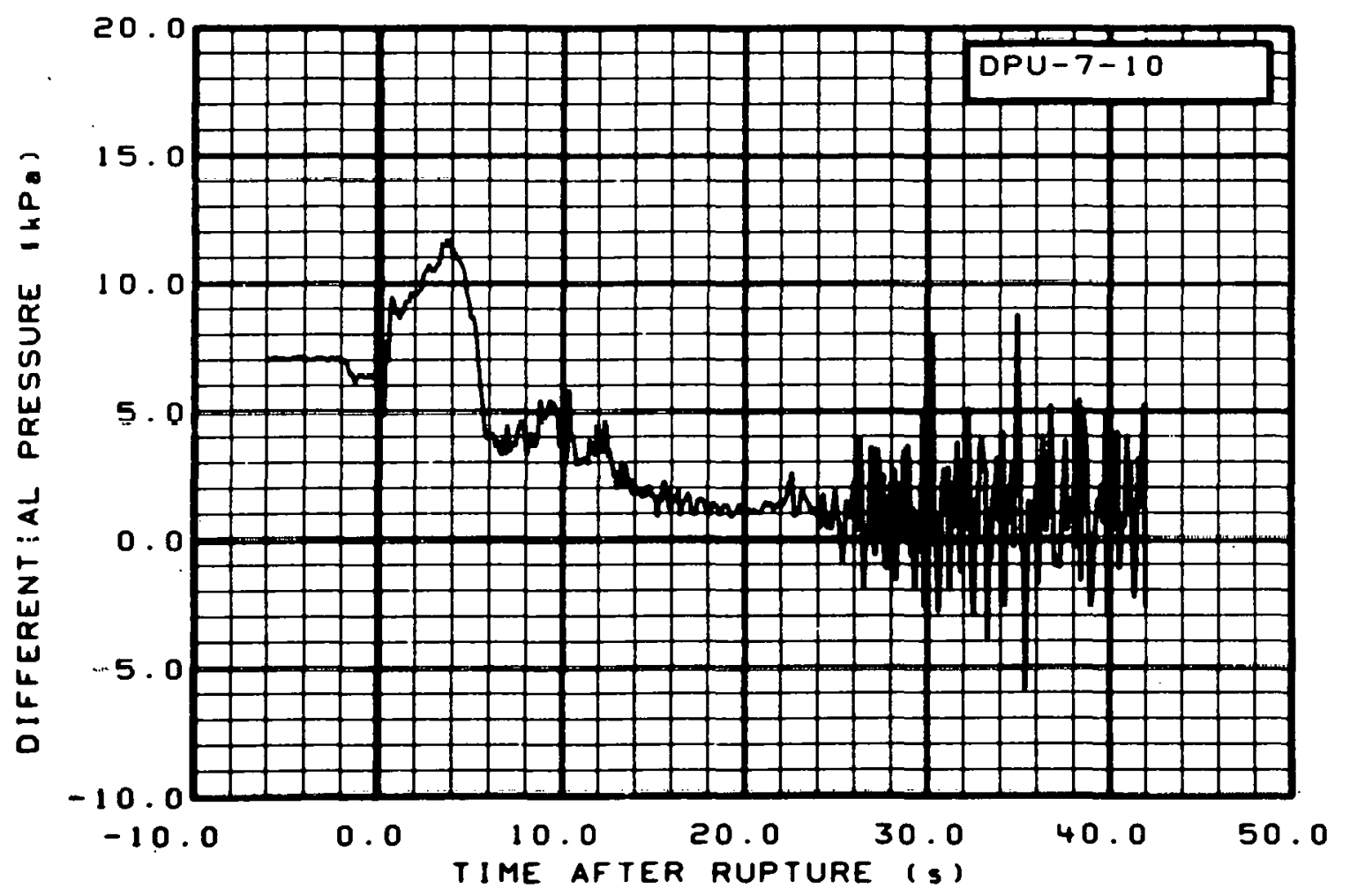

Fig. 158 Differential pressure in intact 1oop (DPU-7-10), from -6 to $42 \mathrm{~s}$. 


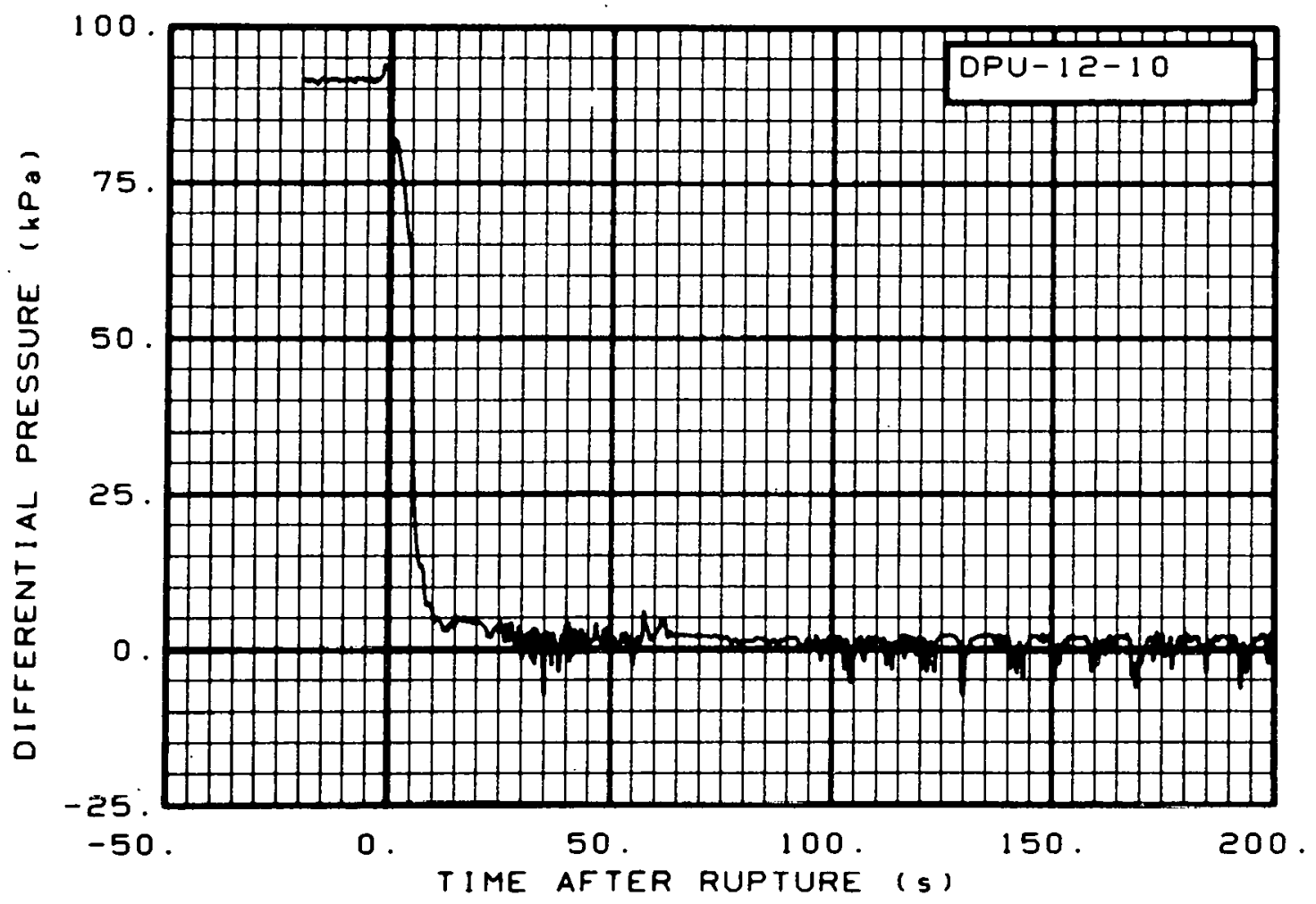

Fig. 159 Differential pressure in intact loop (DPU-12-10), from -20 to $200 \mathrm{~s}$.

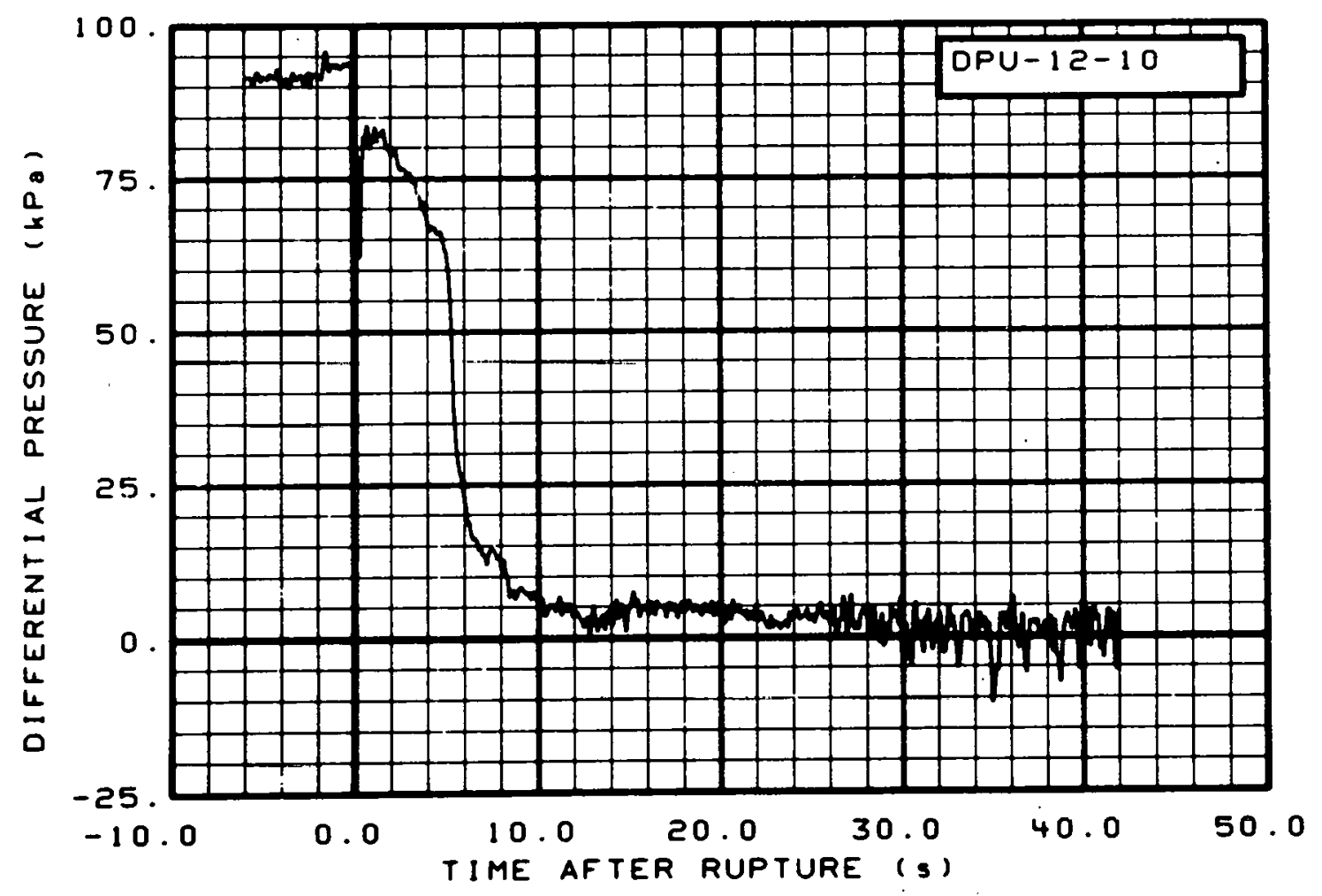

Fig. 160 Differential pressure in intact loop (DPU-12-10), from -6 to $42 \mathrm{~s}$. 


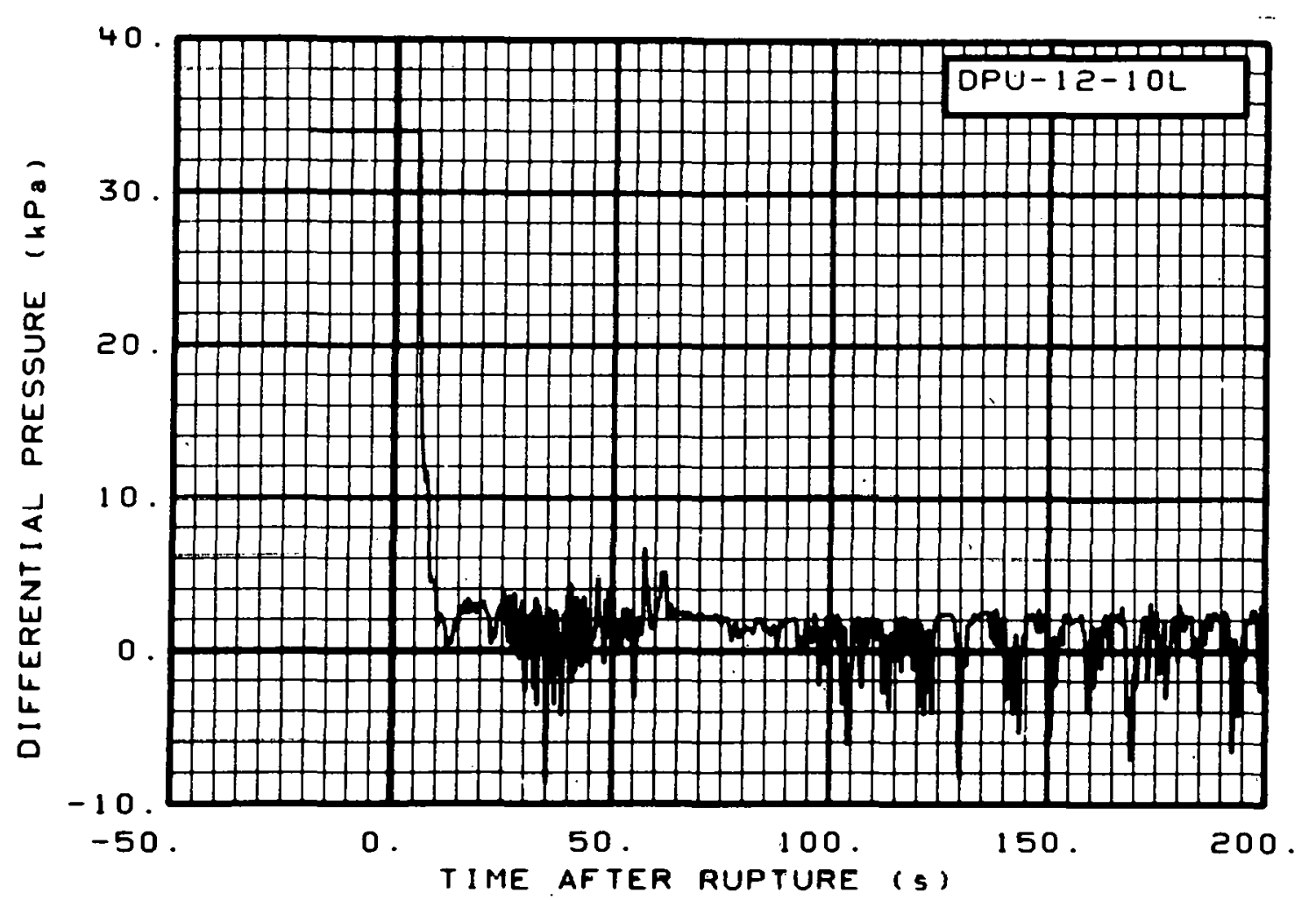

Fig. 161 Differential pressure in intact loop, low range (DPU-12-10L), from -20 to $200 \mathrm{~s}$.

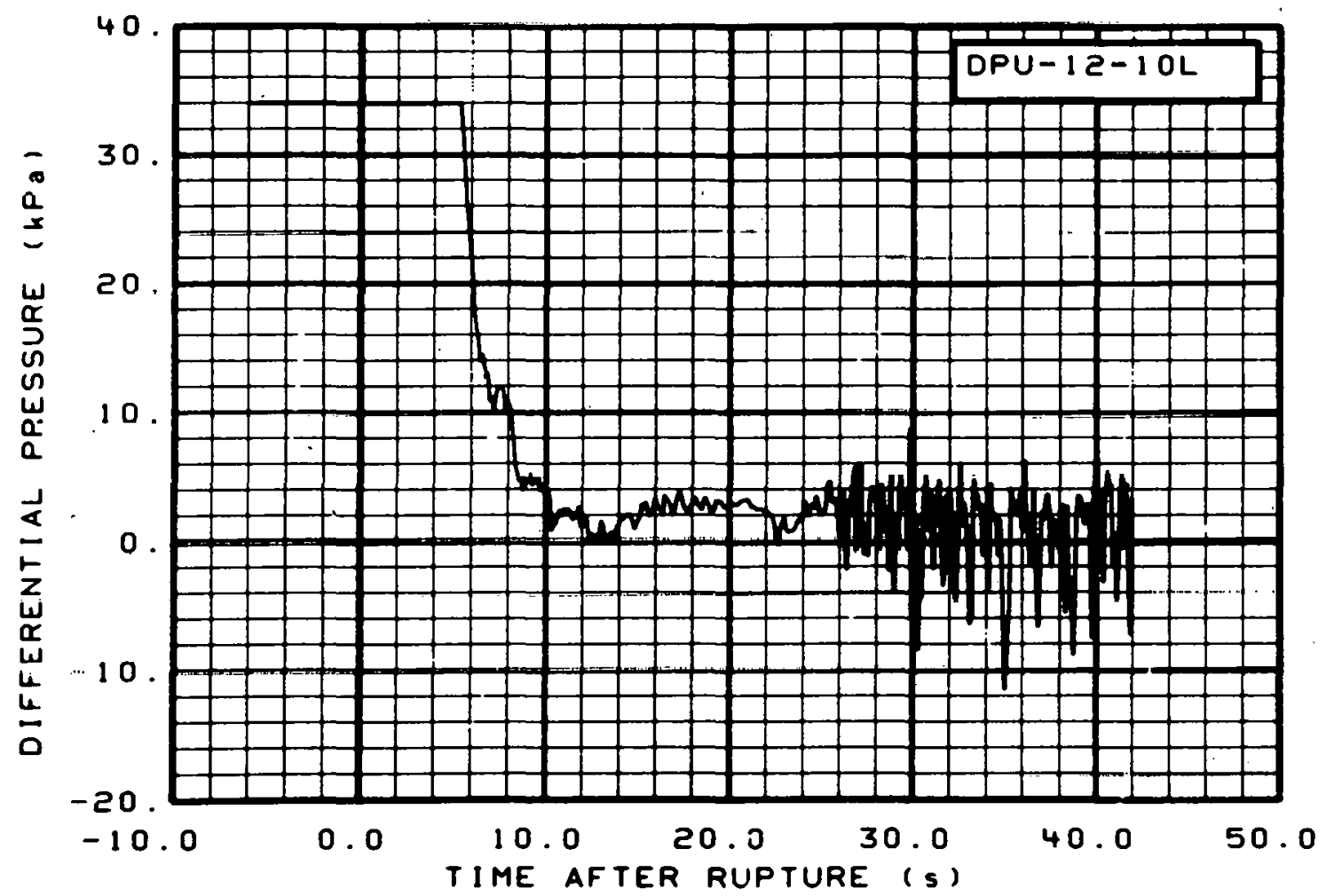

Fig. 162 Differential pressure in intact loop, low range (DPU-12-10L), from -6 to $42 \mathrm{~s}$. 


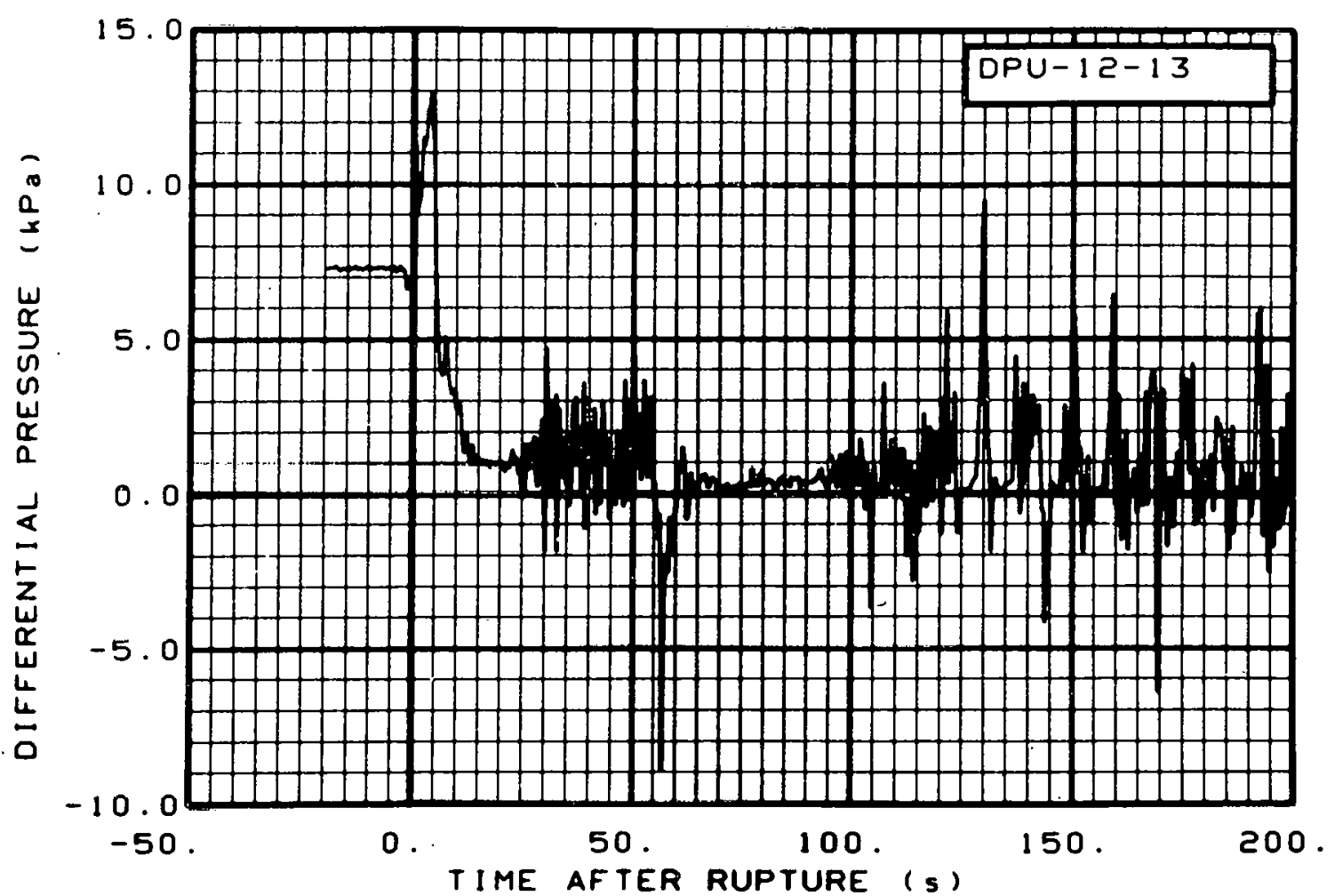

Fig. 163 Differential pressure in intact loop (DPU-12-13), from -20 to $200 \mathrm{~s}$.

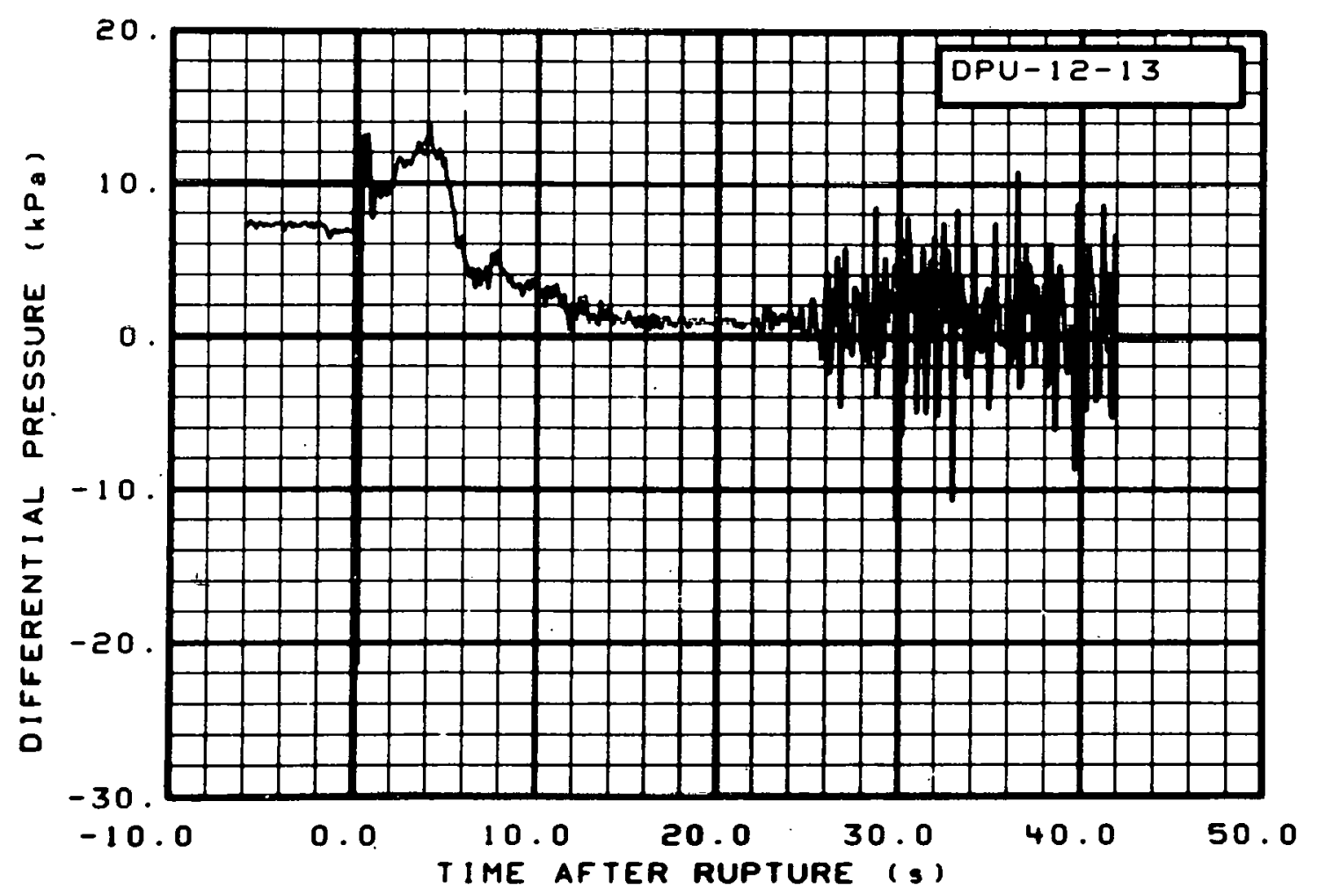

Fig. 164 Differential prossure in intact loop (DPU-12-13), from -6 to $42 \mathrm{~s}$. 


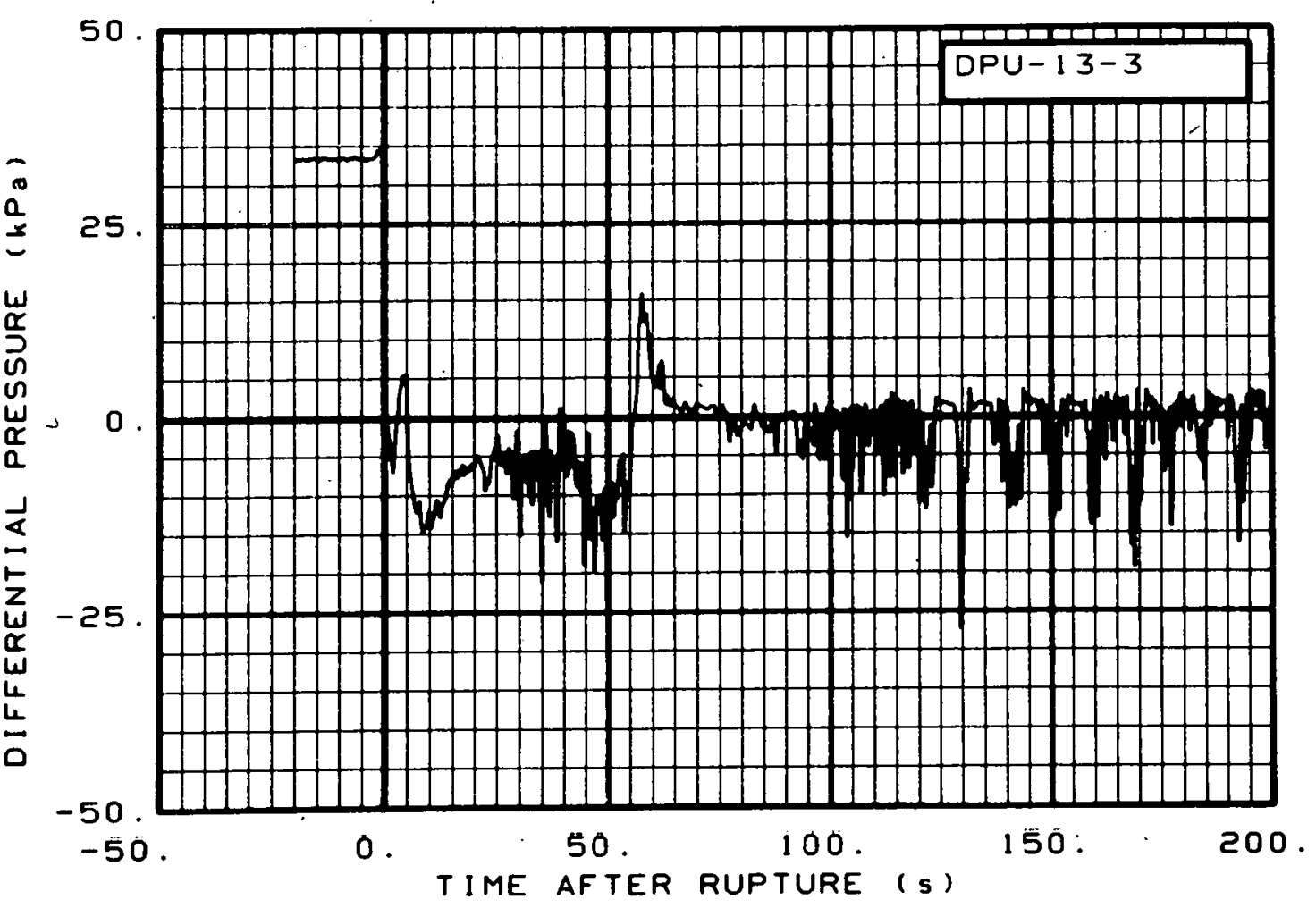

Fig. 165 Differential pressure in intact loop (DPU-13-3), from -20 to $200 \mathrm{~s}$.

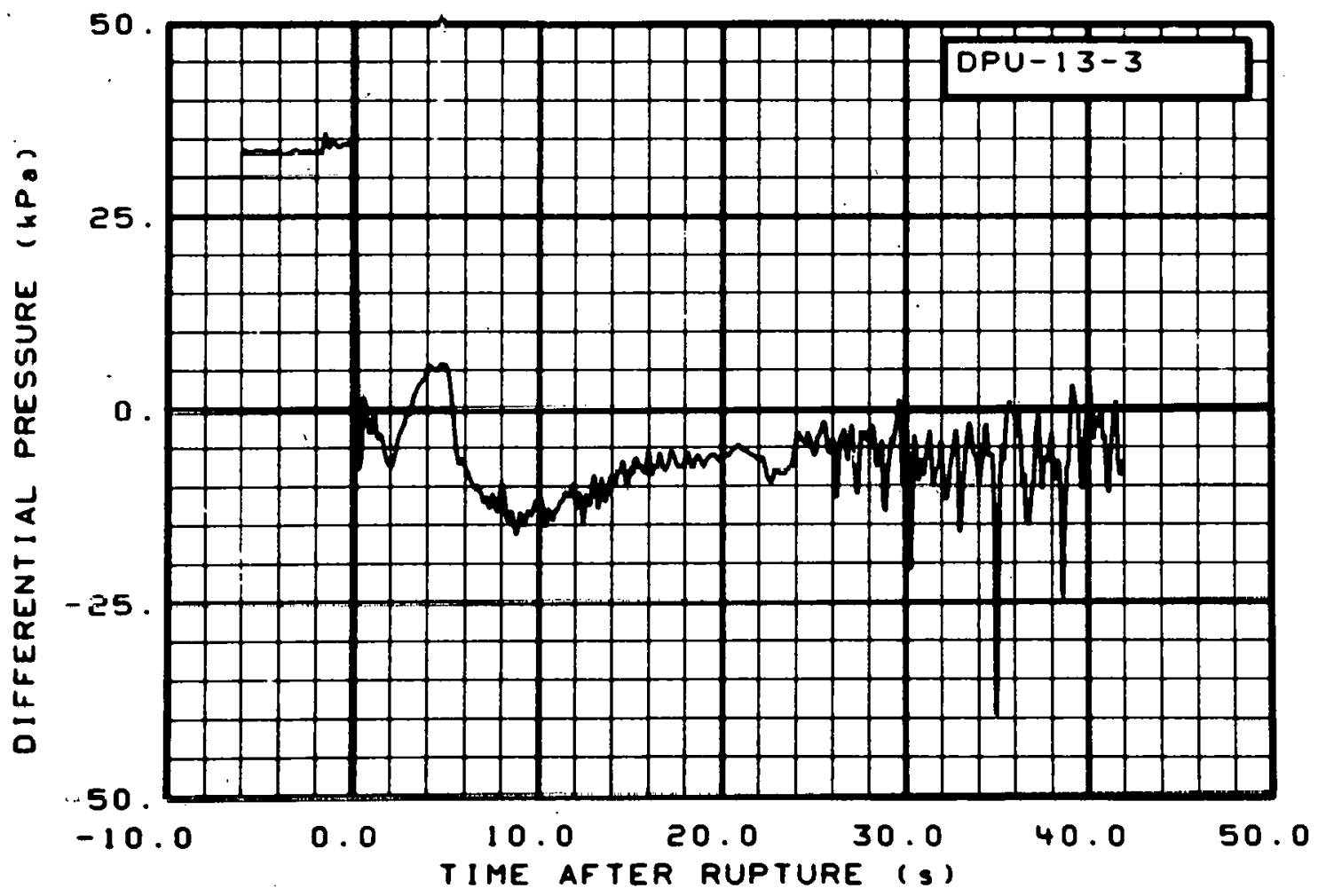

Fig. 166 Differential pressure in intact loop (DPU-13-3), from -6 to $42 \mathrm{~s}$. 


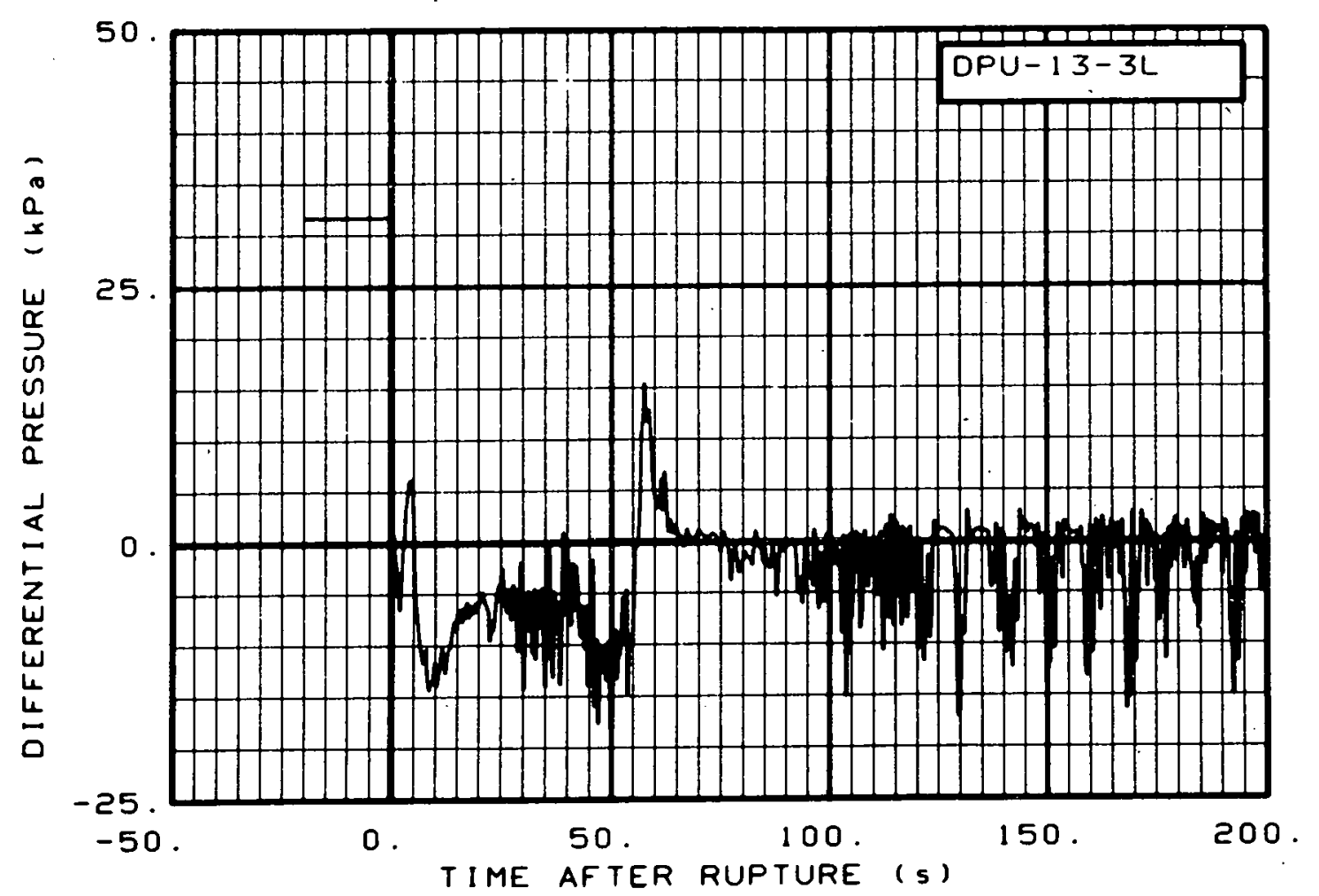

Fig. 167 Differential pressure in intact loop, low range (DPU-13-13L); from -20 to $200 \mathrm{~s}$.

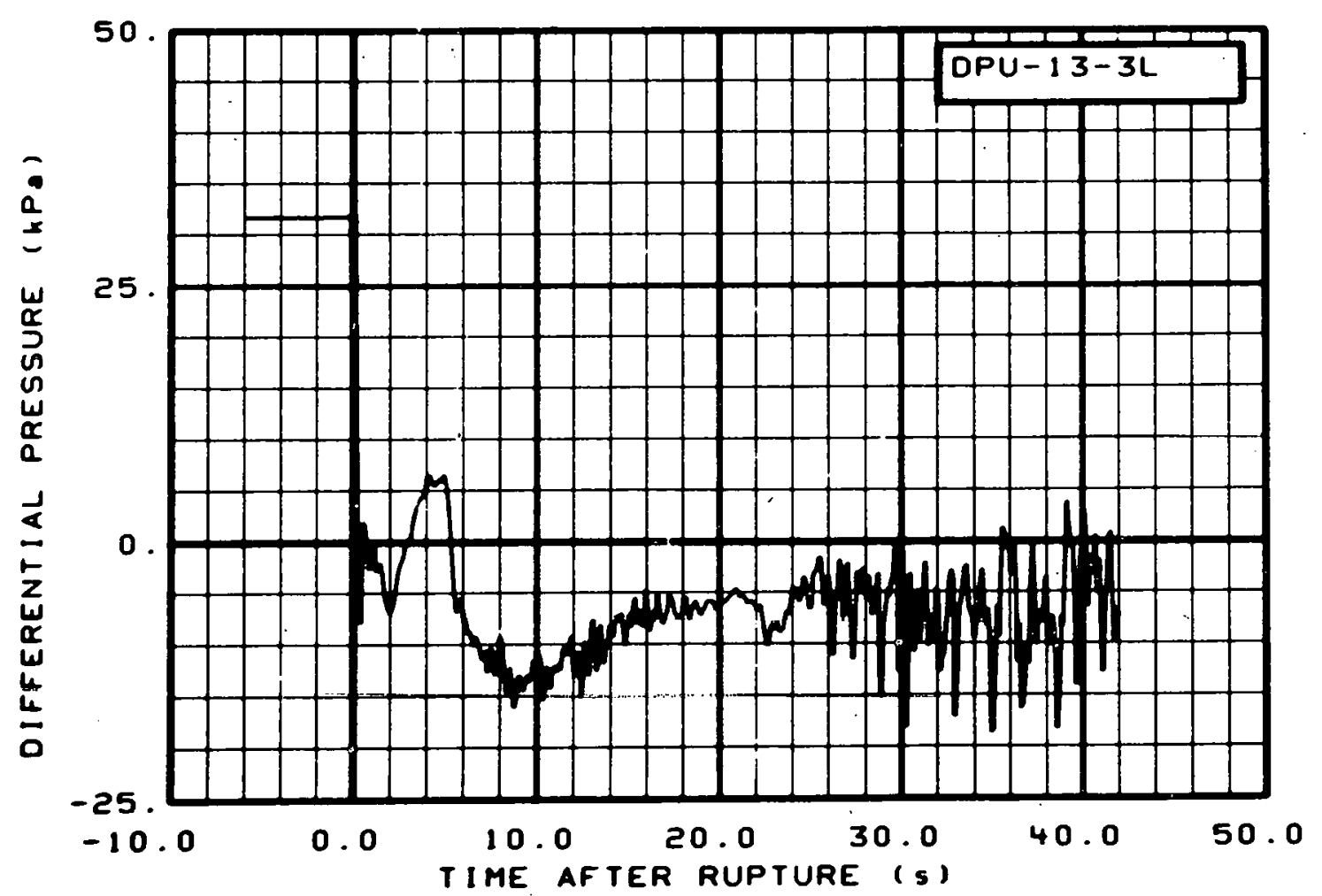

Fig. 168 Differential pressure iil intact loop, low range (DPU-13-13L), from -6 to $42 \mathrm{~s}$. 


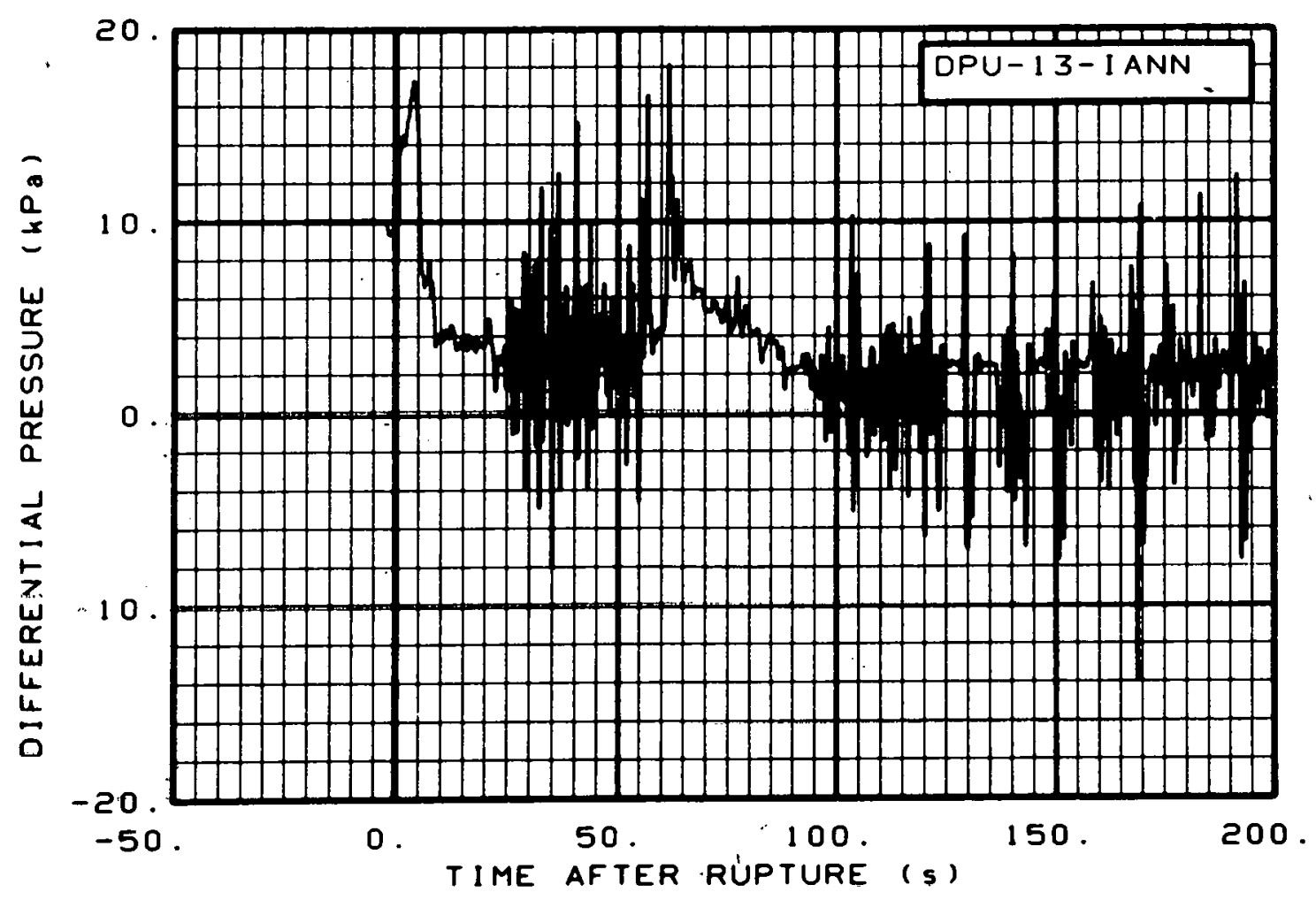

Fig. 169 Differential pressure in intact loop (DPU-13-IANN), from -20 to $200 \mathrm{~s}$.

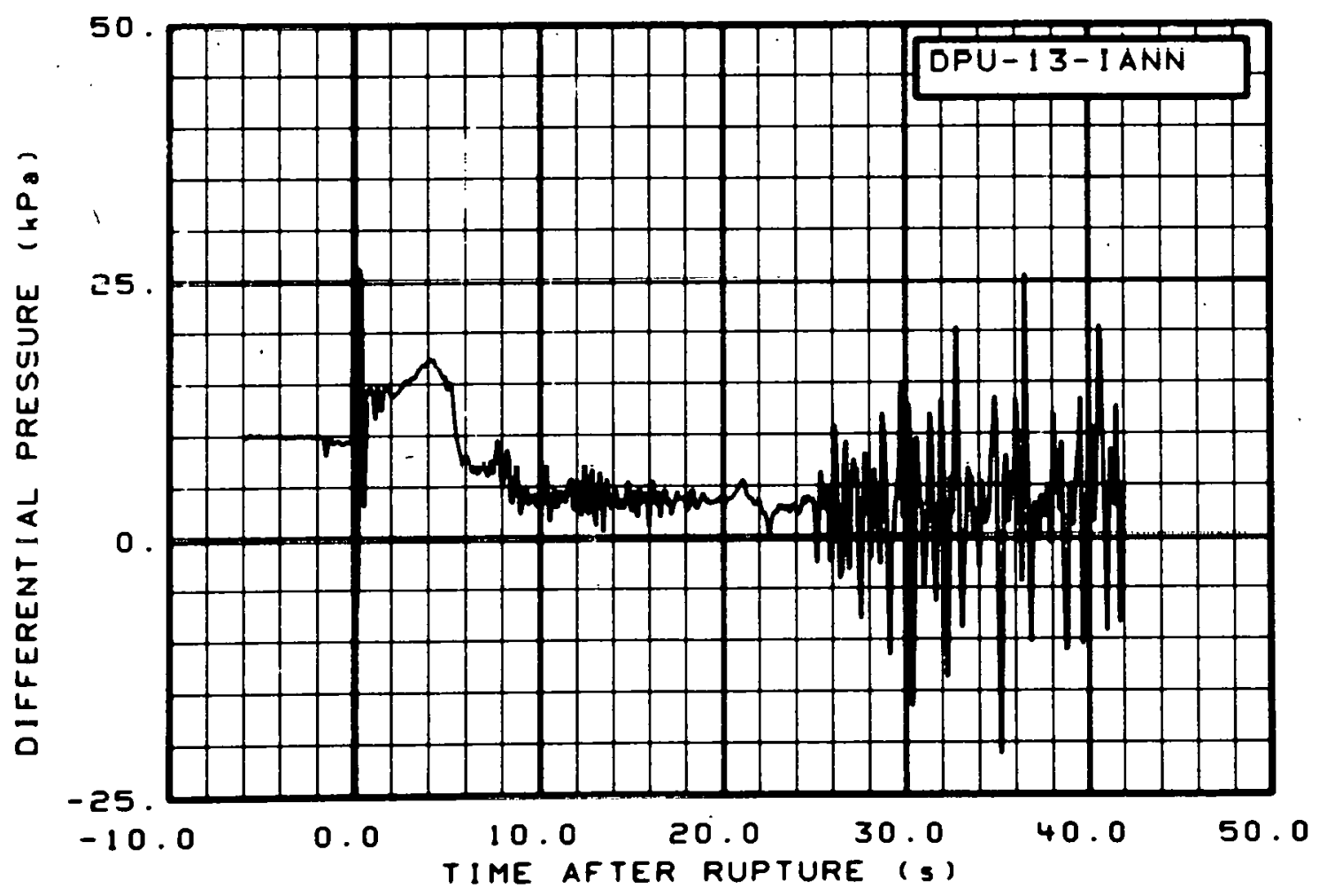

Fig. 170 Differential pressure in intact loop (DPU-13-IANN), from -6 to $42 \mathrm{~s}$. 


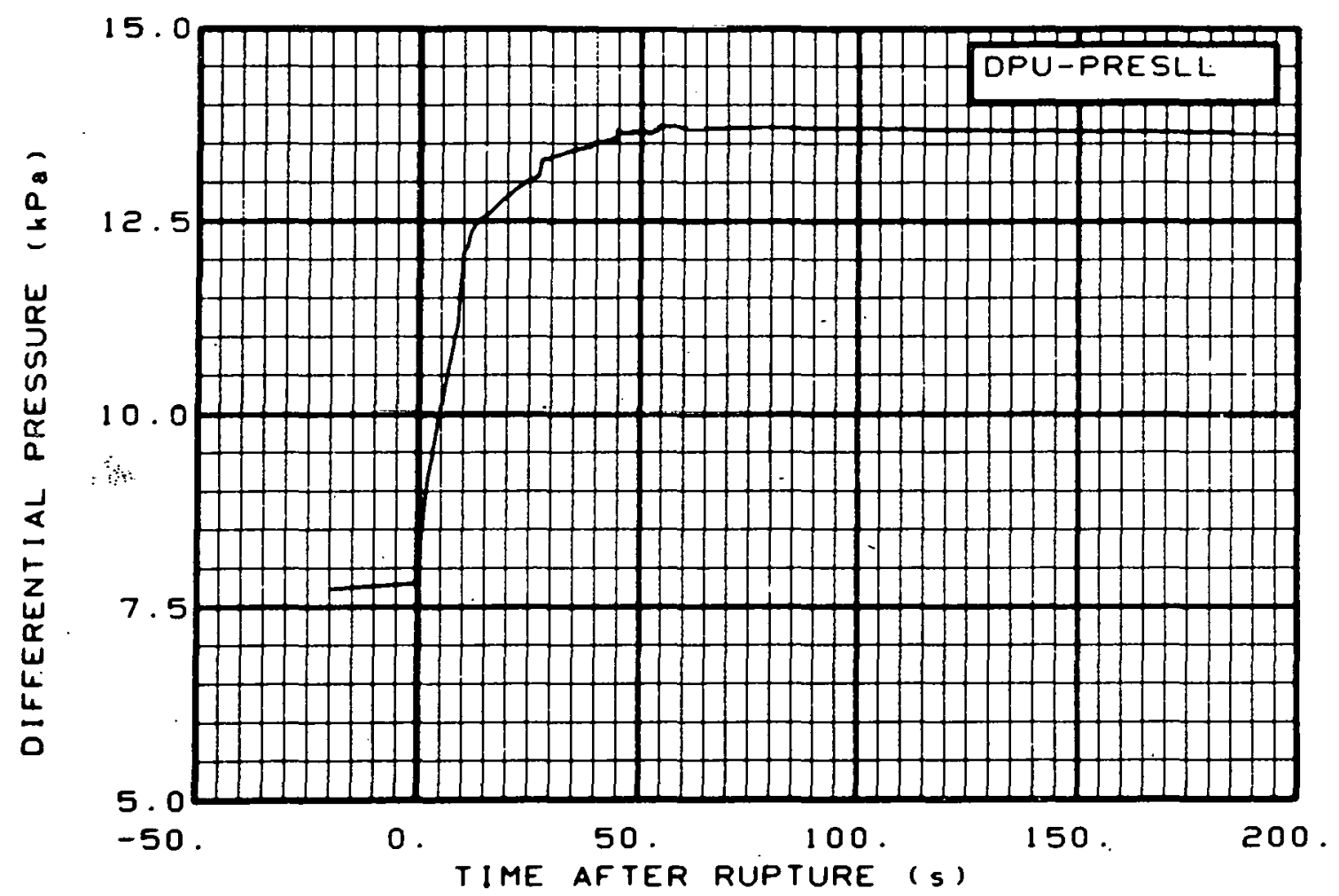

Fig. 171 Differential pressure in intact loop (DPU-PRESLL), from -20 . to $200 \mathrm{~s}$.

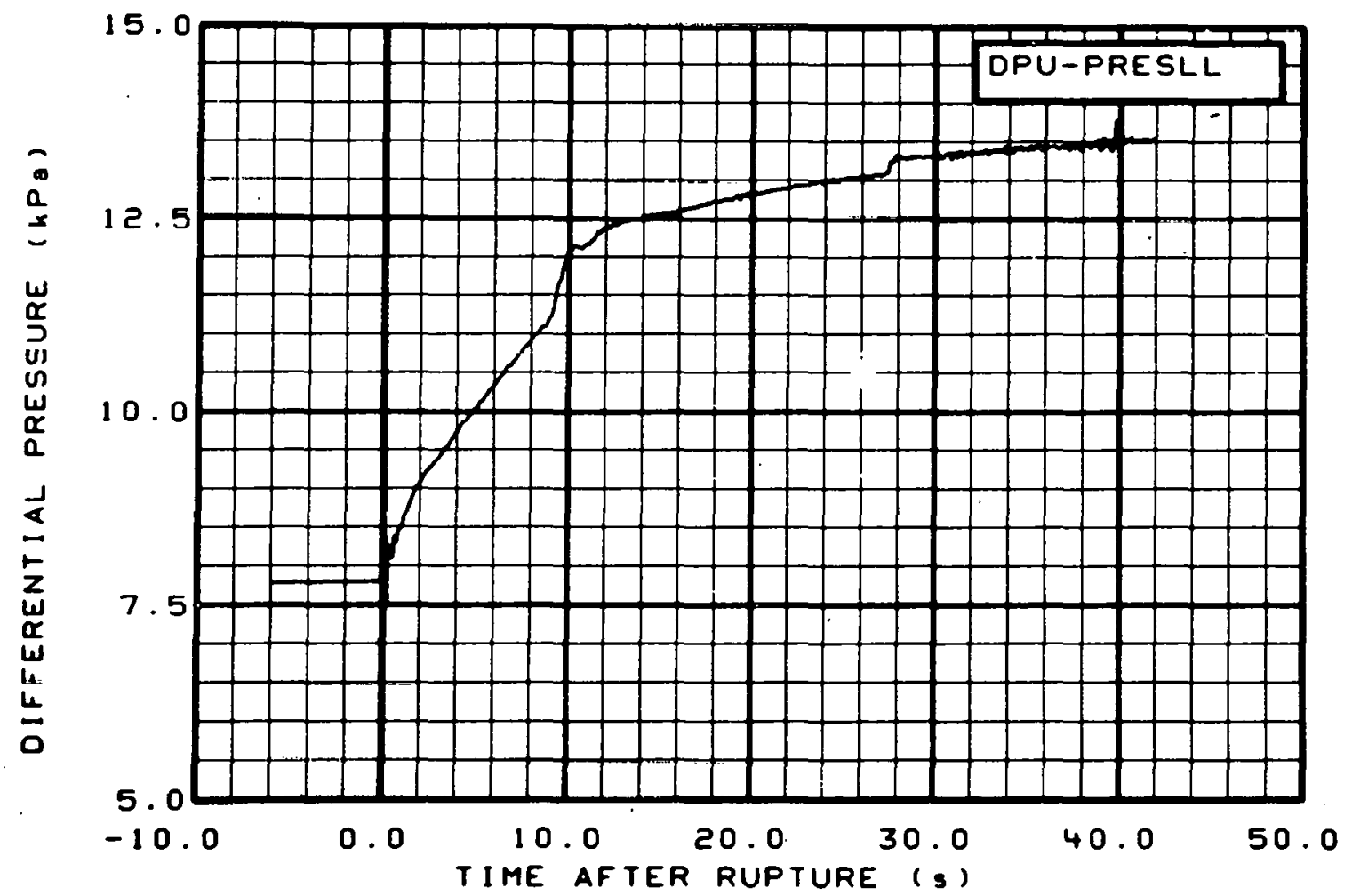

Fig. 172 Differential pressure in intact loop (DPU-PRESLL), from -6 to $42 \mathrm{~s}$. 


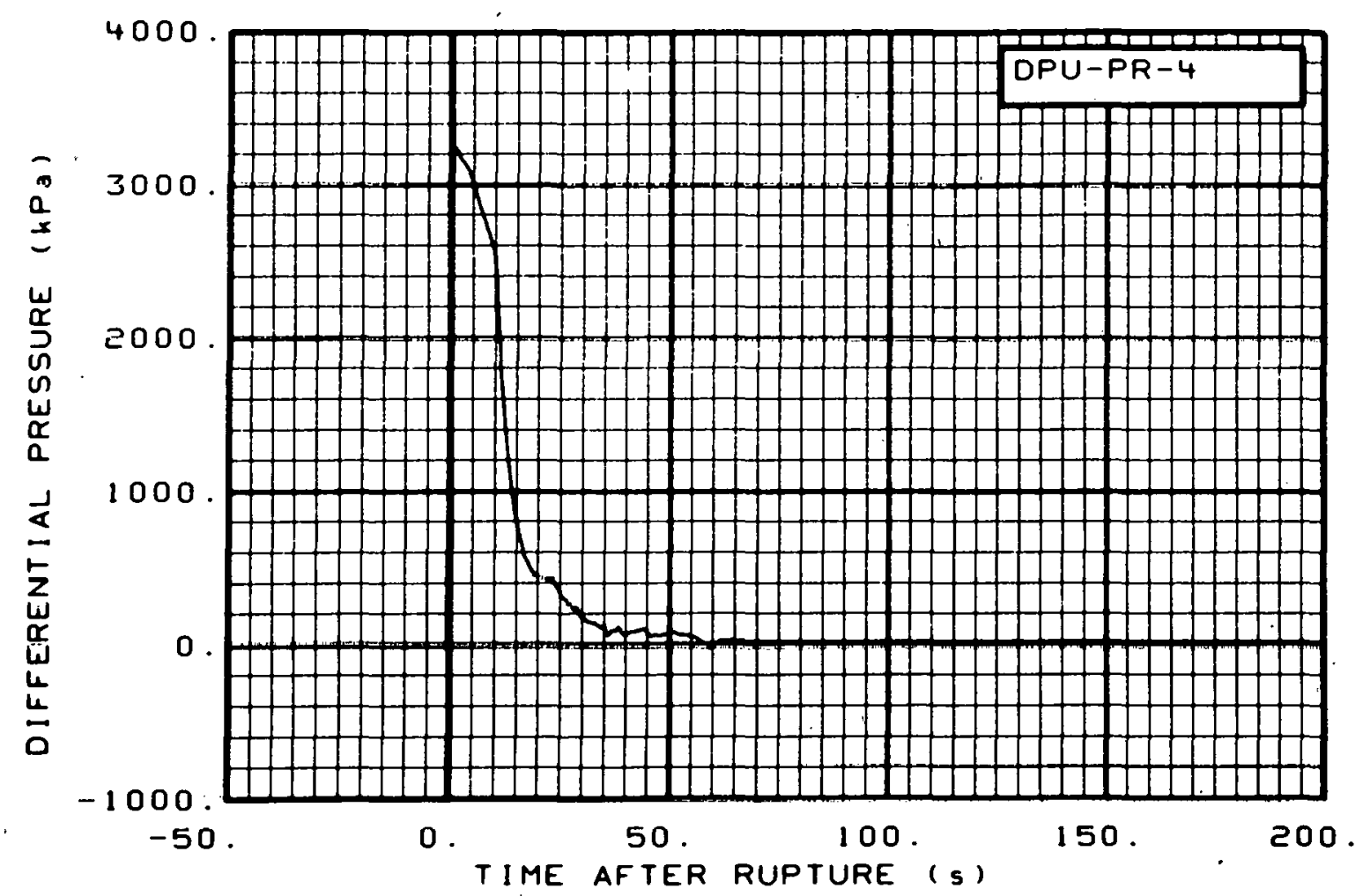

Fig. 173 Differential pressure in intact loop (DPU-PR-4), from -20 to $200 \mathrm{~s}$ :

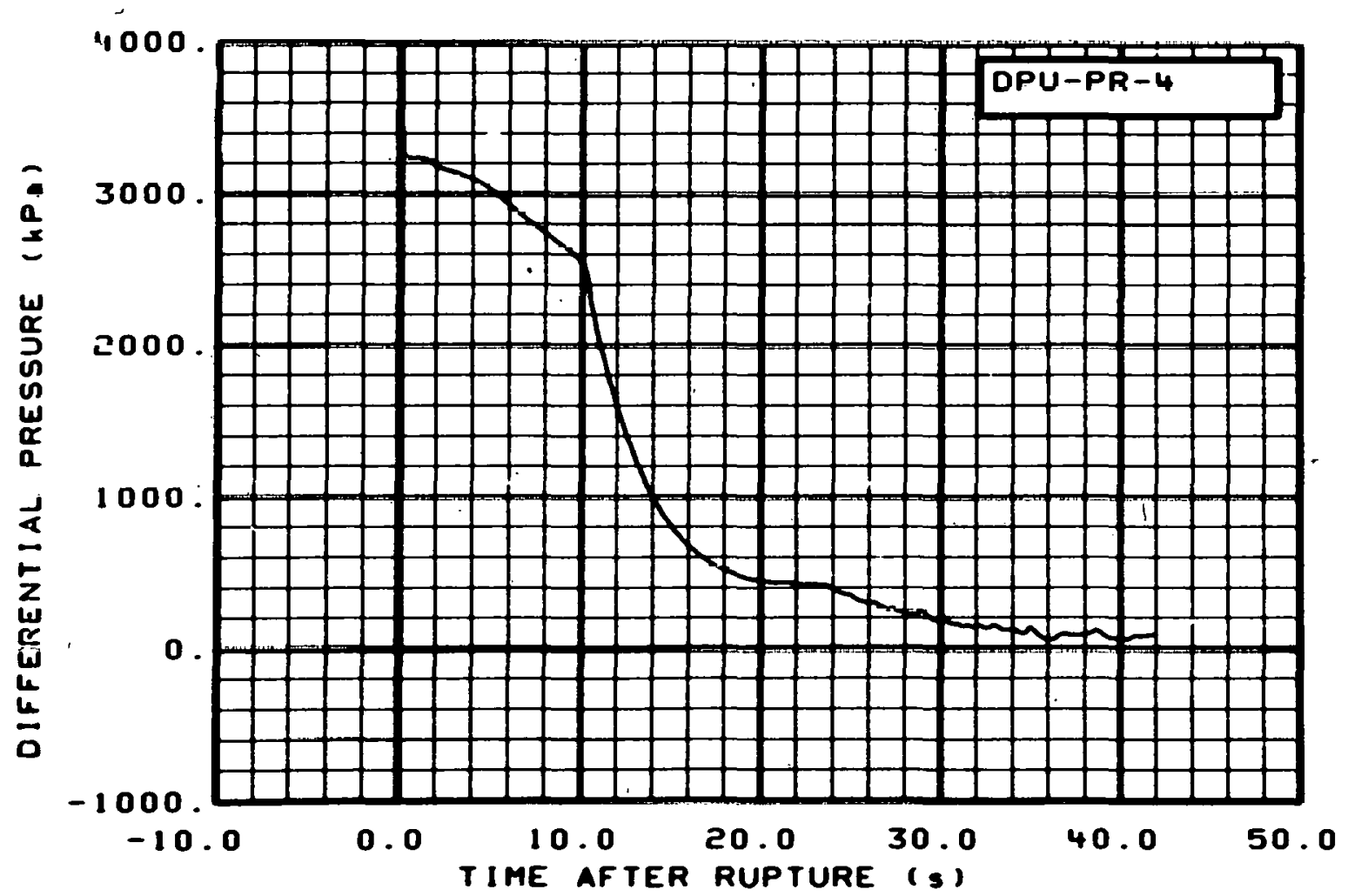

Fig. 174 Differential pressure in intact loop (DPU-PR-4), from -6 to $42 \mathrm{~s}$. 


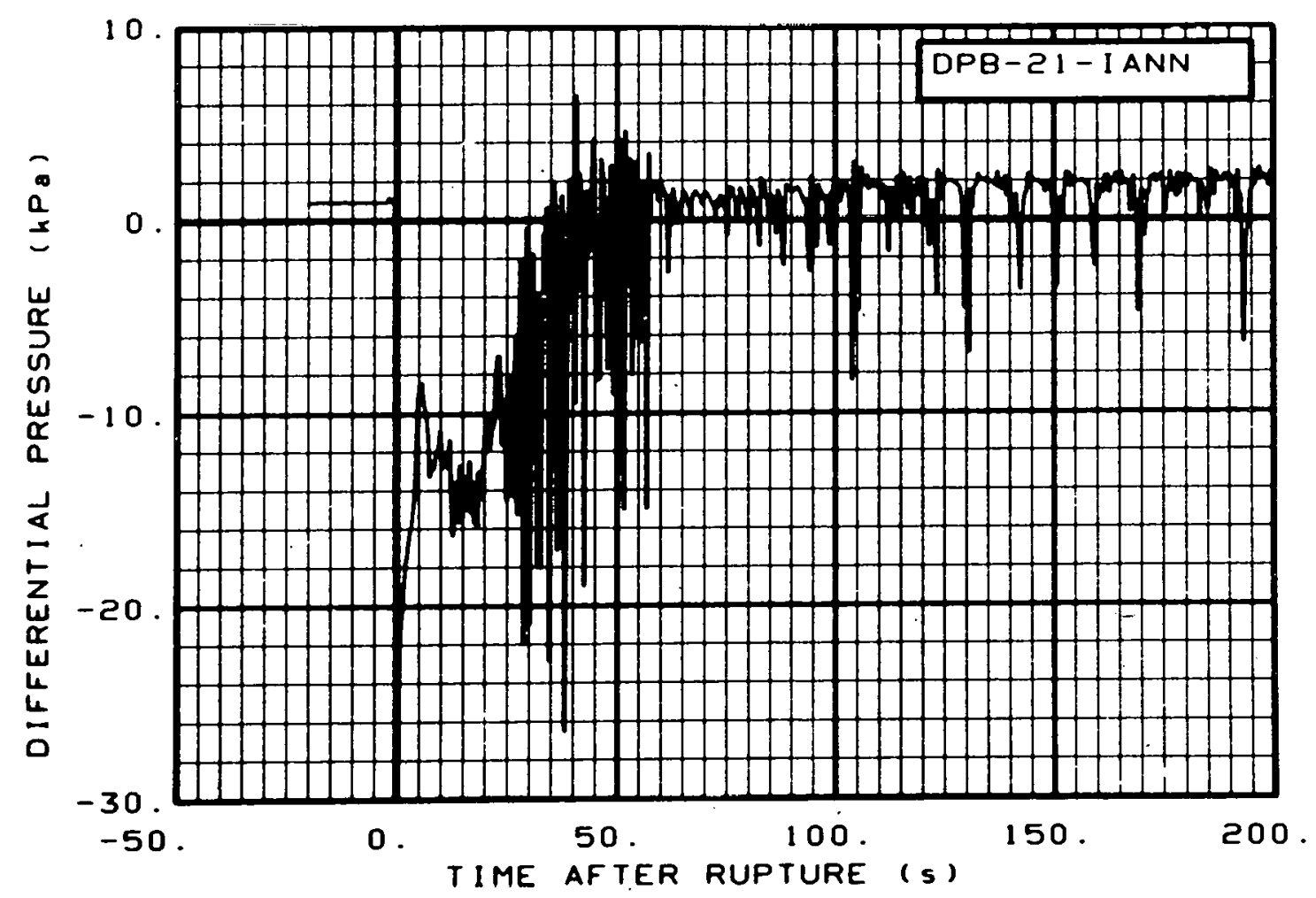

Fig. 175 Differential pressure in broken loop (DPB-21-IANN), from -20 to $200 \mathrm{~s}$.

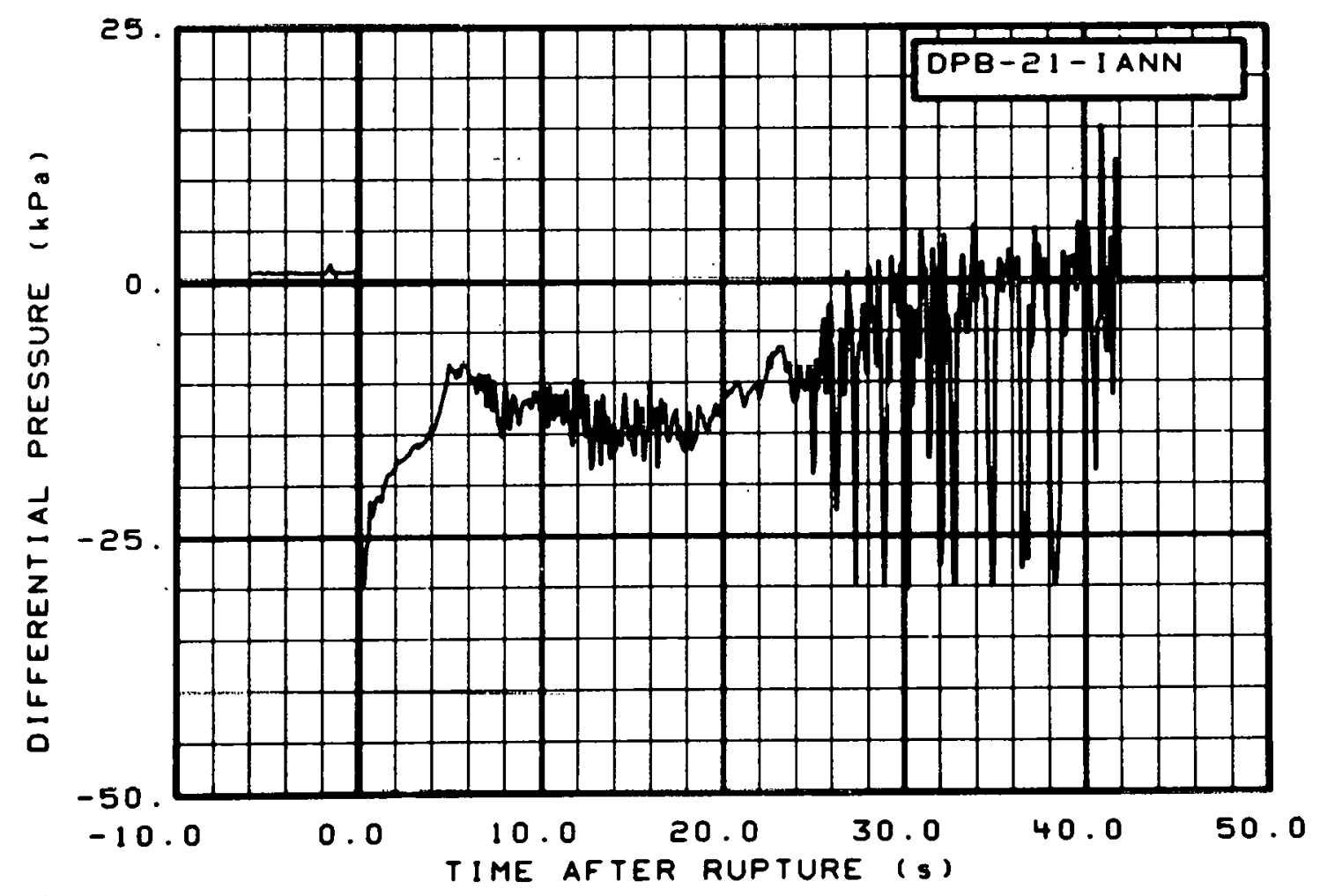

F1g. 176 Differential pressure in broken loop (DPB-21-IANN), from -6 to $42 \mathrm{~s}$. 


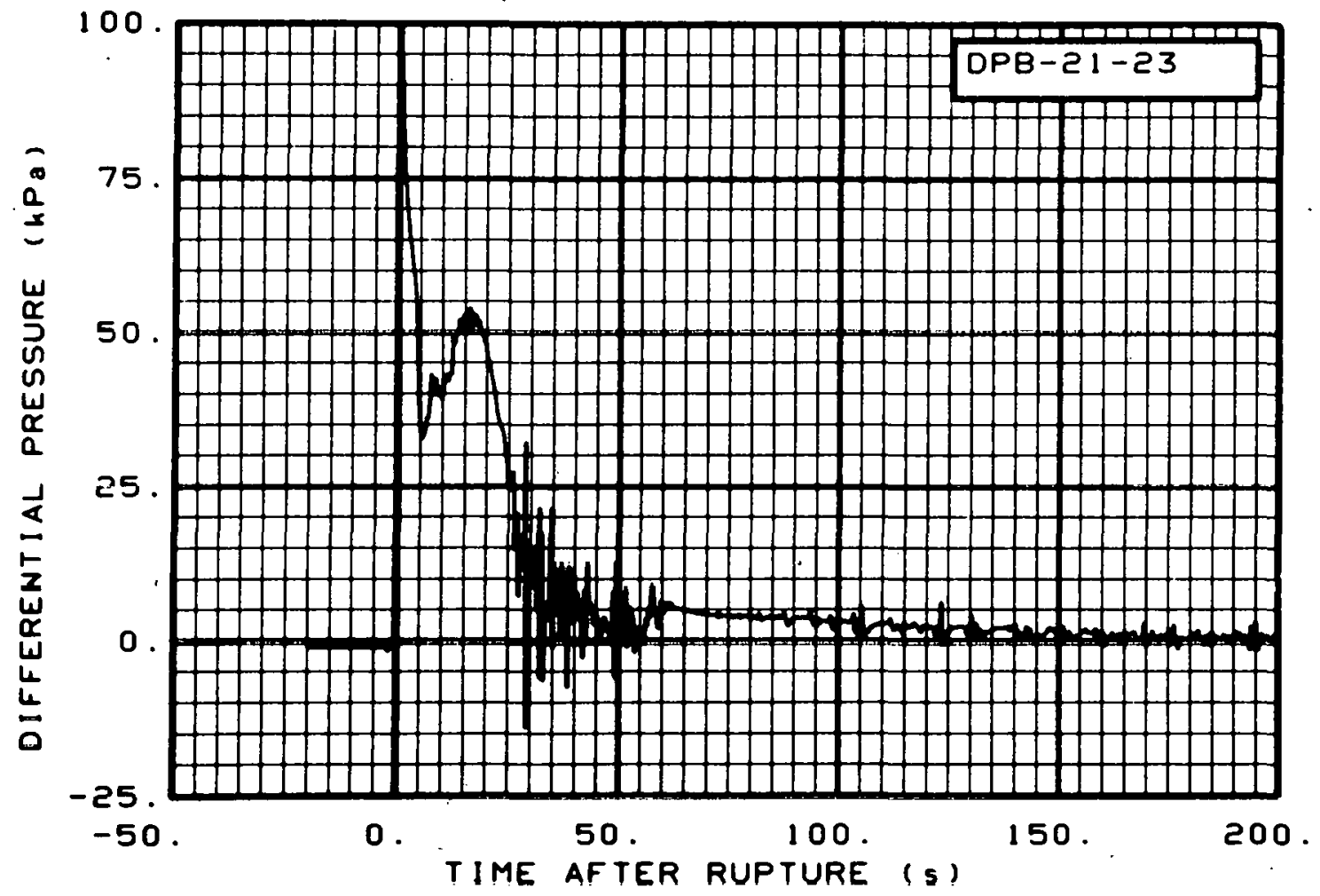

Fig. 177 Differential pressure in broken loop (DPB-21-23), from -20 to $200 \mathrm{~s}$.

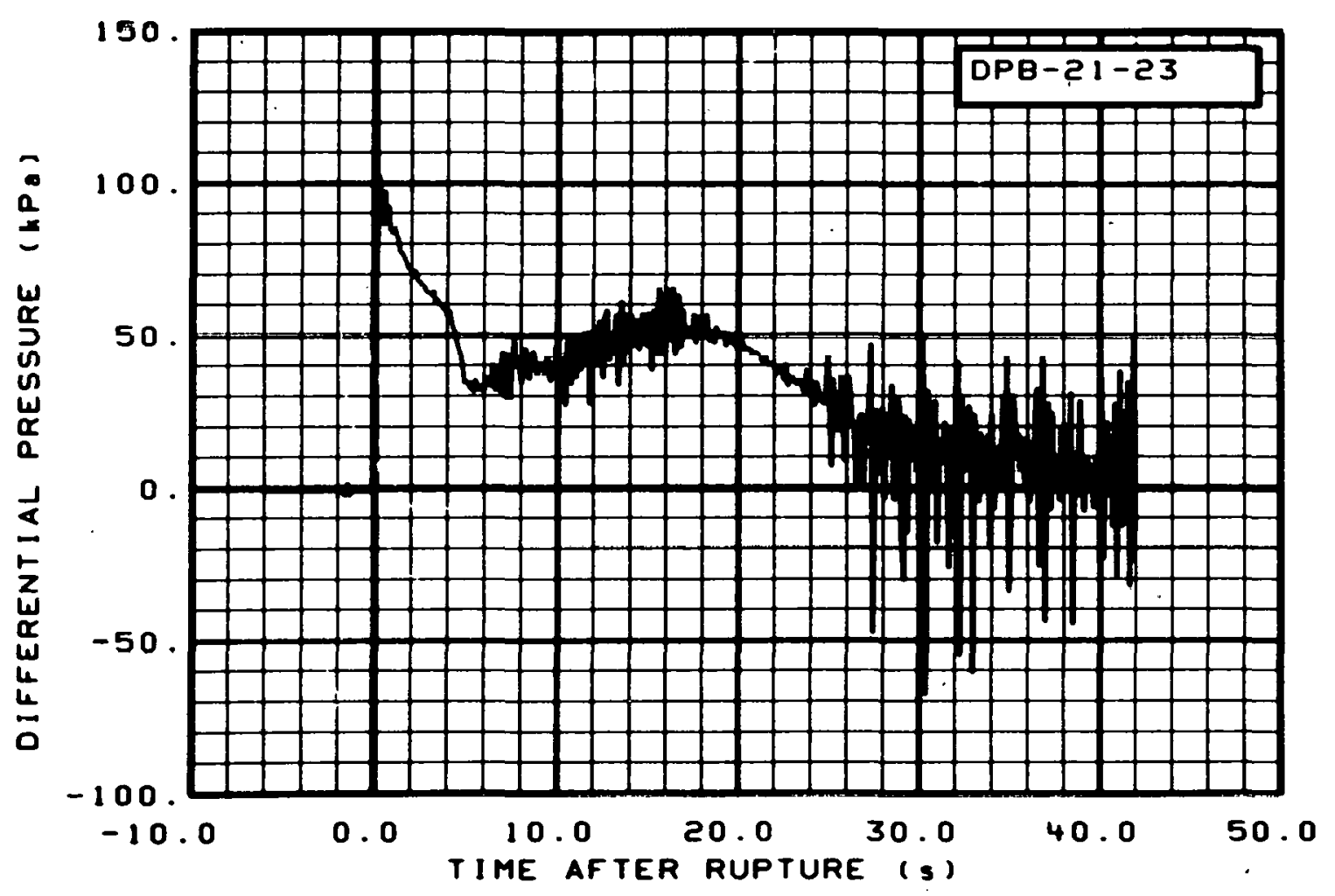

Fig. 178 Differential pressure in broken 10op (DPB-21-23), from -6 to $42 \mathrm{~s}$. 


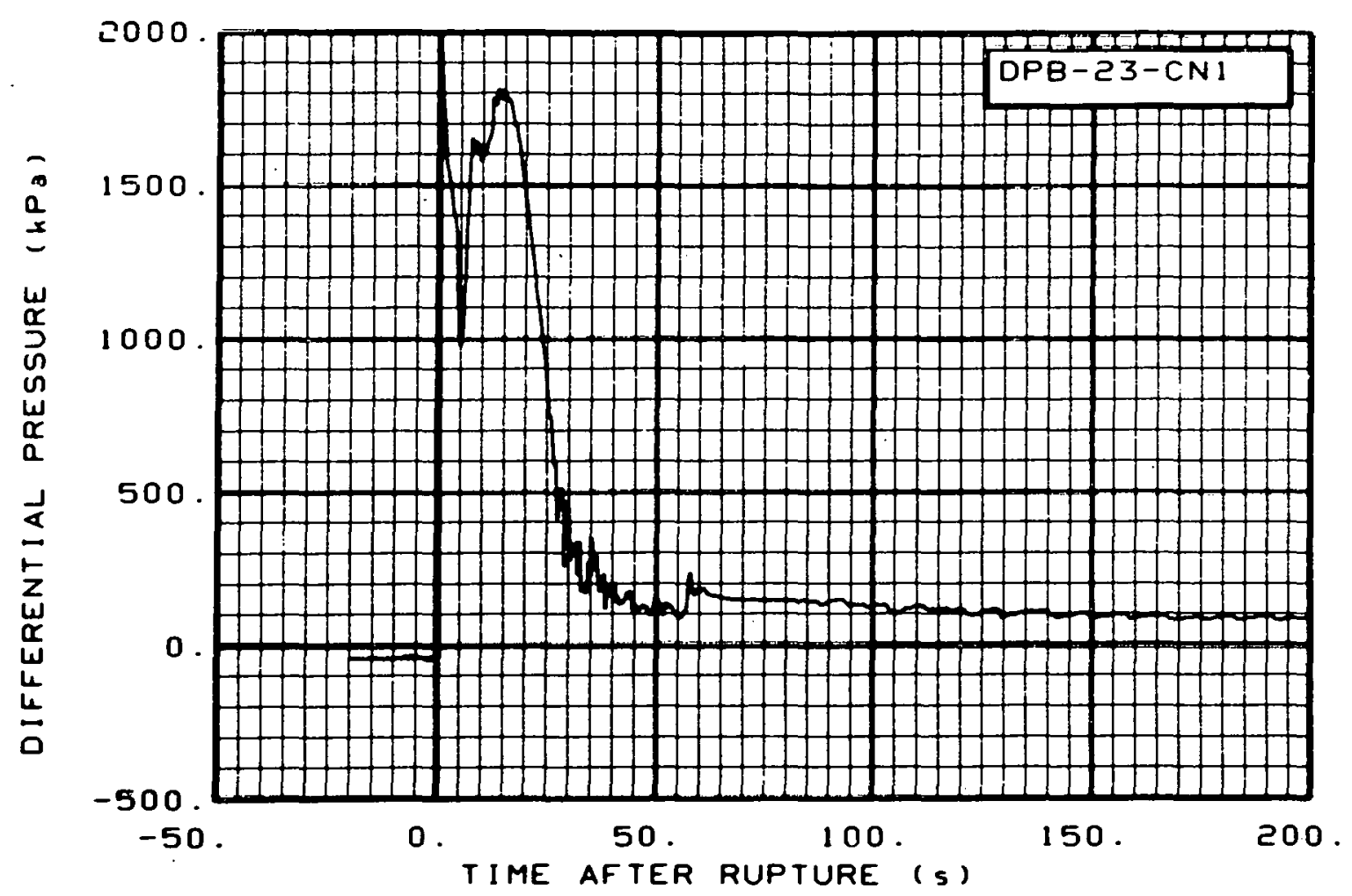

Fig. 179 Differential pressure in broken loop (DPB-23-CN1), from -20 to $200 \mathrm{~s}$.

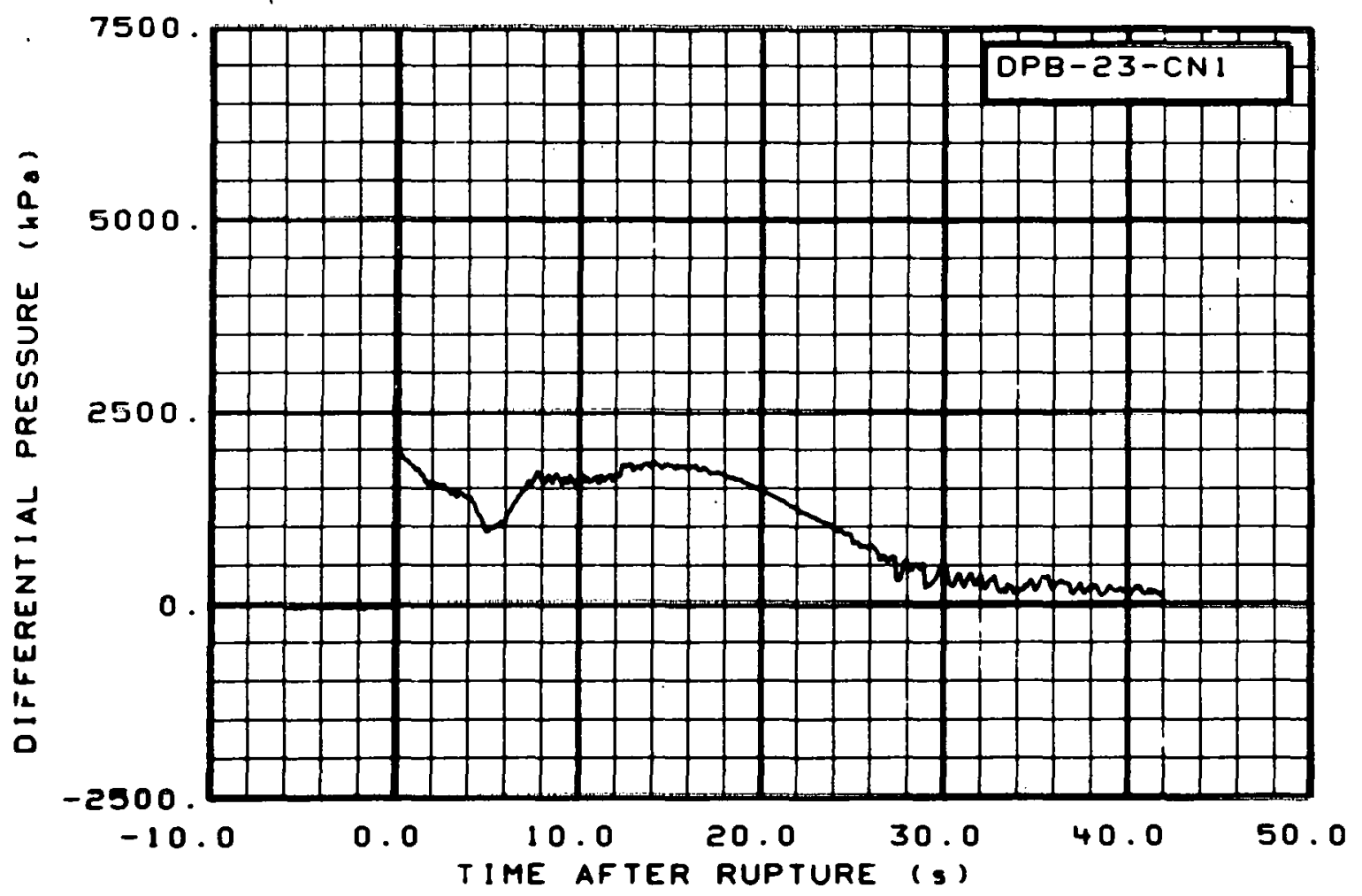

Fig. 180 Differential pressure in broken loop (DPB-23-CN1), from -6 to $42 \mathrm{~s}$. 


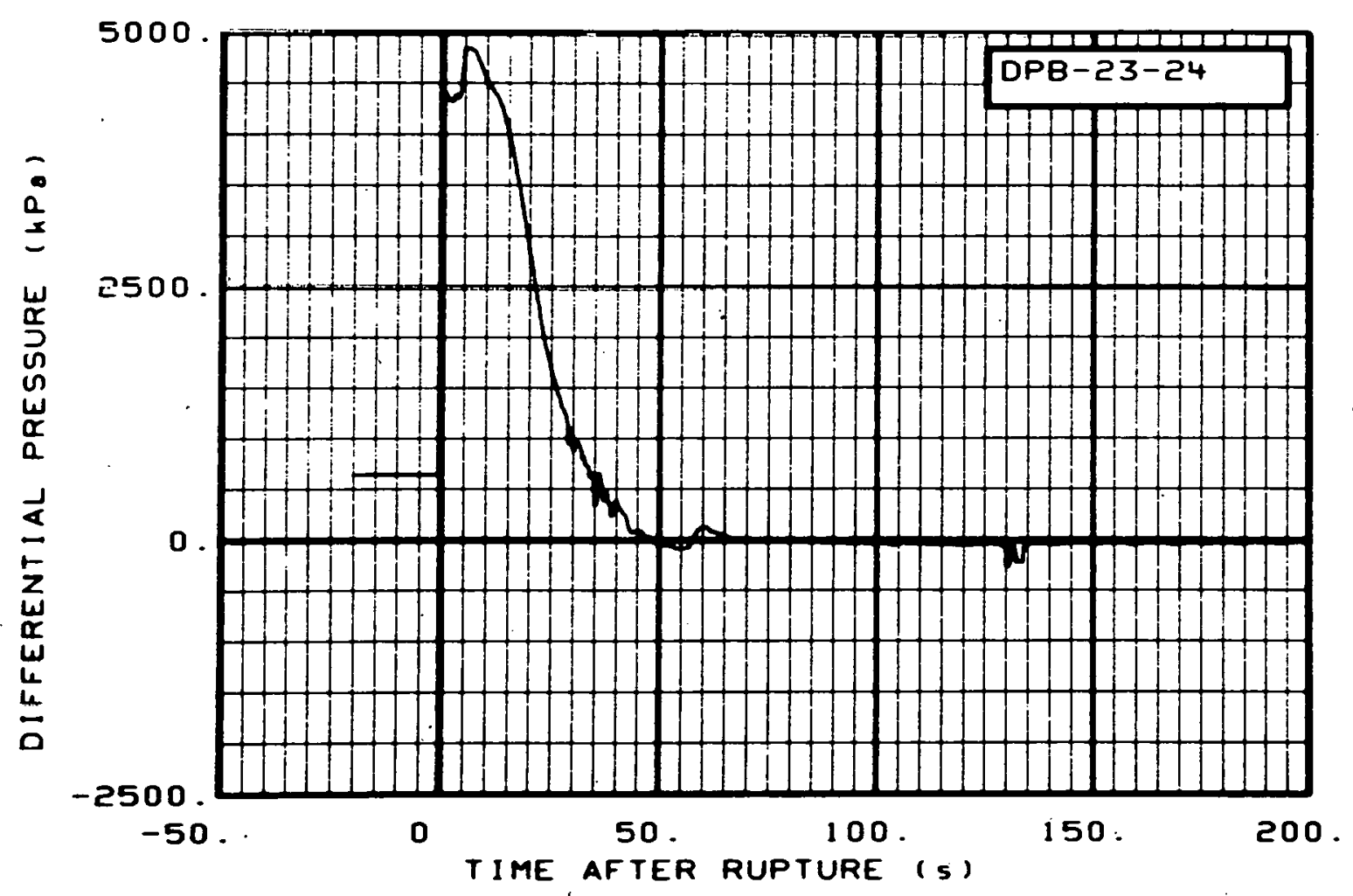

Fig. 181 Differential pressure in broken loop (DPB-23-24), from -20 to $200 \mathrm{~s}$.

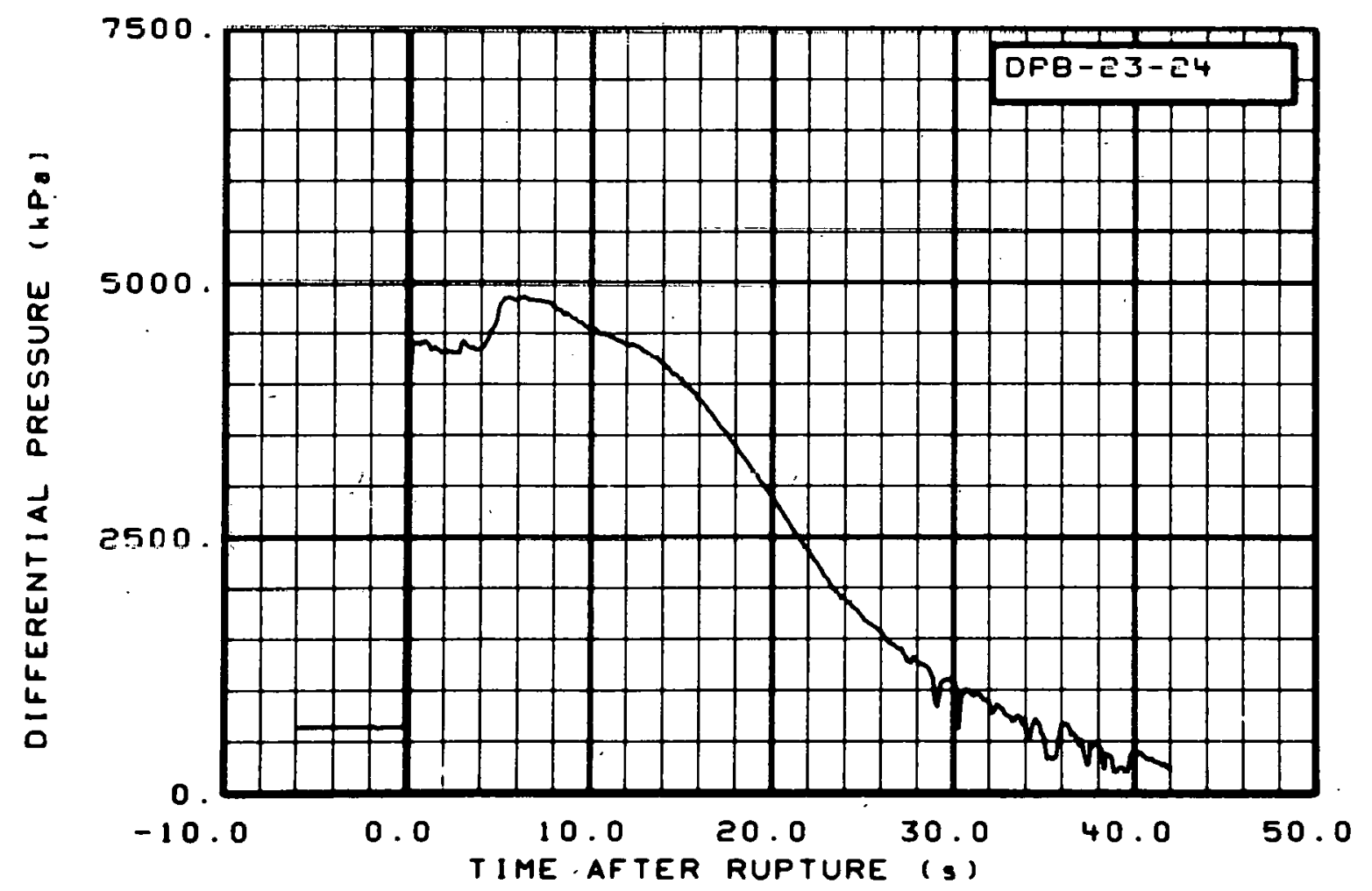

Fig. 182 Differential pressure in broken loop (DPB-23-24), from -6 to $42 \mathrm{~s}$. 


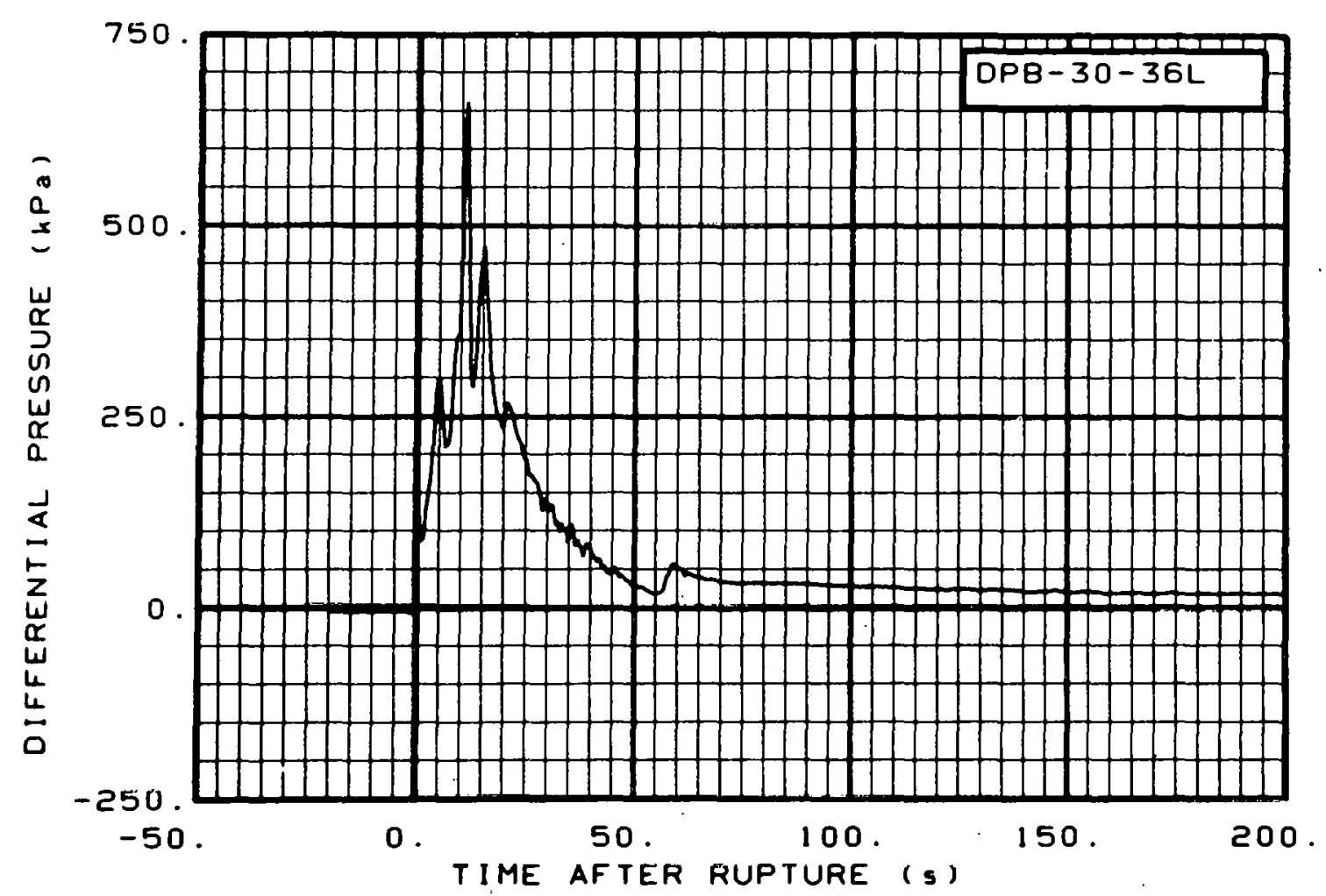

Fig. 183 Differential pressure in broken loop (DPB-30-36L), from -20 to $200 \mathrm{~s}$.

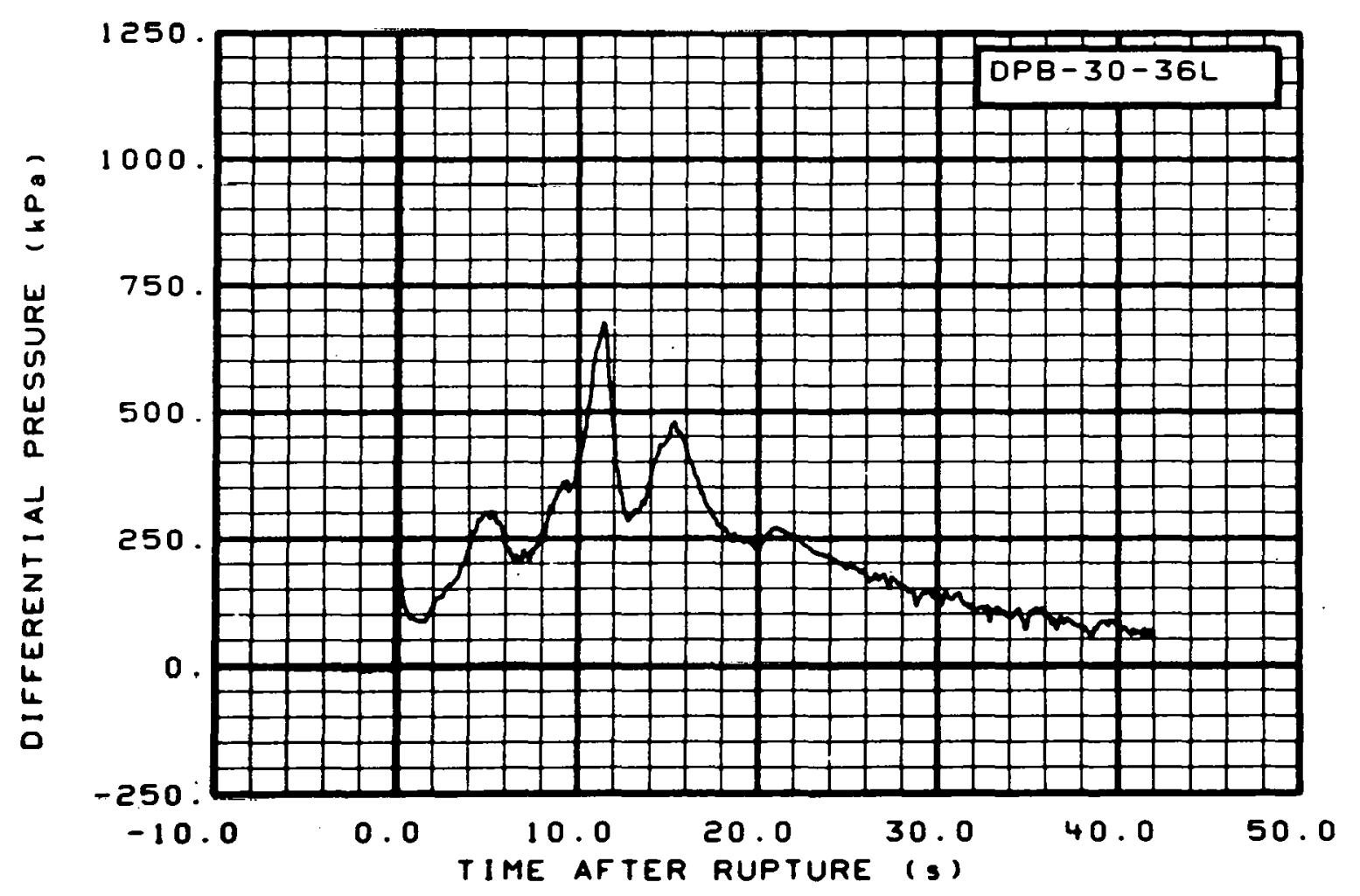

Fig. 184 Differential pressure in broken loop (DPB-30-36L), from -6 to $42 \mathrm{~s}$. 


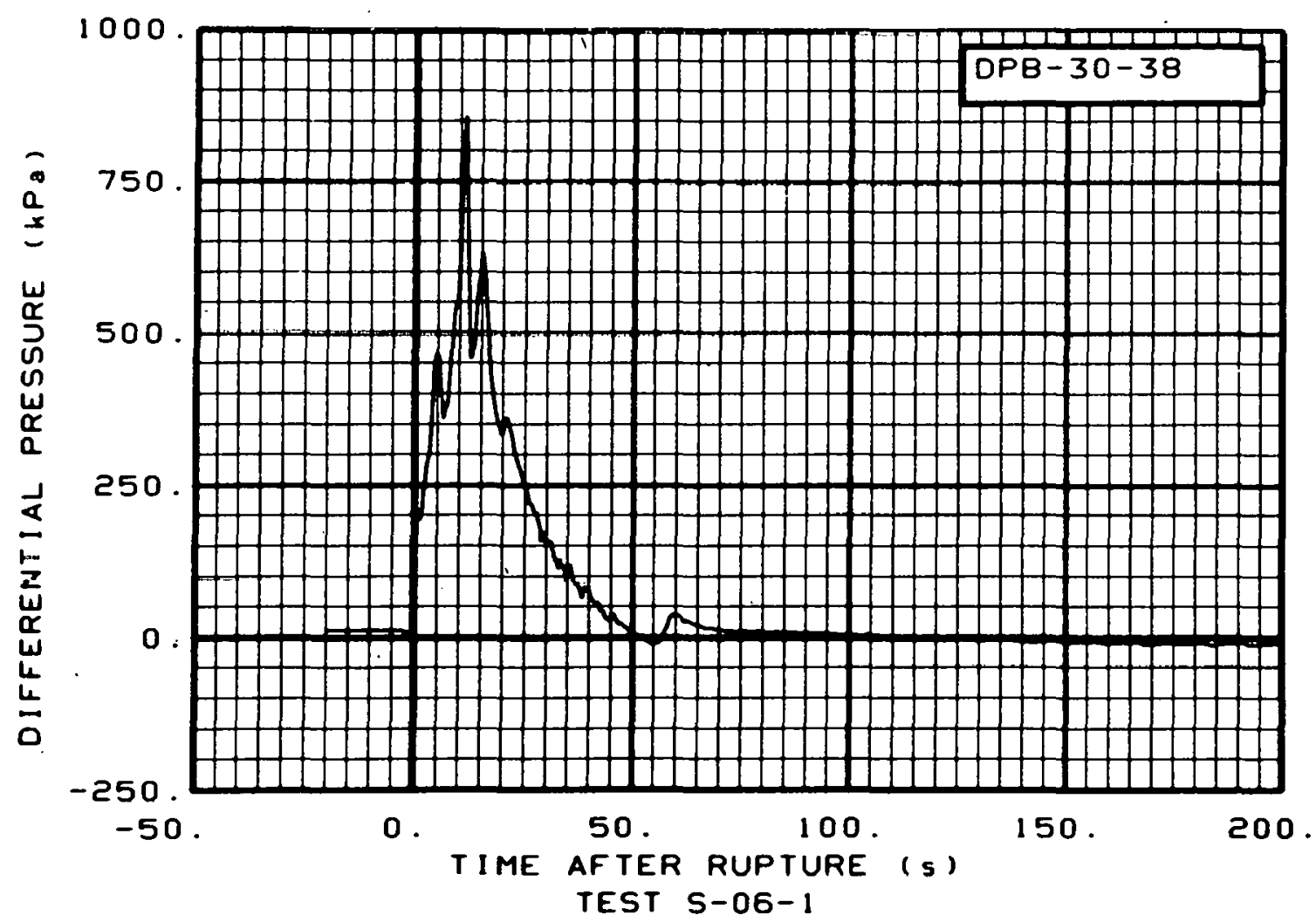

Fig: 185 Differential pressure in broken loop (DPB-30-38), from -20 to $200 \mathrm{~s}$.

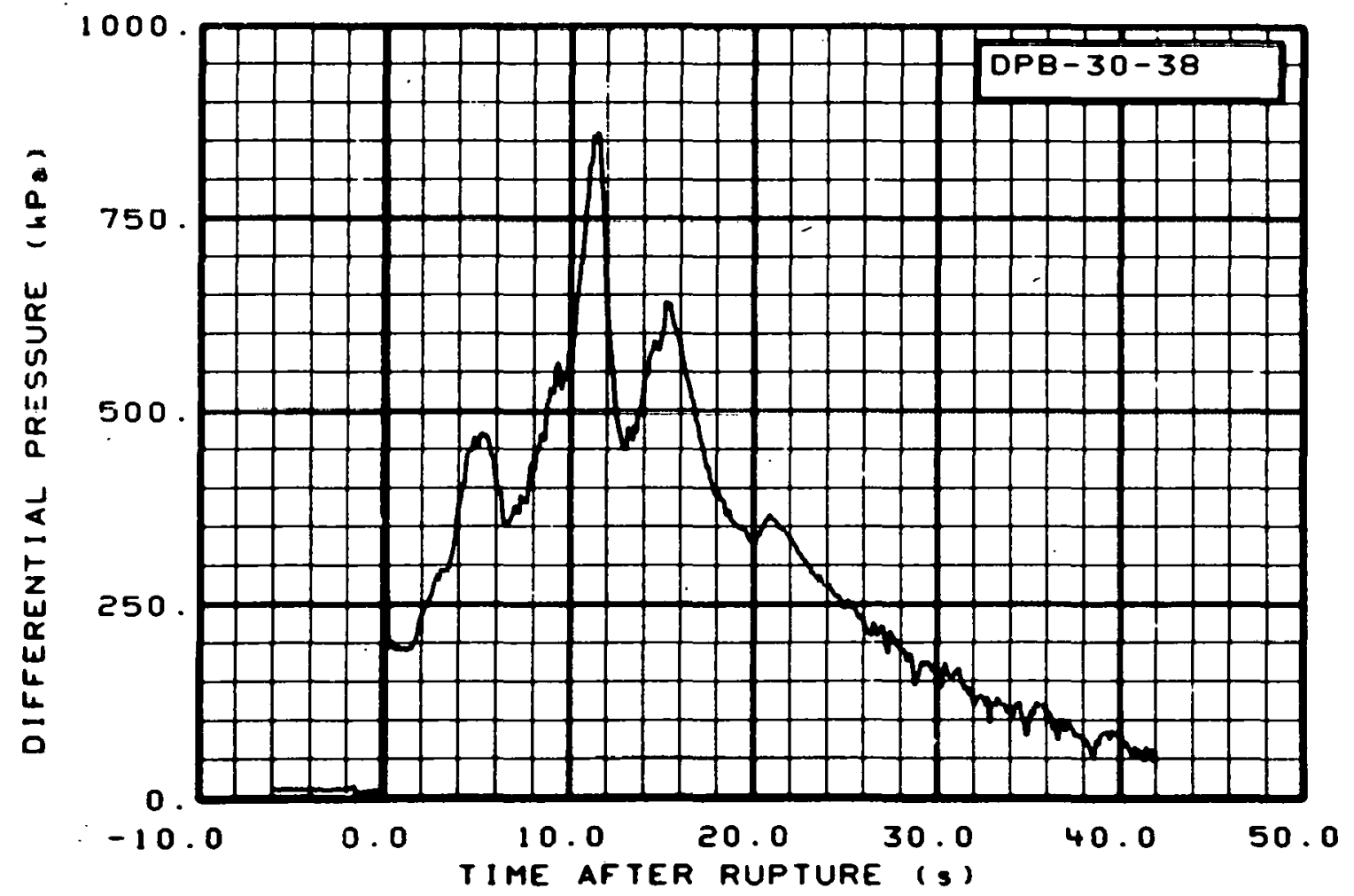

Fig. 186 Differential pressure in broken loop (DPB-30-38), from -6 to $42 \mathrm{~s}$. 


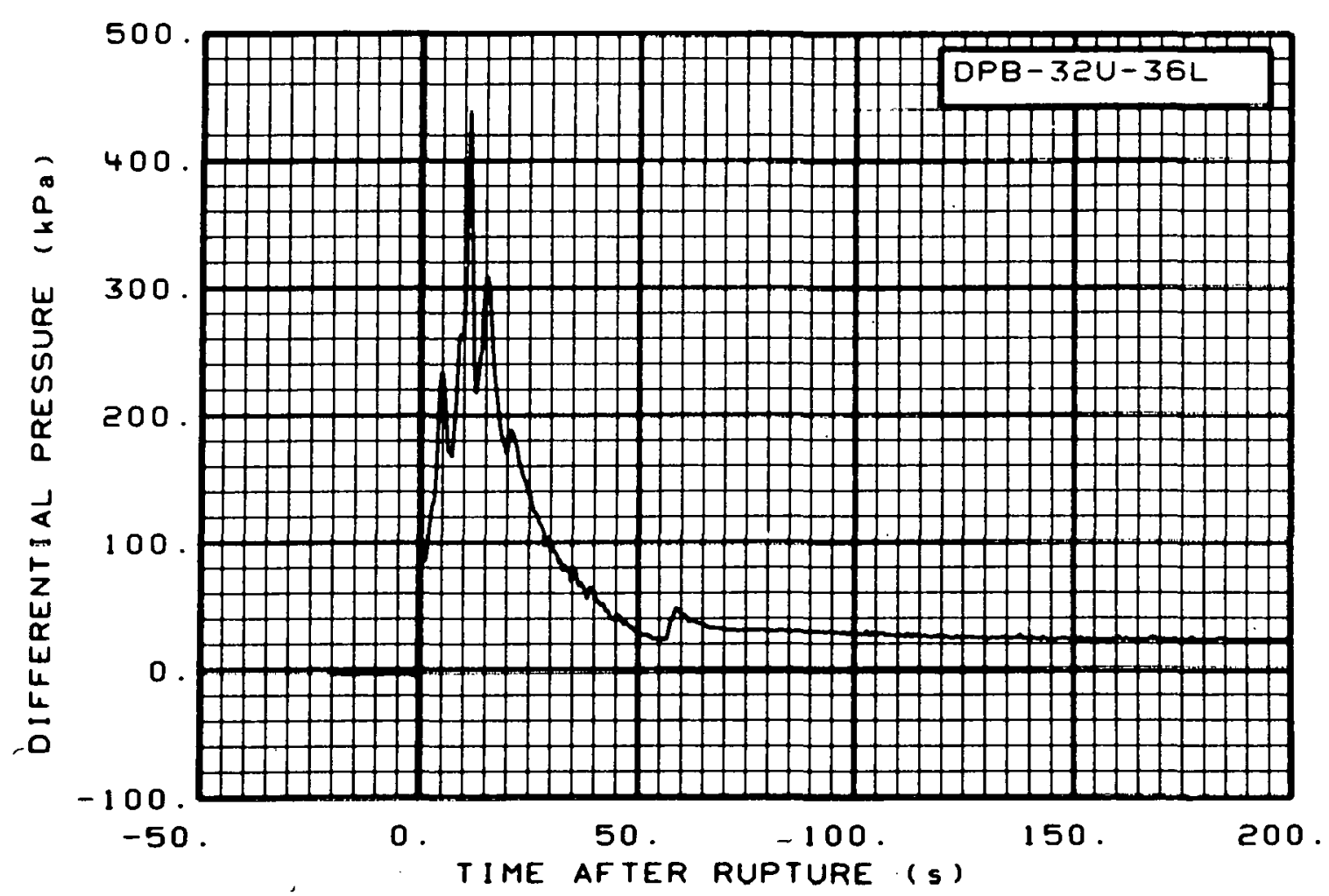

Fig: 187 Differential pressure in broken loop (DPB-32U-36L), from -20 to $200 \mathrm{~s}$.

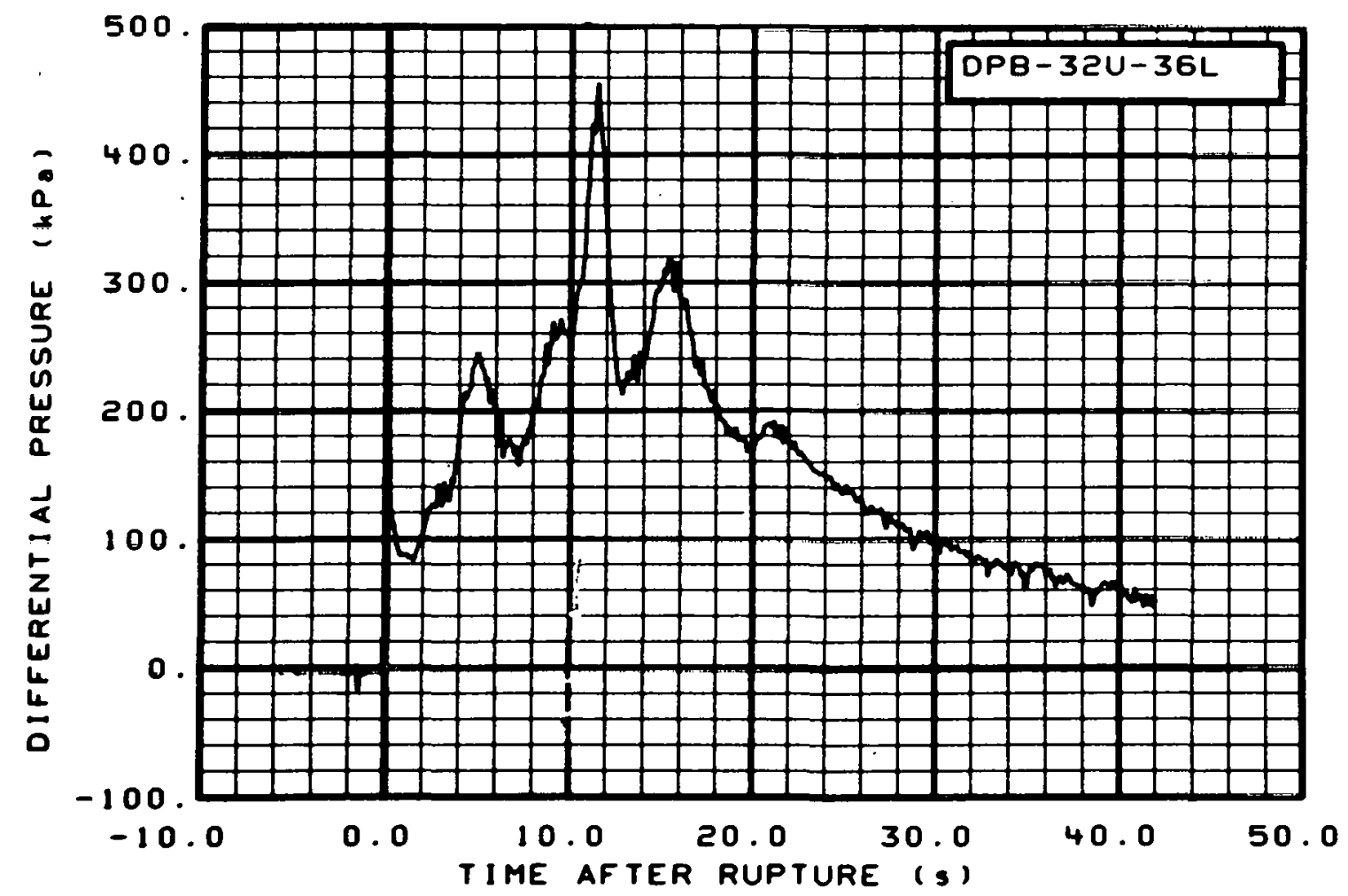

Fig. 188 Differential pressure in broken loop (DPB-32U-36L), from -6 to $42 \mathrm{~s}$. 


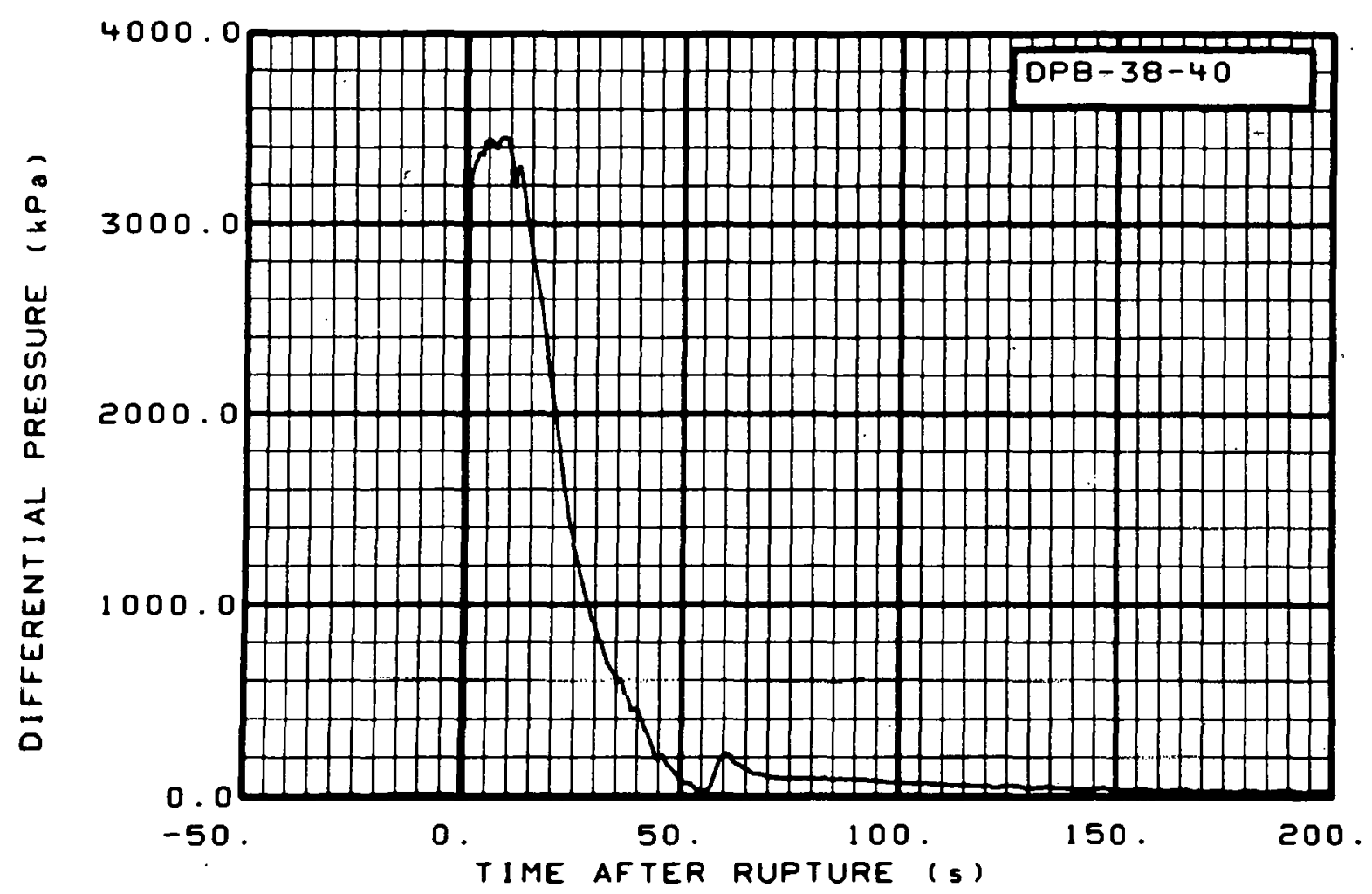

Fig. 189 Differential pressure in broken loop (DPB-38-40), from -20 to $200 \mathrm{~s}$.

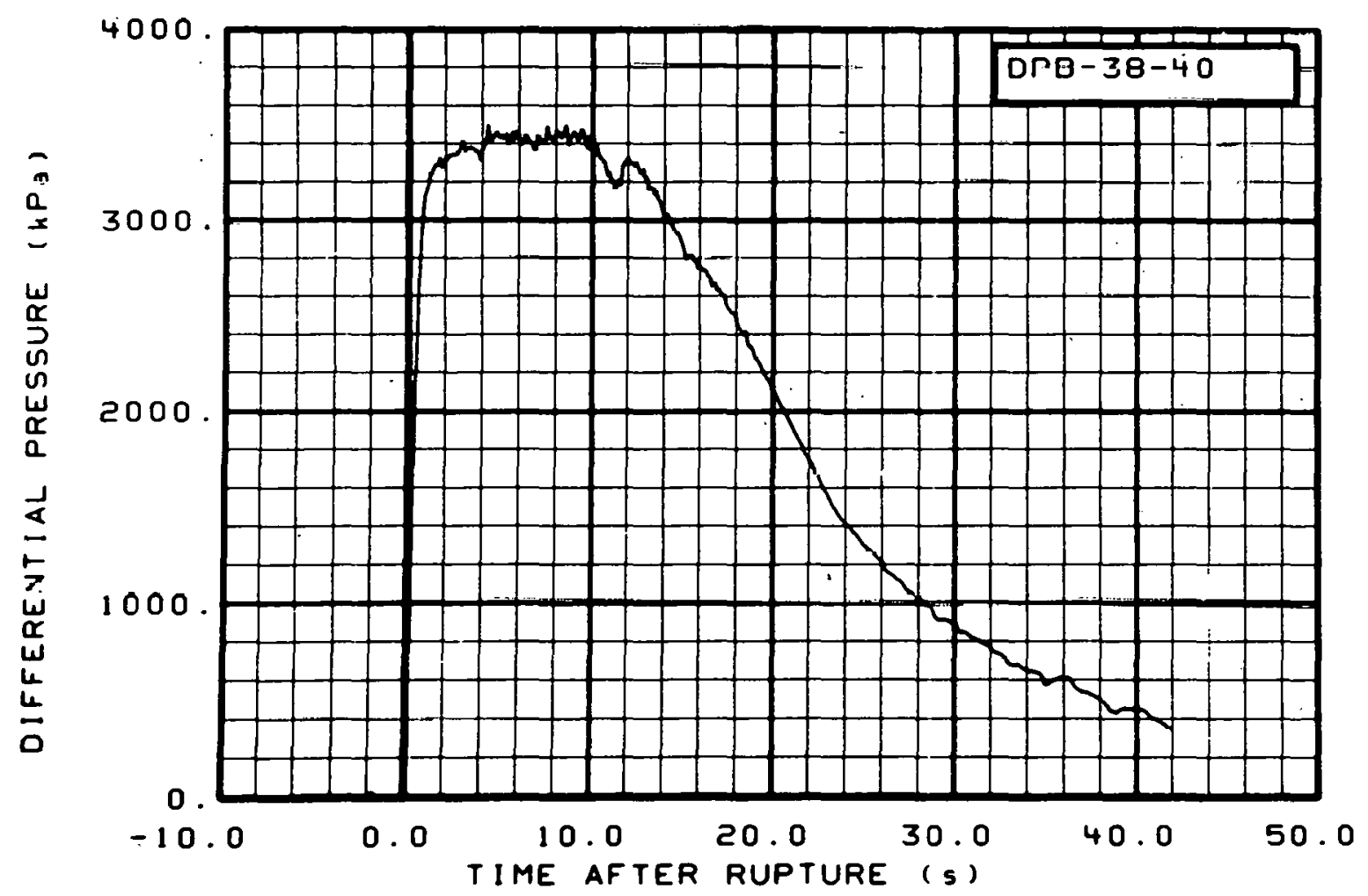

Fig. 190 Differential pressure in broken loop (DPB-38-40), from -6 to $42 \mathrm{~s}$. 


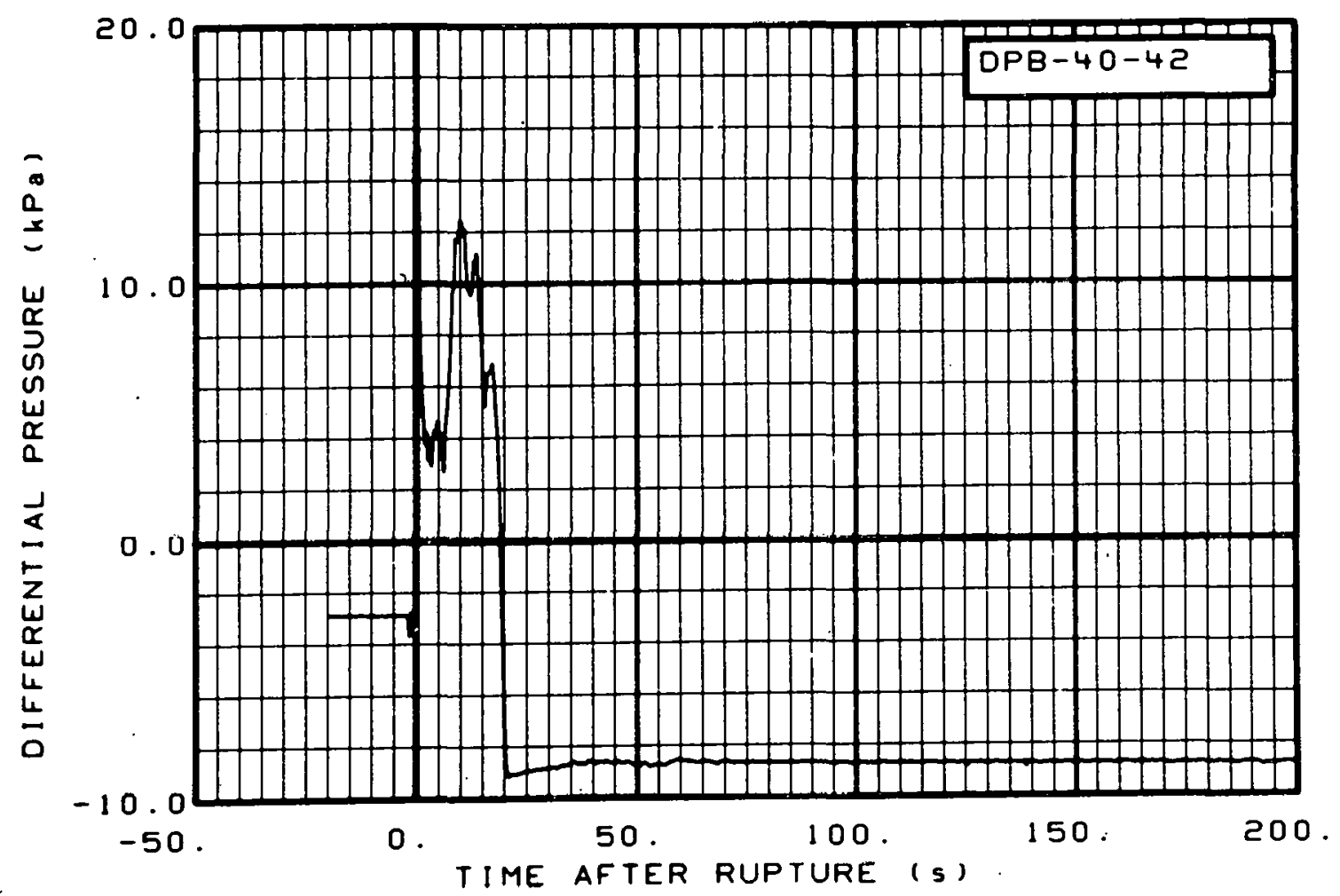

Fig. 191 Differential pressure in broken loop (DPB-40-42), from -20 to $200 \mathrm{~s}$.

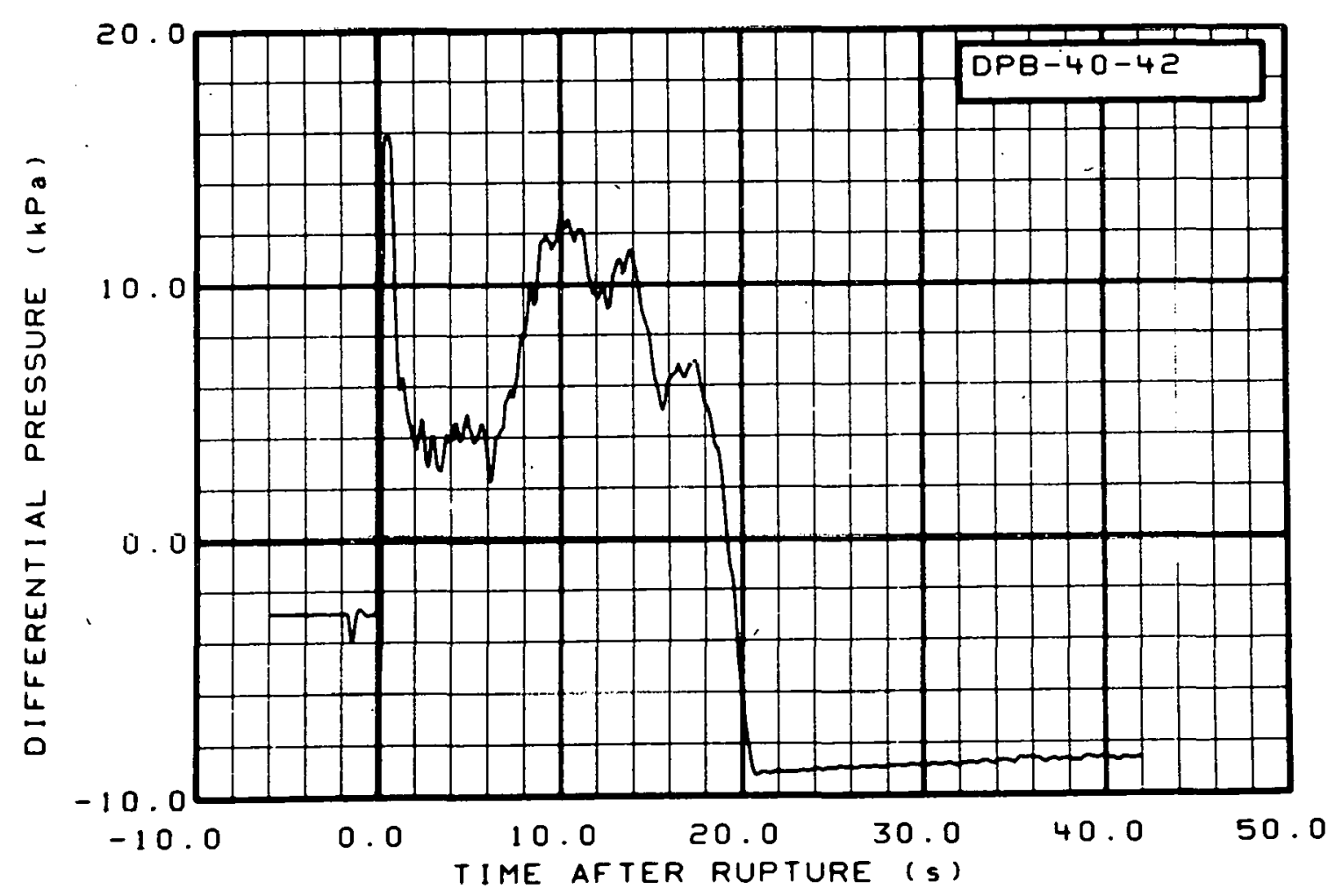

Fig. 192 Differential pressure in broken loop (DPB-40-42), from -6 to $42 \mathrm{~s}$. 


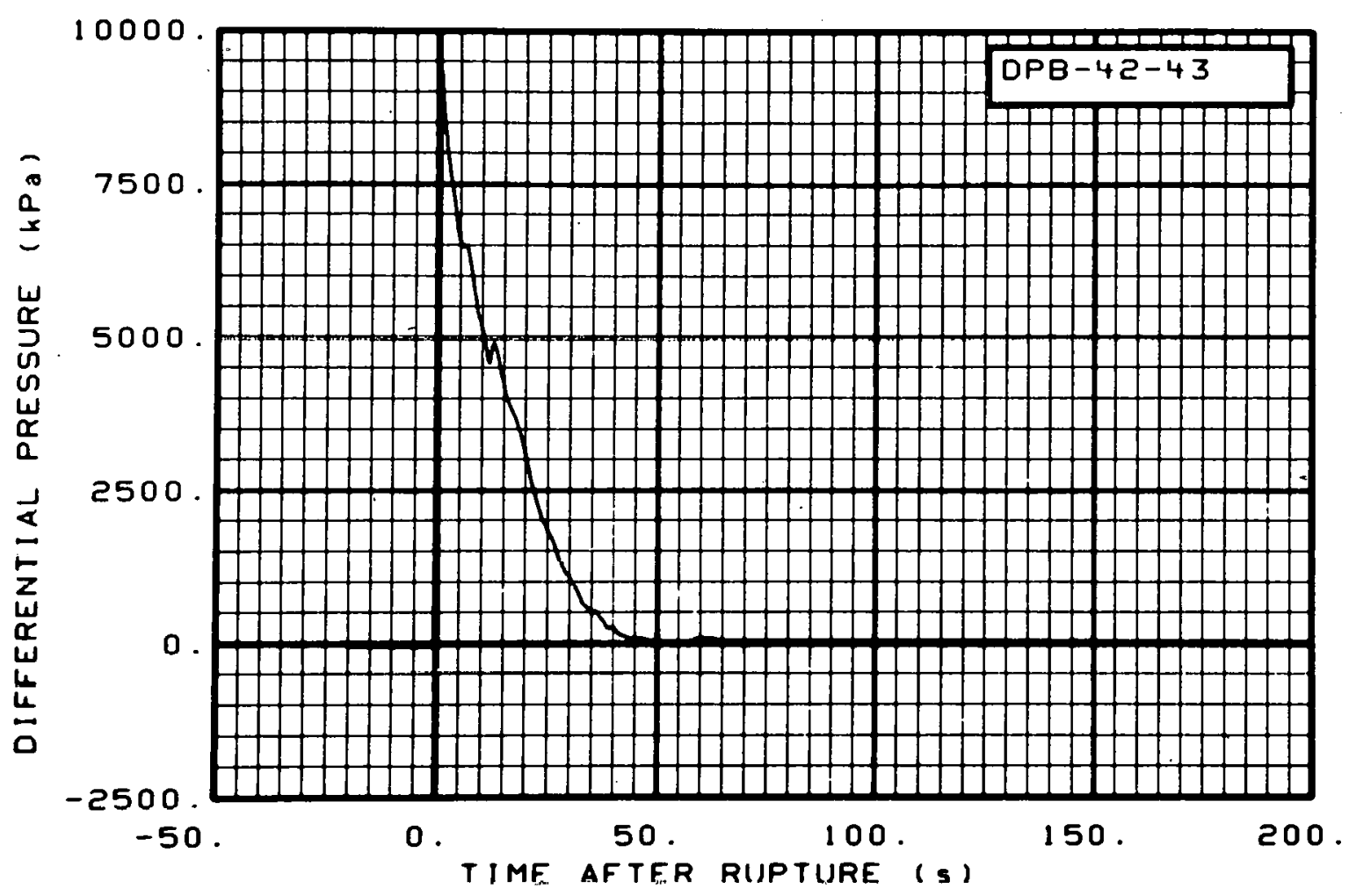

Fig. 193 Differential pressure in broken loop (DPB-42-43), from -20 to $200 \mathrm{~s}$.

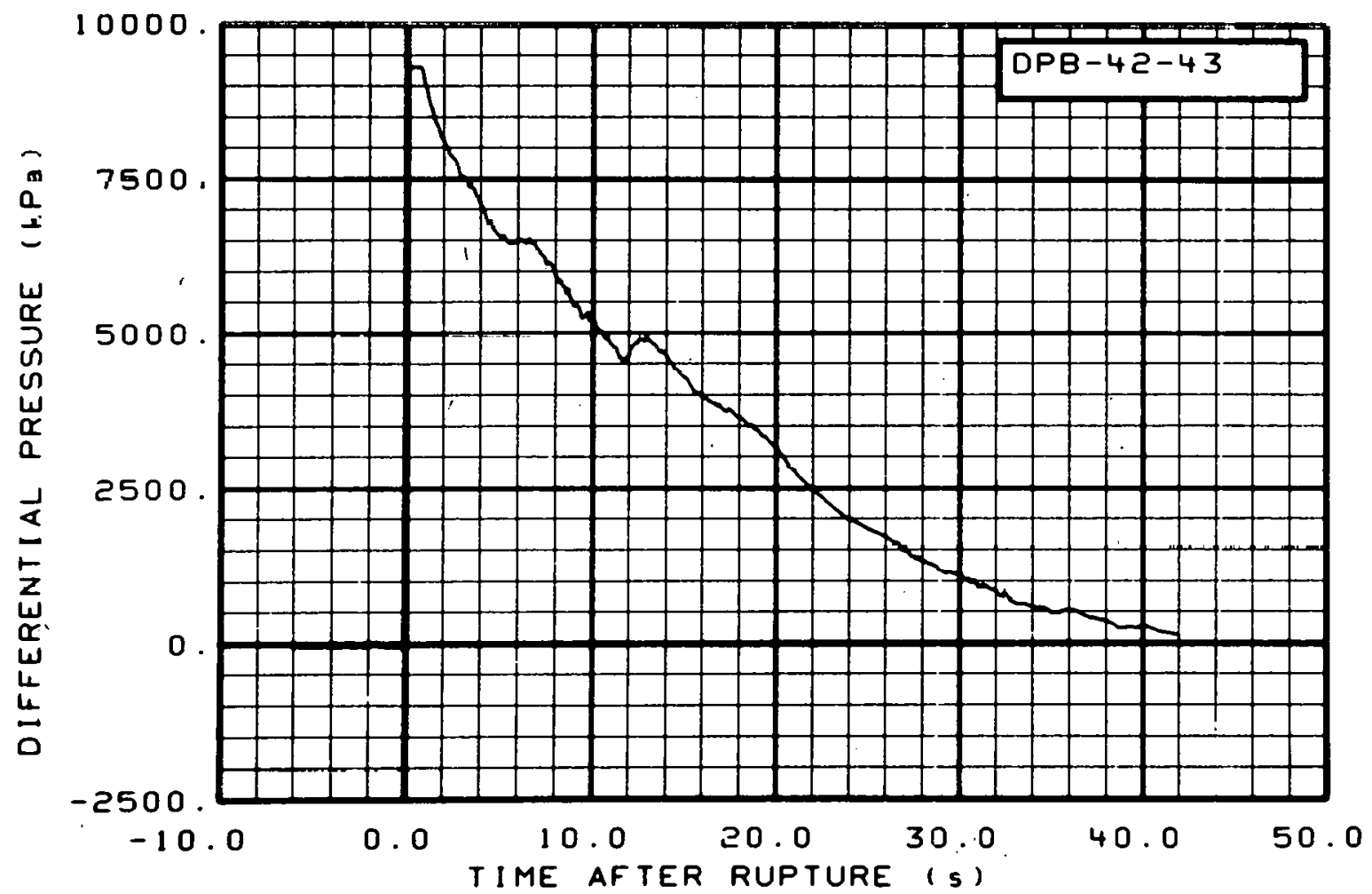

Fig. 194 Differential pressure in broken loop (DPB-42-43), from -6 to $42 \mathrm{~s}$. 


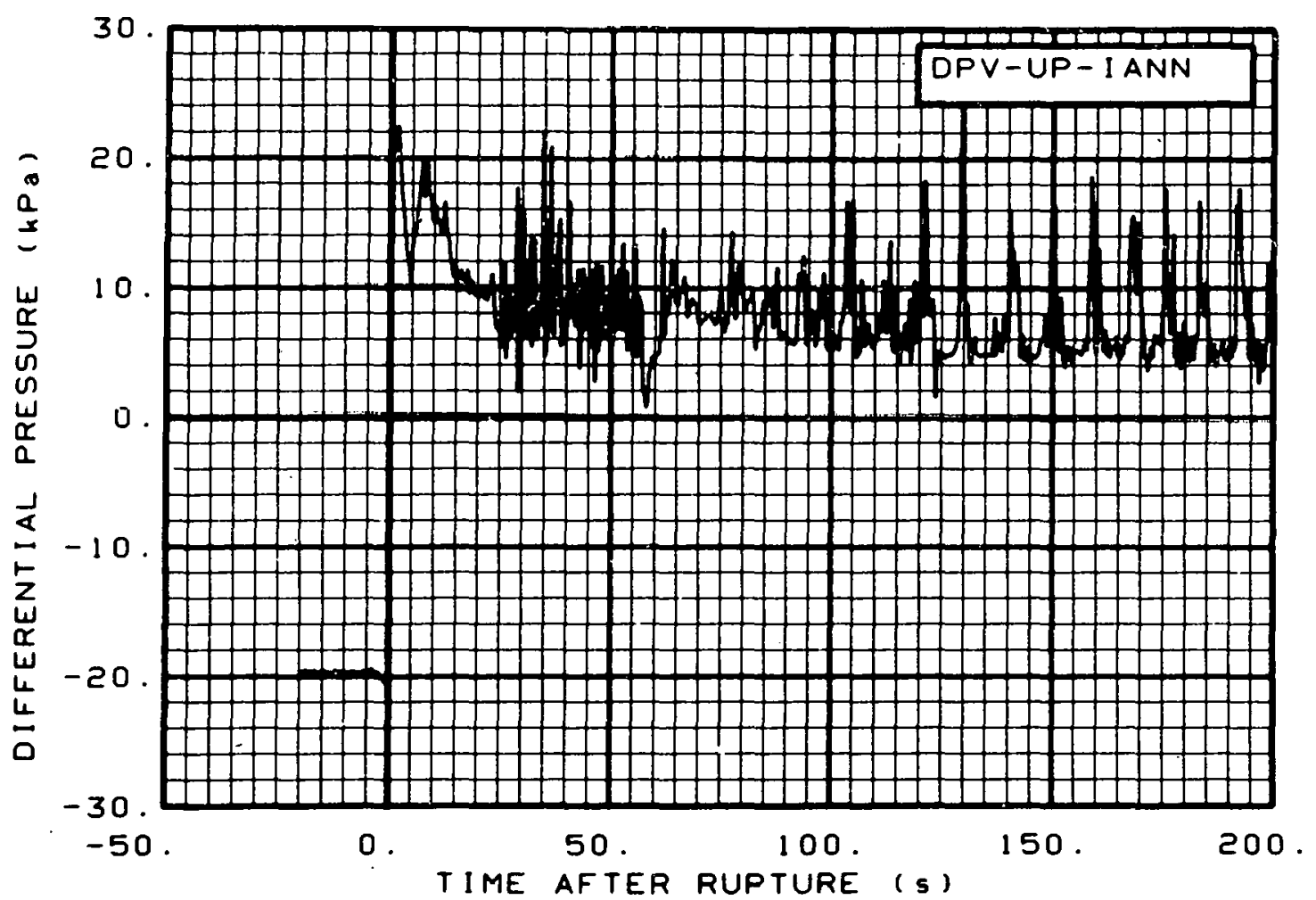

Fig. 195 Differential pressure in vessel (DPV-UP-IANN), from -20 to $200 \mathrm{~s}$.

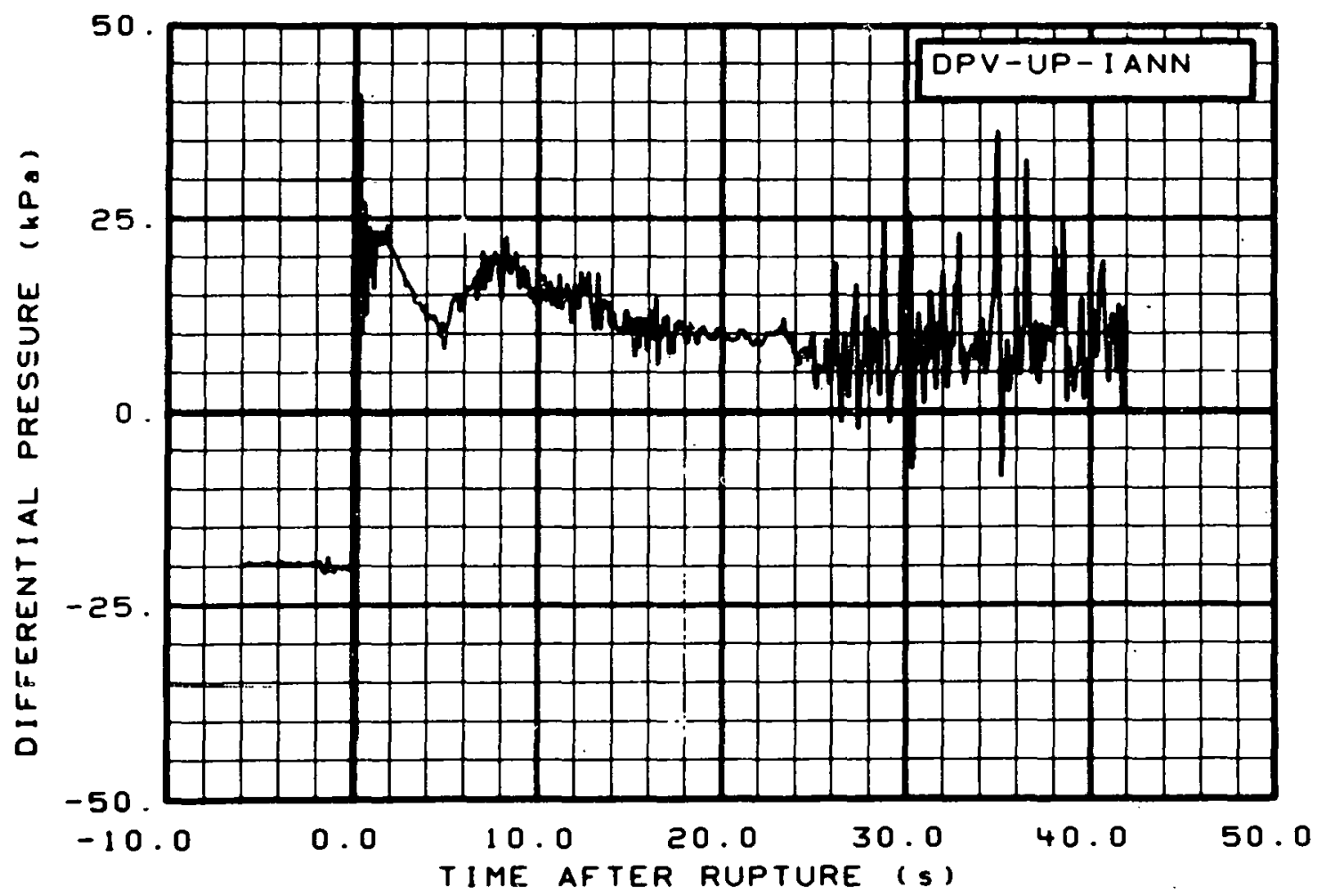

Fig. 196 Differential pressure in vessel (DPV-UP-IANN), trom -6 to $42 \mathrm{~s}$. 


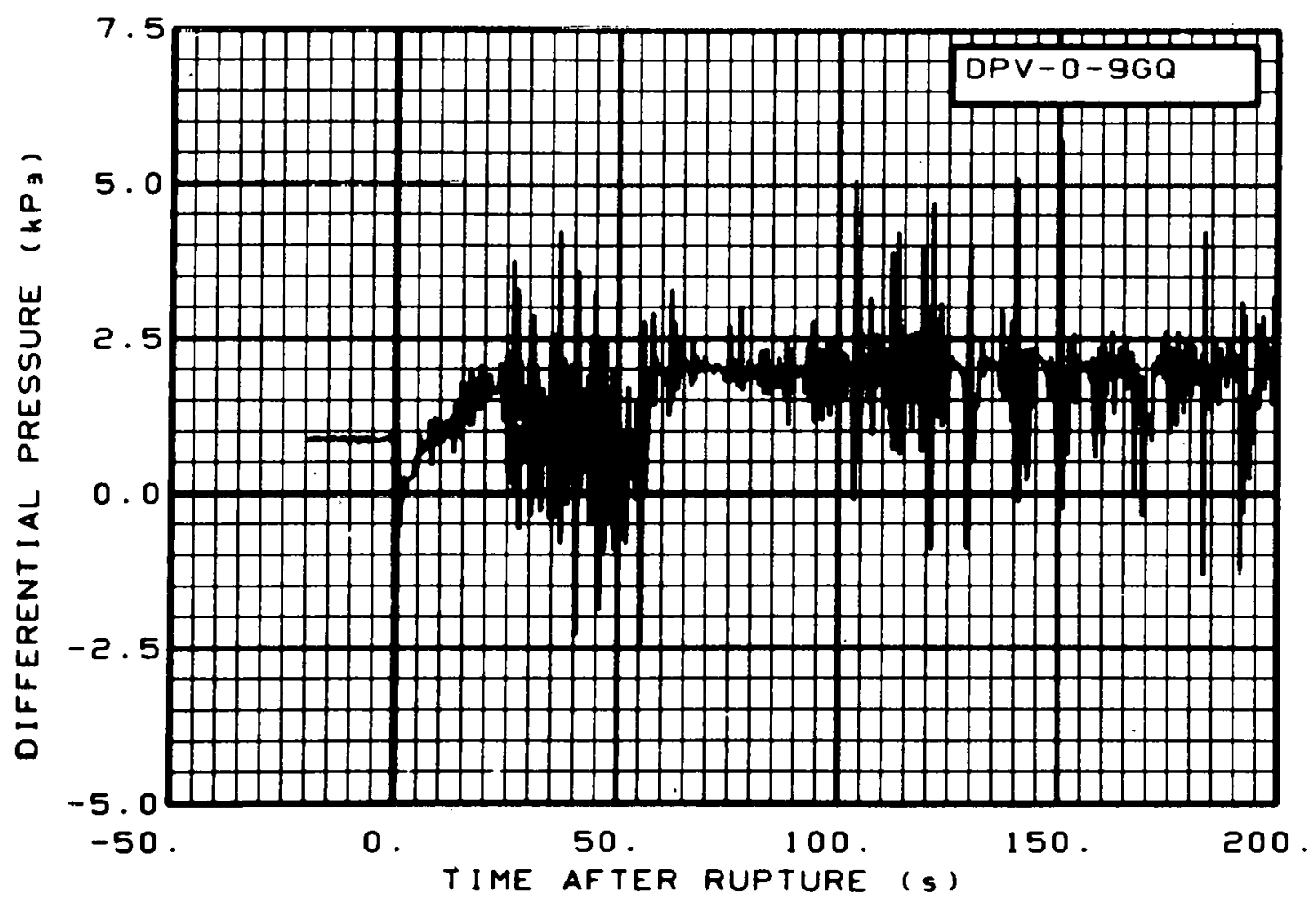

Fig. 197 Differential pressure in vessel (DPV-0-9GQ), from -20 to $200 \mathrm{~s}$.

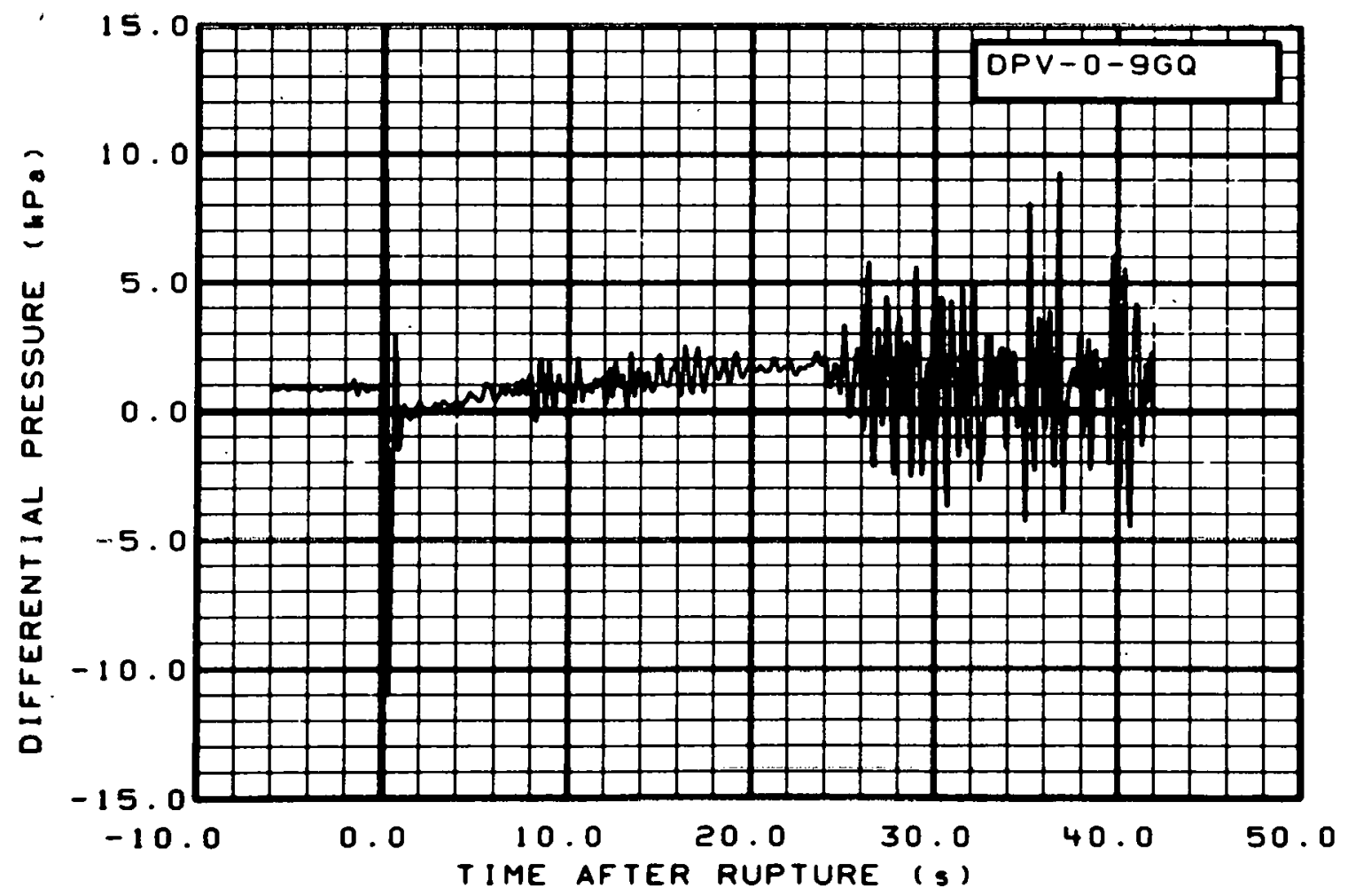

Fig. 198 Differential pressure in vessel (DPV-0-9GQ), from -6 to $42 \mathrm{~s}$. 


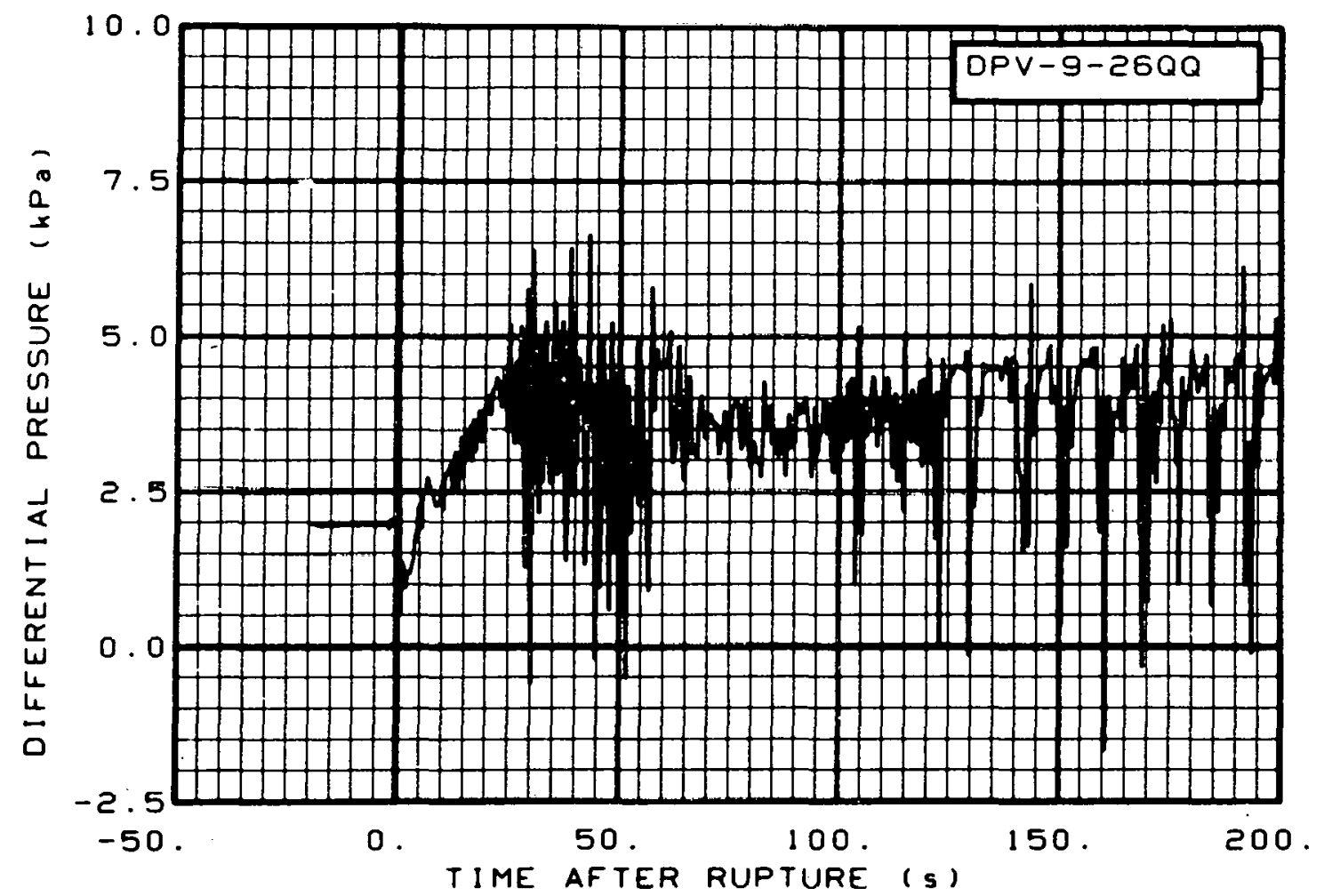

Fig. 199 Differential pressure in vessel (DPV-9-26QQ), from -20 to $200 \mathrm{~s}$.

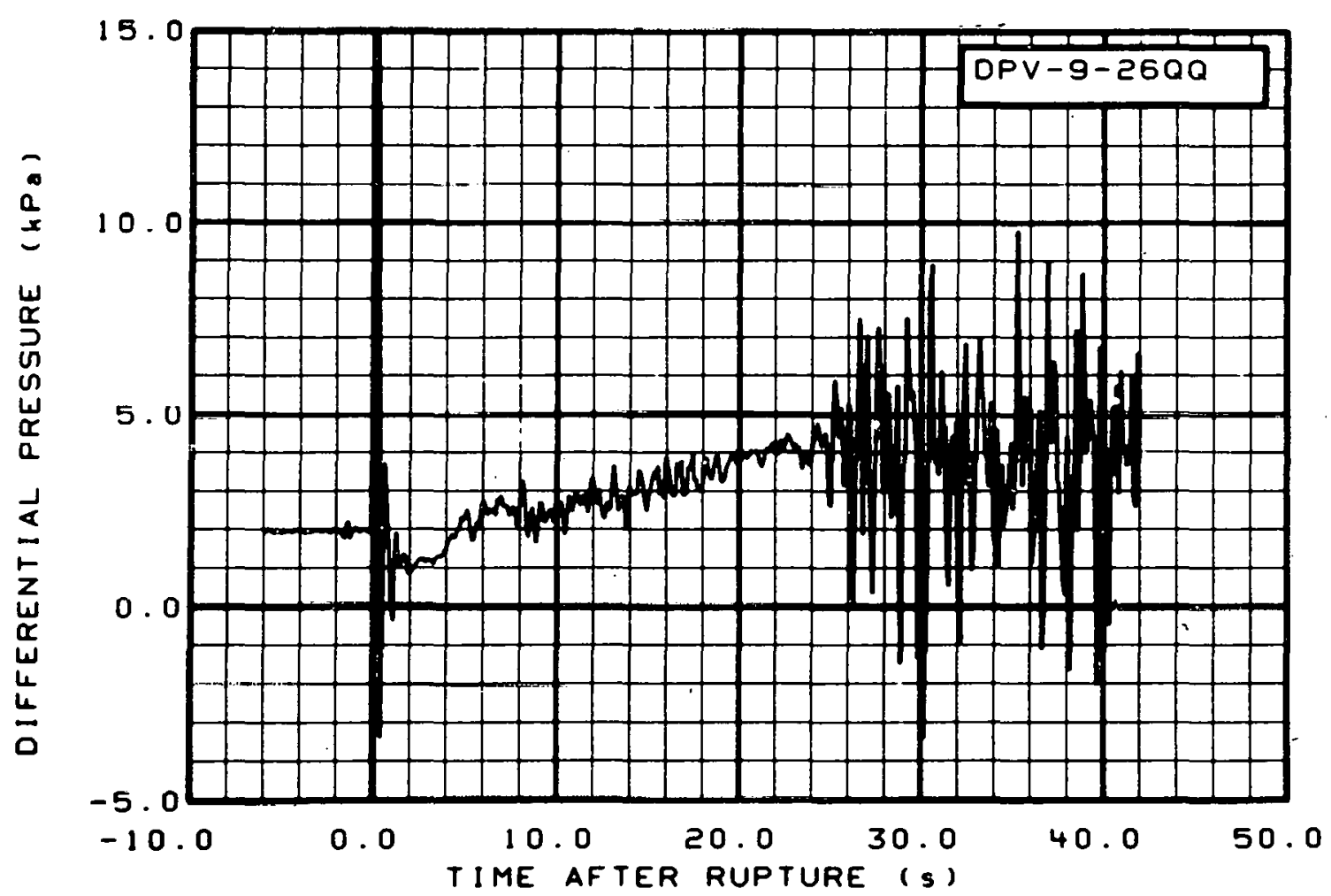

Fig. 200 Differential pressure in vessel (DPV-9-26QQ), from -6 to $42 \mathrm{~s}$. 


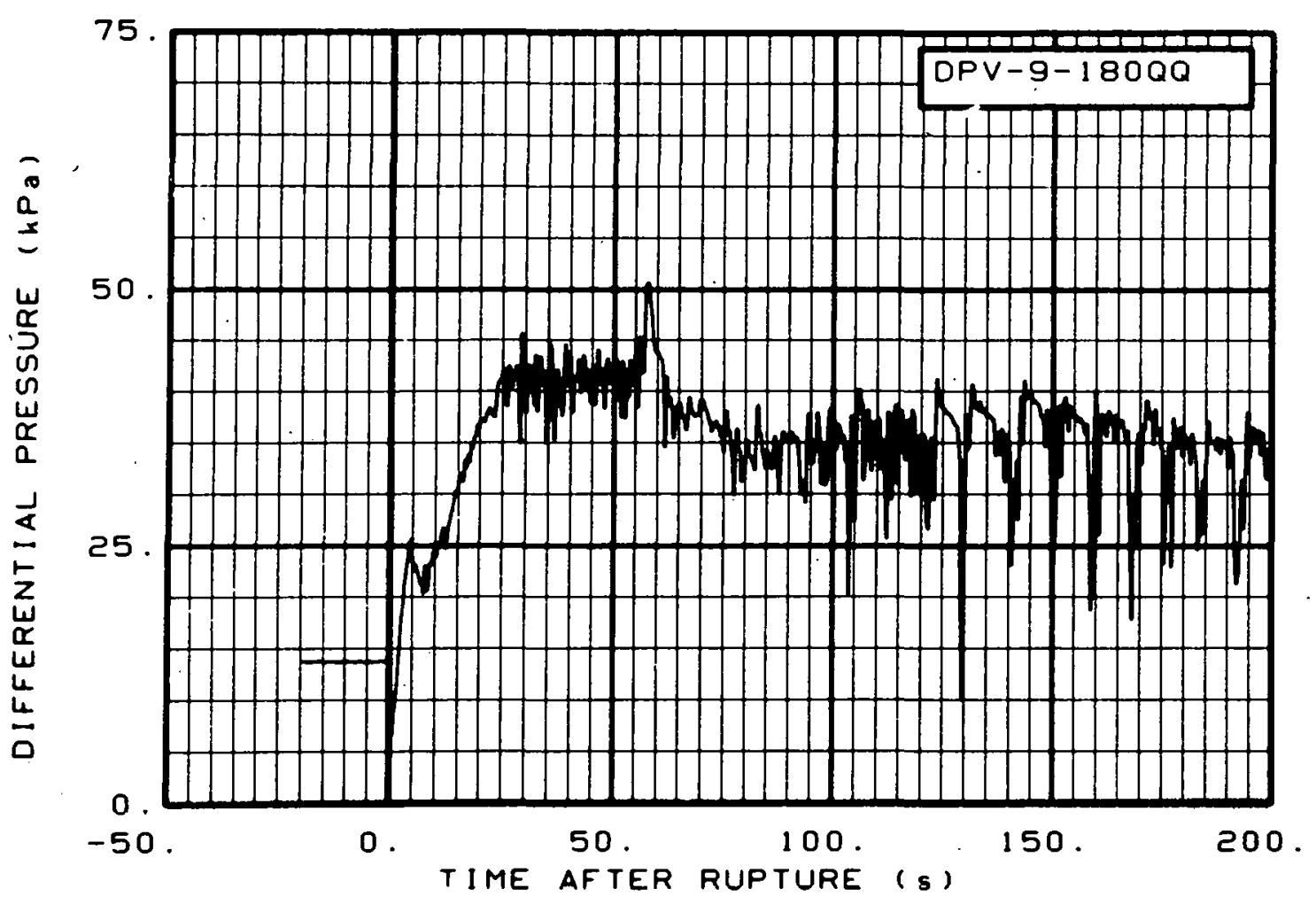

Fig. 201 Differential pressure in vessel (DPV-9-180QQ), from -20 to $200 \mathrm{~s}$.

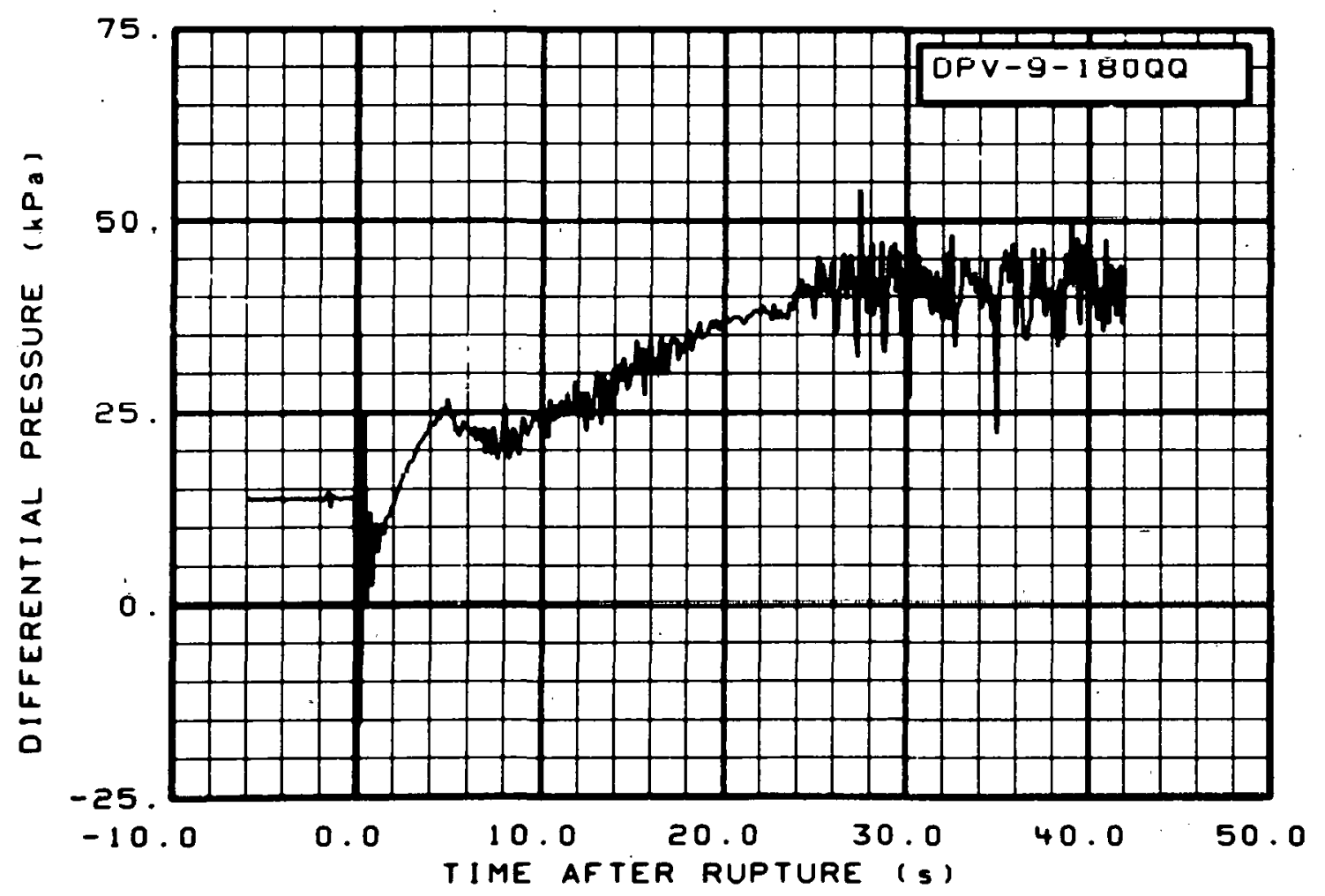

Fig. 202 Differential pressure in vessel (DPV-9-180QQ), from -6 to $42 \mathrm{~s}$. 


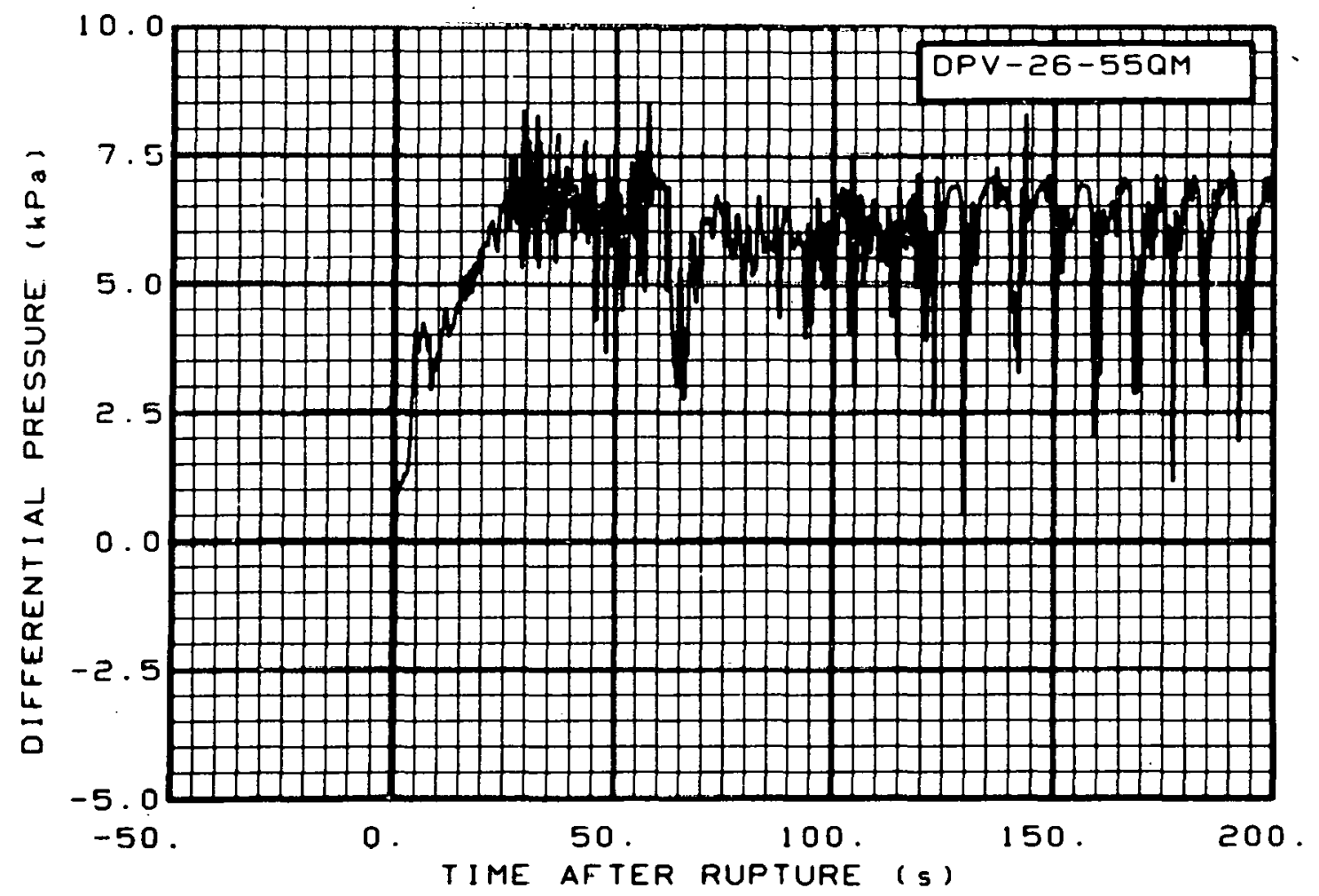

Fig. 203 Differential pressure in vessel (DPV-26-55QM), from -20 to $200 \mathrm{~s}$.

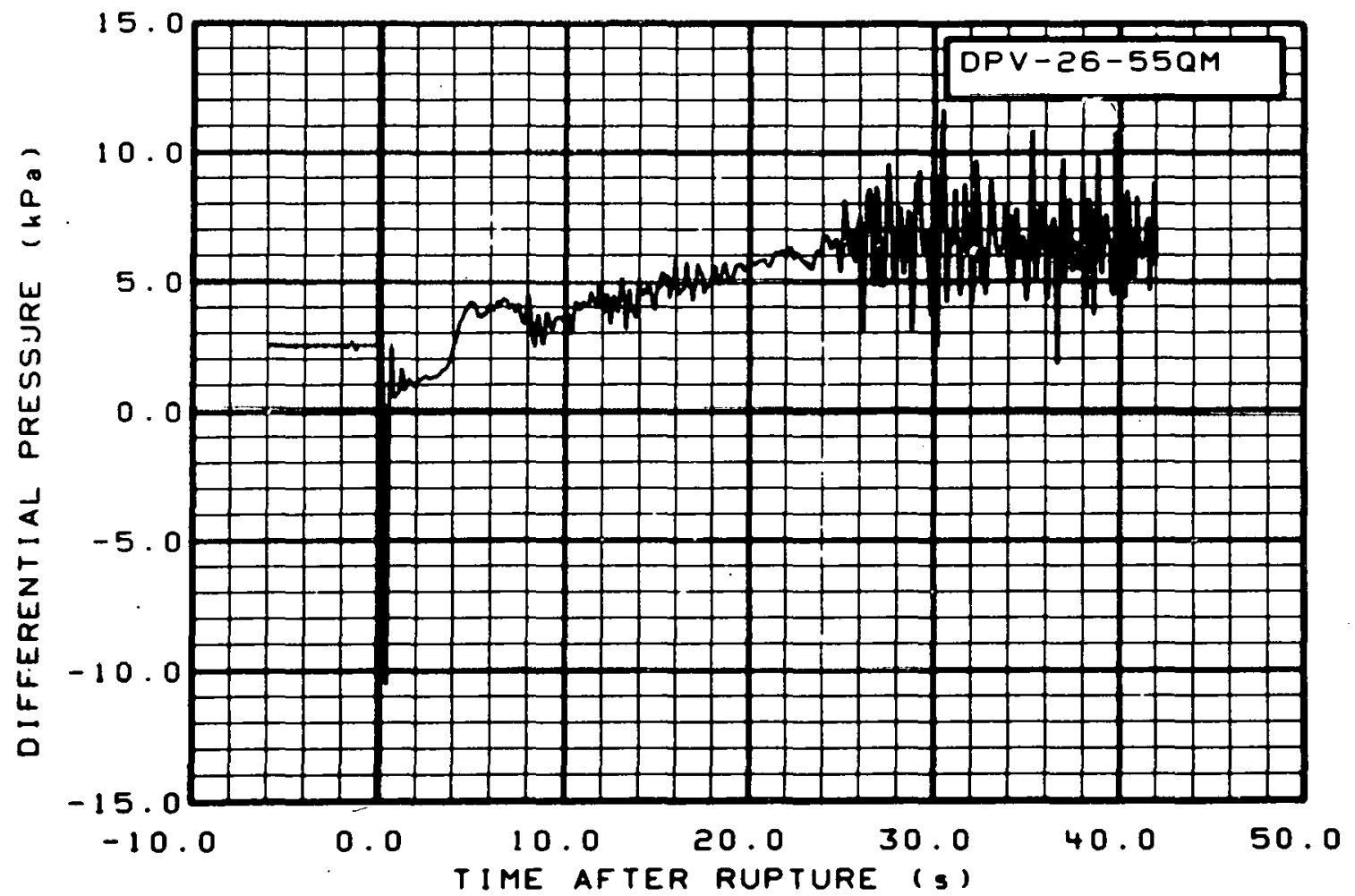

Fig. 204 Differential pressure in vessel (DPV-26-5bUM), from -6 to $42 \mathrm{~s}$. 


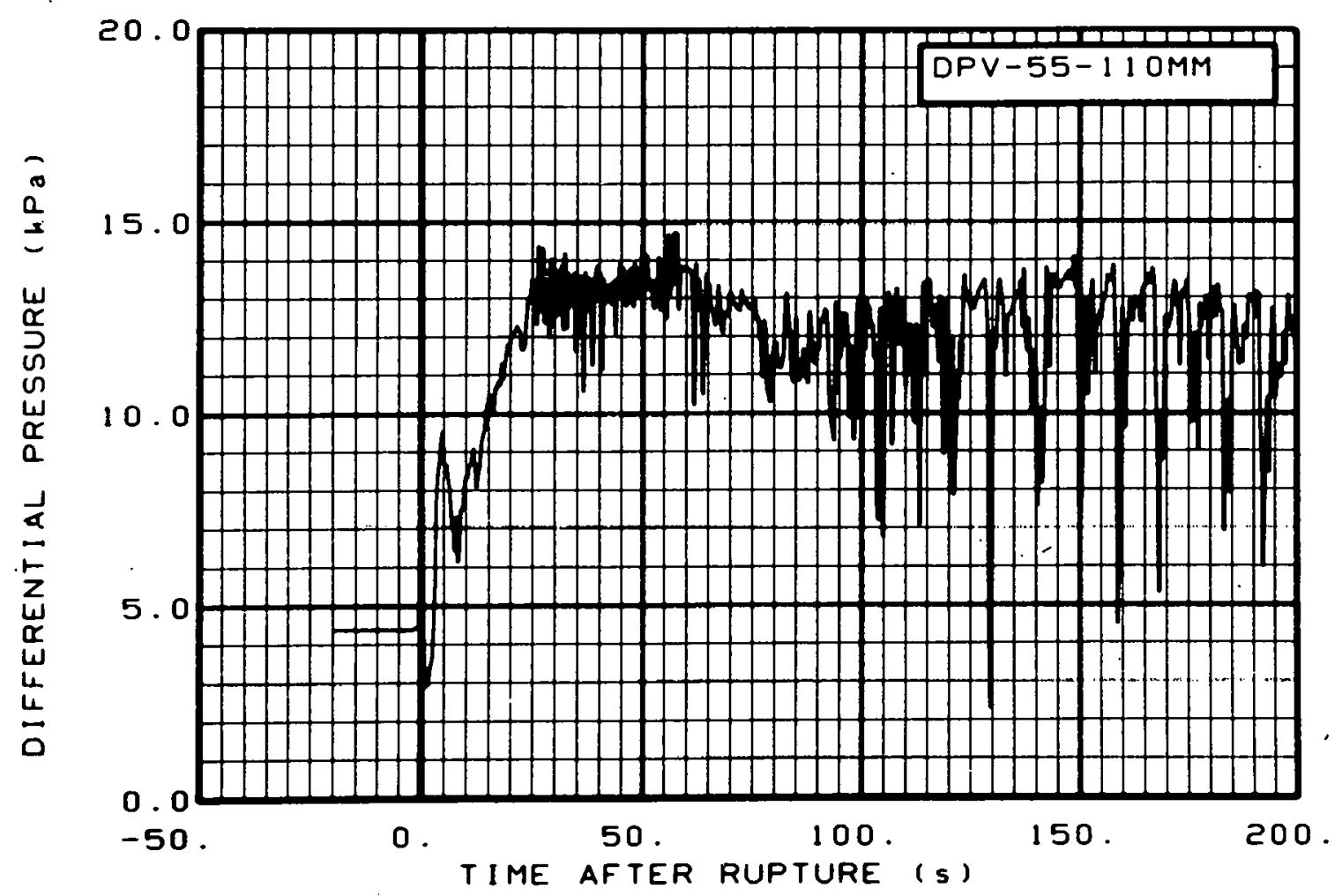

Fig. 205 Differential pressure in vessel (DPV-55-110MM), from -20 to $200 \mathrm{~s}$.

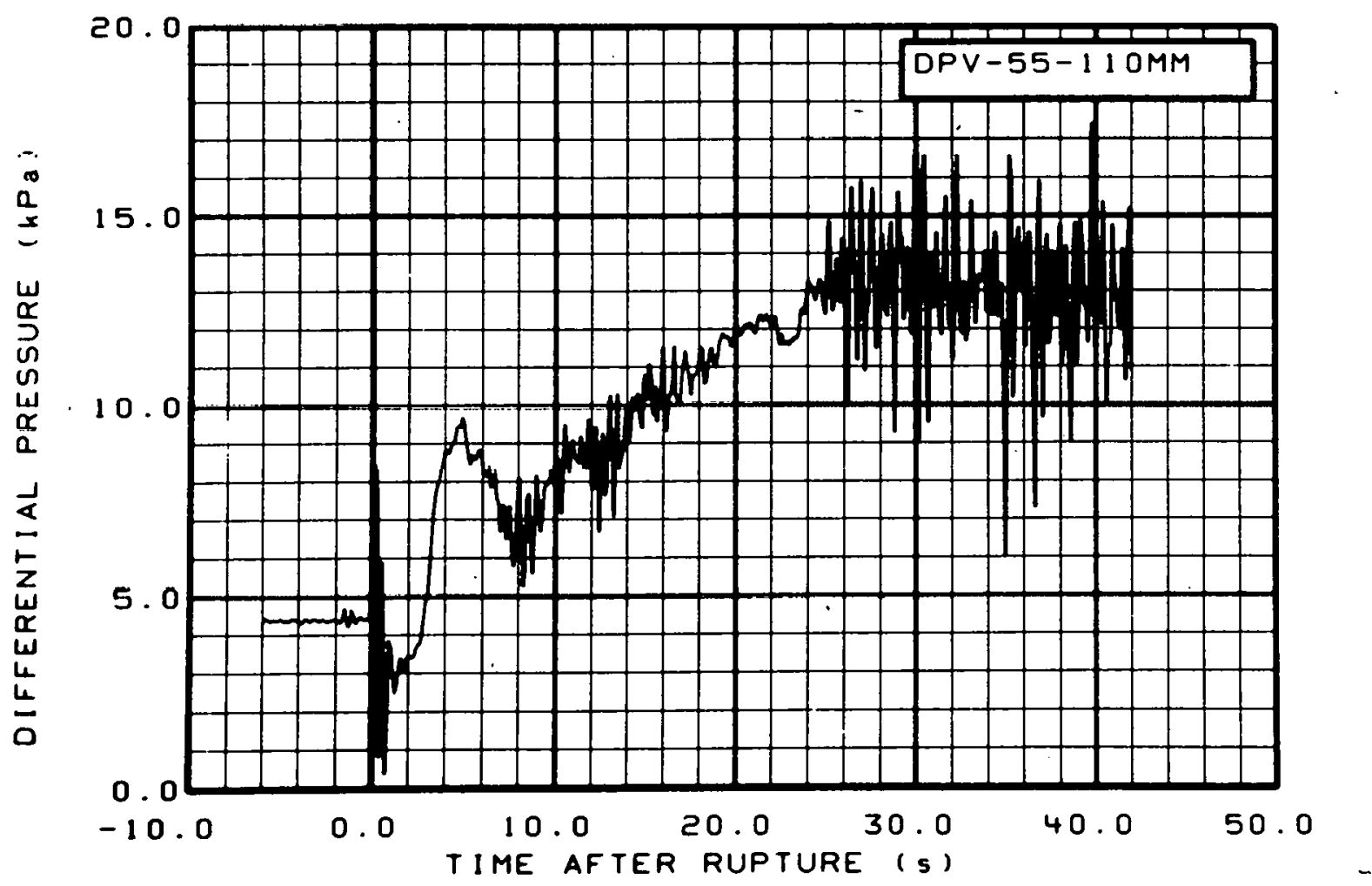

Fig. 206 Differential pressure in vessel (DPV-55-110MM), from -6 to $42 \mathrm{~s}$. 


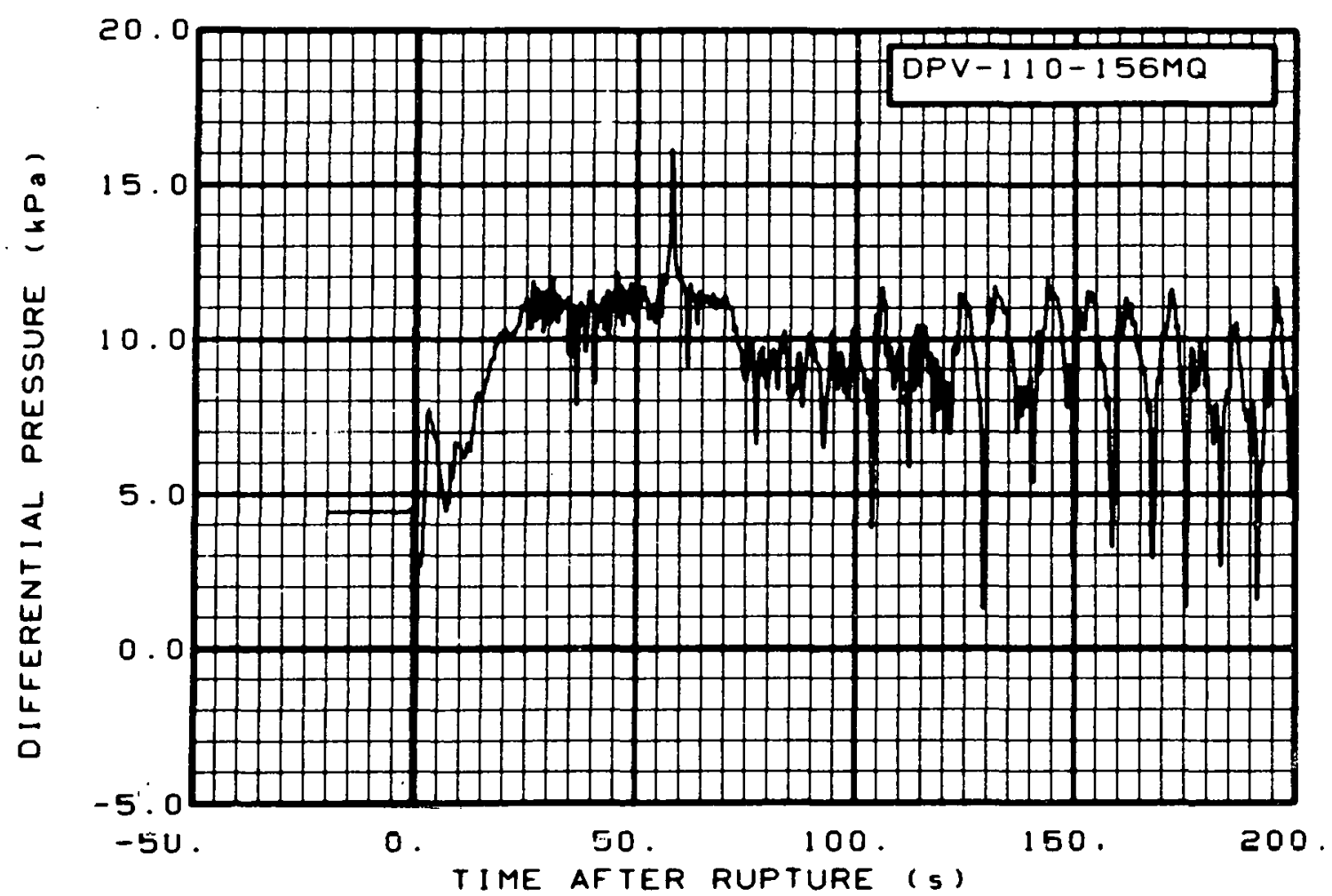

Fig. 207 Differential pressure in vessel (DPV-110-156MQ), from -20 to $200 \mathrm{~s}$.

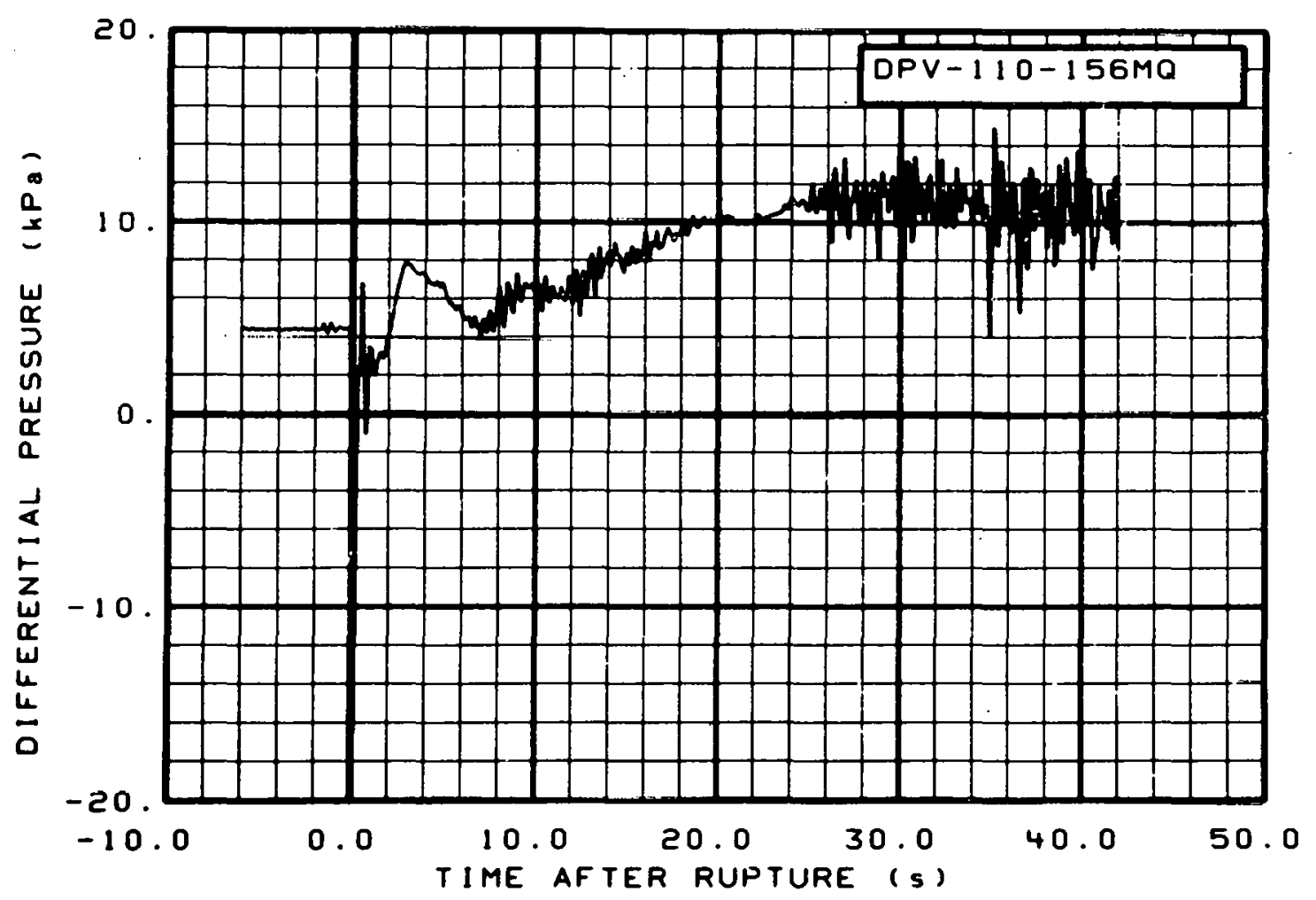

Fig. 208 Differential pressure in vessel (DPV-110-156MQ), from -6 to $42 \mathrm{~s}$. 


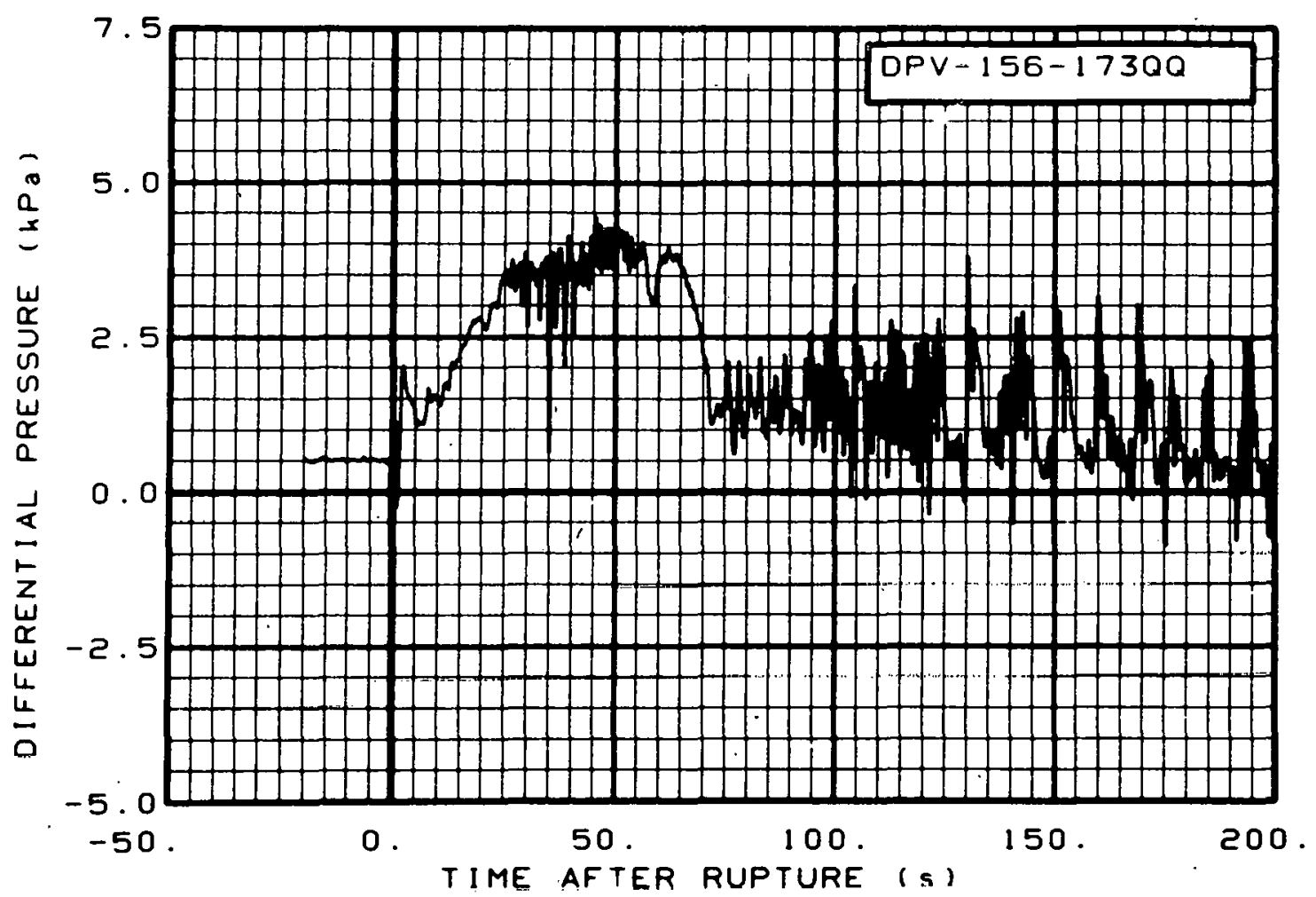

Fig: 209 Differential pressure in vessel (DPV-156-1730Q), from -20 to $200 \mathrm{~s}$.

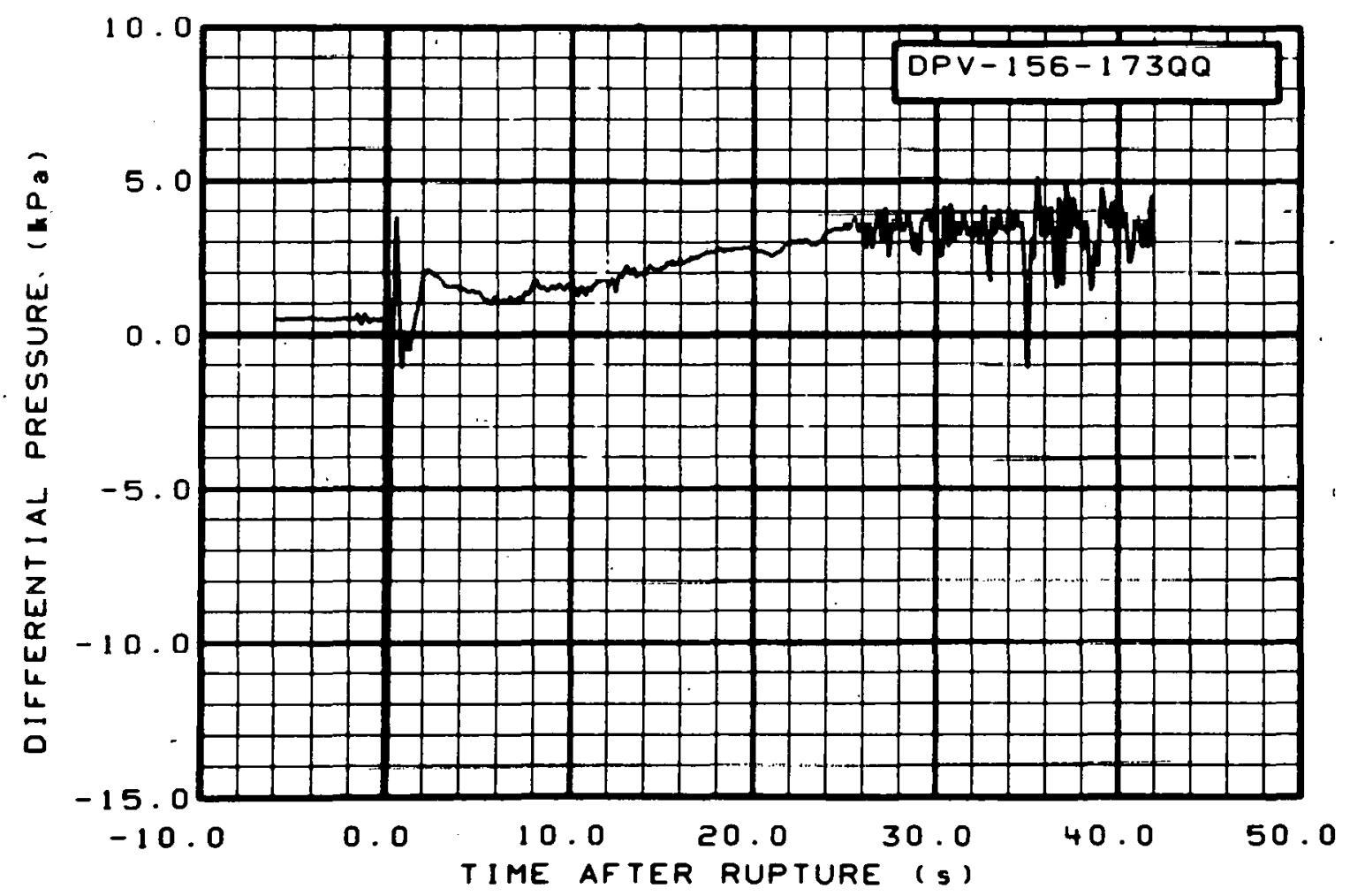

Fig. 210 Differential pressure in vessel (DPV-156-173QQ), from -6 to $42 \mathrm{~s}$. 


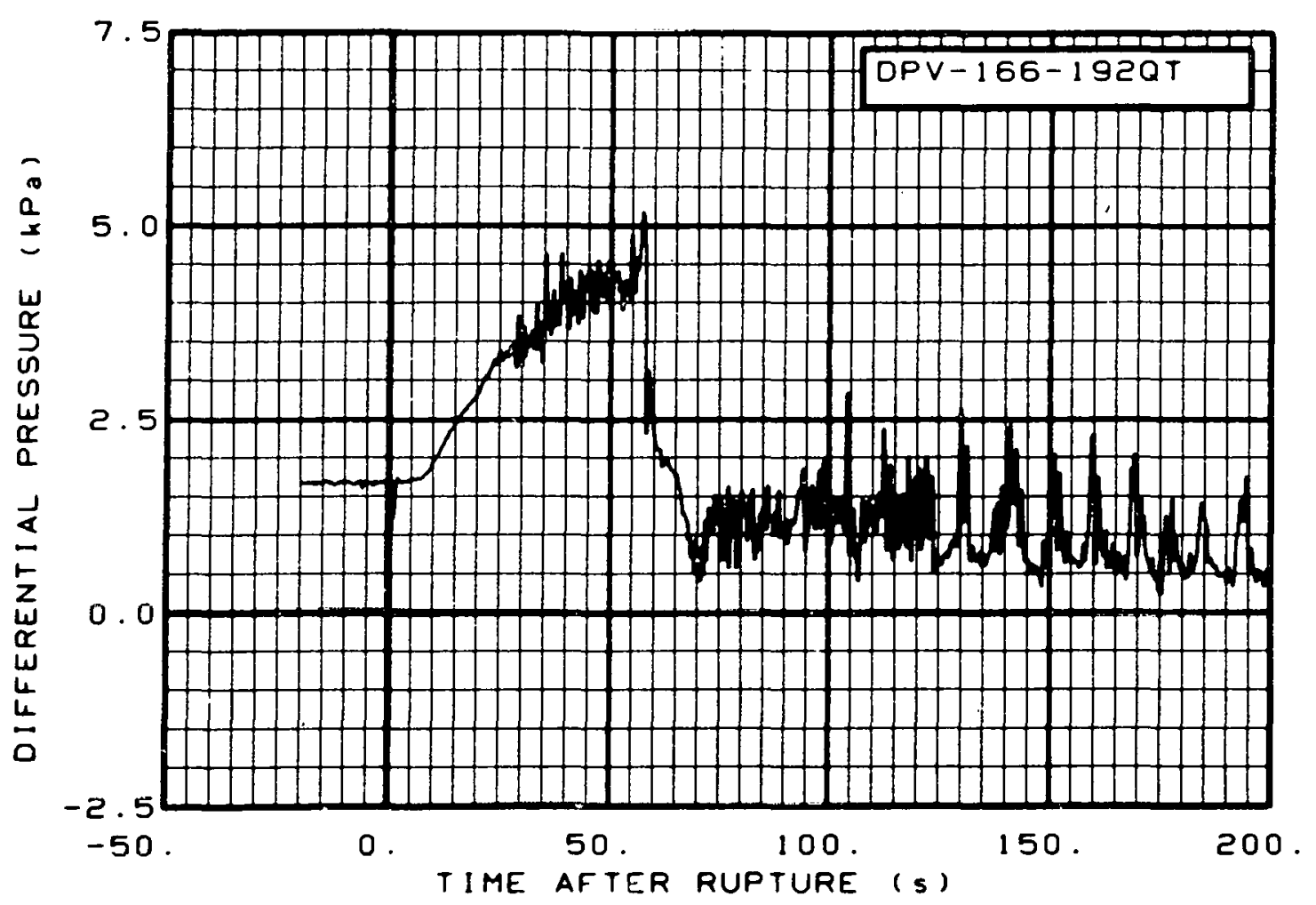

Fig. 211 Differential pressure in vessel (DPV-166-192QT), from -20 to $200 \mathrm{~s}$.

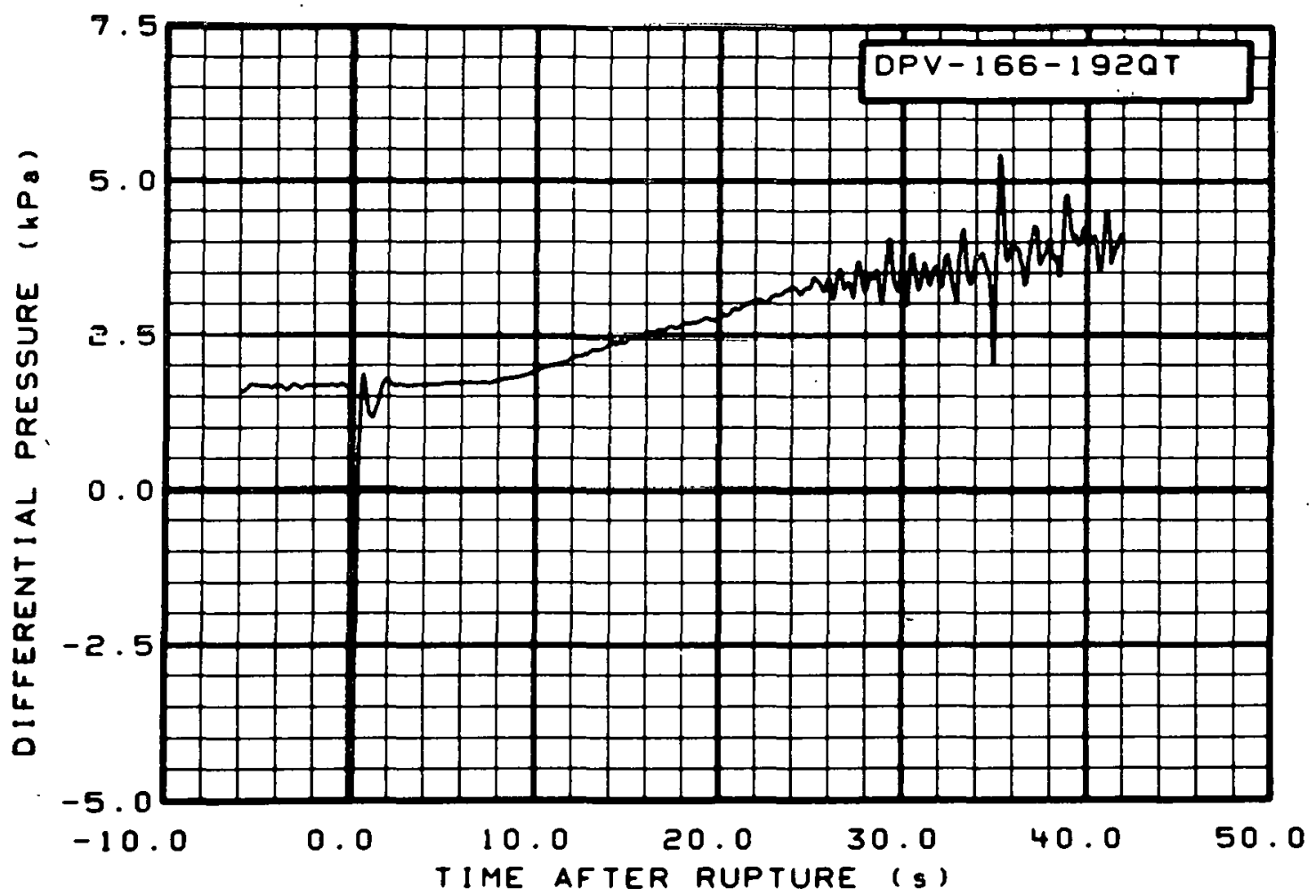

Fig. 212 Differential pressure in vessel (DPV-166-192QT), from -6 to $42 \mathrm{~s}$. 


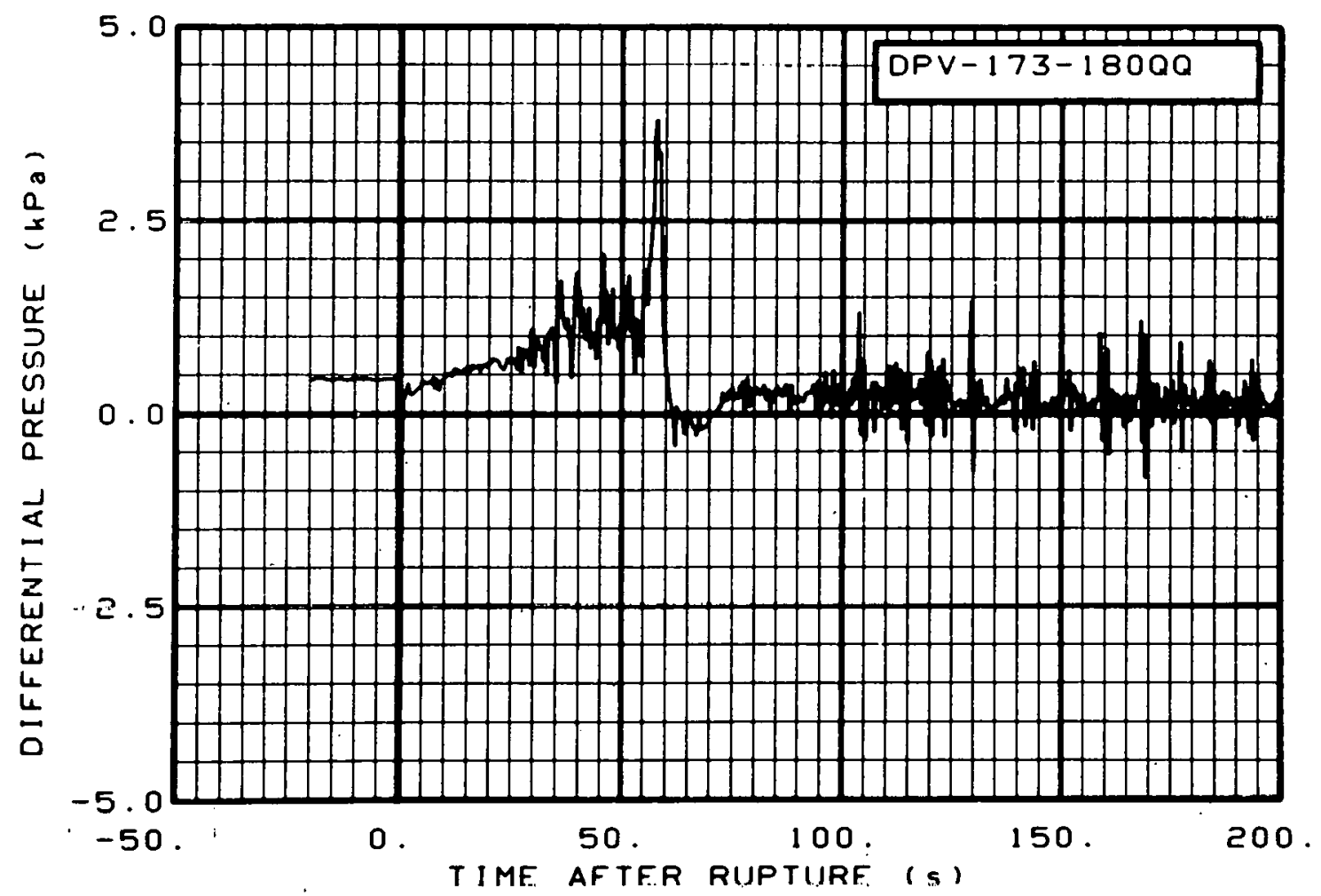

Fig. 213 Differential pressure in vessel (DPV-173-180QQ), from -20 to $200 \mathrm{~s}$.

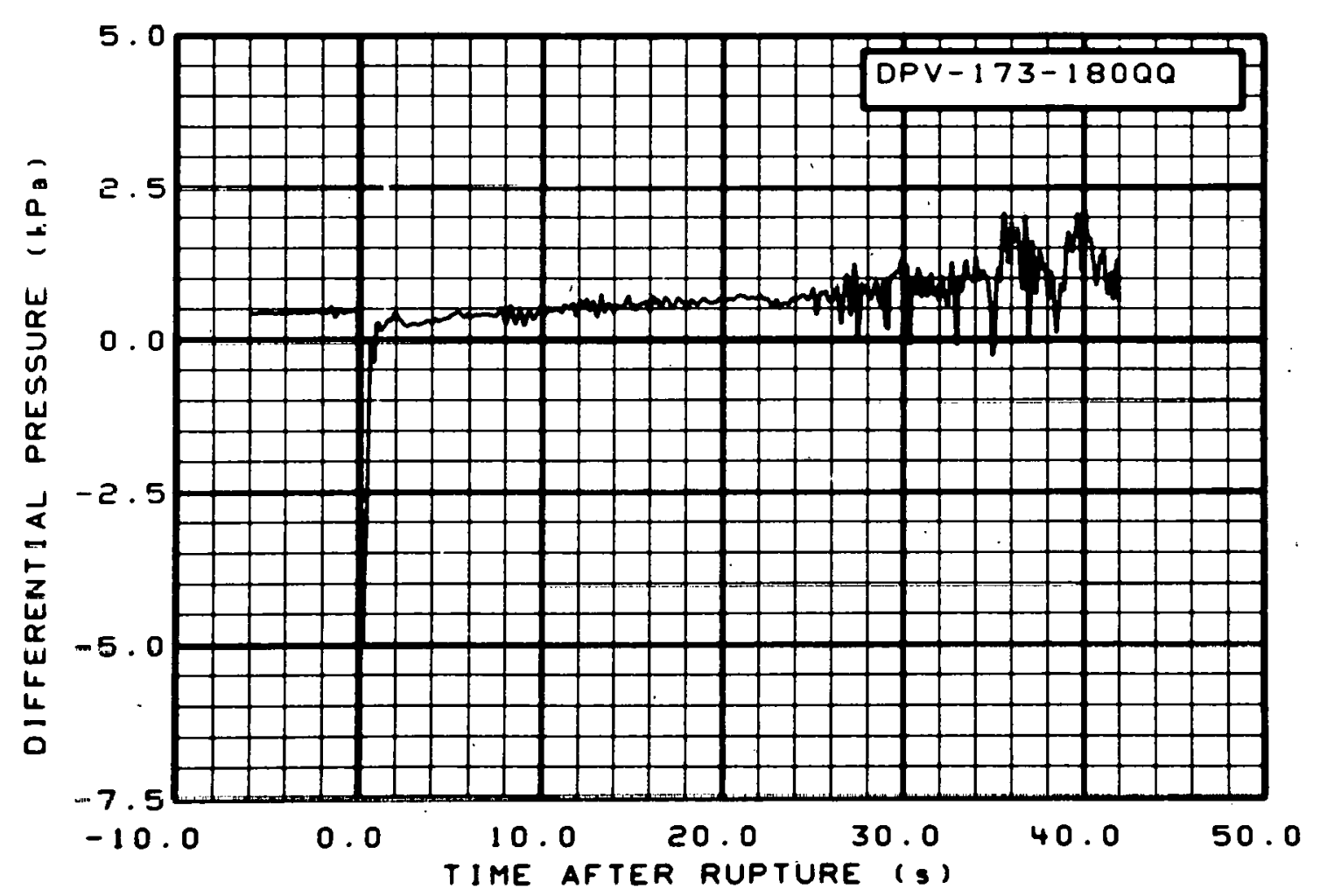

Fig. 214 Differential pressure in vessel (DPV-173-1800Q), from -6 to $42 \mathrm{~s}$. 


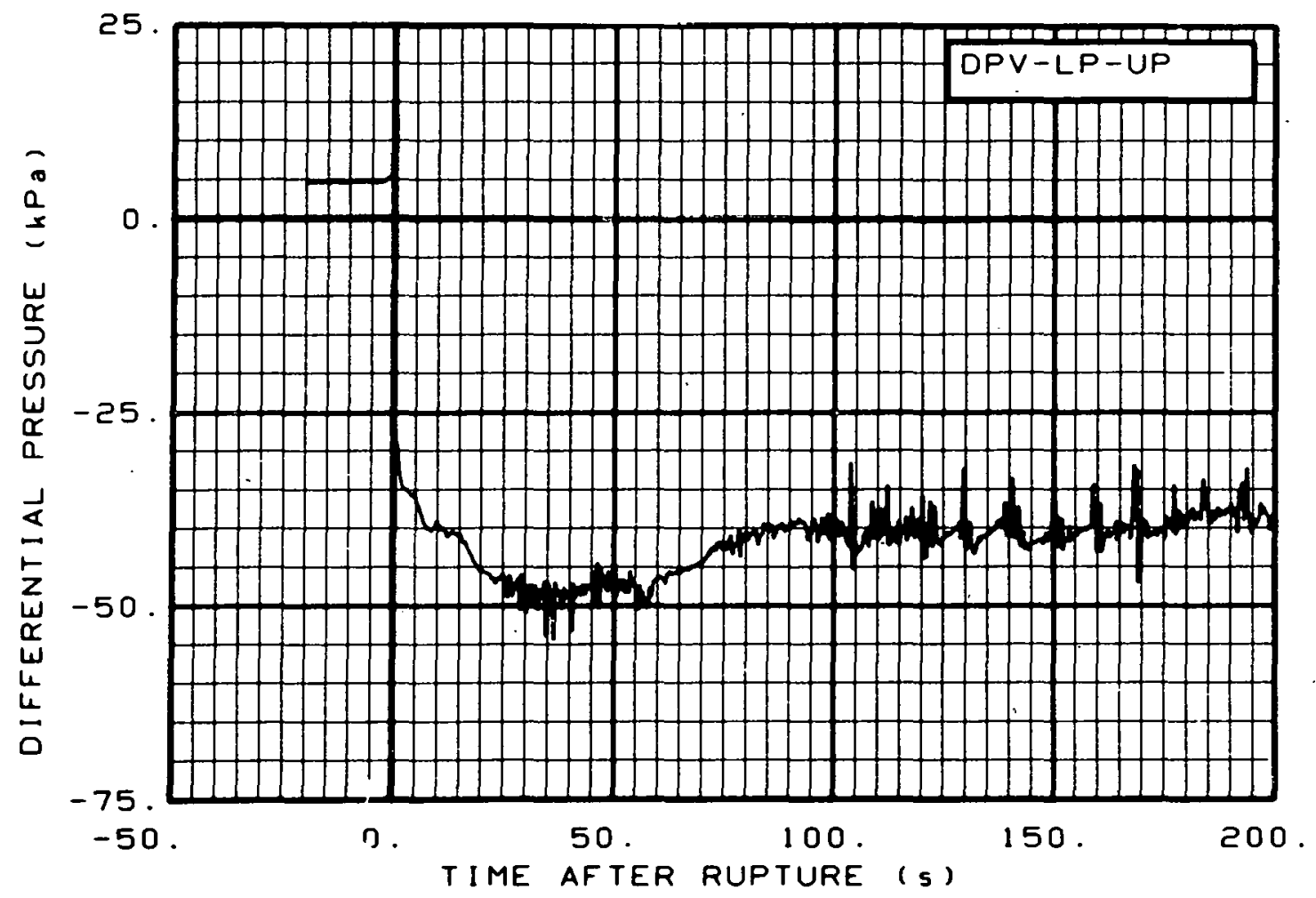

Fig. 215 Differential pressure in vessel (DPV-LP-UP), from -20 to $200 \mathrm{~s}$ :

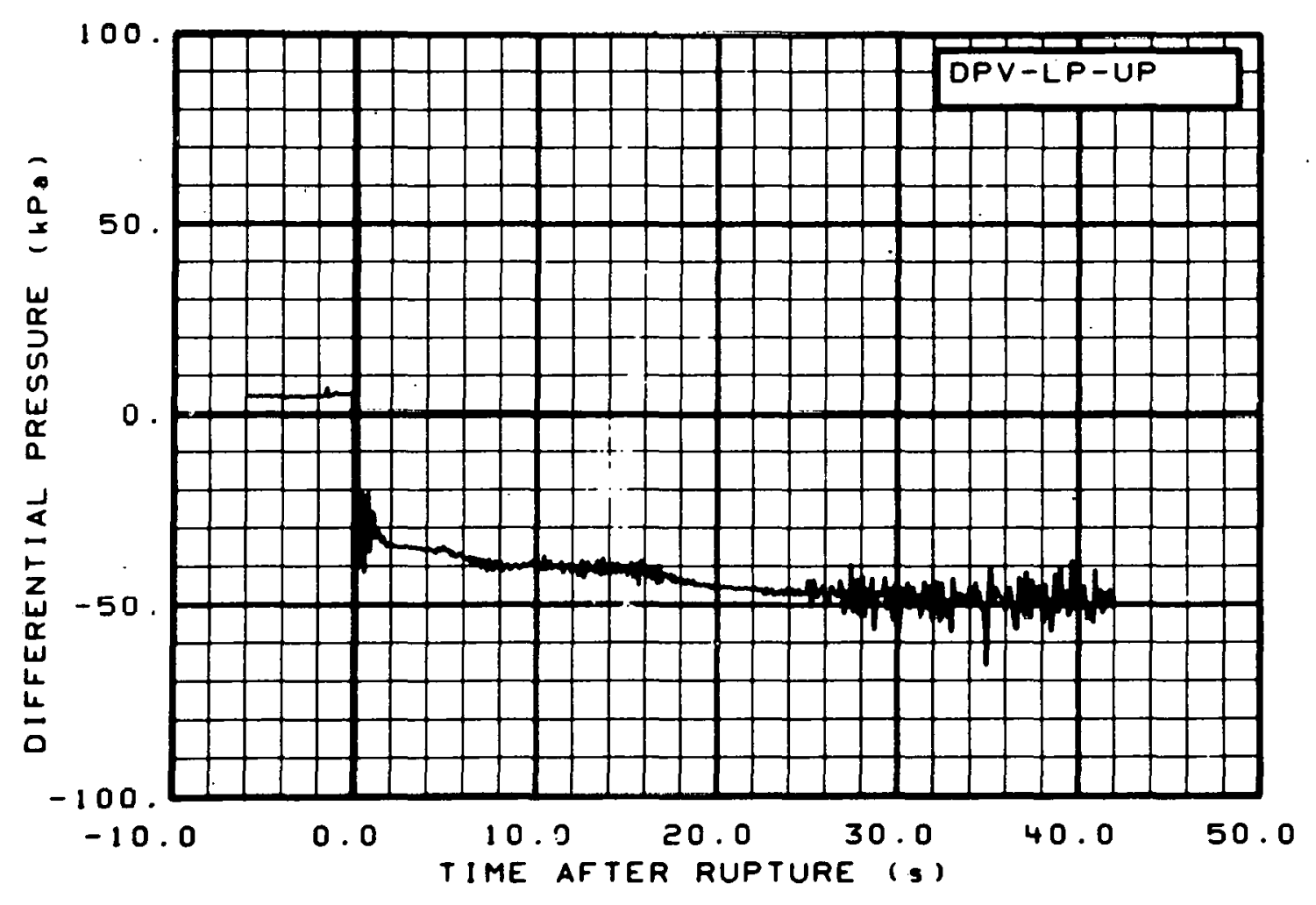

Fig. 216 Vifferential pressure in vessel (DPV-LP-UP), rrom -6 to $42 \mathrm{~s}$. 


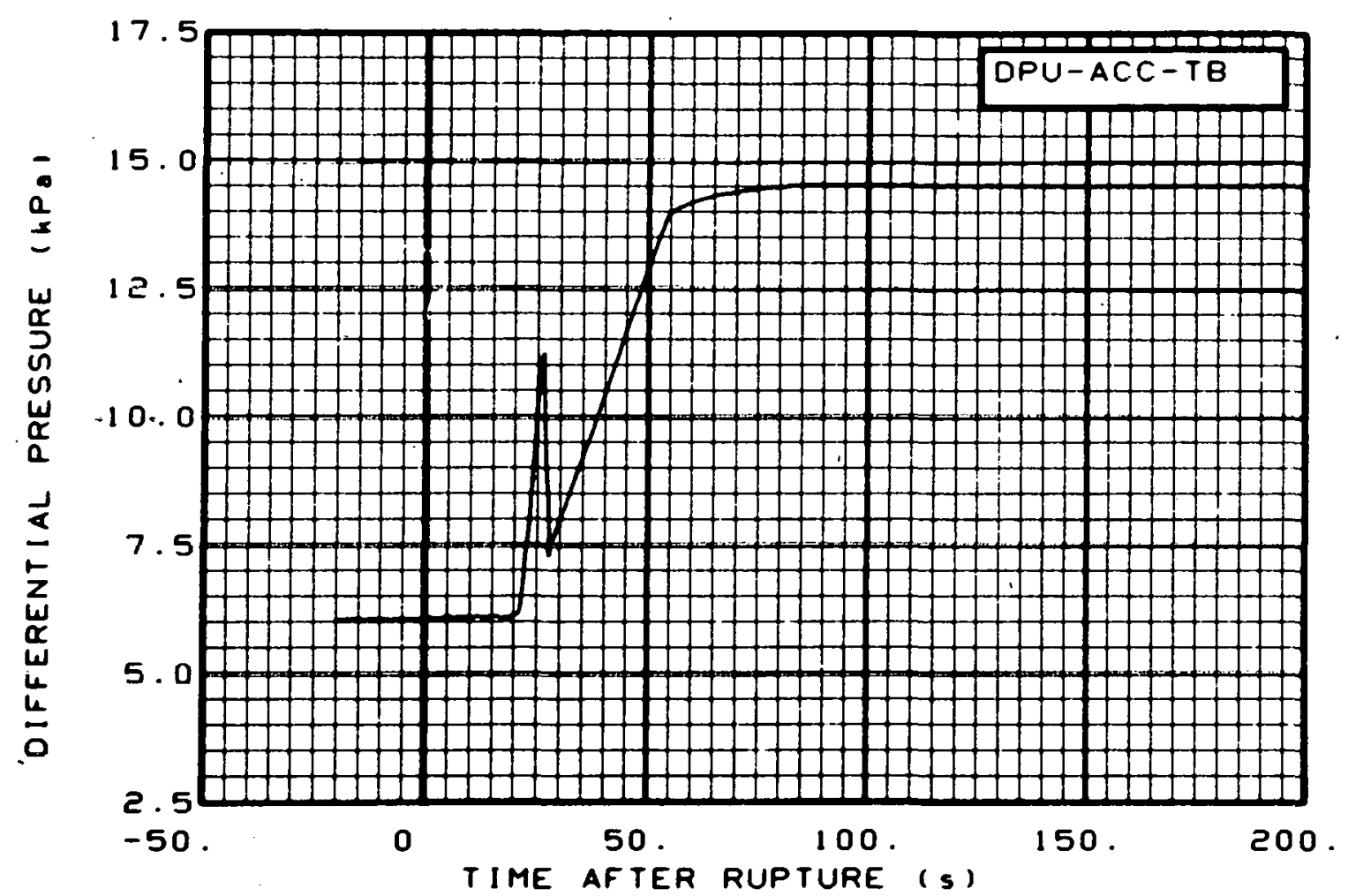

Fig. 217 Differential pressure in intact loop accumulator (DPU-ACC-TB), from -20 to $200 \mathrm{~s}$.

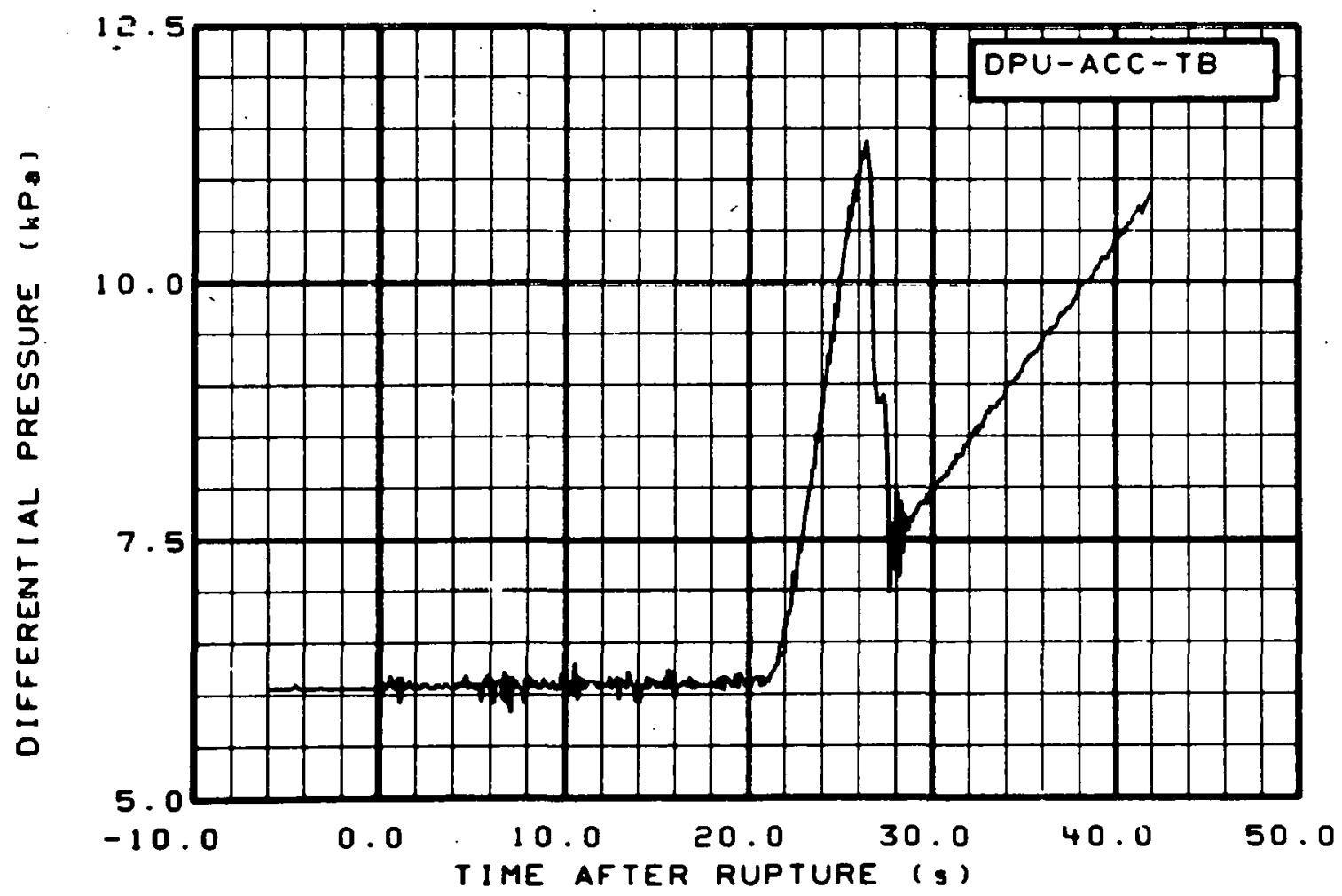

Fig. 218 Differential pressure in intact loop accumulator (DPU-ACC-TB), from -6 to $42 \mathrm{~s}$. 


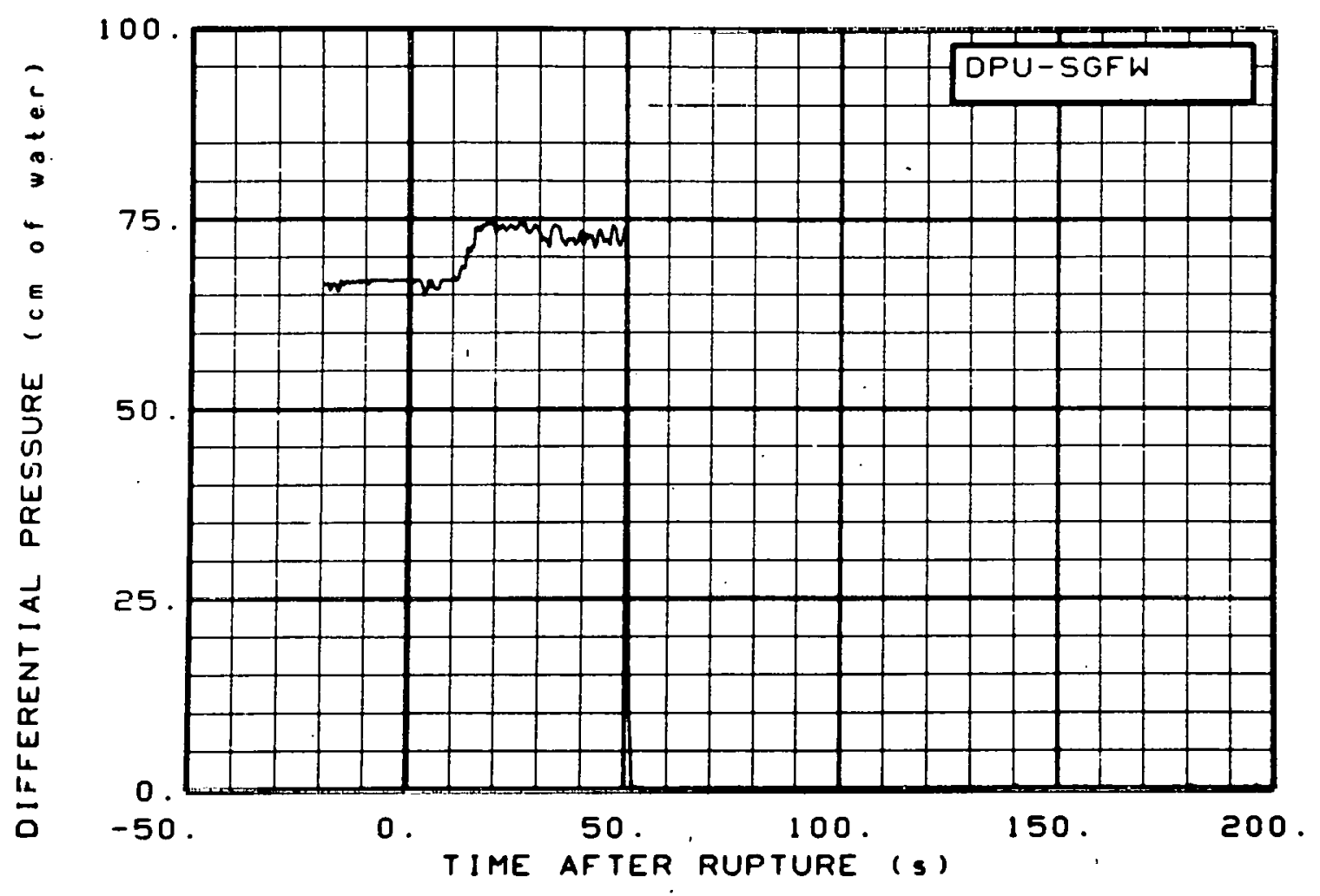

Fig. 219 Differential pressure across steam generator feedwater orifice (DPU-SGFW), from -20 to $200 \mathrm{~s}$.

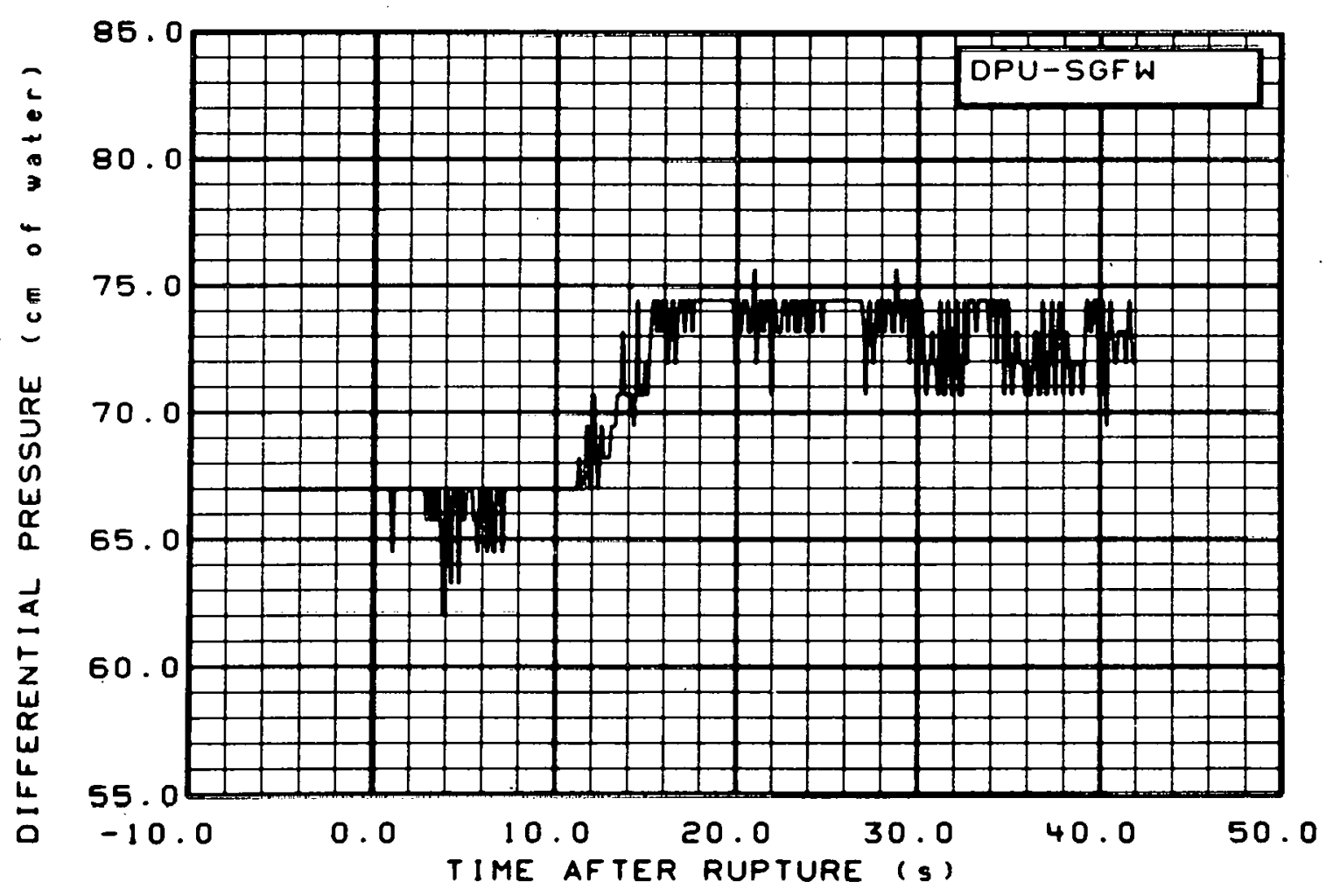

Fig. 220 Differential pressure across steam generator teedwater orifice (DPU-SGFW), from -6 to $42 \mathrm{~s}$. 


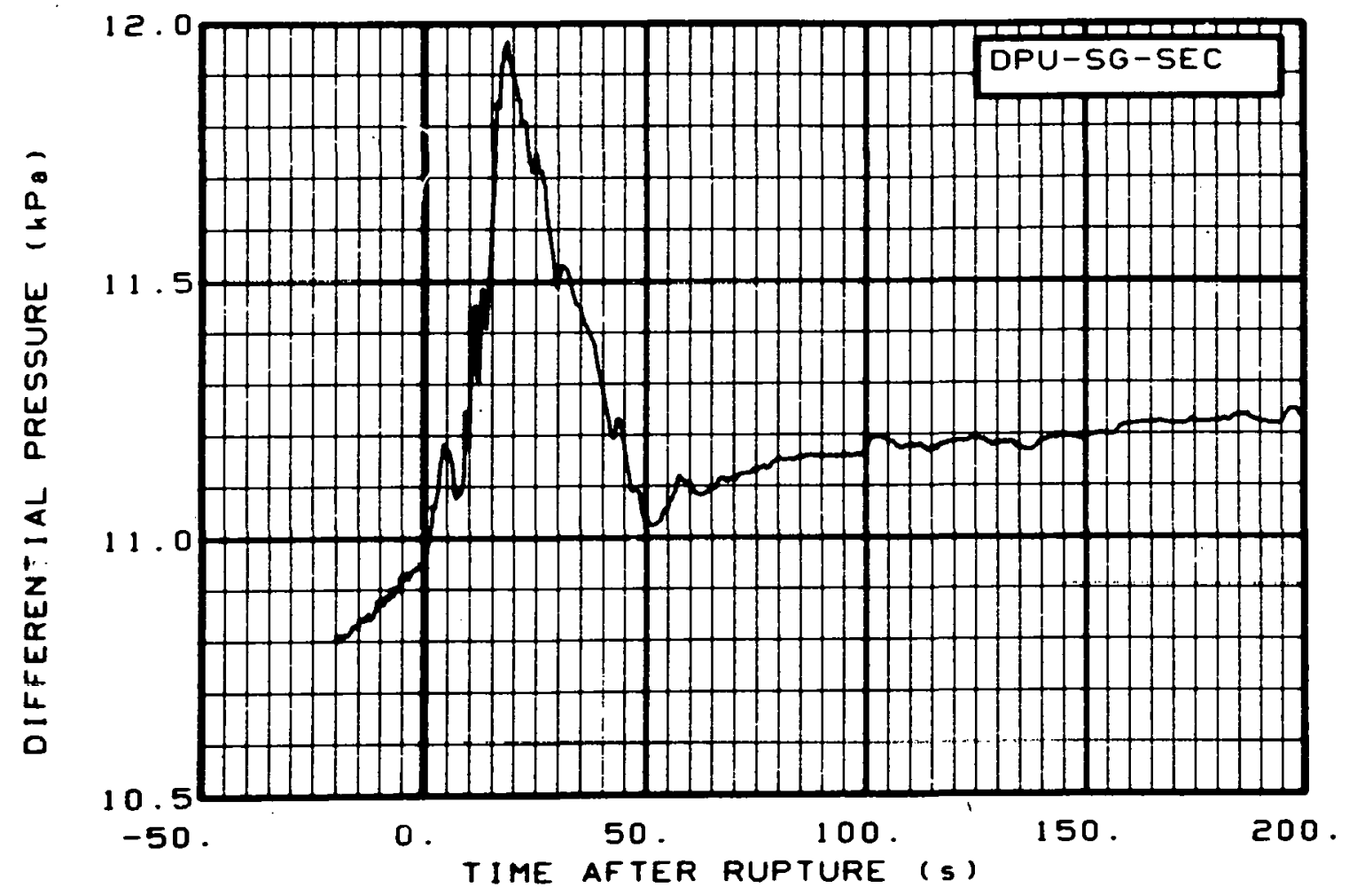

Fig. 221 Differential pressure in steam generator secondary (DPU-SG-SEC), from -20 to $200 \mathrm{~s}$.

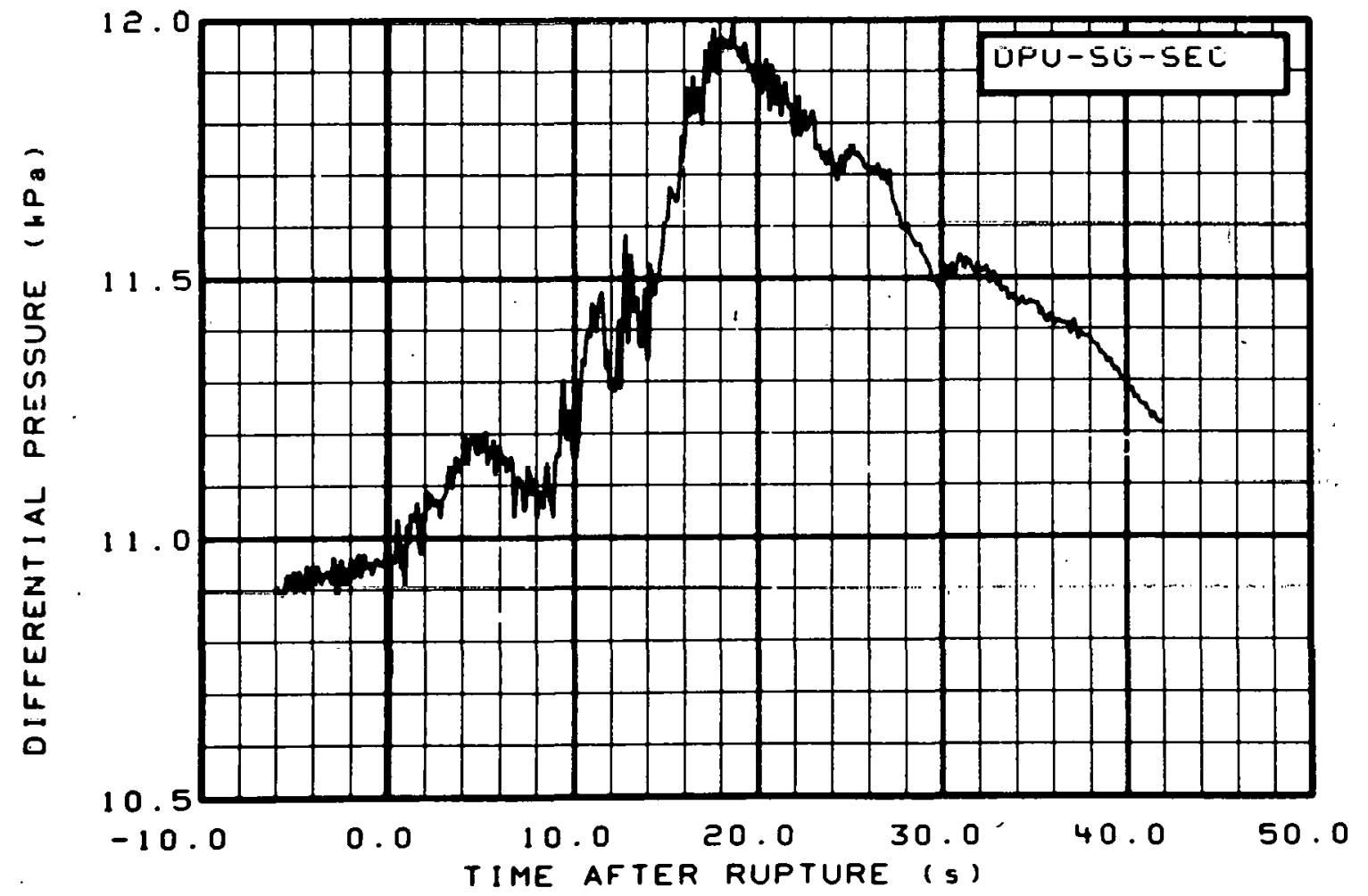

Fig. 222 Differential pressure in steam generator secondary (DPU-SG-SEC), from -6 to $42 \mathrm{~s}$. 


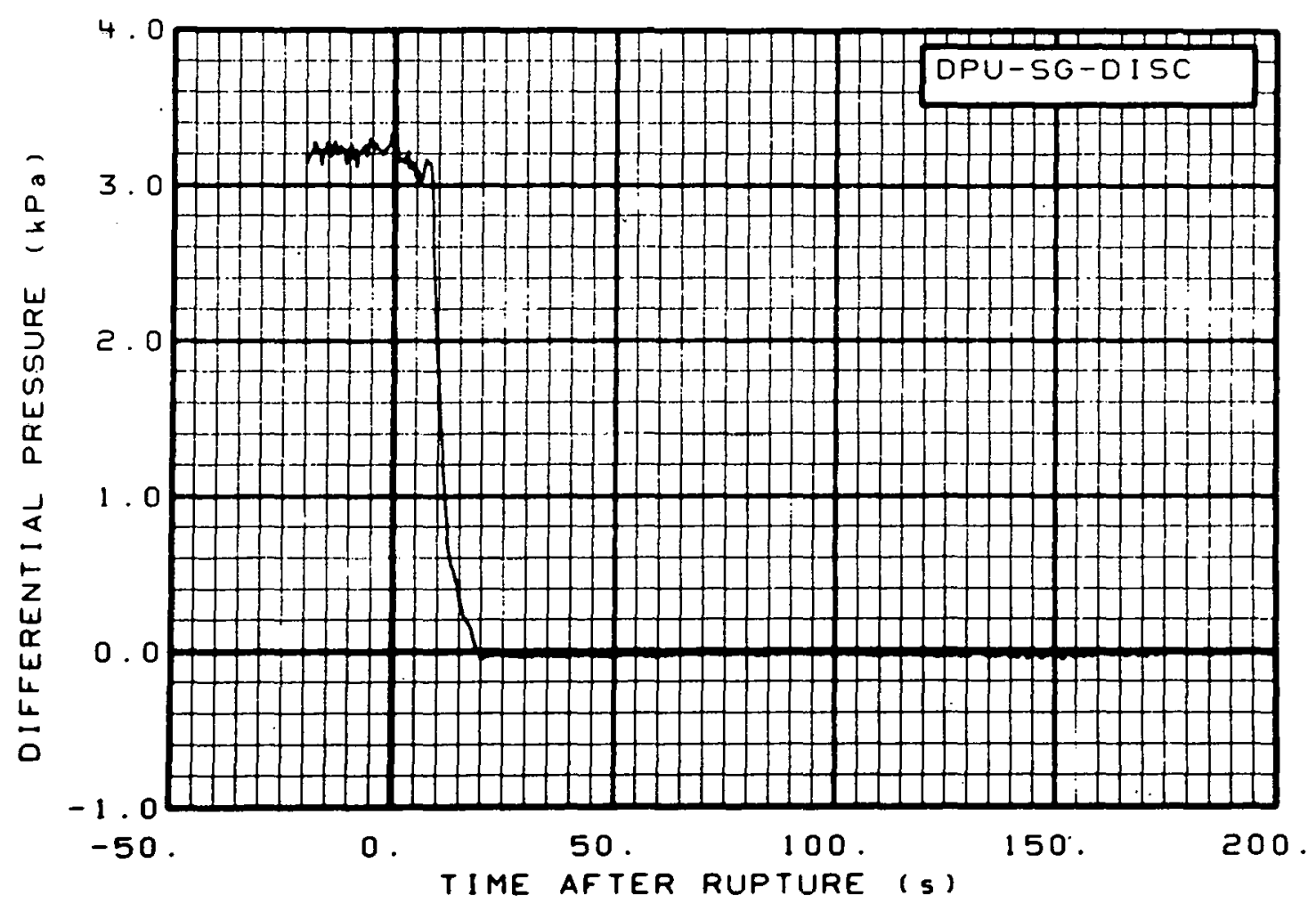

Fig. 223 Differential pressure across steam generator outlet orifice (DPU-SG-DISC), from -20 to $200 \mathrm{~s}$.

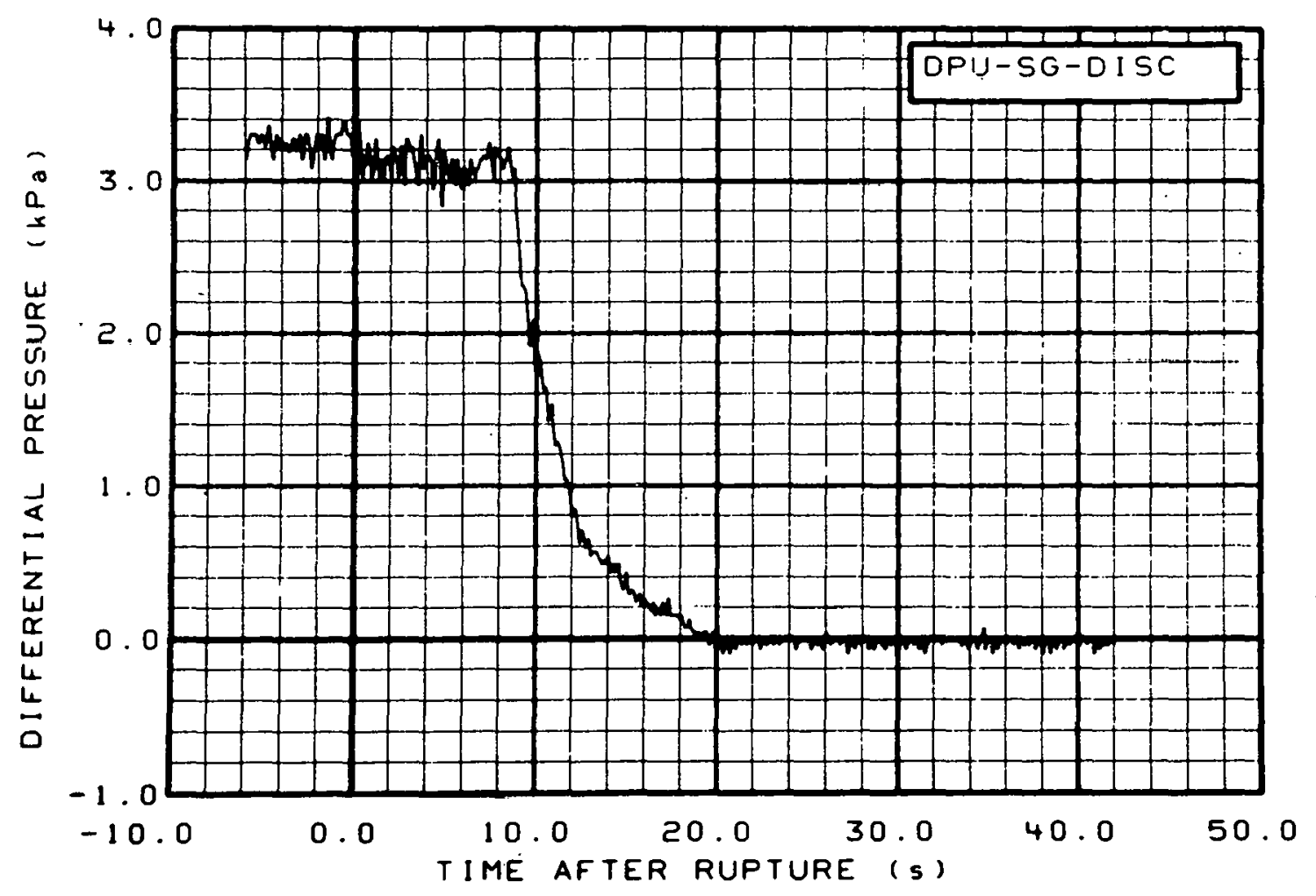

Fig. 224 Differential pressure across steam generator uullet orifice (DPU-SG-DISC), from -6 to $42 \mathrm{~s}$. 


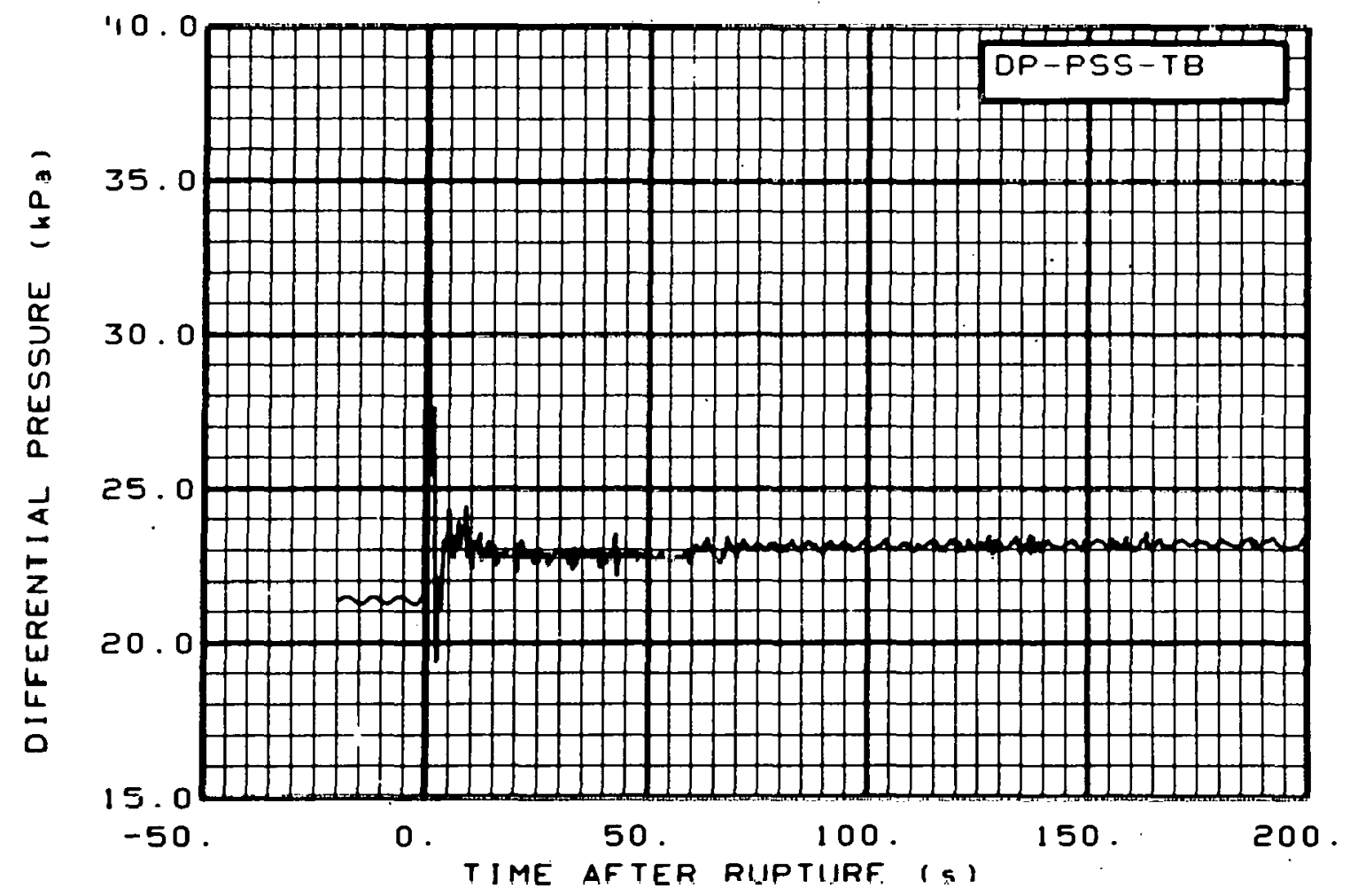

Fig. 225 Differential pressure in pressure suppression tank (DP-PSS-TB), from -20 to $200 \mathrm{~s}$.

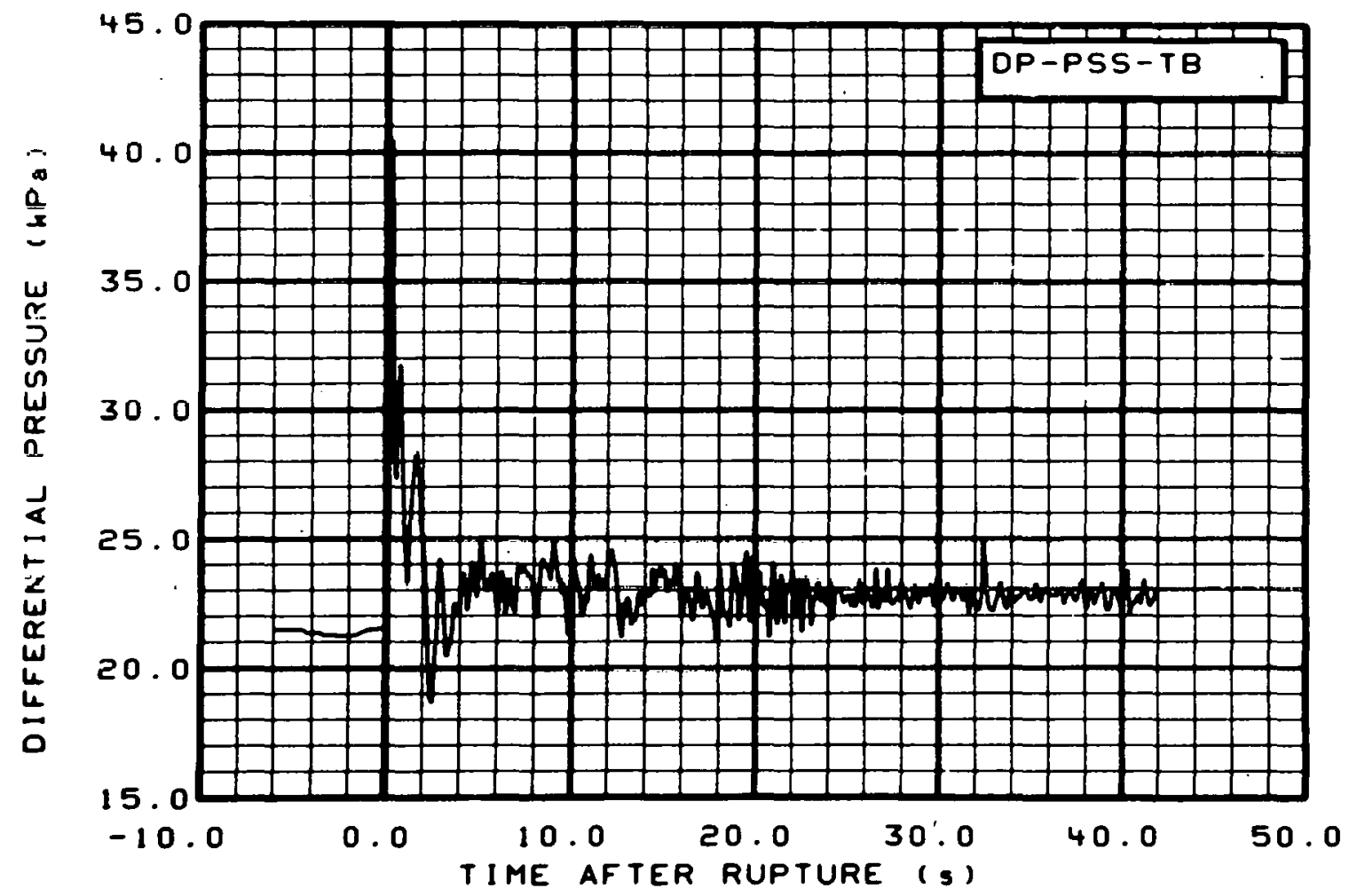

Fig. 226 Differential pressure in pressure suppression tank (DP-PSS-TB), from -6 to $42 \mathrm{~s}$. 


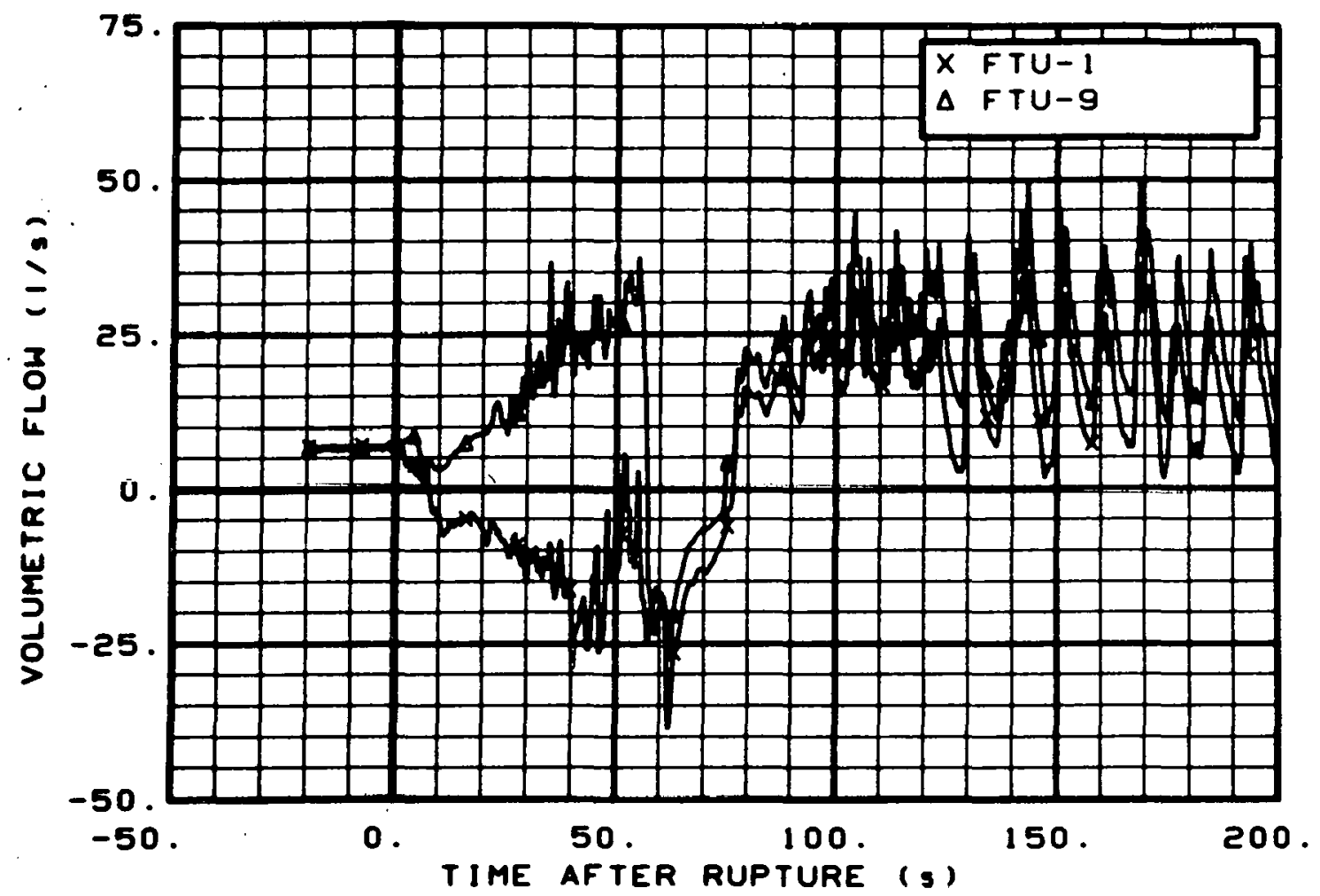

Fig: 227 Volumetric flow in intact loop (FTU-1 and FTU-9), from -20 to $200 \mathrm{~s}$.

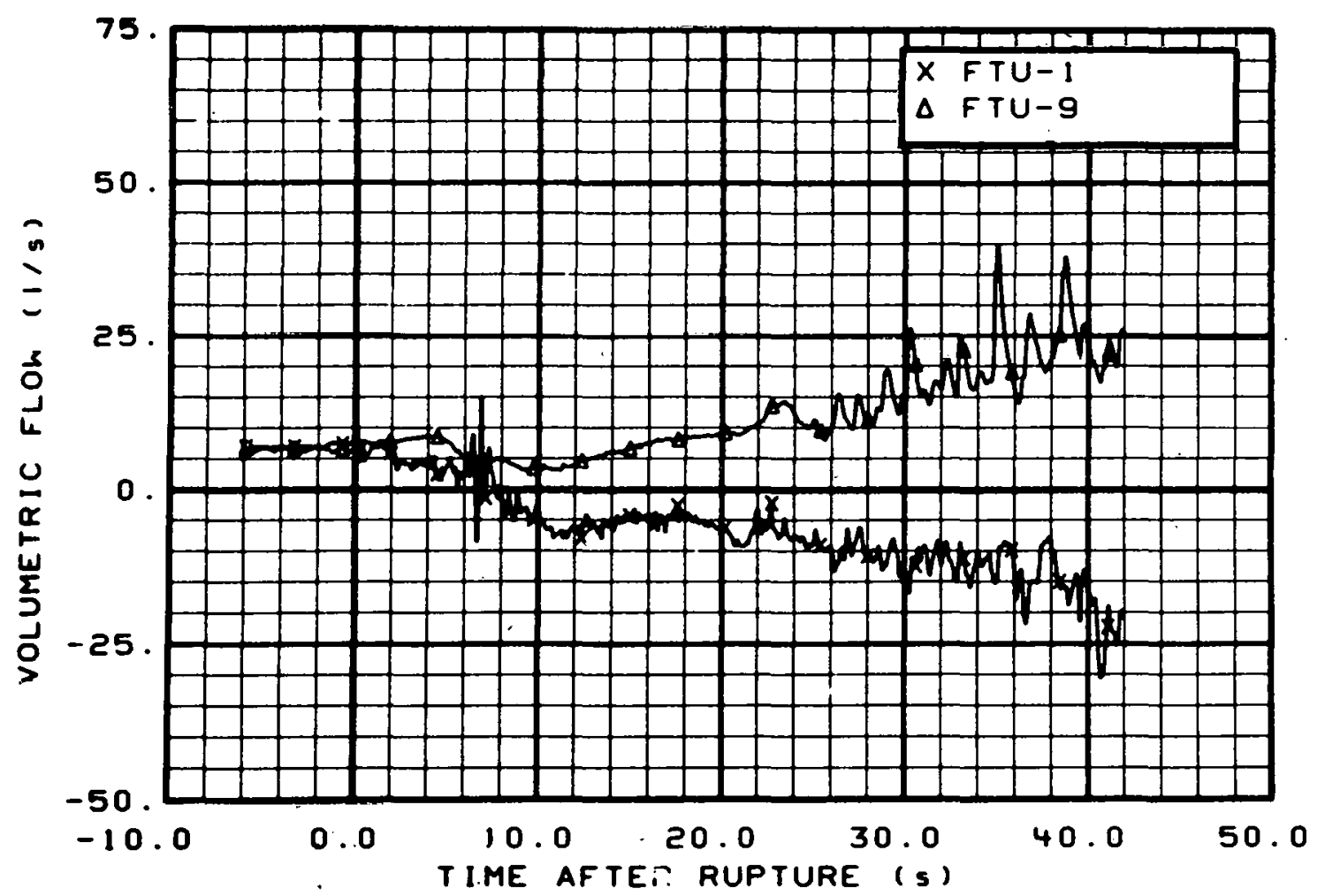

Fig. 228 Volumetric flow in intact loop (FTU-1 and FTU-y), from -6 to $42 \mathrm{~s}$. 


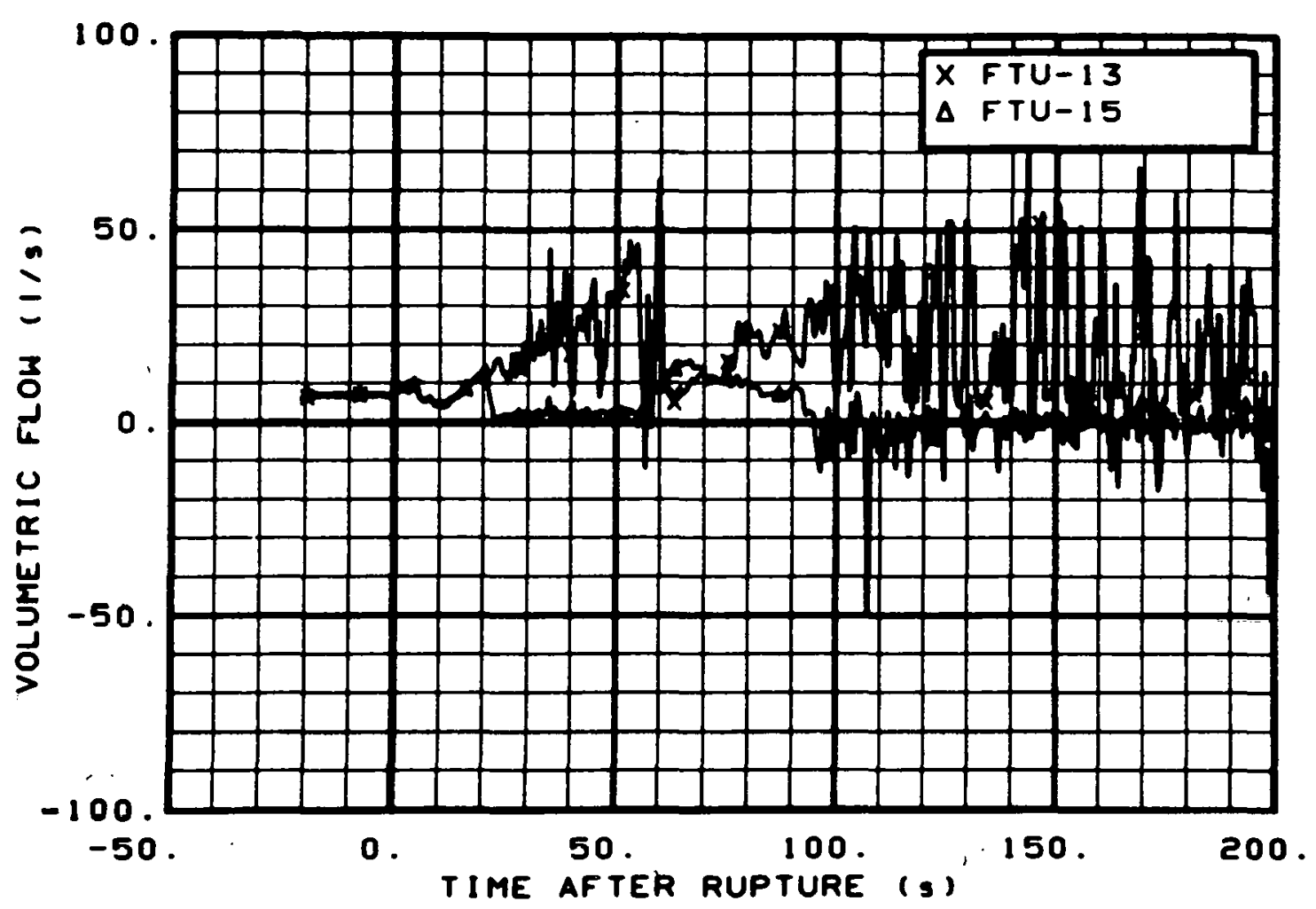

Fig. 229 Volumetric flow in intact loop (FTU-13 and FTU-15), from -20 to $200 \mathrm{~s}$.

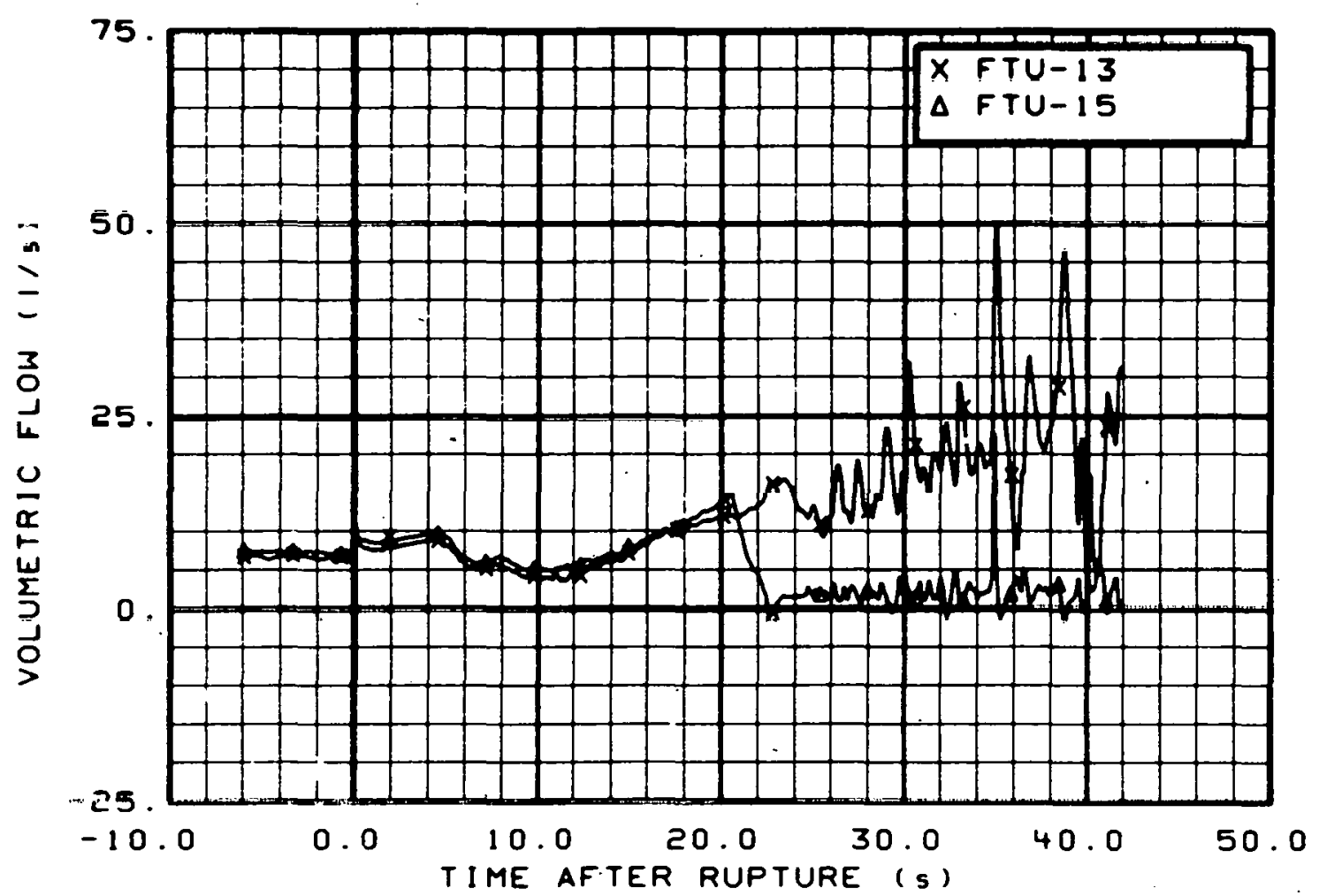

Fig. 230 Volumetric flow in intact loop (FTU-13 and FTU-15), from -6 to $42 \mathrm{~s}$. 


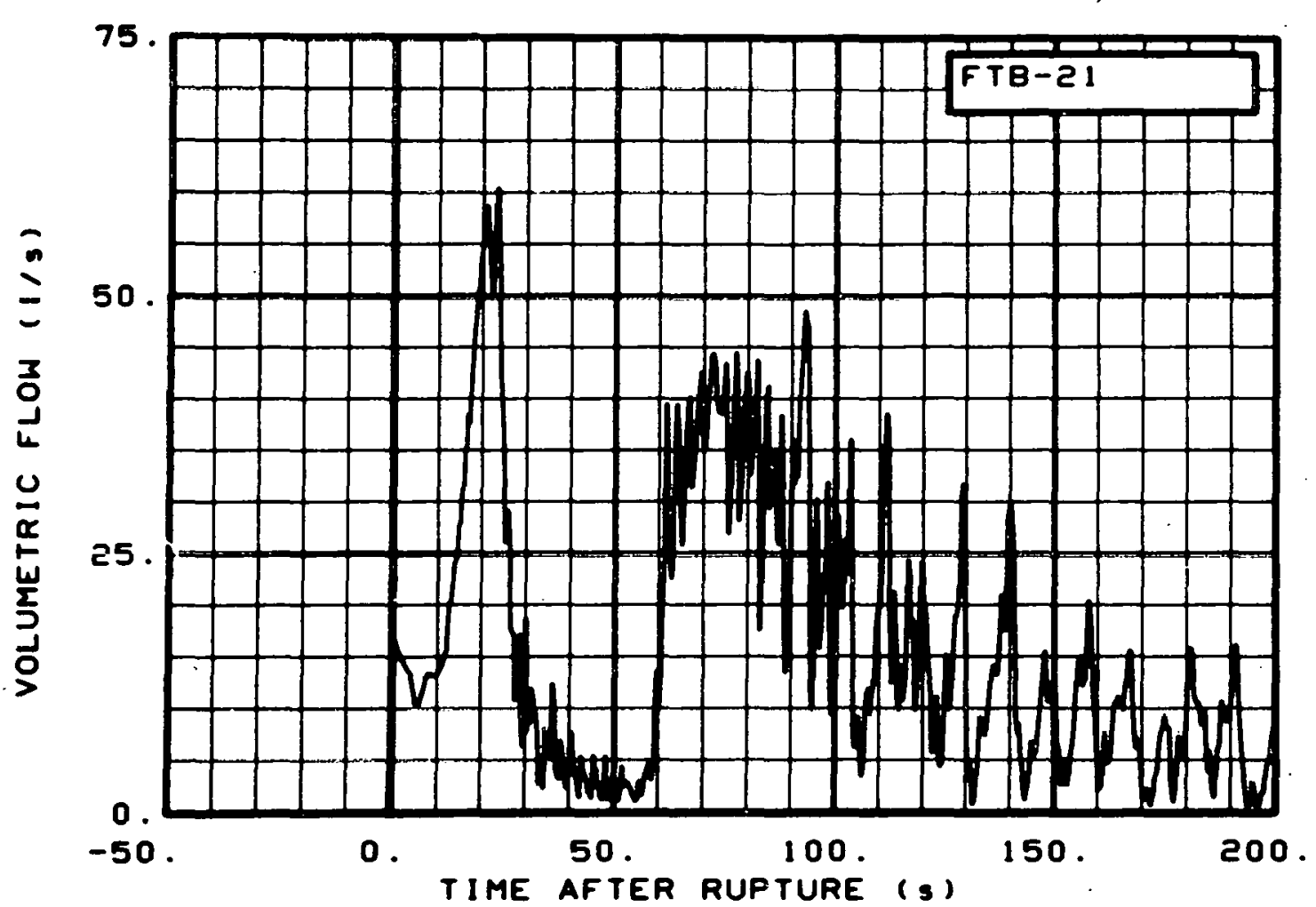

Fig. 231 Volumetric flow in broken loop (FTB-21), from -20 to $200 \mathrm{~s}$.

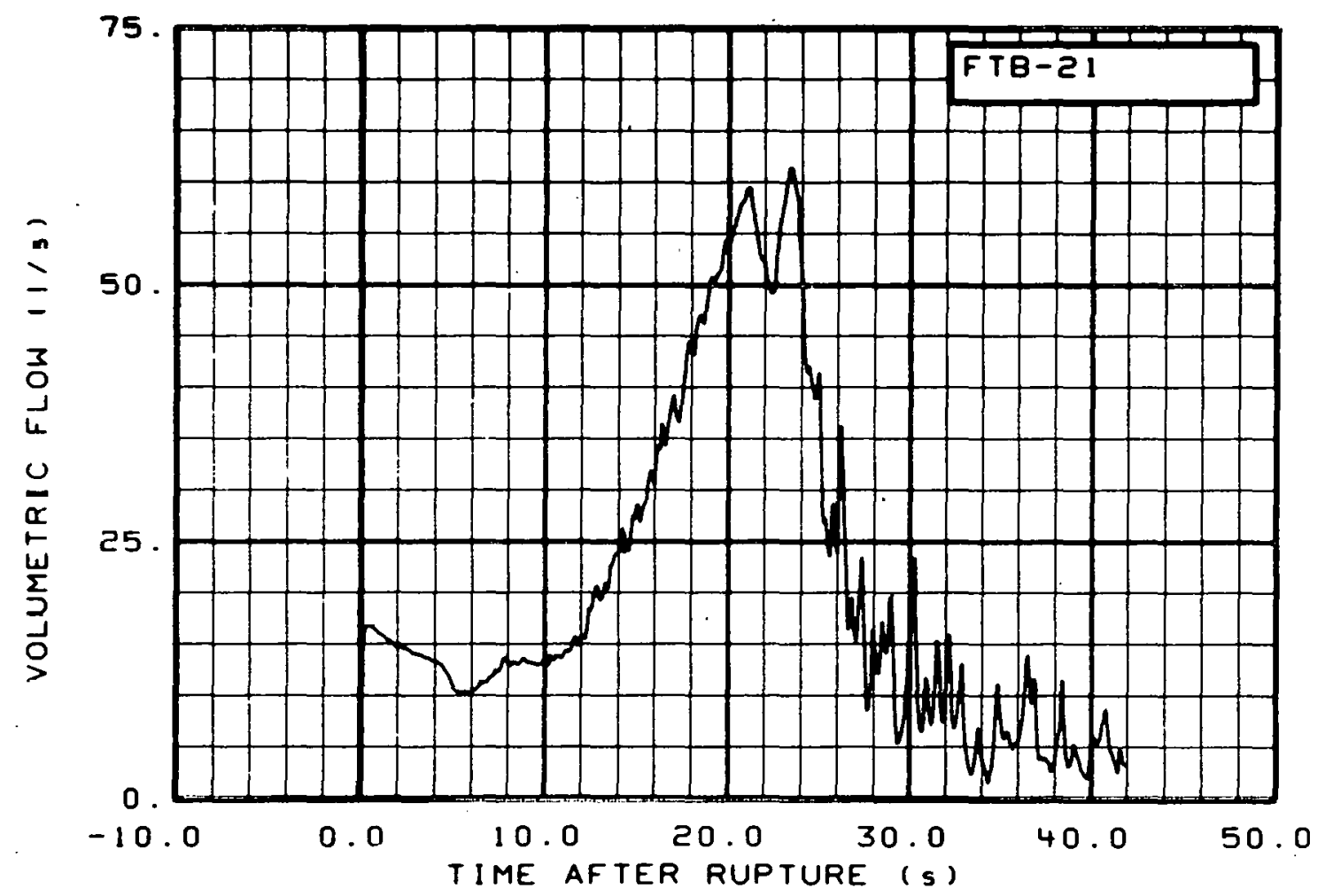

Fig. 232 Volumetric flow in broken loop (FTB-21), from -6 to $42 \mathrm{~s}$. 


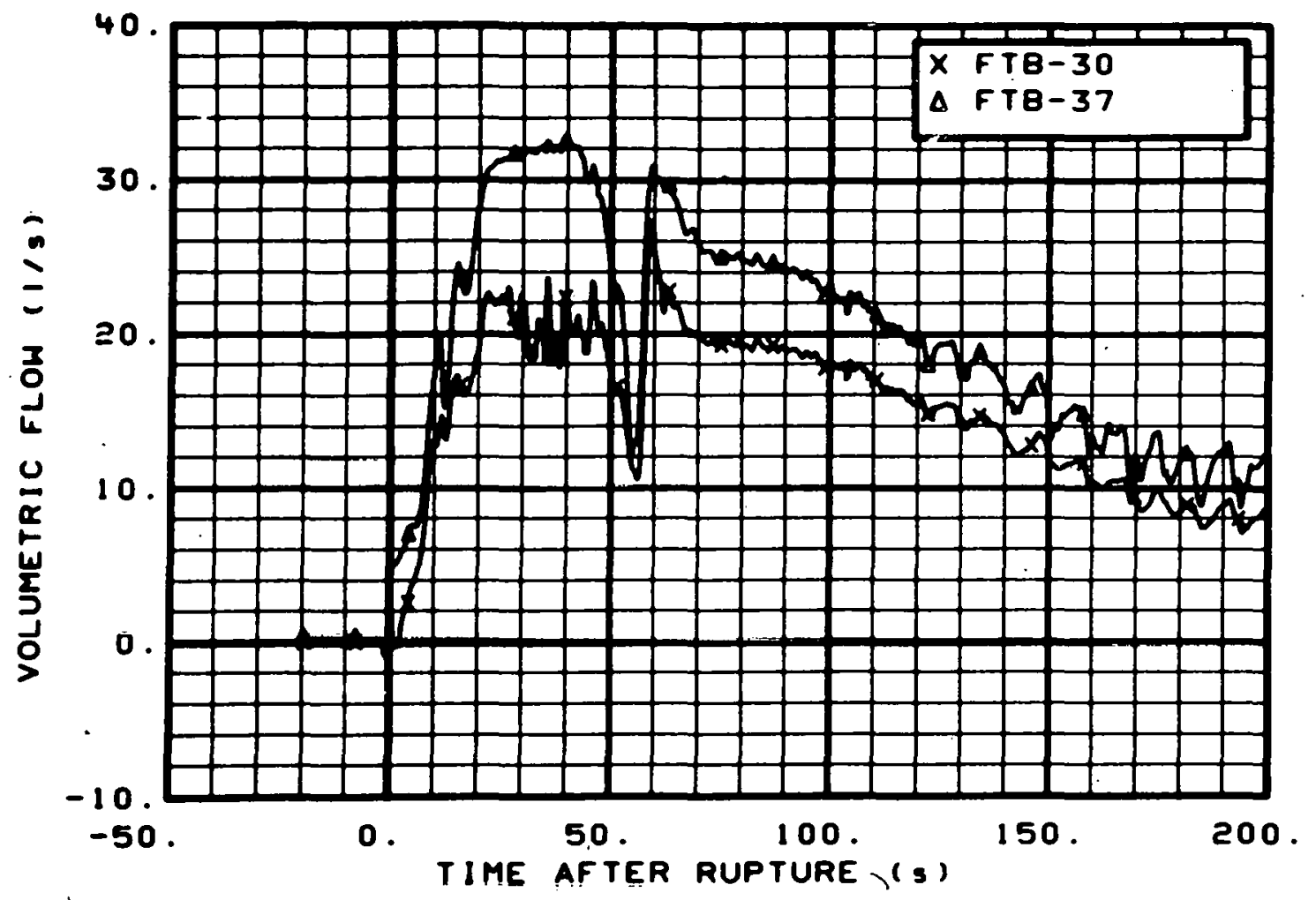

Fig.' 233 Volumetric flow in broken loop (FTB-30 and FTB-37), from -20 to $200 \mathrm{~s}$.

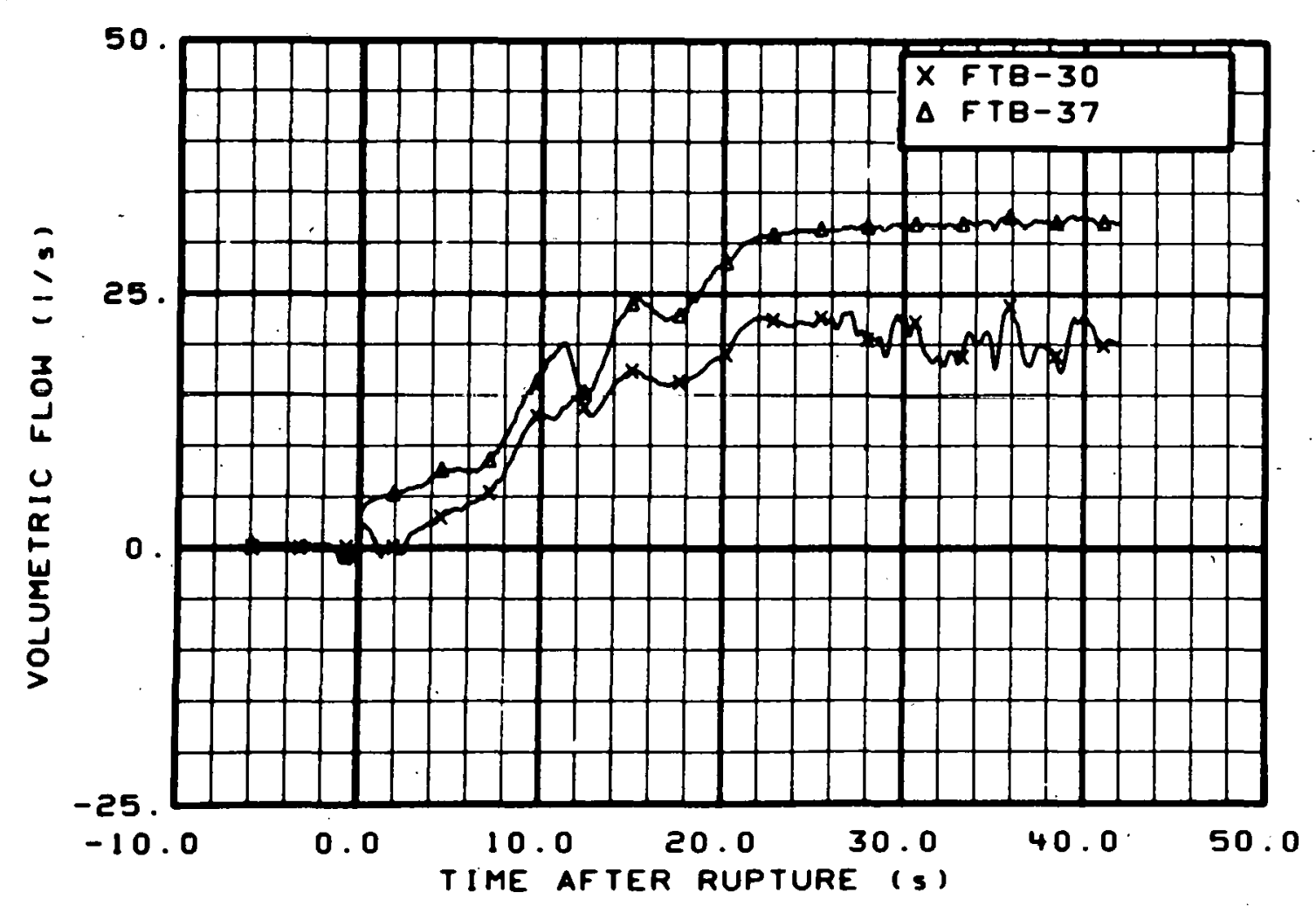

Fig. 234 Volumetric flow in broken loop (FTB-30 and FTB-37), from -6 to $42 \mathrm{~s}$. 


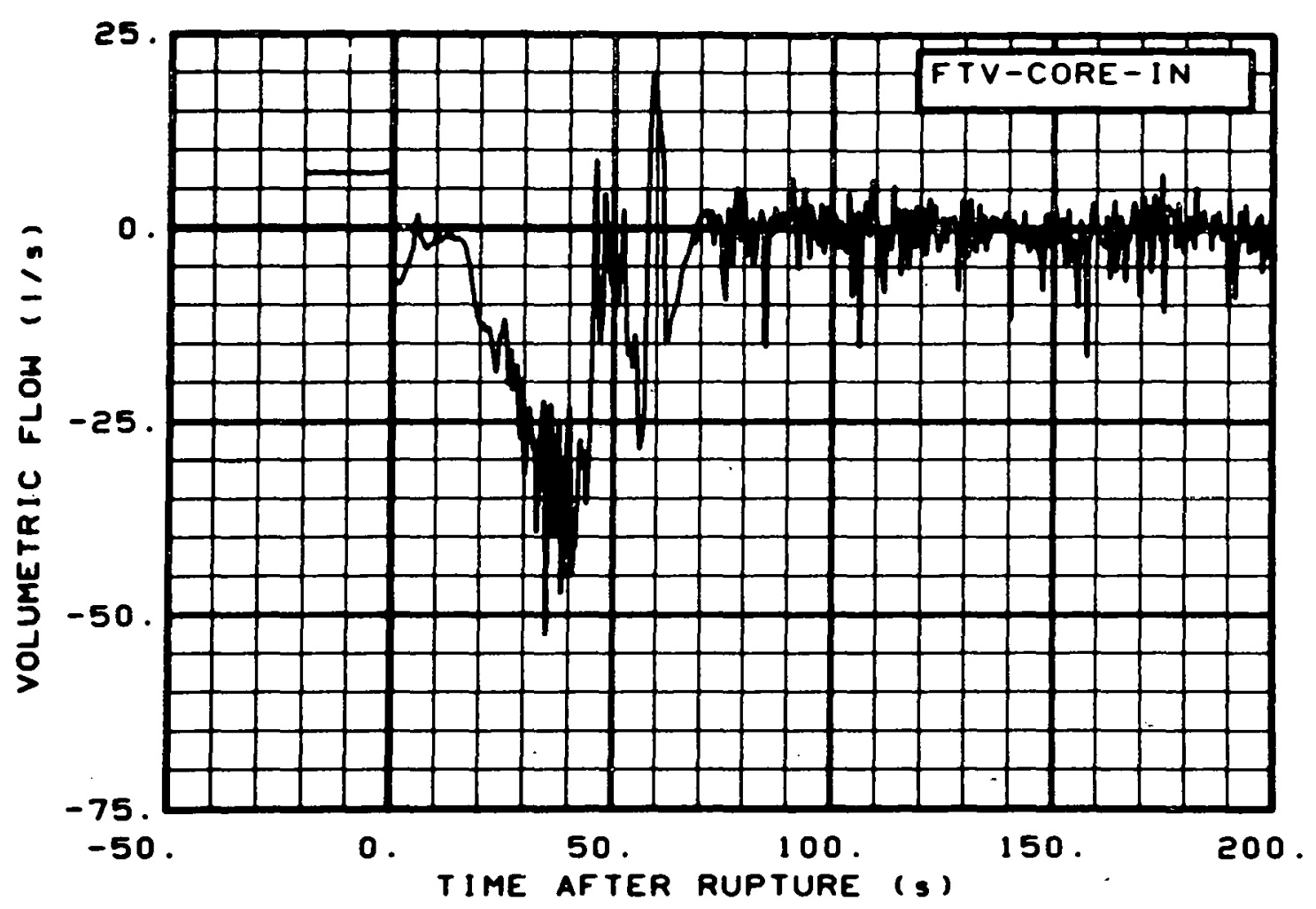

Fig. 235 Volumetric flow in core entrance (FTV-CORE-IN), from -20 to $200 \mathrm{~s}$.

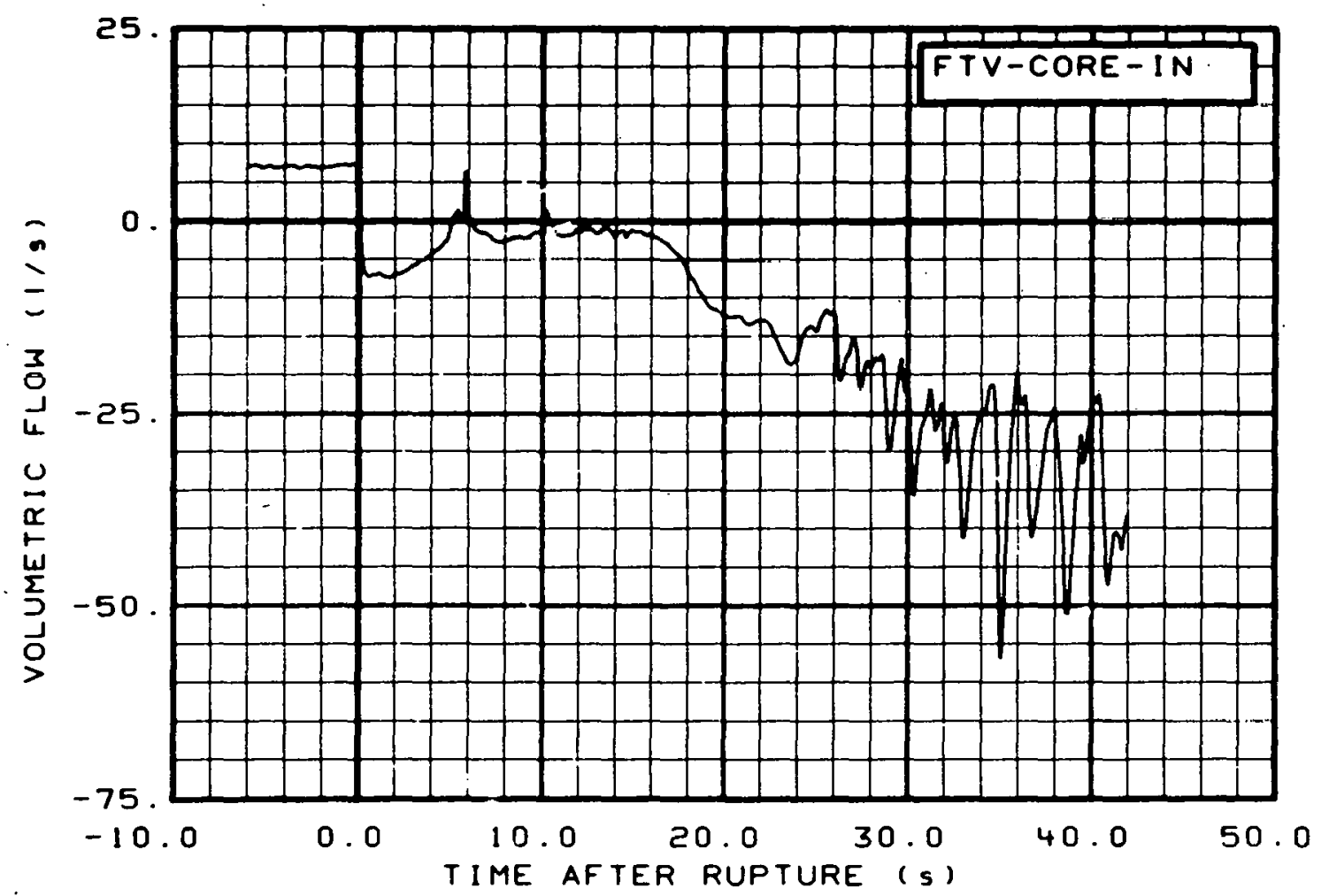

Fig. 236 Volumetric flow in core entrance (FTV-CORE-IN), from -6 to $42 \mathrm{~s}$. 


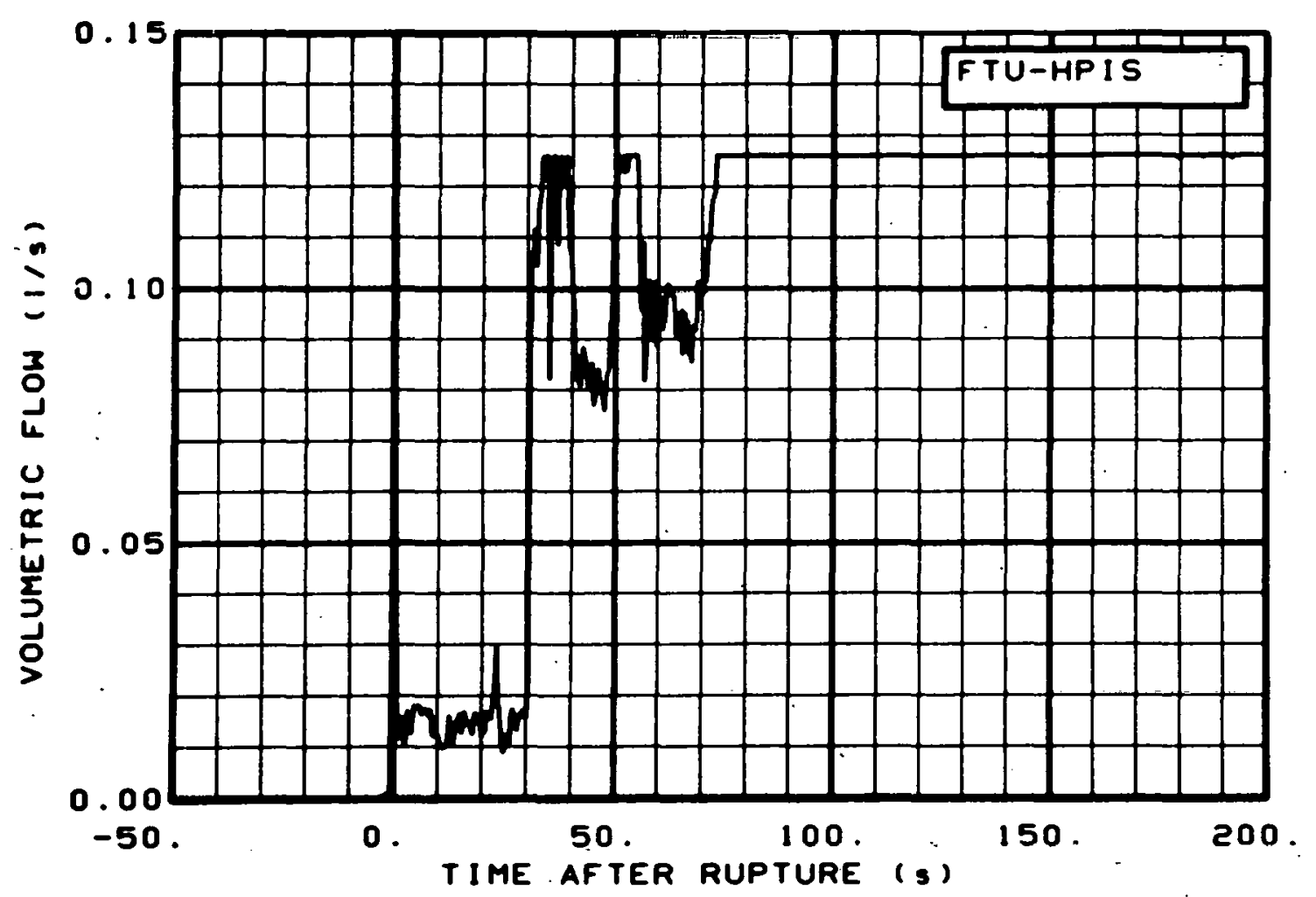

Fig. 237 Volumetric flow in intact loop high pressure injection line (FTU-HPIS), from -20 to $200 \mathrm{~s}$.

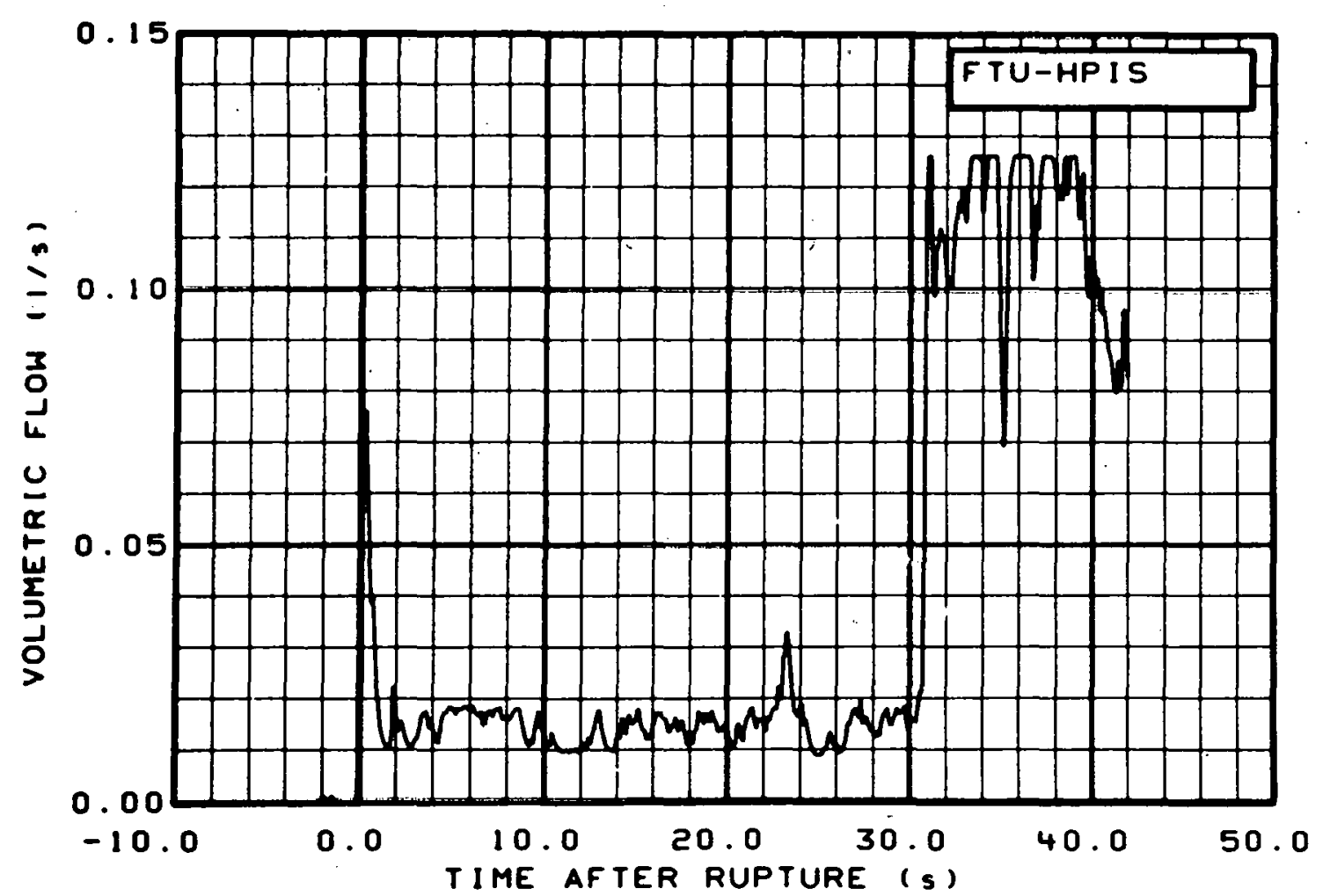

Fig. 238 Volumetric flow in intact loop high pressure injection line (FTU-HPIS), from -6 to $42 \mathrm{~s}$. 


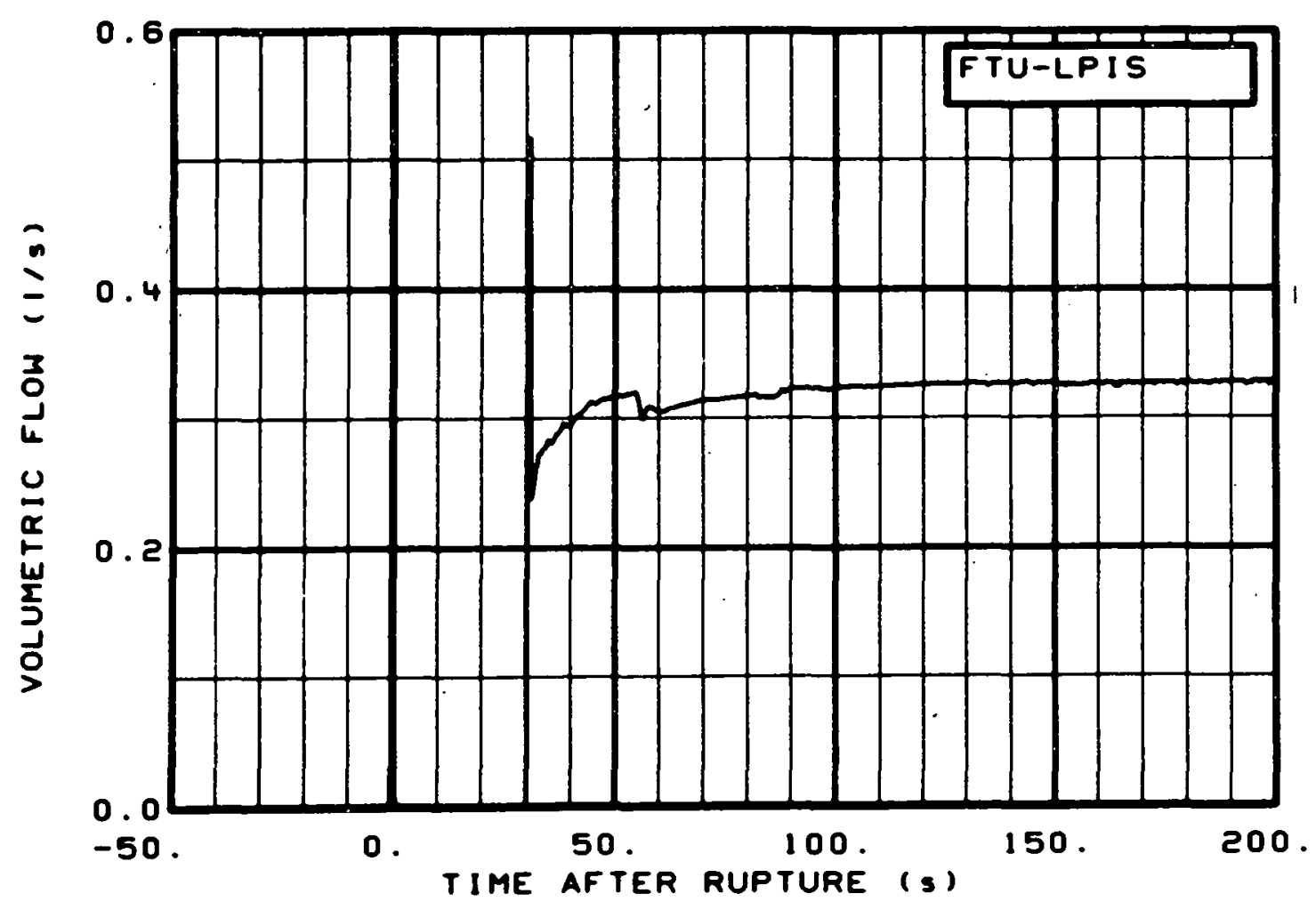

Fig. 239 Volumetric flow in intact loop low pressure injection line (FTU-LPIS), from -20 to $200 \mathrm{~s}$.

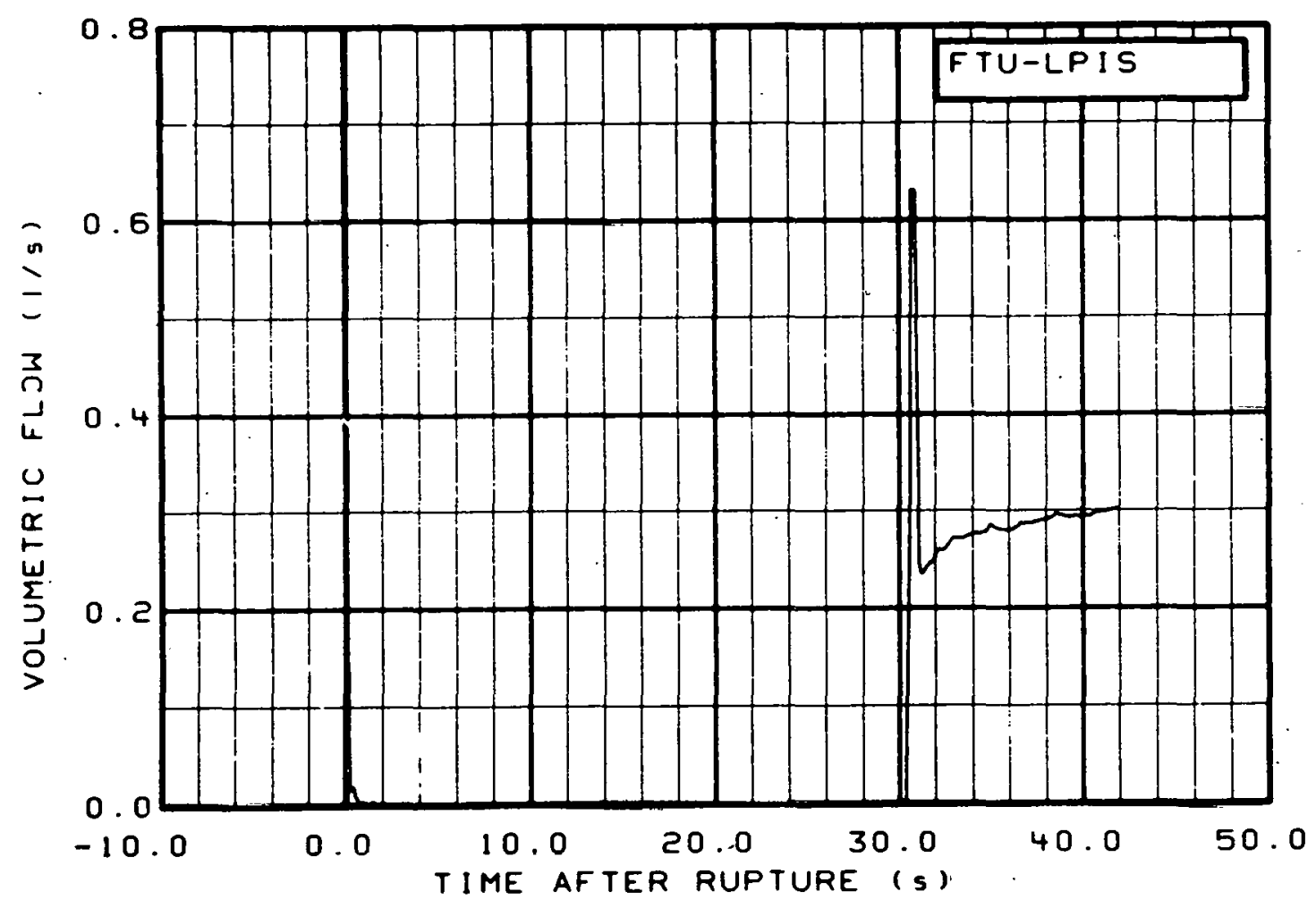

Fig. 240 Volumetric flow in intact loop low pressure injection line (FTU-LPIS), from -6 to $42 \mathrm{~s}$. 


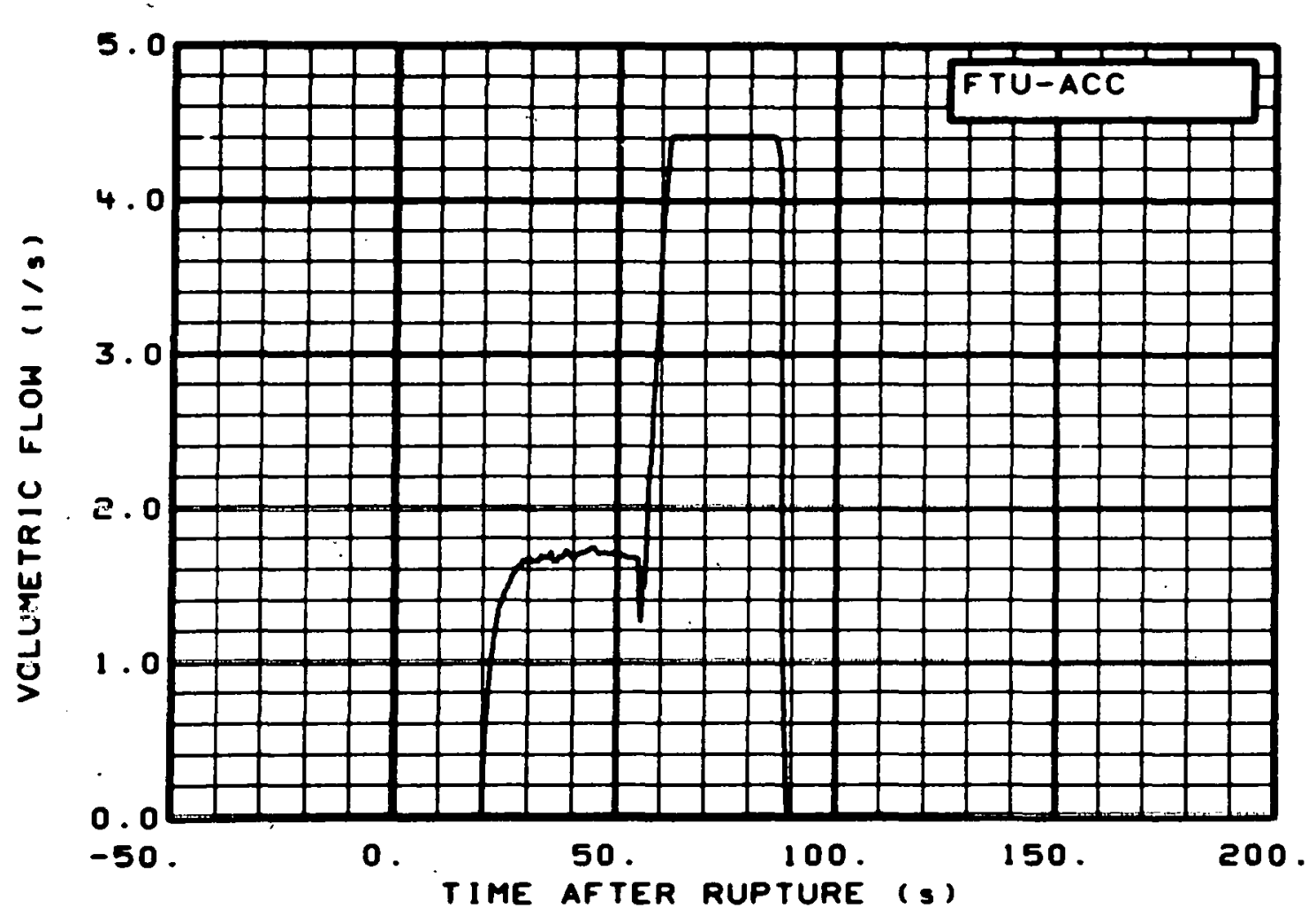

Fig. 241 Volumetric flow in intact loop accumulator discharge line (FTU-ACC), from -20 to $200 \mathrm{~s}$.

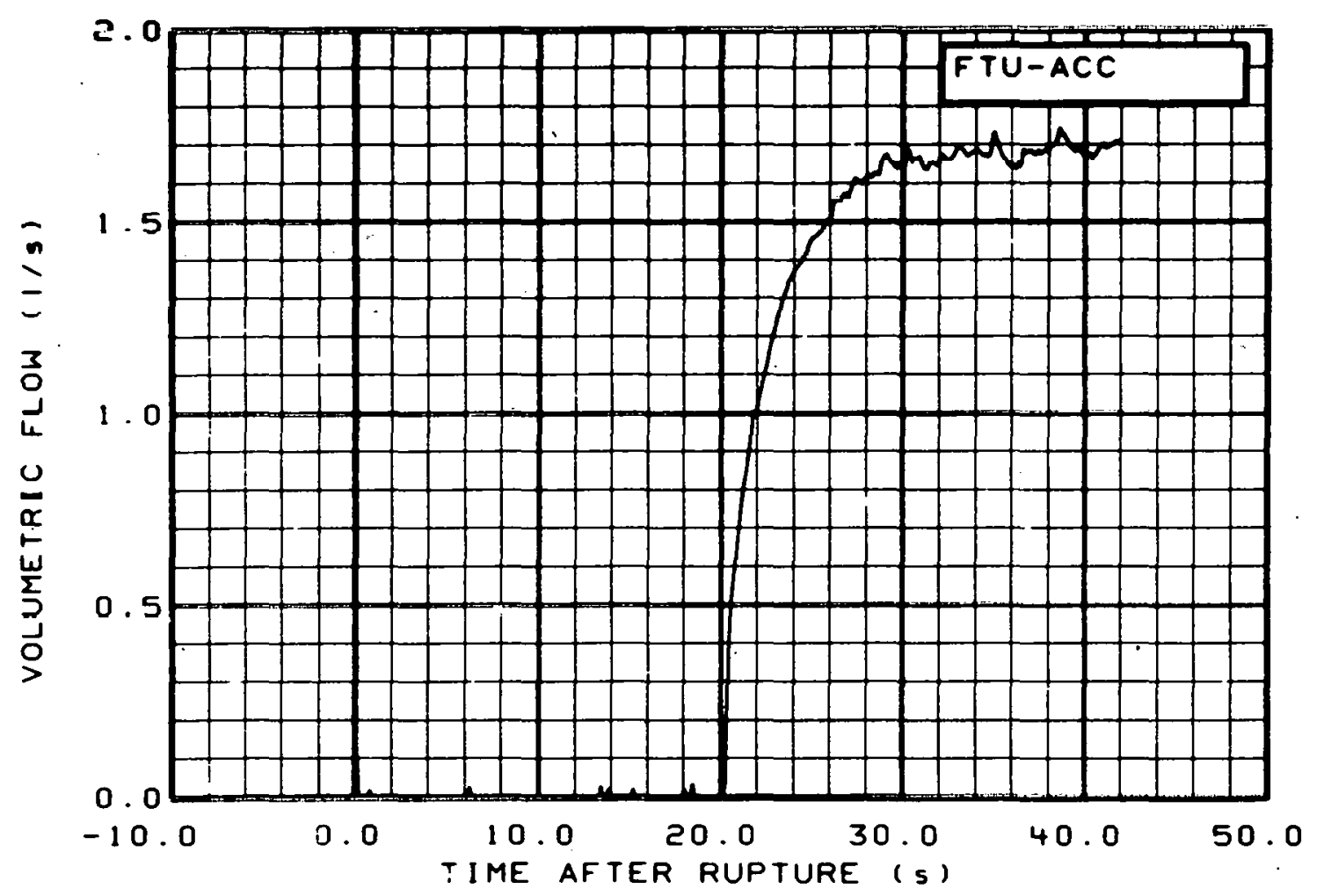

Fig. 242 Volumetric flow in intact loop accumulator discharge line (FTU-ACC), froill -6 to $42 \mathrm{~s}$. 


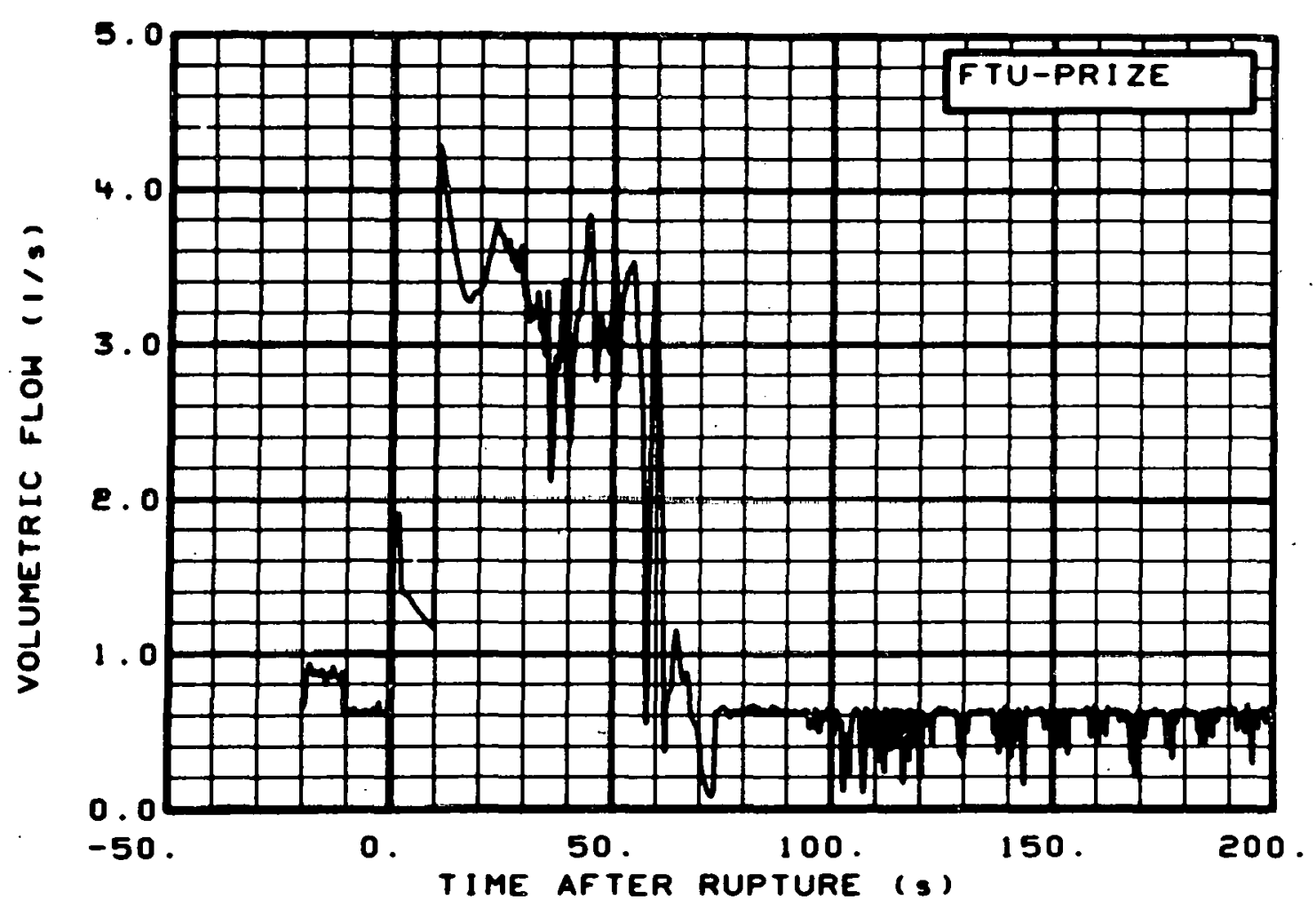

Fig. 243 Volumetric flow from pressurizer (FTU-PRIZE), from -20 to $200 \mathrm{~s}$.

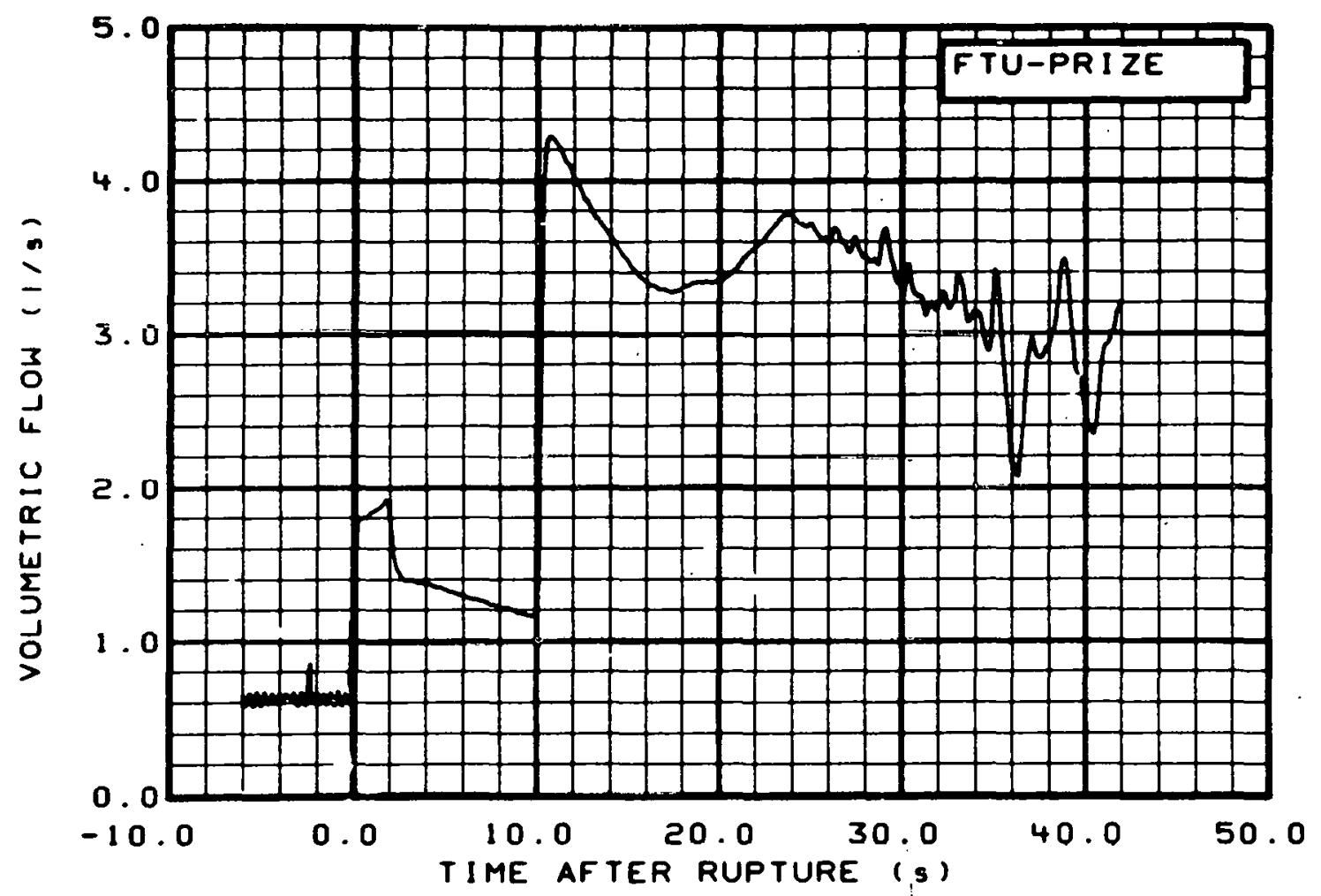

Fig. 244 Volumetric flow from pressurizer (FTU-PRIiZE), from -6 to $42 \mathrm{~s}$. 


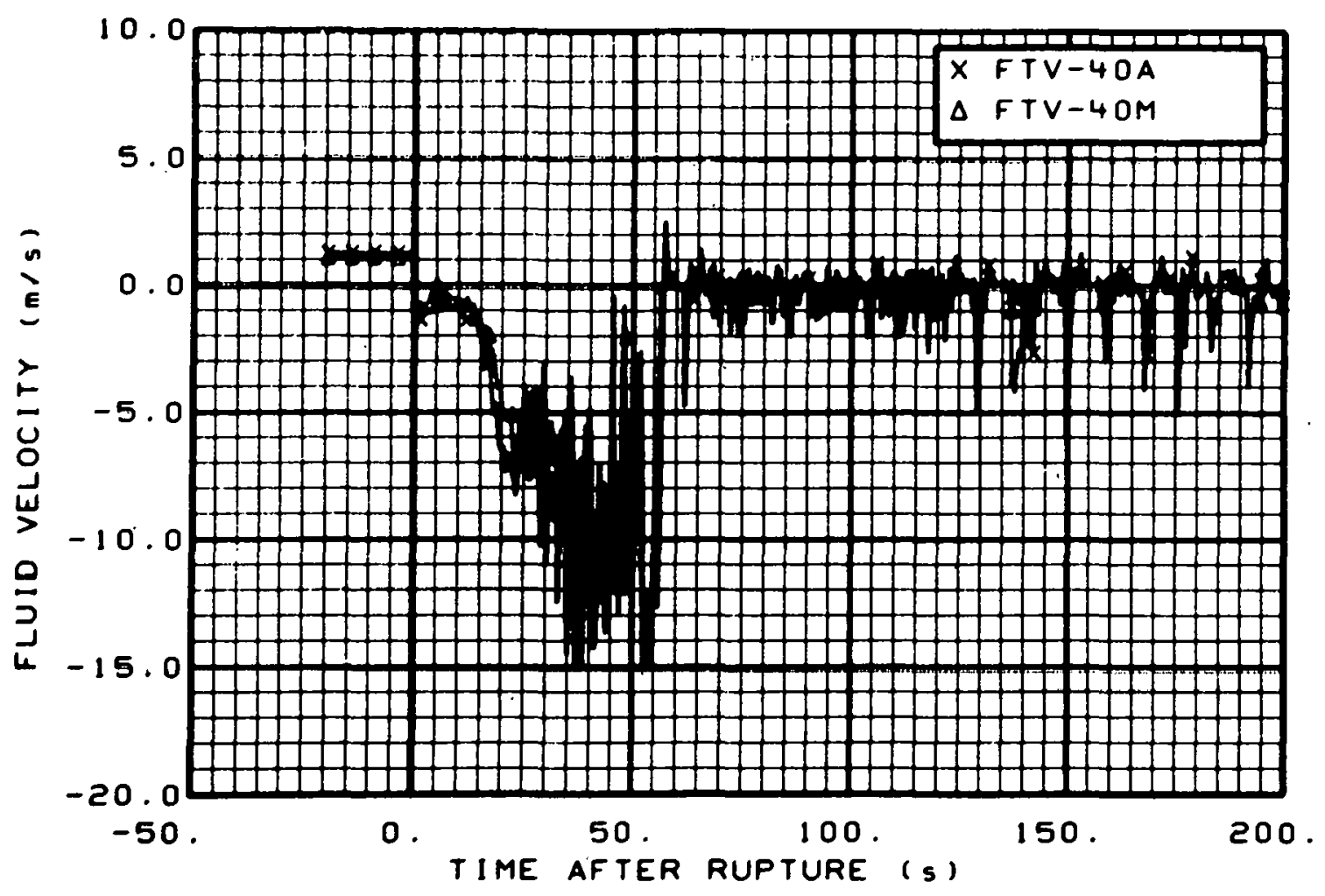

Fig: 245 Fluid velocity in vessel (FTV-40A and FTV-4011), from -20 to $200 \mathrm{~s}$.

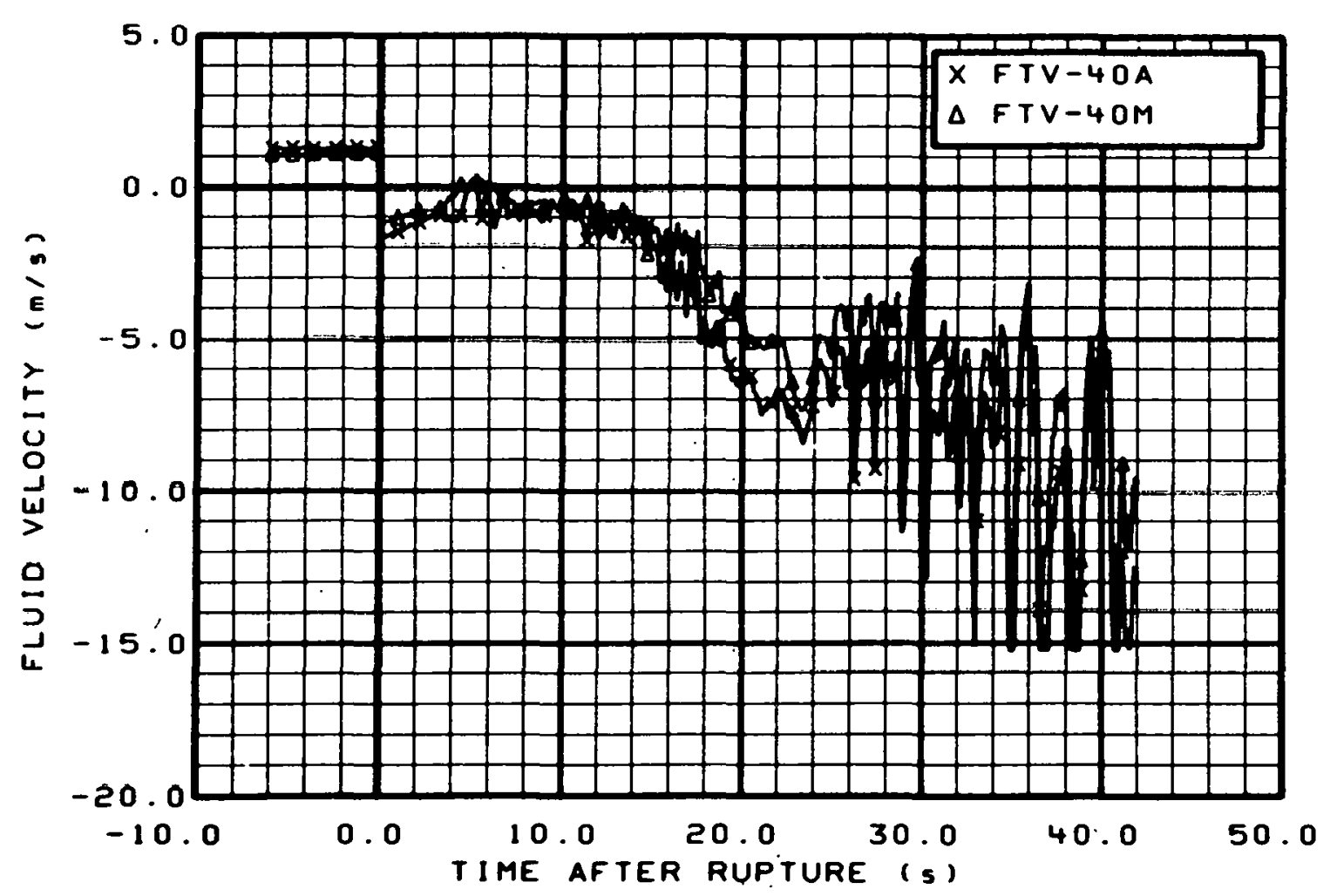

Fig. 246 Fluid velocity in vessel (FTV-40A and FTV-40M), from -6 to $42 \mathrm{~s}$. 


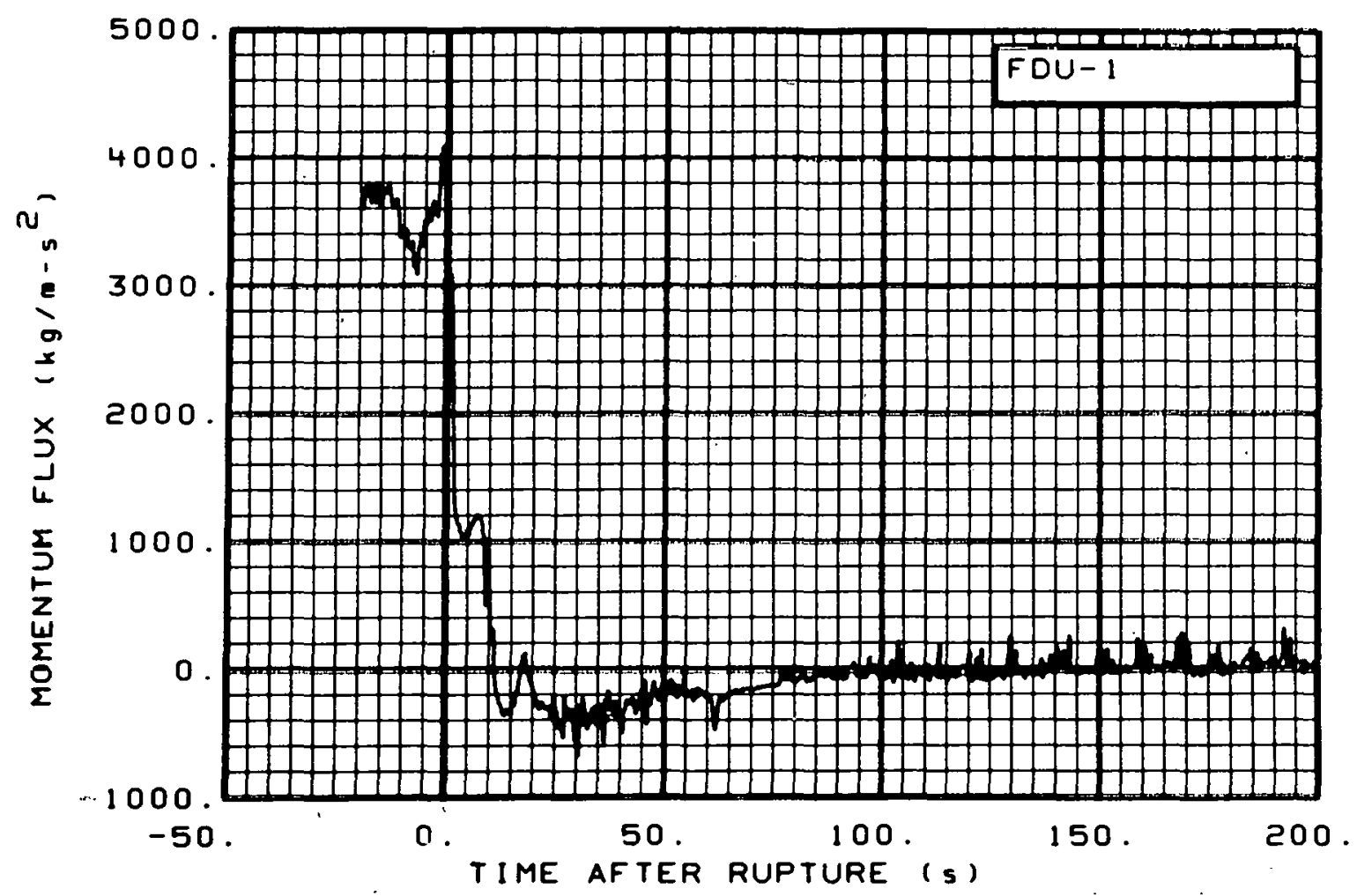

- Fig. 247 Momentum flux in intact loop (FDU-1), from -20 to $200 \mathrm{~s}$.

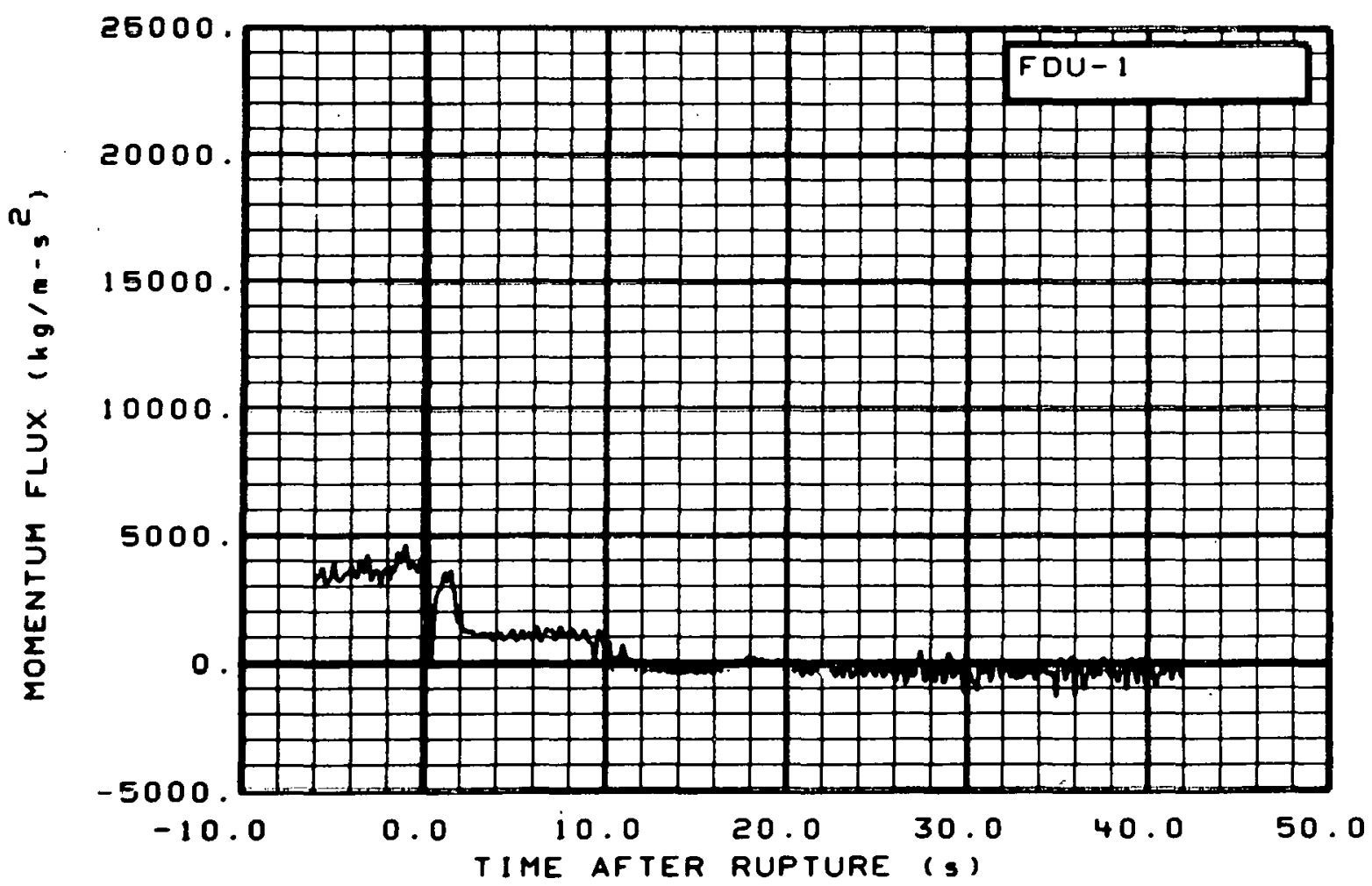

Fig. 248 Momentum flux in intact loop (FDU-1), from -6 to $42 \mathrm{~s}$. 


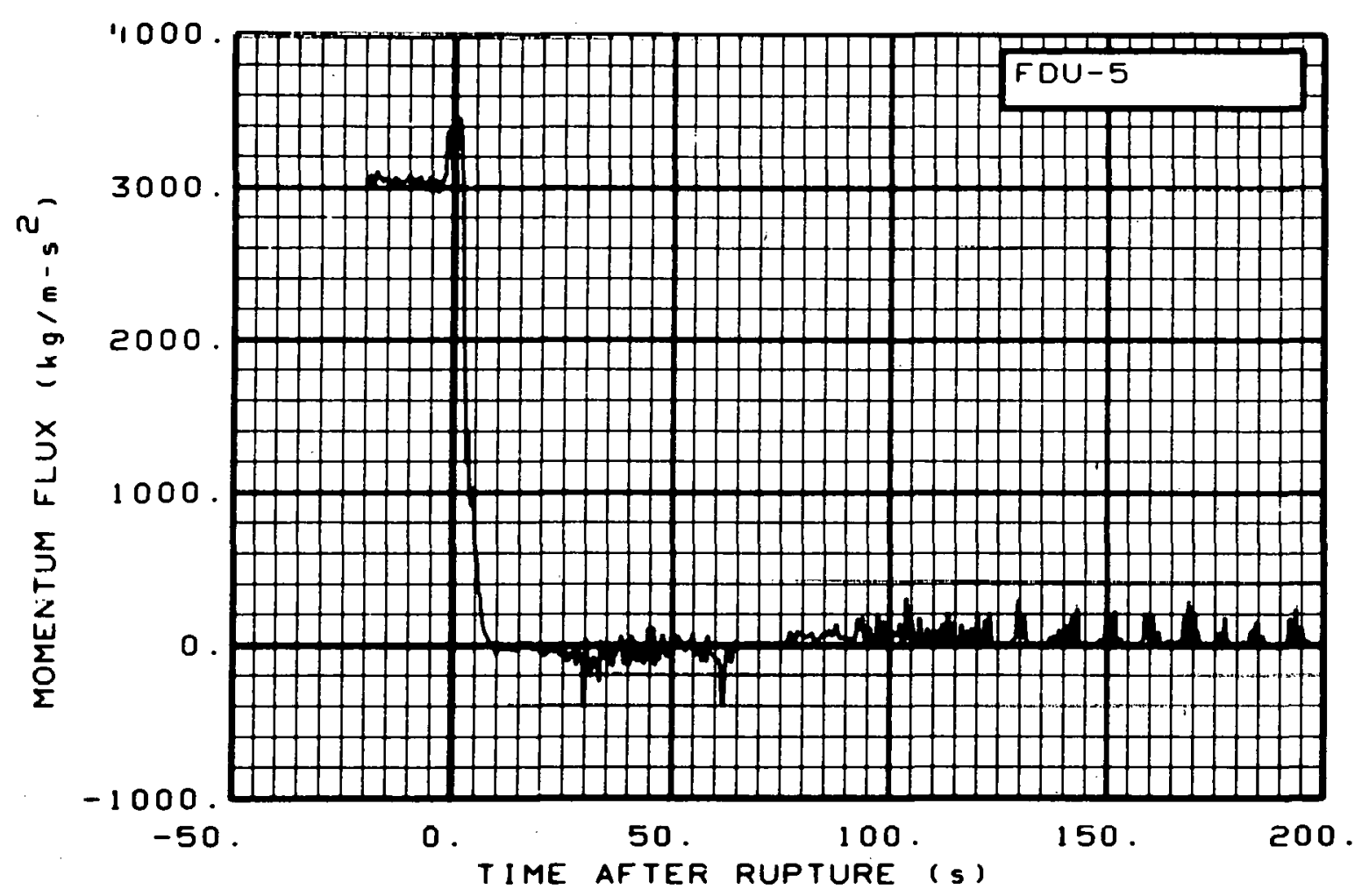

Fig. 249 Momentum flux in intact loop (FDU-5), from -20 to $200 \mathrm{~s}$.

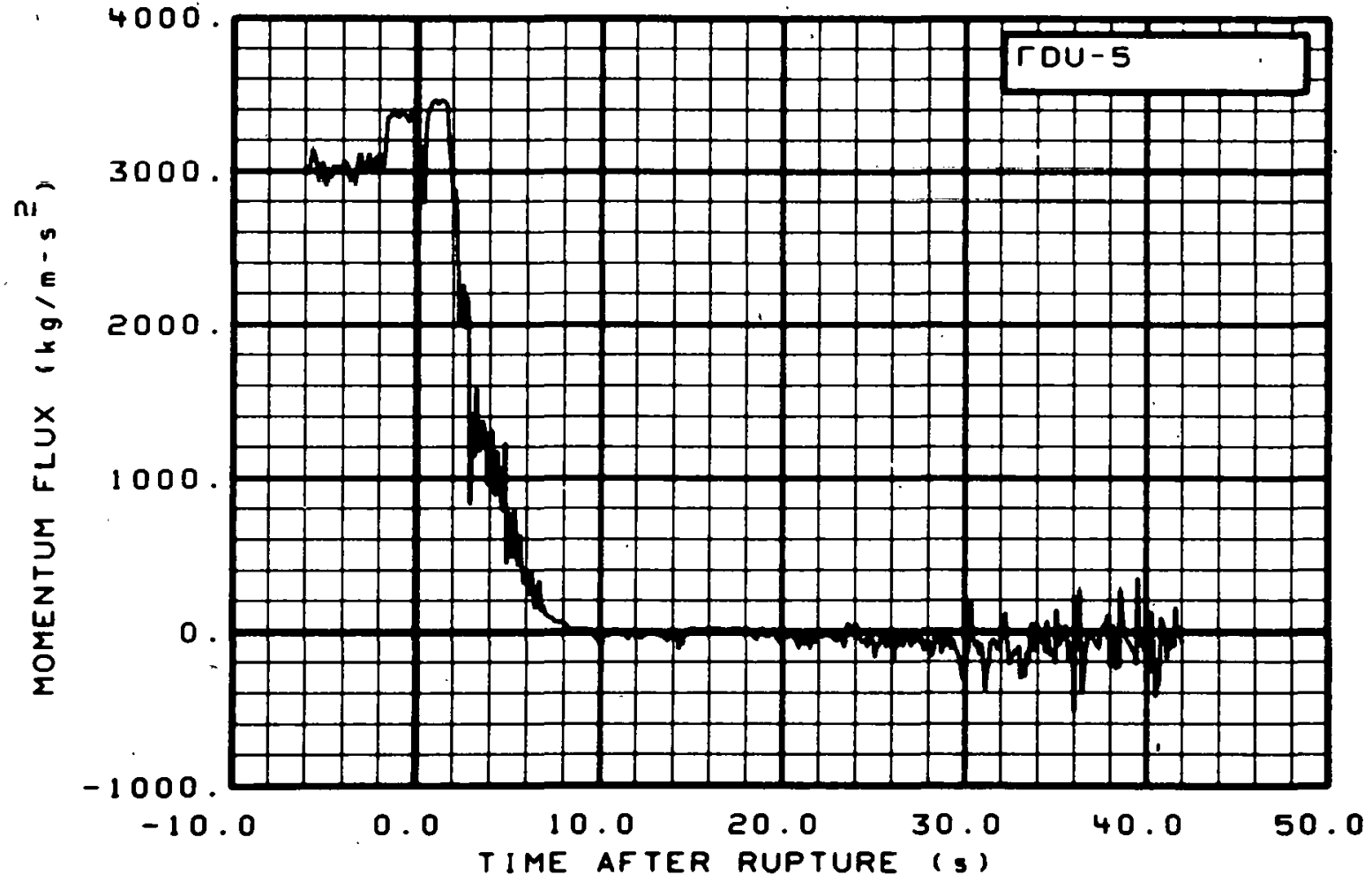

Fig. 250 Momentum flux in intact loop (FDU-5), from -6 to $42 \mathrm{~s}$. 


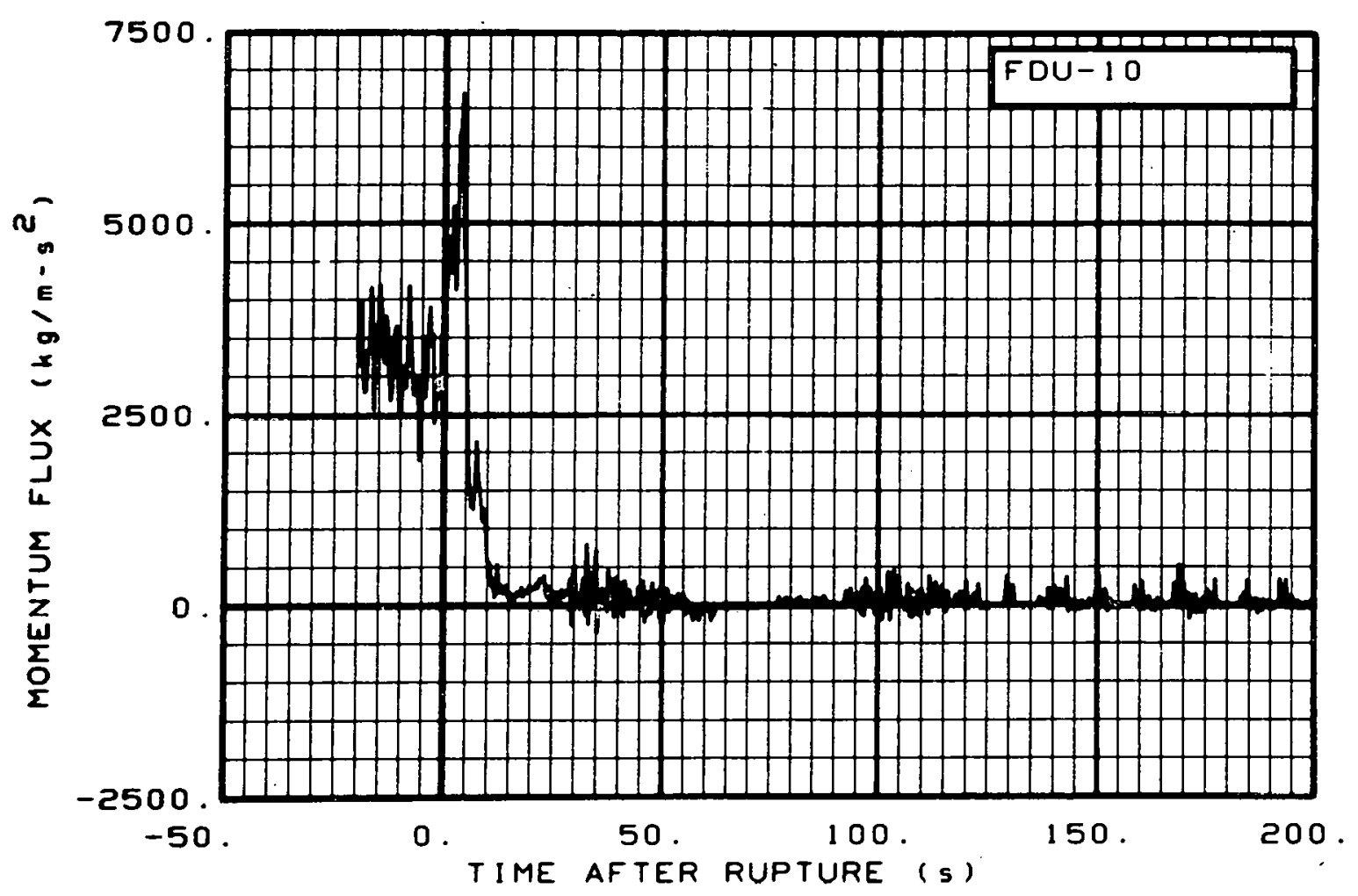

Fig. 251 Momentum flux in intact loop (FDU-10), from -20 to $200 \mathrm{~s}$.

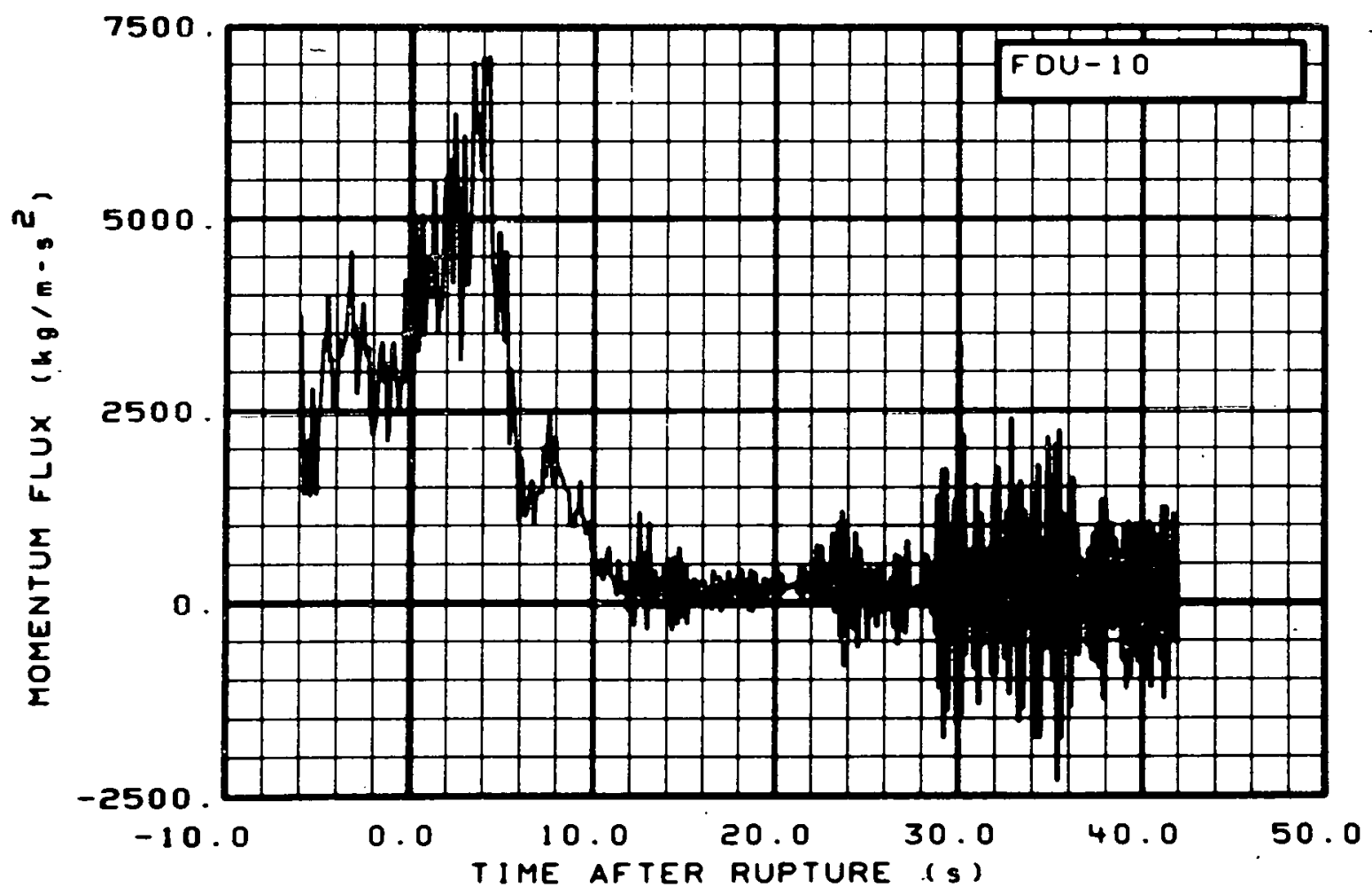

rig. 252 Momentum flux in inlact loop (FOU-10), from -6 to $42 \mathrm{~s}$. 


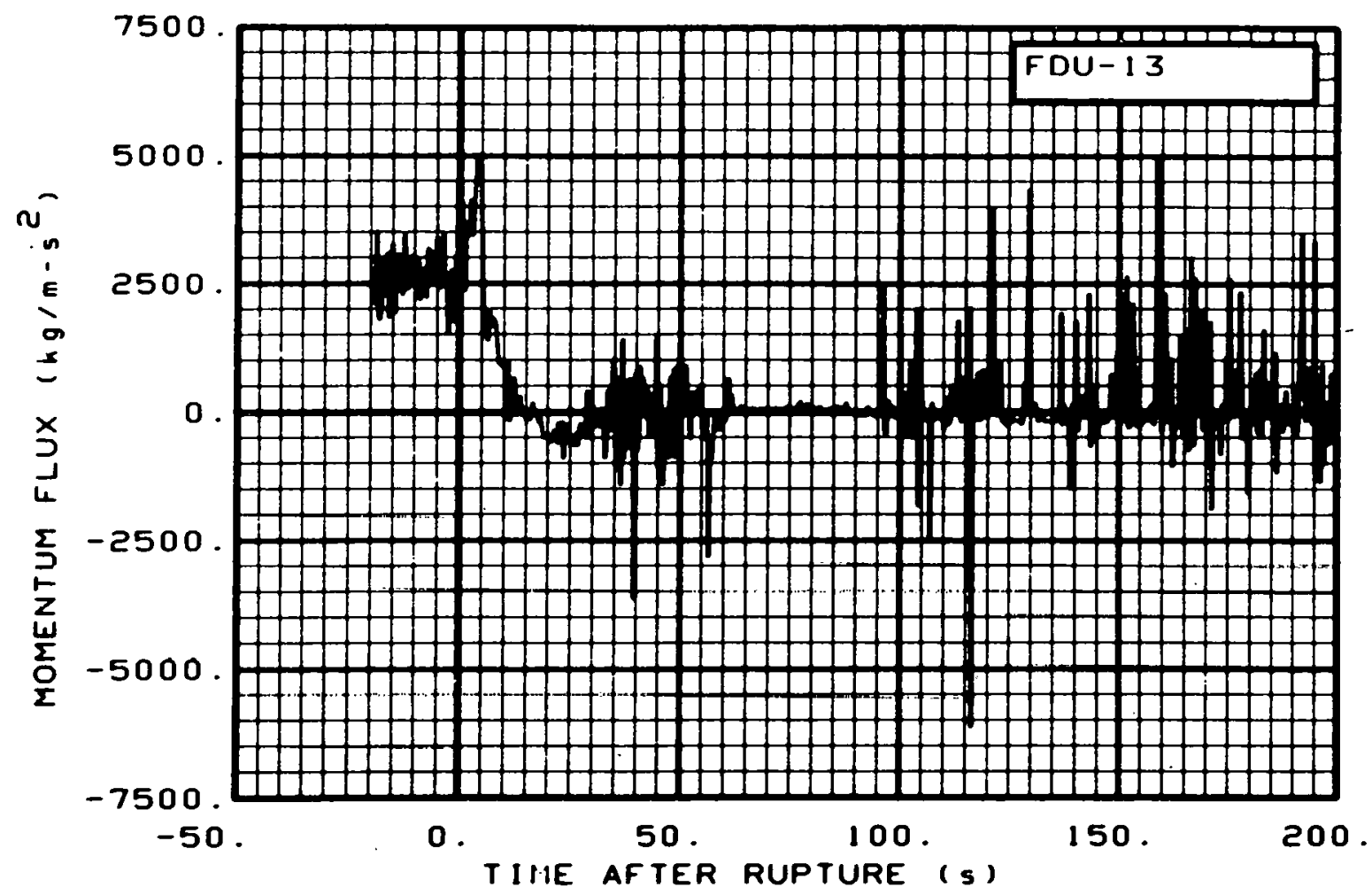

Fig. 253 Momentum flux in intact loop (FDU-13), from -20 to $200 \mathrm{~s}$.

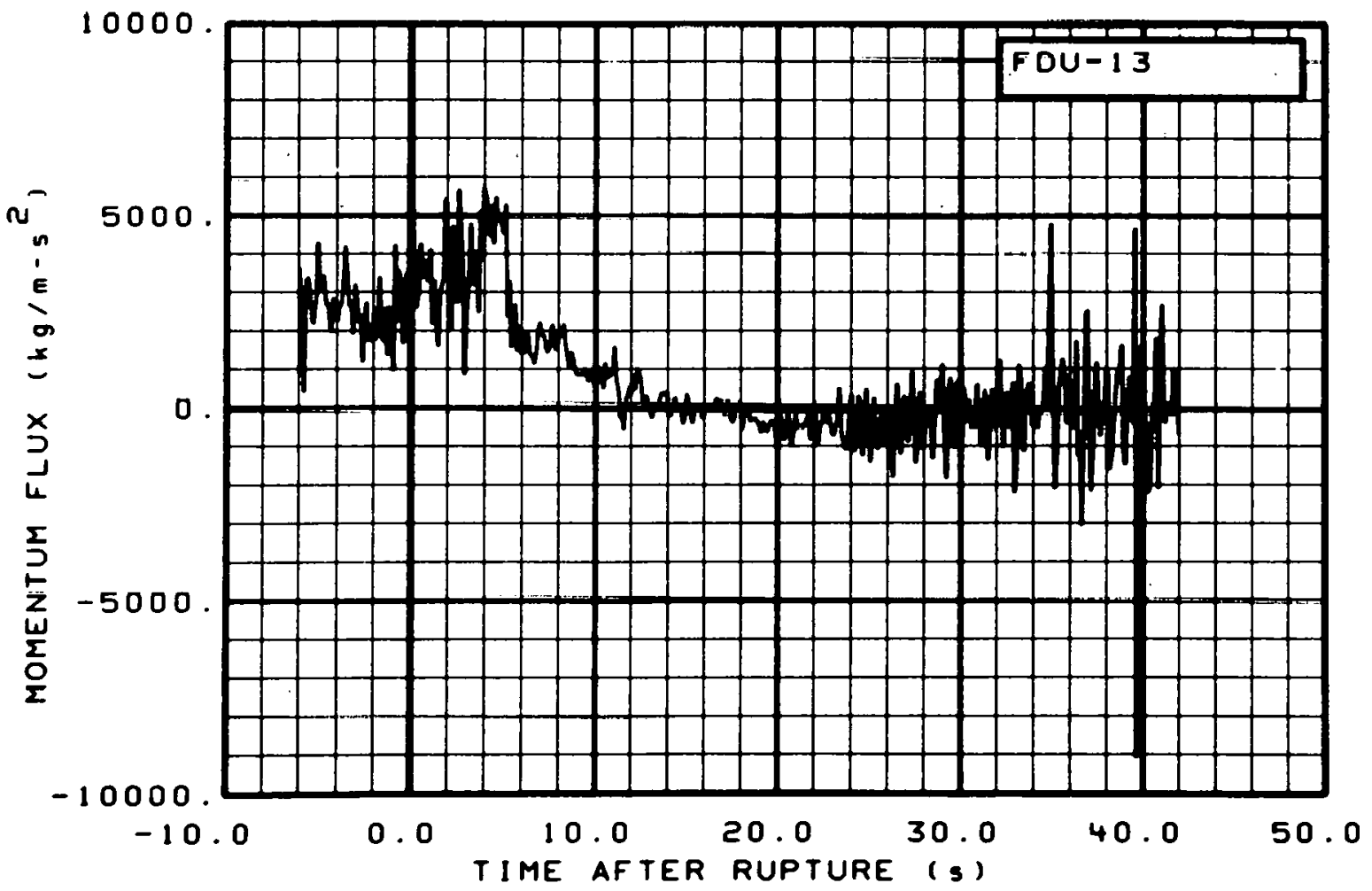

Fig. 254 Momentum flux in intact loop (FDU-13), from -6 to $42 \mathrm{~s}$. 


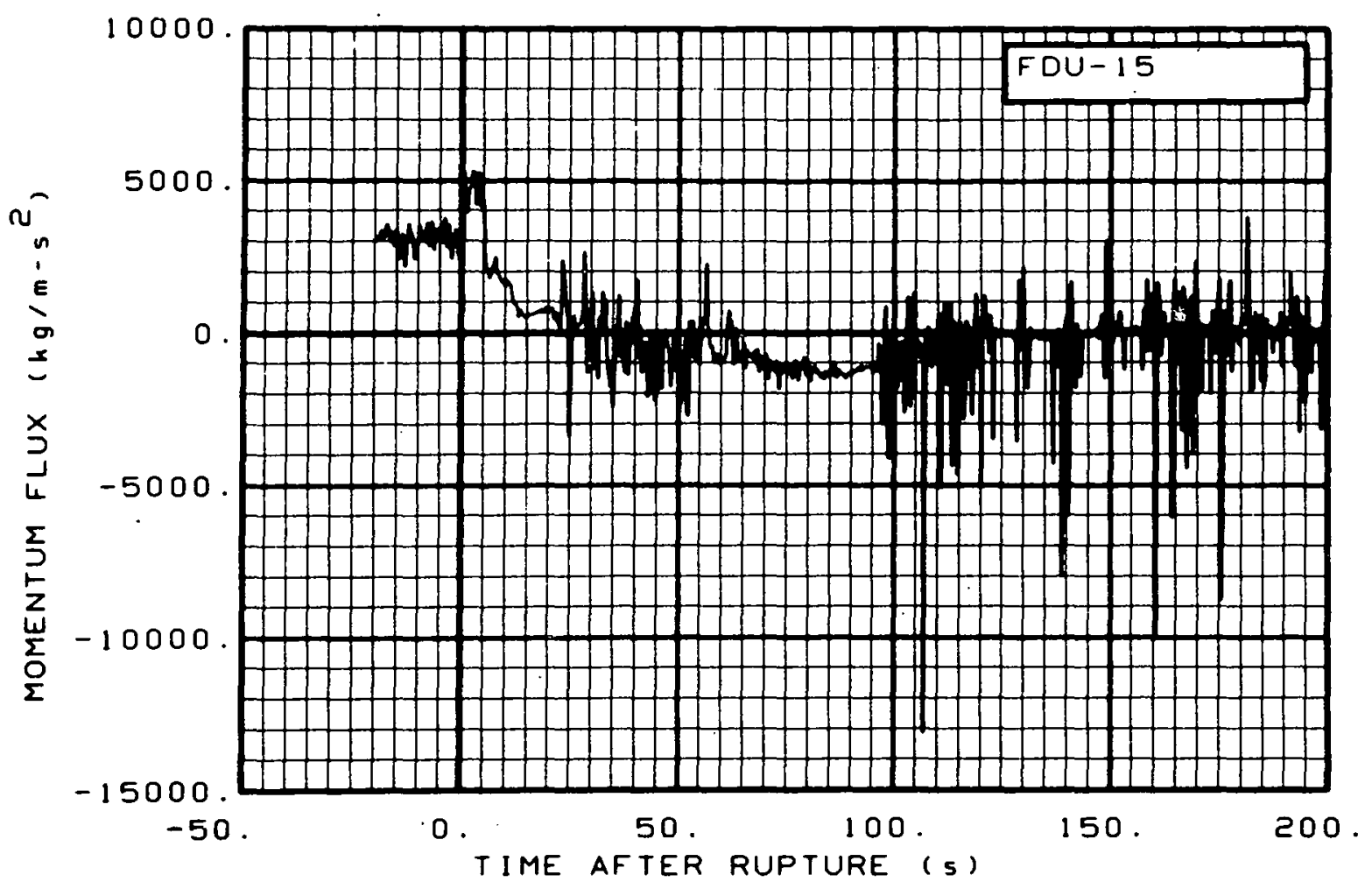

Fig. 255 Momentum flux in intact loop (FDU-15), from -20 to $200 \mathrm{~s}$.

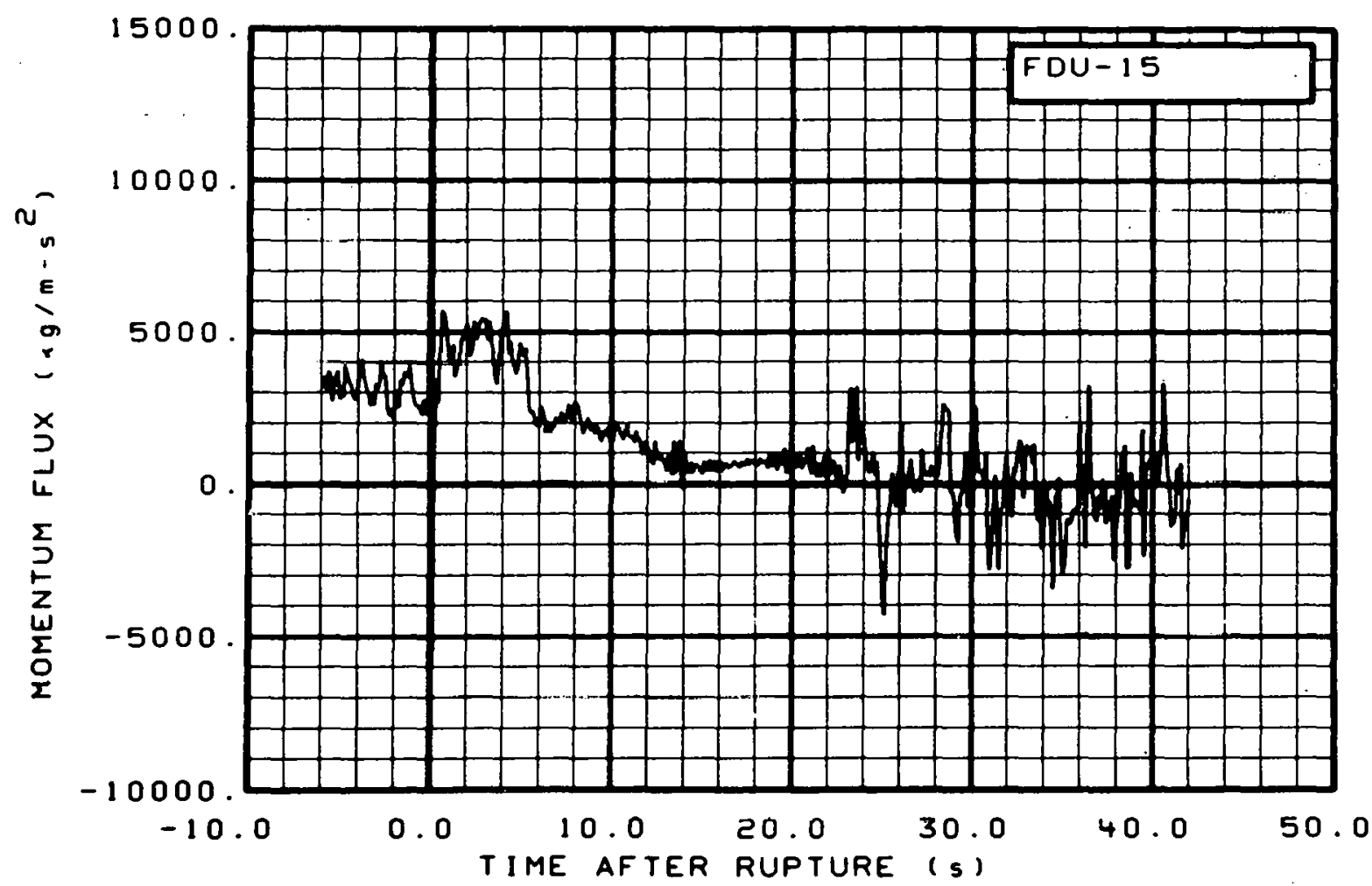

Fig. 256 Momentum flux in intac.t loop (FDU-15), from -6 to $42 \mathrm{~s}$. 


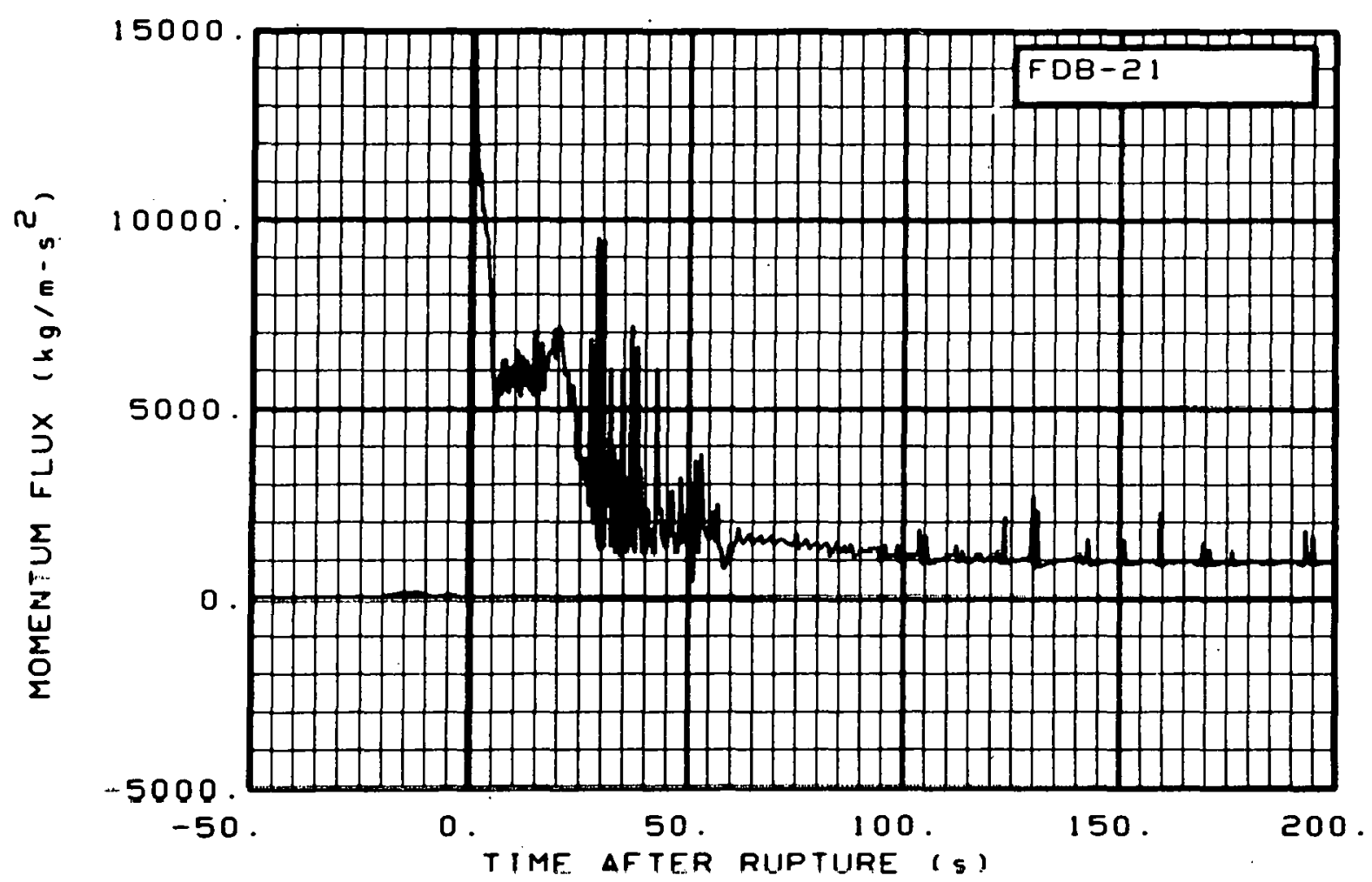

Fig. 257 Momentum flux in broken loop (FDB-21), from -20 to $200 \mathrm{~s}$.

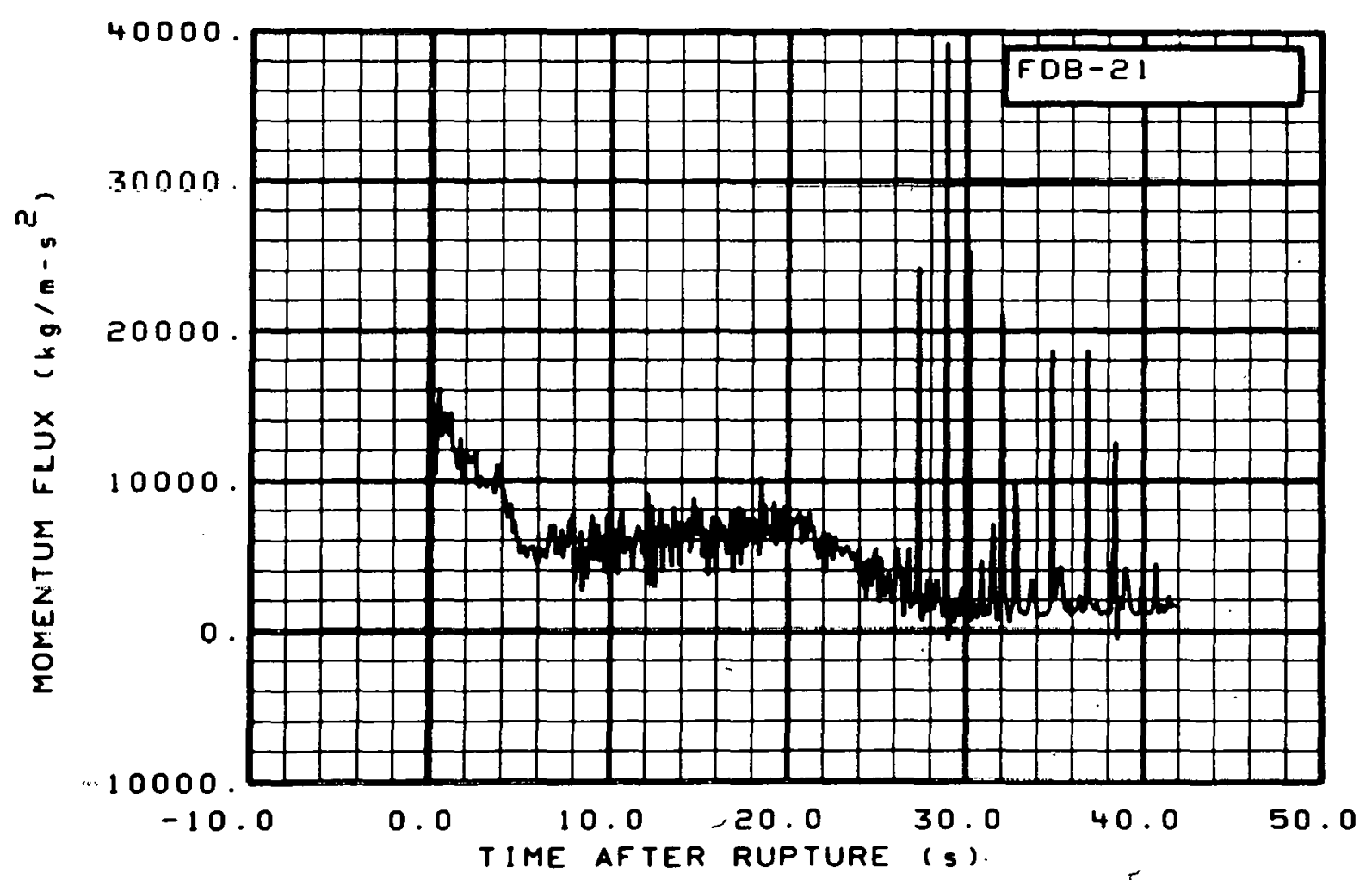

Fig. 258 Momentum flux in broken loop (FDB-21), from -6 to $42 \mathrm{~s}$. 


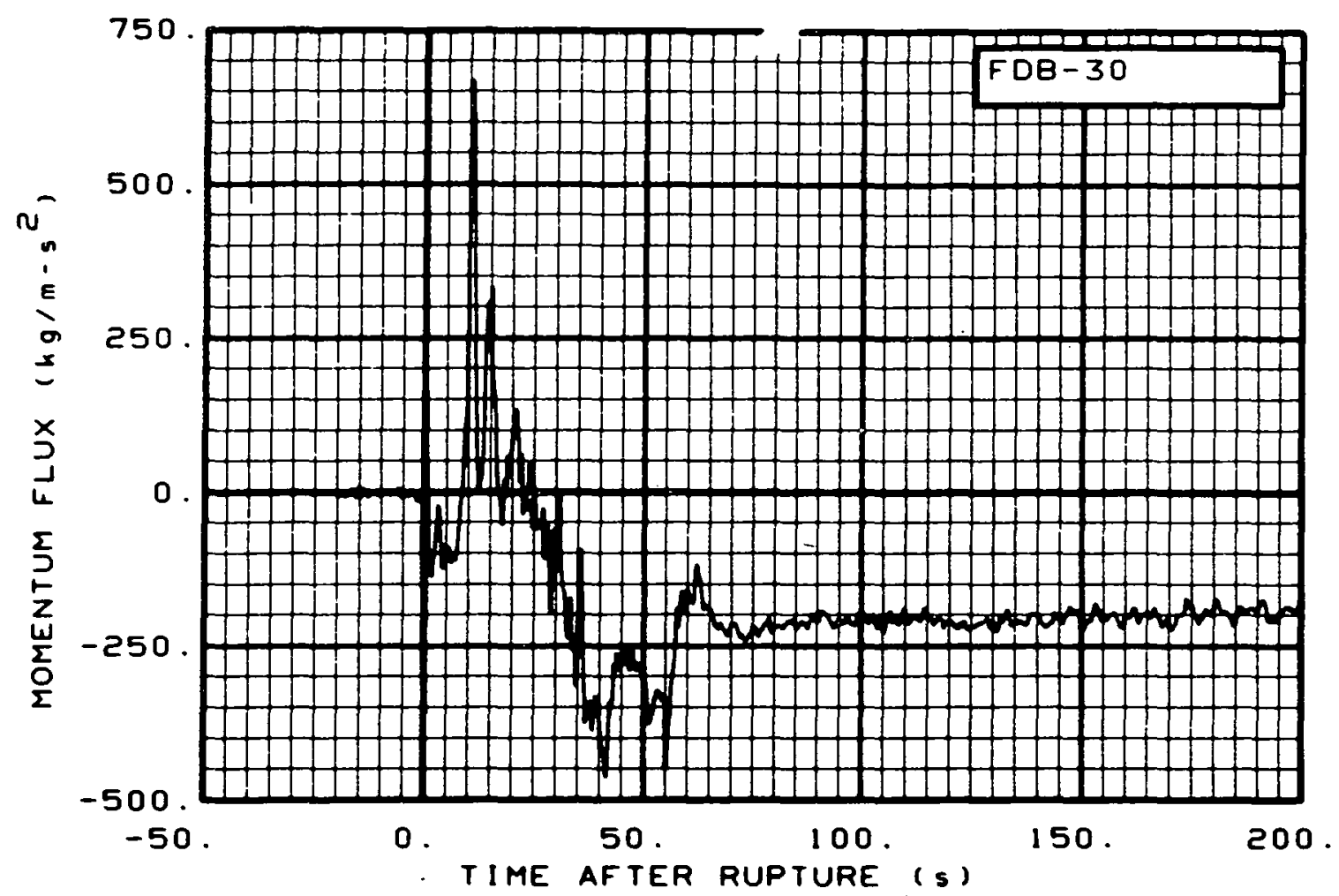

Fig. 259 Momentum flux in broken loop (FDB-30), from -20 to $200 \mathrm{~s}$.

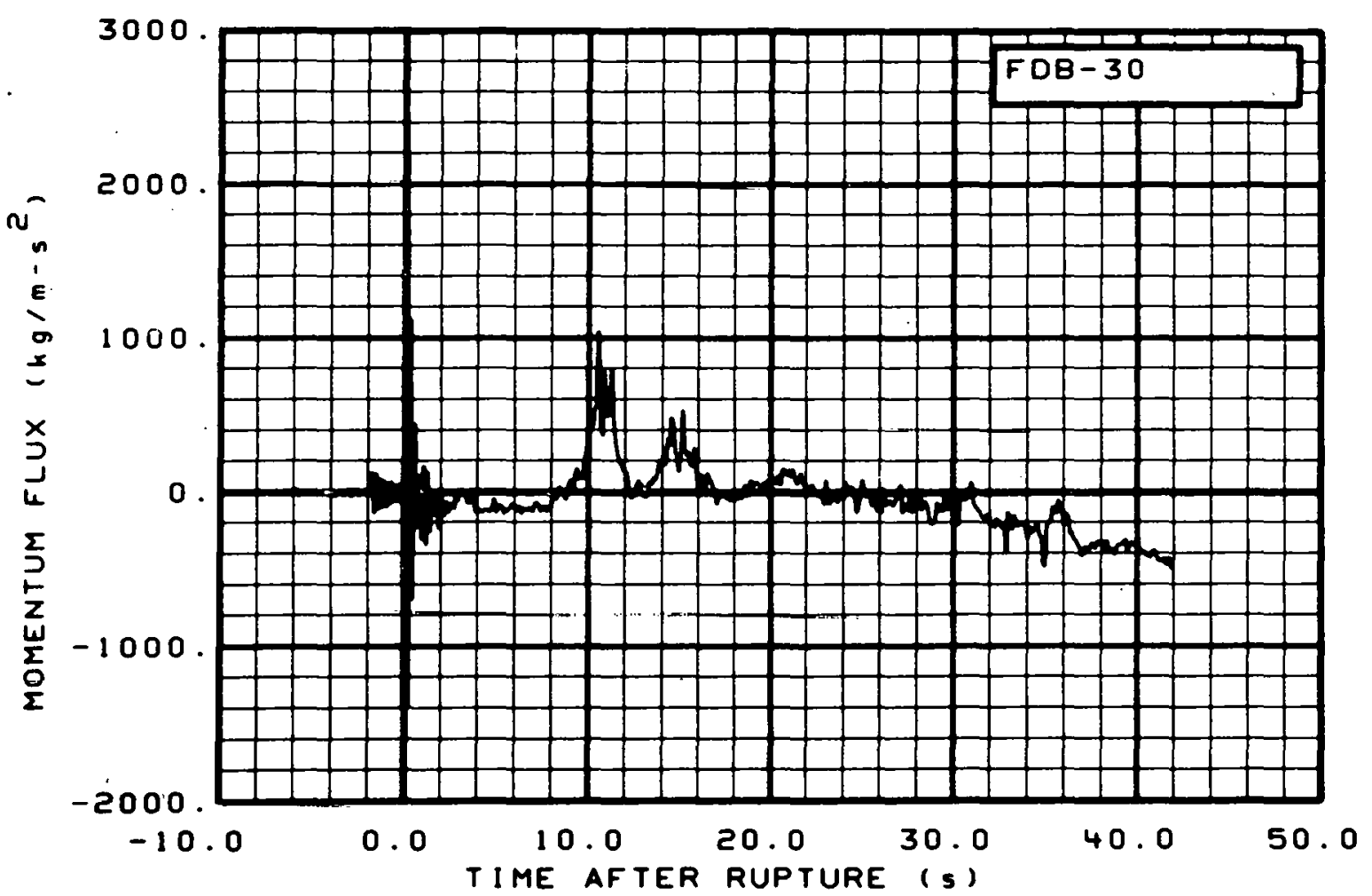

Fig. 260 Momentum flux in broken loop (FDB-30), from -6 to $42 \mathrm{~s}$. 


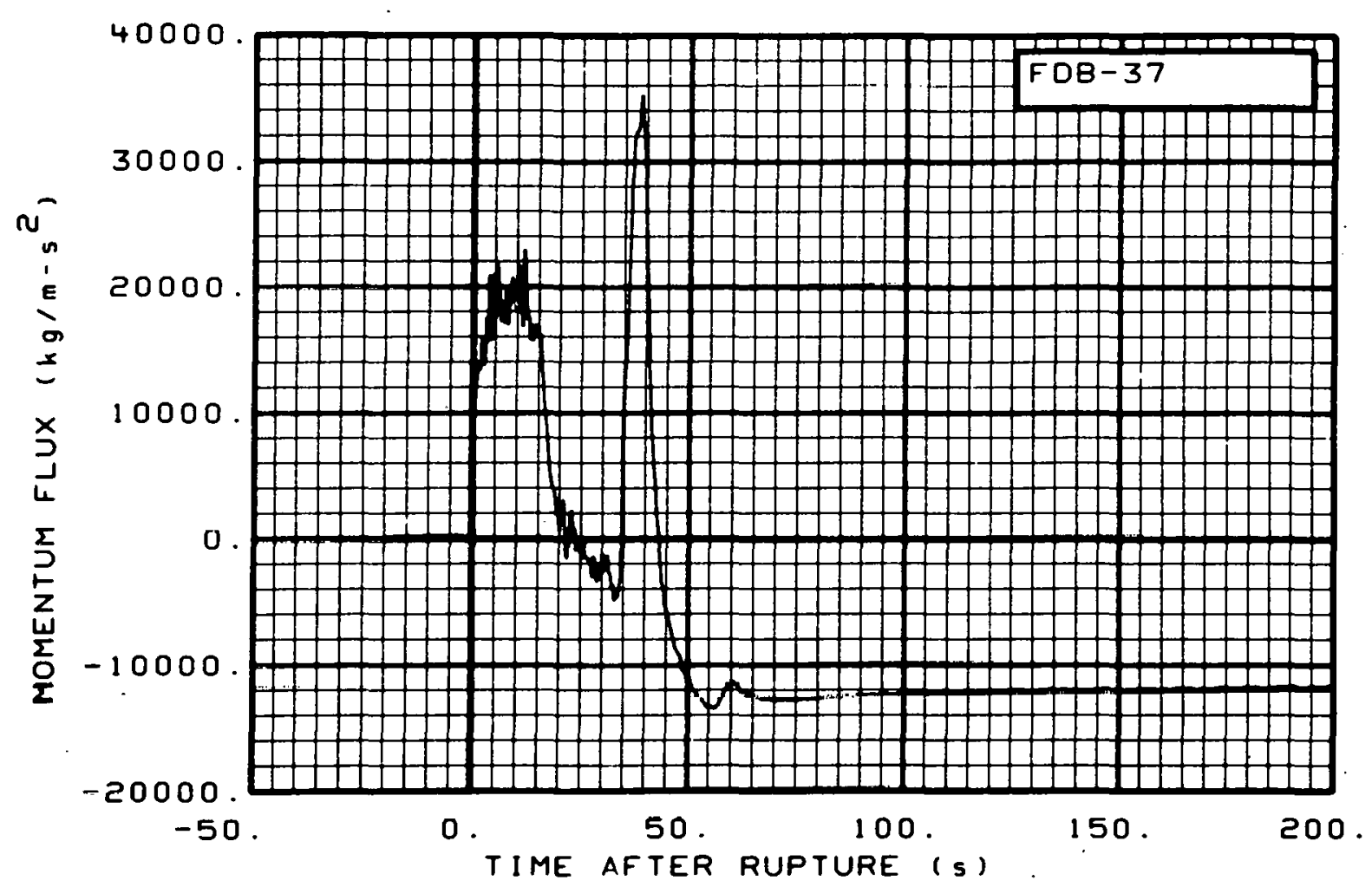

Fig. 261 Momentum flux in broken loop (FDB-37), from -20 to $200 \mathrm{~s}$.

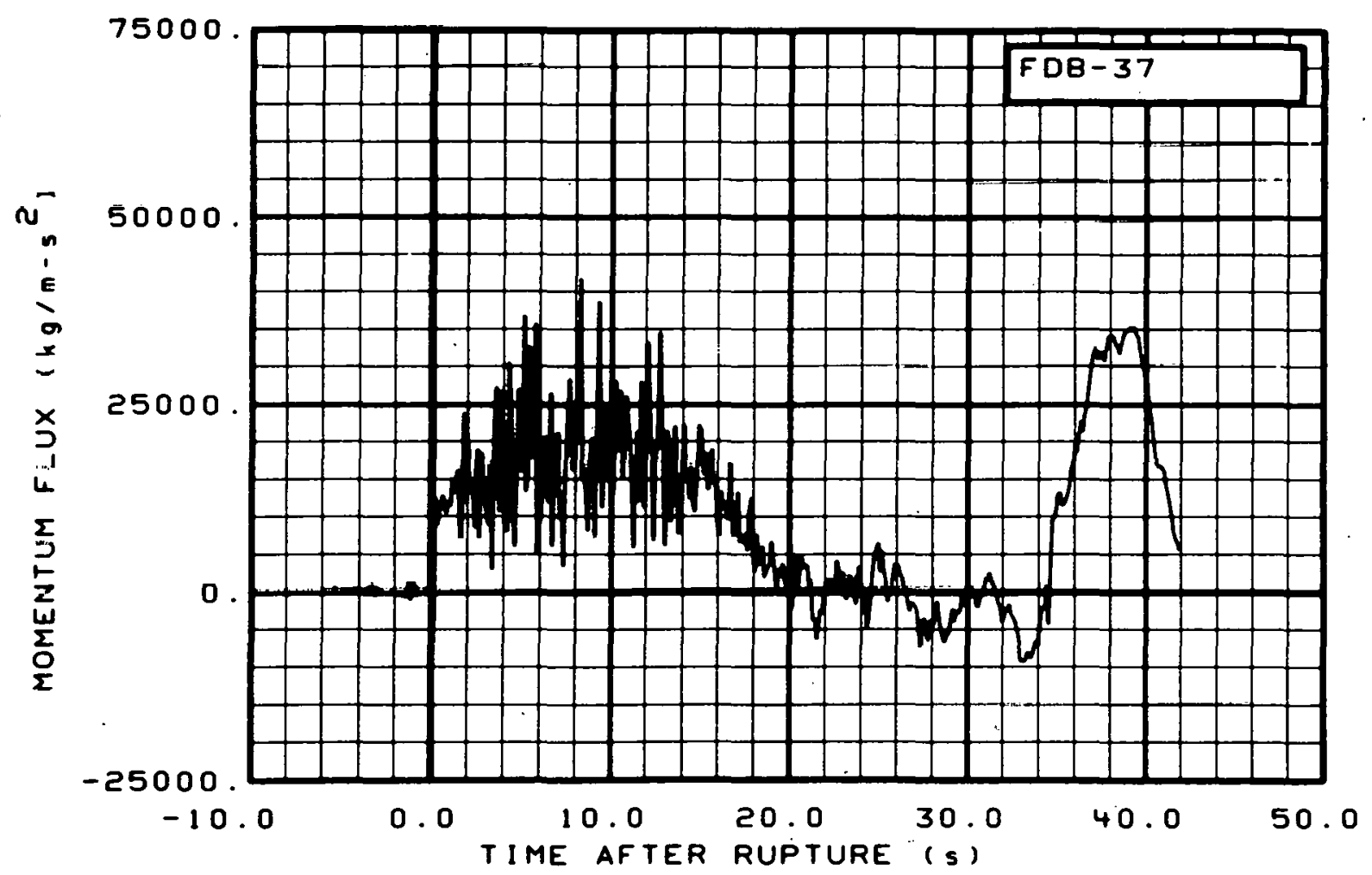

Fig. 262 Momentum flux in broken loop (FDB-37), from -6 to $42 \mathrm{~s}$. 


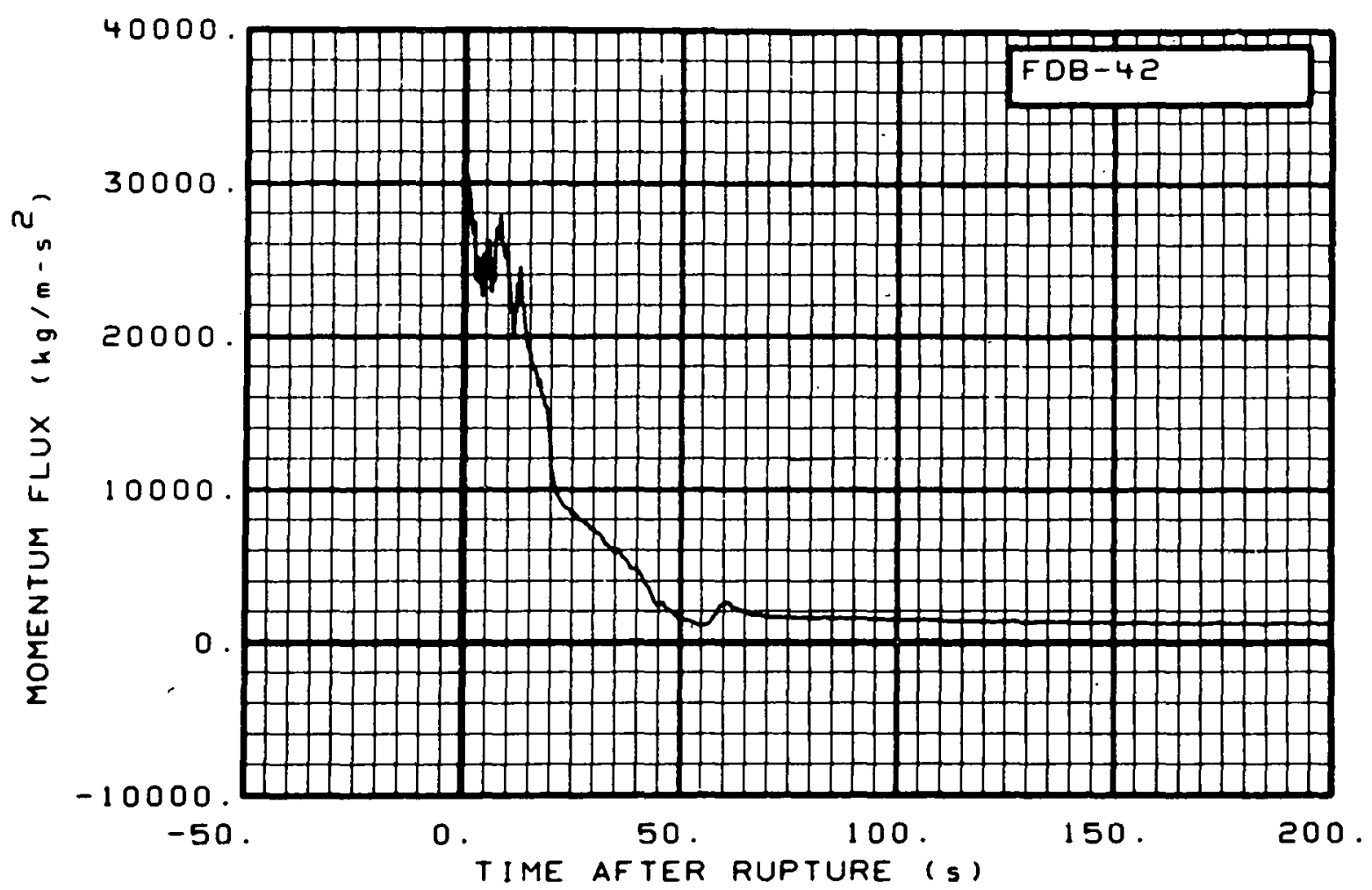

Fig. 263 Momentum flux in broken loop (FDB-42), from -20 to $200 \mathrm{~s} .$.

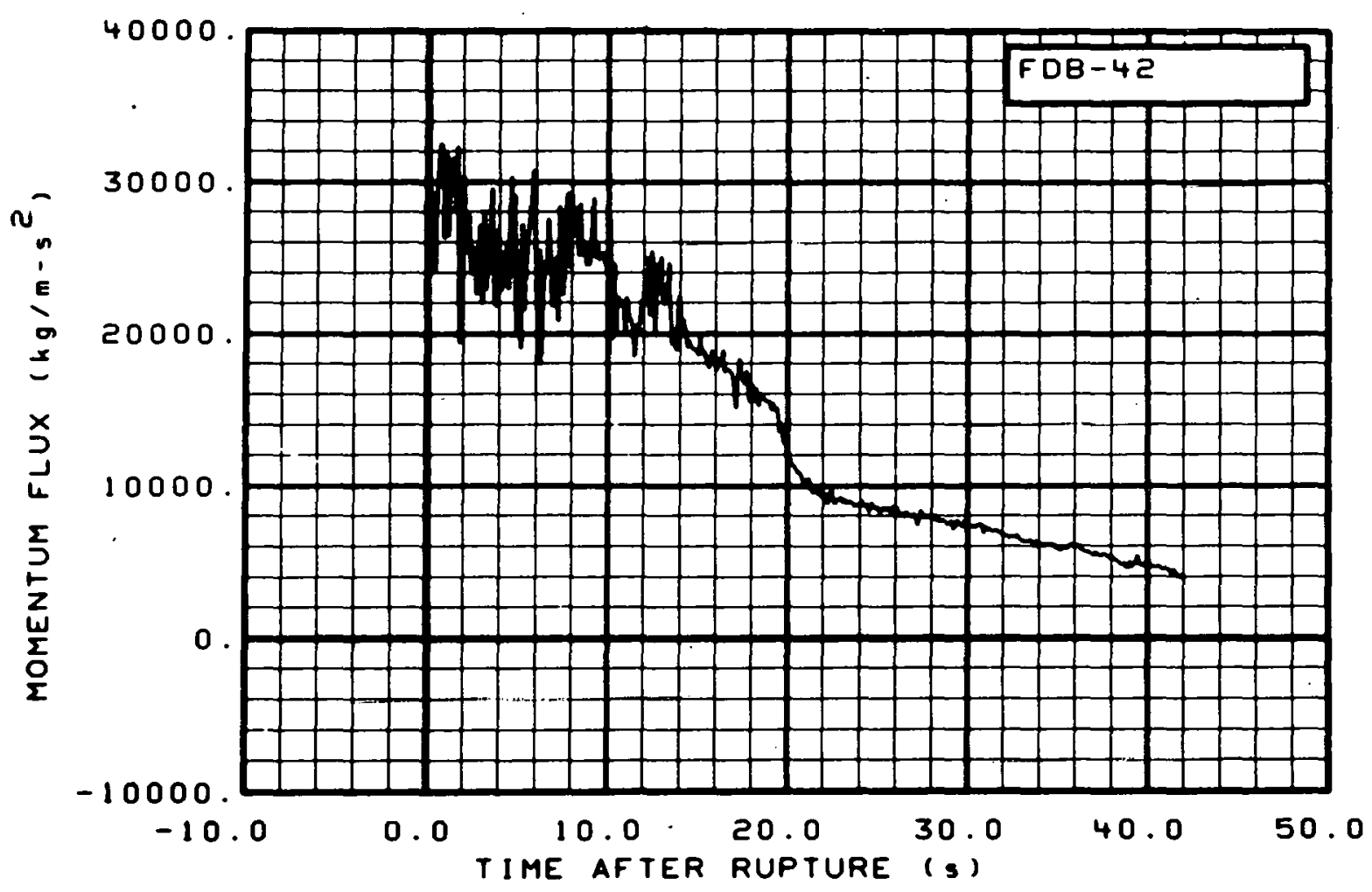

Fig. 264 Momentum flux in broken loop (FDB-42), from -6 to $42 \mathrm{~s}$. 


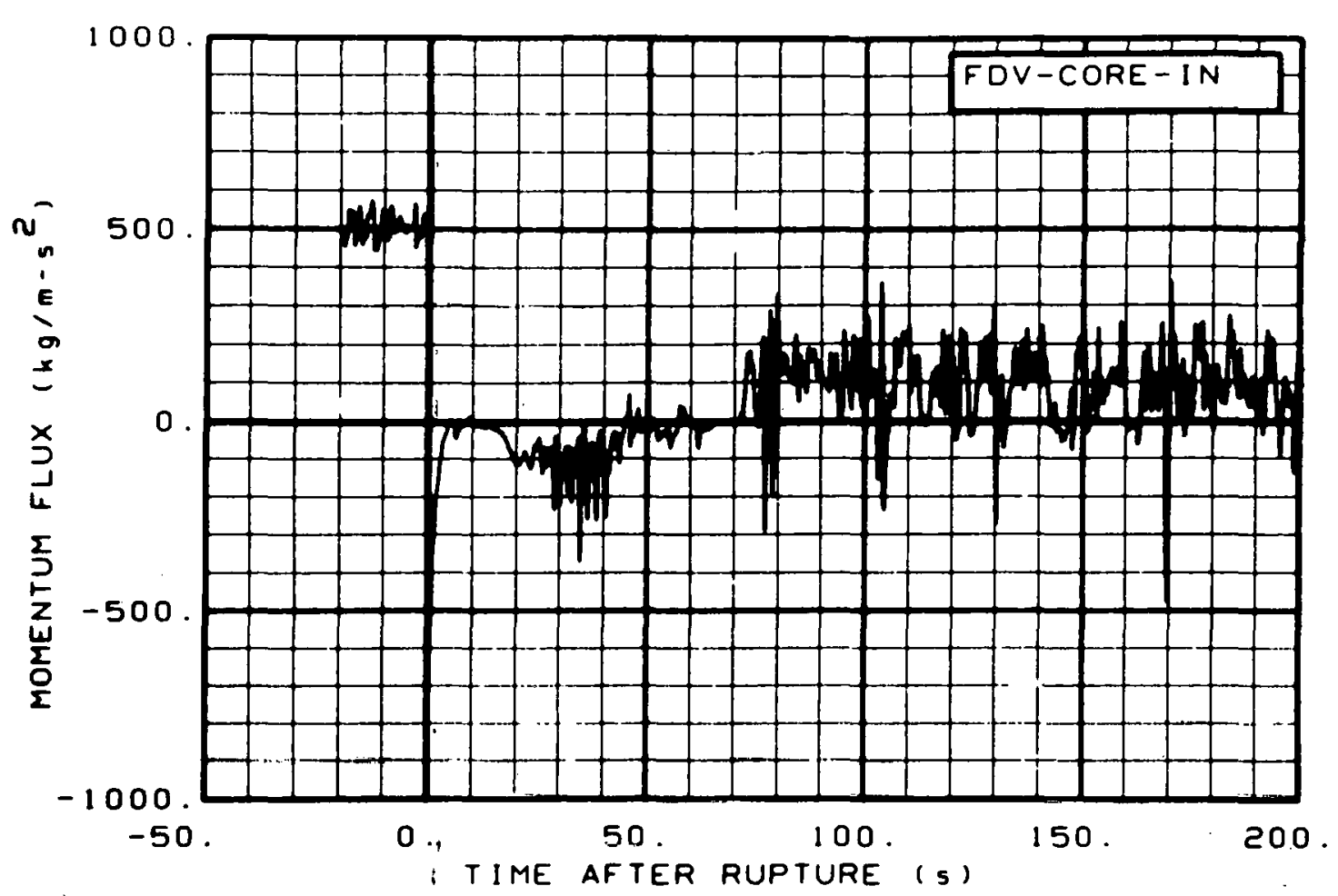

Fig. 265 Momentum flux in core entrance (FDV-CORE-IN), from -20 to $200 \mathrm{~s}$.

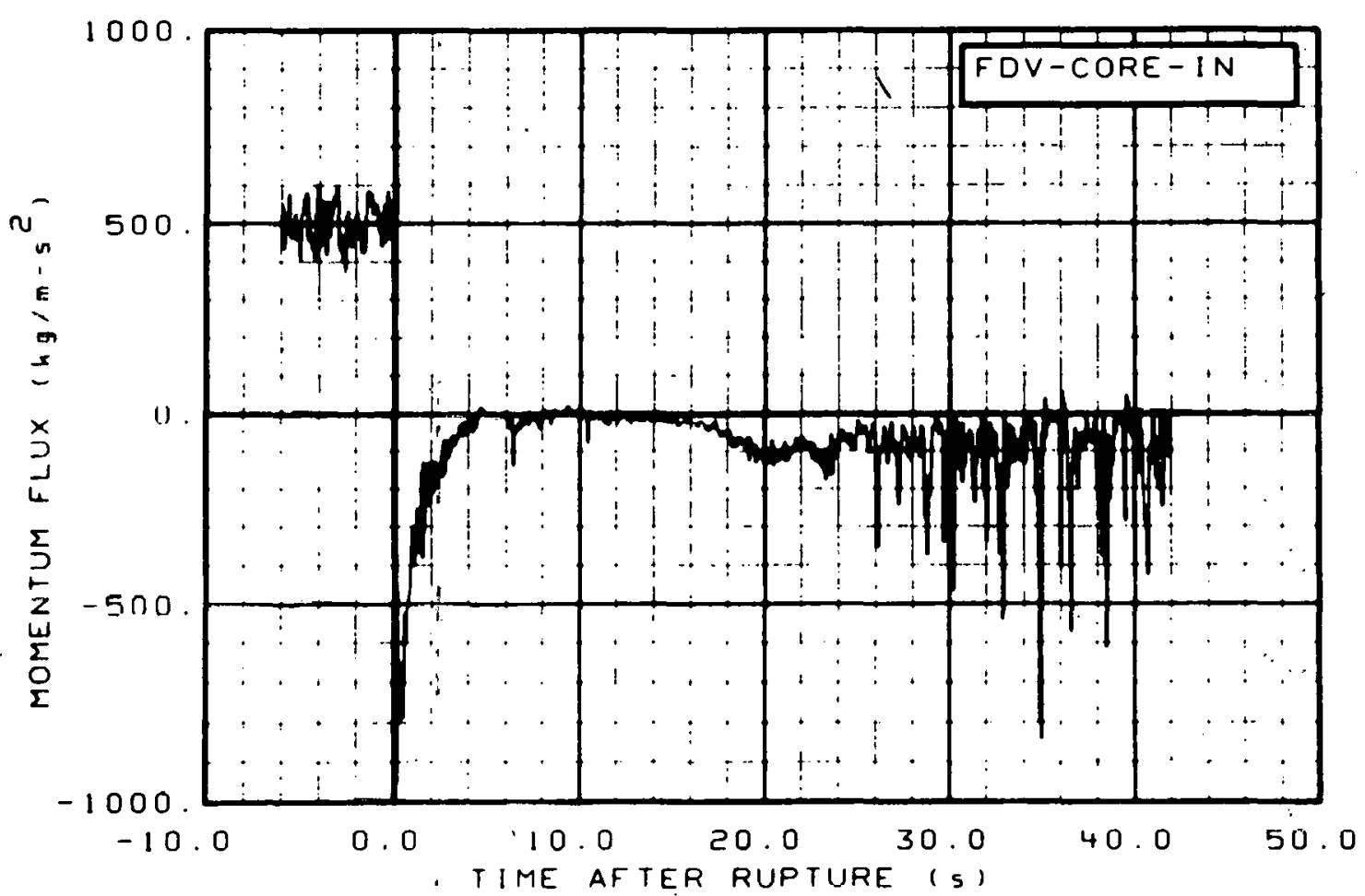

Fig. 266 Momentum flux in core entrance (FDV-CORE-IN), from -6 to $42 \mathrm{~s}$. 


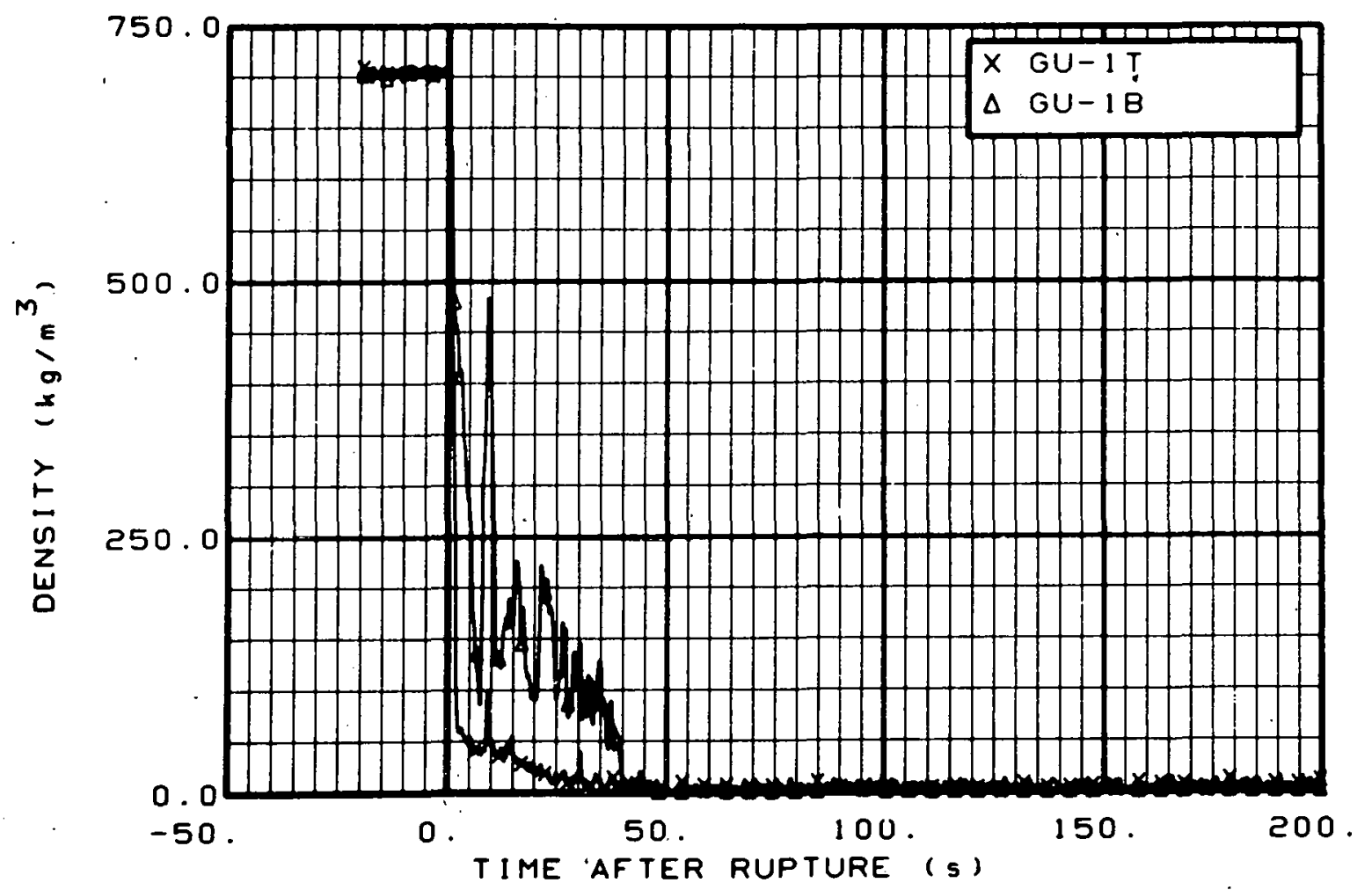

Fig. 267 Density in intact loop (GU-1T and GU-1B), from -20 to $200 \mathrm{~s}$.

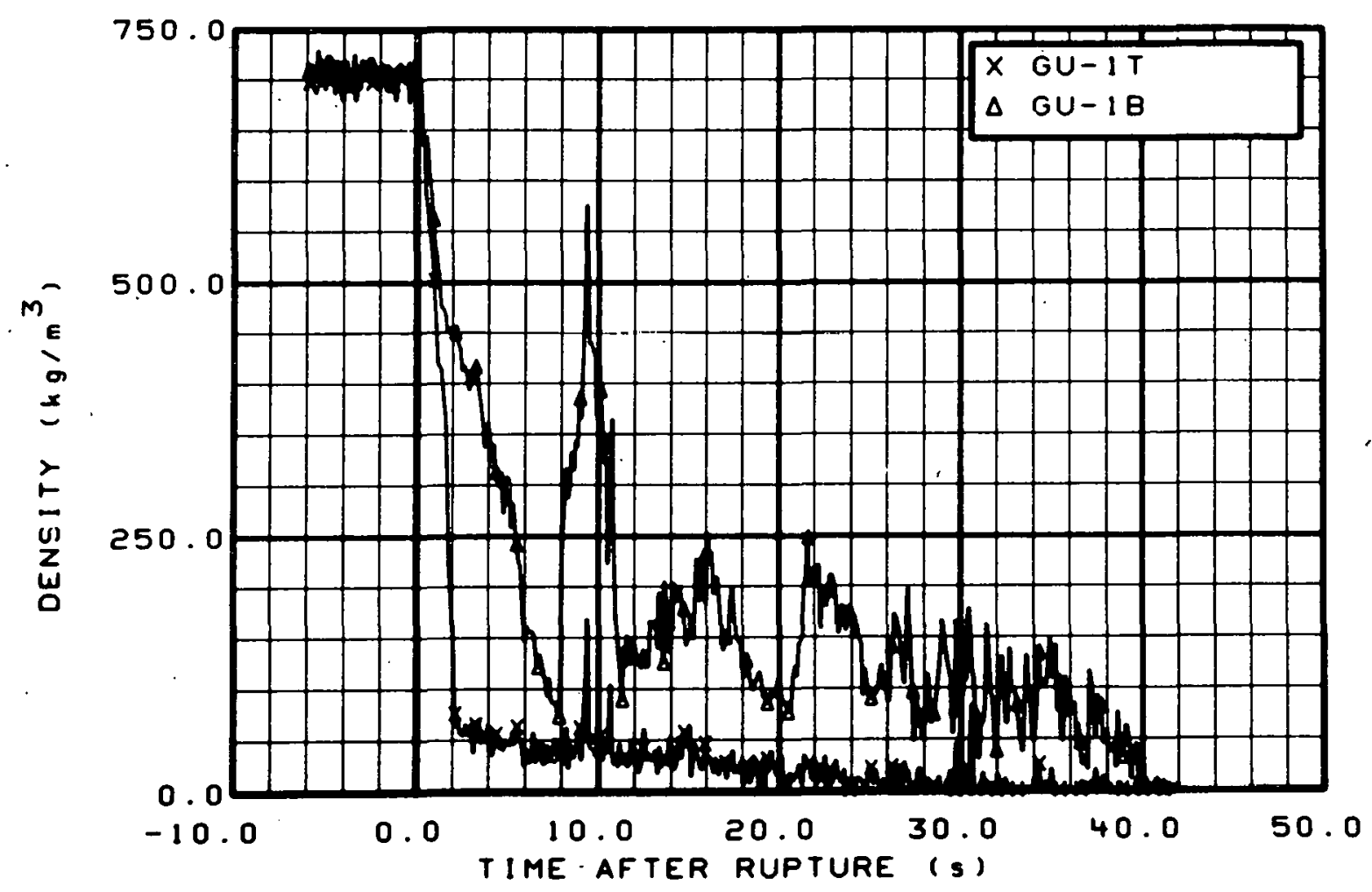

Fig. 268 Density in intact 100p (GU-1T and GU-1B), from -6 to $42 \mathrm{~s}$. 


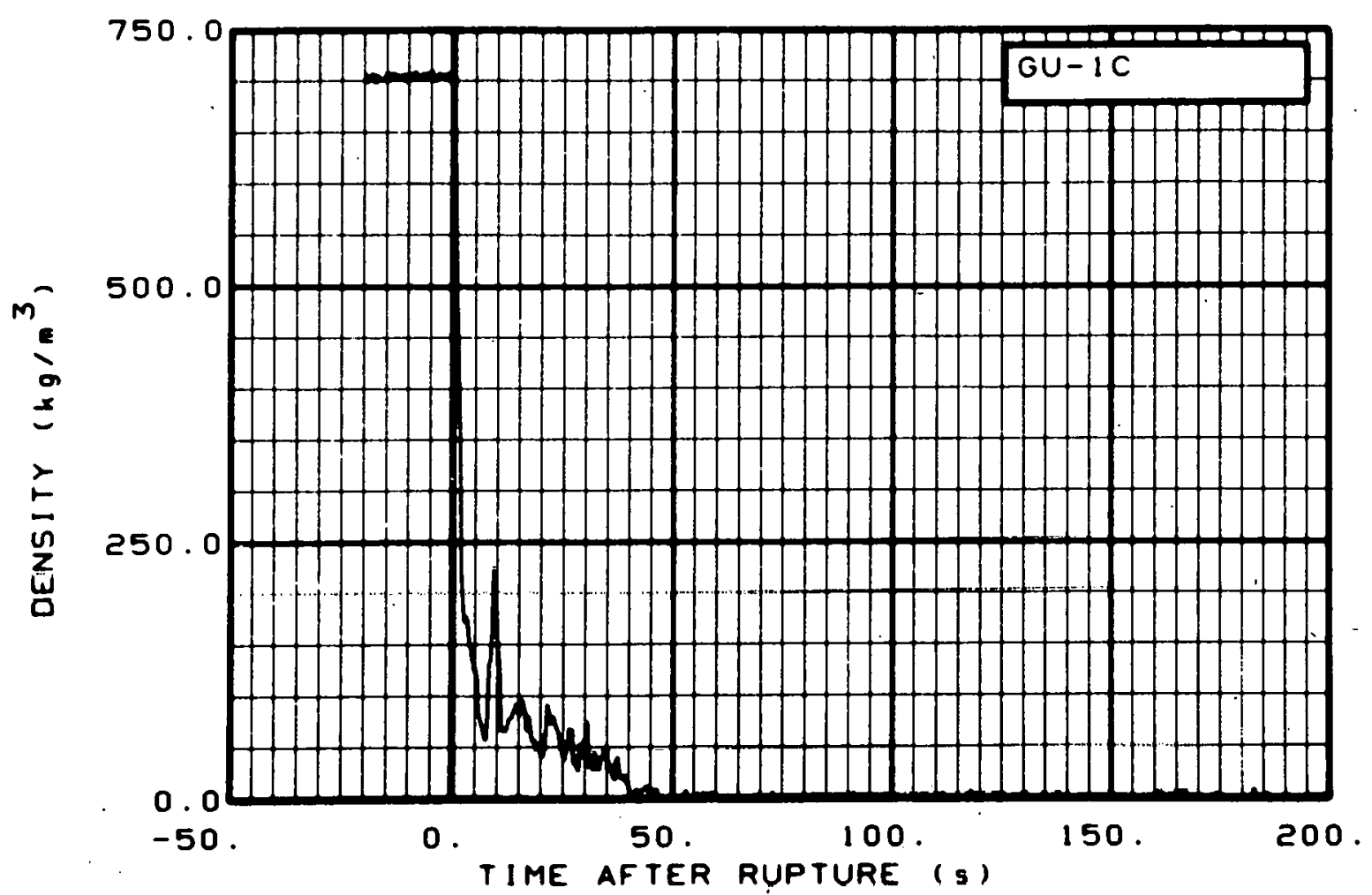

Fig. 269 Density in intact loop (GU-IC), from -20 to $200 \mathrm{~s}$.

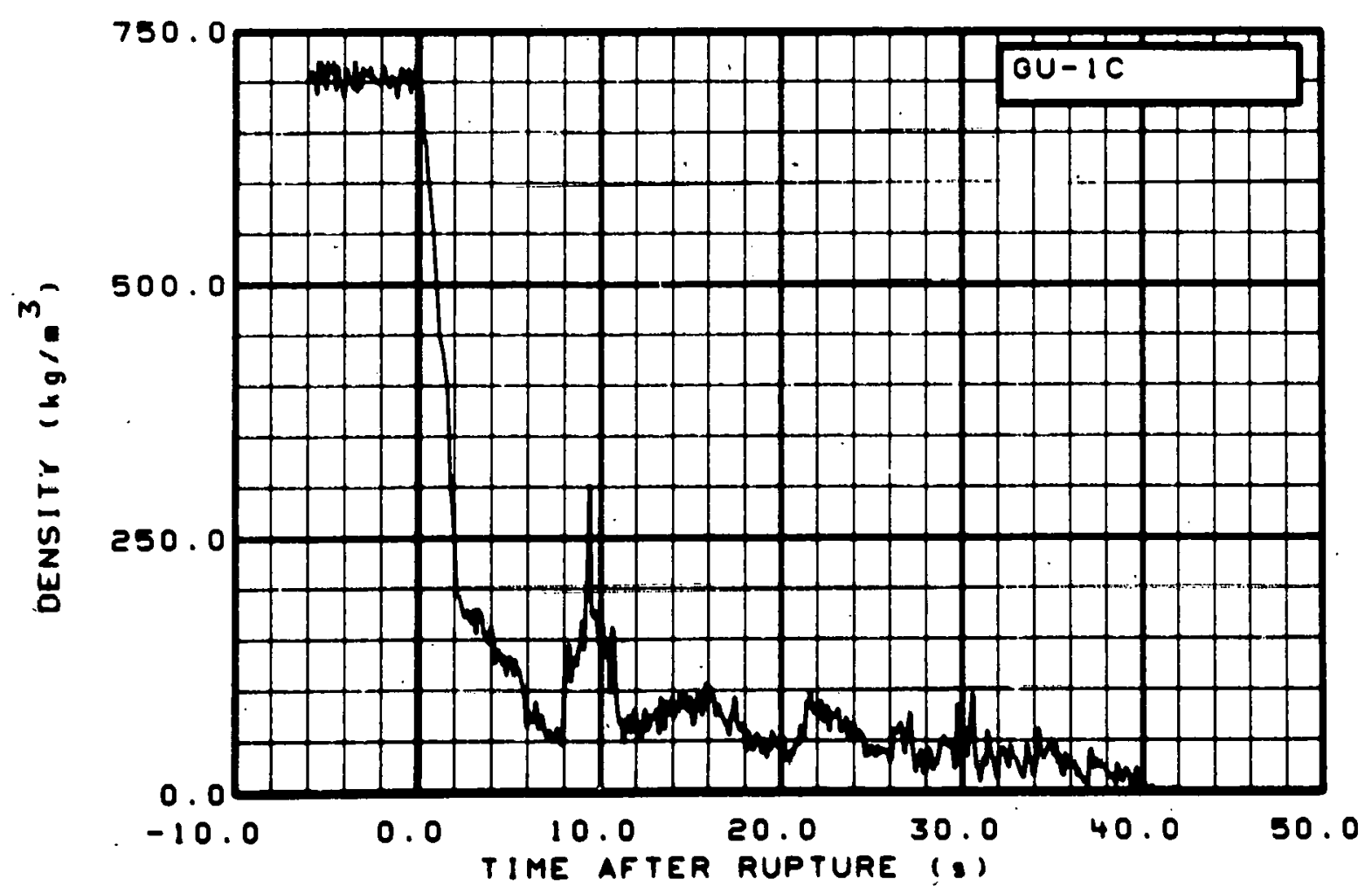

Fig. 270 Density in intact loop (GU-1C), from -6 to $42 \mathrm{~s}$. 


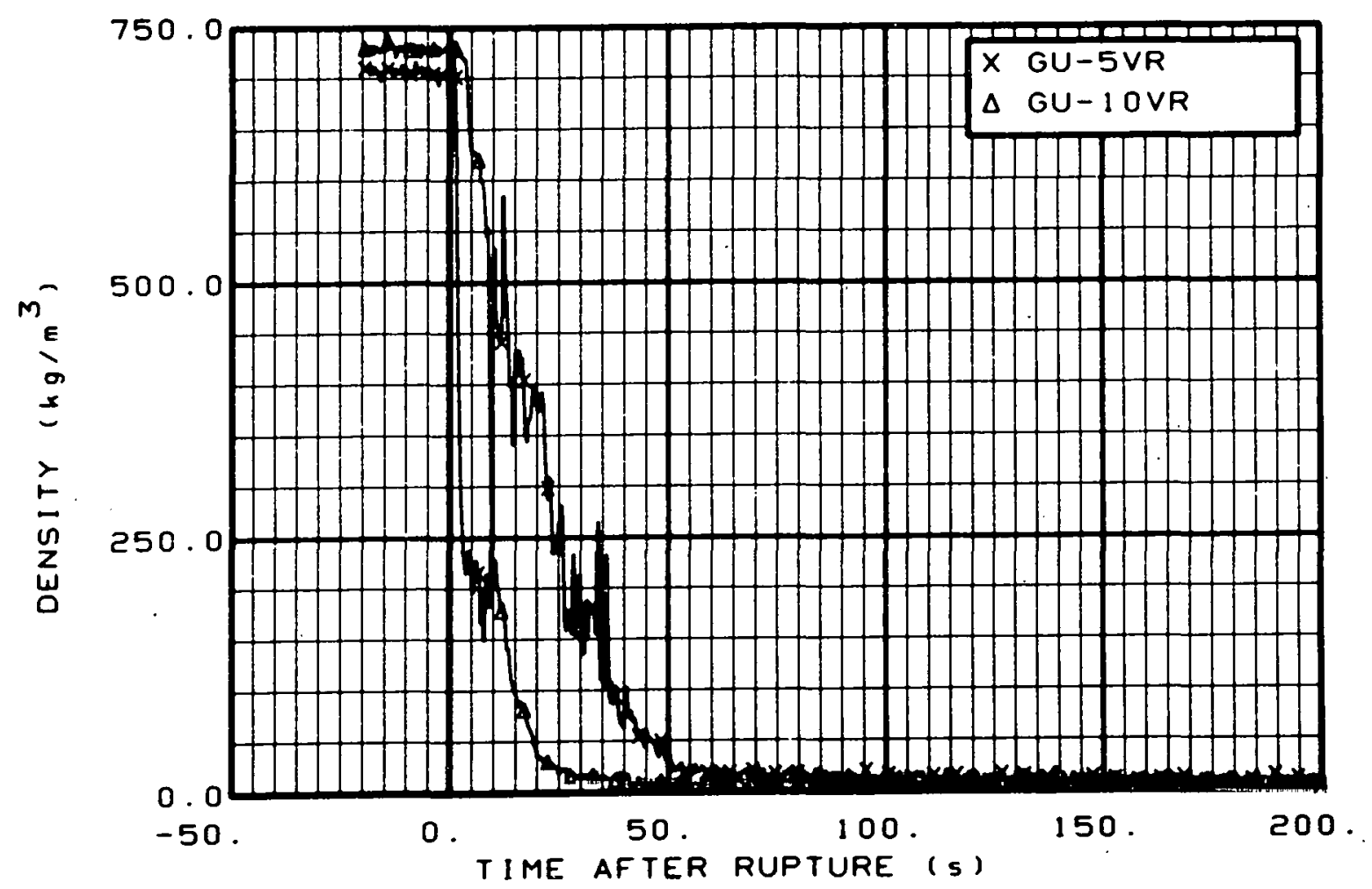

Fig. 271 Density in intact 100p (GU-5VR and GU-10VR), from -20 to $200 \mathrm{~s}$.

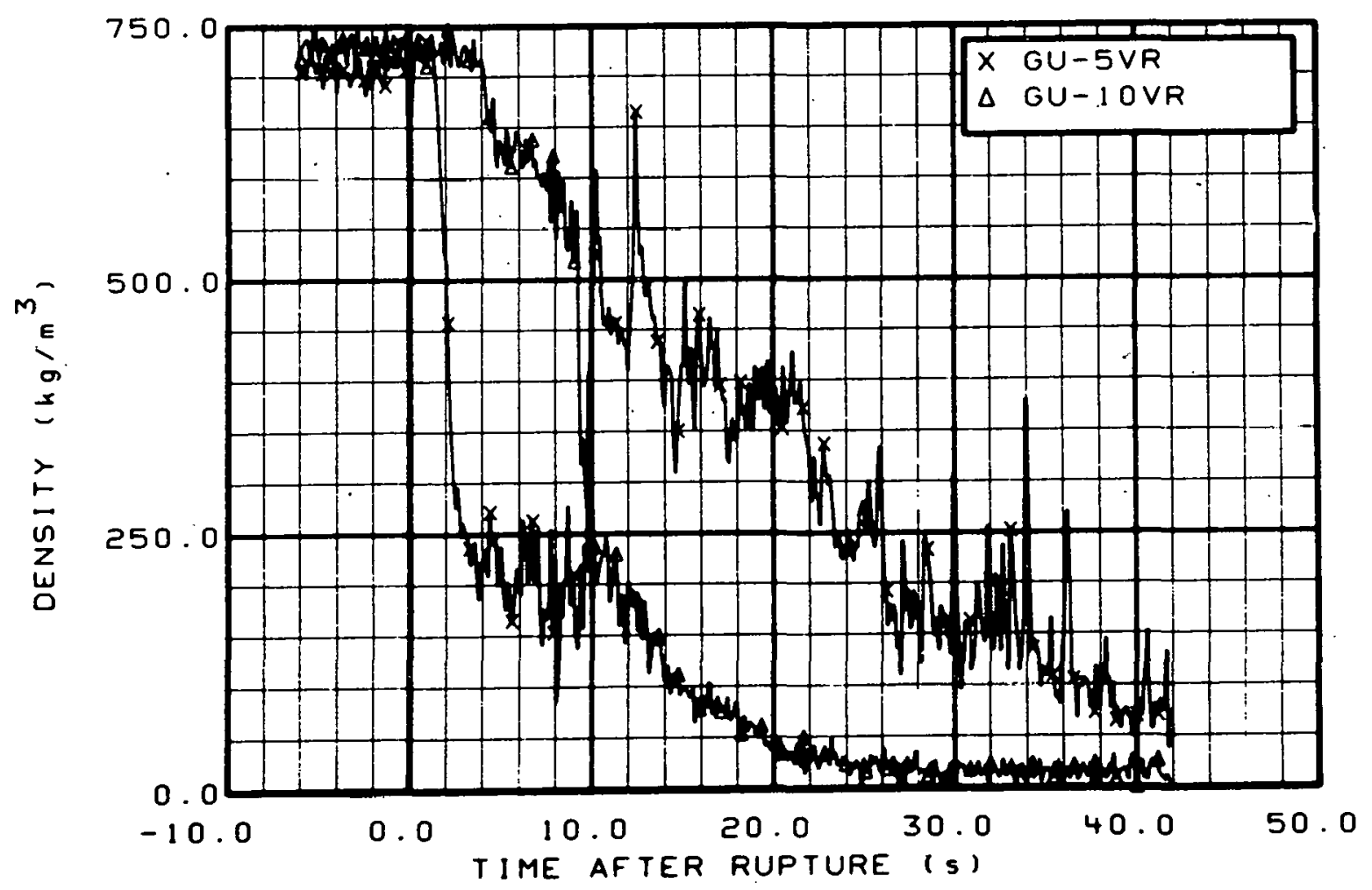

Fig. 272 Density in intact 100p (GU-5VR and GU-10VR), from -6 to $42 \mathrm{~s}$. 


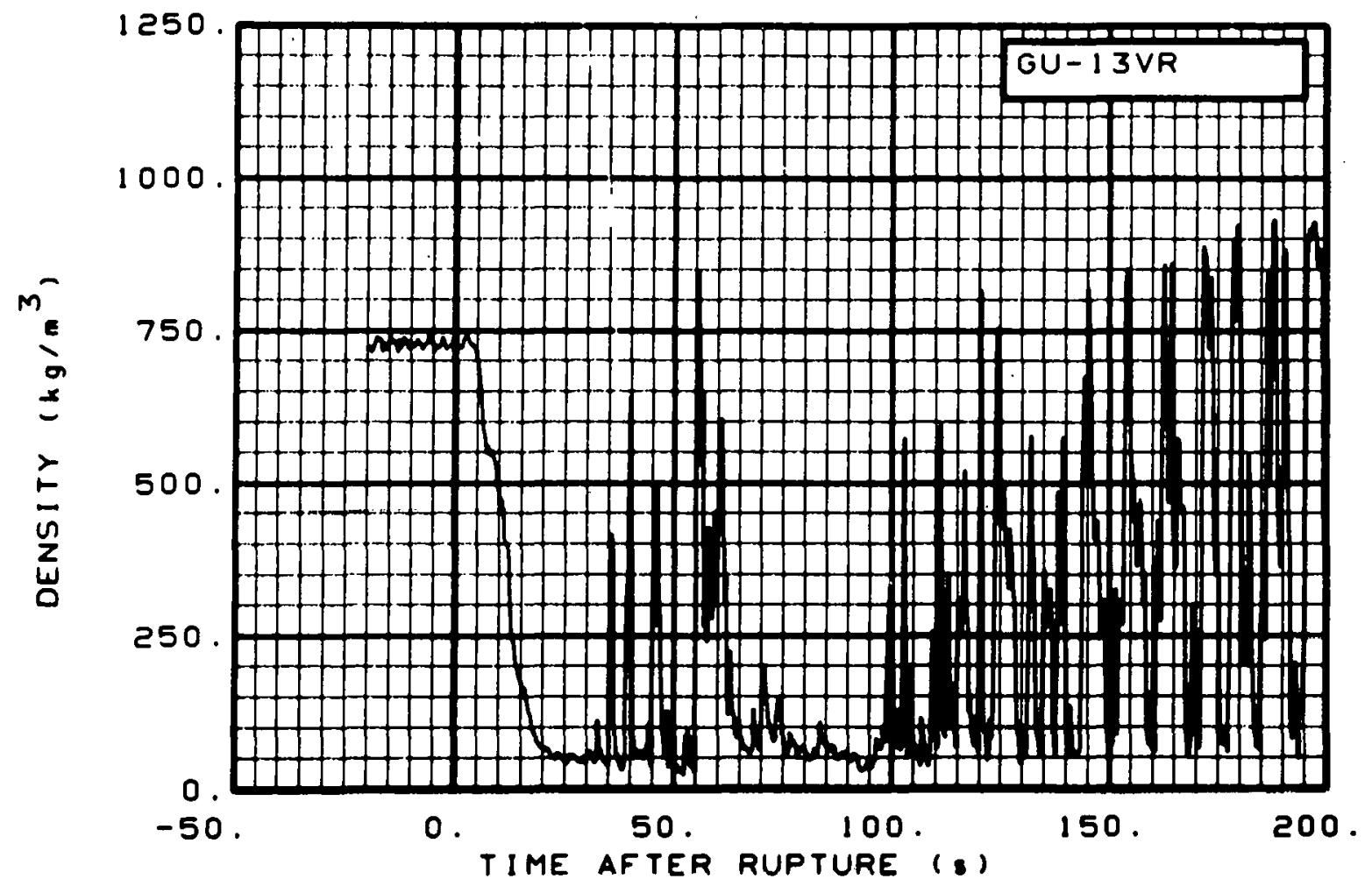

Fig. 273 Density in intact loop (GU-13VR), from -20 to $200 \mathrm{~s}$.

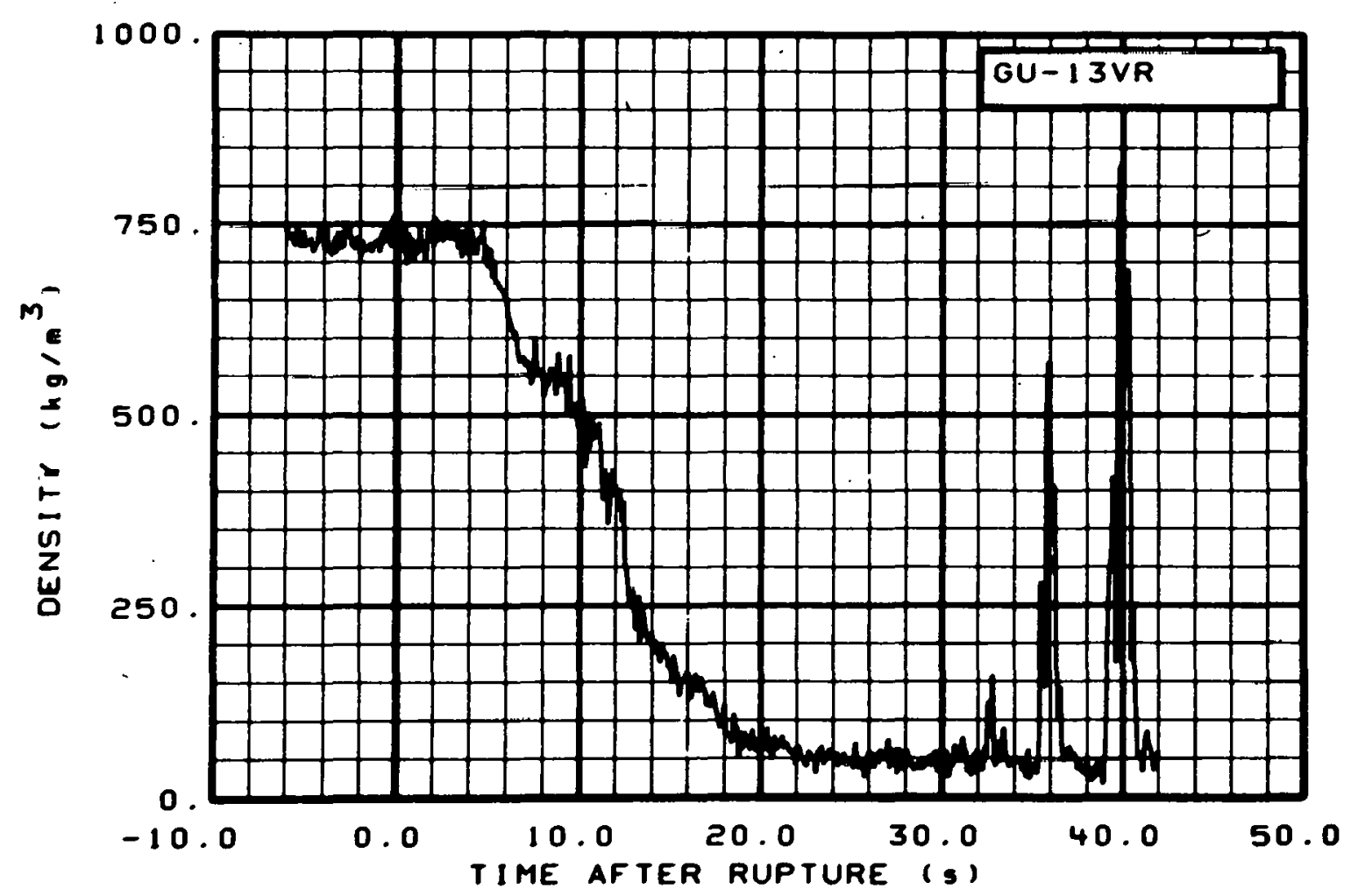

Fig. 274 Density in intact loop (GU-13VR), from -6 to $42 \mathrm{~s}$. 


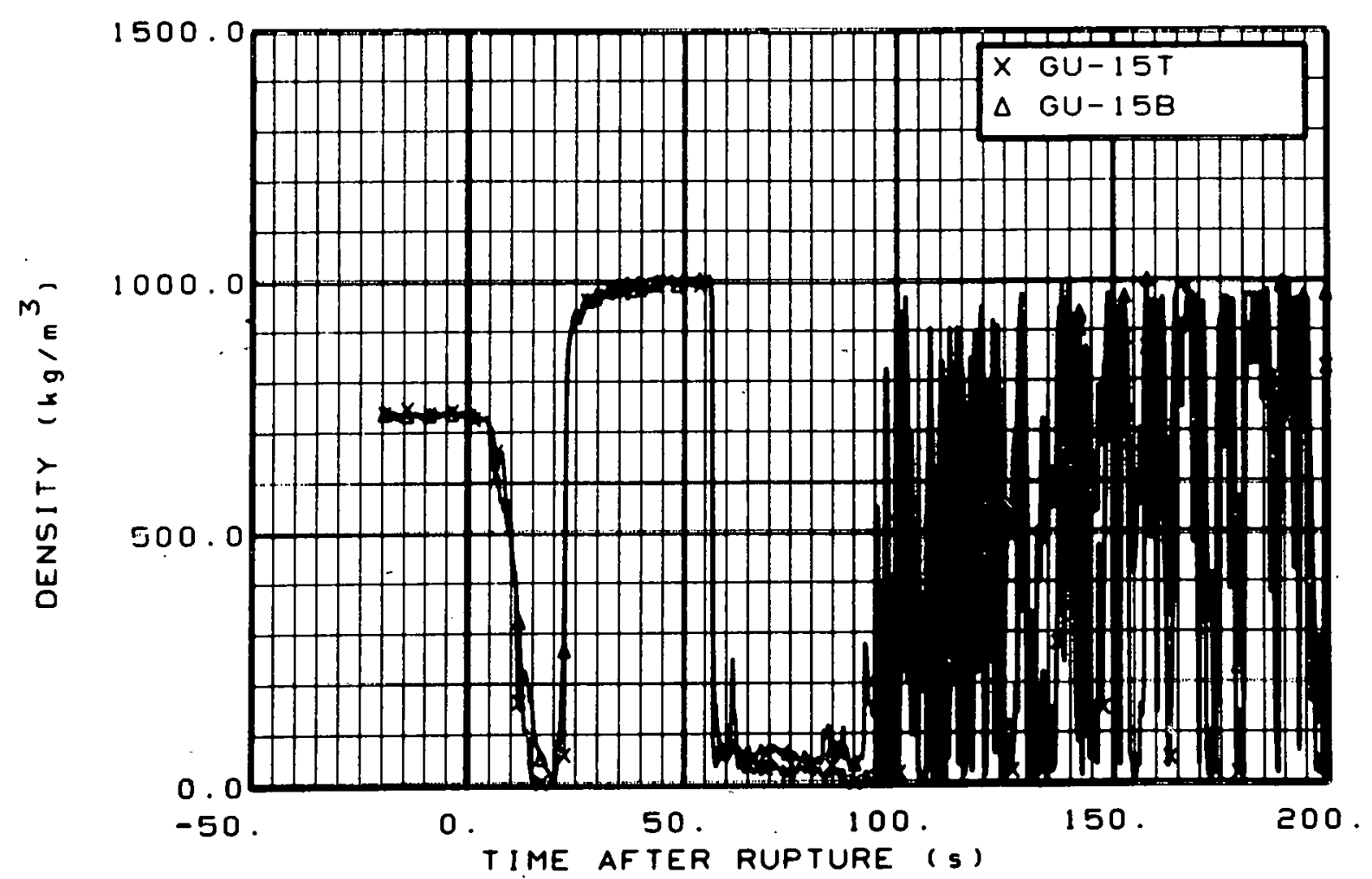

Fig. 275 Density in intact 10op (GU-15T and GU-75B), from -20 to $200 \mathrm{~s}$.

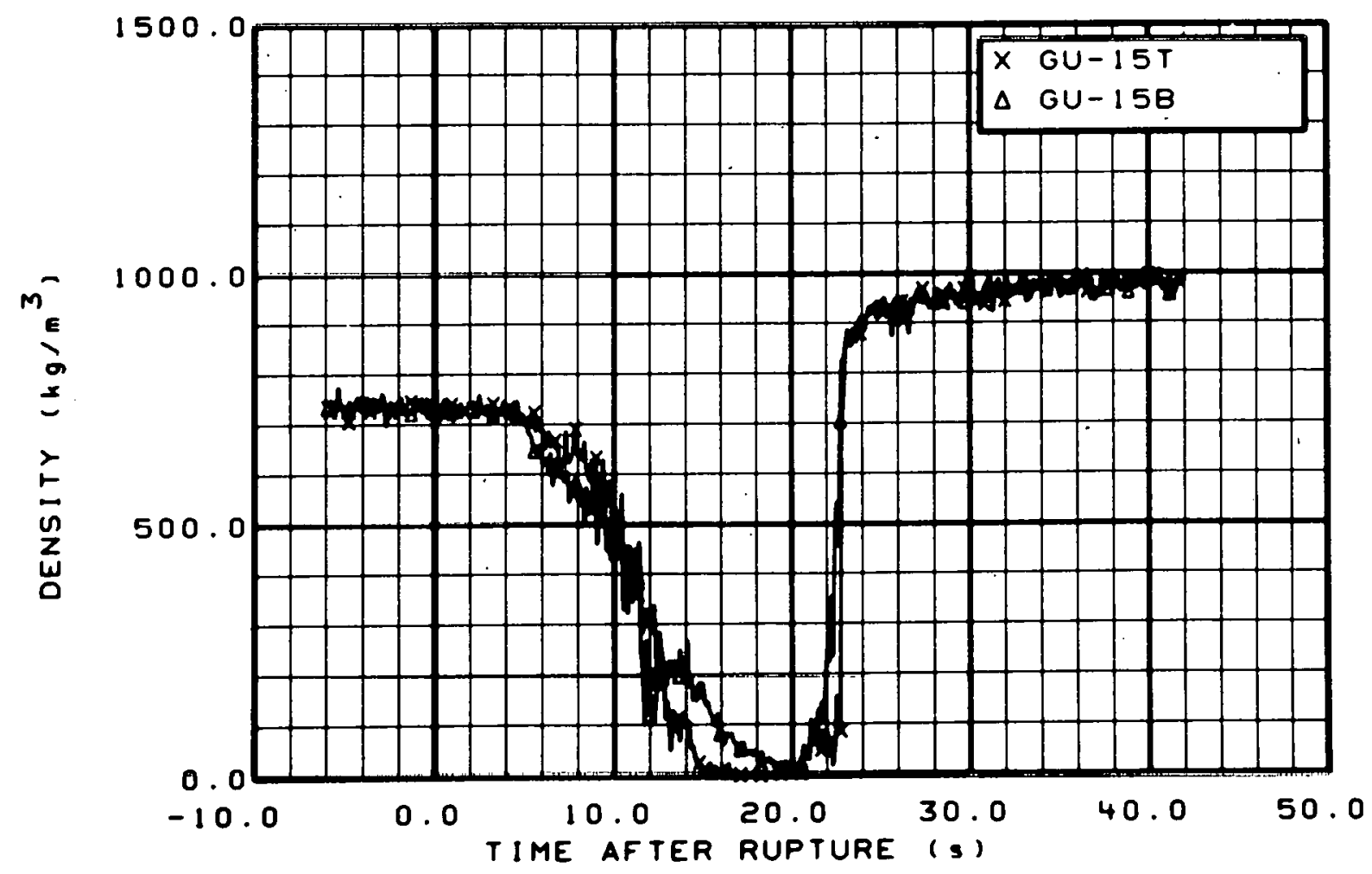

Fig. 276 Density in intacl loop (GU-15T and GU-15B), from -6 to $42 \mathrm{~s}$. 


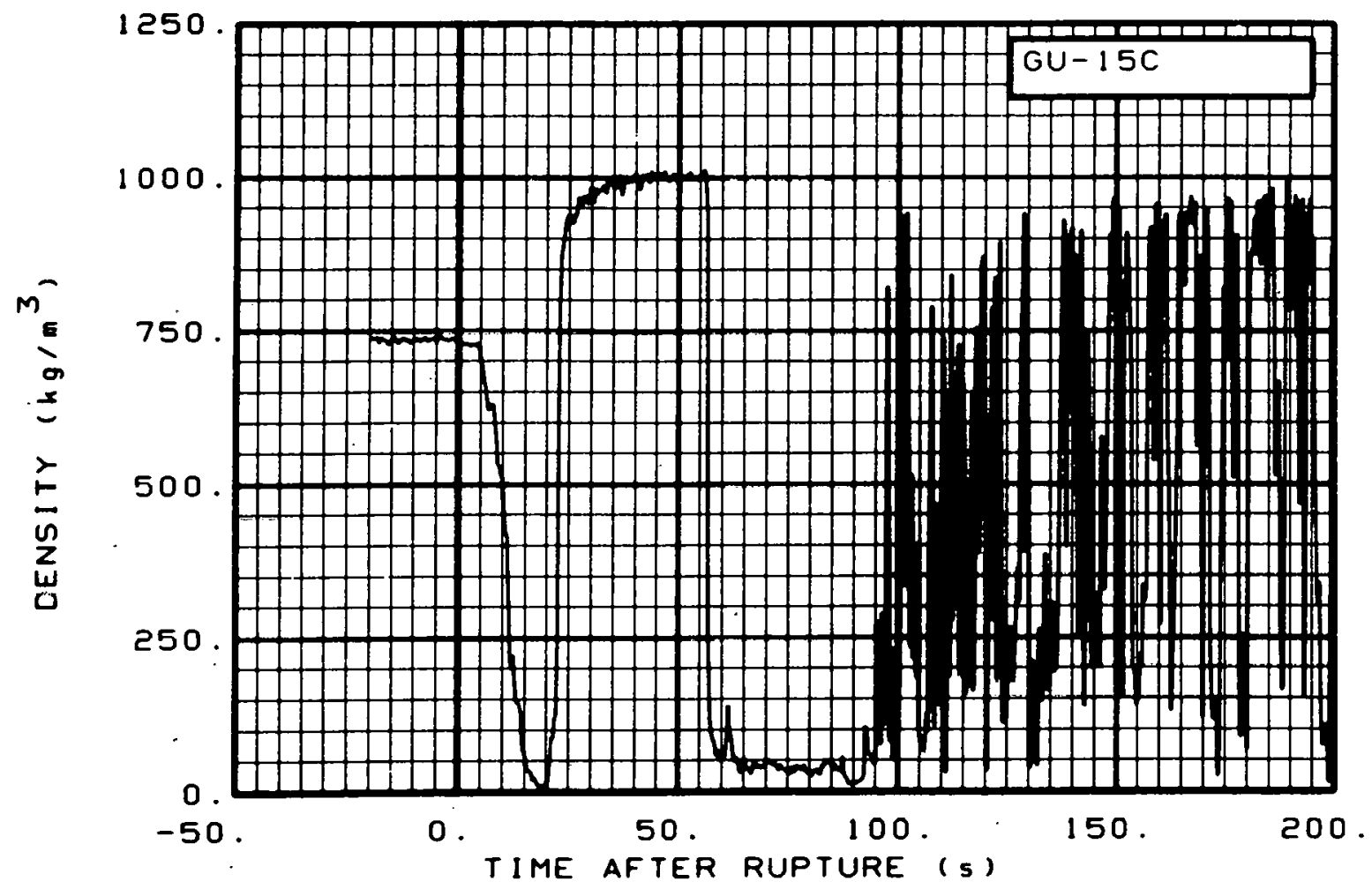

Fig. 277 Density in intact loop (GU-15C), from -20 to $200 \mathrm{~s}$.

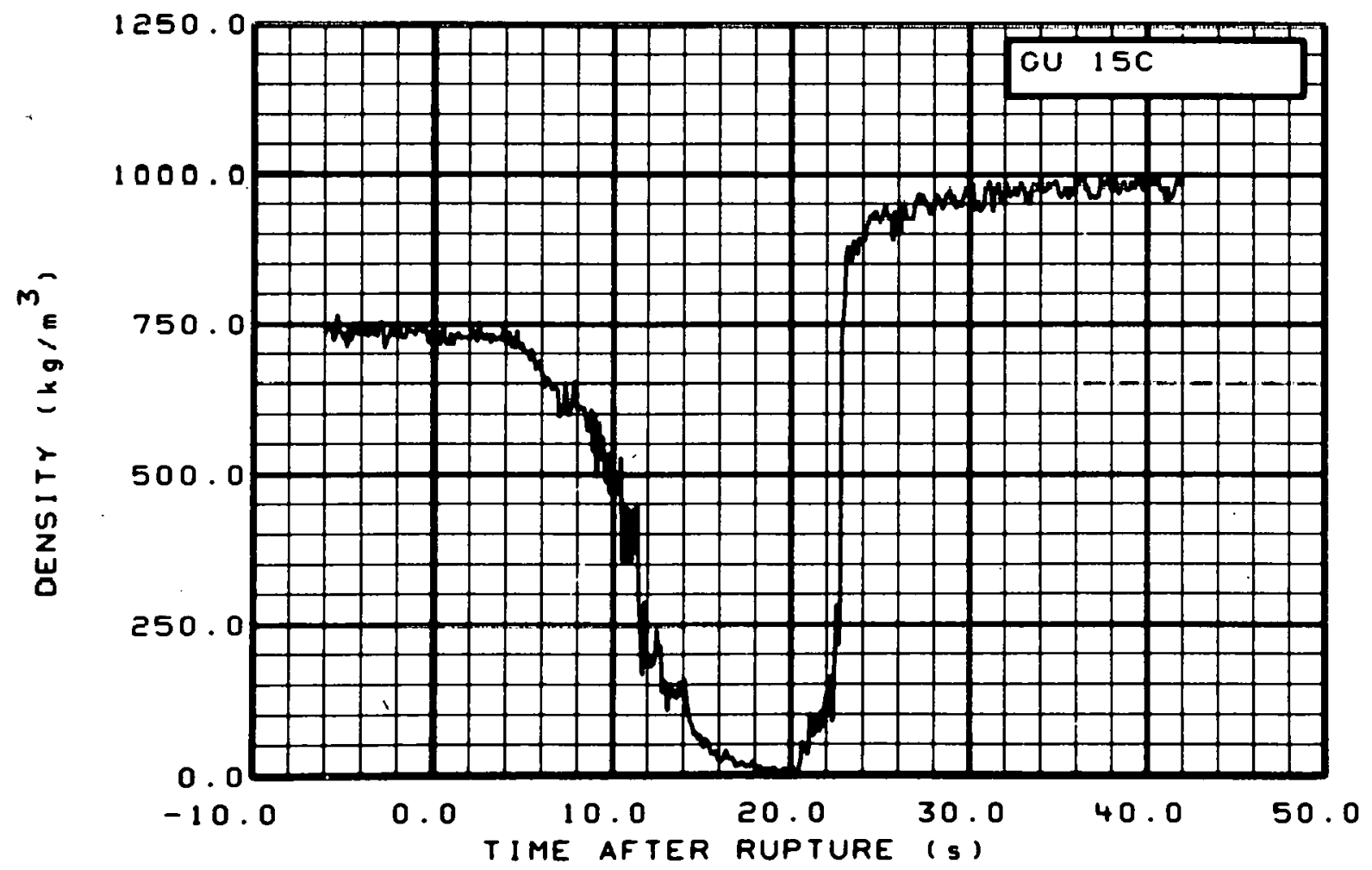

Fig. 278 Density in intact loop (GU-15C), from -6 to $42 \mathrm{~s}$. 


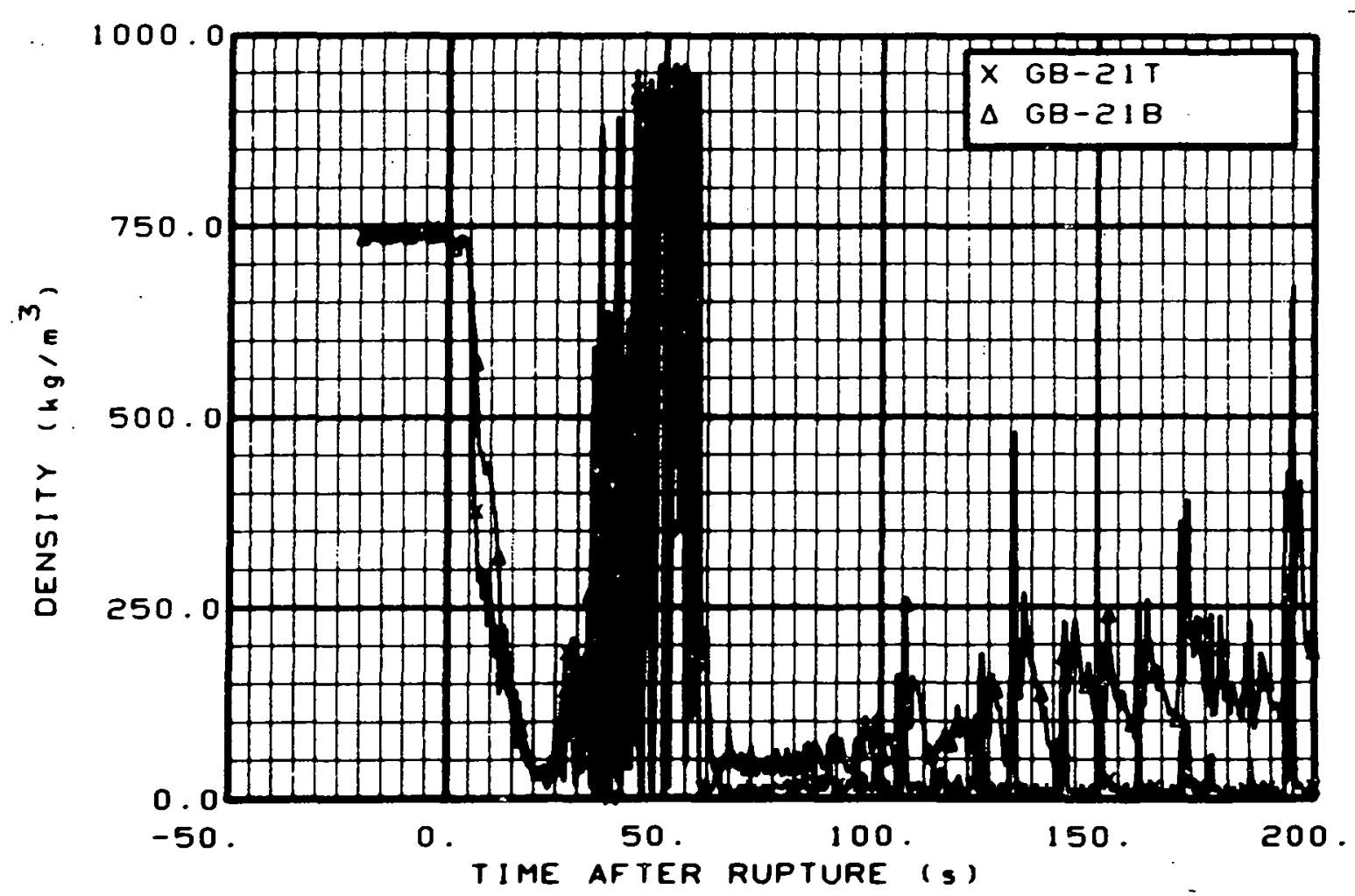

Fig. 279 Density in broken loop (GB-21T and GB-21B), from -20 to $200 \mathrm{~s}$.

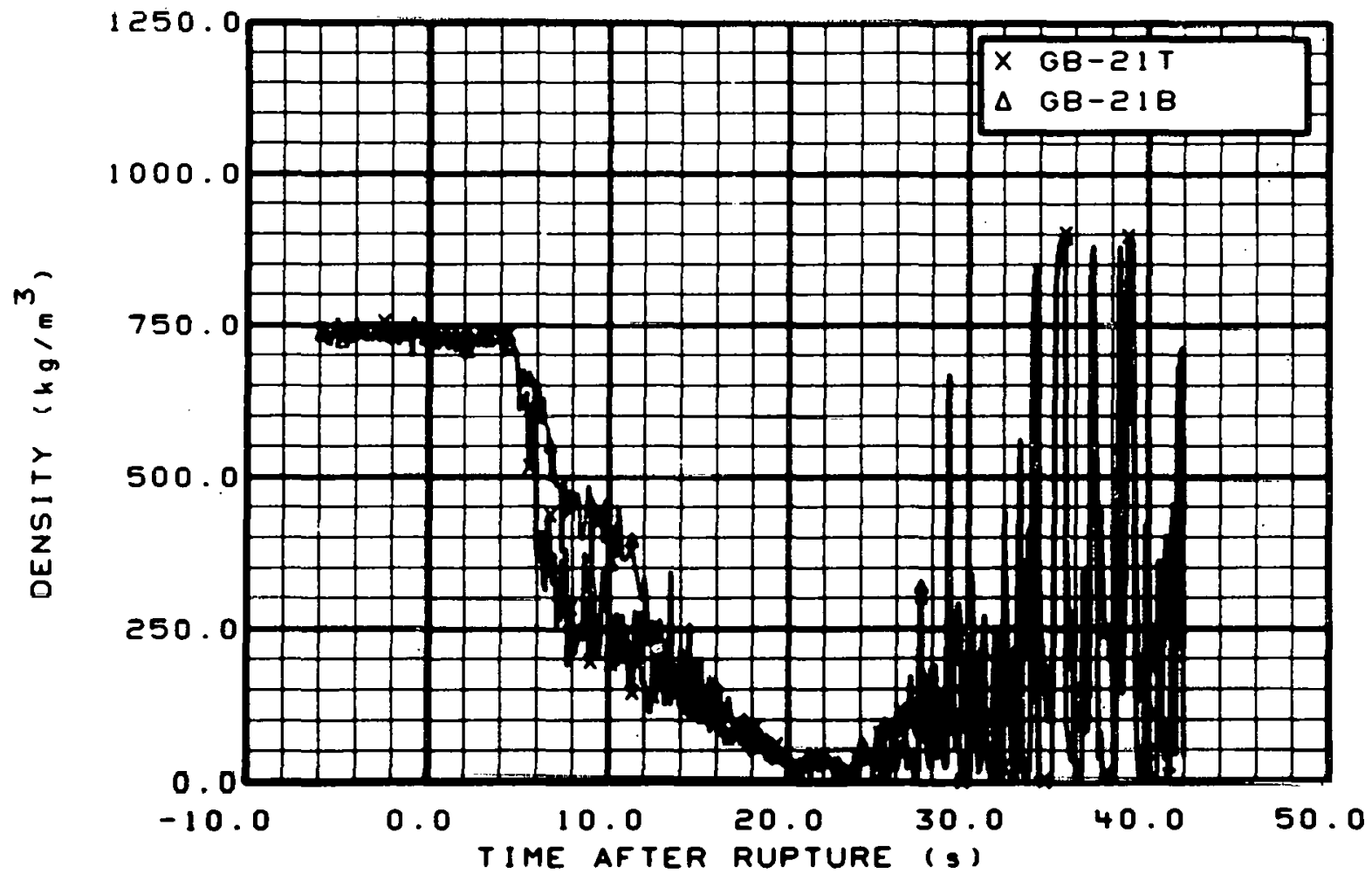

Fig. 280 Density in broken loop (GB-21T and GB-21B), from -6 to $42 \mathrm{~s}$. 


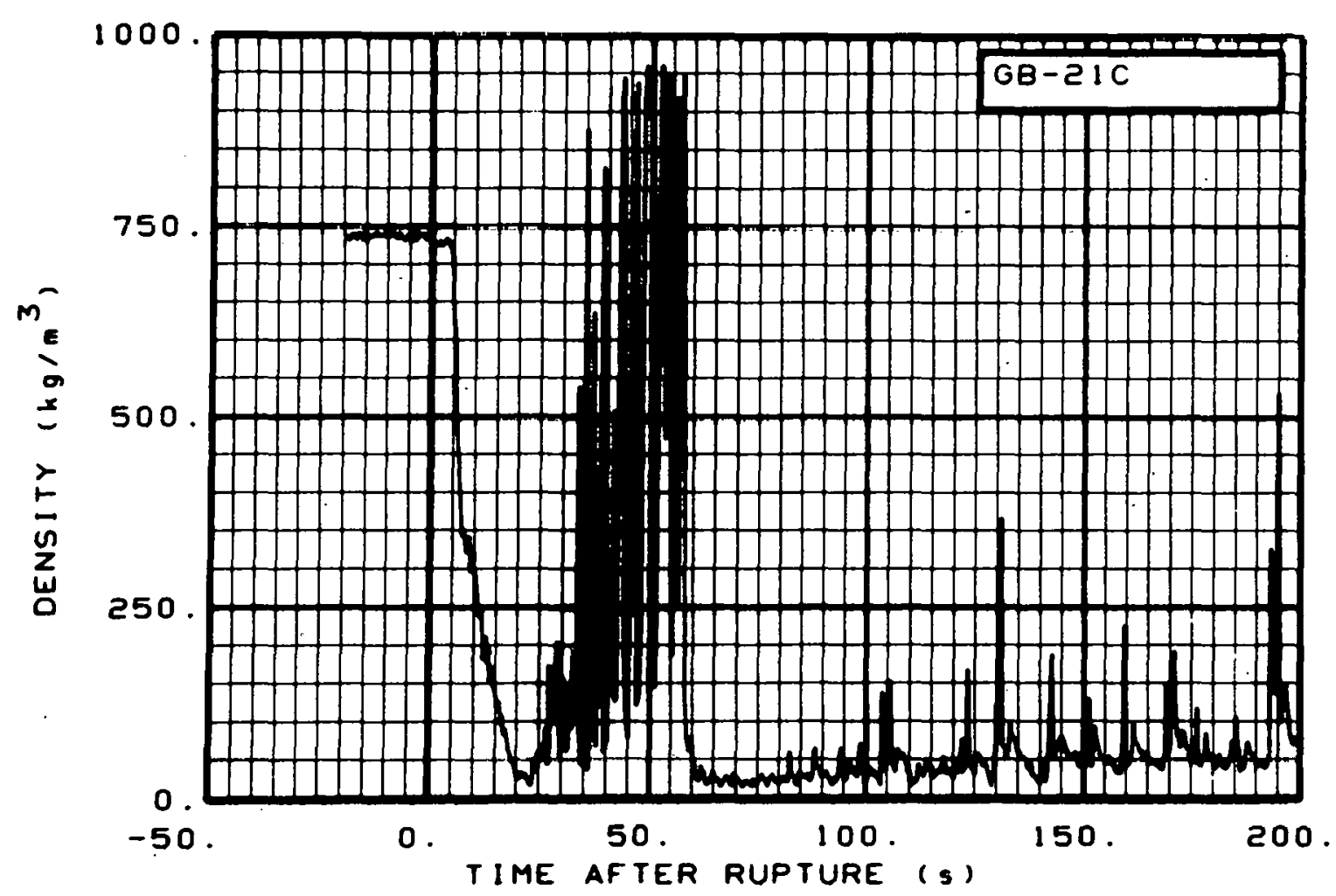

Fig. 281 Density in broken loop (GB-21C), from -20 to $200 \mathrm{~s}$.

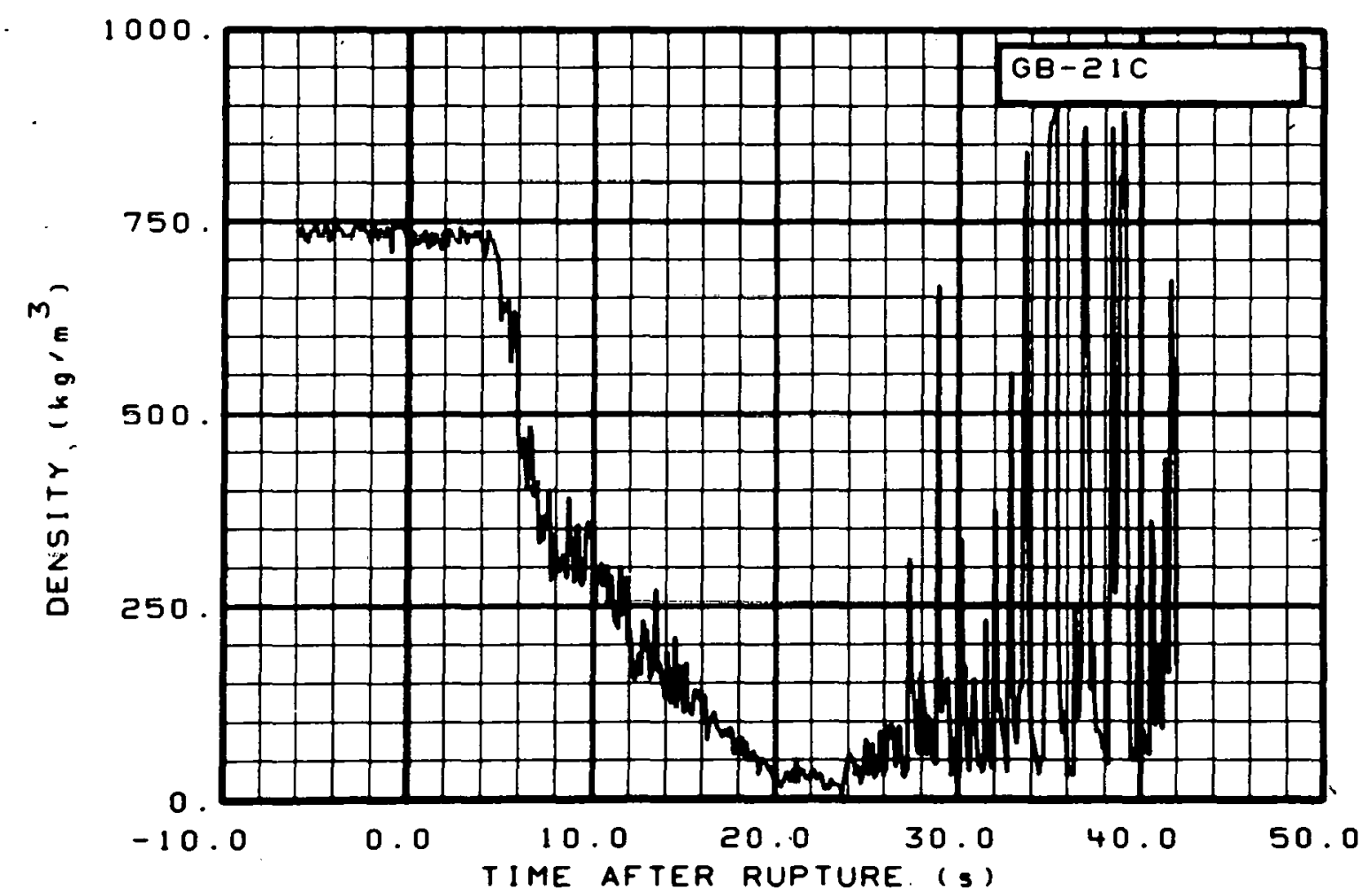

Fig. 282 Density in broken loop (GB-21C), from -6 to $42 \mathrm{~s}$. 


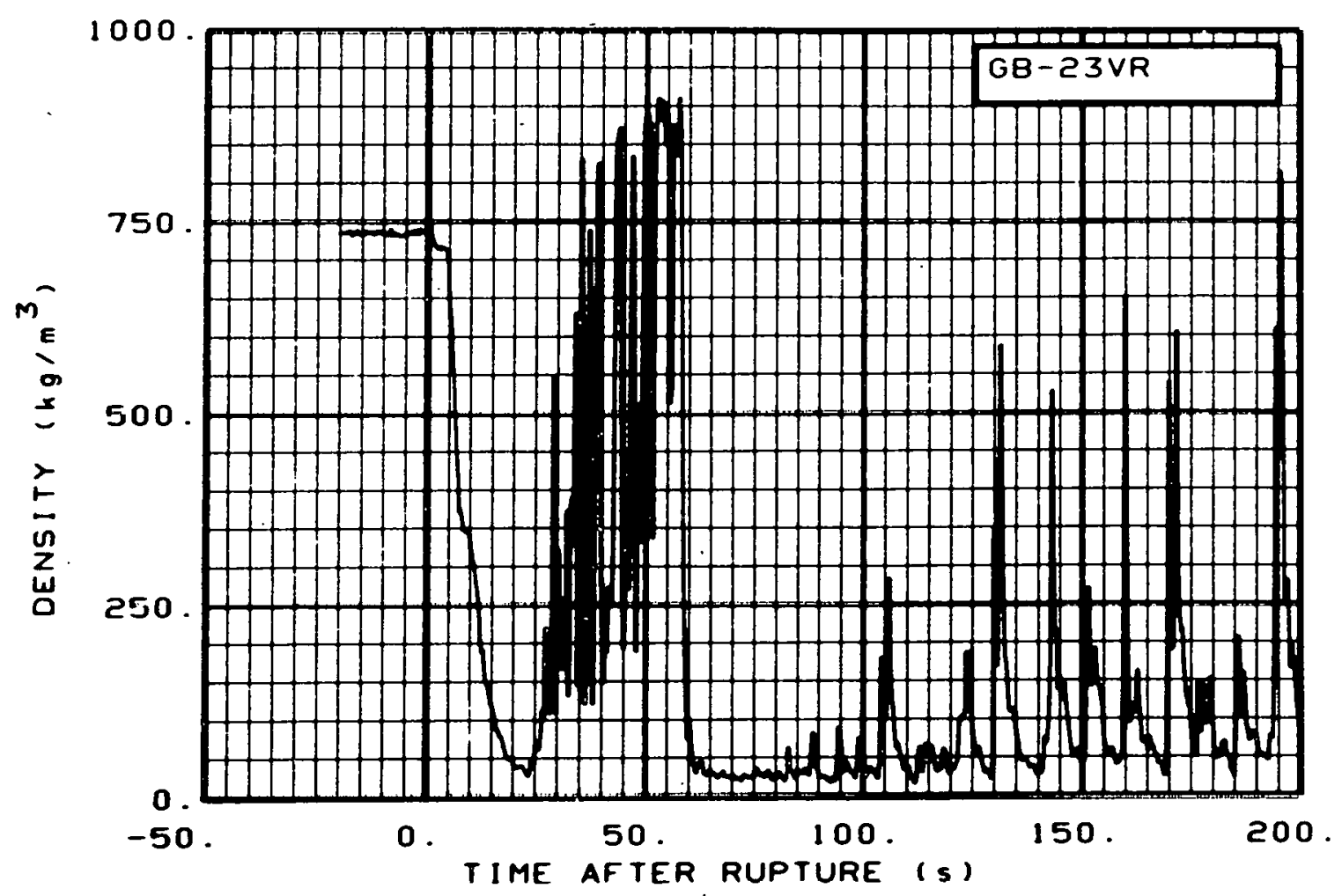

Fig. 283 Density in broken loop (GB-23VR), from -20 to $200 \mathrm{~s}$.

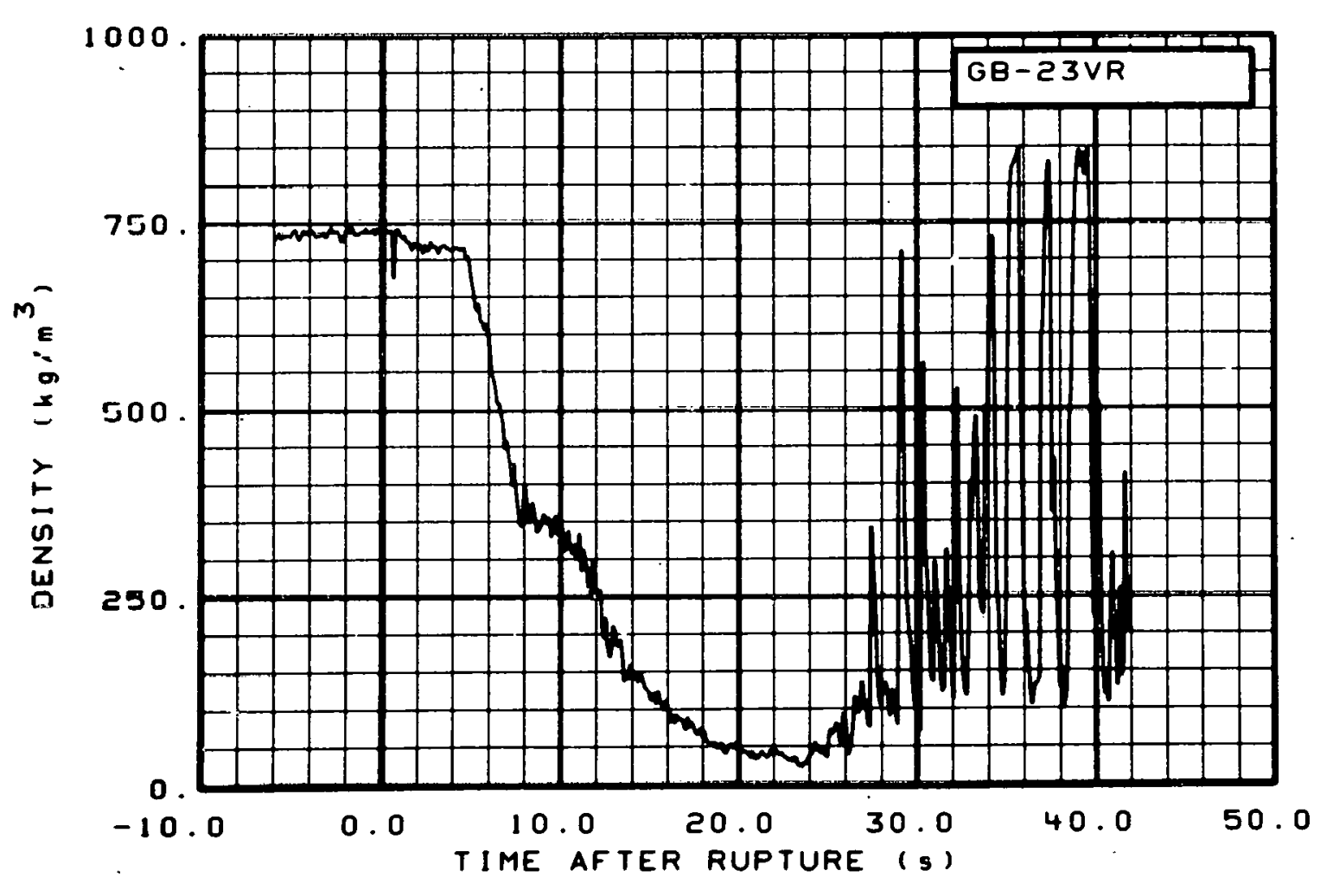

Fig. 284 Density in broken loop (GB-23VR), from -6 to $42 \mathrm{~s}$. 


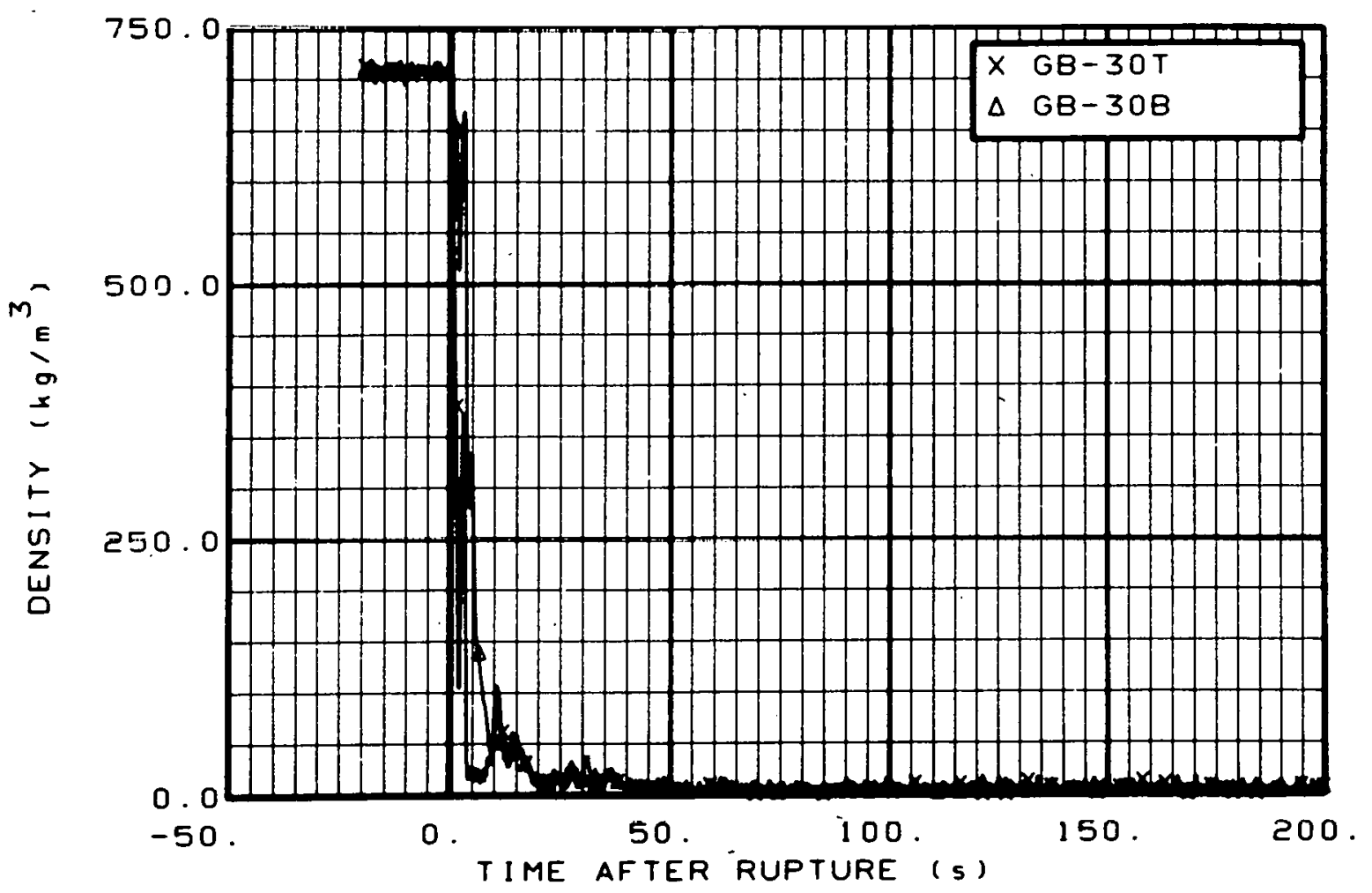

Fig. 285 Density in broken loop (GB-30T and GB-30B), from -20 to $200 \mathrm{~s}$.

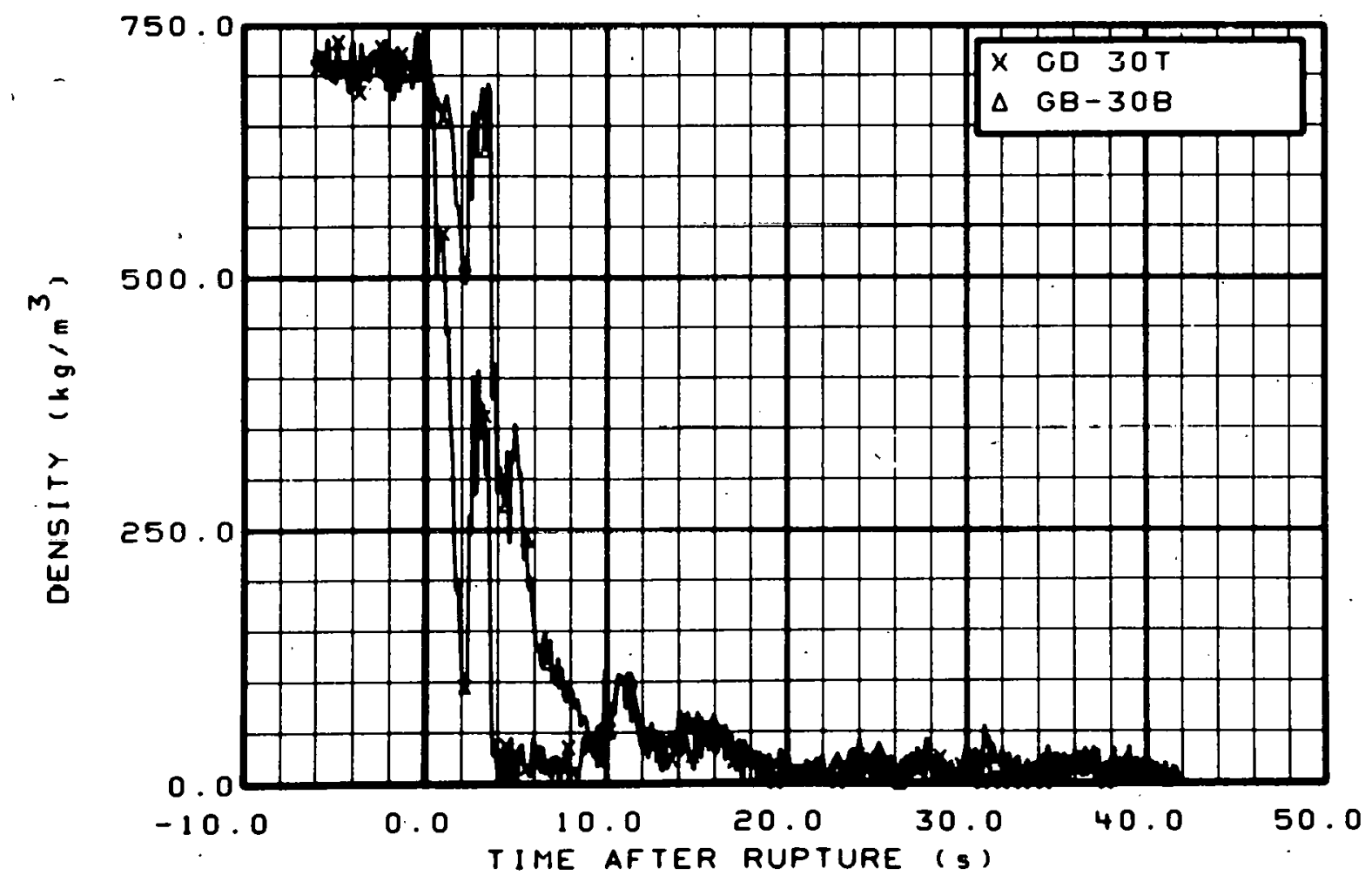

Fig. 286 Density in broken loop (GB-30T and GB-30B), from -6 to $42 \mathrm{~s}$. 


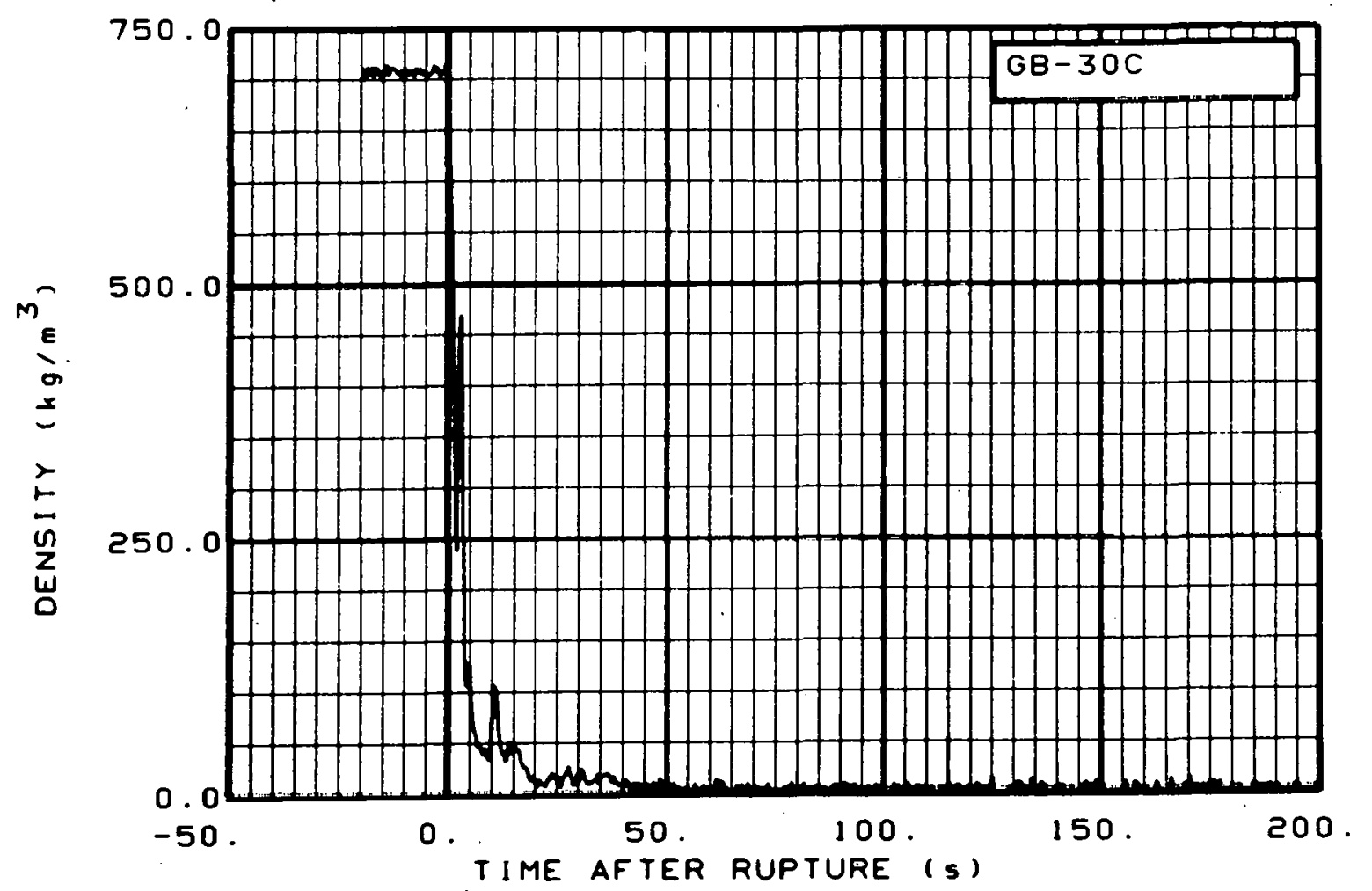

Fig. 287 Density in broken loop (GB-30C), from -20 to $200 \mathrm{~s}$.

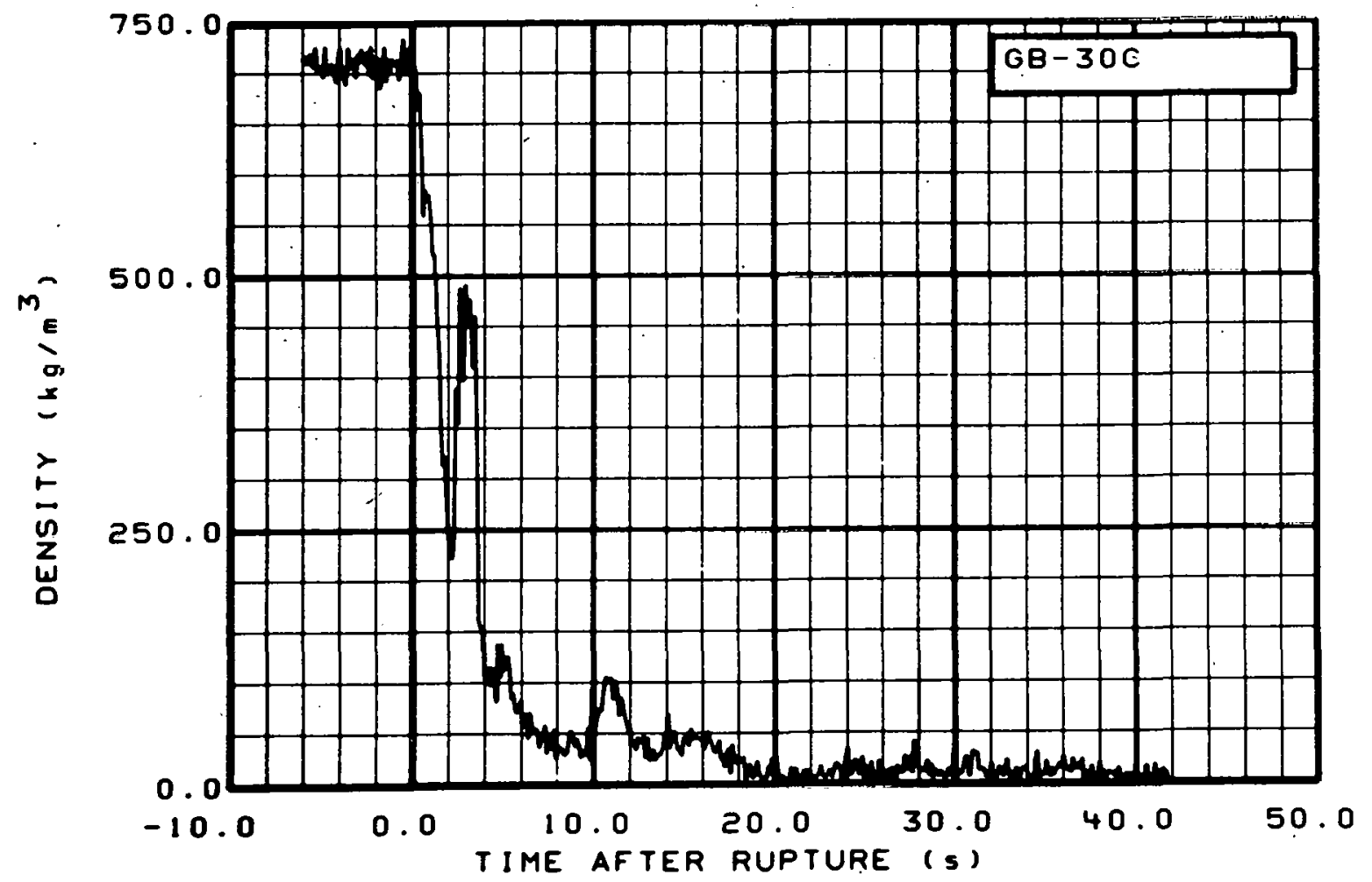

Fig. 288 Density in broken loop (GB-30C), fromll -6 to $42 \mathrm{~s}$. 


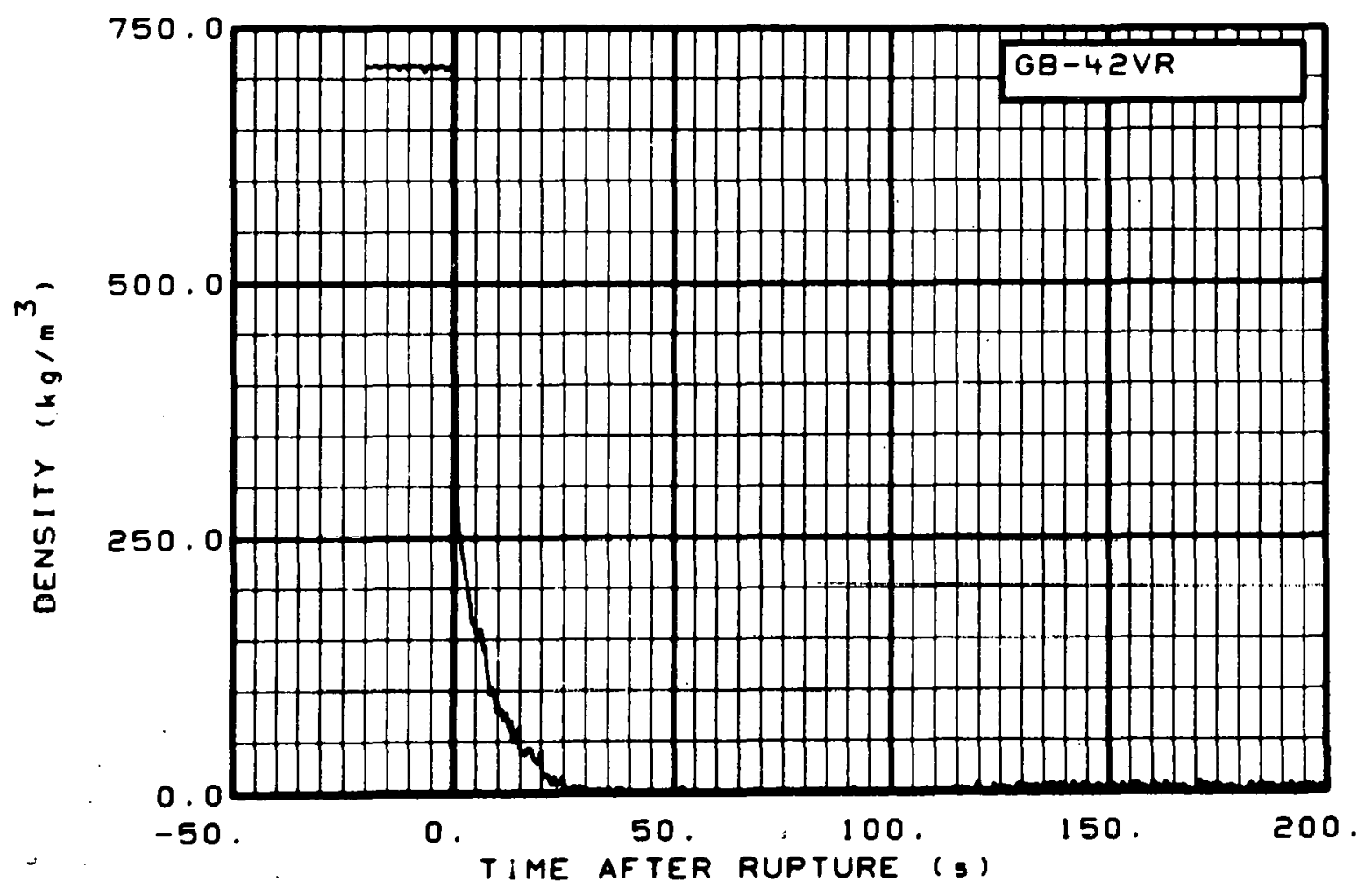

Fig. 289 Density in broken loop (GB-42VR), from -20 to $200 \mathrm{~s}$.

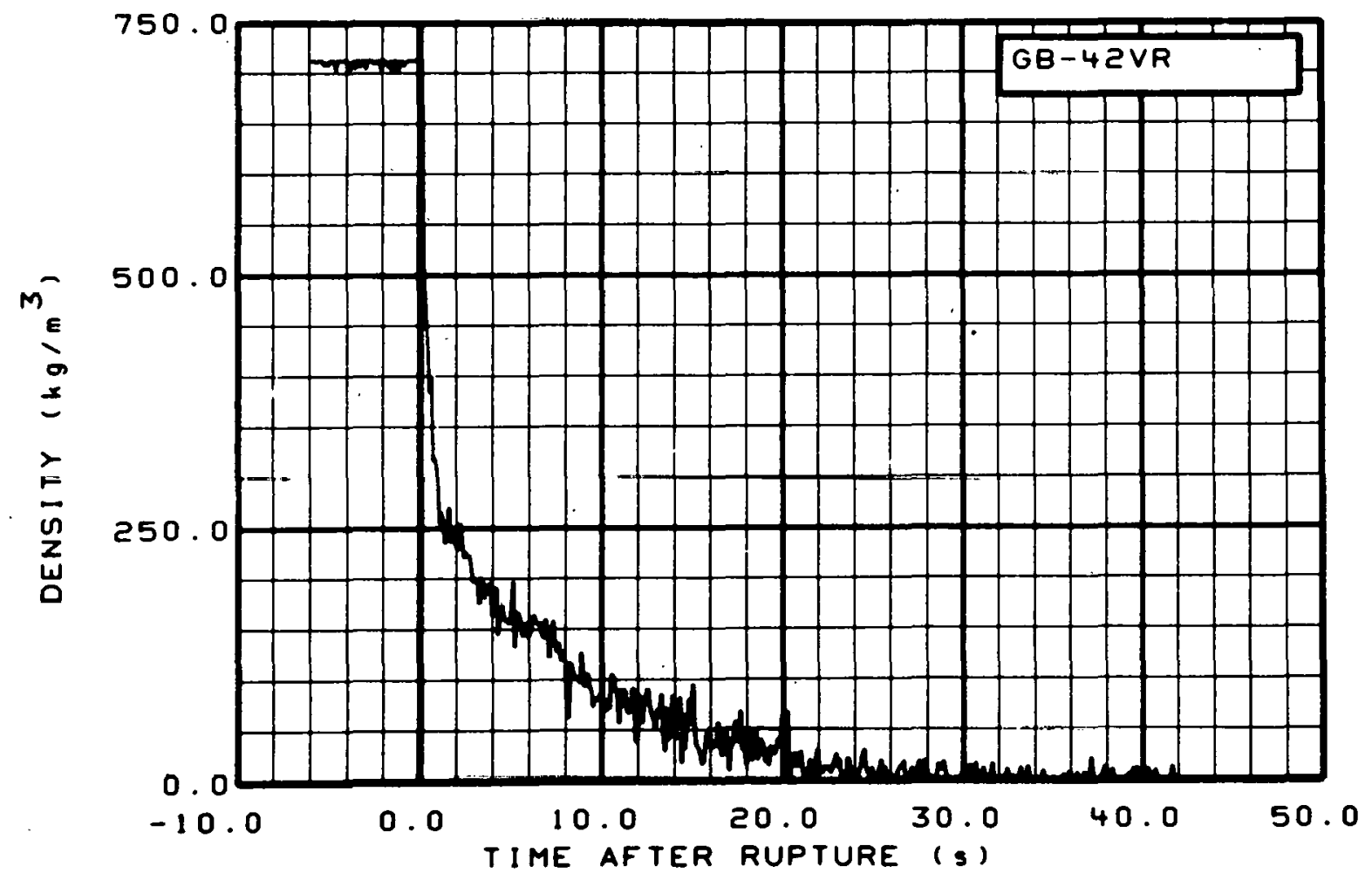

Fig. 290 Density in broken loop (GB-42VR), from -6 to $42 \mathrm{~s}$. 


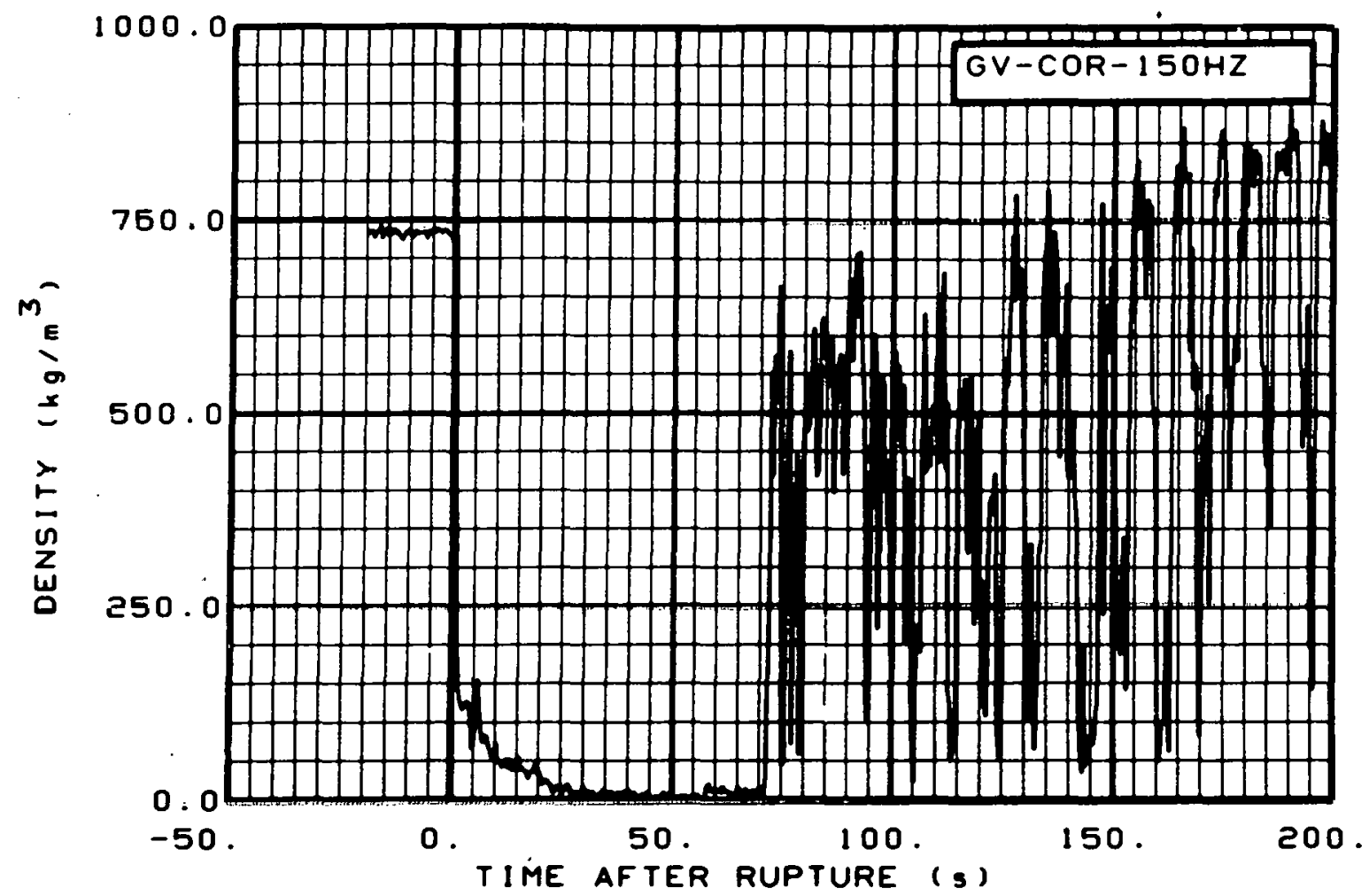

Fig. 291 Density in vessel (GV-COR-150HZ), from -20 to $200 \mathrm{~s}$.

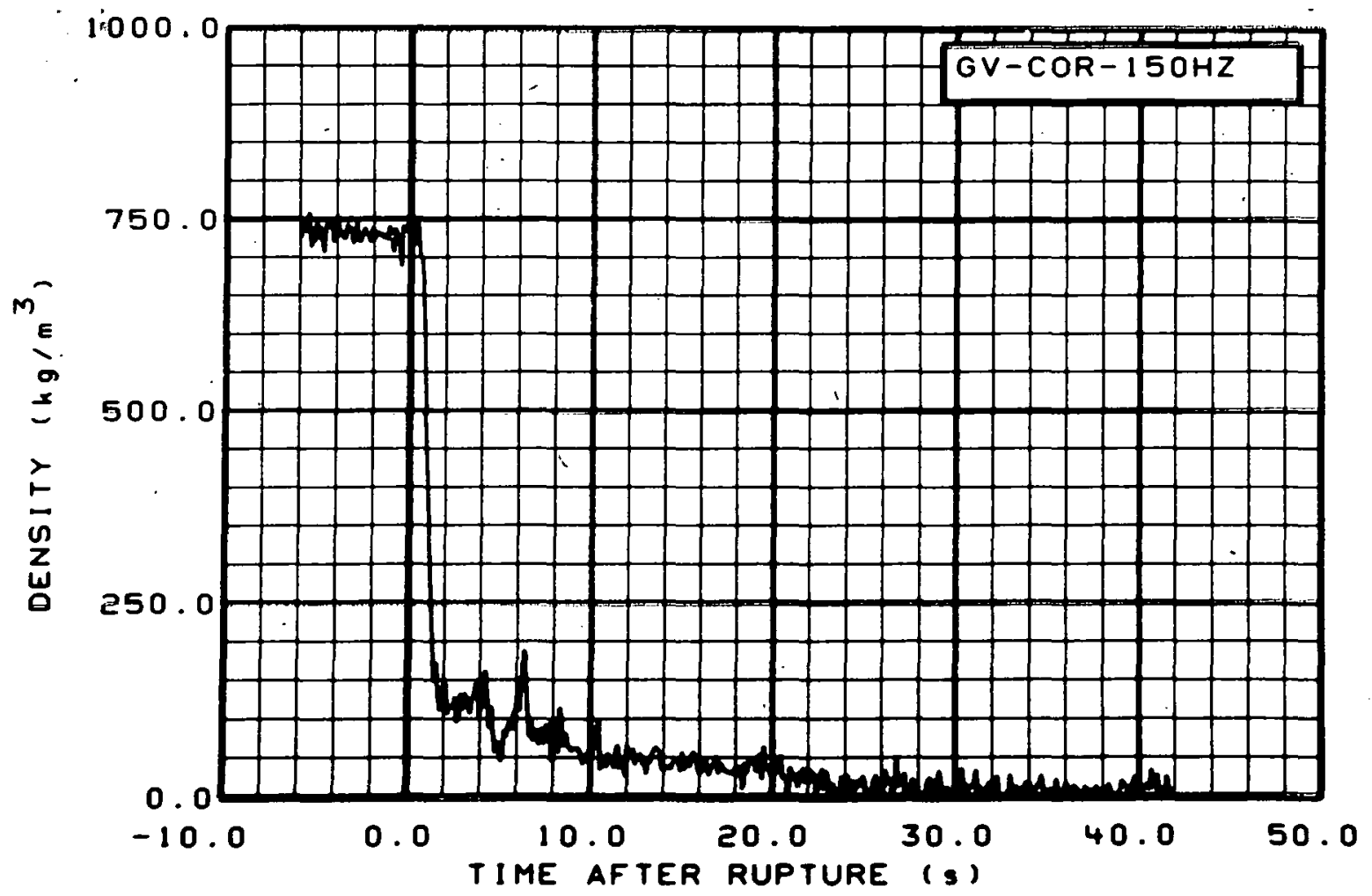

Fig. 292 Density in vessel (GV-COR-150HZ), from -6 to $42 \mathrm{~s}$. 


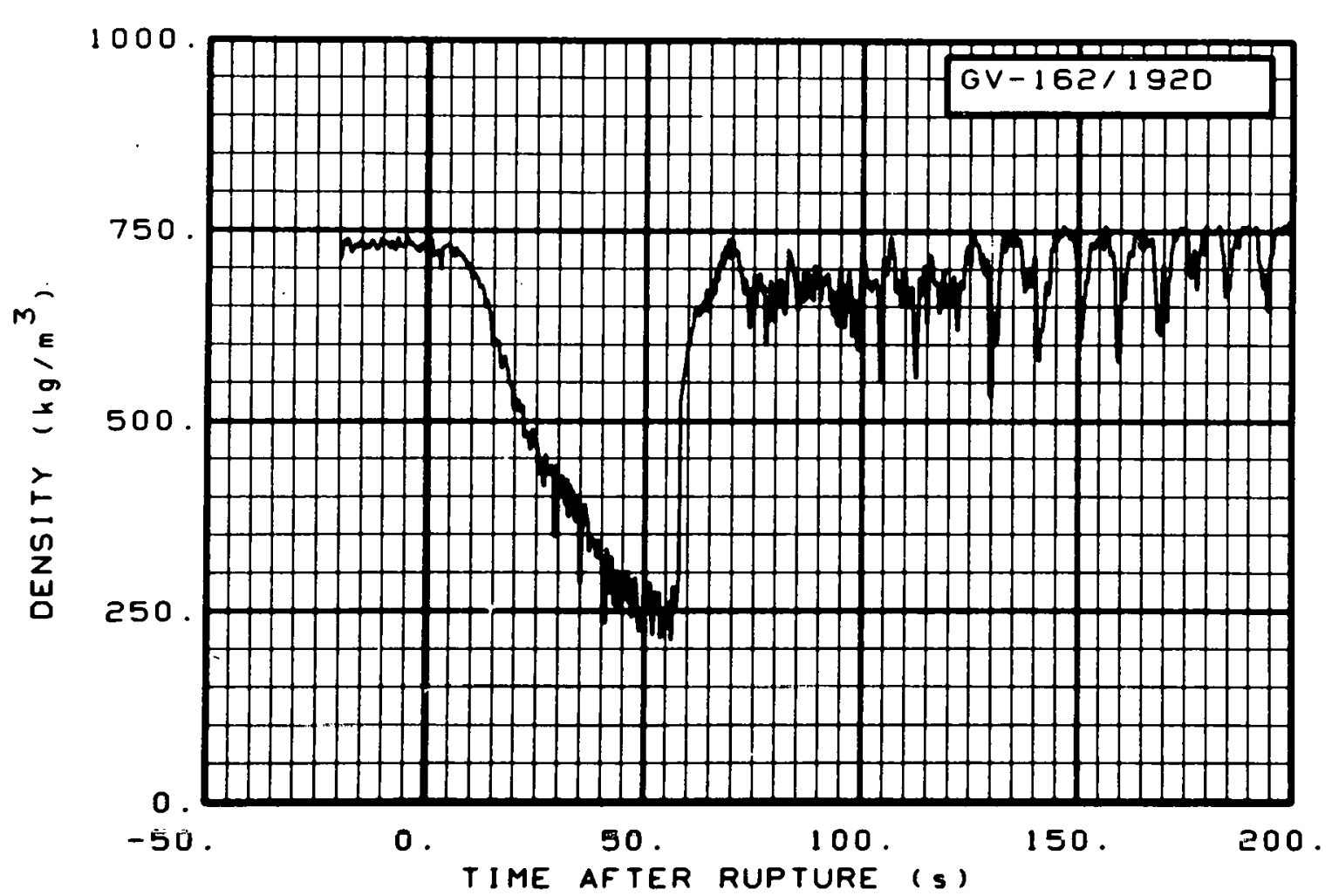

Fig. 293 Density in vessel (GV-162/192D), from -20 to $200 \mathrm{~s}$.

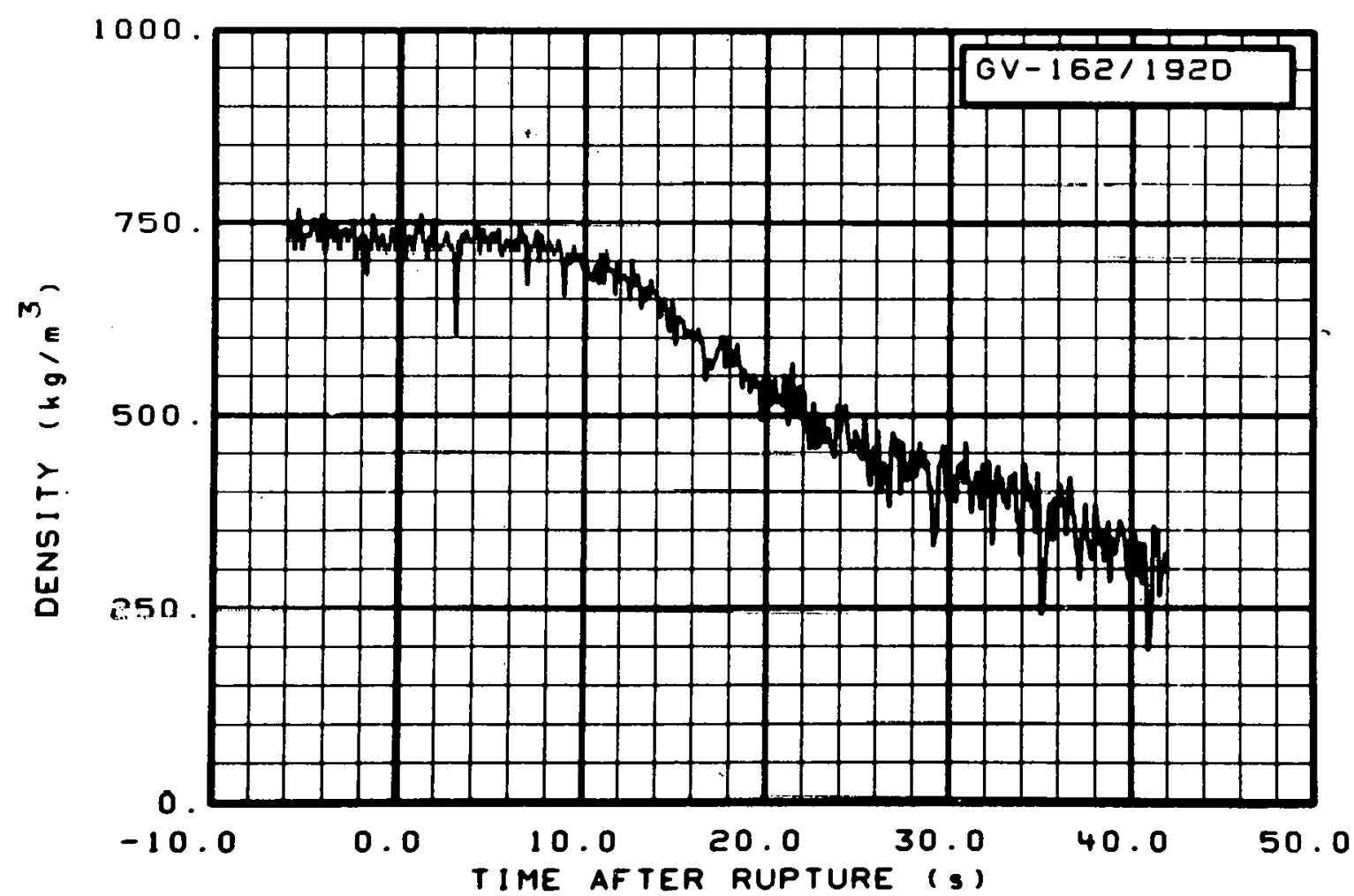

Fig. 294 Density in vessel (GV-162/192D), from -6 to $42 \mathrm{~s}$. 


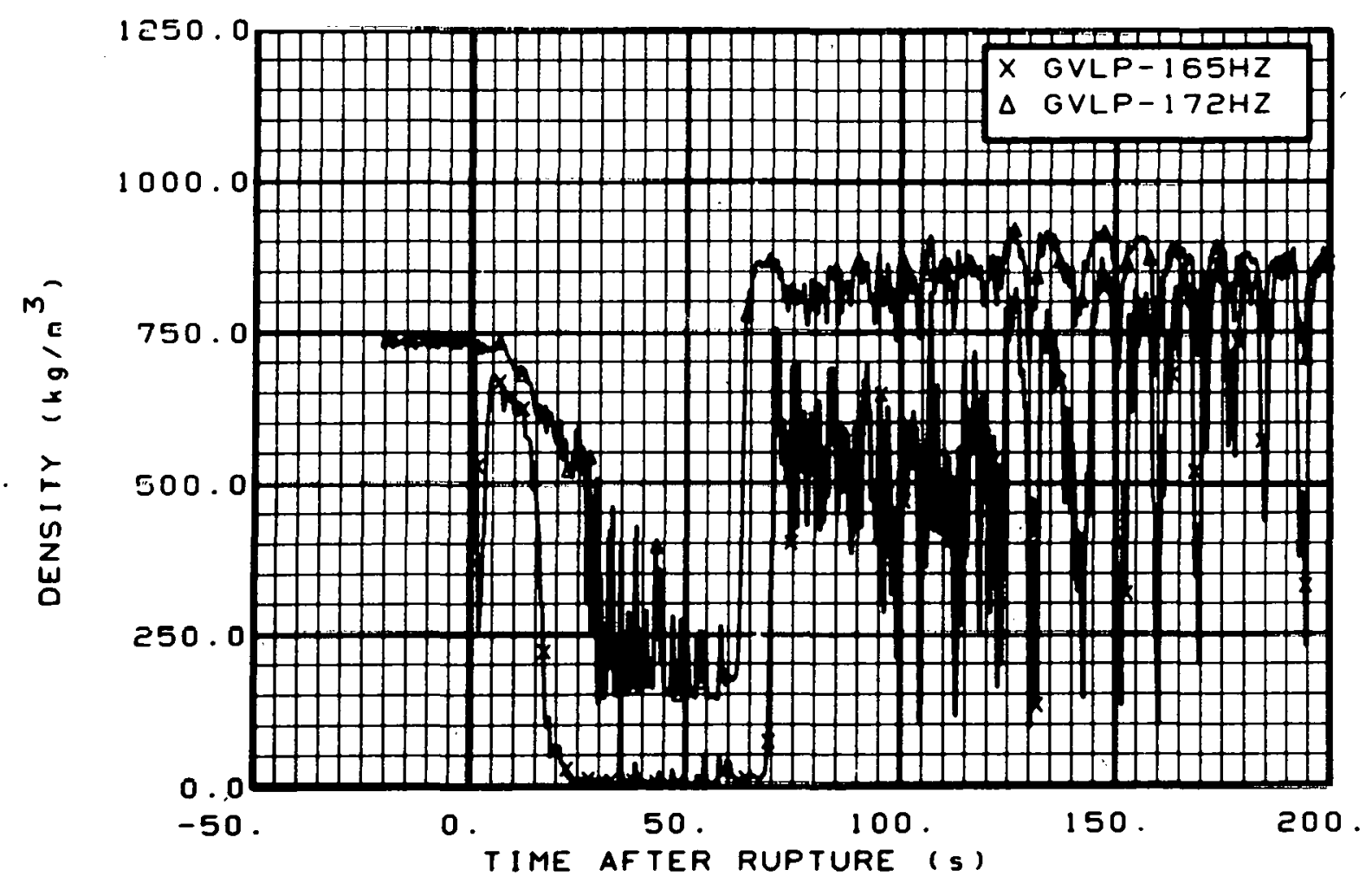

Fig. 295 Density in vessel (GVLP-165HZ and GVLP-172HZ), from -20 to $200 \mathrm{~s}$.

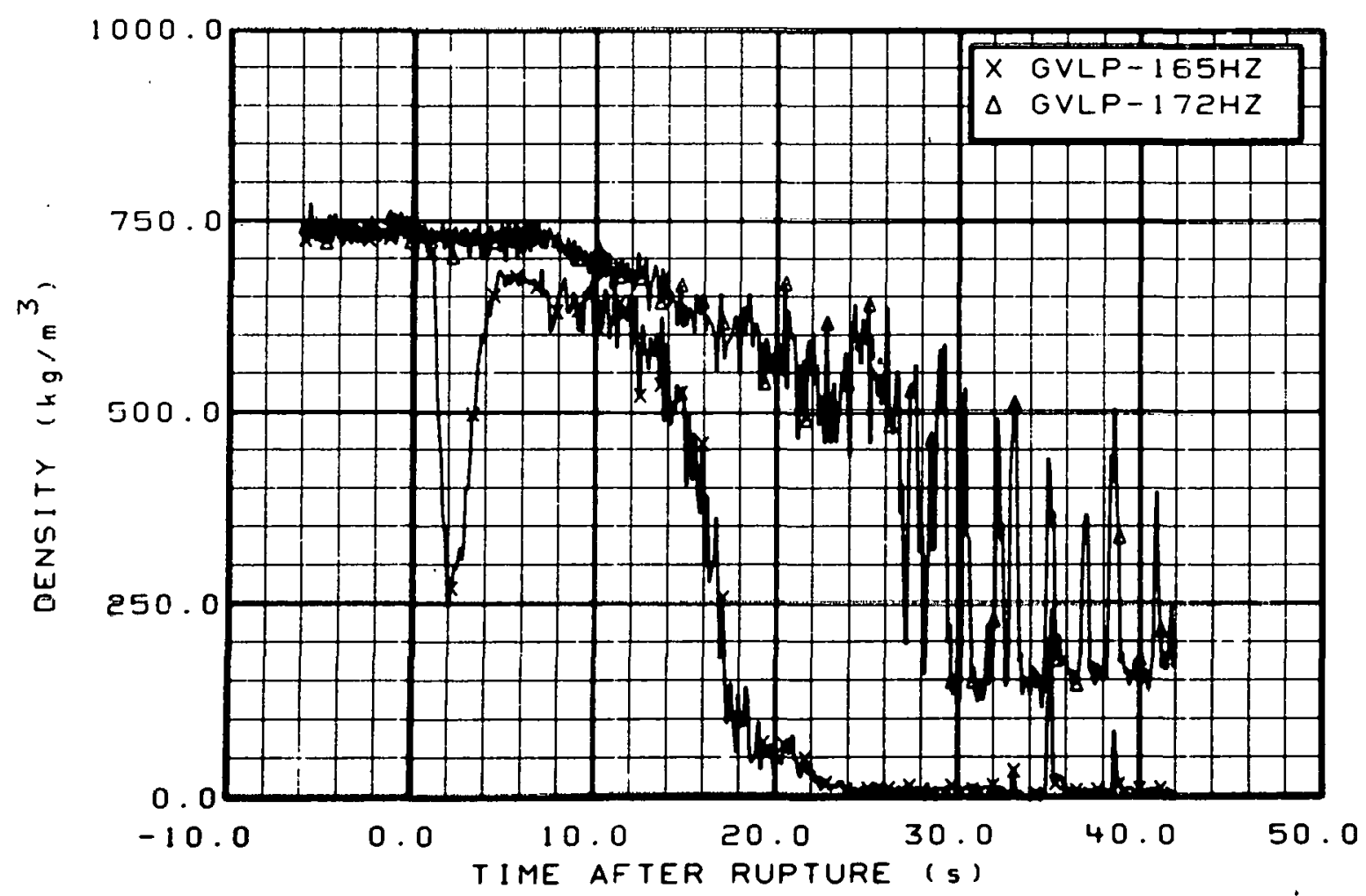

Fig. 296 Density in vessel (GVLP-165HZ and GVLP-172HZ), from -6 to 42 s. 


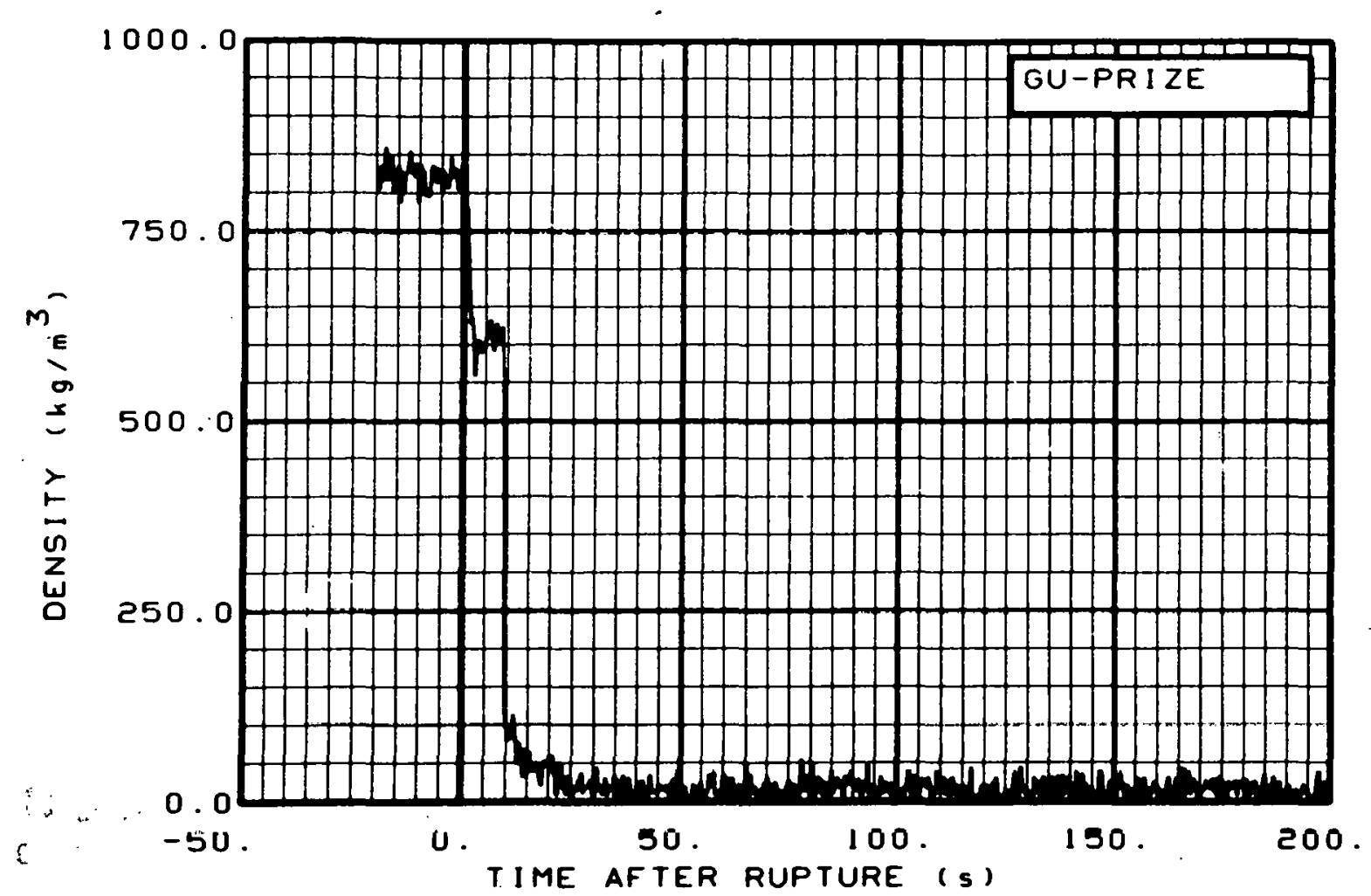

Fig. 297 Density in pressurizer (GU-PRIZE), from -20 to $200 \mathrm{~s}$.

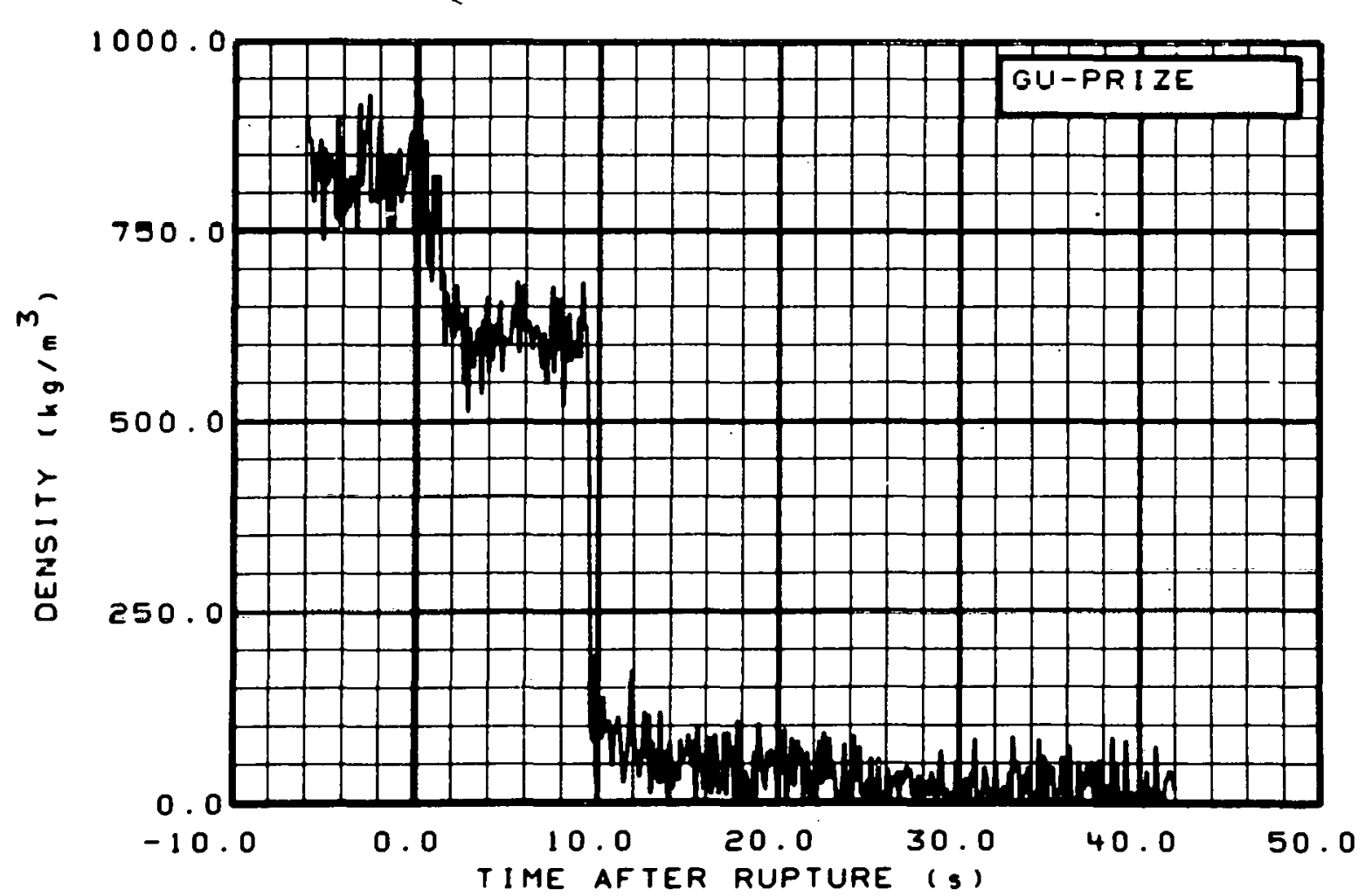

Fig. 298 Density in pressurizer (GU-PRIZE), from -6 to $42 \mathrm{~s}$. 


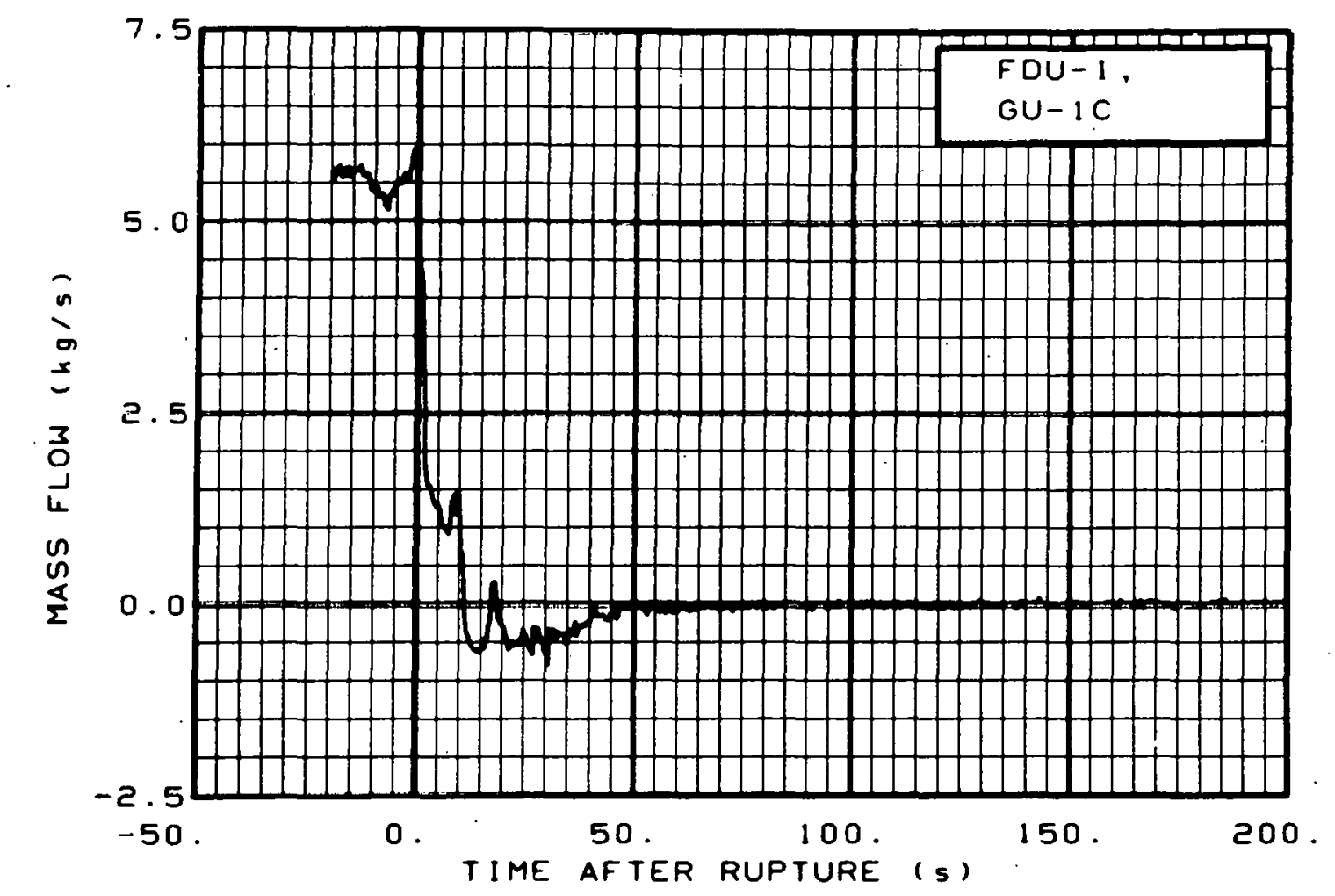

Fig. 299 Mass flow in intact loop (FDU-1 and GU-1C), from -20 to $200 \mathrm{~s}$.

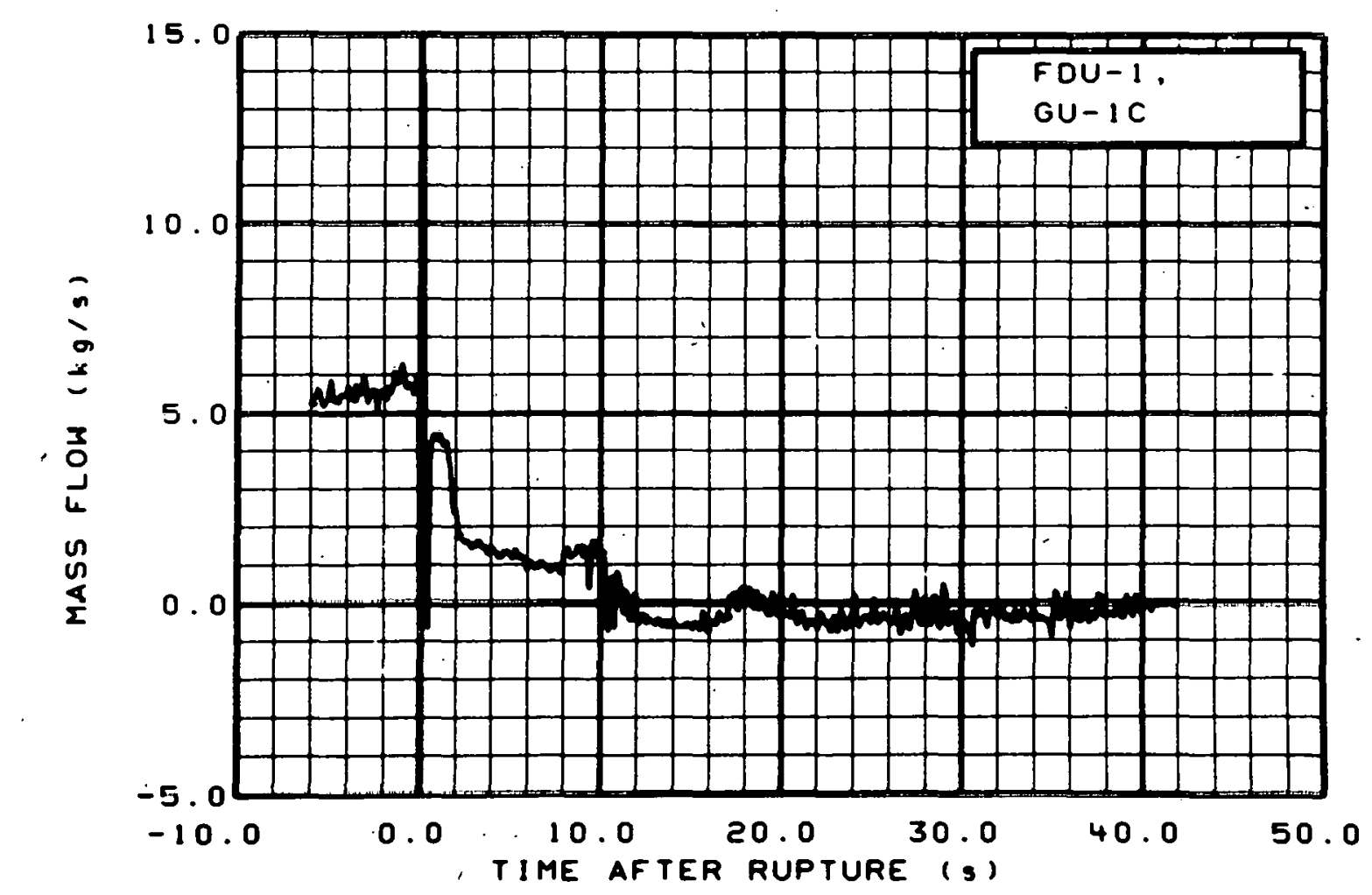

Fig. 300 Mass flow in intact 100p (FDU-1 and GU-1C), from -6 to $42 \mathrm{~s}$. 


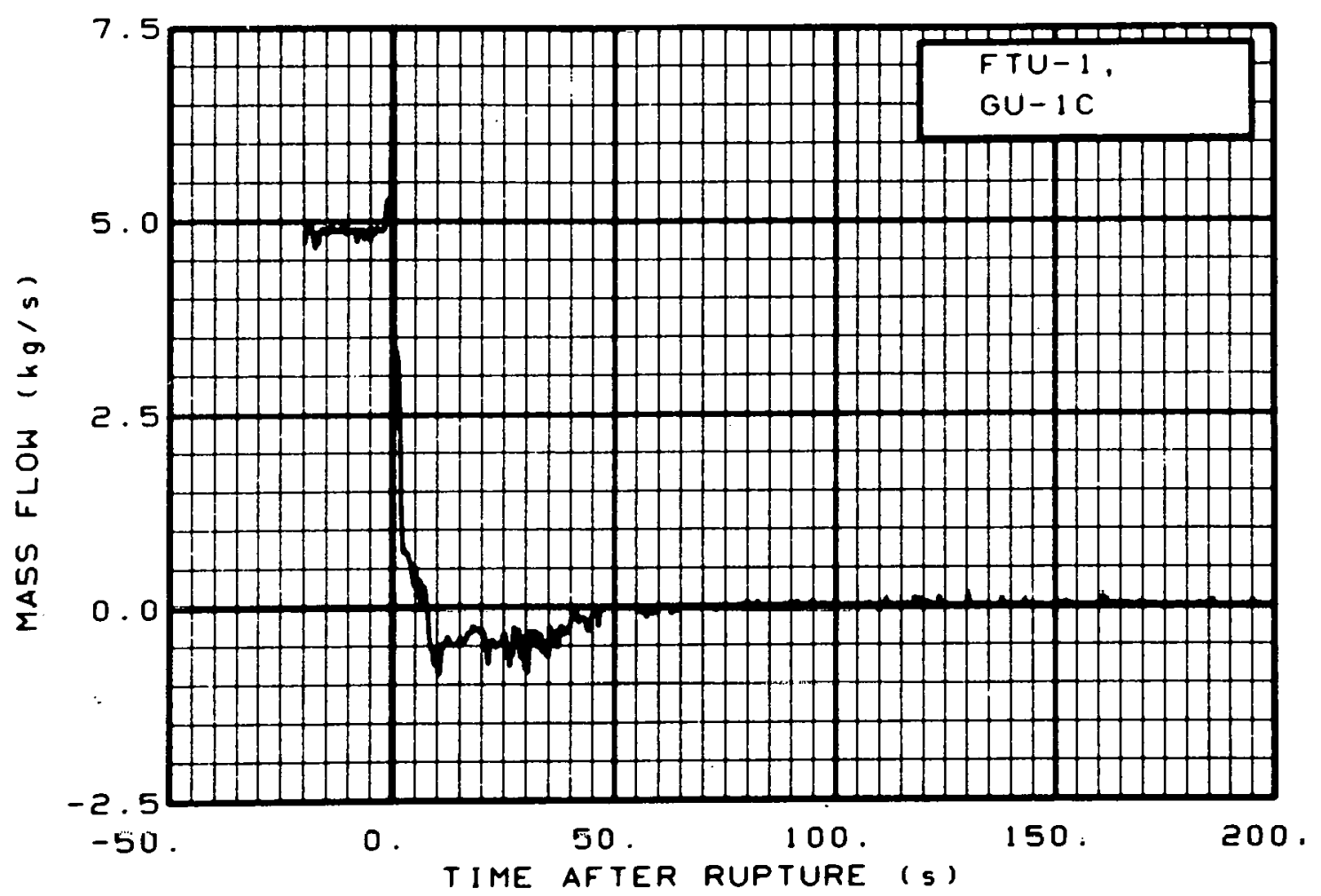

Fig. 301 Mass flow in intact loop (FTU-1 and GU-1C), from -20 to $200 \mathrm{~s}$.

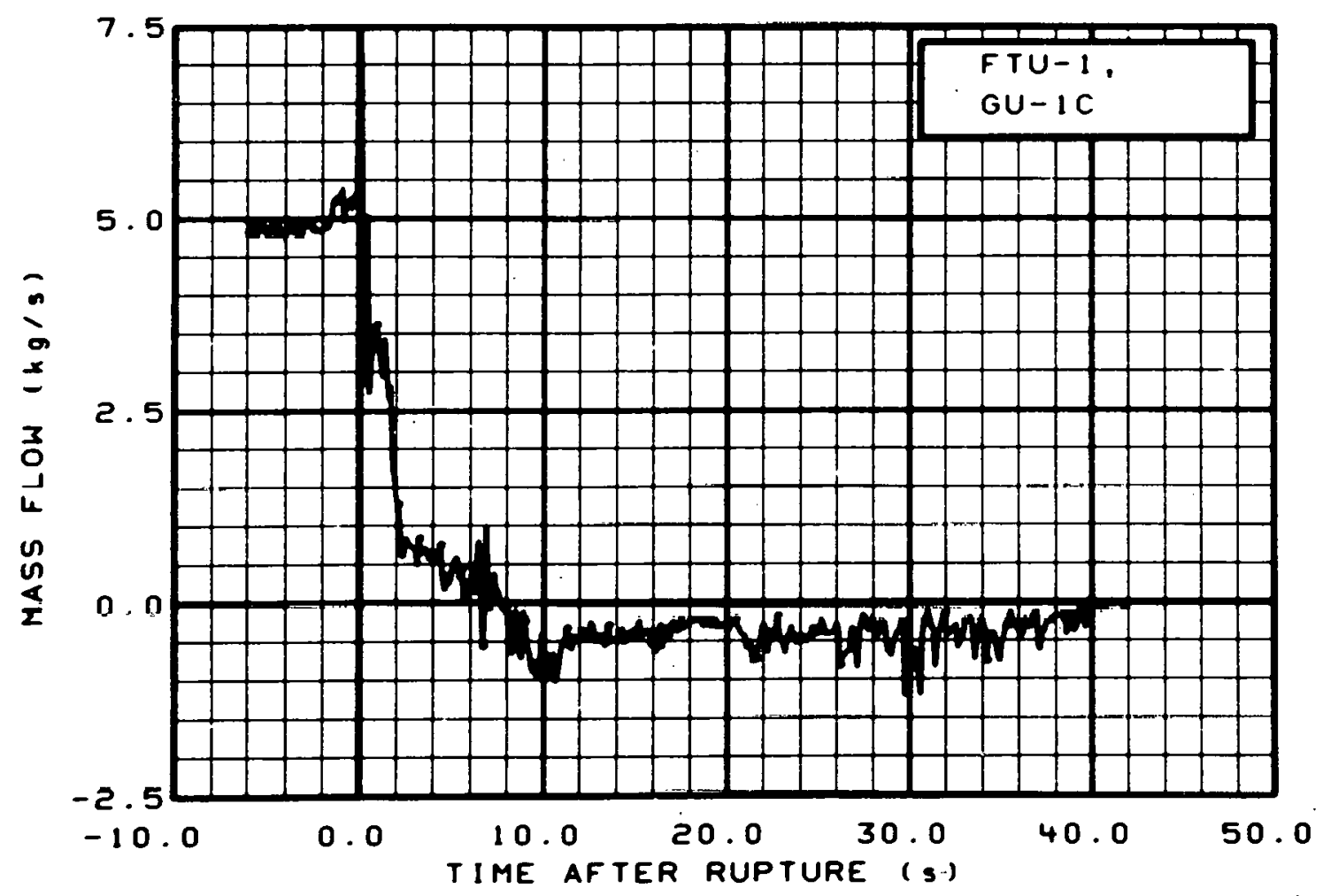

Fig. 302 Mass flow in intact loop (FTU-1 and GU-1C), from -6 to $42 \mathrm{~s}$. 


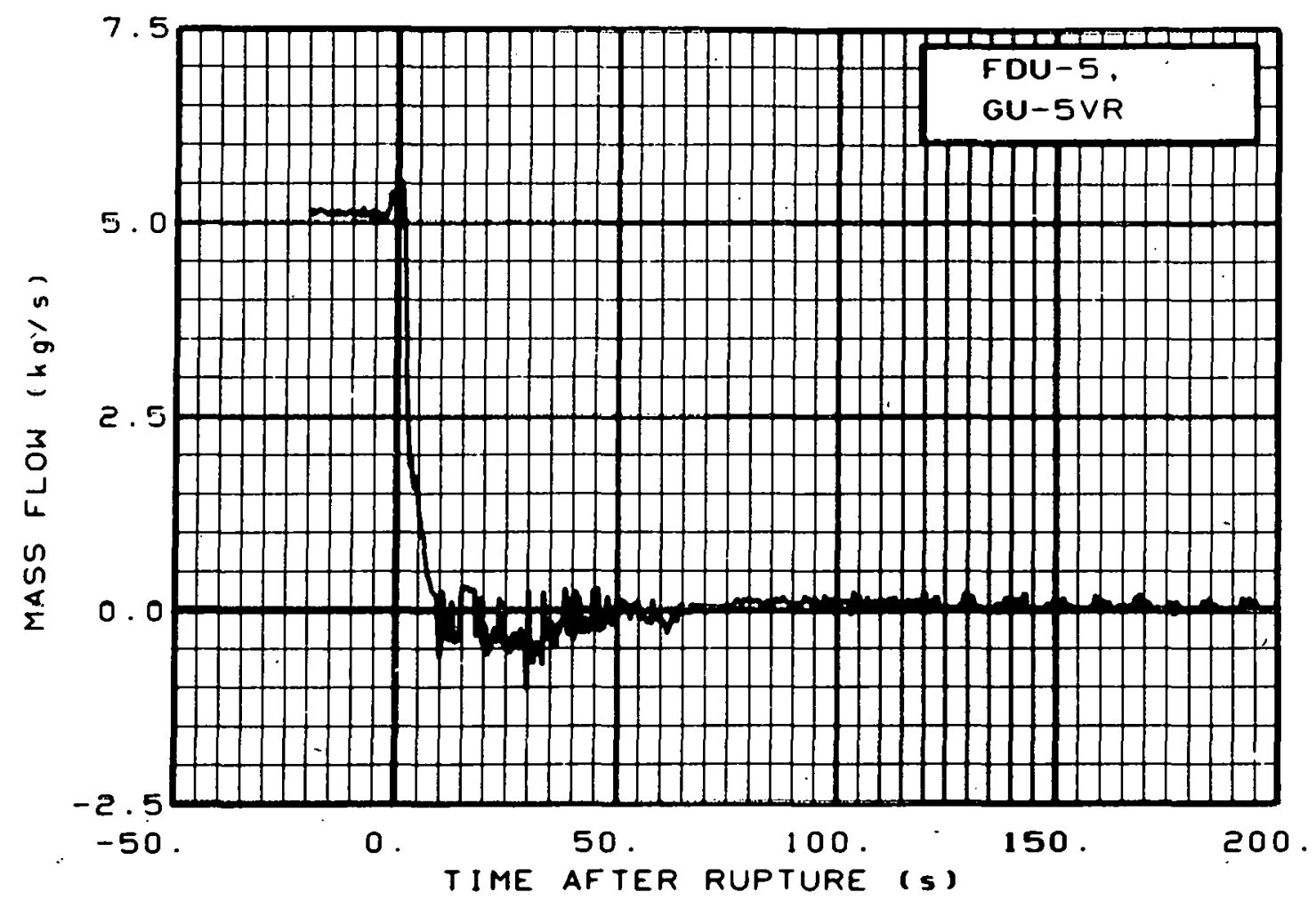

Fig. 303 Mass flow in intact loop (FDU-5 and GU-5VR), from -20 to $200 \mathrm{~s}$.

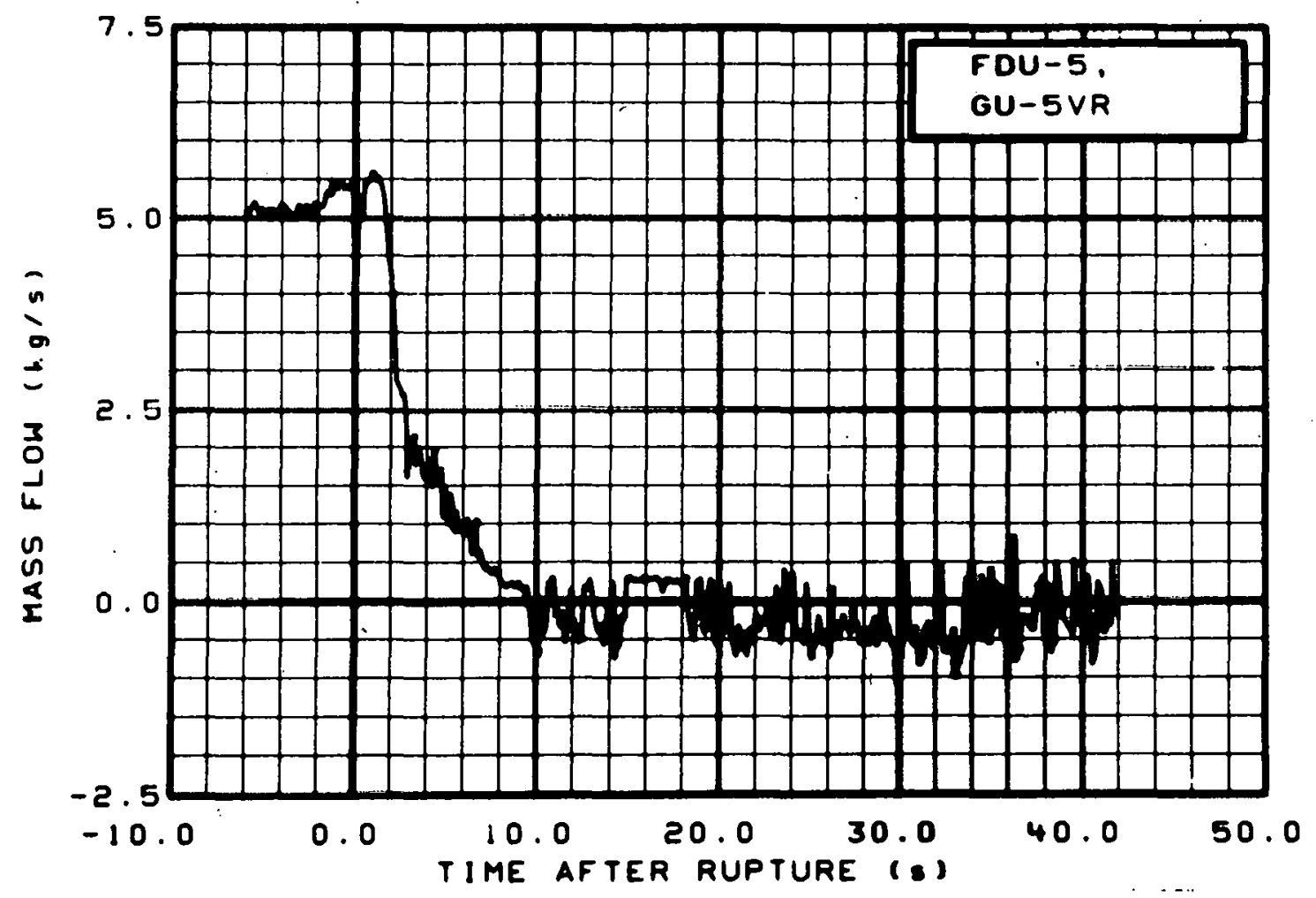

Fig. 304 Mass flow in intact loop (FDU-5 and GU-5VR), from -6 to $42 \mathrm{~s}$. 


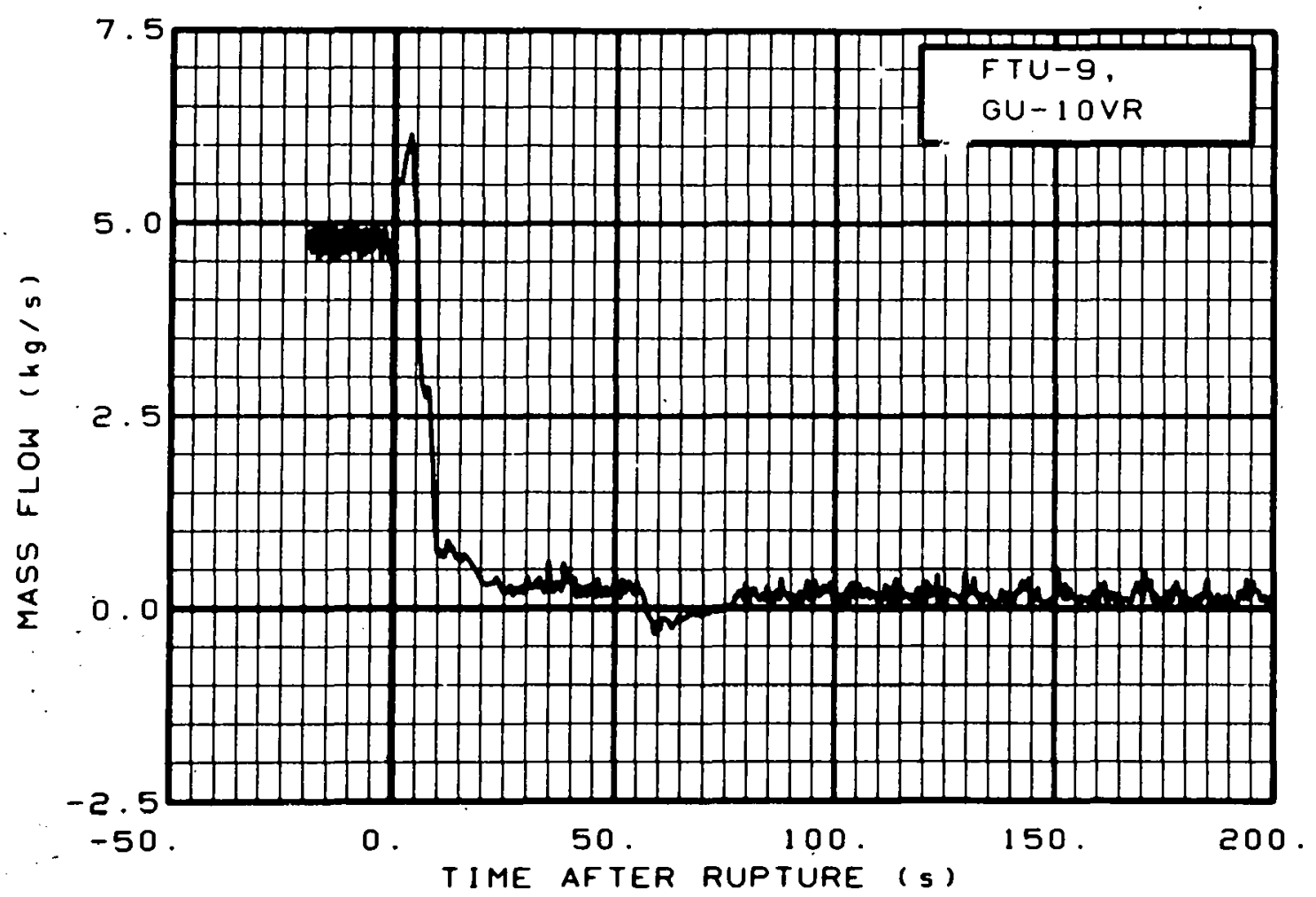

Fig. 305 Mass flow in intact loop (FTU-9 and GU-10VR), from -20 to $200 \mathrm{~s}$.

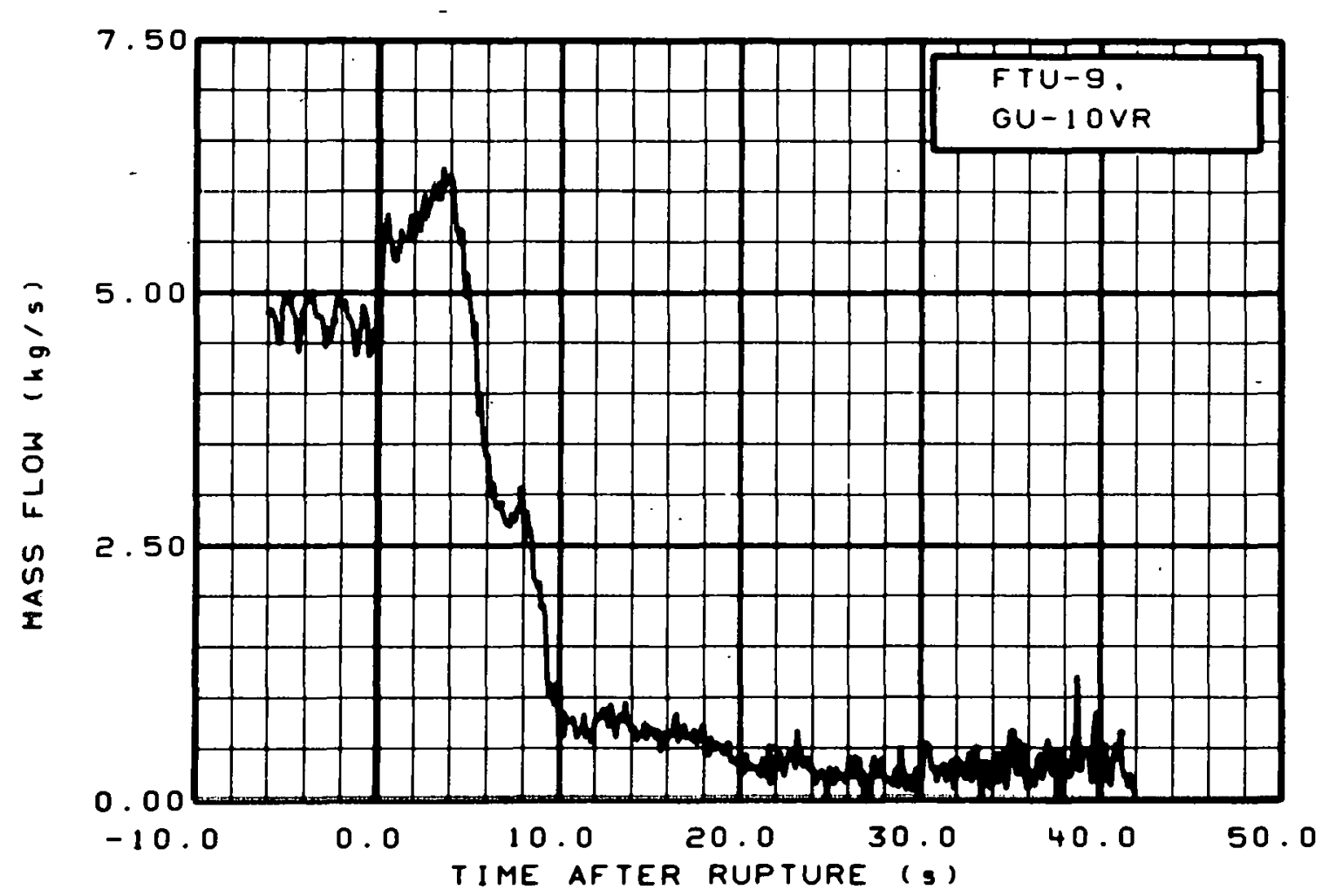

Fig. 306 Mass flow in intact loop (FTU-9 and GU-10VR), from -6 to $42 \mathrm{~s}$. 


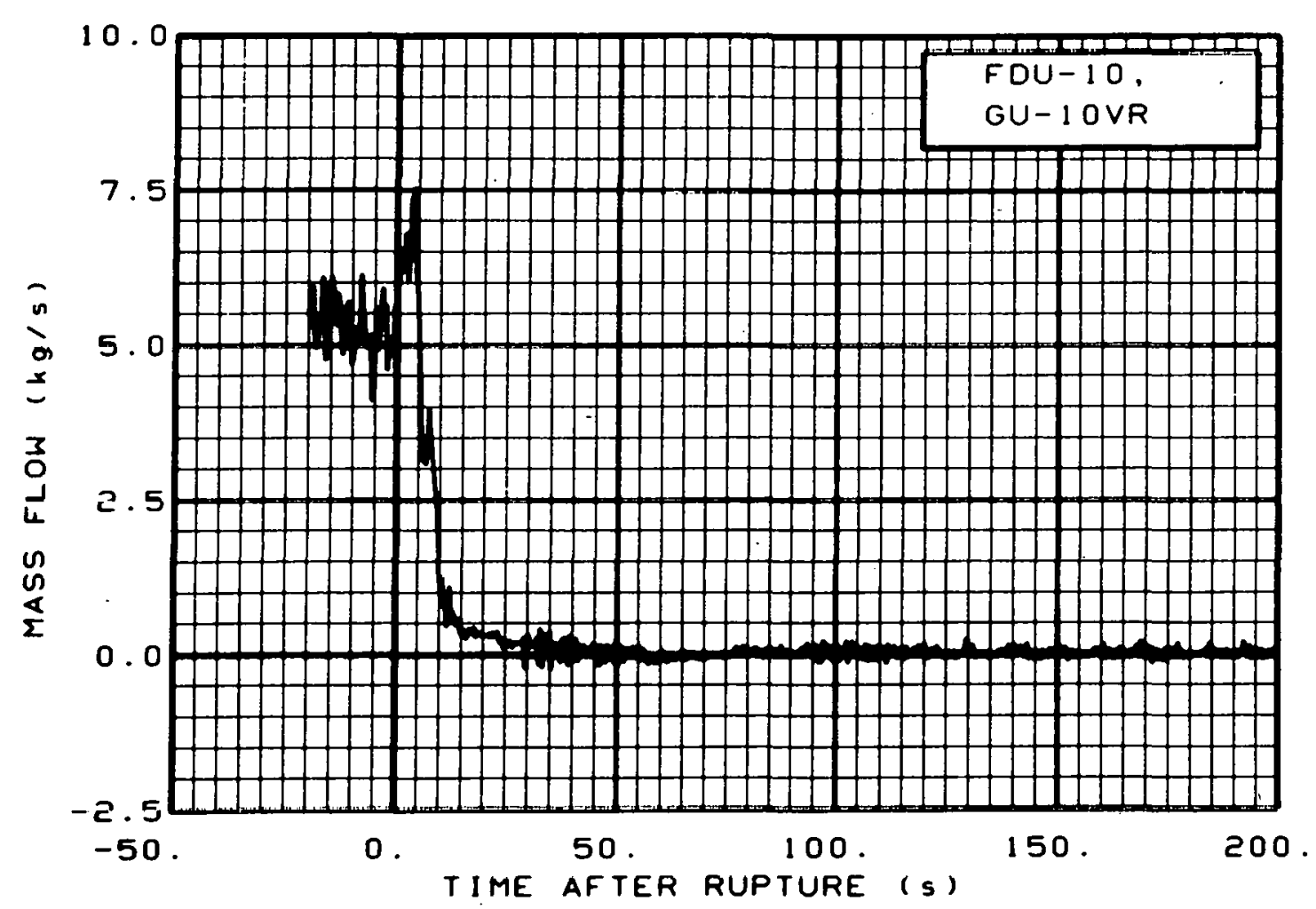

Fig. 307 Mass flow in intact loop (FDU-10 and GU-10VR), from -20 to $200 \mathrm{~s}$.

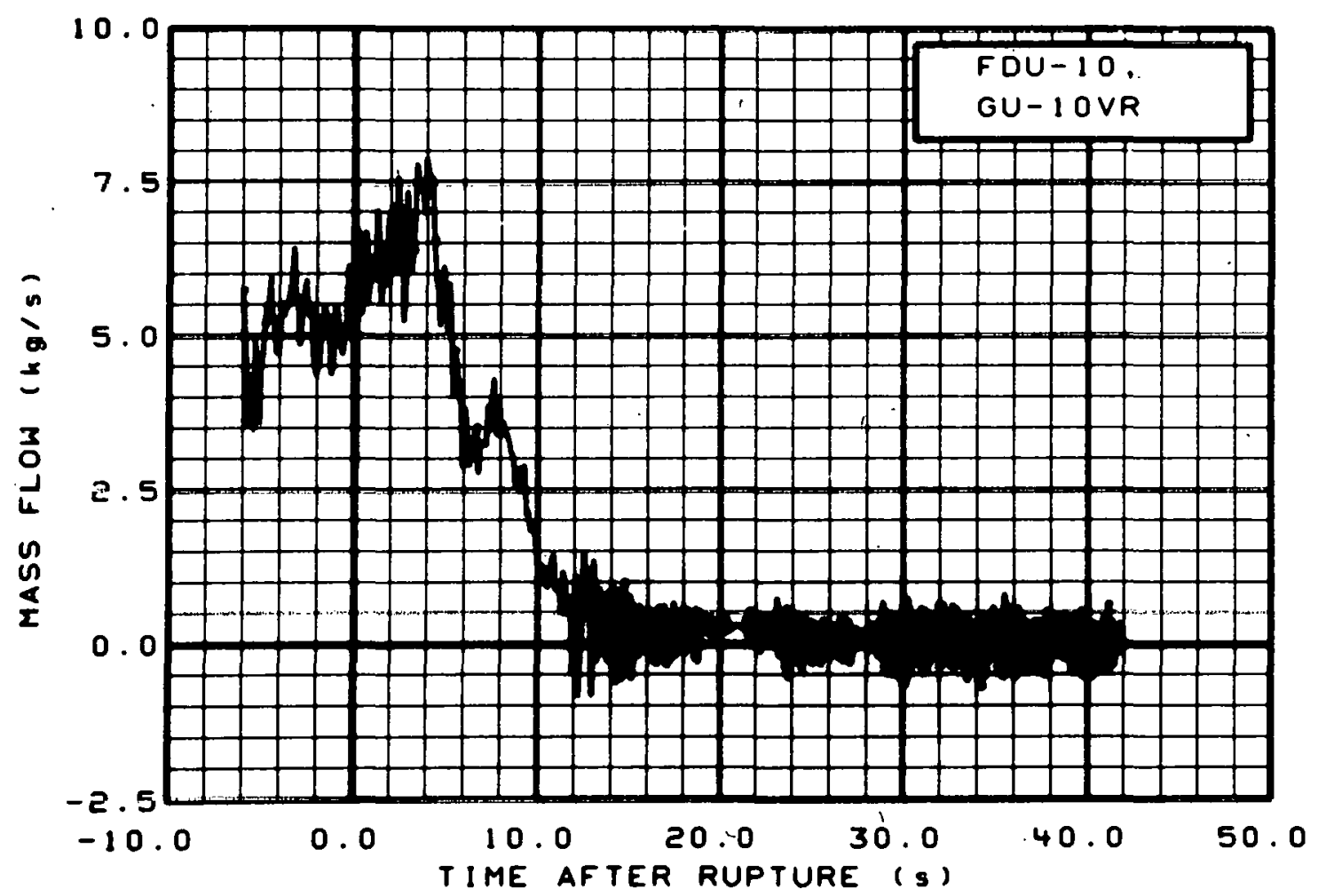

Fig. 308 Mass flow in intact loop (FDU-10 and GU-10VR), from -6 to $42 \mathrm{~s}$. 


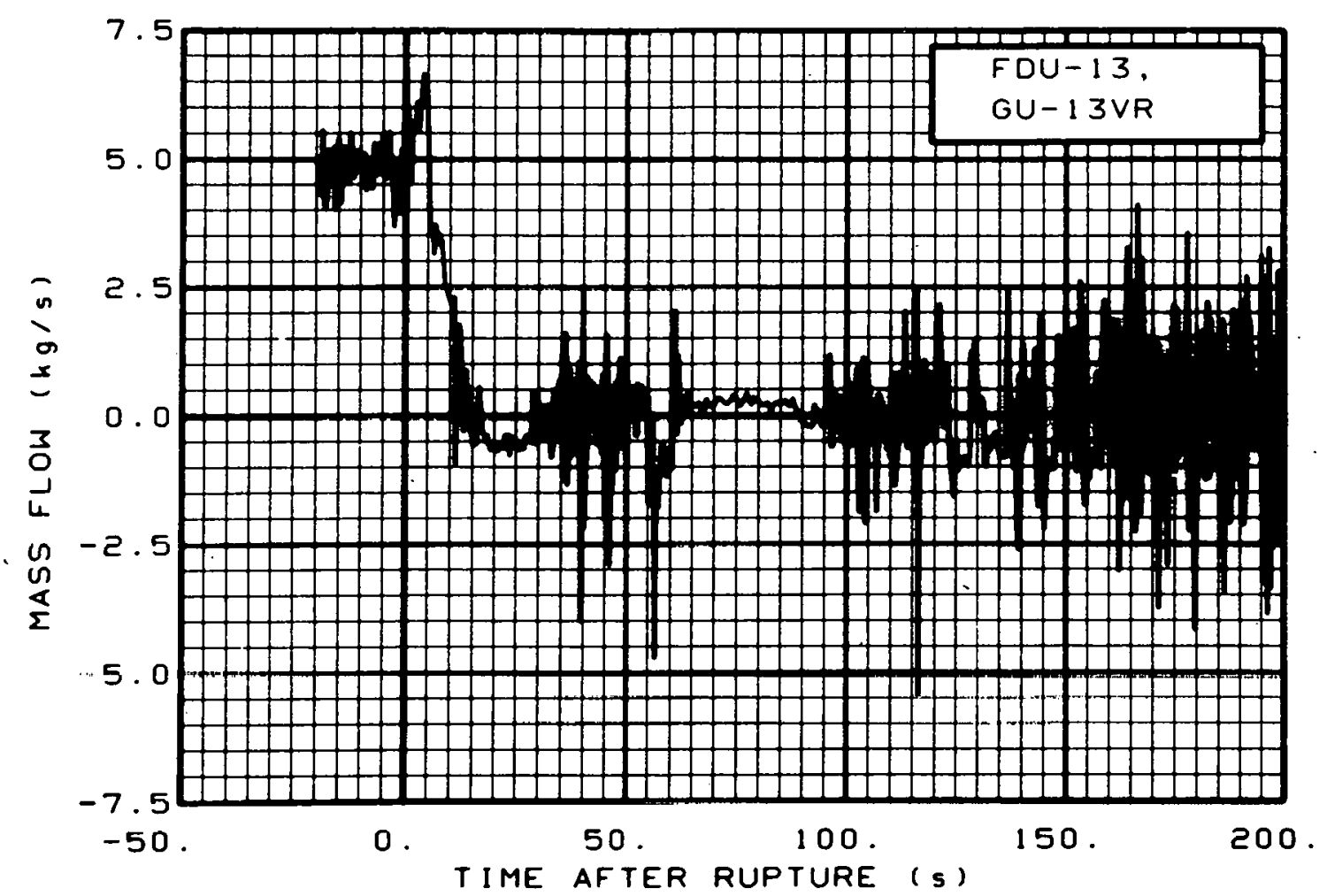

Fig. 309 Mass flow in intact loop (FDU-13 and GU-13VR), from -20 to $200 \mathrm{~s}$.

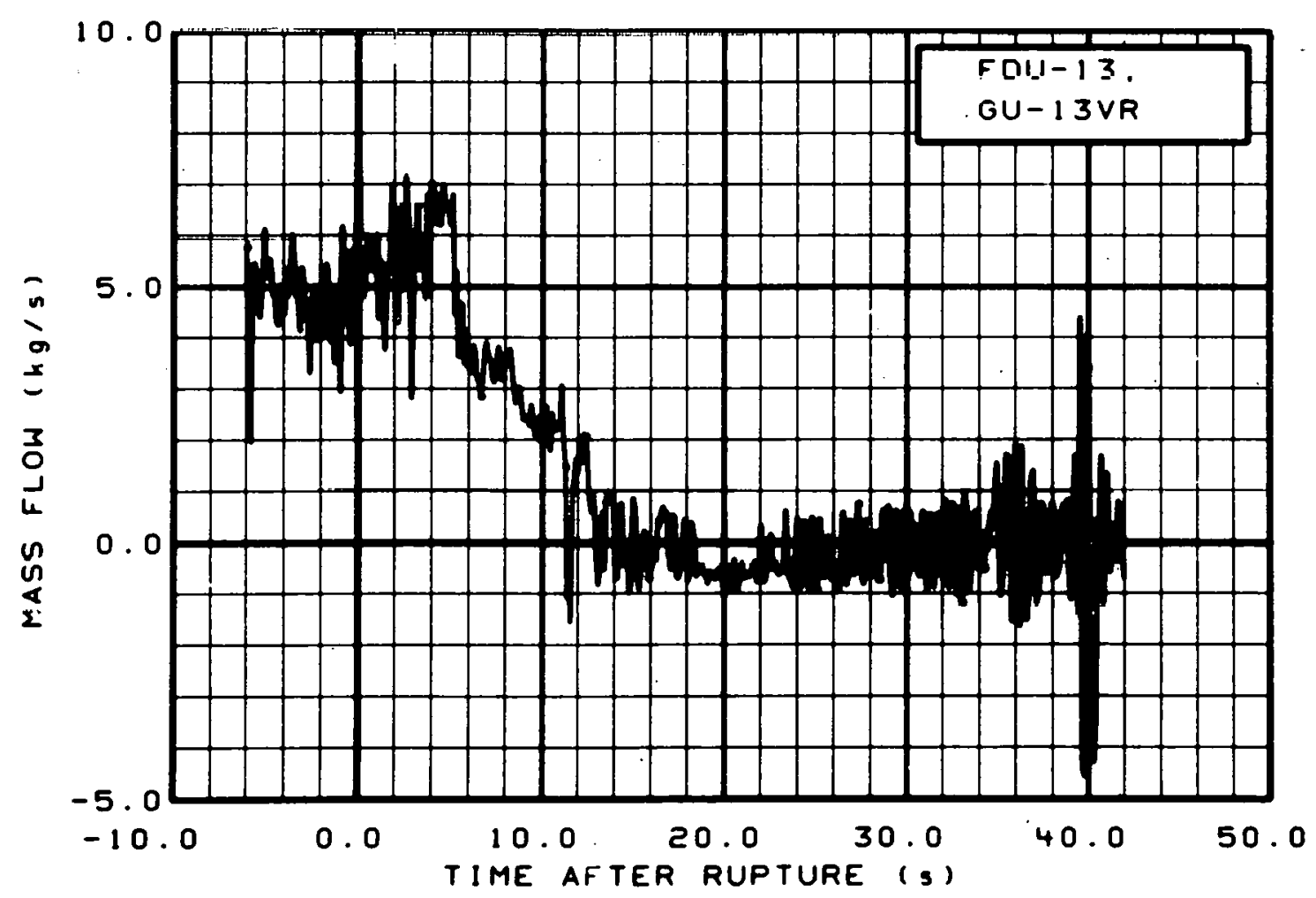

Fig. 310 Mass flow in intact loop (FDU-13 and GU-13VR), from -6 to $42 \mathrm{~s}$. 


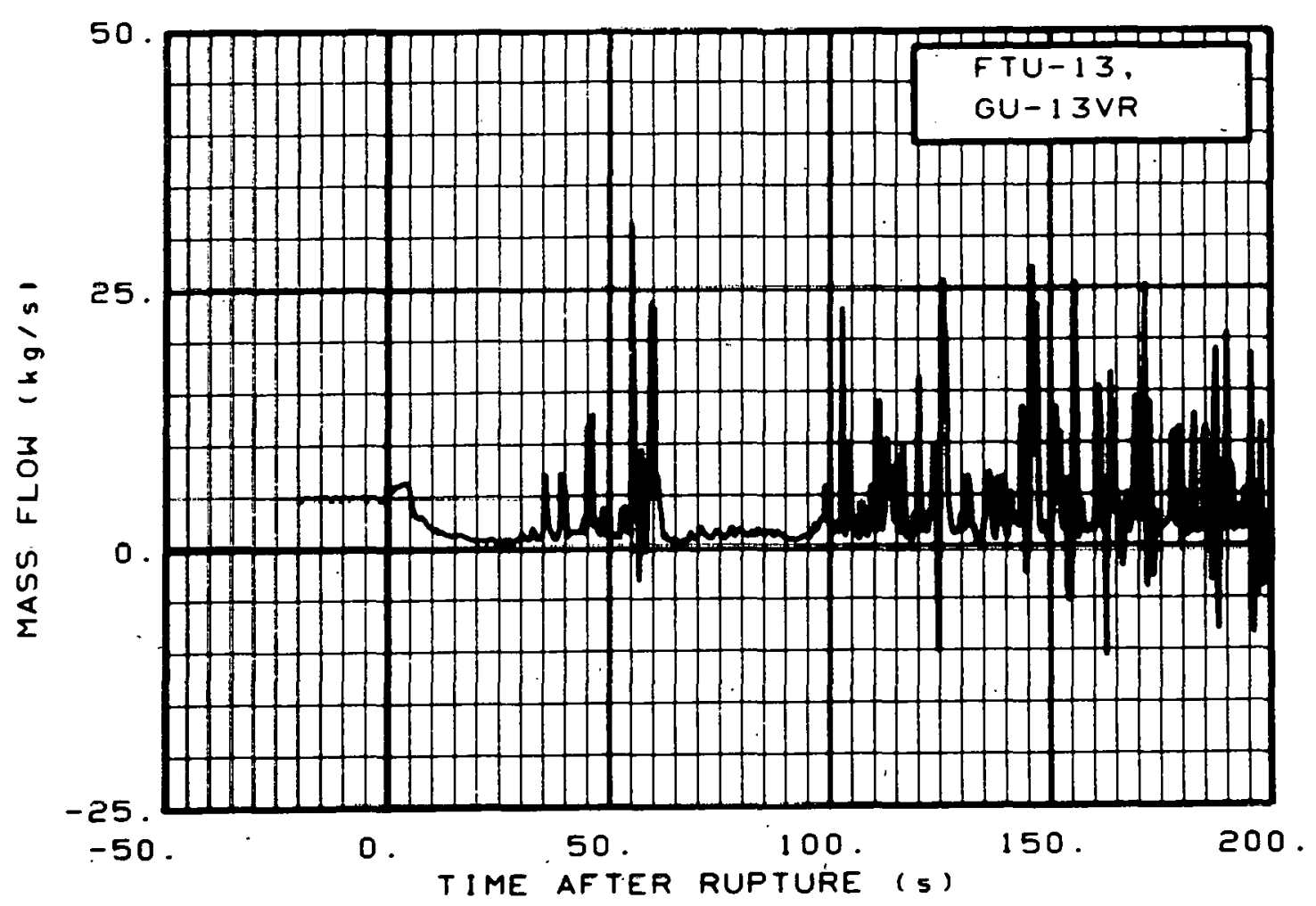

Fig. 311 Mass flow in intact loop (FTU-13 and GU-13VR), from -20 to $200 \mathrm{~s}$.

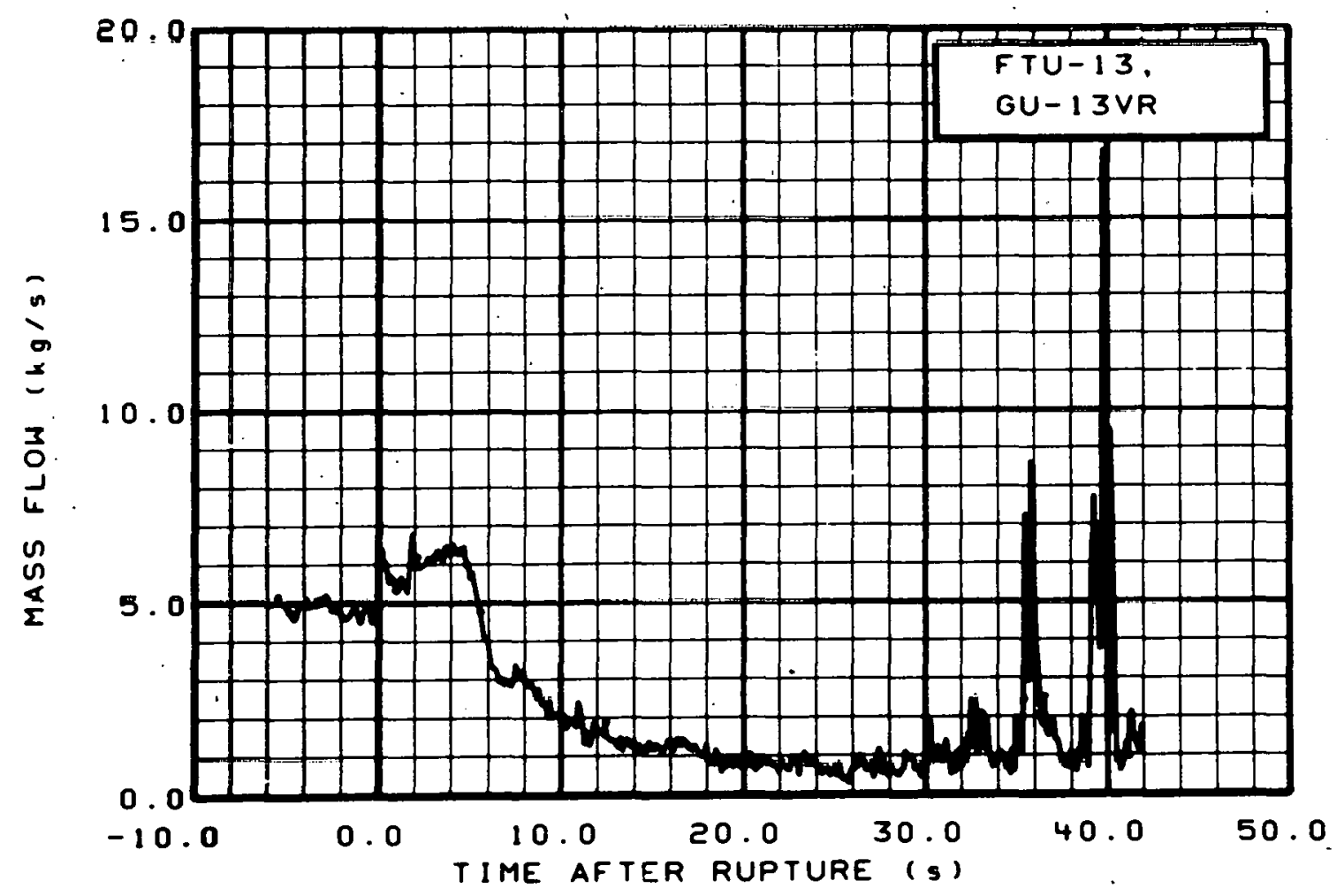

Fig. 312 Mass flow in intact loop (FTU-13 and GU-13VR), from -6 to $42 \mathrm{~s}$. 


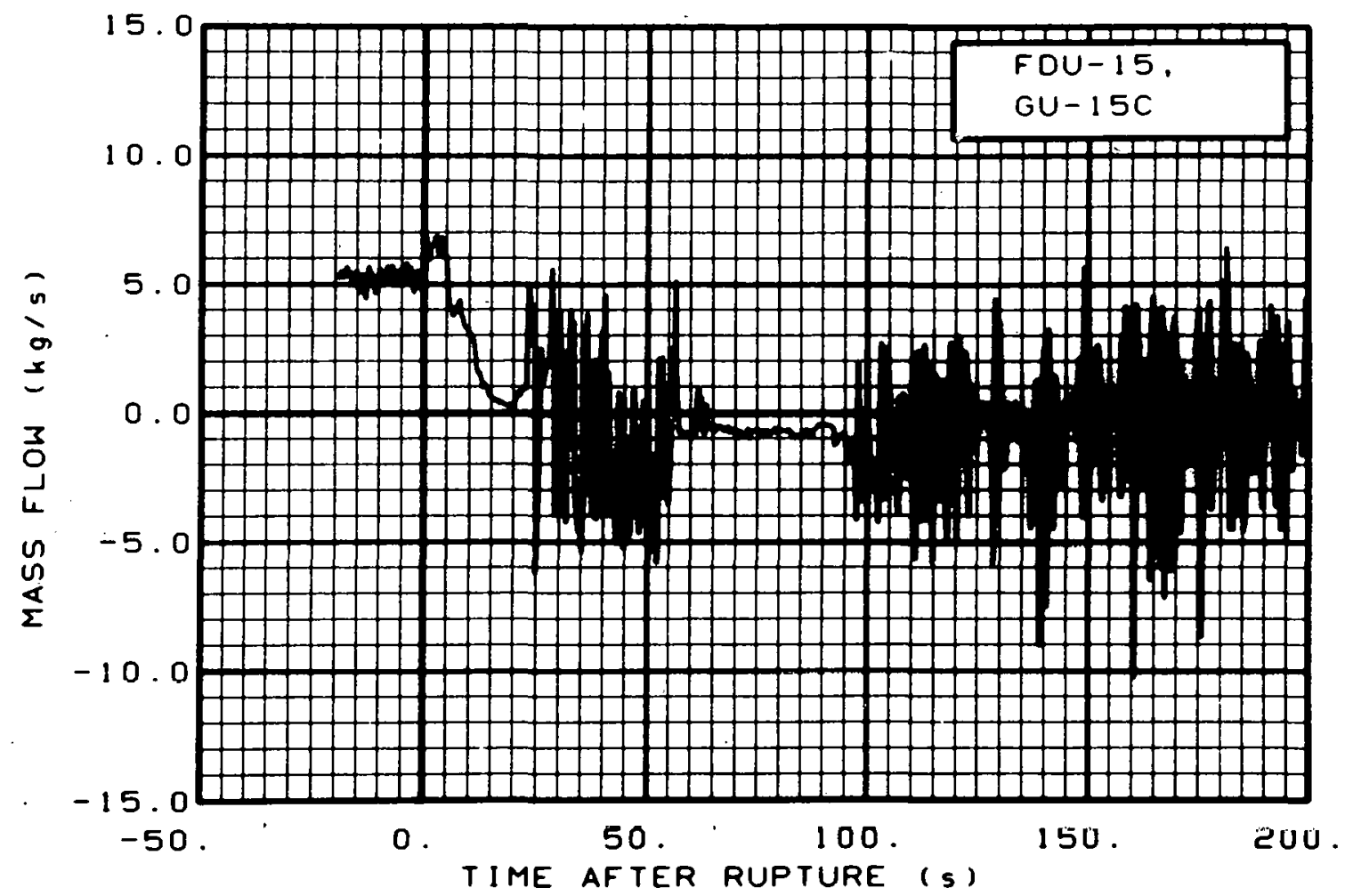

Fig. 313 Mass flow in intact loop (FDU-15 and GU-15C), from -20 to $200 \mathrm{~s}$.

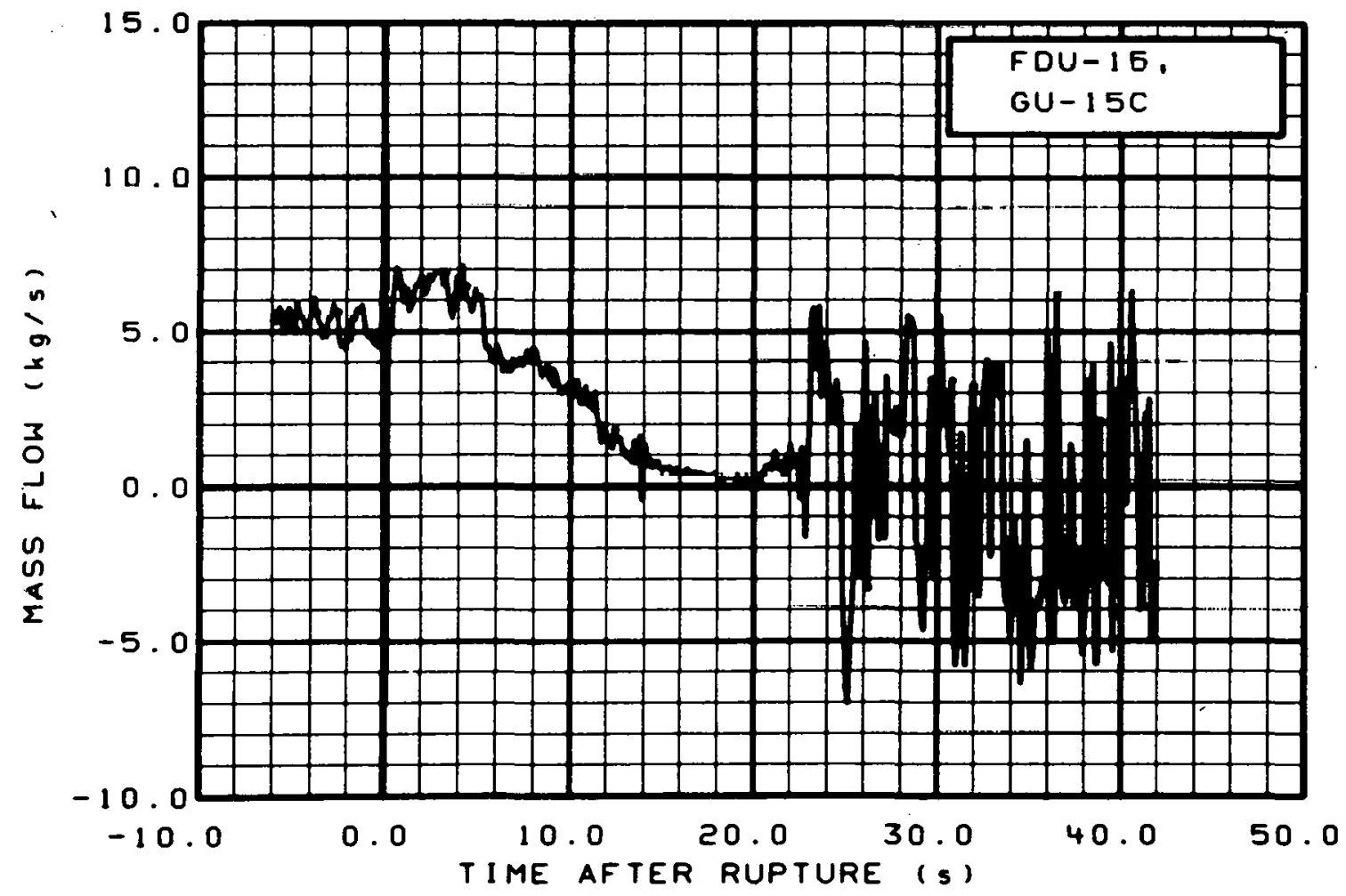

Fig. 314 Mass flow in intact loop (FDU-15 and GU-15C), from -6 to $42 \mathrm{~s}$. 


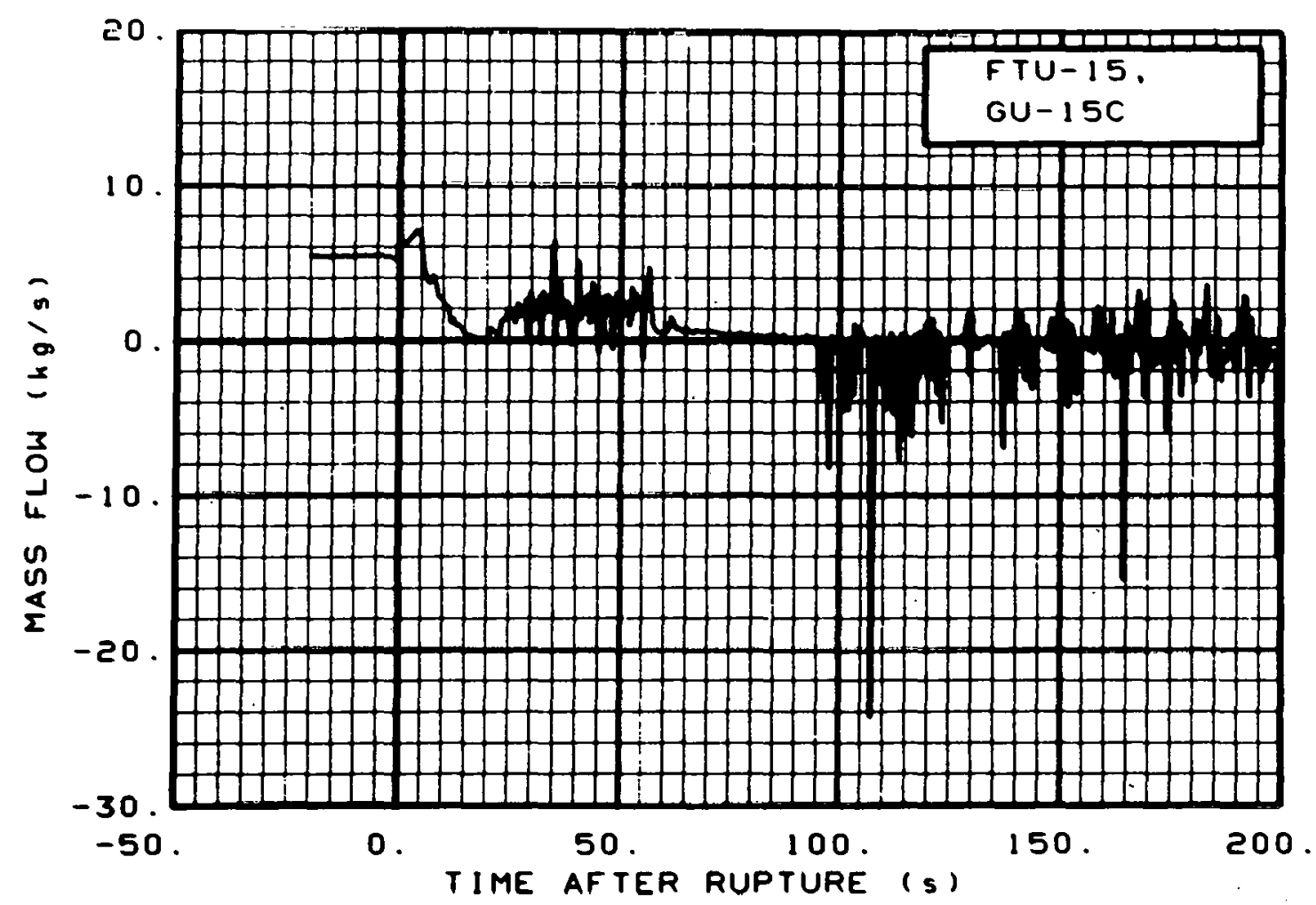

Fig. 315 Mass flow in intact loop (FTU-15 and GU-15C), from -20 to $200 \mathrm{~s}$.

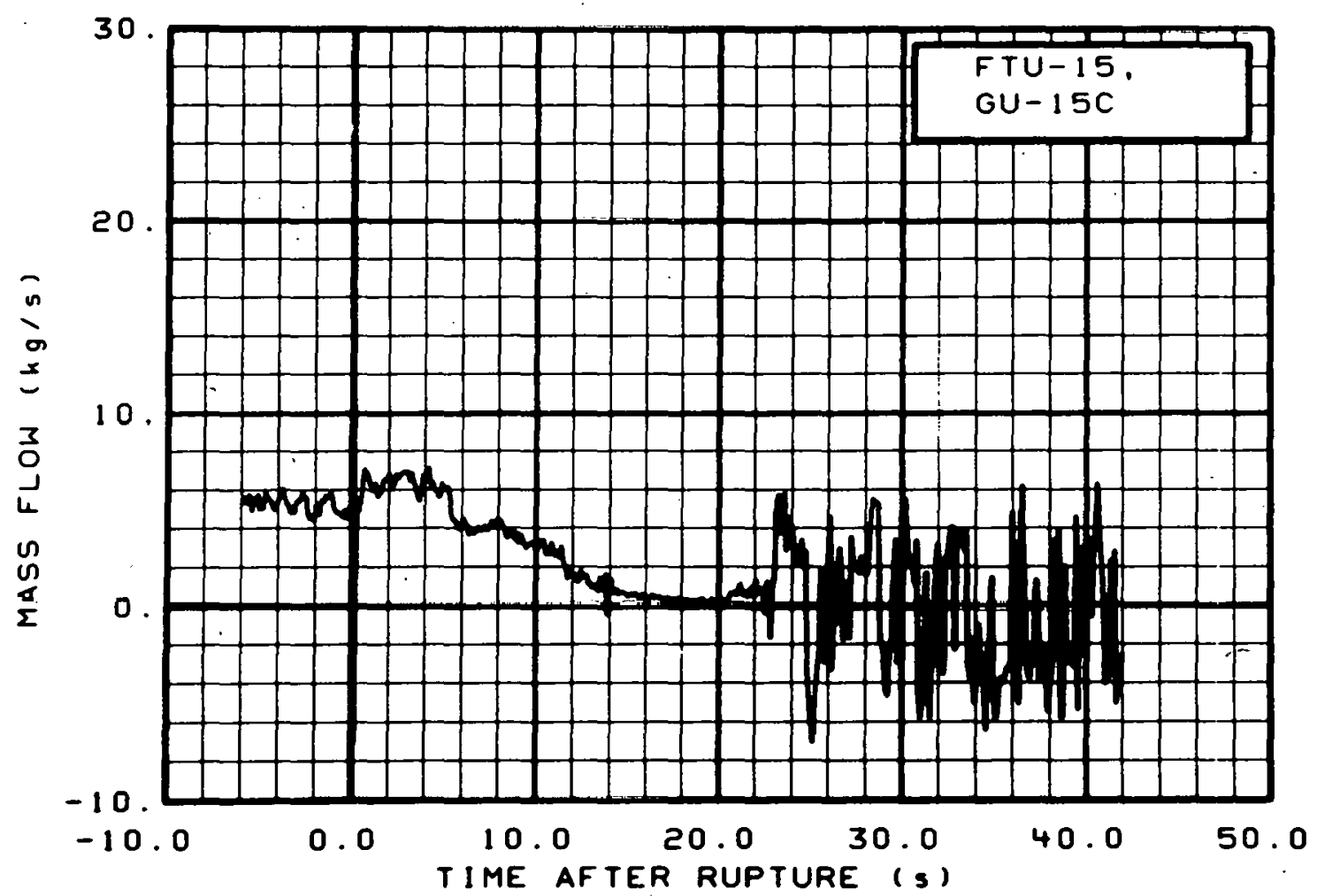

Fig. 316 Mass flow in intact loop (FTU-15 and GU-15C), from -6 to $42 \mathrm{~s}$. 


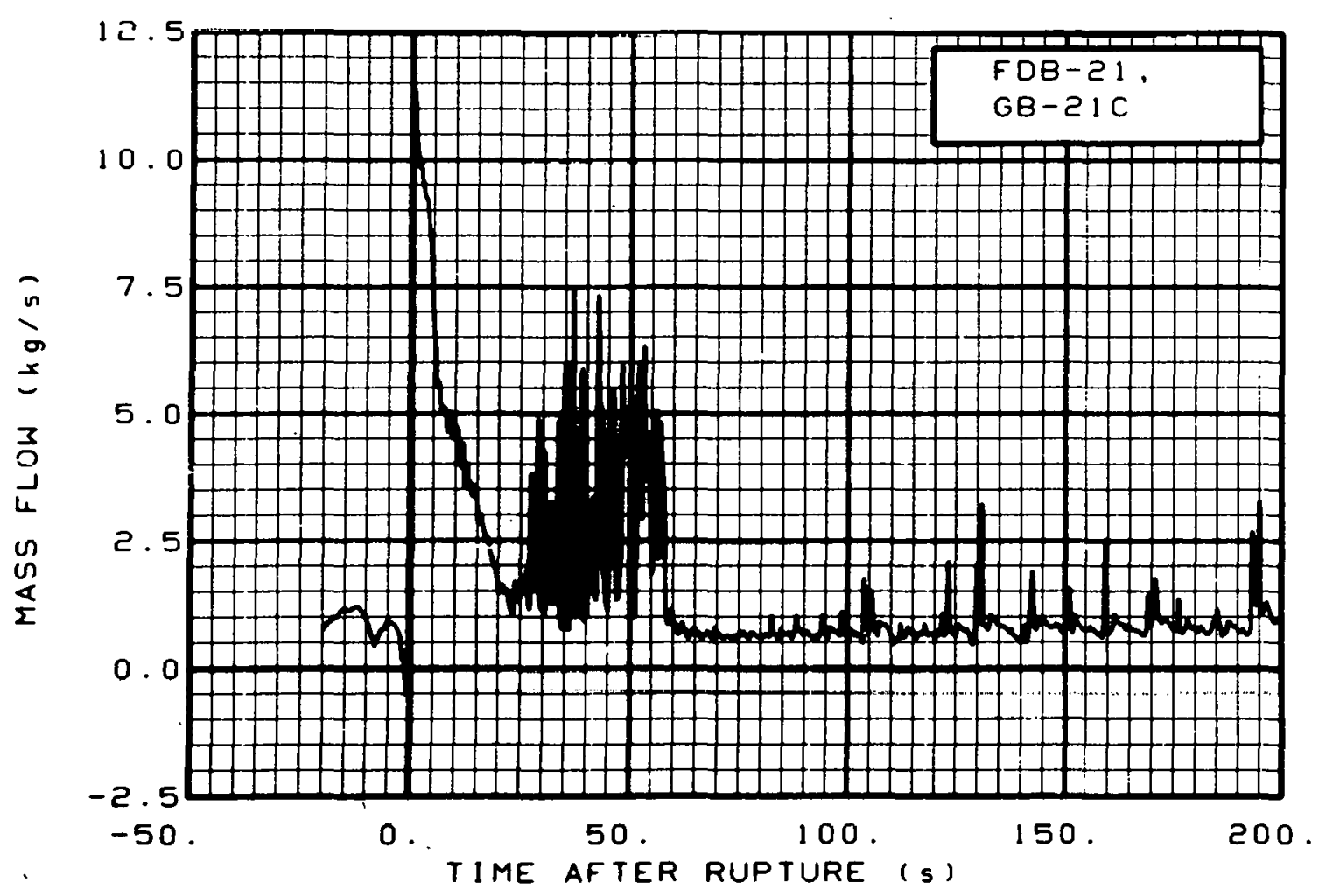

Fig. 317 Mass flow in intact loop (FDB-21 and GB-21C), from -20 to $200 \mathrm{~s}$.

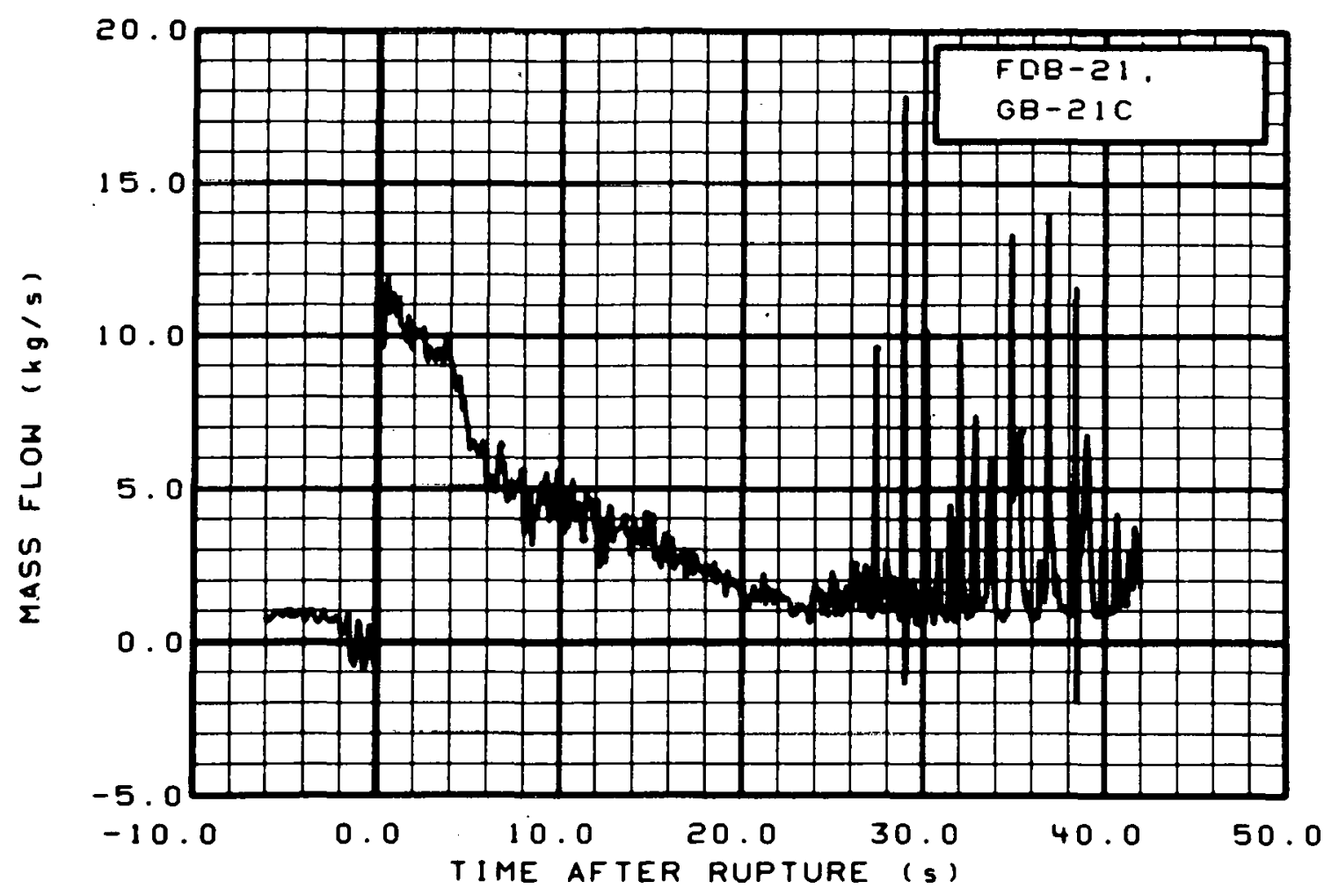

Fig. 318 Mass flow in intact loop (FDB-21 and GB-21C), from -6 to $42 \mathrm{~s}$. 


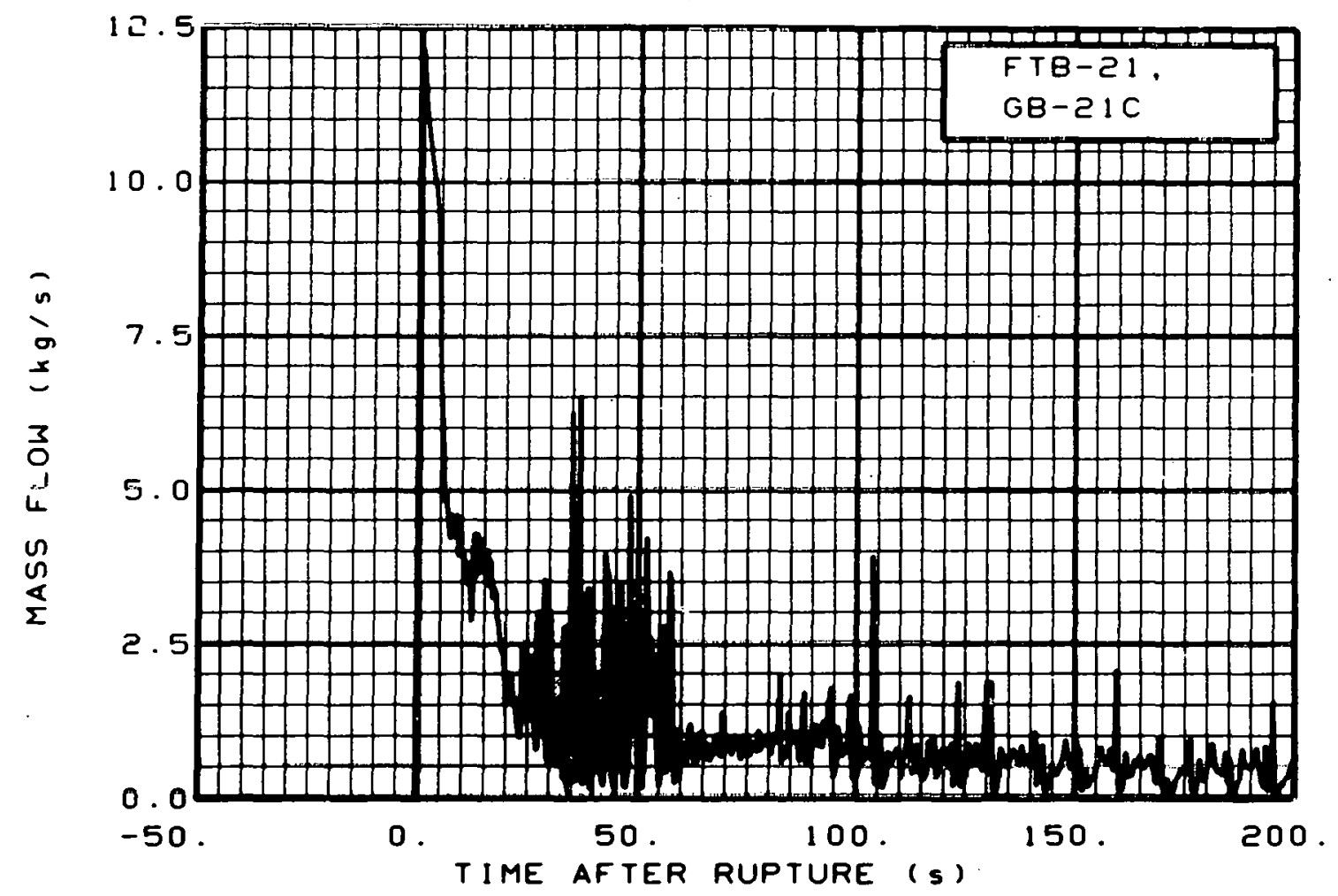

Fig. 319 Mass flow in broken loop (FTB-21 and GB-21C), from -20 to $200 \mathrm{~s}$.

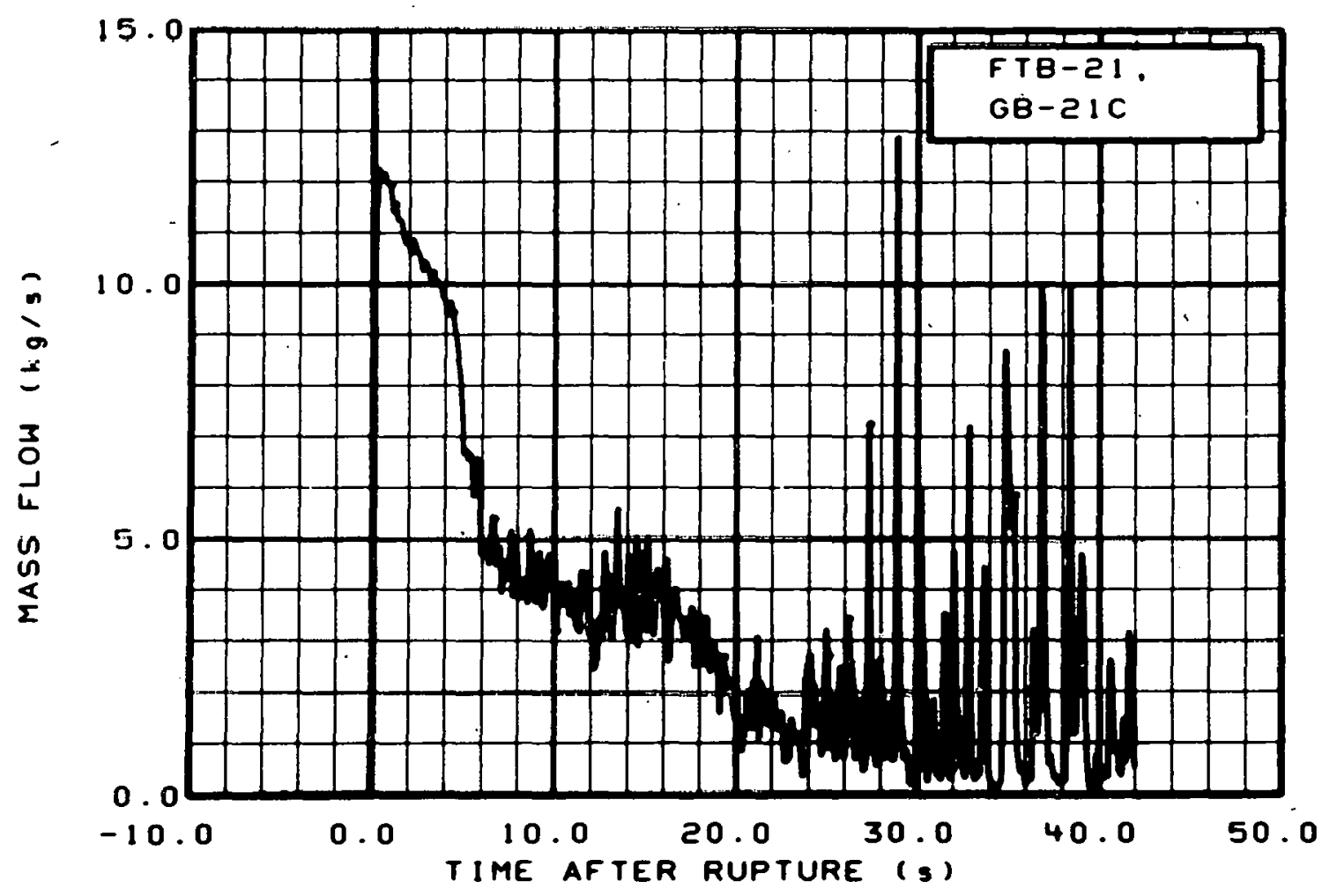

Fig. 320 Mass flow in broken loop (FTB-21 and GB-21C), from -6 to $42 \mathrm{~s}$. 


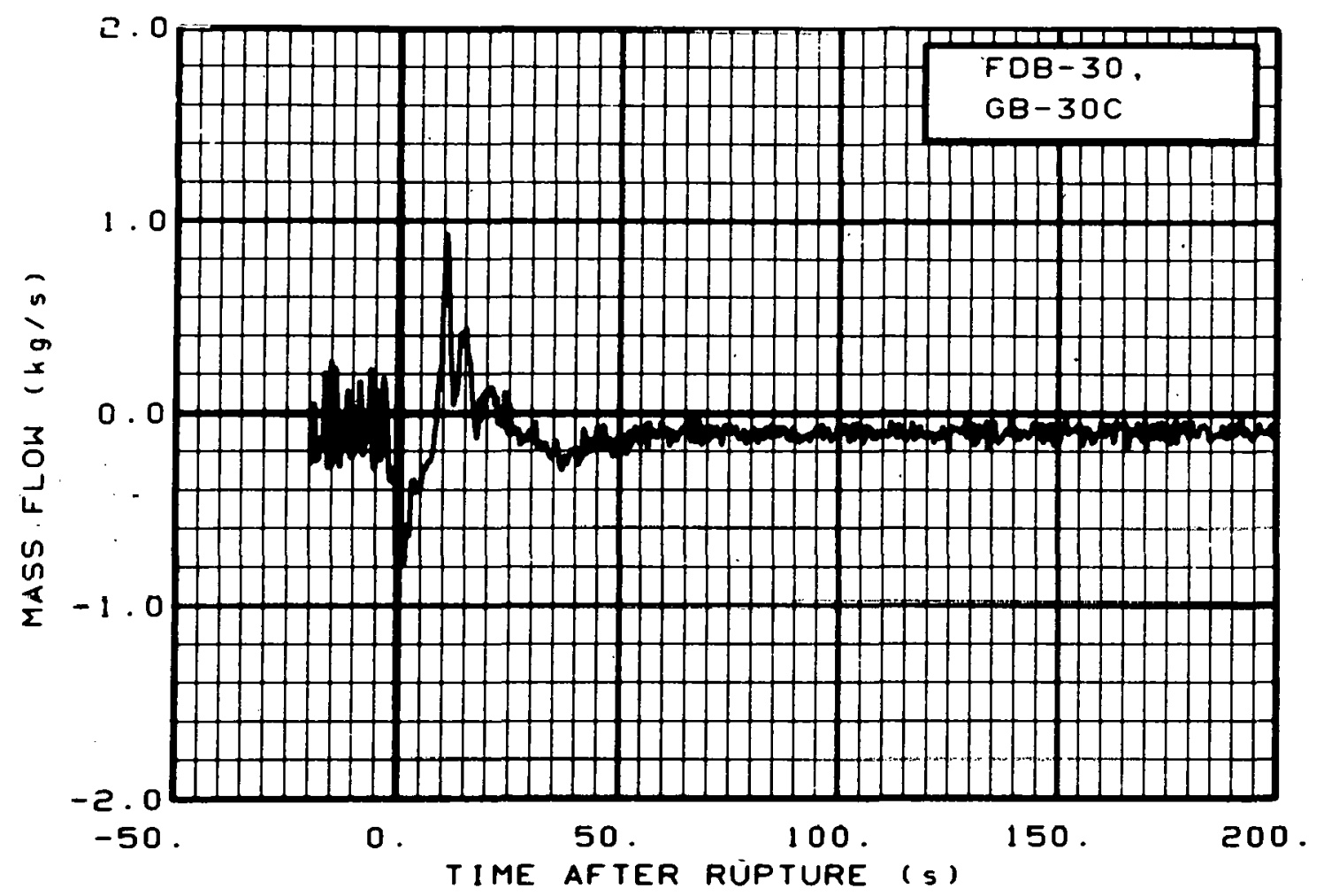

Fig. 321 Mass flow in broken loop (FDB-30 and GB-30C), from -20 to $200 \mathrm{~s}$.

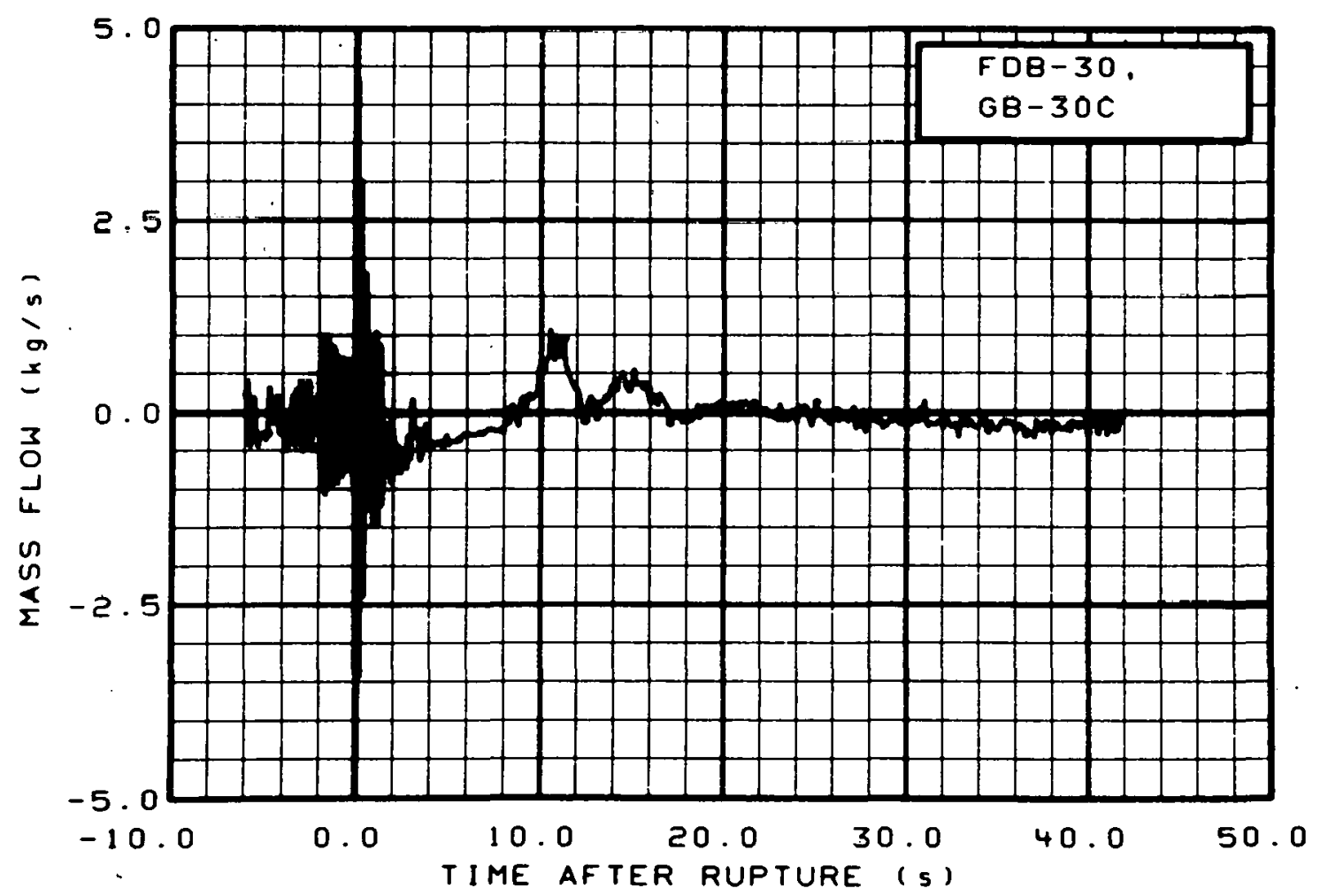

Fig. 322 Mass flow in broken loop (FDB-30 and GB-30C), from -6 to $42 \mathrm{~s}$. 


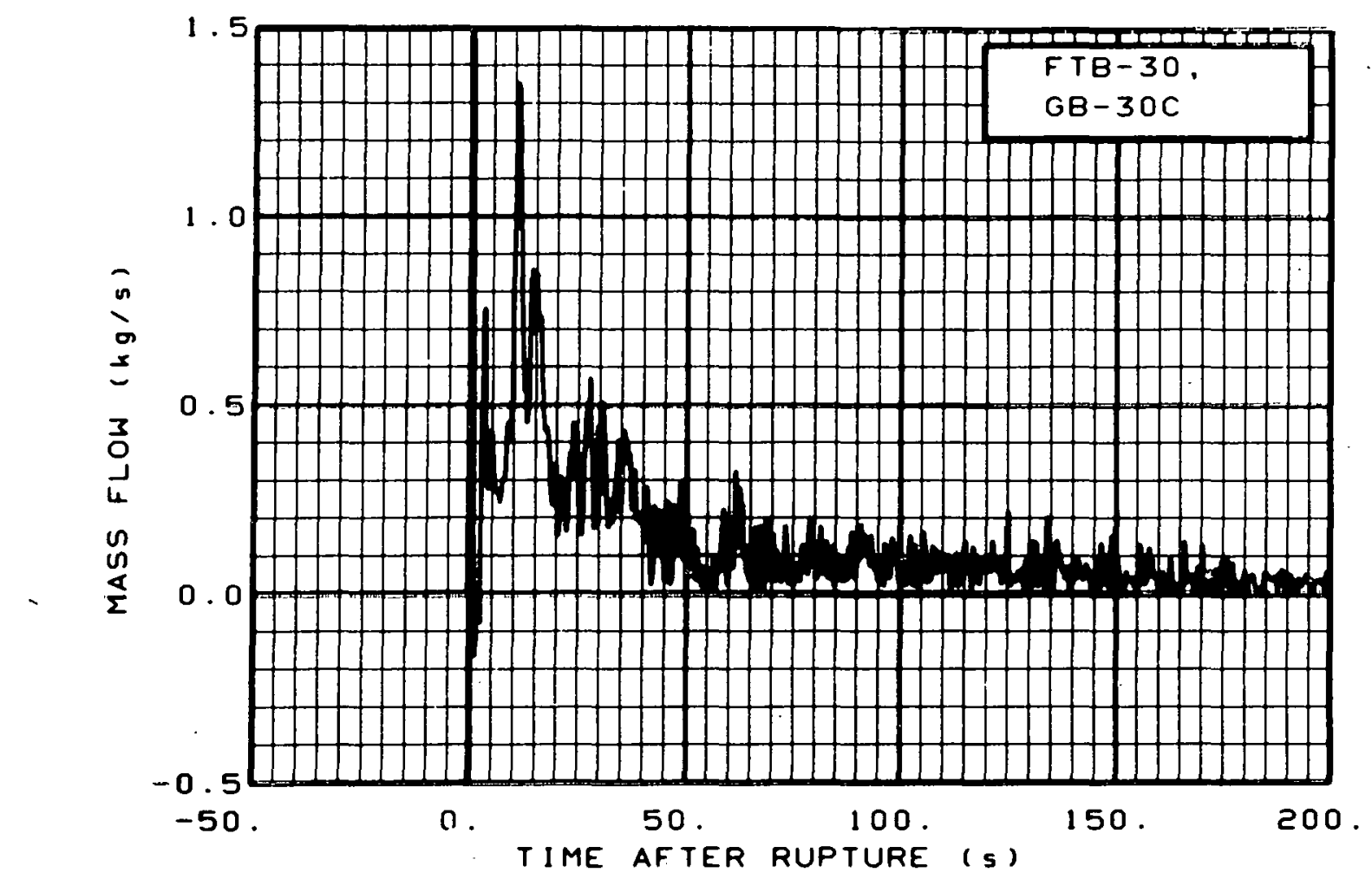

Fig. 323 Mass flow in broken loop (FTB-30 and GB-30C), from -20 to $200 \mathrm{~s}$.

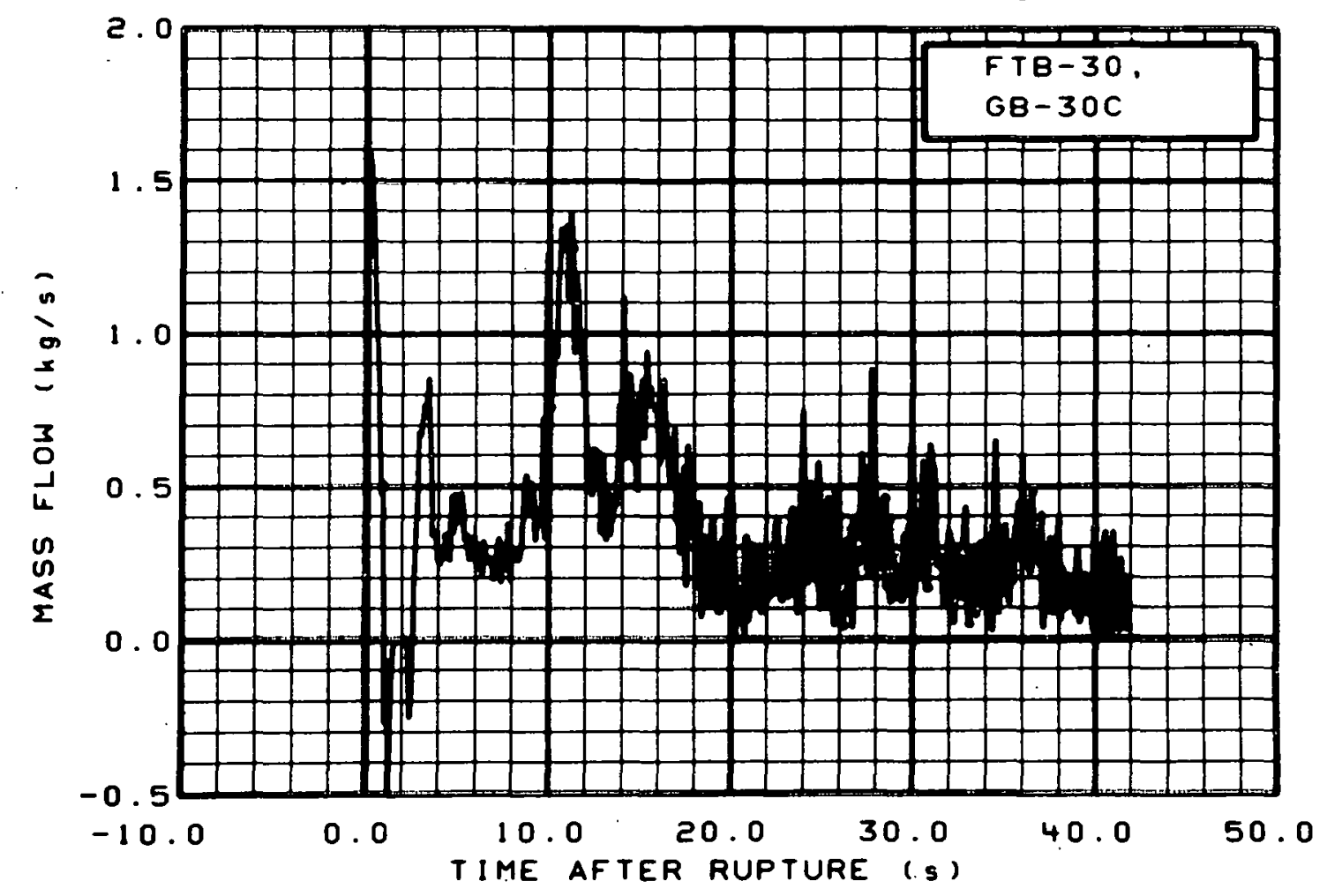

Fig. 324 Mass flow in broken loop (FTB-30 and GB-30C), from -6 to $42 \mathrm{~s}$. 


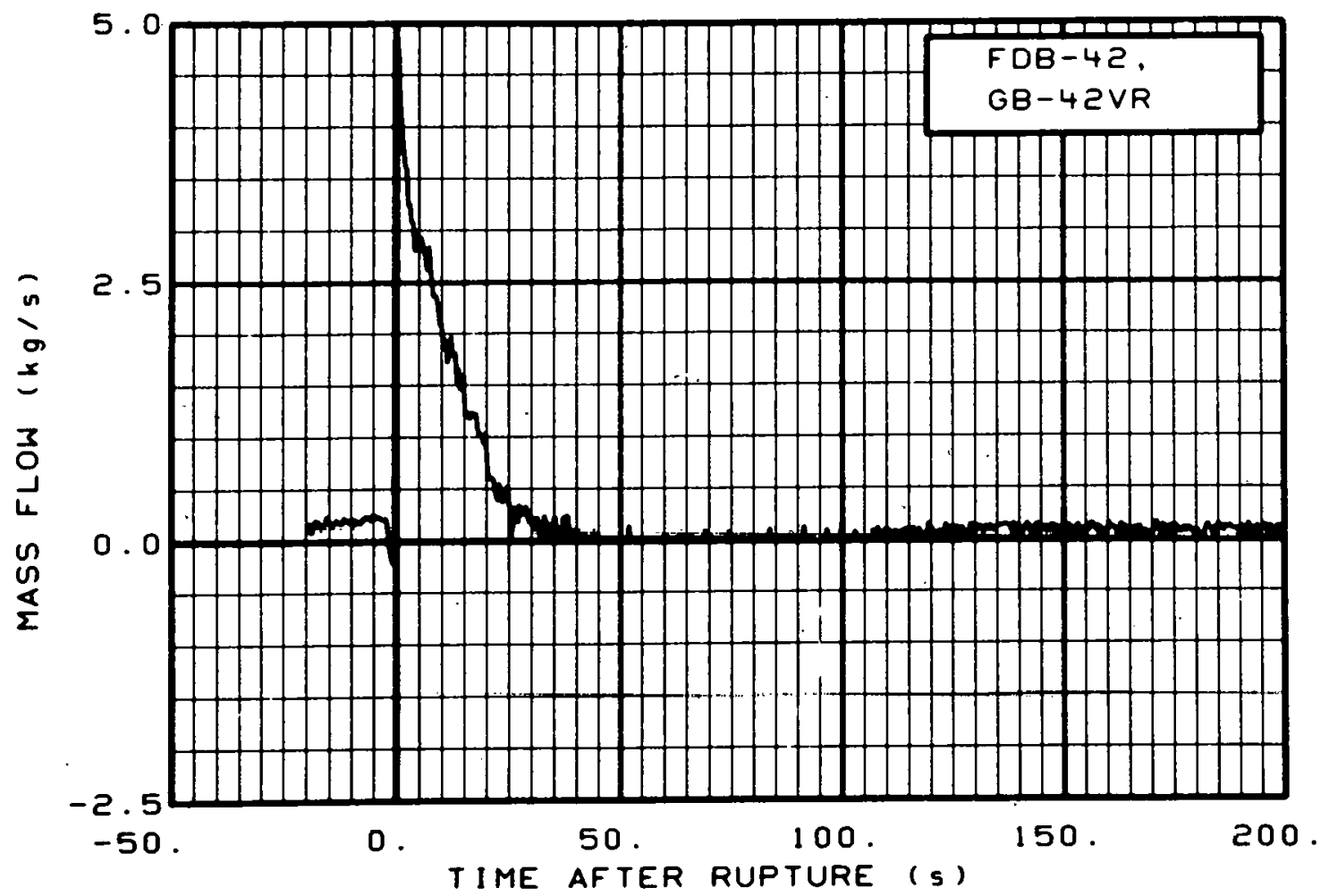

Fig. 325 Mass flow in broken loop (FDB-42 and GB-42VR), from -20 to $200 \mathrm{~s}$.

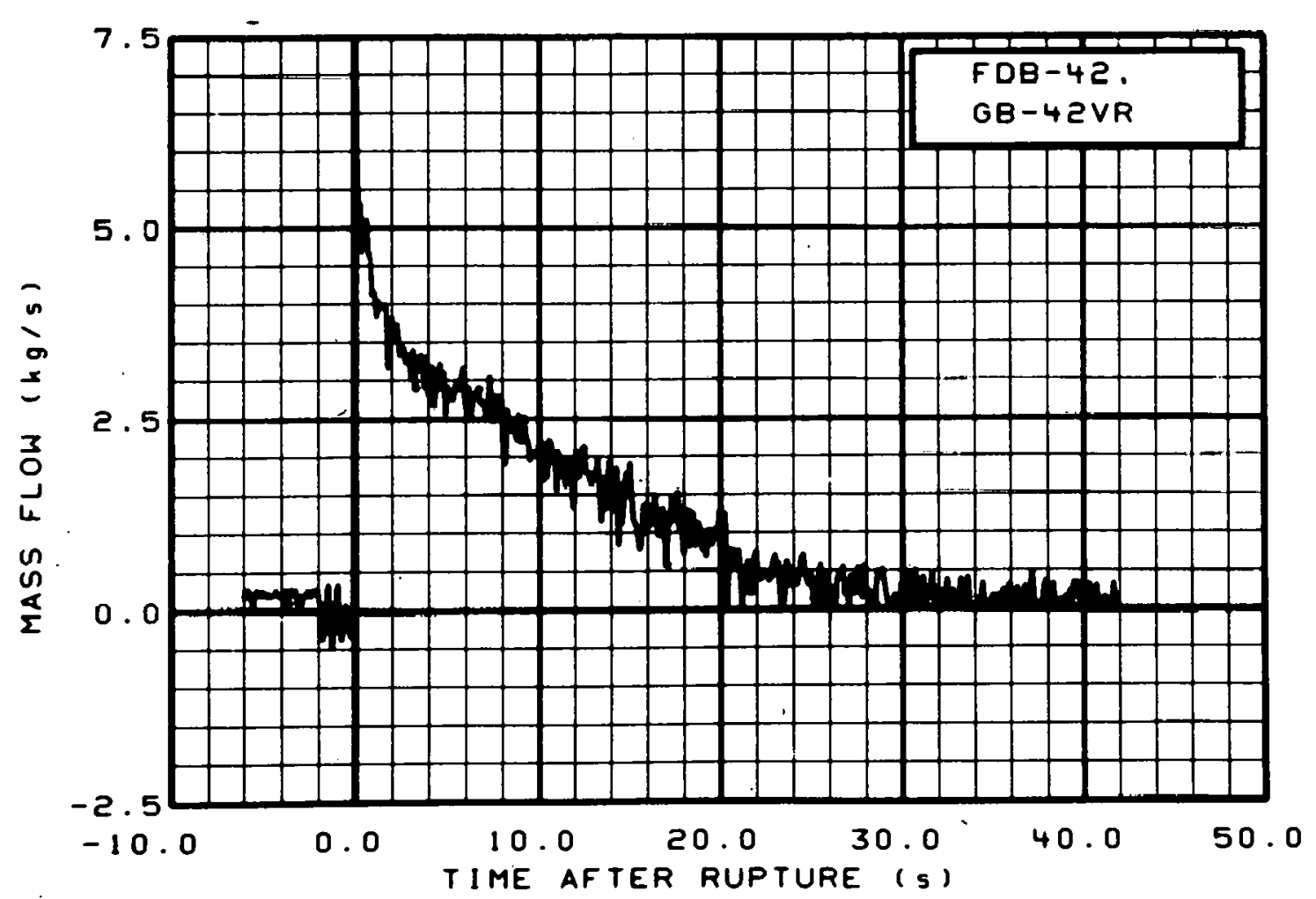

Fig. 326 Mass flow in broken loop (FDB-42 and GB-42VR), from -6 to $42 \mathrm{~s}$. 


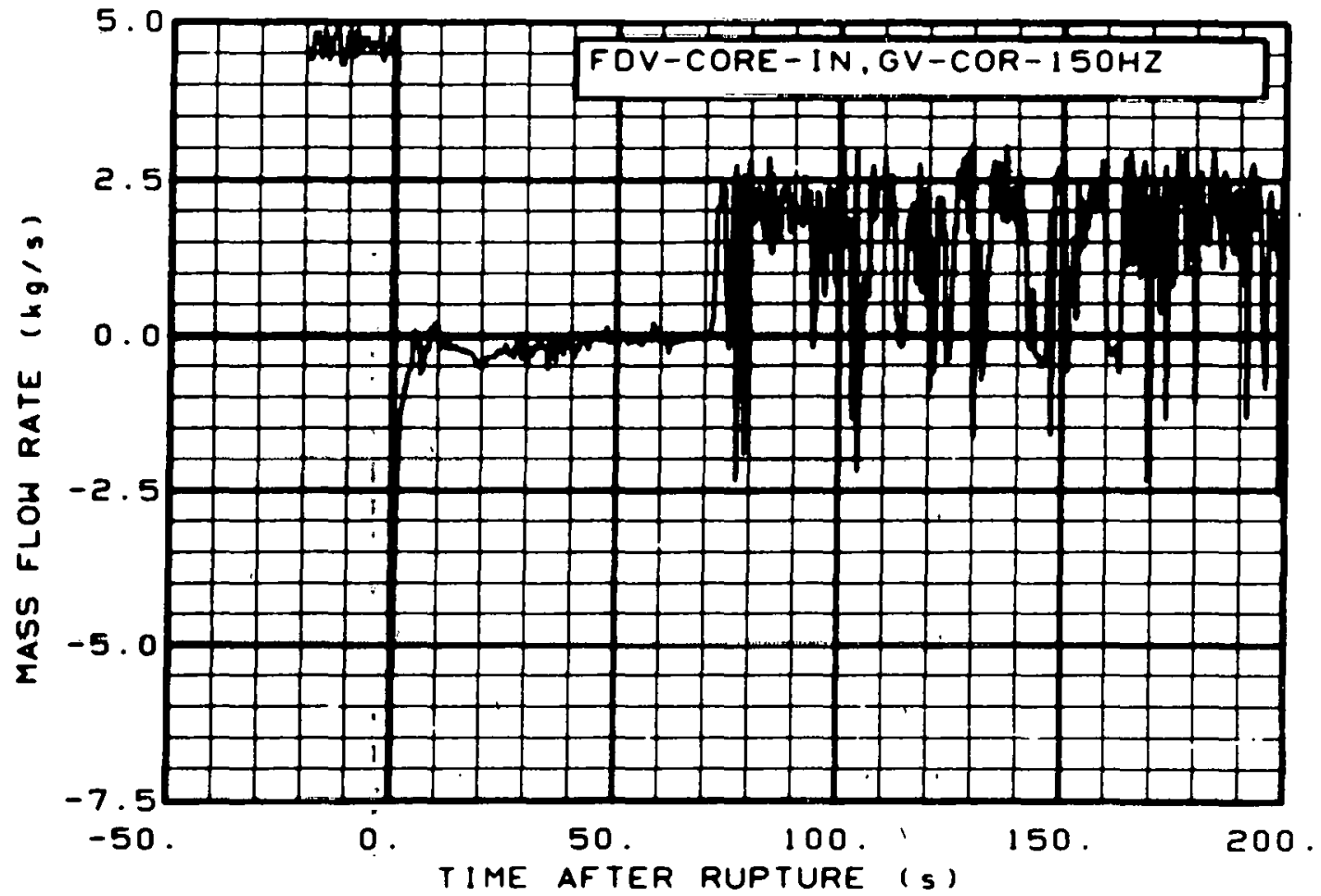

Fig. 327 Mass flow in vessel (FDV-CORE-IN and GV-COR-150HZ), from -20 to $200 \mathrm{~s}$.

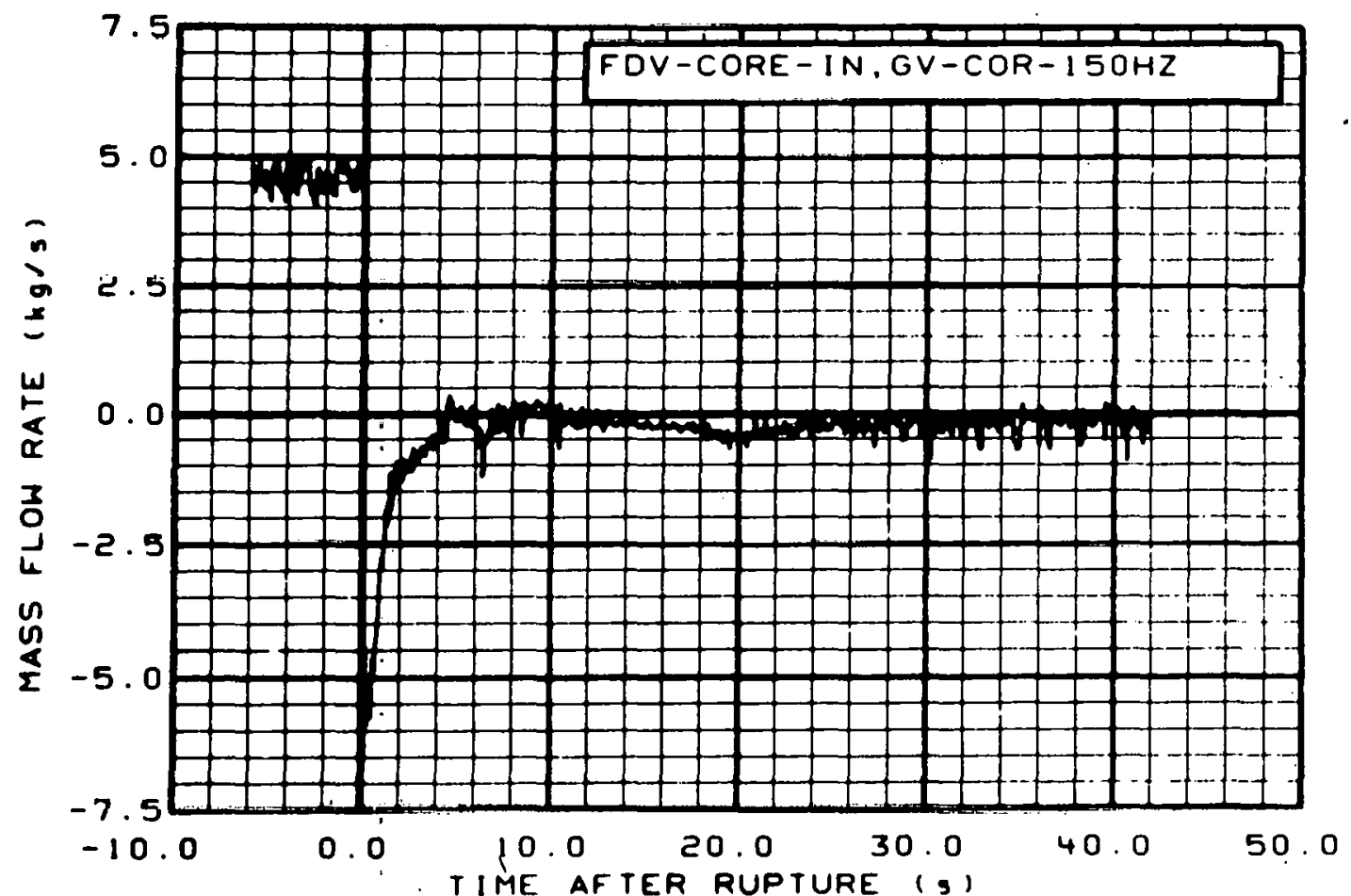

Fig. 328 Mass flow in ,vessel (FDV-CORE-IN and GV-COR-150HZ), from -6 to $42 \mathrm{~s}$. 


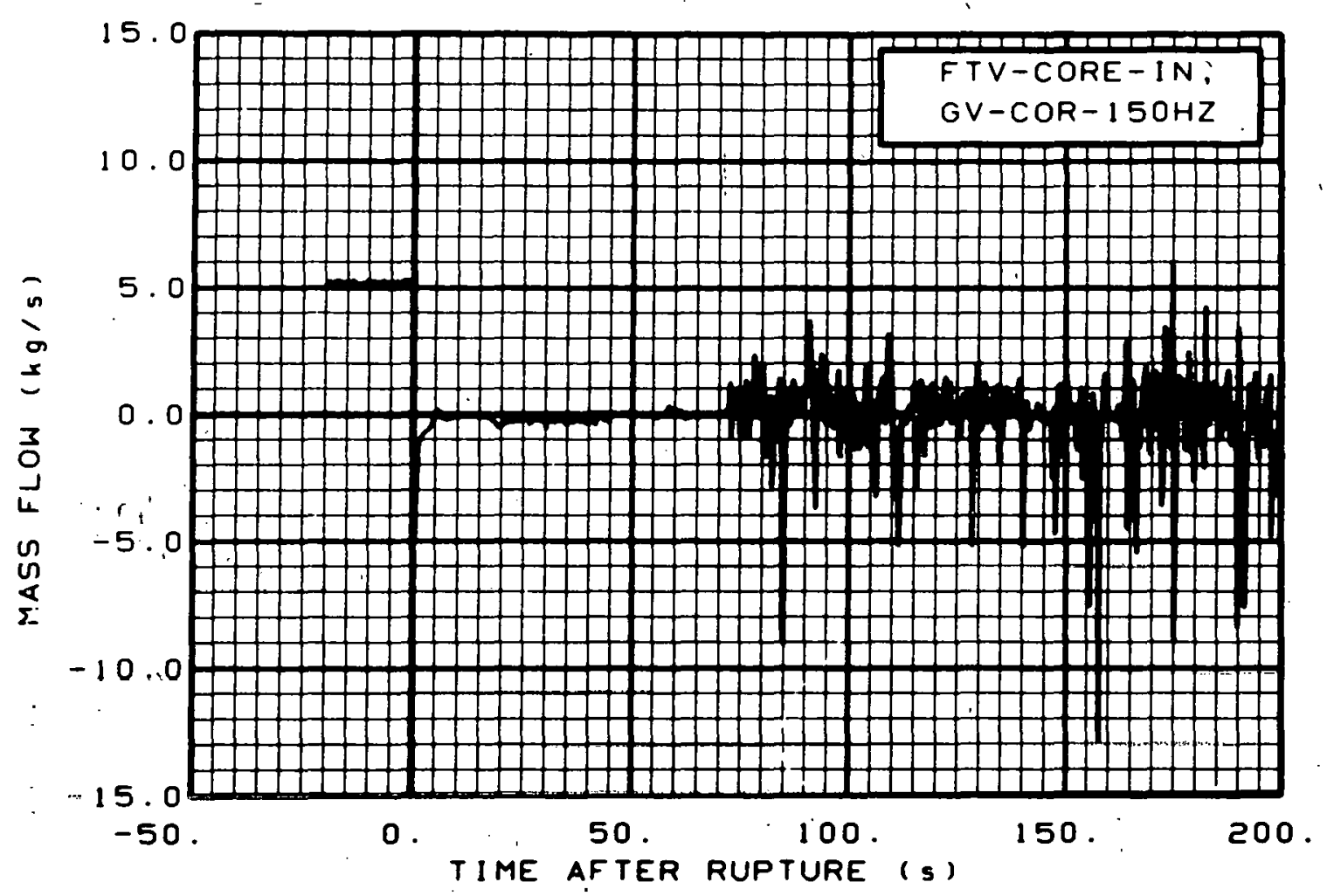

Fig: 329 Mass flow in vessel (FTV-CORE-IN and GV-COR-150HZ), from -20 to $200 \mathrm{~s}$.

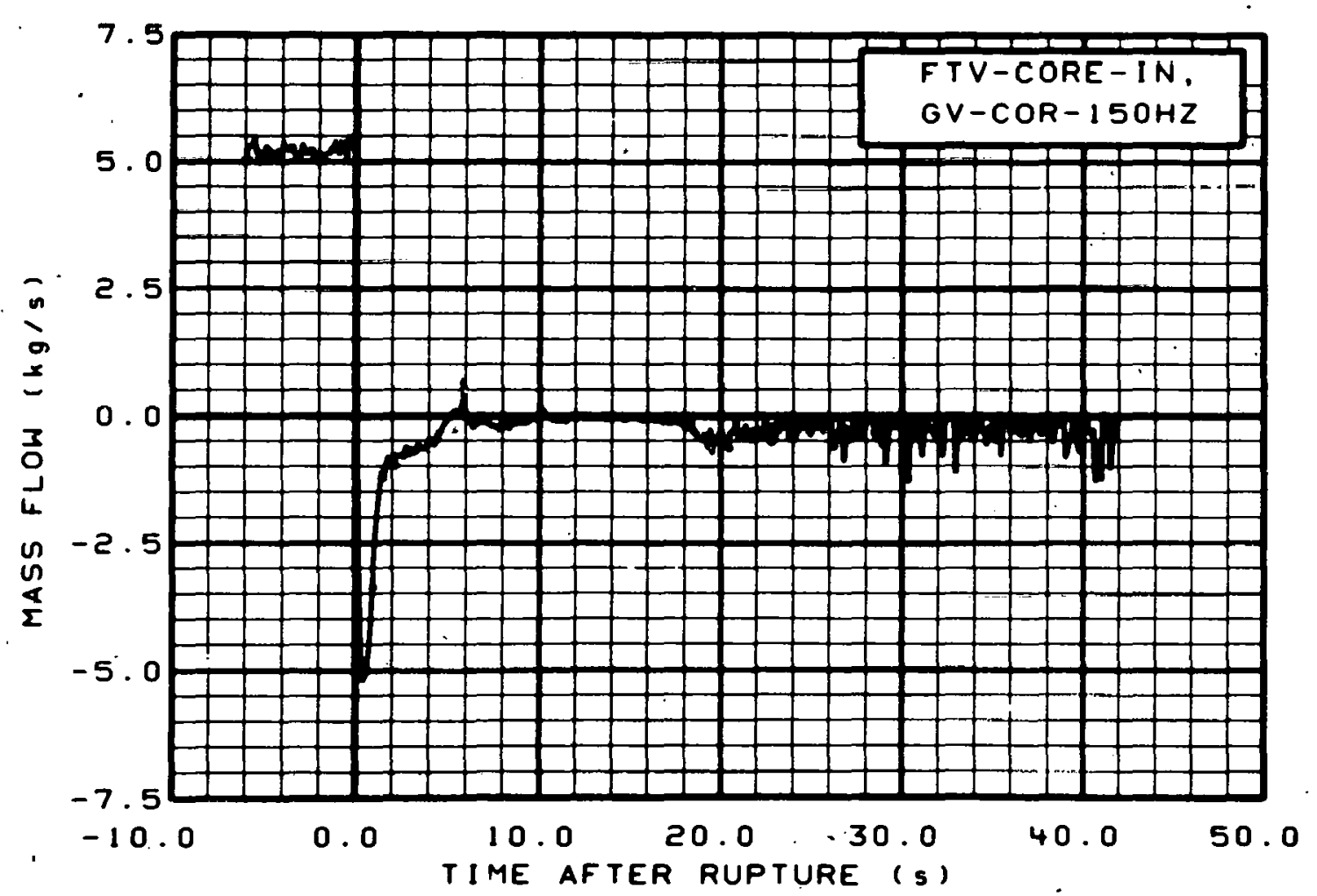

Fig. 330 Mass flow in vessel (FTV-CORE-IN and GV-COR-150HZ), from -6 to $42 \mathrm{~s}$. 


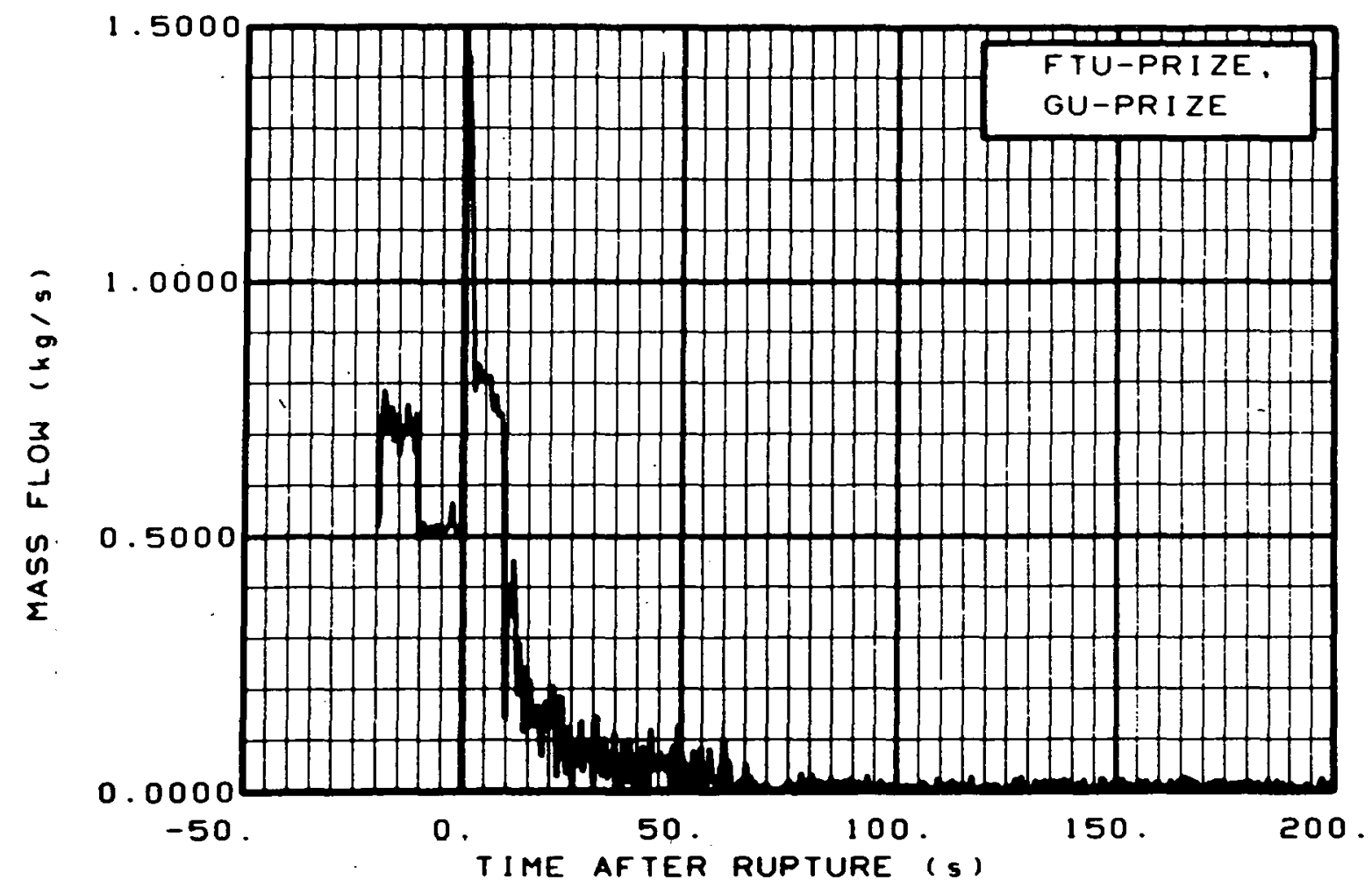

Fig: 331 Mass flow in pressurizer (FTU-PRIZE and GU-PRIZE), from -20 to $200 \mathrm{~s}$.

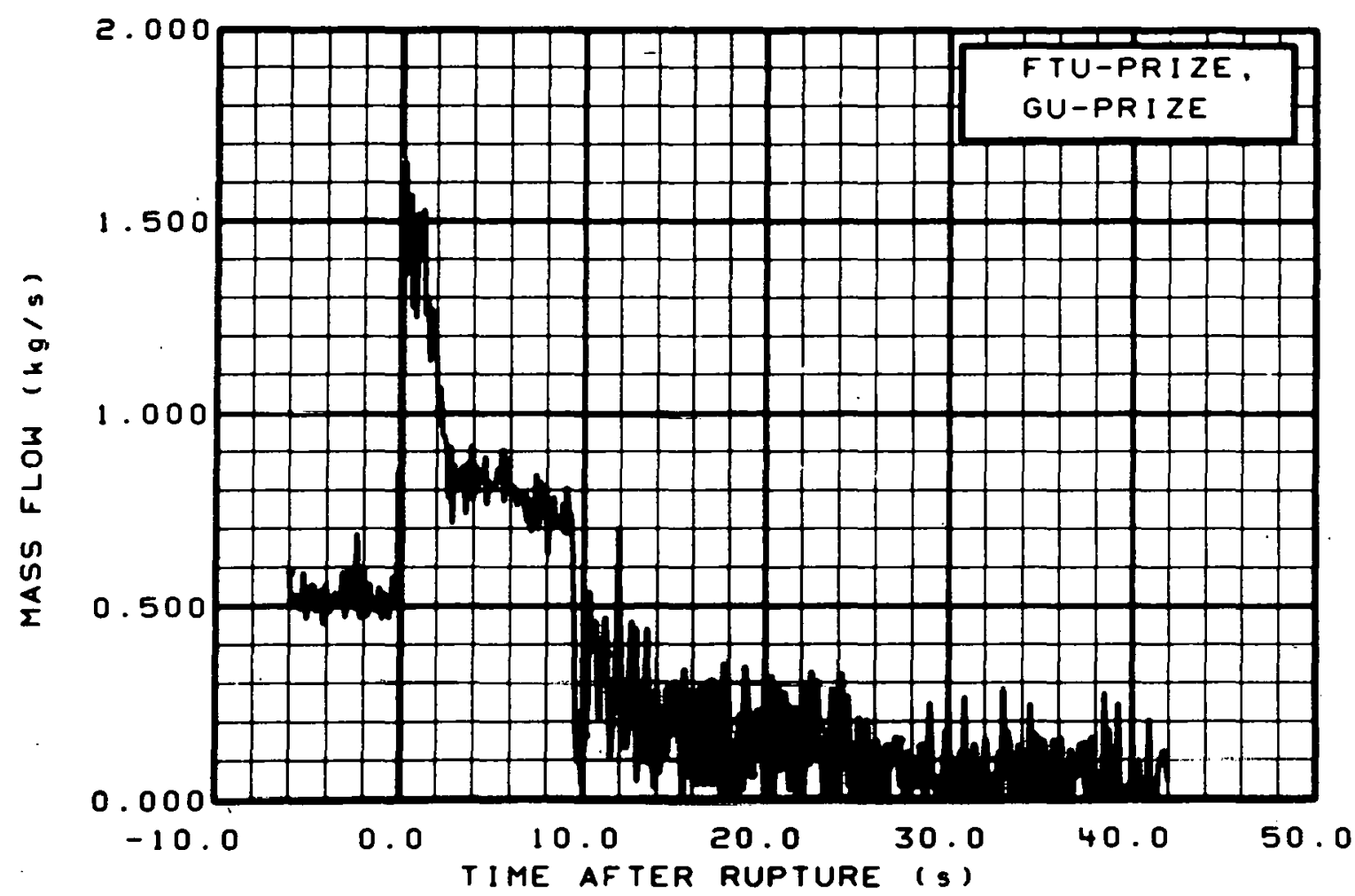

Fig. 332 Mass flow in pressurizer (FTU-PRIZE and GU-PRIZE), from -6 to $42 \mathrm{~s}$. 


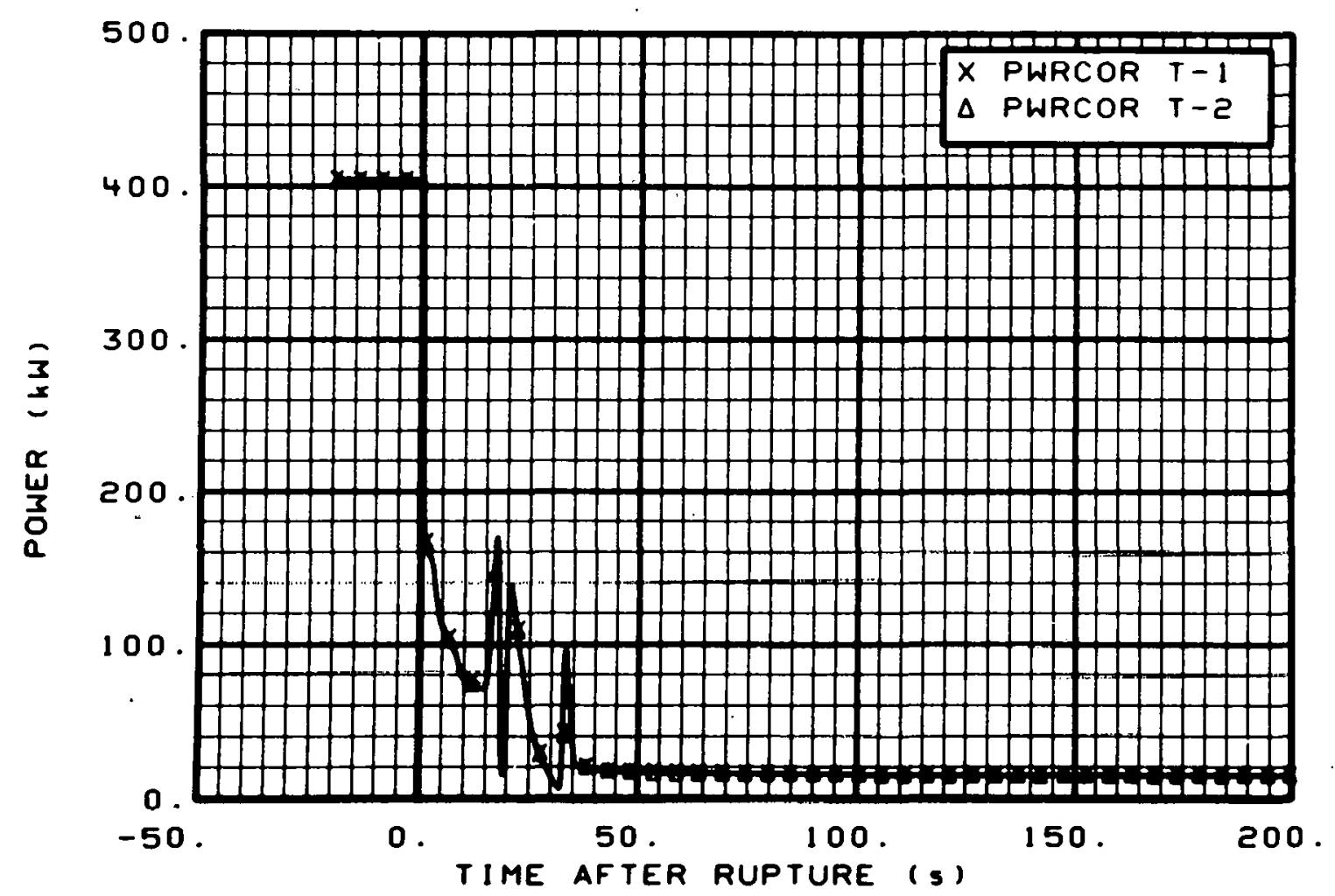

Fig. 333 Core heater rod total power (PWRCOR T-1 and PWRCOR T-2), from -20 to $200 \mathrm{~s}$.

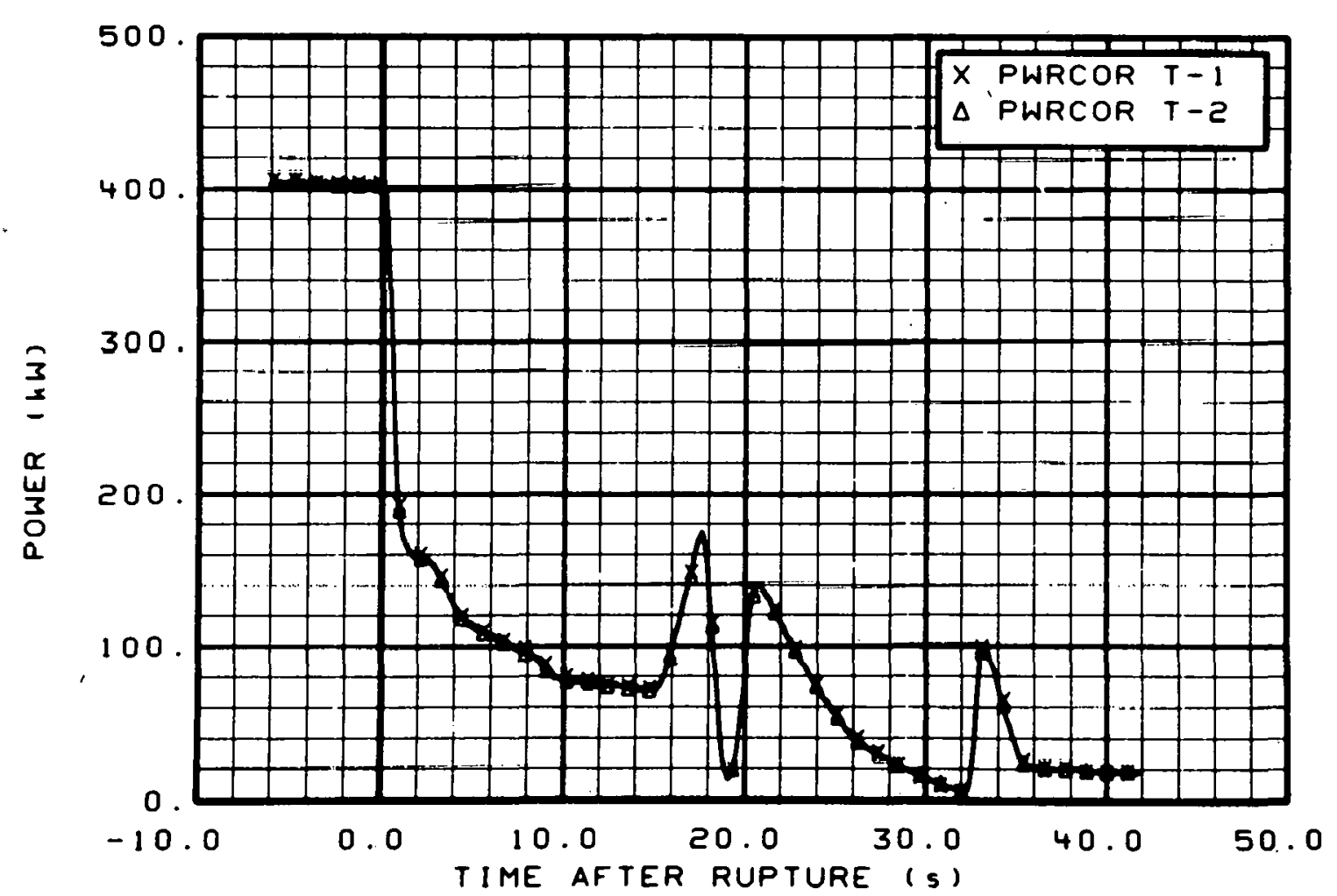

Fig. 334 Core heater rod total power (PWRCOR T-1 and PWRCOR T-2), from -6 to $42 \mathrm{~s}$. 


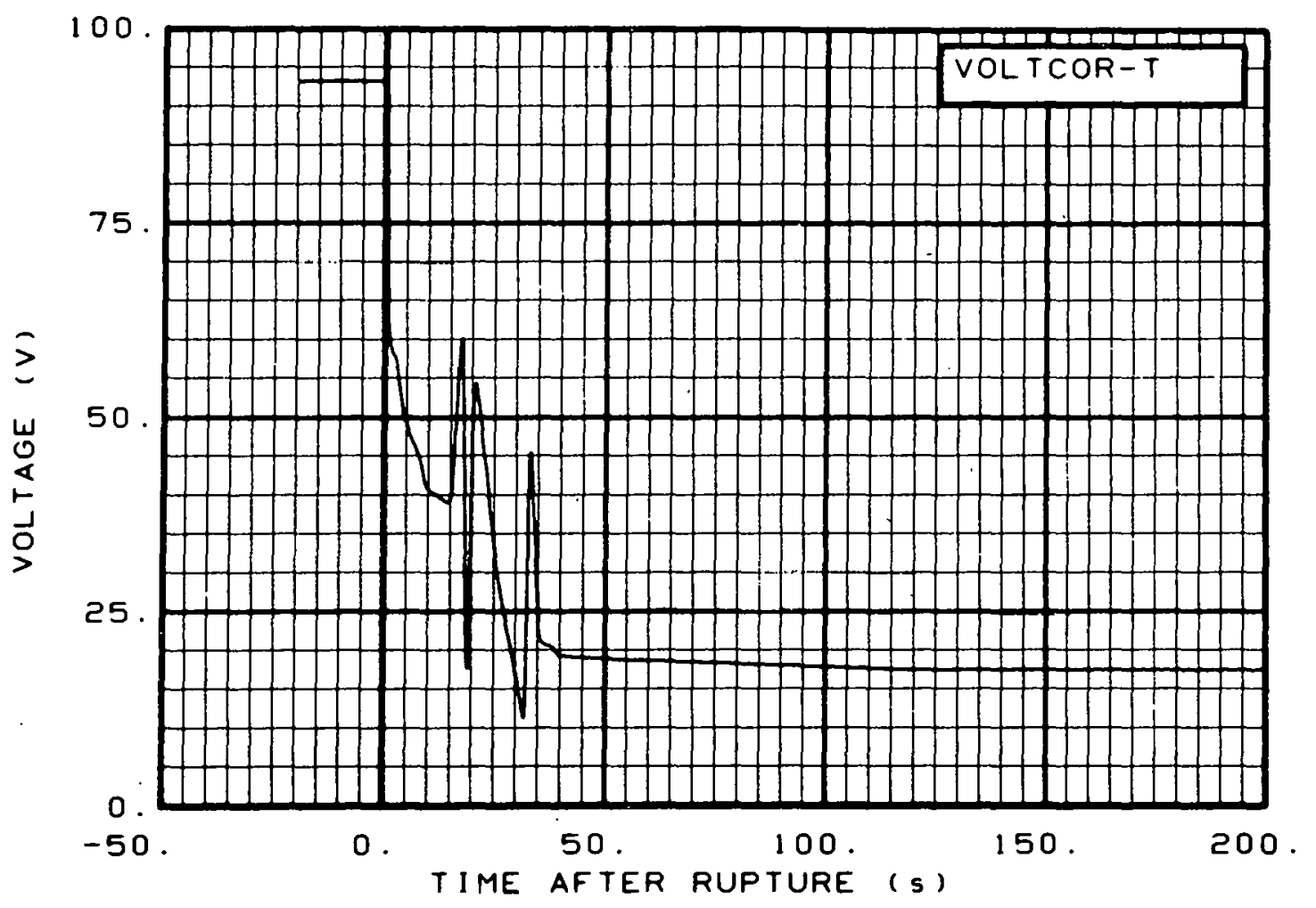

Fig. 335 Core heater voltage (VOLTCOR-T), from -20 to $200 \mathrm{~s}$.

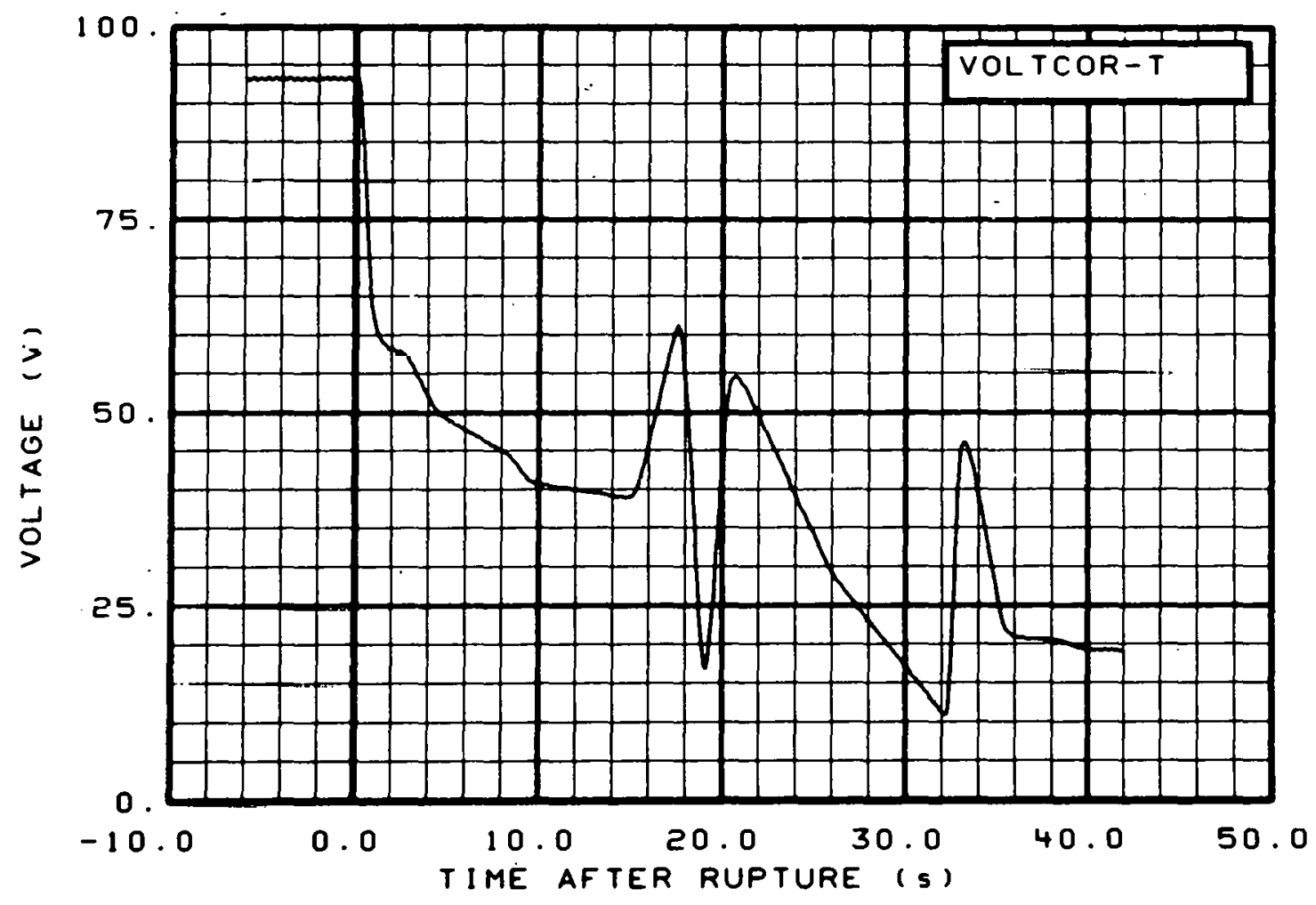

Fig. 336 Core heater voltage (VOLTCOR-T), from -6 to $42 \mathrm{~s}$. 


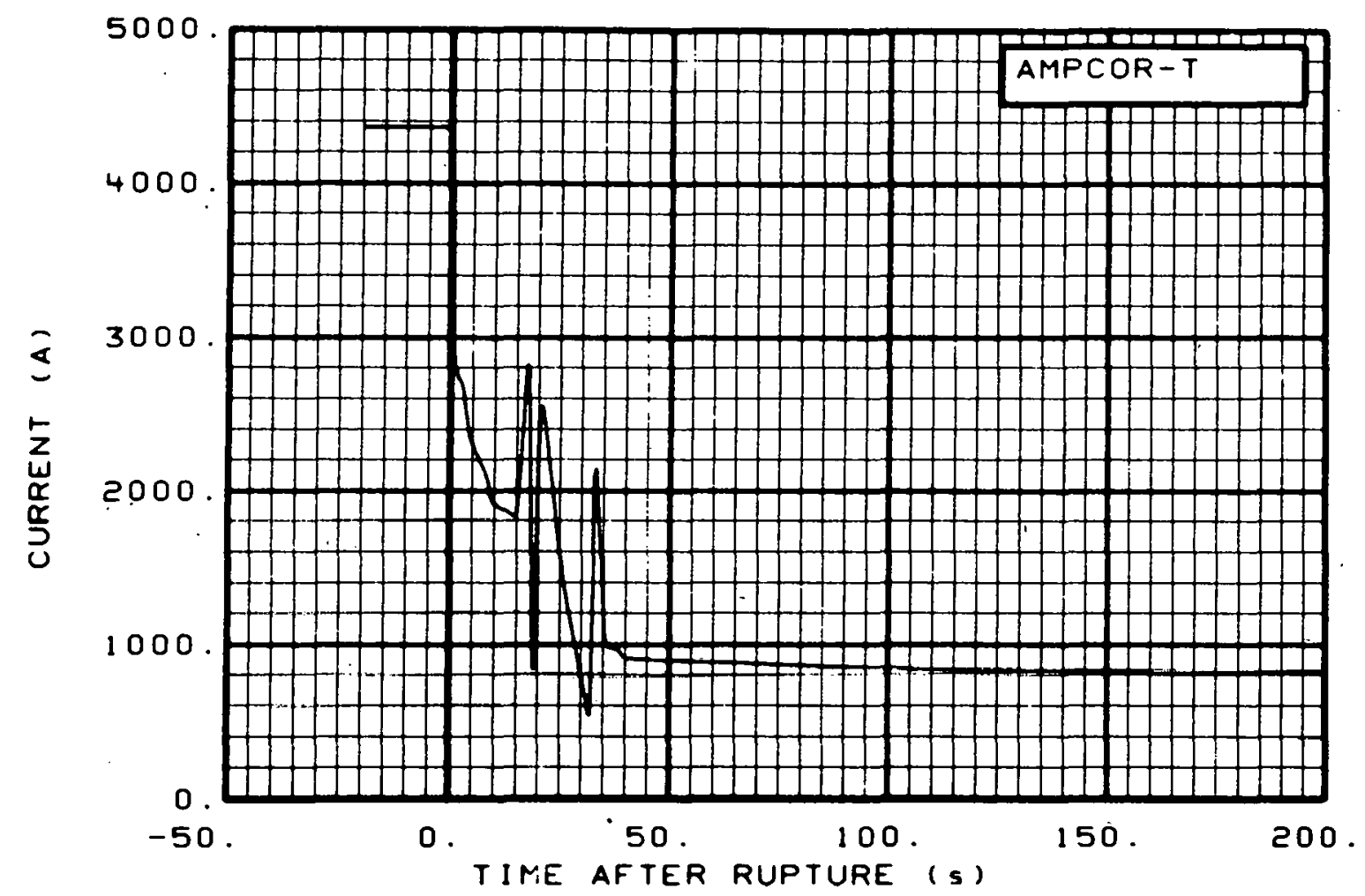

Fig. 337 Core heater total current (AMPCOR-T), from -20 to $200 \mathrm{~s}$.

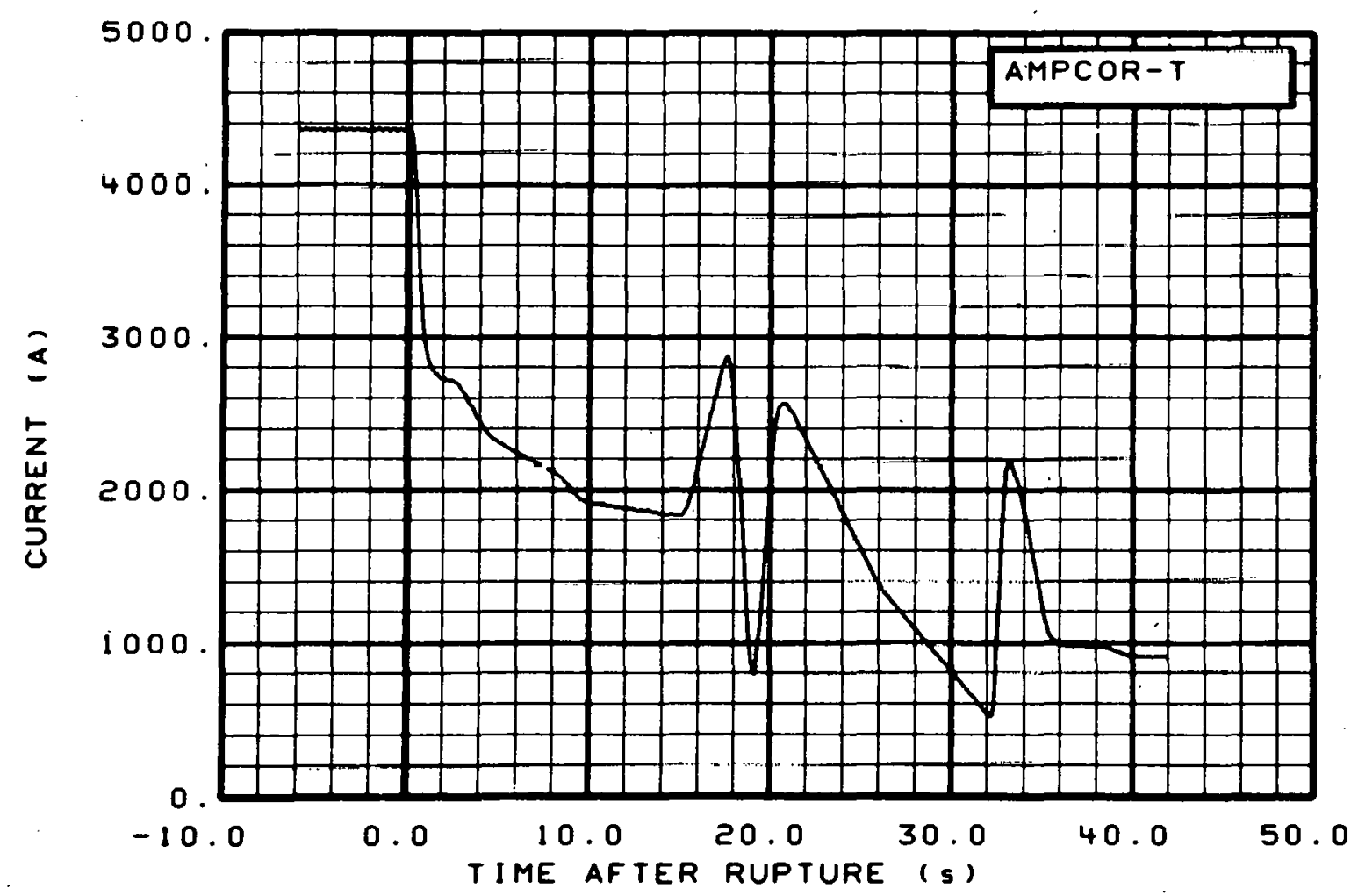

Fig. 338 Core heater total current (AMPCOR-T), from -6 to $42 \mathrm{~s}$. 


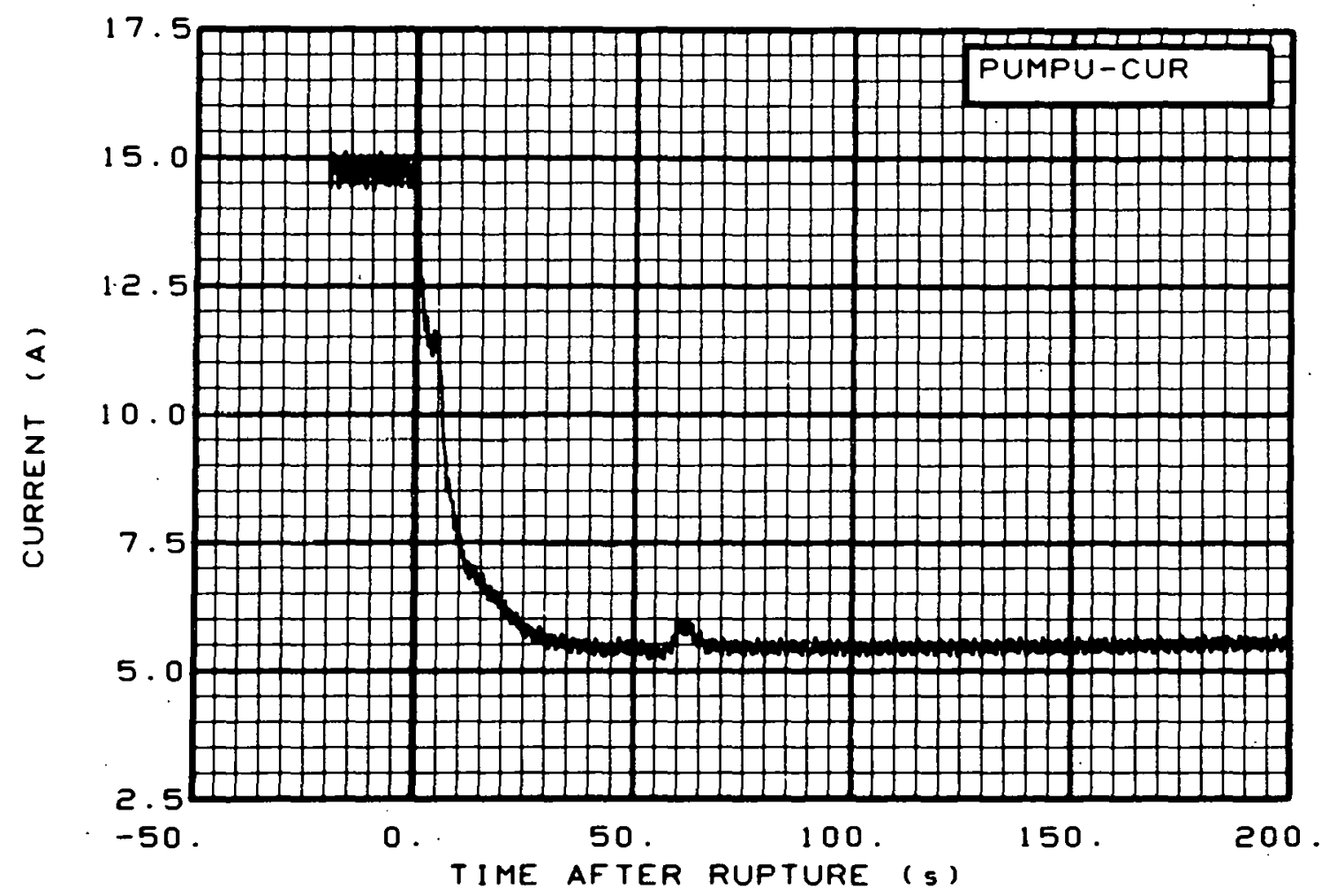

Fig. 339 Primary pump current (PUMPU-CUR), from -20 to $200 \mathrm{~s}$.

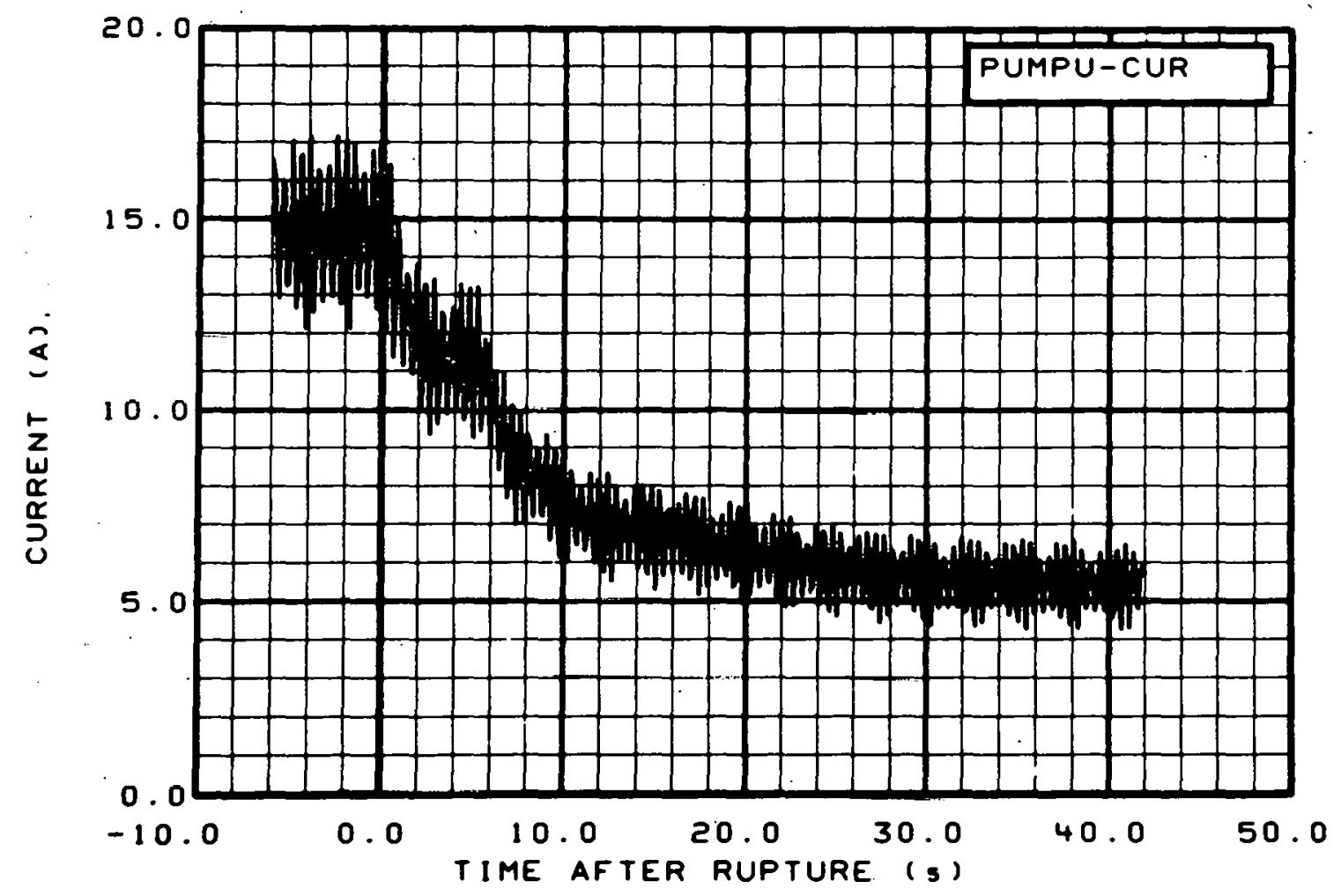

Fig. 340 Primary pump current (PUMPU-CUR), from -6 to $42 \mathrm{~s}$. 


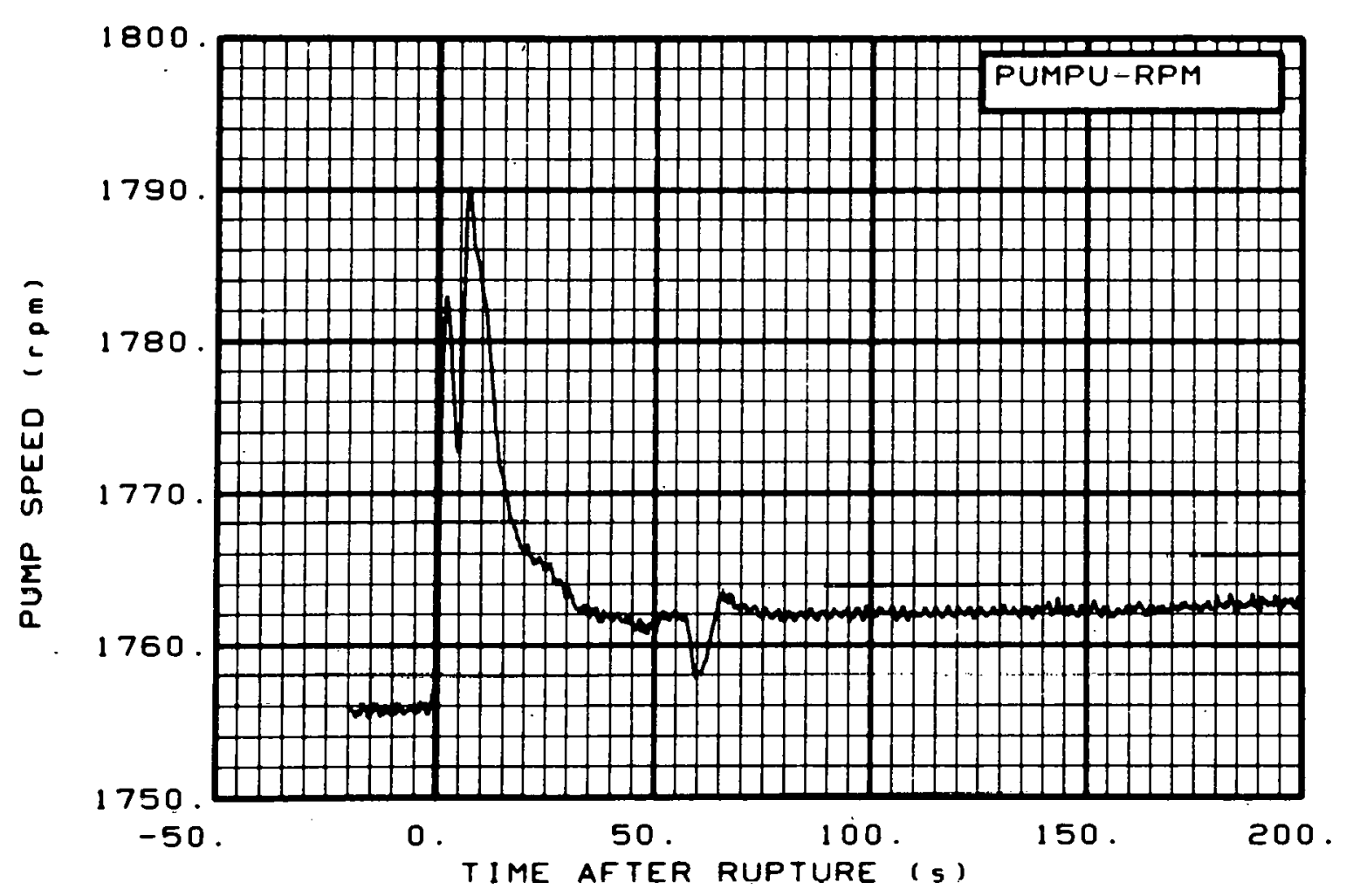

Fig. 341 Primary pump speed (PUMPU-RPM), from -20 to $200 \mathrm{~s}$.

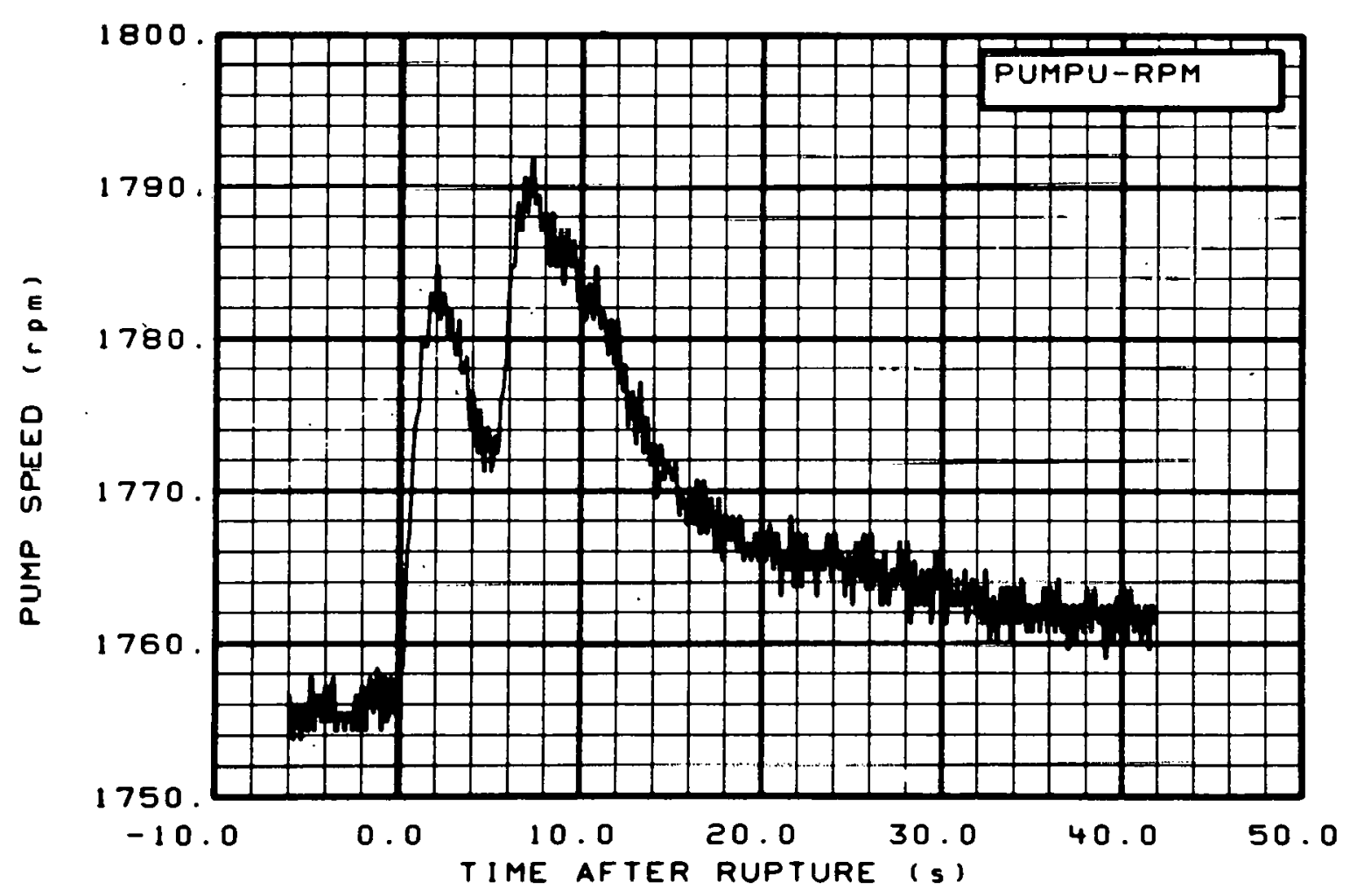

Fig. 342 Primary. pump speed (PUMPU-RPM), from -6 to $42 \mathrm{~s}$. 


\section{REFERENCES}

1. E. M. Feldman and D. J. Olson, Semiscale Mod-1 Program and System Description for the Blowdown Heat Transfer Tests (Test Series 2), ANCR-1230 (August 1975).

2. V. Esparza and K. E. Sackett, Experiment Data Report for Semiscale Mod-1 Test S-06-5 (LOFT Counterpart Test), TREE-NUREG-1 125 (June 1977). 
THIS PAGE

\section{WAS INTENTIONALLY LEFT BLANK}


APPENDIX A

POSTTEST ADJUSTMENTS TO DATA FROM SEMISCALE MOD-1 TEST S-06-1 
?

THIS PAGE

WAS INIIENTIONALLY

LEFT BLANK 


\section{APPENDIX A}

\section{POSTTEST ADJUSTMENTS TO DATA FROM SEMISCALE MOD-1 TEST S-06-1}

Many of the transducers used in the Semiscale Mod-1 system exhibit significant sensitivity to one or more spurious inputs. Strain gage bridge circuits used in pressure transducers, differential pressure transducers, and drag discs are sensitive to changes in ambient temperature. Differential pressure cells are also sensitive to changes in system pressure. Photomultiplier tubes used as gamma ray detectors in the density transducers are sensitive to temperature changes, as well as to random variations in the locations of the radiation sources. Core power measurements, depend on a calibrated resistor, whose resistance changes in value as a function of time and power level as it heates up.

Although the errors introduced into the data by spurious secondary inputs generally do not exceed the specified error ranges of the transducers, significant improvement in measurement accuracy can be achieved if the secondary sensitivity can be identified and removed. In the case of the drag discs, corrections are absolutely necessary because the signal due to temperature fluctuations can exceed that due to flow by several hundred percent. Since the exact values of the spurious inputs to which different transducers might be sensitive cannot often be easily predicted and are sometimes inconvenient to measure, secondary effects have been accounted for by correcting the data after the test rather than by using elaborate real time programs in the data acquisition system computer. The methods and results of the posttest data correction analysis for Test S-06-1 are presented in the following paragraphs and tables.

\section{PRESSURE MEASUREMENTS}

Corrections to pressure transducer measurements in the main system loop are based on data taken from the standard reference (Heise) gauge at Spool 4, taken $15 \mathrm{~s}$ before initiation of blowdown and at $300 \mathrm{~s}$ after initiation of blowdown. The pressure readings are adjusted to account for pressure variations around the main loop, using the readings of nearby differential pressure cells. A linear correction is then applied to the pressure data to match the data to the calculated reference data at the two specified time points.

Correction of the steam generator secondary pressure (PU-SGSD) and intact loop emergency core coolant (ECC) accumulator pressure (PU-ACC) measurements are done in the same manner as for the main loop pressures using Heise gauges installed expressly for this purpose. The data from the pressure transducer for the pressure suppression system (P-PSS) are corrected to match the process instrumentation at preblowdown conditions.

Pressure measurement corrections are performed using the data acquisition system (DAS) computer using the following equation: 


$$
F^{\prime}(t)=C_{0}+C_{1} \cdot[F(t)]
$$

where

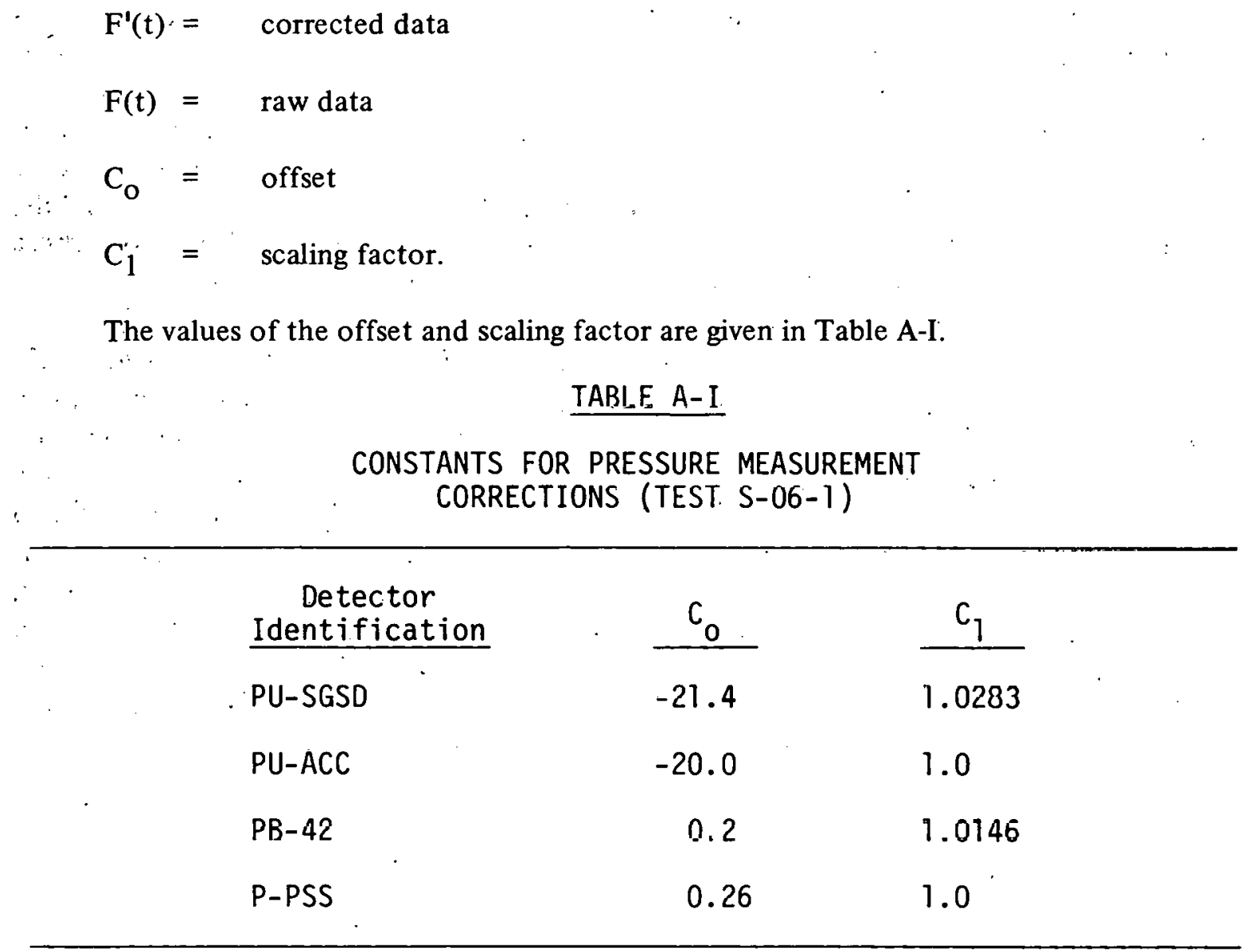

\section{DIFFERENTIAL PRESSURE MEASUREMENTS}

Pressure sensitivity in the differential pressure cells in the main system Inop is determined from the pretest system pressure check. Digital data are recorded for all measurements at ambient temperature, with no system flow, at pressures of ambient, 1380, $3450,6900,10350,13800$, and $15500 \mathrm{kPa}$. The output of the differential pressure cells is plotted against system pressure, with the resulting plots used to describe the pressure response of the transducers.

The response of the differential pressure cells due to ambient temperature is determined from a digital data scan taken at $533 \mathrm{~K}$ and $12150 \mathrm{kPa}$ with no system flow. 
The measured transducer outputs are corrected for pressure and compared with the values calculated due only to the density difference between the water inside the loop $(533 \mathrm{~K})$ and outside the loop in the sense lines ( 300 to $311 \mathrm{~K}$ ).

The difference between the measured pressure corrected value and the calculated value is the thermal drift. After the data scan at $533 \mathrm{~K}$ and $12150 \mathrm{kPa}$, with no system flow, the measured transducer outputs are corrected for pressure and compared with the values calculated due only to the density difference between the water inside the loop $(533 \mathrm{~K})$ and outside the loop in the sense lines (300 to $311 \mathrm{~K})$.

The difference between the measured pressure corrected value and the calculated value is the thermal drift. After the data scan at $533 \mathrm{~K}$ is made, no more opportunities exist to obtain data with the pump stopped and the system full of liquid; therefore, for lack of later data, the thermal drift calculated from the $533 \mathrm{~K}$ data is assumed to be constant throughout the test.

For some differential pressure measurements, the data scan at $533 \mathrm{~K}$ cannot be used as a reference for thermal drift, so other references are used. The reading from the steam generator discharge venturi (DPU-SG-DISC) is shifted to read zero after flow is stopped. For these detectors, and those having nonlinear pressure sensitivities, the corrections are performed according to the following equations:

$$
F^{\prime}(t)=K F(t)+c_{1} \text { for } t<t_{1} \text { or when no } t_{i} \text { are } 1 \text { isted }
$$

for time points $t$, where $t_{1} \leqslant t \leqslant t_{n}$

$$
F^{\prime}(t)=K F(t)+c_{i}+\frac{t-t_{i}}{t_{i+1}-t_{i}}\left(c_{i+1}-c_{i}\right) \text { for } t_{i} \leq t \leq t_{i+1}+1
$$

where $i$ takes on values 1 to $n-1$

$$
F^{\prime}(t)=K F(t)+C_{n}^{\cdot} \text { for } t>t_{n}
$$

where

$$
\begin{array}{lll}
\mathrm{t} & = & \text { time } \\
\mathrm{F}^{\prime}(\mathrm{t}) & = & \text { corrected data } \\
\mathrm{F}(\mathrm{t}) & = & \text { raw data } \\
\mathrm{K} & = & \text { scaling factor } \\
\mathrm{C}_{\mathrm{i}} \text { and } \mathrm{t}_{\mathrm{i}}= & \text { corrections and time points. }
\end{array}
$$


The values of the constants are given in Table A-II.

TABLE A-II

CONSTANTS FOR DIFFERENTIAL PRESSURE

MEASUREMENT CORRECTIONS (TEST S-06-1)

\begin{tabular}{|c|c|c|c|c|c|}
\hline$\cdot$ & $\begin{array}{c}\text { Detector } \\
\text { Identification } \\
\end{array}$ & $K$ & $c_{1}$ & $\cdot$. & . \\
\hline . & DPU-12-10 & 1.0 & 0.7 & & \\
\hline$\ldots$ & $D P B-23-24$ & 1.0 & 75.0 & & : \\
\hline & DPV-LP-UP & $1 . .0$ & -2.8669 & & $\cdot$ \\
\hline & DPU-SG-DISC & 1.0 & 0.022 & & \\
\hline & DP-PSS-TB & 1.0 & -0.12 & . & $\cdot$ \\
\hline
\end{tabular}

3. MOMENTUM FLUX MEASUREMENTS

The temperature sensitivity of drag discs is determined from pretest warmup data taken at 366 and $533 \mathrm{~K}$ with no system flow. The temperature sensitivity is removed before the data are converted to momentum flux. The temperature of each transducer is taken from the signal of a nearby fluid or metal temperature thermocouple. Slight corrections for errors in setting the transducer output to zero at ambient conditions are also made at this time. Corrections are made using the following equation:

$$
F^{\prime}(t)=F(t)+D_{0}-D_{1}[T(t)]
$$

where

$$
\begin{aligned}
& F^{\prime}(t)=\text { corrected data } \\
& F(t)=\text { raw data } \\
& T(t)=\quad \begin{array}{l}
\text { temperature data from the transducer used for tem- } \\
\text { perature correction sensitivity }
\end{array}
\end{aligned}
$$




$$
\begin{aligned}
& D_{0}=\text { ambient offset } \\
& D_{1}=\text { temperature sensitivity. }
\end{aligned}
$$

Values of the constants are given in Table A-III.

TABLE A-III

CONSTANTS FOR MOMENTUM FLUX

\begin{tabular}{|c|c|c|c|c|c|c|}
\hline \multicolumn{2}{|c|}{$\begin{array}{c}\text { Detector } \\
\text { Identification } \\
\end{array}$} & $D_{0}$ & $D_{1}$ & - & $T(t)^{[a]}$ & \\
\hline \multicolumn{2}{|c|}{ FDU-1 } & 0.200 & 0.000357 & & \multicolumn{2}{|c|}{ TMU-1T16 ... } \\
\hline \multicolumn{2}{|c|}{ FDU -5} & 0.030 & -0.000235 & & \multicolumn{2}{|l|}{ TMU-1T16 } \\
\hline \multicolumn{2}{|c|}{ FDU- 10} & 0.010 & 0.000195 & & \multicolumn{2}{|l|}{ TMU-1T16 } \\
\hline \multicolumn{2}{|c|}{ FDU- 13} & -0.090 & 0.000952 & & \multicolumn{2}{|l|}{ TMU-15T16 } \\
\hline \multicolumn{2}{|c|}{ FDU- 15} & 0 & -0.001348 & & \multicolumn{2}{|l|}{ TMU-15T16 } \\
\hline \multicolumn{2}{|c|}{ FDB-21 } & 0.210 & -0.000513 & & \multicolumn{2}{|l|}{ TMB-20B 16} \\
\hline \multicolumn{2}{|c|}{$F D B-30^{[b]}$} & -0.110 & -0.000908 & - & \multicolumn{2}{|l|}{ TFB -30} \\
\hline \multicolumn{2}{|c|}{$\mathrm{FDB}-37^{[\mathrm{b}]}$} & -0.330 & 0.000430 & . & \multicolumn{2}{|l|}{ TMB-37 } \\
\hline \multicolumn{2}{|c|}{ FDB -42} & 0.020 & -0.000781 & & \multicolumn{2}{|l|}{ TFB -42} \\
\hline \multicolumn{2}{|c|}{ FDV-CORE-IN } & -0.0014 & -0.000034 & & \multicolumn{2}{|c|}{ TFV-CORE-IN } \\
\hline \multicolumn{7}{|c|}{$\begin{array}{l}\text { [a] } T(t) \text { is the temperature data used for temperature sensitivity } \\
\text { correction. The symbols listed identify the thermocouples from } \\
\text { which the data are obtained. }\end{array}$} \\
\hline \multicolumn{7}{|c|}{$\begin{array}{l}\text { [b] Temperature sensitivity corrections were applied as usual; however, } \\
\text { since FDB-30 and FDB- } 37 \text { are mounted horizontally, during blowdown } \\
\text { they were partially filled with subcooled water which affected the } \\
\text { temperature sensitivity. Therefore, the temperature sensitivity } \\
\text { correction is more uncertain than that applied to other temperature } \\
\text { sensitivity corrections. }\end{array}$} \\
\hline
\end{tabular}

MEASUREMENT CORRECTIONS (TEST S-06-1) 


\section{DENSITY MEASUREMENTS}

Some of the density measurements exhibit significant temperature sensitivity due to inefficient or improper cooling of the densitometers. This thermal drift problem was corrected, prior to the density calculations, using the following equations:

$$
\begin{aligned}
& F^{\prime}(t)=F(t)+c_{1} \text { for } t<t_{1} \\
& F^{\prime}(t)=F(t)+\left[\left(c_{i}-c_{i-1}\right) /\left(t-t_{i-1}\right)\right]+c_{i-1} \text { for } t_{i-1}<t<t_{j} \\
& F^{\prime}(t)=F(t)+c_{n} \text { for } t>t_{n}
\end{aligned}
$$

where

$$
\begin{aligned}
& \therefore F^{\prime}(t):=\quad \text { corrected data } \\
& \mathrm{F}(\mathrm{t})^{-}=\text {raw data } \\
& \mathrm{C}=\text { correction } \\
& \mathrm{t}=\text { time } \\
& \mathrm{i} .=2,3,4, \ldots, \mathrm{n} \text {. }
\end{aligned}
$$

Values of $\mathrm{C}$ and $\mathrm{t}$ are given in Tablc A-IV.

Density calculations are based on the voltage output of the photomultiplier tubes in the gamma-attenuation densitometer assemblies. The equation used for converting voltage to density is as follows:

$$
\rho=(1 / C) \ln \{D /[A F(t)+B]\}
$$

where

$$
\begin{aligned}
& \rho=\text { the density in } \mathrm{kg} / \mathrm{m}^{3} \\
& \mathrm{C}=\text { a constant based on the length of the gamma beam path } \\
& \mathrm{D}=\text { a theoretical voltage for zero attenuation inside the vessel } \\
& \mathrm{A}=\text { an amplification factor }
\end{aligned}
$$


TABLE A-IV

CONSTANTS FOR DENSITY MEASUREMENT

CORRECTIONS (TEST S-06-1)

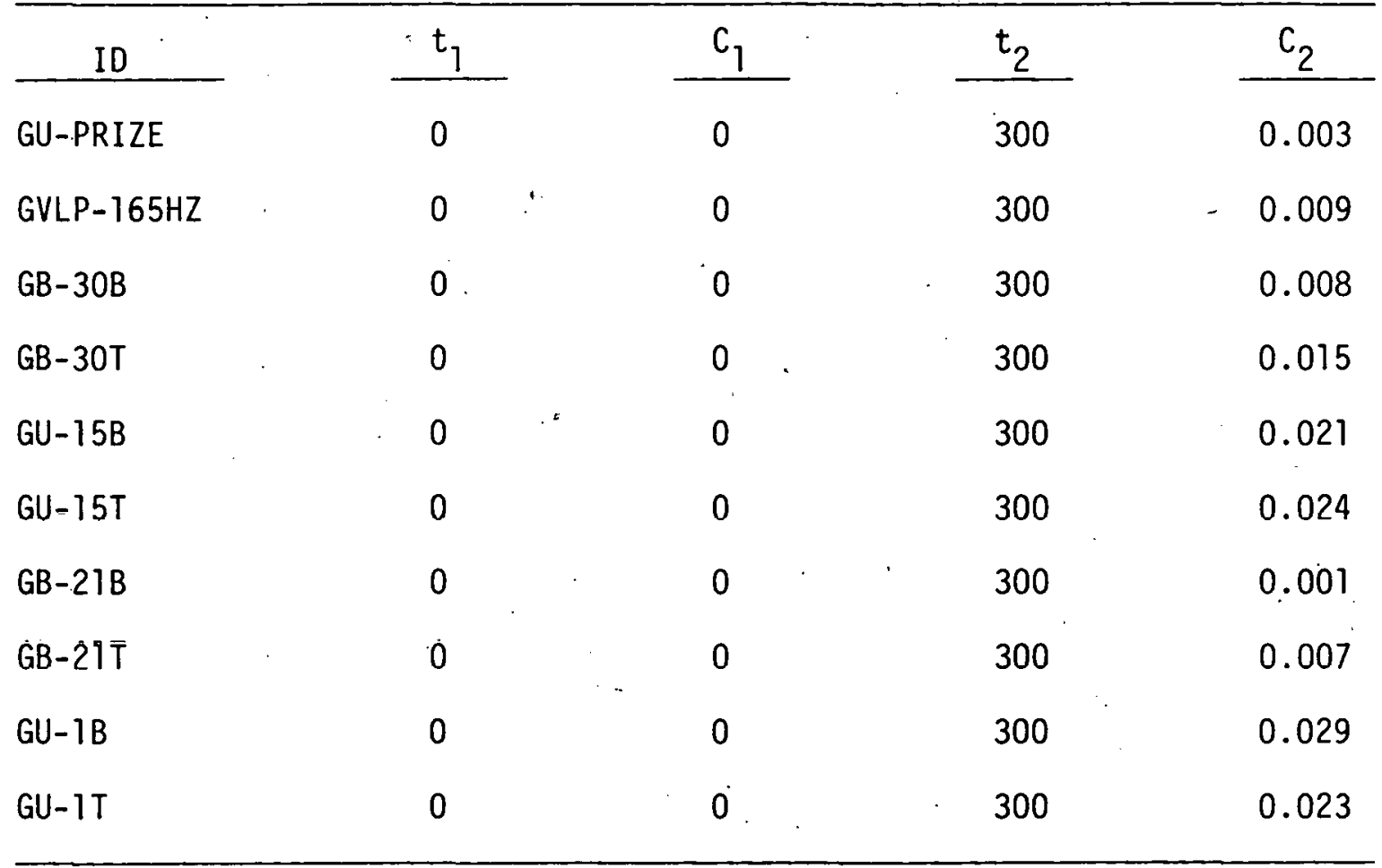

$\mathrm{B}=\mathrm{a}$ biasing factor

$F(t)=$ the transducer voltage output.

The density measurements GVLP-172HZ and GV-COR-15OHZ use amplifiers which precalculate the logarithm function, and hence have a simpler conversion formula:

$$
\begin{array}{ll}
\text { GVLP-172HZ } & \rho=-2.81 F(t)-180.50 \\
\text { GV-COR-150HZ } & \rho=-3.27 F(t)-139.90 .
\end{array}
$$

Some density measurements are obtained using a two-beam gamma densitometer which operates on the same basic principle of gamma attenuation as does the single-beam gamma densitometer. Each beam originates from the same gamma source and is allowed to pass through separate portions of the piping cross-sectional flow area to obtain an average density measurement in that particular region. The geometrical relationship of the gamma beam path through the piping and geometrically related variables used for processing of data from a two-beam gamma densitometer are slown in Figure A-1. 


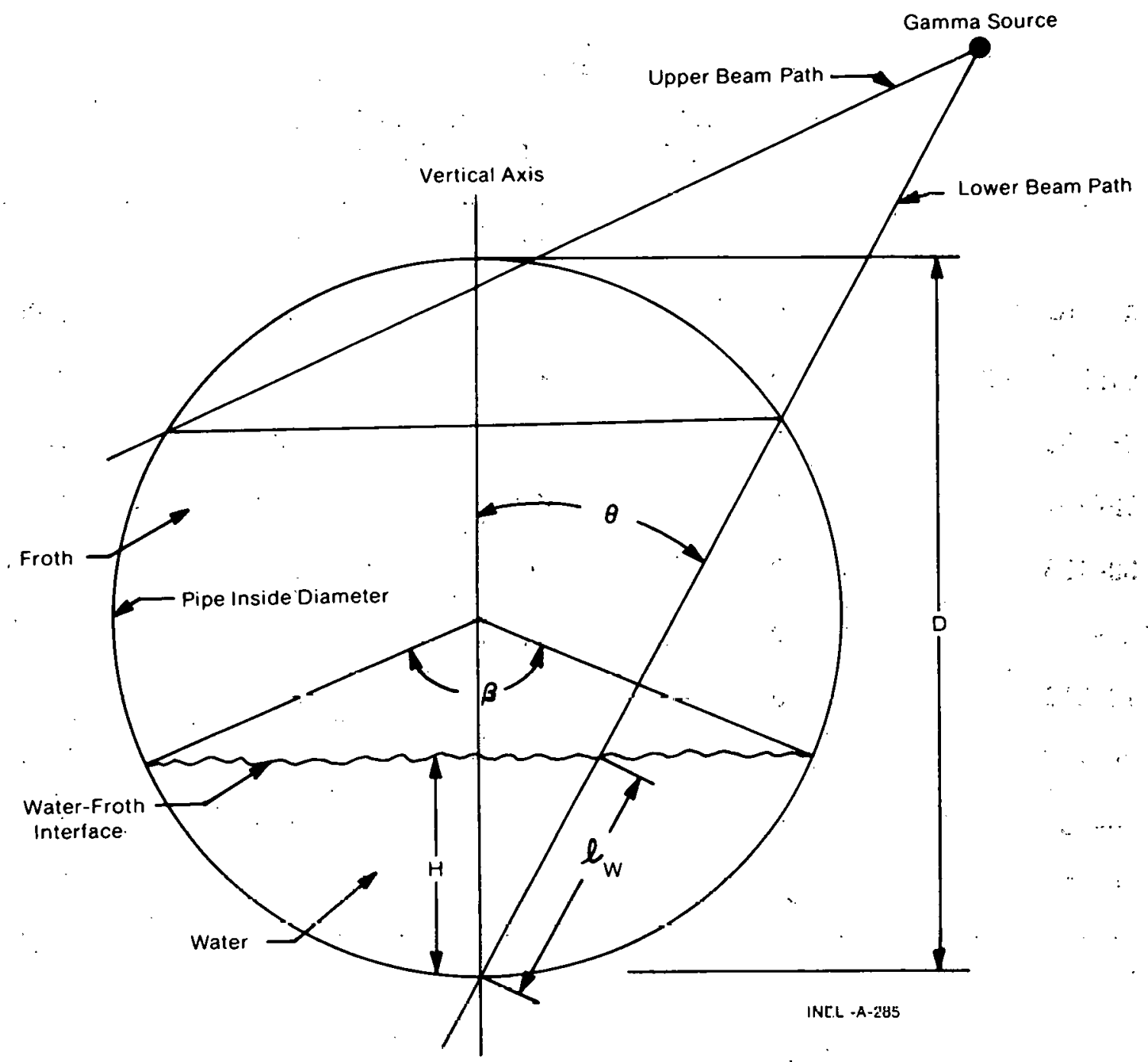

Fig. A-1 Geometry used for processing of density data obtained from two-beam gamma densitometers.

Constants A and B are adjusted to match the final data to density values calculated from measured pressure and temperature values at the preblowdown and postdrain conditions, effectively giving the data an in-place calibration. The values of the constants for various transducers are given in Table A-V.

The average density measured by each individual gamma beam is obtained using the same equation as is used for the single-beam gamma densitometers. Values for the constants for the single-beam density measurements obtained with the two-beam gamma: densitometers are presented in Table A-IV along with the constants for single-beam gamma densitometers. 
TABLE A-V

CONSTANTS FOR DENSITY MEASUREMENT

CONVERSIONS TO ENGINEERING UNITS (TEST S-06-1)

\begin{tabular}{|c|c|c|c|c|}
\hline $\begin{array}{c}\text { Detector } \\
\text { Identification } \\
\end{array}$ & A & B & c. & $n$ \\
\hline GV $-162 / 192 D$ & 0.973 & 0.099 & 0.0541 & 6.52 \\
\hline GV-42VR & 0.887 & 1.019 & 0.0004 & 7.10 \\
\hline GU-5VR & 1.129 & -0.516 & 0.0006 & 5.53 \\
\hline GU-10VR & 1.101 & -0.471 & 0.0006 & 6.95 \\
\hline GU-13VR & 1.223 & -0.528 & 0.0006 & 2.89 \\
\hline GB-23VK & $1 . .0 \dot{y} 3$ & -0.477 & 0.0004 & 8.77 \\
\hline GU-PRIZE & 1.121 & -0.076 & 0.0006 & 0.869 \\
\hline GVLP- $165 \mathrm{HZ}$ & 1.017 & -0.028 & 0.0015 & 7.93 \\
\hline$G B-21-B$ & 1.091 & -0.457 & 0.0005 & 8.23 \\
\hline$G B-21-T$ & 1.071 & -0.223 & 0.0004 & 6.94 \\
\hline$G B-30-B$ & 1.003 & 0.234 & 0.0005 & 8.05 \\
\hline$G B-30-T$ & 1.166 & -0.834 & 0.0004 & 6.83 \\
\hline GU-1-B & 1.042 & -0.055 & 0.0005 & 6.76 \\
\hline GU-1-T & 1.063 & -0.147 & 0.0004 & 6.29 \\
\hline$G U-15-B$ & 1.062 & -0.144 & 0.0005 & 5.49 \\
\hline GU-15-T & 1.221 & -0.926 & 0.0004 & 5.28 \\
\hline
\end{tabular}

In the Semiscale Mod-1 system, two-beam gamma densitometers provide added information which allows the calculation of a better average density than that obtained from a single beam. A mathematical model is used for processing the two-beam data to obtain the improved average density information. The processing method used is based on a froth-water model coupled with information from the two individual gamma beams and related beam path and piping cross-sectional geometry. The resulting information is recorded and reported under the density measurement identification ending with a " $\mathrm{C}$ ", for example, GB-21C. 
The use of the froth-water model for obtaining average density from a two-beam gamma densitometer is based on observations indicating that flow regimes in the Semiscale Mod-1 system can be modeled by a layer of water on the bottom of the pipe with a degree of froth on the surface. For homogeneous flow conditions such as all froth or all liquid the model remains valid. At any point in time slug flow is also modeled. The froth-water model does not model annular or inverted annular flows very well. However, these flows are not expected to exist for significant portions of a Semiscale Mod-1 system blowdown in horizontal piping. Density gradients from the top to the bottom of the pipe may exist showing no distinct location change from water to froth. This flow is neither totally homogeneous nor stratified, but the froth-water model does provide an adequate approximation of the average density characteristic of this flow pattern.

The average density obtained by using the gamma beam geometry shown in Figure A-1 and by applying the froth-water model is given by

$$
\bar{\rho}=\alpha_{f} \rho_{1}+\left(1-\alpha_{f}\right) \rho_{w} \mathrm{~kg} / \mathrm{m}^{3}
$$

where :

$$
\begin{aligned}
& \bar{\rho}=\text { average cross-sectional density } \\
& \rho_{1}=\begin{array}{l}
\text { average density measured by the upper gamma beam } \\
\text { (measures the froth density) }
\end{array} \\
& \rho_{\mathrm{w}}=\text { density of liquid water (at local system conditions) } \\
& \alpha_{\mathrm{f}}=1+(1 / 2 \pi)(\sin \beta-\beta)=\text { froth fraction. }
\end{aligned}
$$

The angle which $\beta$ represents is shown in Figure A-1. Values for $\beta$ are obtained as follows:

$$
B=2 \cos ^{-1} \cdot(1-2 h)
$$

where

$$
\mathrm{h}=\frac{\mathrm{H}}{\mathrm{D}}=\cos ^{2} \theta \frac{\rho_{2}-\rho_{1}}{\rho_{\mathrm{w}}-\rho_{1}}
$$

where

$$
\begin{aligned}
& \mathrm{H}=\ell_{\mathrm{w}} \cos \theta\left(\ell_{\mathrm{w}} \text { and } \dot{\theta} \text { are defined in Figure A-1 }\right) \\
& \mathrm{D}=\text { piping inside diameter } \\
& \rho_{2}=\text { the average density measured by the lower gamma beam. }
\end{aligned}
$$


Average density is not calculated using the two-beam froth-water model when the angle $\theta$ is not favorable due to system hardware restrictions in positioning the source. The froth-water model requires separate density sampling in both the upper and lower portions of the piping cross section.

\section{VOLUMETRIC FLOW MEASUREMENTS}

An error in instrumentation set-up caused the data obtained from the turbine flowmeter in Spool 9 (FTU-9) to read low. These data were corrected using the same formula as was used for the pressure measurements (Section 1), where $C_{O}=0$ and $\mathrm{C}_{1}=1.369$.

\section{CORE POWER MEASUREMENTS}

Corrections to core power readings are determined from the core voltage and core current readings, with a slight adjustment for the power lost in setting the core radial peaking factor. The adjustments are as follows:

$$
\text { PWRCOR T-2: } F^{\prime}(t)=0.9988 F(t)+2.74=\text { (voltage) (current) }(0.991) \text {. }
$$

where

$$
\begin{aligned}
& F^{\prime}(t)=\text { core power in kilowatts } \\
& F(t)=\text { the raw core power reading. }
\end{aligned}
$$


THIS PAGE

\section{WAS INTENTIONALLY \\ LEFT BLANK}


APPENDIX B

SELECTED DATA 'WITH ESTIMATED TOTAL ERROR

BANDS FROM SEMISCALE MOD-1 TEST S-06-1 
THIS PAGE

\section{WAS INTENTIONALLY LEFT BLANK}




\section{APPENDIX B \\ SELECTED DATA WITH ESTIMATED TOTAL ERROR BANDS FROM SEMISCALE MOD-1 TEST S-06-1}

Analysis has been performed on selected data from Test S-06-1 to provide a guide to the uncertainty associated with data measurements in the Semiscale Mod-1 system. The end result of the analysis is presented as error bands about the measured data which represent a $95 \%$ confidence level.

The error bands are obtained by combining uncertainties obtained from analysis of the data itself (random error) and engineering analysis of the measurement system (engineering error). The procedure by which error bands were established for the data presented in this appendix is described in the following paragraphs.

The data trace under analysis was empirically fitted with a linear difference equation, which was subject to a white noise input at each sampling time point. The objective of the empirical fitting procedure was to characterize the white noise, which was taken to represent the random error. The procedures for fitting the difference equation are discussed in depth in Reference B-1. A data trace was often segmented and different equations were fitted to each segment with statistical correlations between successive observations accounted for by the fitting procedure. The white noise input was assumed to arise from a normally distributed population. The standard deviation of the white noise, as found during the fitting procedures, was taken as an estimate of the random error standard deviation and is shown in Table B-I.

Other errors in the data exist because of such factors as variability in installation procedures and techniques, calibration errors, variability in materials, and temperature and pressure sensitivities. These errors and the procedures for estimating them are discussed in Reference B-2. They are referred to as engineering errors and the estimates are largely subjective. Because of the continuing effort to improve the accuracy of the measured data, such as through the use of better transducers, better signal conditioning and processing equipment, and better calibration and installation techniques, the engineering errors for data from most of the transducer systems have changed from those published in Reference B- 2 . Table B-II provides a summary of engineering error values obtained from current analysis techniques as applied to the data presented herein.

In addition to the normal hardware and installation related sources of engineering error, a significant measurement uncertainty results when the current transducer systems are subjected to separated two-phase flow regimes during the course of the blowdown transient. Accordingly, for those data affected (fluid density, momentum flux, volumetric flow, and mass flow), which are presented in this appendix, a more extensive assessment was conducted for additional engineering error due to flow regime effects. Table B-III identifies the data analyzed and the period in the blowdown process for which flow regime errors 


\section{TABLE B-I}

RANDOM ERROR VARIANCE

\begin{tabular}{|c|c|c|c|c|}
\hline Measurement & $\begin{array}{c}\text { Random Error } \\
\text { Varjance } \\
\sigma_{R}\end{array}$ & $\begin{array}{l}\text { Period of } \\
\text { Appitication } \\
\text { (s) }\end{array}$ & Figure & Comments \\
\hline TFU-PRIZE & $\begin{array}{l}2.46 \\
C .08\end{array}$ & $\begin{array}{r}0 \text { to } 62.4 \\
62.4 \text { to } 200\end{array}$ & $B-1$ & \\
\hline TFU-SGI & $\begin{array}{l}0.12 \\
0.02\end{array}$ & $\begin{aligned} .0 & \text { to } 56.5 \\
56.5 & \text { to } 200\end{aligned}$ & $B-2$ & . \\
\hline TFU-SG4 & $\begin{array}{l}0.04 \\
0.03\end{array}$ & $\begin{array}{r}0 \text { to } 21.7 \\
21.7 \text { to } 200\end{array}$ & $B-3$ & . \\
\hline TFB-23 & $\begin{array}{l}4.52 \\
1.83 \\
1.23\end{array}$ & $\begin{array}{l}0 \text { to } 60.6 \\
60.6 \text { to } 84.3 \\
84.3 \text { to } 200\end{array}$ & $B-4$ & 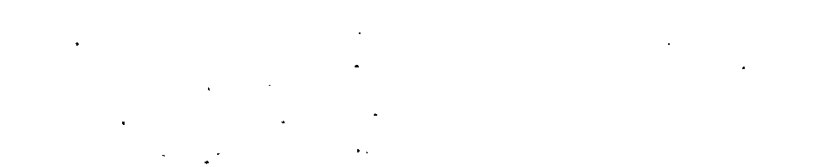 \\
\hline TFV-ANN-35A & $\begin{array}{l}4.67 \\
0.38\end{array}$ & $\begin{array}{ccc}0 & \text { to } & 69 \\
69 & \text { to } 200\end{array}$ & $B-5$ & $\begin{array}{l}\text { The error bands should be smaller than } \\
\text { what is represented from } 0 \text { to } 72 \text { s ex- } \\
\text { cept for periods when sharp transients } \\
\text { in the data occur[a]. }\end{array}$ \\
\hline TFV-ANN-35T & $\begin{array}{l}5.68 \\
.0 .37\end{array}$ & $\begin{array}{r}0 \text { to } 68 \\
68 \text { to } 200\end{array}$ & B-6. & $\begin{array}{l}\text { The error bands should be smalier than } \\
\text { what is represented from } 0 \text { to } 72 \text { s ex- } \\
\text { cept for periods when sharp transients } \\
\text { in the data occur[a]. }\end{array}$ \\
\hline$T F V-L P-8$ & $\begin{array}{l}0.87 \\
0.11\end{array}$ & $\begin{array}{r}0 \text { to } 70.4 \\
70.4 \text { to } 200\end{array}$ & $B-7$ & \\
\hline
\end{tabular}


TABLE B-I (continued)

\begin{tabular}{|c|c|c|c|c|}
\hline Measurement & $\begin{array}{c}\text { Random Error } \\
\text { Variance } \\
\sigma_{R}\end{array}$ & $\begin{array}{c}\text { Period of } \\
\text { Application } \\
\text { (s) }\end{array}$ & Figure & Comments \\
\hline TFV-LP-15 & $\begin{array}{l}1.14 \\
0.11\end{array}$ & $\begin{array}{r}0 \text { to } 70.4 \\
70.4 \text { to } 200\end{array}$ & B-8 & \\
\hline TFV-LP-22 & $\begin{array}{l}1.15 \\
0.09\end{array}$ & $\begin{aligned} 0 & \text { to } 70.4 \\
70.4 & \text { to } 200\end{aligned}$ & B-9 & \\
\hline TFG-6DE- 67 & $\begin{array}{l}2.55 \\
2.86 \\
0.33\end{array}$ & $\begin{array}{l}0 \text { to } 79.4 \\
79.4 \text { to } 140 \\
140 \text { to } 200\end{array}$ & $B-10$ & $\begin{array}{l}\text { The error bands should be smaller than } \\
\text { what is represented from } 113 \text { to } 143 \mathrm{~s} \\
\text { [b]. }\end{array}$ \\
\hline TMU-15T16 & $\begin{array}{l}0.16 \\
0.17 \\
0.21\end{array}$ & $\begin{aligned} & 0 \text { to } 62 \\
& 62 \text { to } 98.2 \\
& 98.2 \text { to } 200\end{aligned}$ & $B-11$ & . \\
\hline TMV-CI-35A & $\begin{array}{l}0.52 \\
0.96 \\
0.12 \\
0.13\end{array}$ & $\begin{aligned} 0 & \text { to } 53 \\
53 & \text { to } 90.6 \\
90.6 & \text { to } 135.1 \\
135.1 & \text { to } 200\end{aligned}$ & $\mathrm{~B}-12$ & : \\
\hline TH-E4-09 & $\begin{array}{l}0.85 \\
3.30 \\
0.13\end{array}$ & $\begin{aligned} 0 & \text { to } 35.6 \\
35.6 & \text { to } 86 \\
86 & \text { to } 200\end{aligned}$ & $B-13$. & $\begin{array}{l}\text { The error bands should be smaller than } \\
\text { what is represented from } 38 \text { to } 80 \text { s }[b]\end{array}$ \\
\hline TH-E4-27 & $\begin{array}{l}4.21 \\
0.25\end{array}$ & $\begin{array}{r}0 \text { to } 112 \\
112 \text { to } 200\end{array}$ & $B-14$ & $\cdot$ \\
\hline TH-E4-55 & $\begin{array}{l}1.69 \\
0.17\end{array}$ & $\begin{aligned} 0 & \text { to } 100.6 \\
100.6 & \text { to } 200\end{aligned}$ & $B-15$ & \\
\hline
\end{tabular}


TABLE B-I (continued)

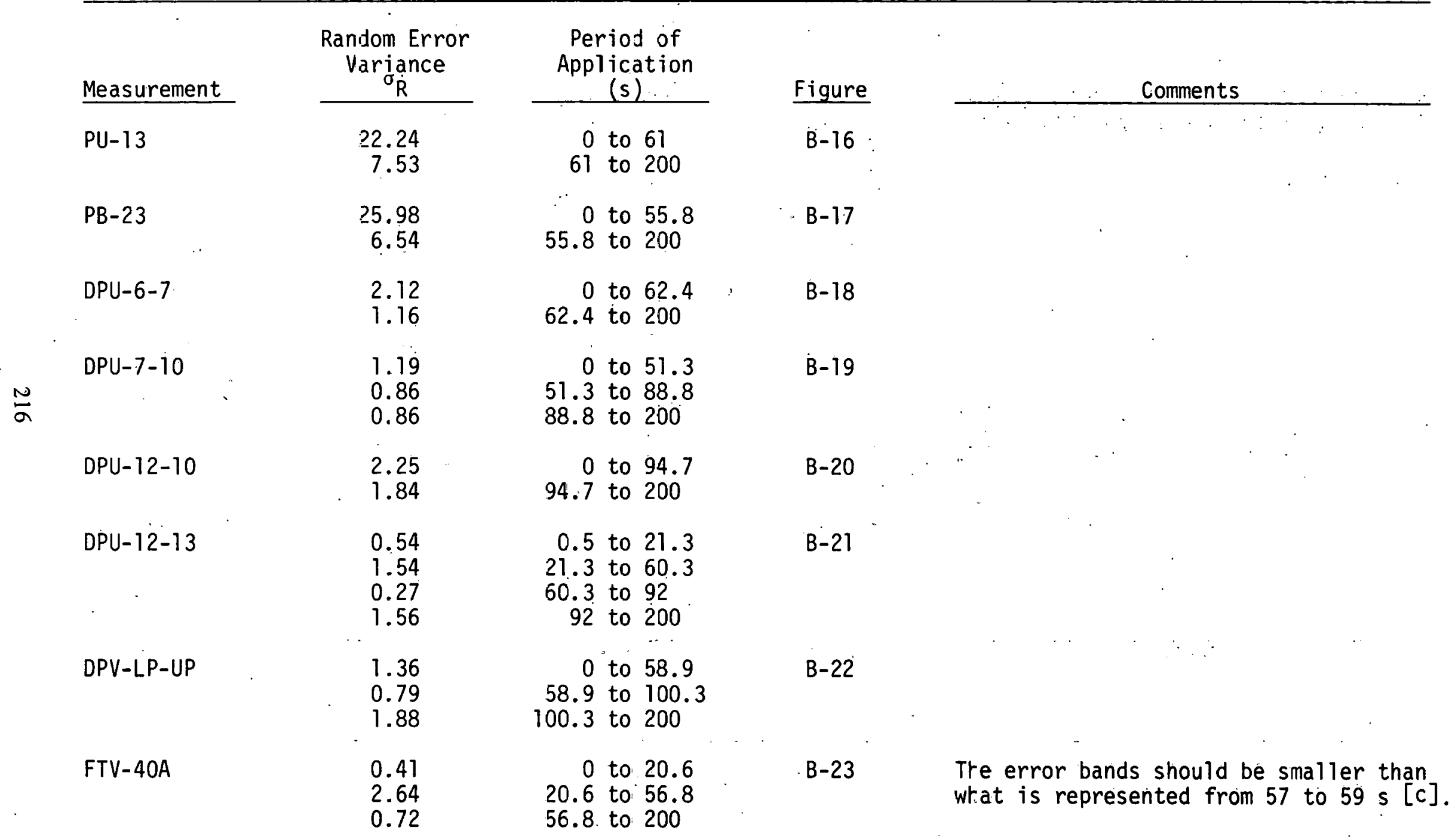


TABLE B-I (continued)

\begin{tabular}{|c|c|c|c|c|}
\hline Measurement & $\begin{array}{c}\text { Random Error } \\
\text { Varjance } \\
\sigma_{\mathrm{R}}\end{array}$ & $\begin{array}{l}\text { Period of } \\
\text { Application } \\
\text { (s) }\end{array}$ & Figure & Comments \\
\hline FTV-70M & $\begin{array}{l}0.33 \\
2.36 \\
0.61\end{array}$ & $\begin{array}{l}0 \text { to } 20.6 \\
20.6 \text { to } 56.8 \\
56.8 \text { to } 200\end{array}$ & B-24 & $\begin{array}{l}\text { The error bands should be smaller than } \\
\text { what is represented from } 57 \text { to } 59 \mathrm{~s} \text { [c] }\end{array}$ \\
\hline FTU-ACC & $\begin{array}{l}0.05 \\
0.15 \\
0.00\end{array}$ & $\begin{array}{r}0 \text { to } 53 \\
53 \text { to } 89.2 \\
89.2 \text { to } 200\end{array}$ & $B-25$ & $\begin{array}{l}\text { The error bands should be smaller than } \\
\text { what is represented from } 88 \text { to } 92 \text { s[b]. } \\
\text { The error bands do not apply from } 63 \text { to } \\
87 \text { s because the data acquisition sys- } \\
\text { tem was saturated. }\end{array}$ \\
\hline FTU-APIS & $\begin{array}{l}0.00 \\
0.01 \\
0.00\end{array}$ & $\begin{array}{l}0 \text { to } 27.3 \\
27.3 \text { to } 73.2 \\
73.2 \text { to } 200\end{array}$ & $B-26$ & $\begin{array}{l}\text { The error bands do not apply from } 74 \text { to } \\
200 \text { s because the data acquisition sys- } \\
\text { tem was saturated. }\end{array}$ \\
\hline FTU-LPIS & $\begin{array}{l}0.00 \\
0.01\end{array}$ & $\begin{aligned} 0 & \text { to } 26.9 \\
26.9 & \text { to } 200\end{aligned}$ & B-27 & \\
\hline$G U-13$ & $\begin{array}{r}32.57 \\
0.92\end{array}$ & $\begin{aligned} 0 & \text { to } \\
46.7 & \text { to } 200\end{aligned}$ & $B-28$ & $\begin{array}{l}\text { The error bands should be smaller than } \\
\text { what is represented from } 47 \text { to } 50 \text { s[b]. }\end{array}$ \\
\hline GU-1T & $\begin{array}{r}17.92 \\
3.38\end{array}$ & $\begin{aligned} 0 \text { to } & 47.4 \\
47.4 & \text { to } 200\end{aligned}$ & $B-29$ & $\begin{array}{l}\text { The error bands should be smaller than } \\
\text { what is represented from } 30 \text { to } 50 \mathrm{~s}[\mathrm{~b}] \text {. }\end{array}$ \\
\hline GU-1C & $\begin{array}{r}16.07 \\
1.36\end{array}$ & $\begin{aligned} 0 . \text { to } & 46.7 \\
46.7 & \text { to } 200\end{aligned}$ & $B-30$ & $\begin{array}{l}\text { The error bands should be smaller than } \\
\text { what is represented from } 40 \text { to } 50 \mathrm{~s} \text { [b]. }\end{array}$ \\
\hline GU-10VR & $\begin{array}{r}25.63 \\
3.11\end{array}$ & $\begin{aligned} 0 & \text { to } 18.2 \\
18.2 & \text { to } 200\end{aligned}$ & $B-31$ & $\begin{array}{l}\text { The error bands should be smaller than } \\
\text { what is represented from } 0 \text { to } 9 \mathrm{~s}[\mathrm{~b}] \text {. }\end{array}$ \\
\hline
\end{tabular}


TABLE B-I (continued)

\begin{tabular}{|c|c|c|c|c|}
\hline Measurement & $\begin{array}{c}\text { Raridom Error } \\
\text { liarjance } \\
\sigma_{R}\end{array}$ & $\begin{array}{l}\text { Period of } \\
\text { Application } \\
\text { (s) }\end{array}$ & Figure & Comments \\
\hline GU-15B & $\begin{array}{r}17.32 \\
30.47 \\
23.44 \\
198.11\end{array}$ & $\begin{array}{l}0 \text { to } 16.8 \\
16.8 \text { to } 56.8 \\
56.8 \text { to } 89.2 \\
89.2 \text { to } 200\end{array}$ & B-32 & $\begin{array}{l}\text { The error bands should be smaller than } \\
\text { what is represented from } 27 \text { to } 62 \text { s[b]. }\end{array}$ \\
\hline GU-15T. & $\begin{array}{r}31.06 \\
30.96 \\
16.61 \\
230.83\end{array}$ & $\begin{array}{l}0 \text { to } 16.8 \\
16.8 \text { to } 57.9 \\
57.9 \text { to } 92.6 \\
92.6 \text { to } 200\end{array}$ & B-33 & $\begin{array}{l}\text { Tre error bands should be smaller than } \\
\text { what is represented from } 27 \text { to } 62 \text { s[b]. }\end{array}$ \\
\hline GU-15C & $\begin{array}{r}25.45 \\
79.71 \\
13.51 \\
246.57\end{array}$ & $\begin{array}{l}0 \text { to } 19.3 \\
19.3 \text { to } 57.9 \\
57.9 \text { to } 92 \\
92 \text { to } 200\end{array}$ & $B-34$ & . \\
\hline$G B-23 V R$ & $\begin{array}{r}13.12 \\
174.01 \\
10.21 \\
102.83\end{array}$ & $\begin{aligned} & 0 \text { to } 23.8 \\
& 23.8 \text { to } 60.6 \\
& 60.6 \text { to } 100.6 \\
& 100.6 \text { to } 200\end{aligned}$ & $B-35$ & $\begin{array}{l}\text { The error bands should be smal ler than } \\
\text { what is represented from } 61 \text { to } 63 \text { s [b] }\end{array}$ \\
\hline GV-COR-15OHZ & $\begin{array}{r}8.86 \\
177.67\end{array}$ & $\begin{array}{r}0 \text { to } 68 \\
68 \text { to } 200\end{array}$ & $B-36$ & . \\
\hline GVLP- $165 \mathrm{HZ}$ & $\begin{array}{l}29.85 \\
95.93\end{array}$ & $\begin{array}{r}0 \text { to } 65.5 \\
65.5 \text { to } 200\end{array}$ & $B-37$ & \\
\hline
\end{tabular}


TABLE B-I (continued)

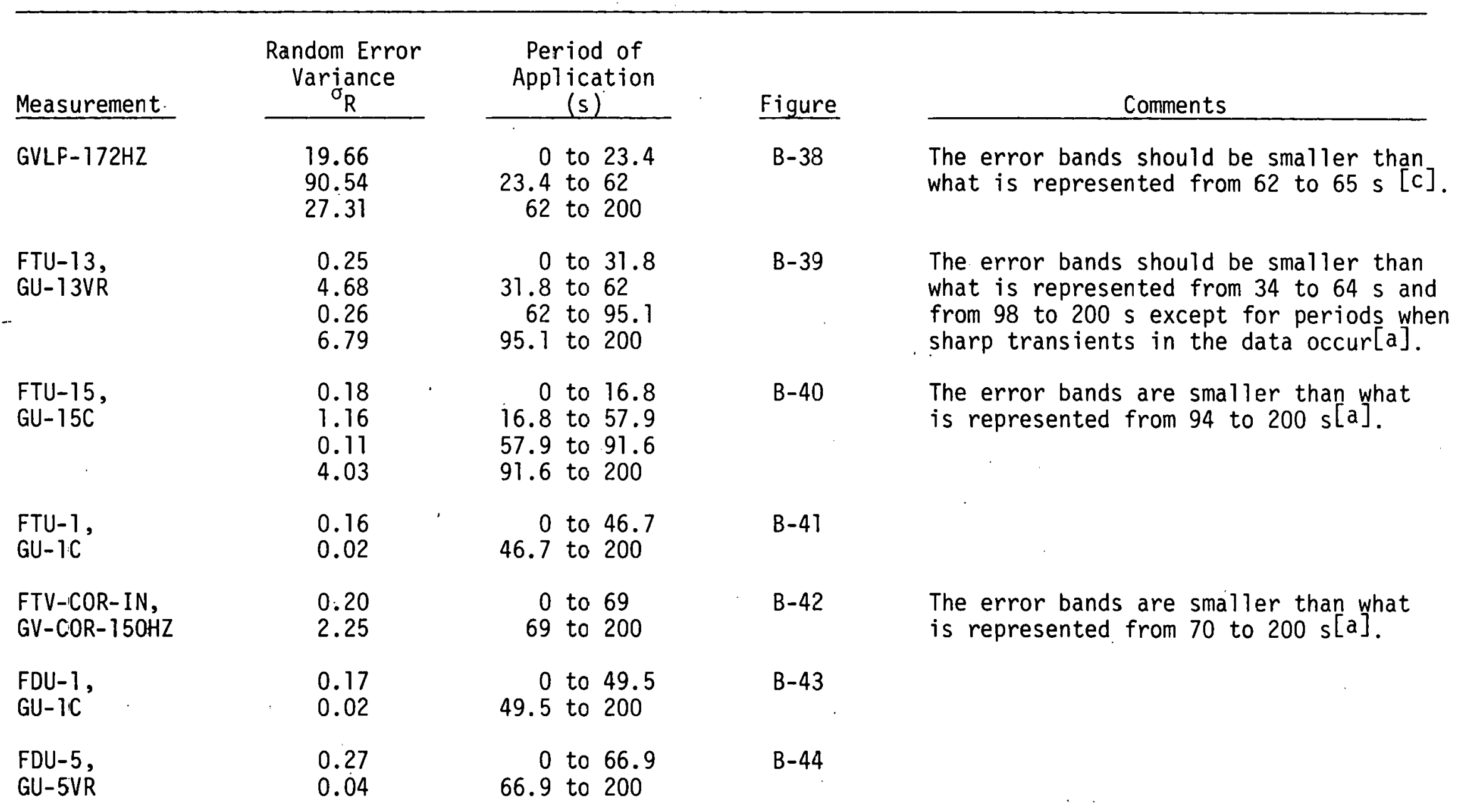




\section{TABLE B-I (continued)}

\begin{tabular}{|c|c|c|c|c|}
\hline Measurement & $\begin{array}{c}\text { Random Error } \\
\text { Iarjance } \\
\sigma_{\mathrm{R}} \\
\end{array}$ & $\begin{array}{l}\text { Periad of } \\
\text { Application } \\
\text { (s) }\end{array}$ & Figure & Comments \\
\hline $\begin{array}{l}\text { FTB-21, } \\
\text { GB-21C }\end{array}$ & $\begin{array}{l}0.45 \\
1.10 \\
0.46\end{array}$ & $\begin{array}{l}0 \text { to } 20.3 \\
20.3 \text { to } 56.5 \\
56.5 \text { to } 200\end{array}$ & $B-45$ & $\begin{array}{l}\text { The error bands are smaller than what } \\
\text { is represented from } 0 \text { to } 23 \mathrm{~s} \text { and } 60 \\
\text { to } 200 \mathrm{~s}[\mathrm{a}] \text {. }\end{array}$ \\
\hline
\end{tabular}

[a] The variability in the data has two components. One is the random error and the other is the systematic error. In this region, the random comfonent dominates the systematic component. The width of the error band is due primarily. to the variance of the random underlying process. The large variability does not reflect the inability $o^{=}$the measuring instrument to accurately measure the process.

N [b] The larger estimated error bard occurs when there is a rapid transient change during which insufficient data are provided to allow estimation cf the error. Inclusion of large transients in the estimation always increases the es:imatec error.

[c] Due to present saftware limitations, error bards wi11 appear larger than expected wherever segments with different size error bands are rerged tocether. 
were included as a part of the total engineering error. The time of occurrence of separated two-phase flow and the resulting effect on the uncertainty of the data were evaluated by considering, on an individual basis, each detector output with reference to indications by other auxiliary measurements.

The gamma densitometer density measurement data are affected by two-phase separated flow regimes. The resulting transducer output is a measurement of the average attenuation of the gamma beam through the measured medium. The beam attenuation, in turn, is interpreted through physical relationship to be a measure of the average density along the beam path. When stratified type flow was considered present, the gamma beam attenuation was considered to be a result of a liquid layer and steam at system conditions. With this assumption and the system geometry, a void fraction was calculated and a new "effective" average density was calculated. The difference between the average density. based on the assumption of homogeneous conditions and the average density for stratified conditions was considered to be the error.

Momentum flux measurement uncertainties for two-phase flow regimes present the most difficult engineering evaluation problems. The drag target and arm location, degree of flow stratification, transducer temperature sensitivity, and slip ratios all combine to produce possible flow regime errors ranging from a small fraction of the transducer output value to multiples of it. Therefore, the error values were obtained, where possible, through use of the observed discrepancies between the momentum flux and turbine flowmeter data in combination with system pressure measurements and the analysis of system fluid density measurements.

The flow regime errors of the turbine flowmeter were estimated by calculating a void fraction and the cross-sectional liquid and steam flow areas for stratified flow. This calculation was accomplished using methods similar to those used to calculate the average density for stratified flows. A simple model was used to equate the forces on the turbine with the assumption of a known void fraction, stratified flow, known component densities, and slip ratio greater than unity. This process provided phase velocities. With the phase densities, velocities, and void fraction, a volumetric flow rate could be calculated. The difference between this value and the measured value was considered to be the error.

The overall standard deviation of a data point is taken as the root mean of the sum of the random error variation and the total engineering error variance; that is,

$$
\sigma_{0}=\sigma_{R}^{2}+\sigma_{E}^{2}
$$

where

$$
\begin{aligned}
& \sigma_{\mathrm{O}}=\text { overall standard deviation of a data point } \\
& \sigma_{\mathrm{R}}=\text { random error standard deviation } \\
& \sigma_{\mathrm{E}}=\text { engineering error standard deviation. }
\end{aligned}
$$


The error bands for the data are computed about the value given by the fitted difference equation $y_{i}$ at time point, $i$; that is,

$$
\text { error band }=y_{i} \pm 1.96 \sigma_{0}
$$

With due regard to the fact that $\sigma_{\mathrm{E}}$ has been estimated subjectively, the error band may be interpreted as an approximate $95 \%$ confidence interval within which any true value of the measured variable is consistent with the data.

On certain occasions, the symmetrical error band given by Equation (B-2) is not appropriate. On those occasions, asymmetrical error bands were computed. (That is, with the width being greater on one side of $y_{i}$ than on the other.)

Finally, the original data trace, along with its error band from Equation (B-2), was input to a computer plot package. The resulting plot contained the actual data trace surrounded by an error band derived both from random error and engineering error considerations. The indicated error bands after thermocouple dryout occurred for the fluid temperature measurements should be ignored. Error bands for these segments of the data were not obtained and bands only appear because of limitations in the plotting package.

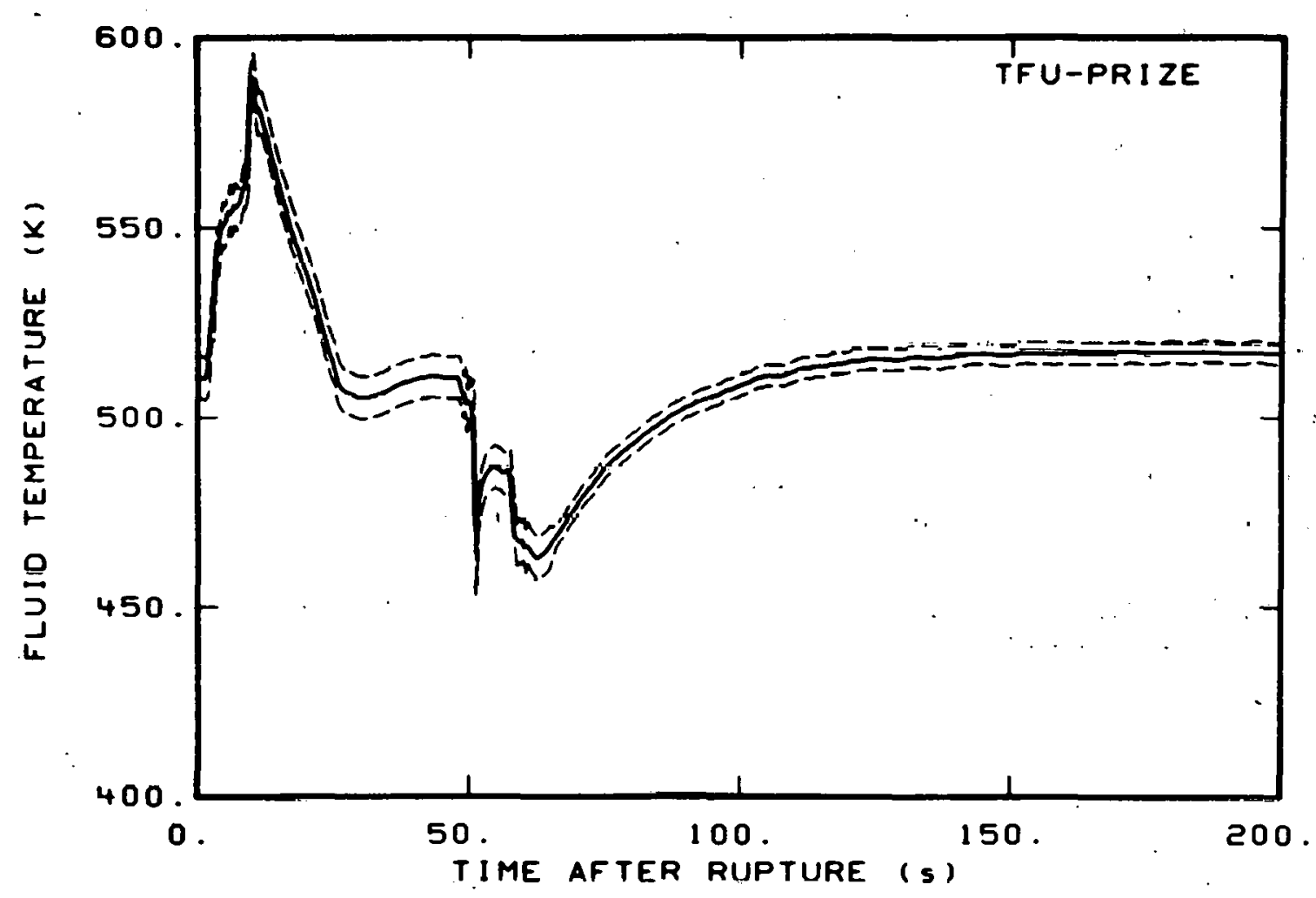

Fig. B-l Fluid temperature in pressurizer surge line (TFU-PRIZE). 


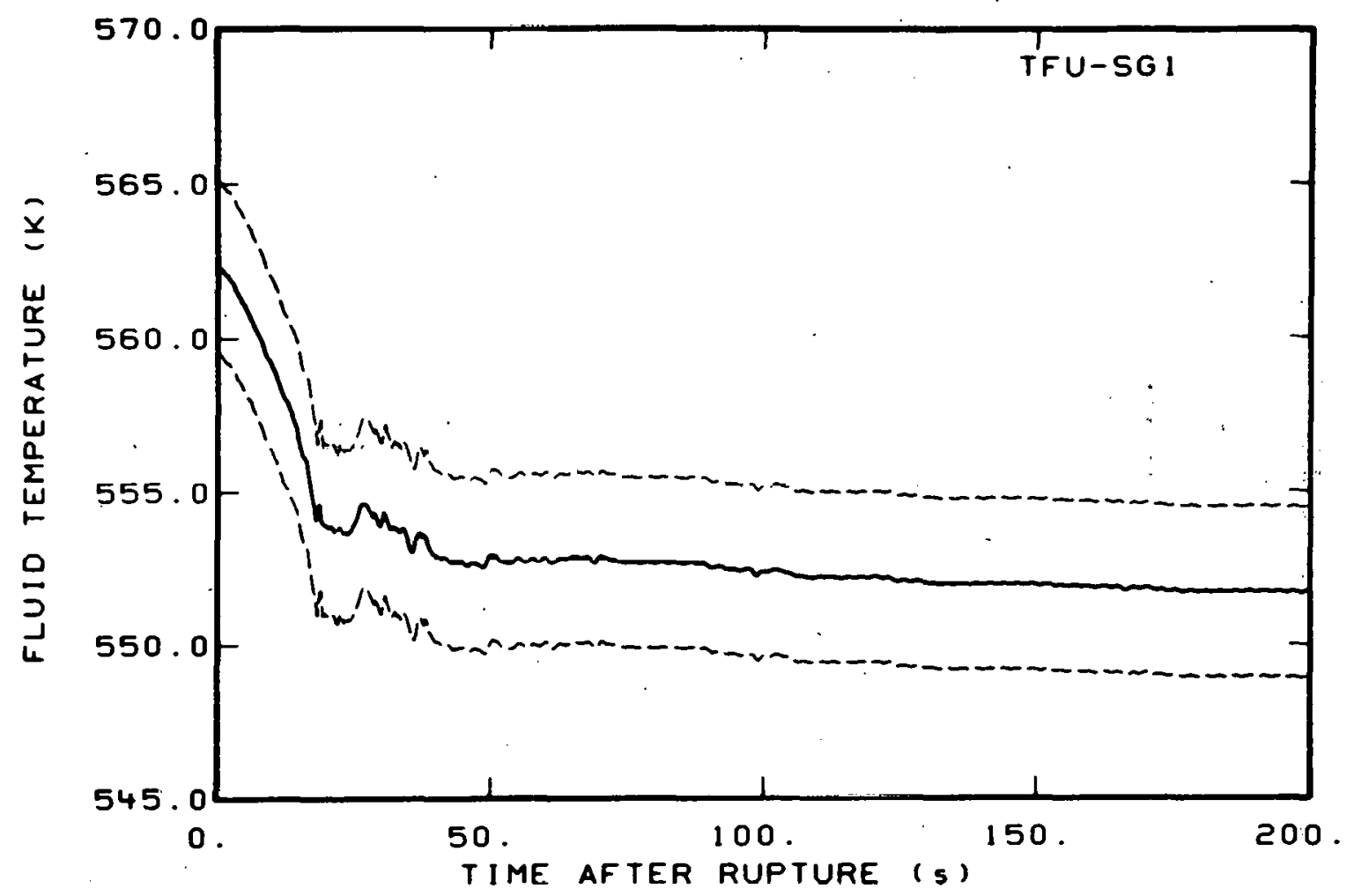

Fig. B-2 Fluid temperature in steam generator (TFU-SGI).

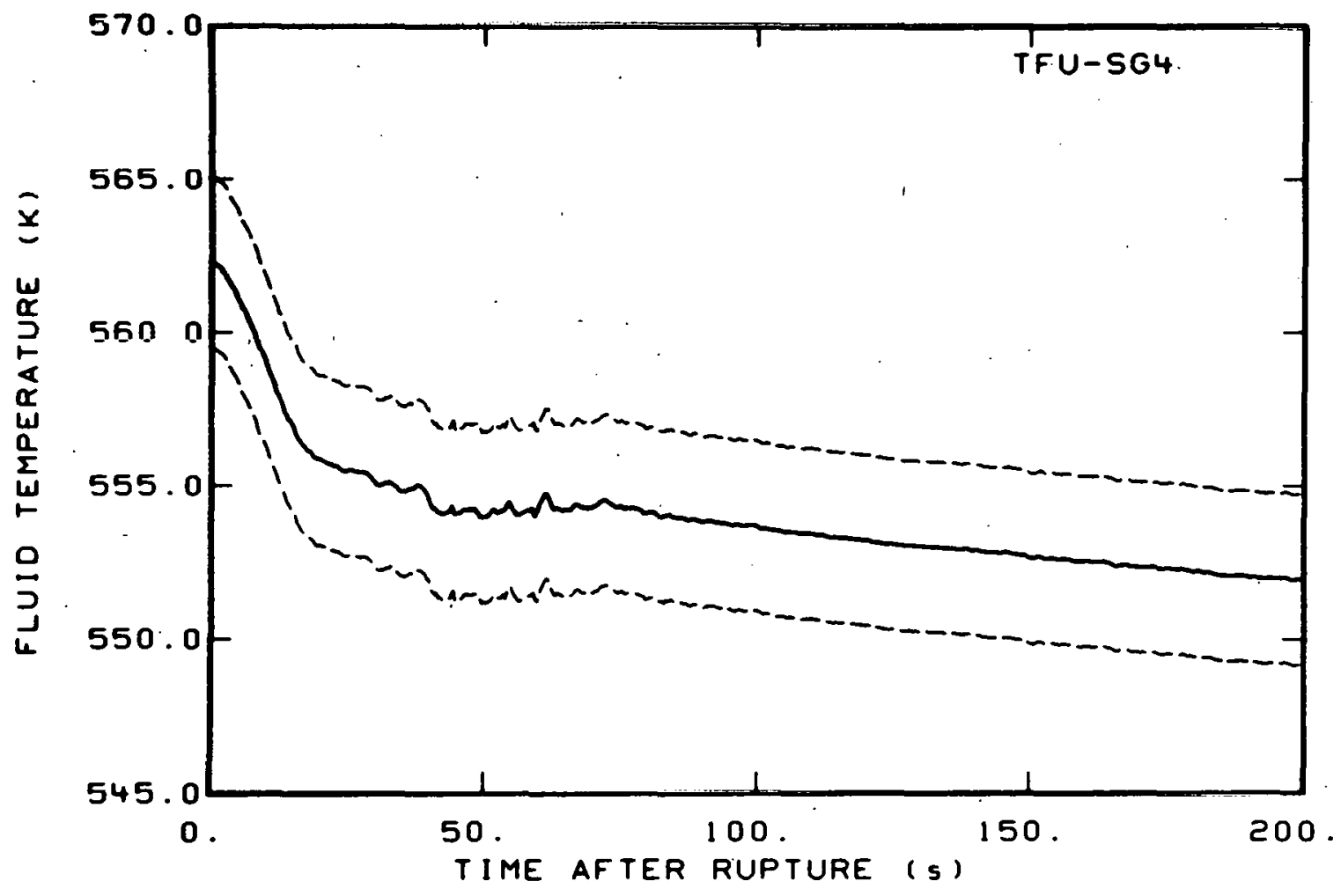

Fig. B-3 Fluid temperature in steam generator (TFU-SG4). 


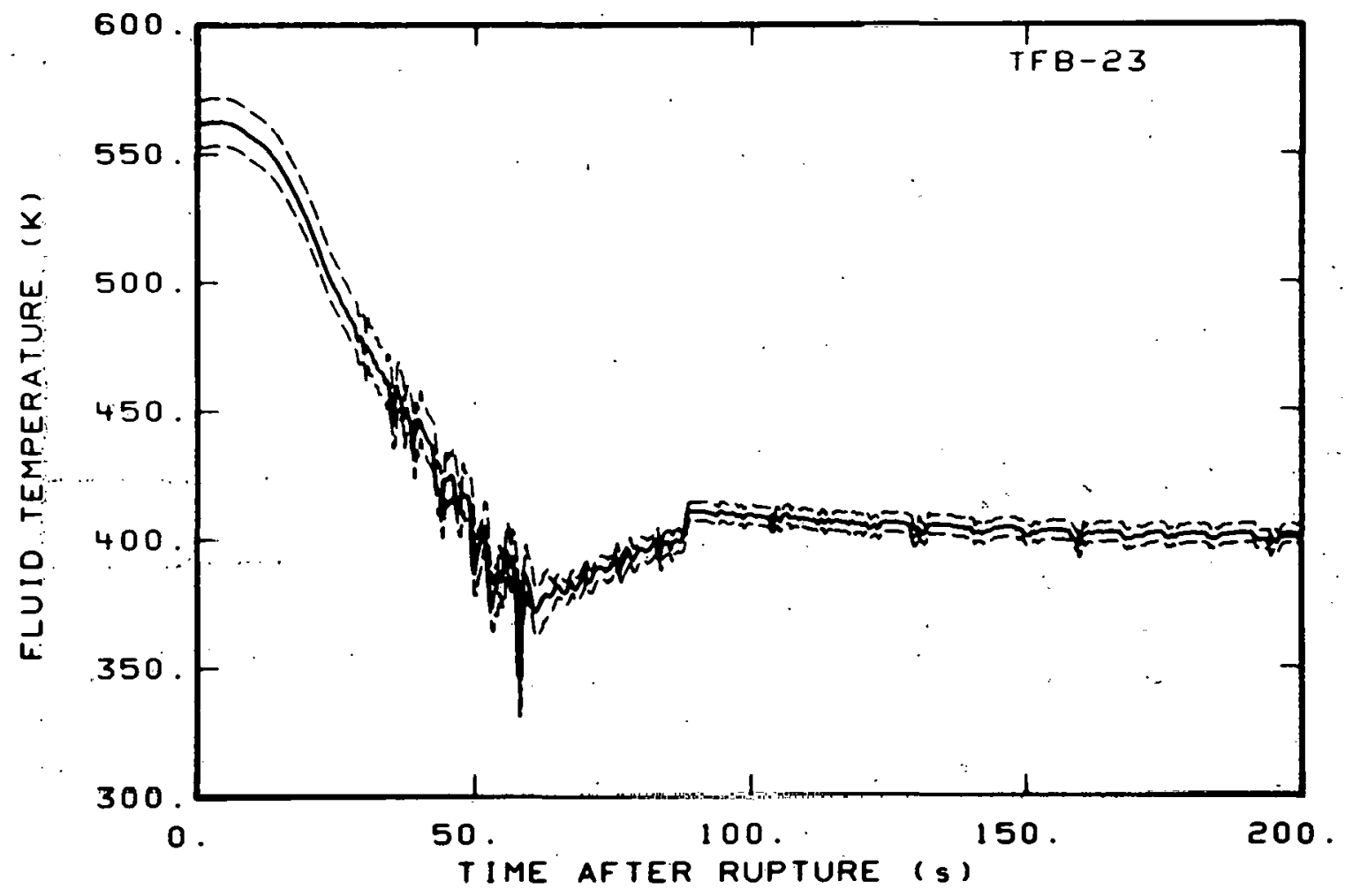

Fig. B-4 Fluid temperature in broken loop, vessel side (TFB-23).

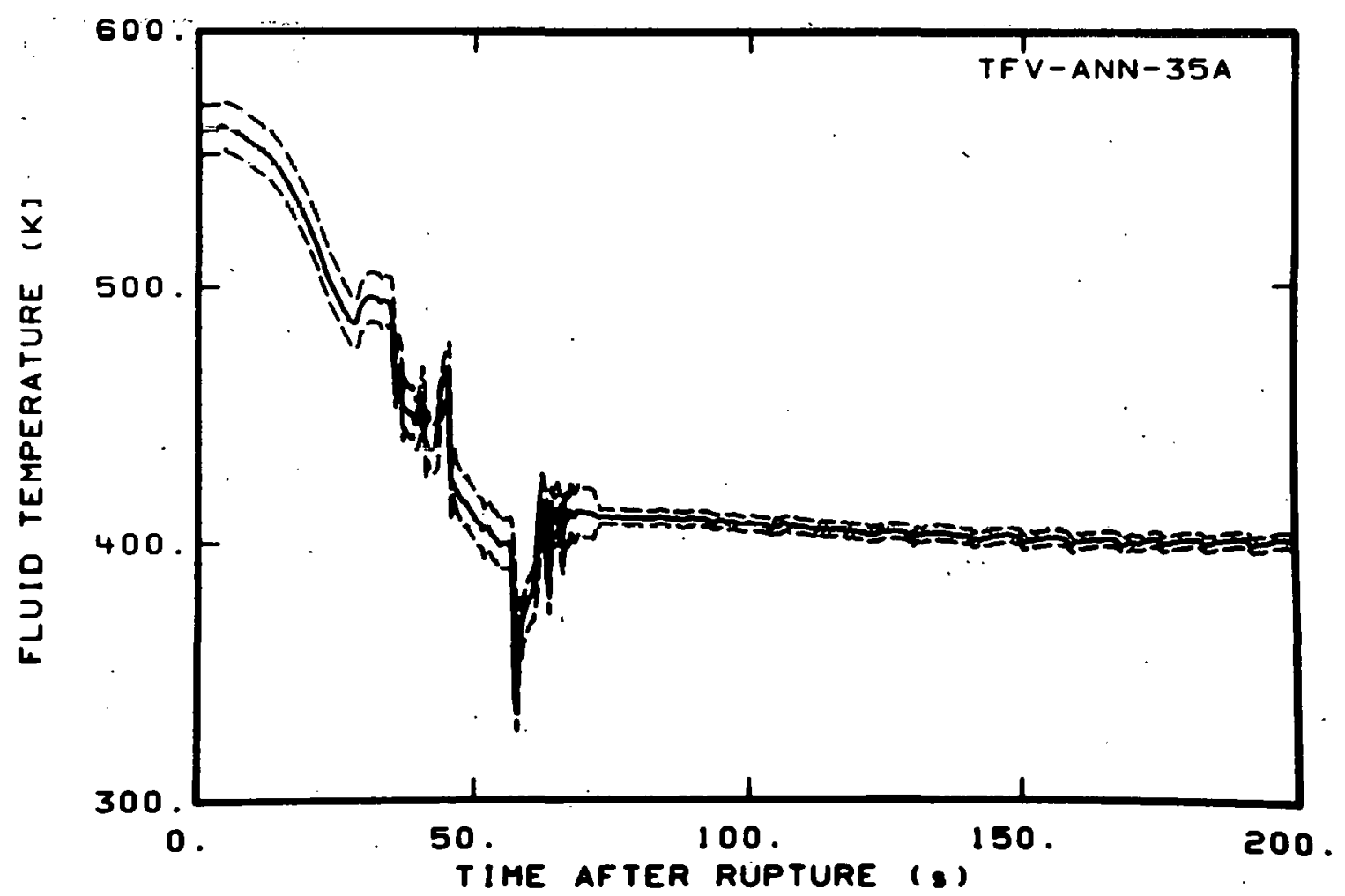

Fig. B-5 Fluid temperature in downcomer annulus (TFV-ANN-35A). 


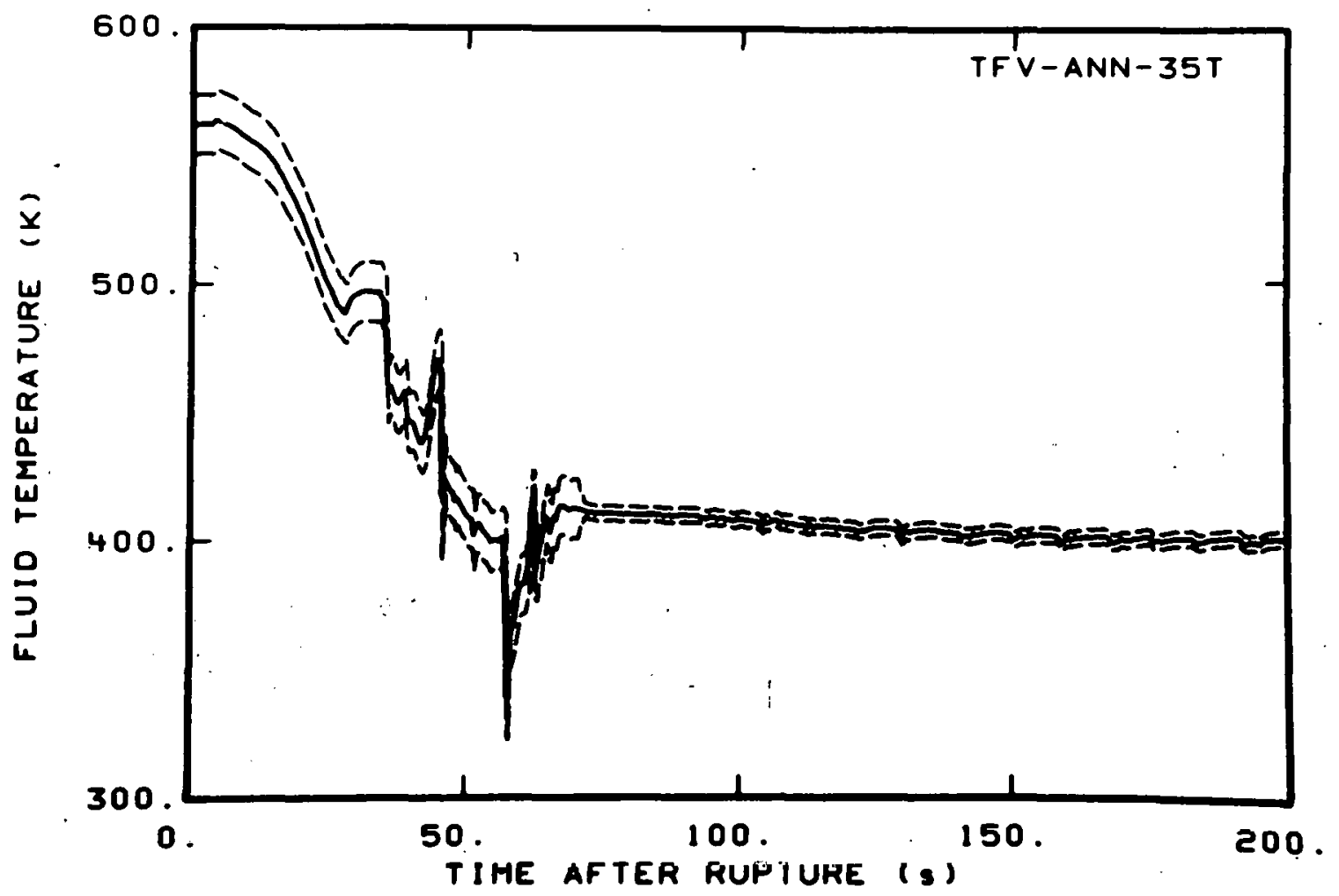

Fig. B-6 Fluid temperature in downcomer annulus (TFV-ANN-35T).

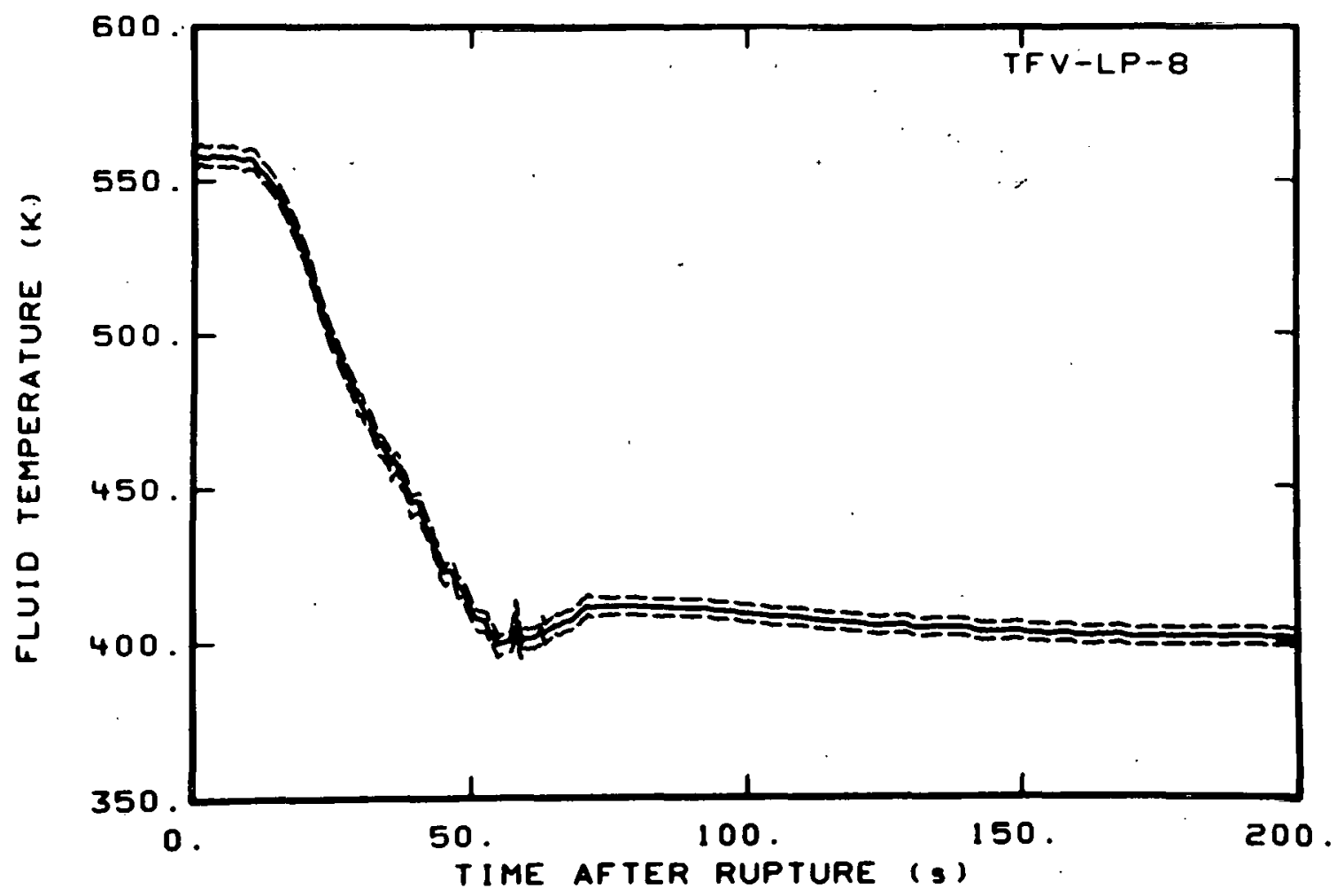

Fig. B-7 Fluid temperature in lower plenum (TFV-LP-8). 


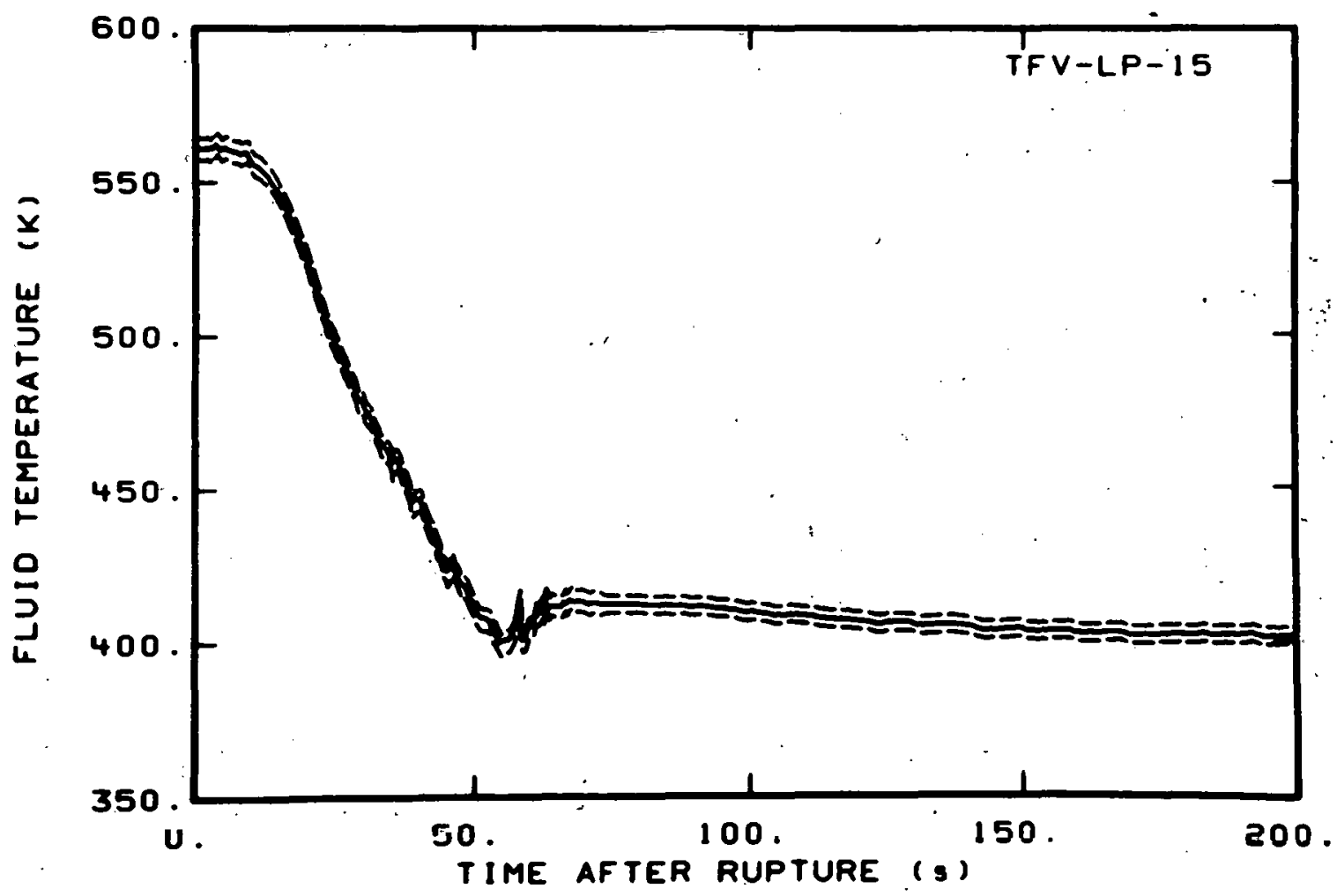

Fig. B-8 Fluid temperature in lower plenum (TFV-LP-15).

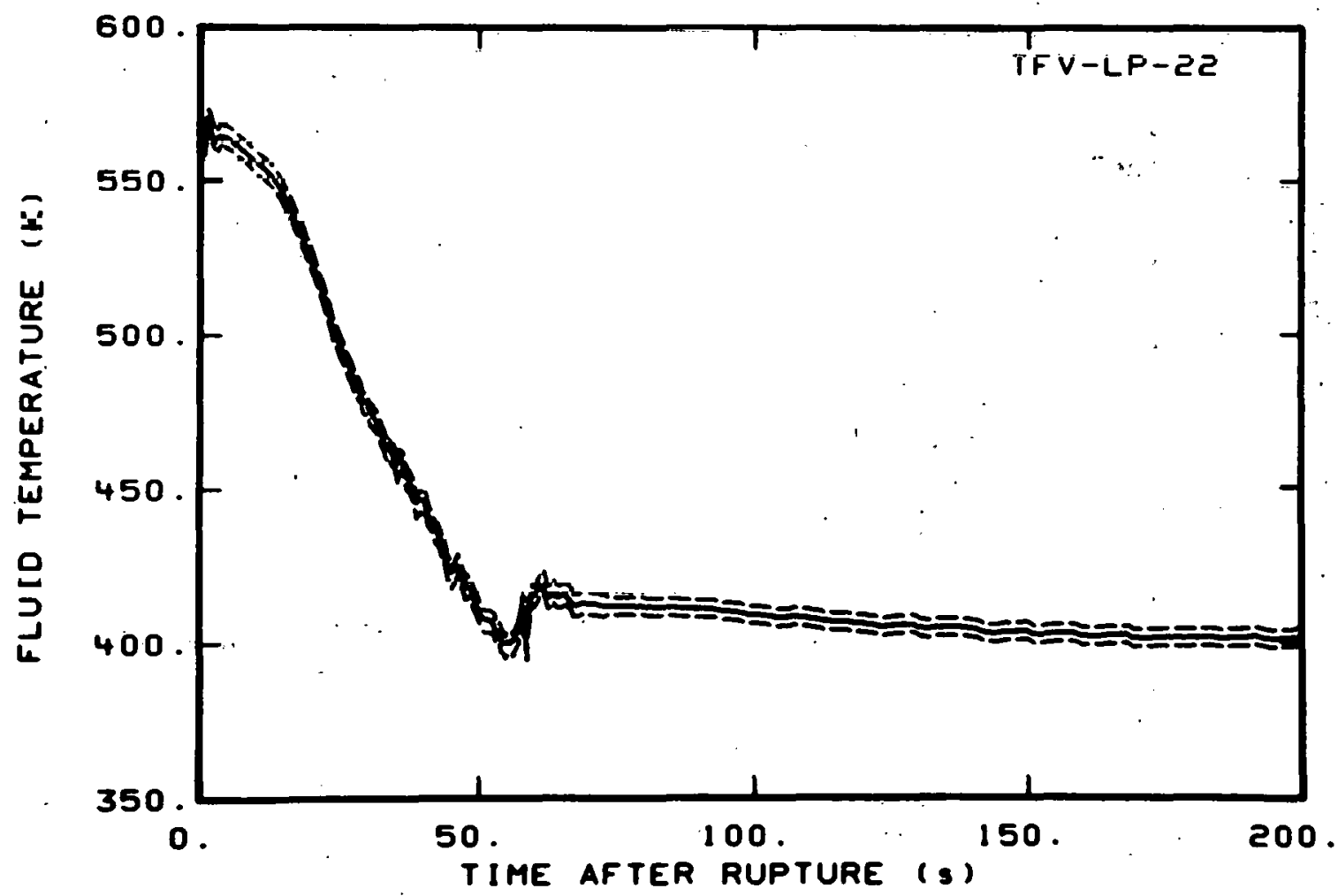

Fig. B-9 Fluid temperature in lower plenum (TFV-LP-22). 


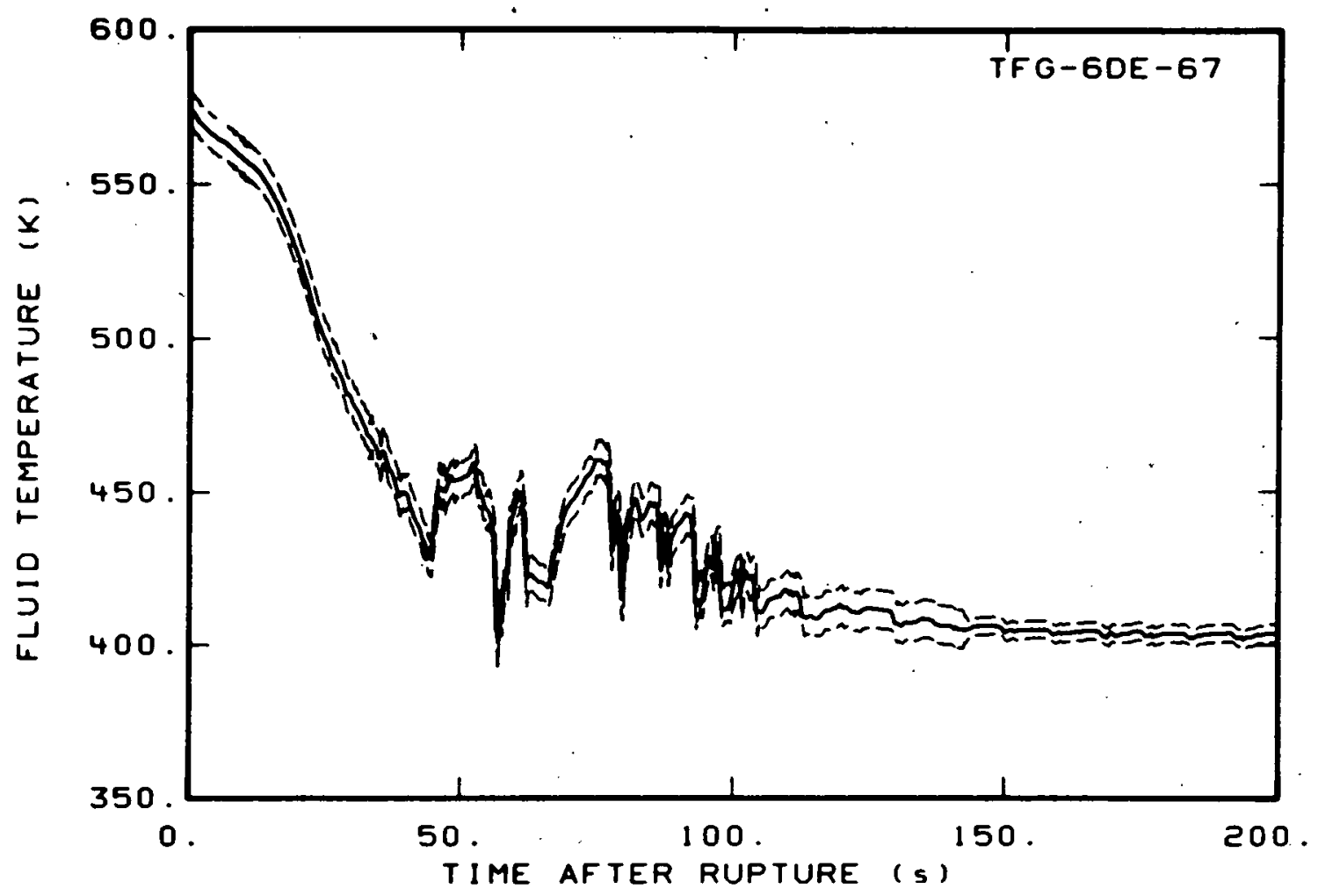

Fig. B-10 Fluid temperature in core, Grid Spacer 6 (TFG-6DE-67).

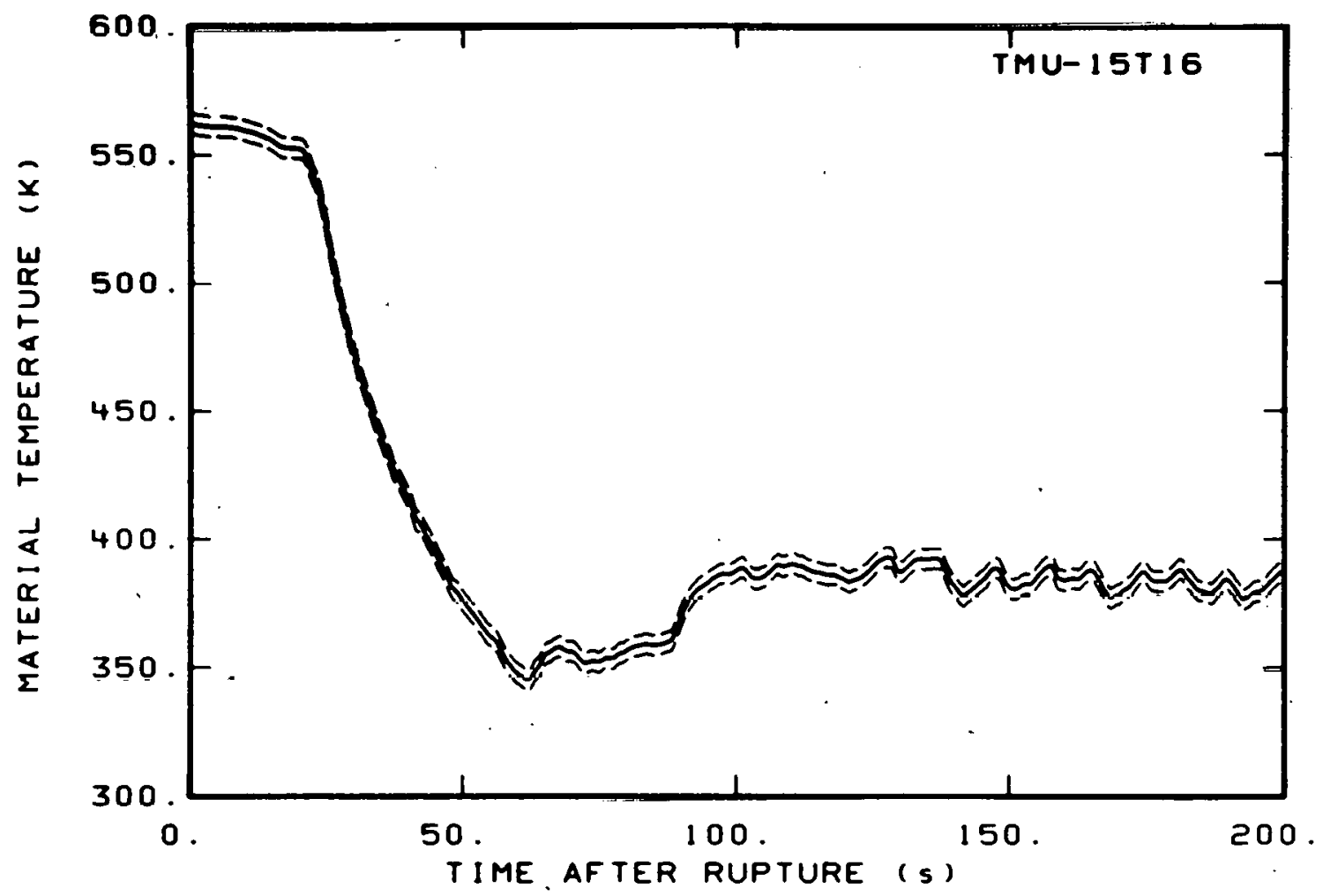

Fig. B-11 Material temperature in intact loop (TMU-15T16). 


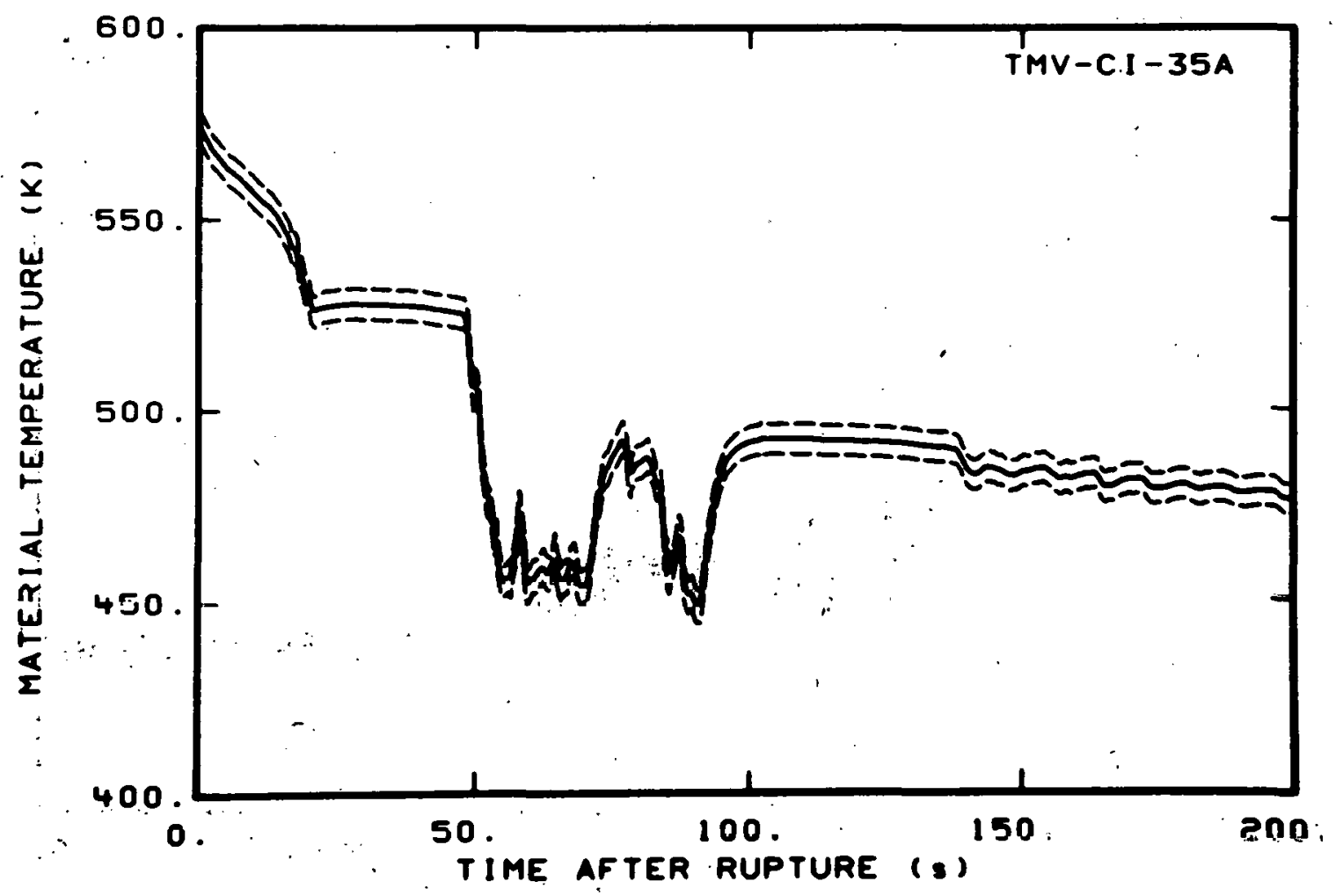

Fig. B-12 Material temperature in core barrel inner diameter (TMV-CI-35A).

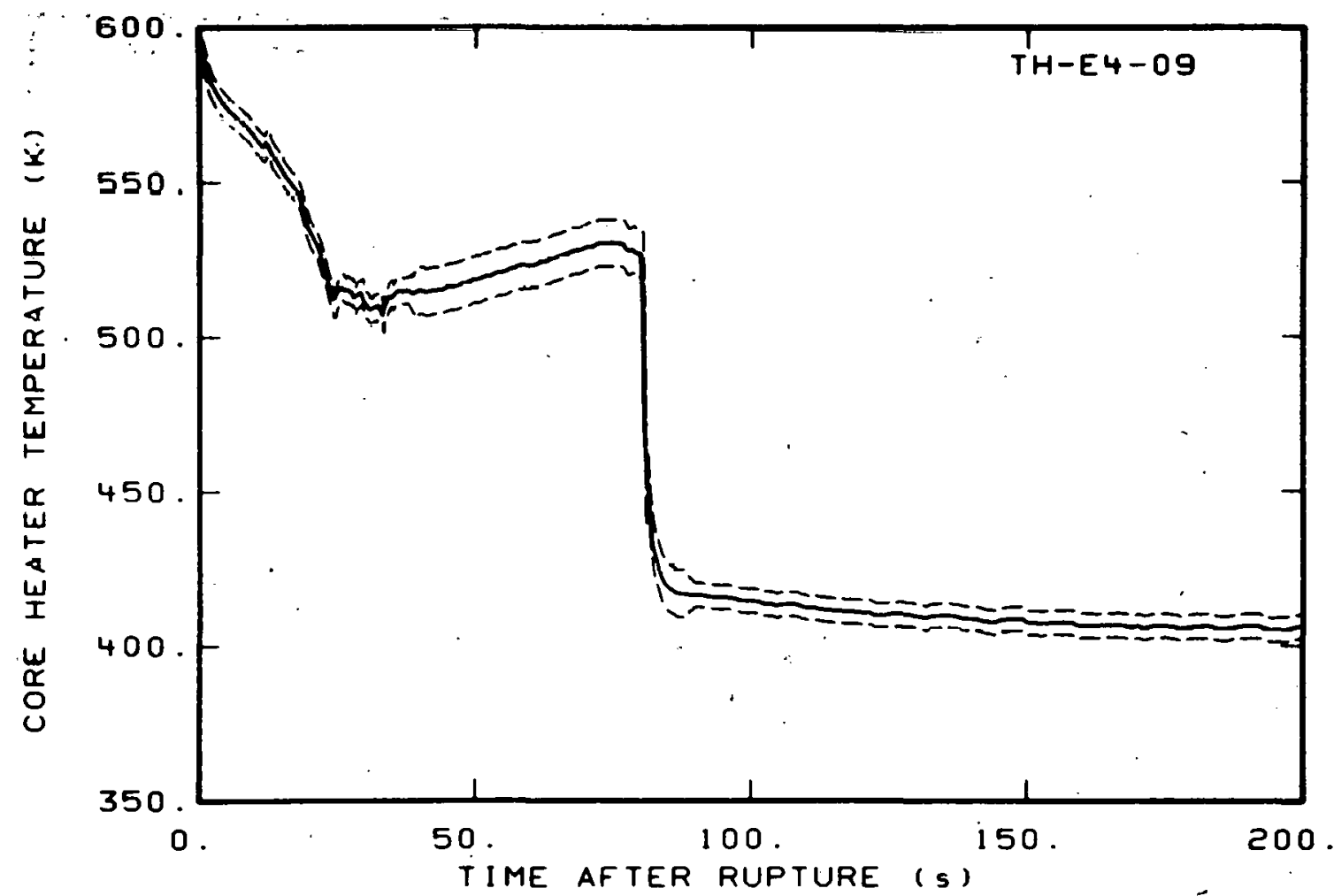

Fig. B-13 Core heater temperature, Rod E-4 (TH-E4-09). 


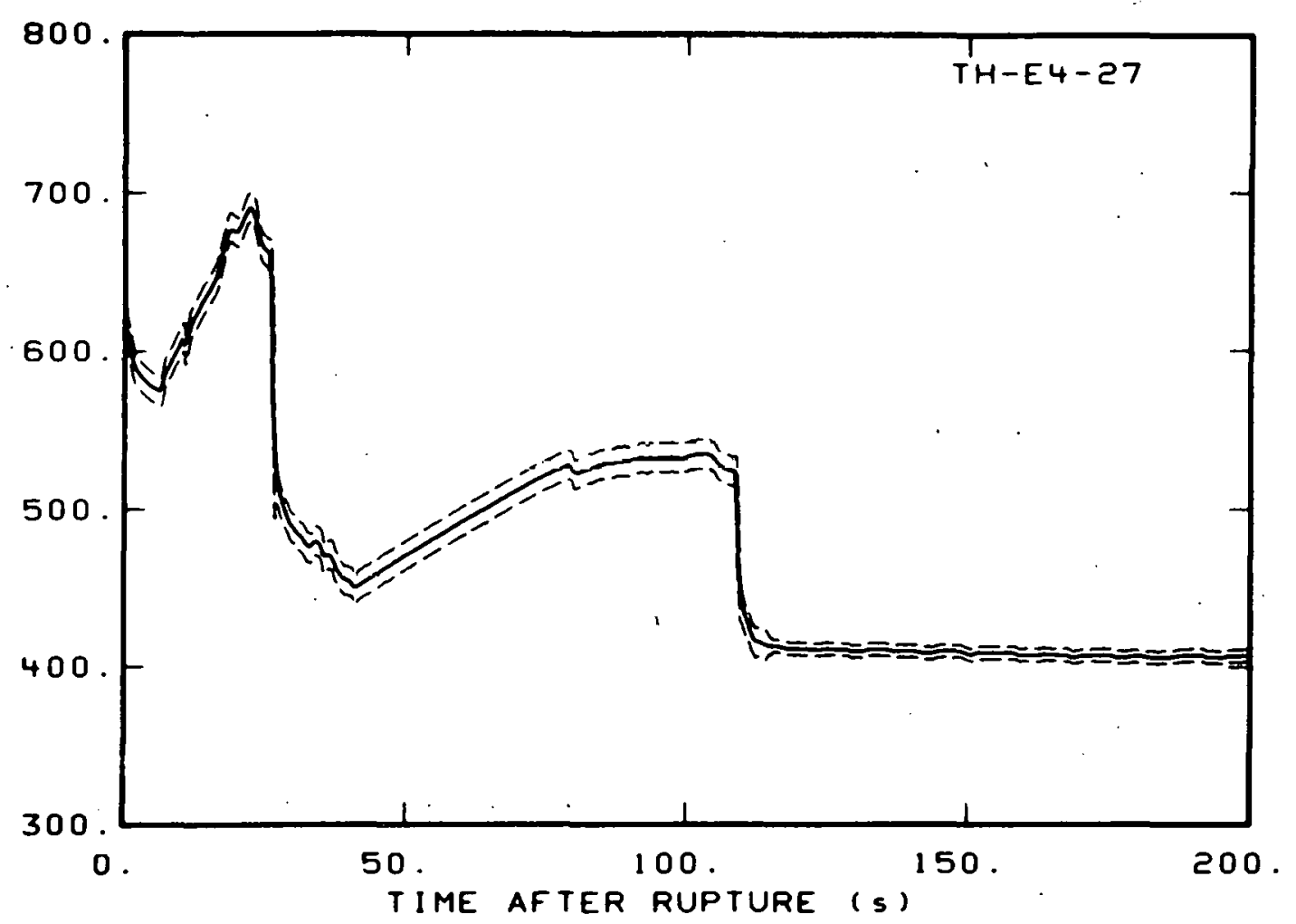

Fig. B-14 Core heater temperature, Rod E-4 (TH-E4-27).

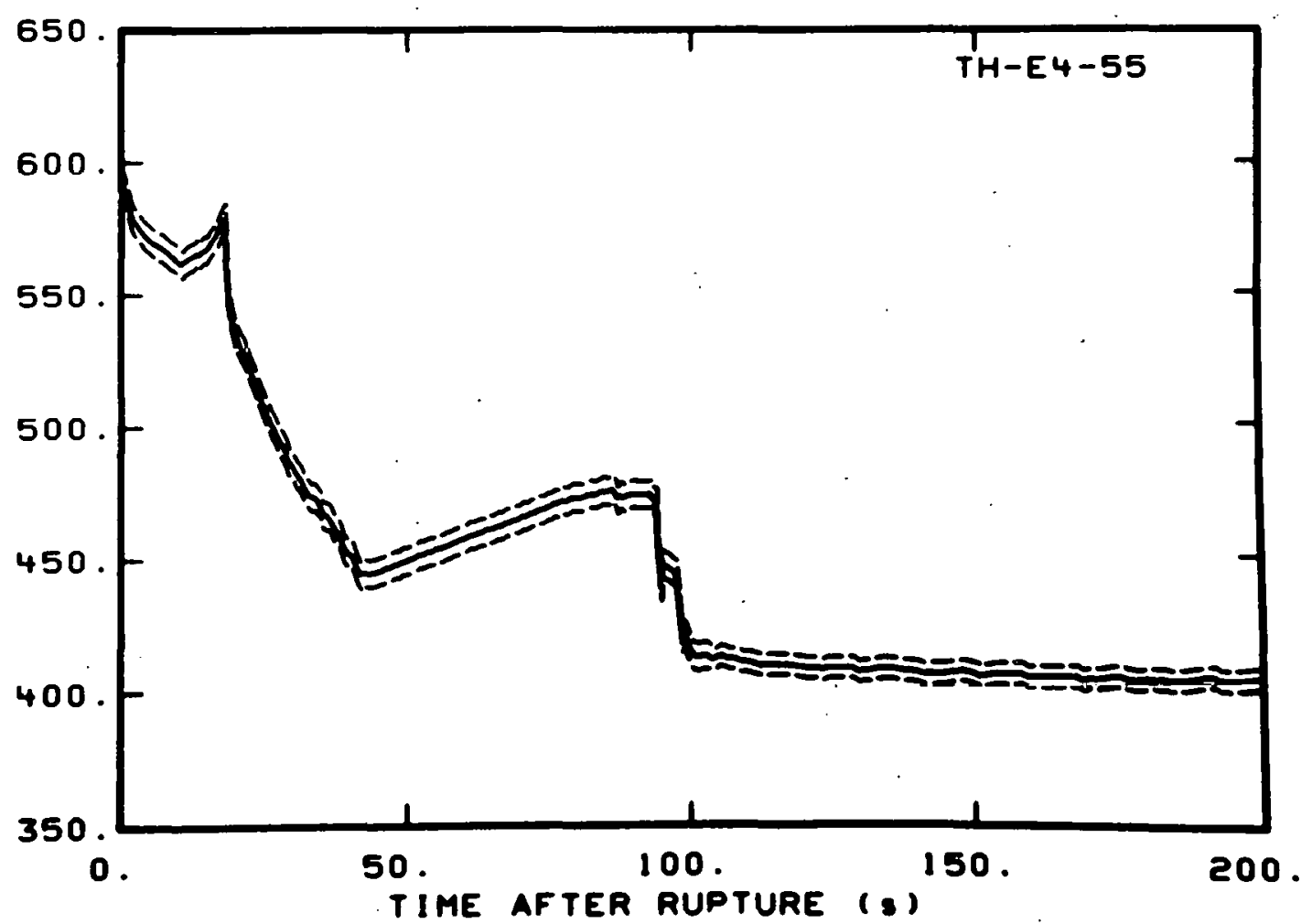

Fig. B-15 Core heater temperature, Rod E-4 (TH-E4-55). 


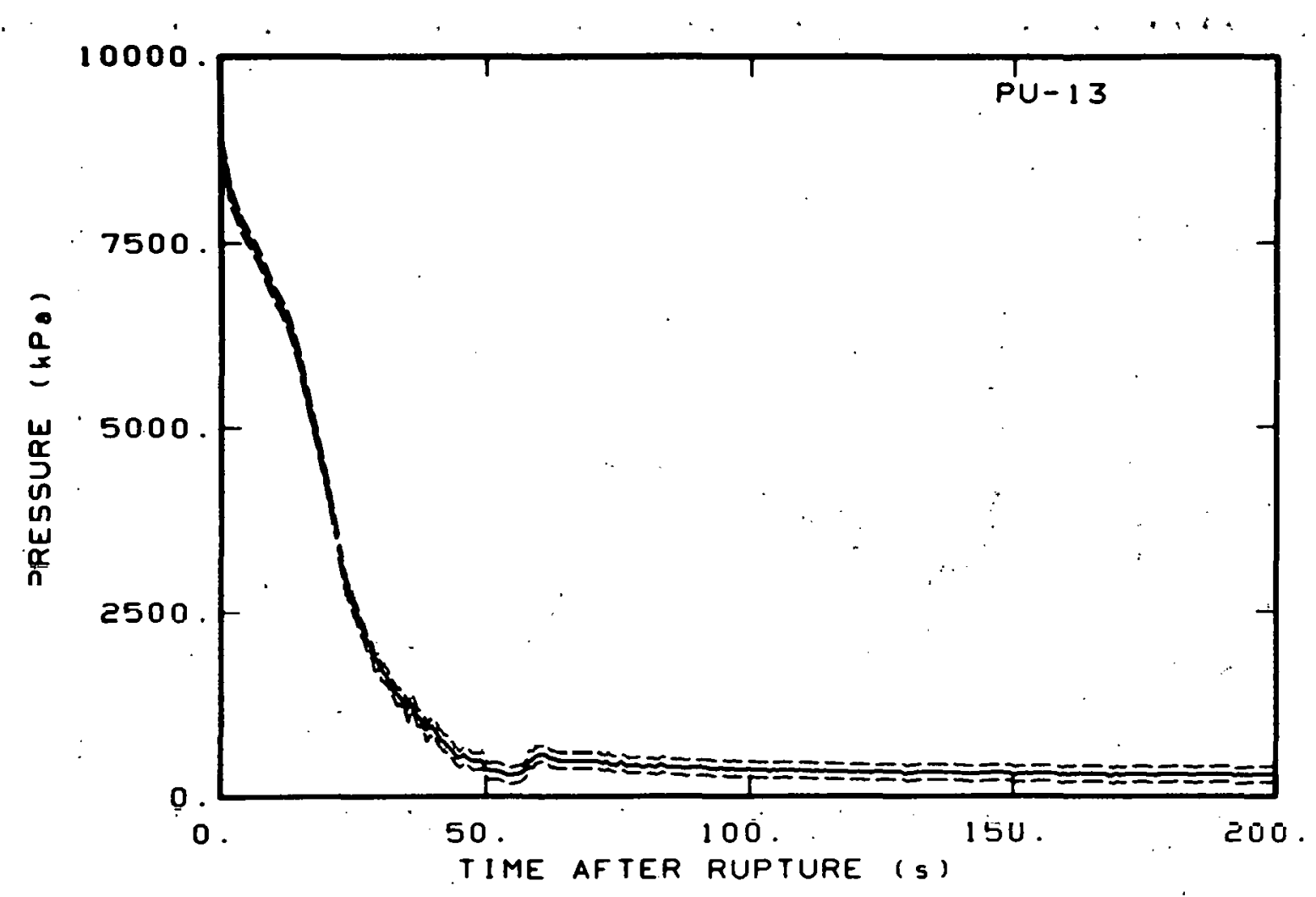

Fig. B-16. Pressure in intact loop (PU-13).

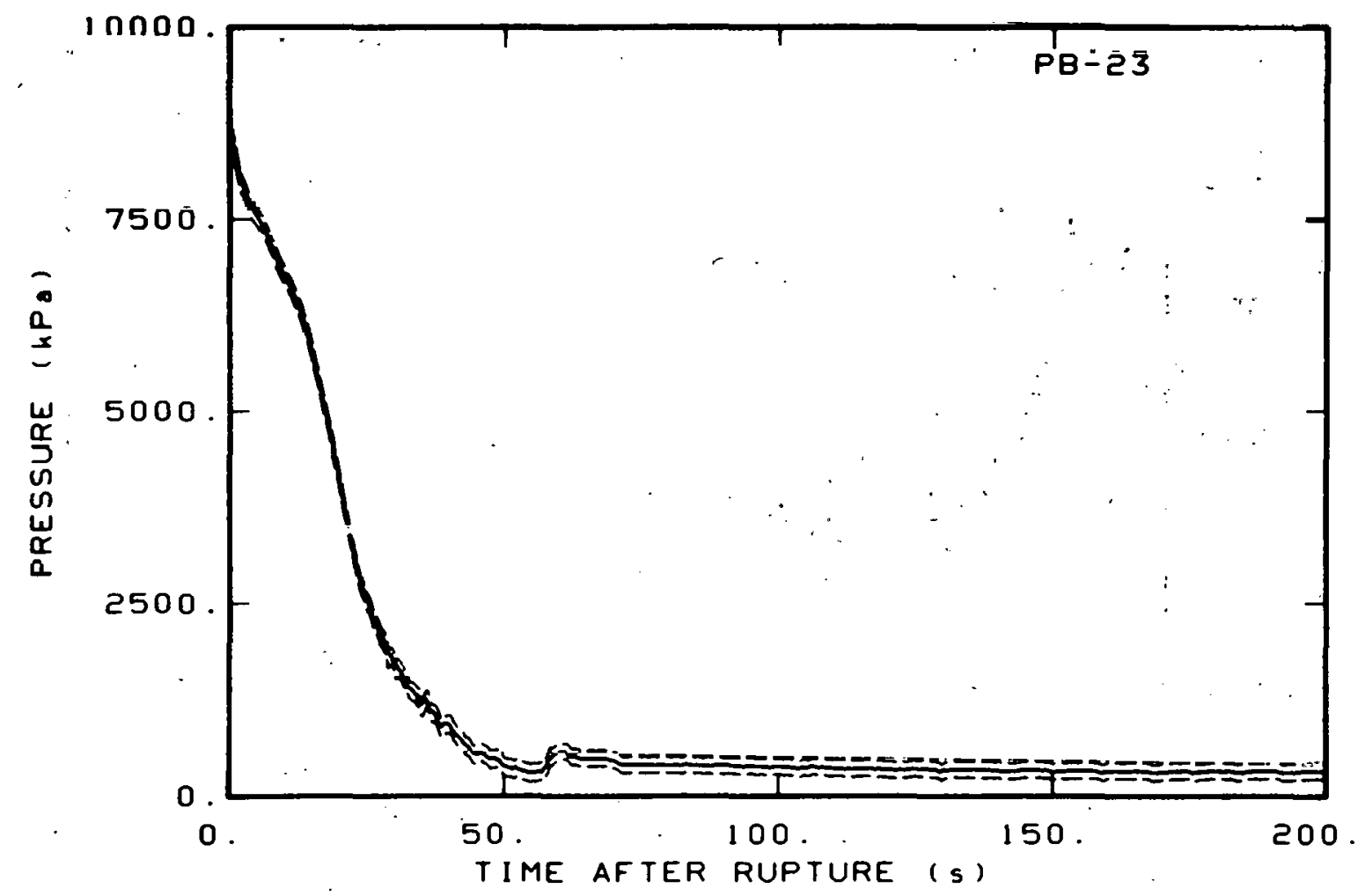

Fig. B-17 Pressure in broken loop, Spool 23 (PB-23). 


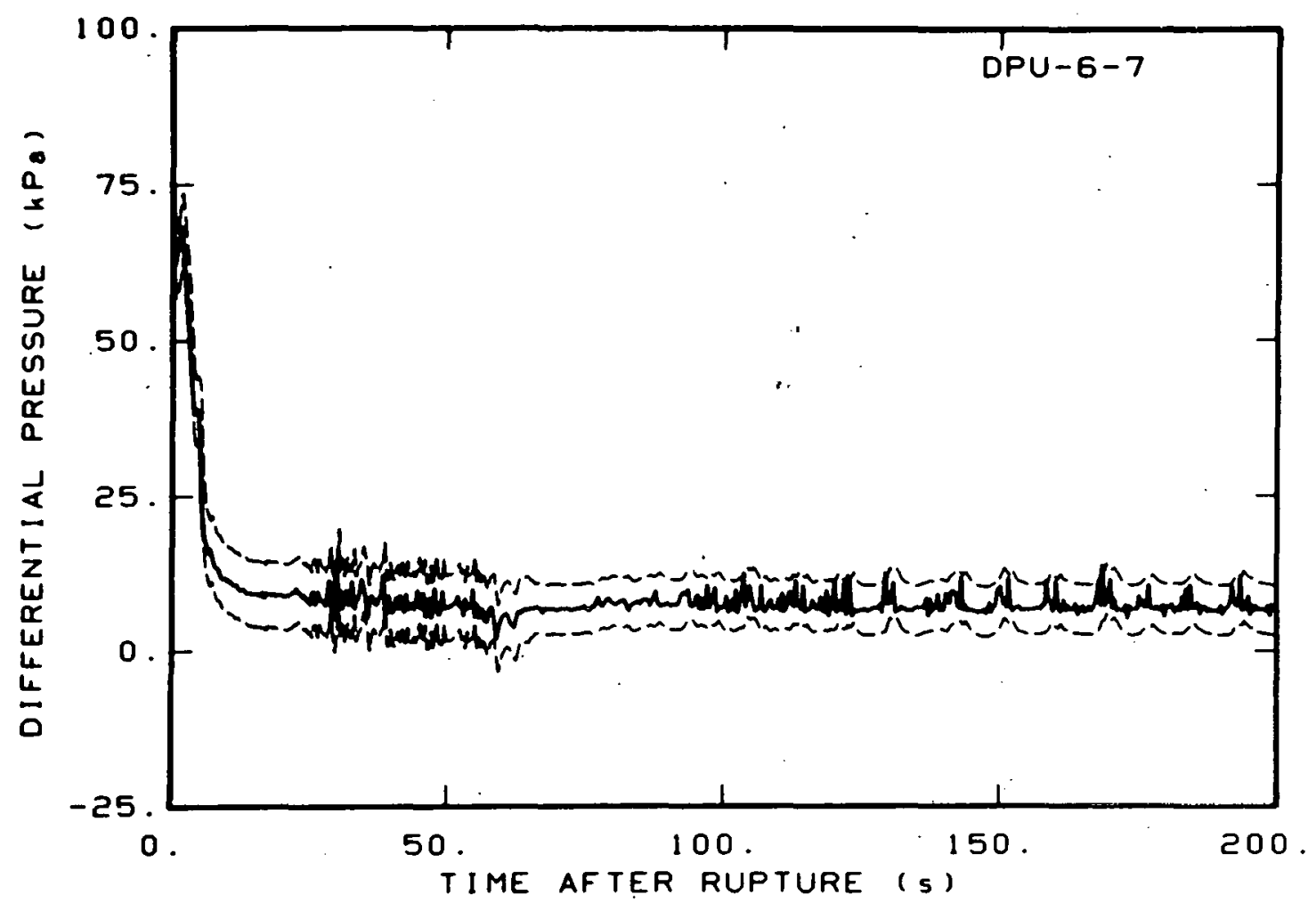

Fig. B-18 Differential pressure in intact 10op (DPU-6-7).

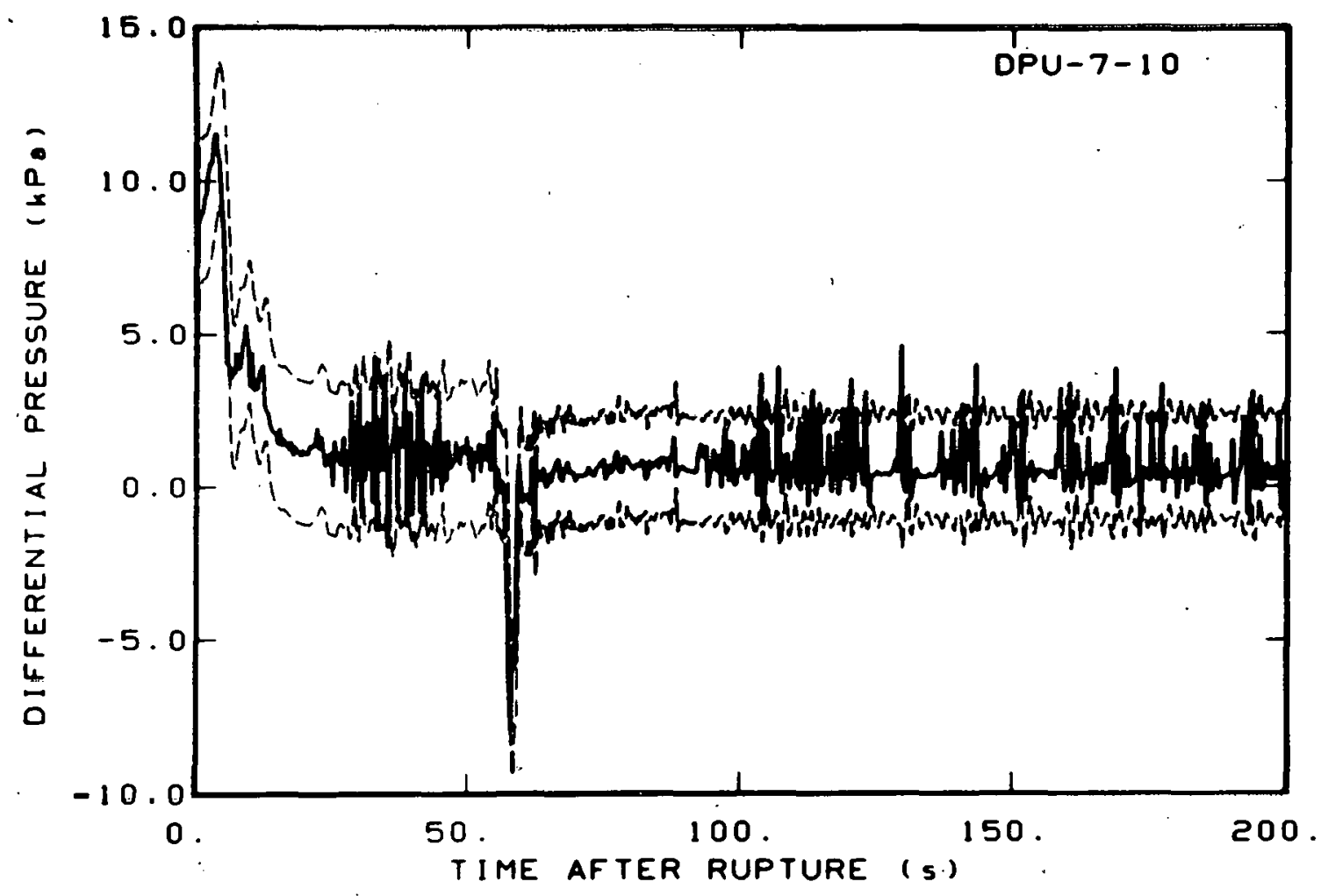

Fig. B-19 Differential pressure in intact loop (DPU-7-10). 



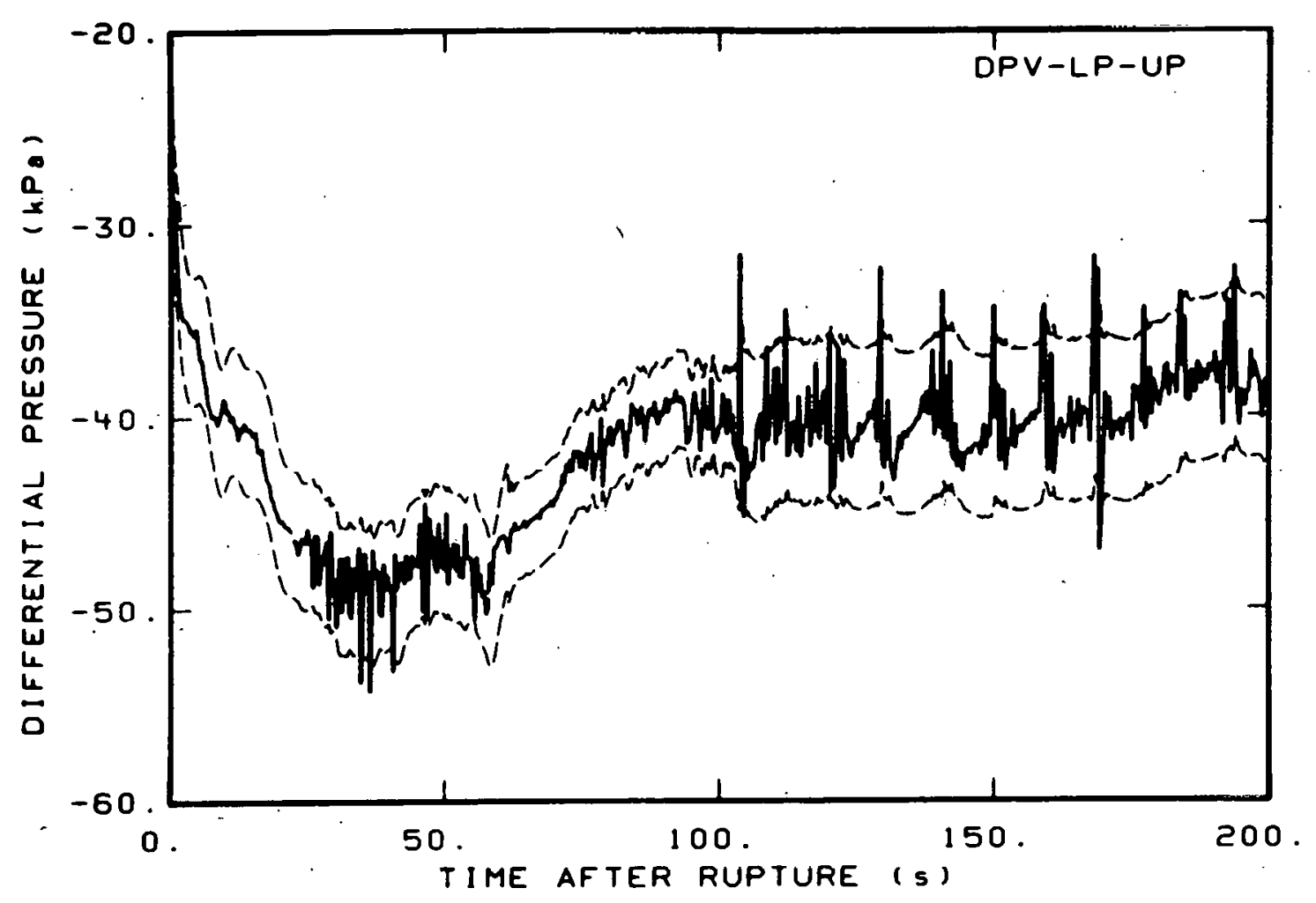

Fig. B-22 Differential pressure in vessel (DPV-LP-UP).

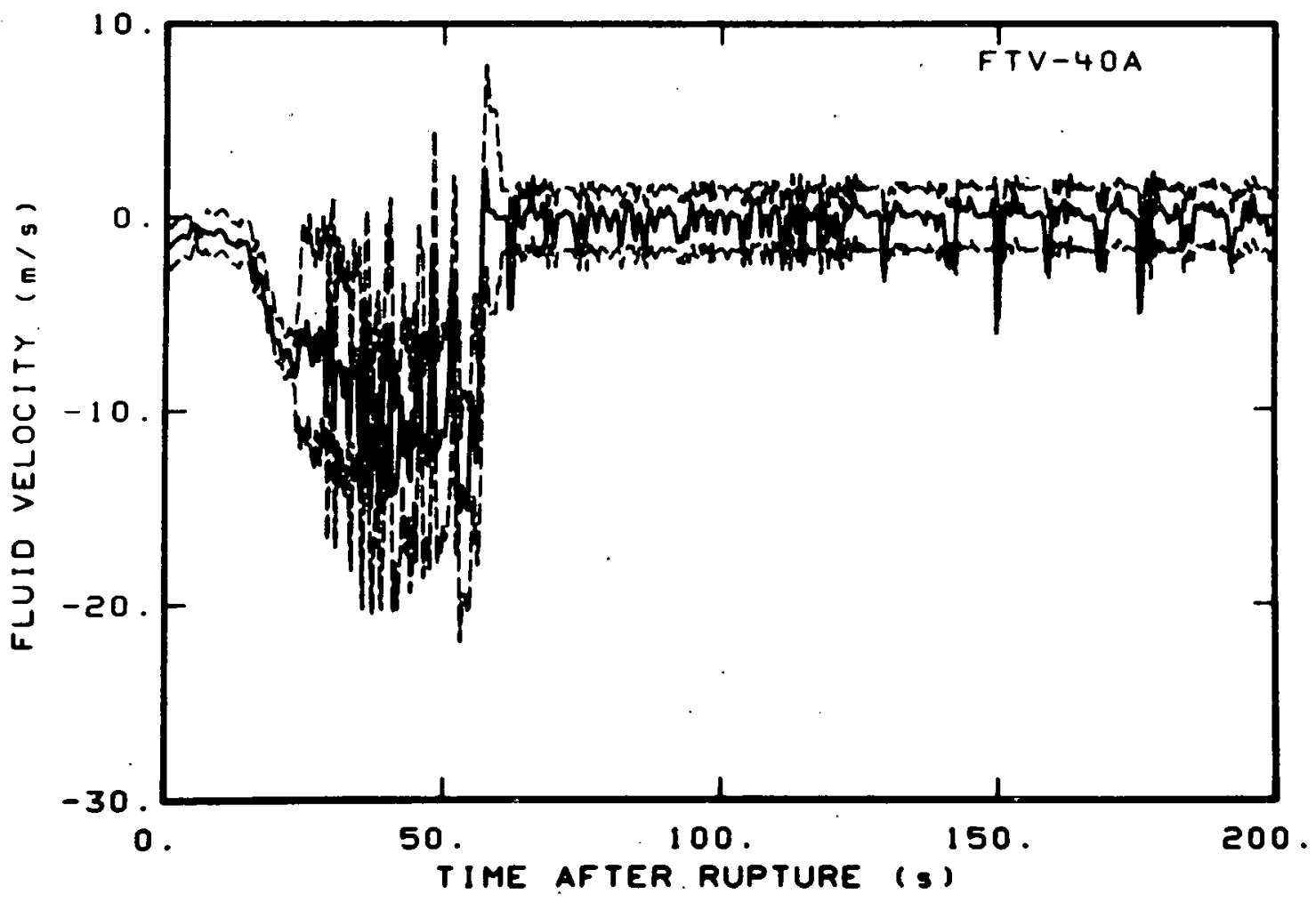

Fig. B-23 Fluid velocity in vessel (FTV-40A). 


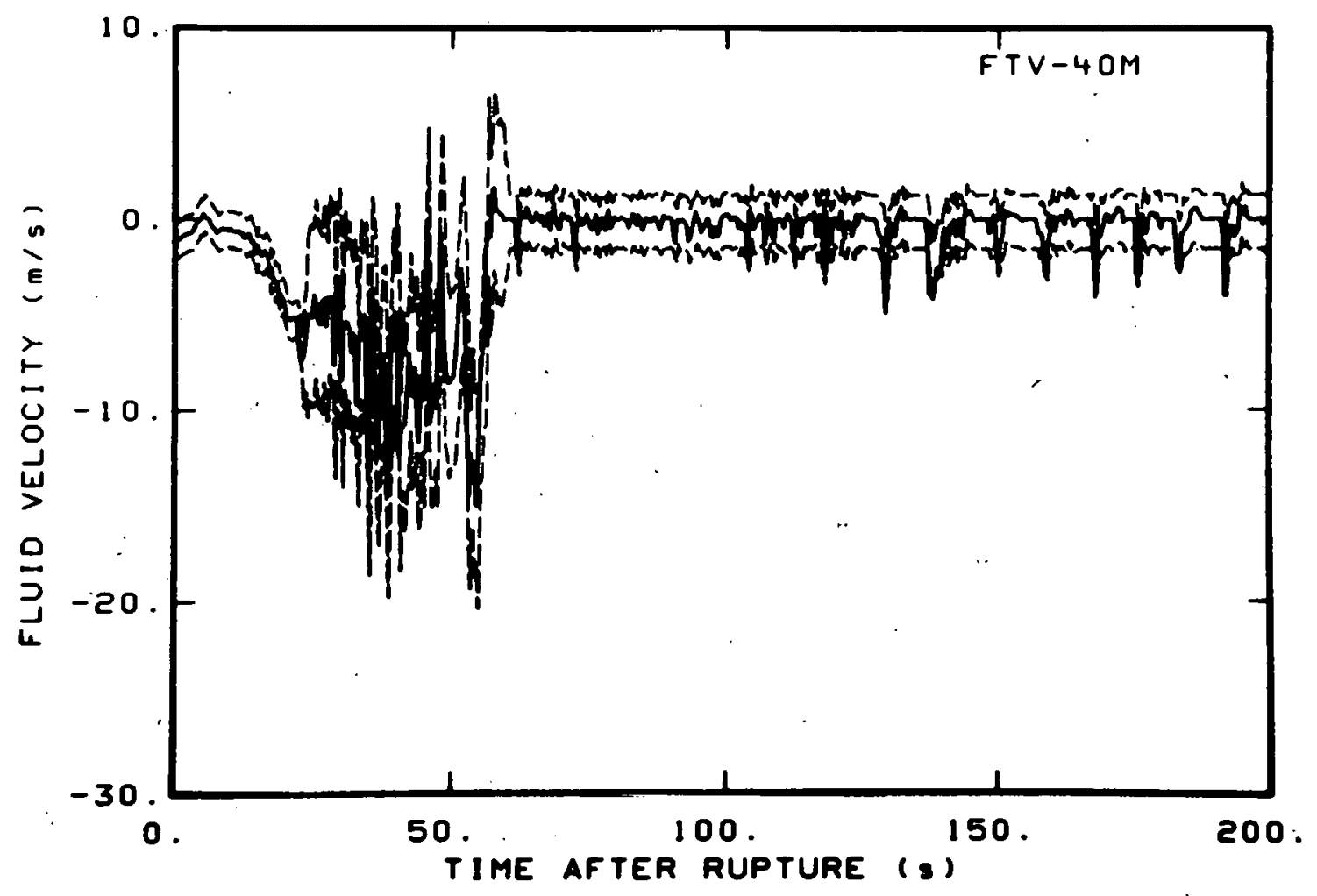

Fig. B-24 Fluid velocity in vessel (FTV-40M).

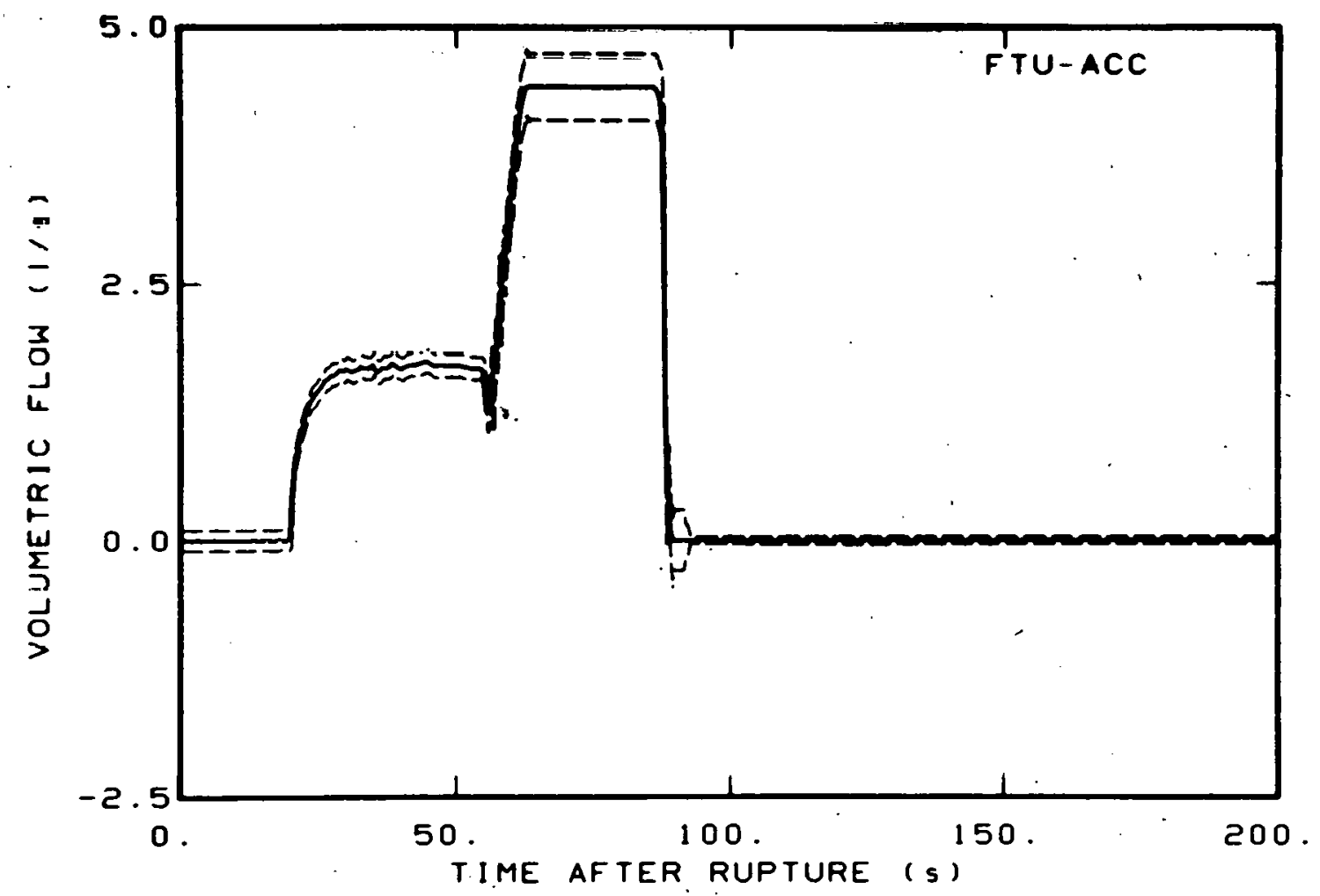

Fig. B-25 Volumetric flow in intact loop accumulator discharge line (FTU-ACC). 


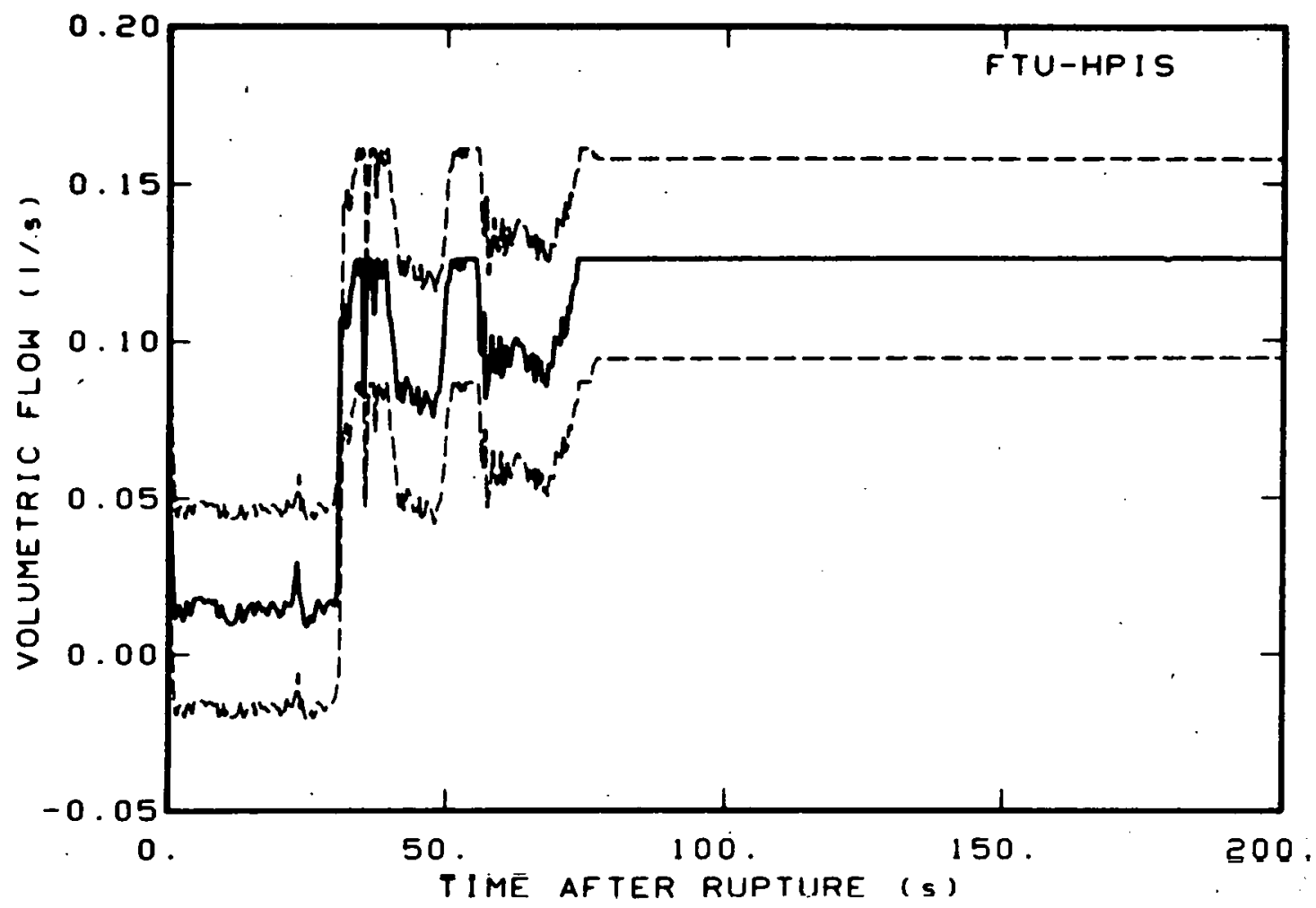

Fig. B-26 Volumetric flow in intact loop high pressure injection line (FTU-HPIS).

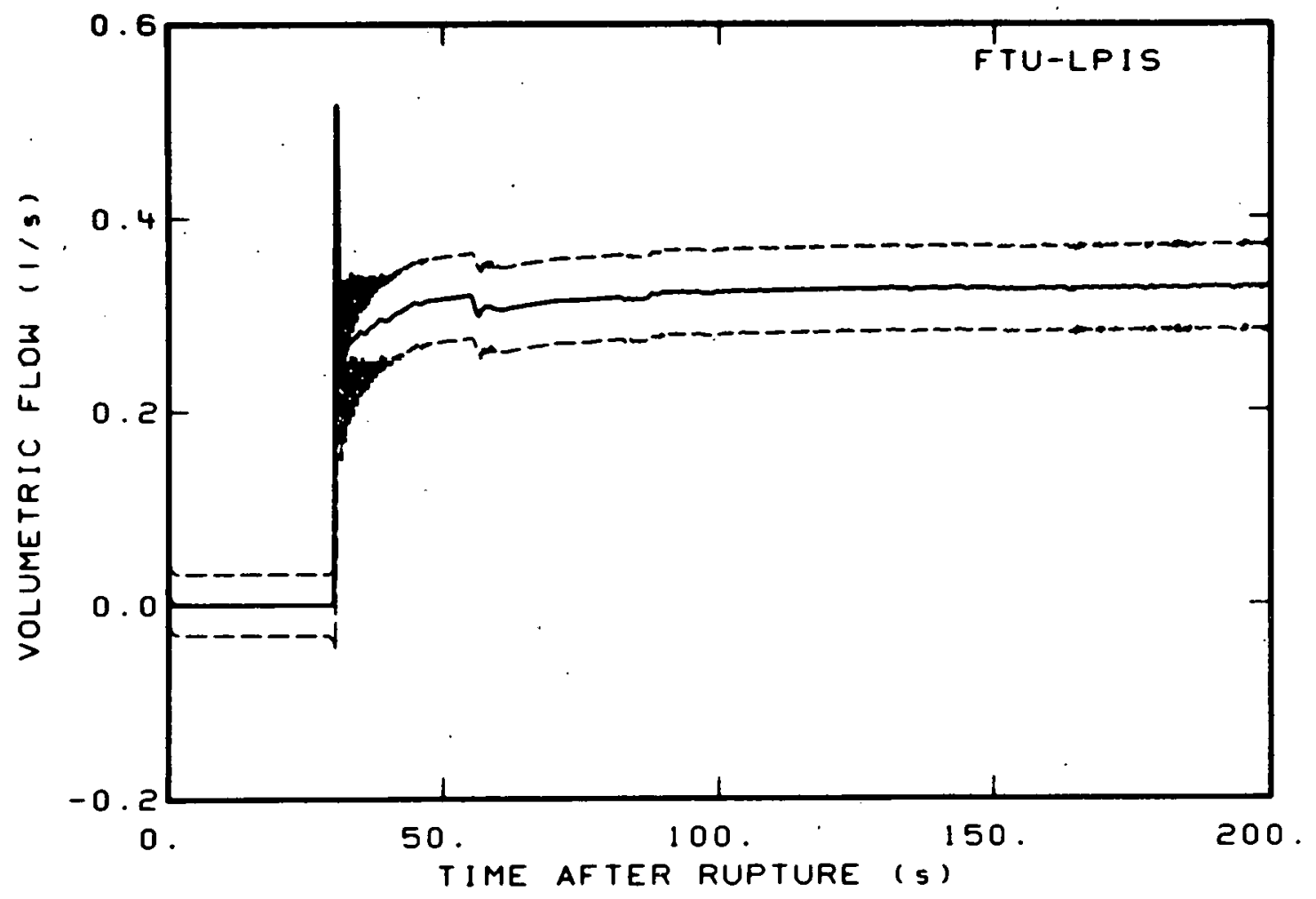

Fig. B-27 Volumetric flow in intact loop low pressure injection line (FTU-LPIS). 


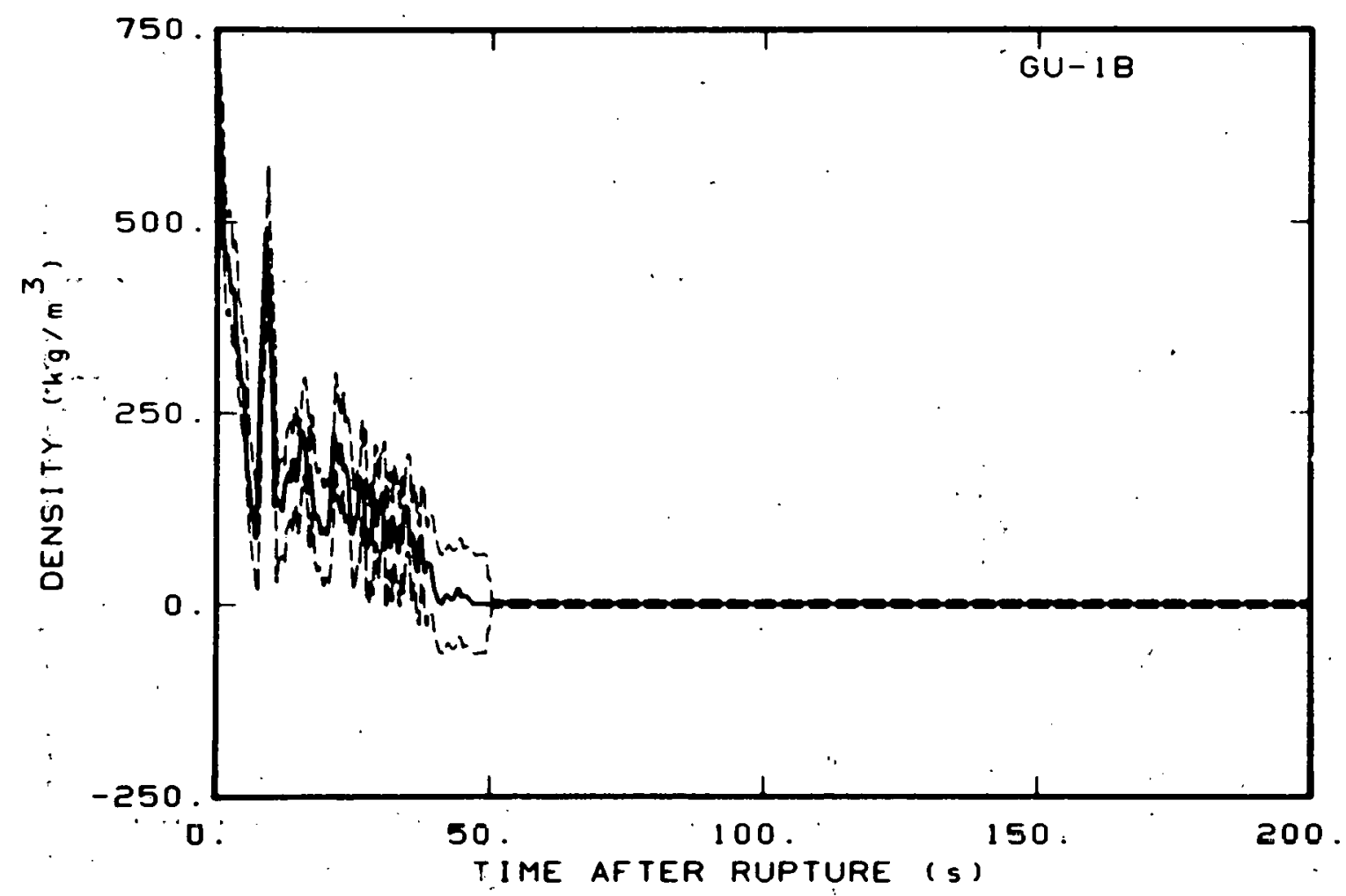

Fig. B-28 Density in intact loop (GU-1B).

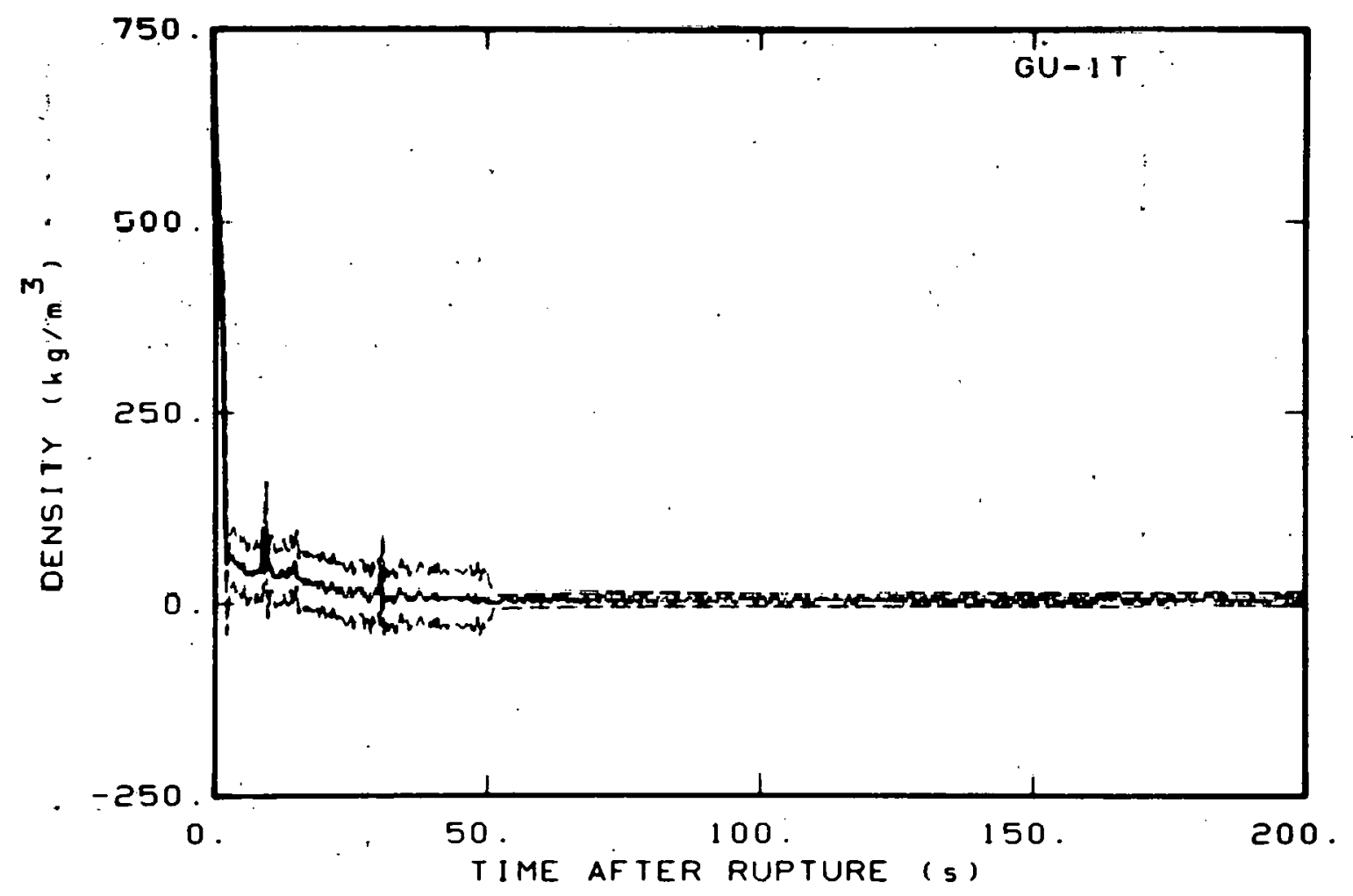

Fiǵ. B-29 Density in intact loop (GU-1T). 


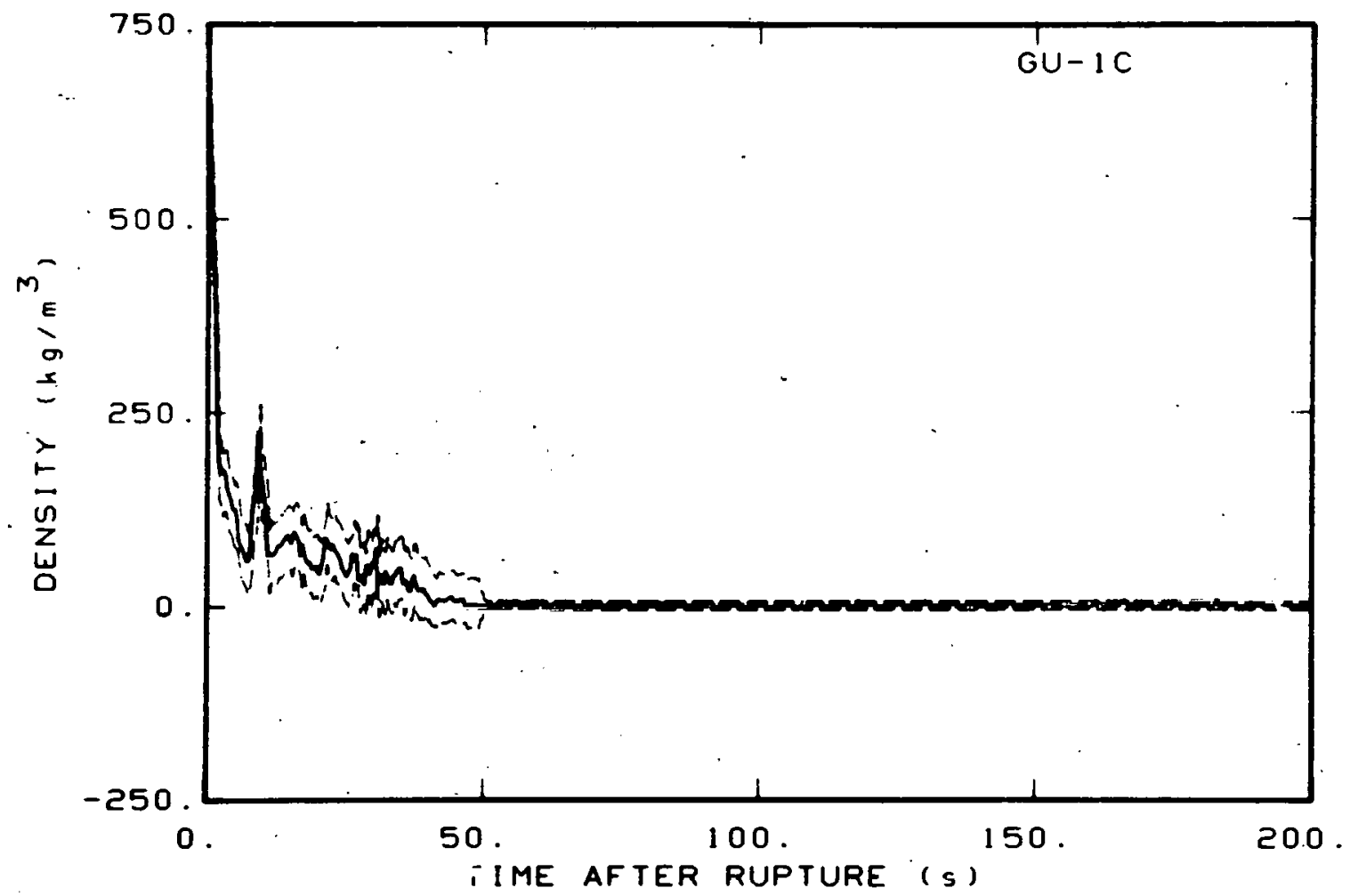

Fig. B-30 Density in intact loop (GU-1C).

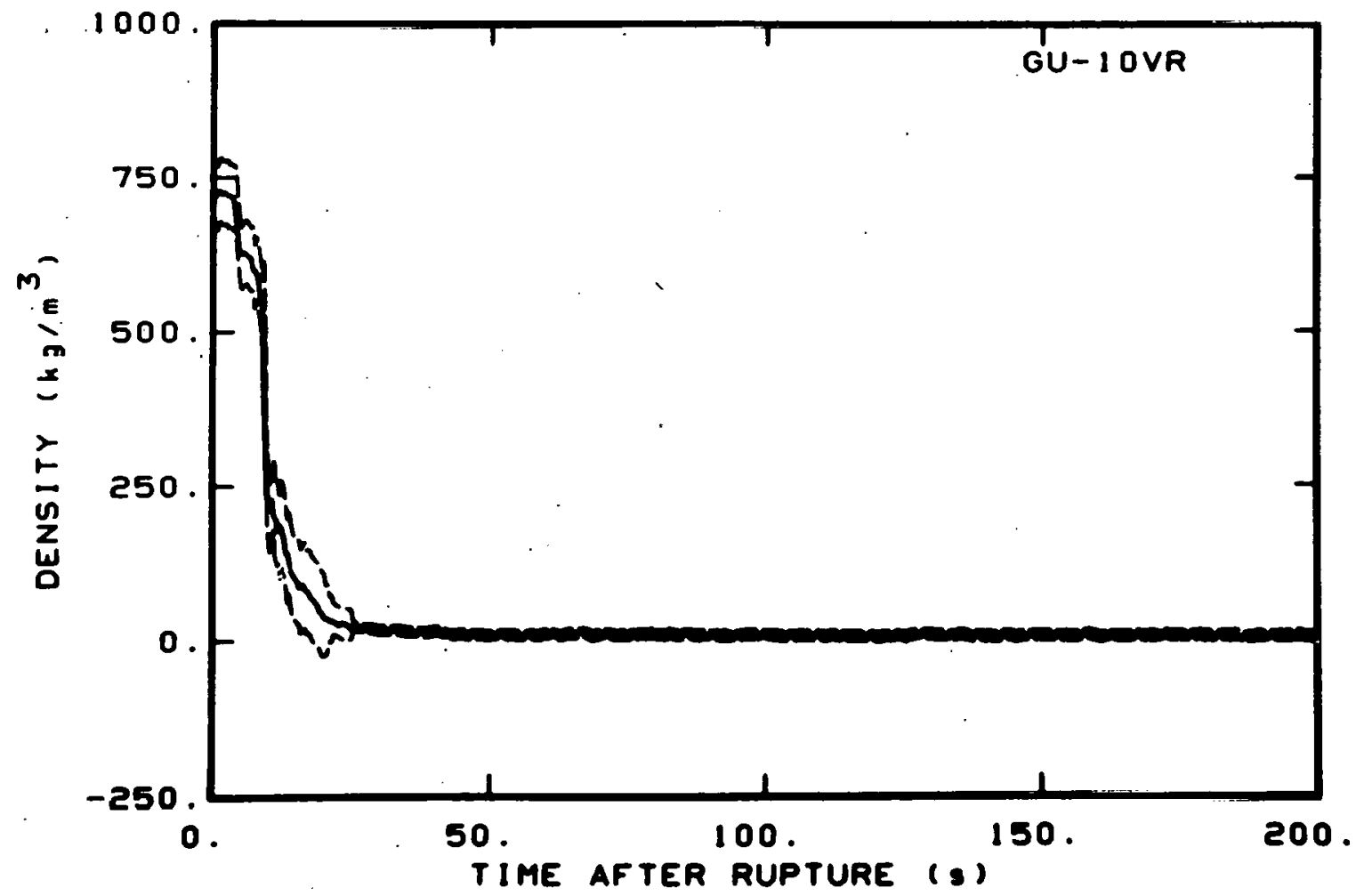

Fig. B-31 Density in intact loop (GU-10VR). 


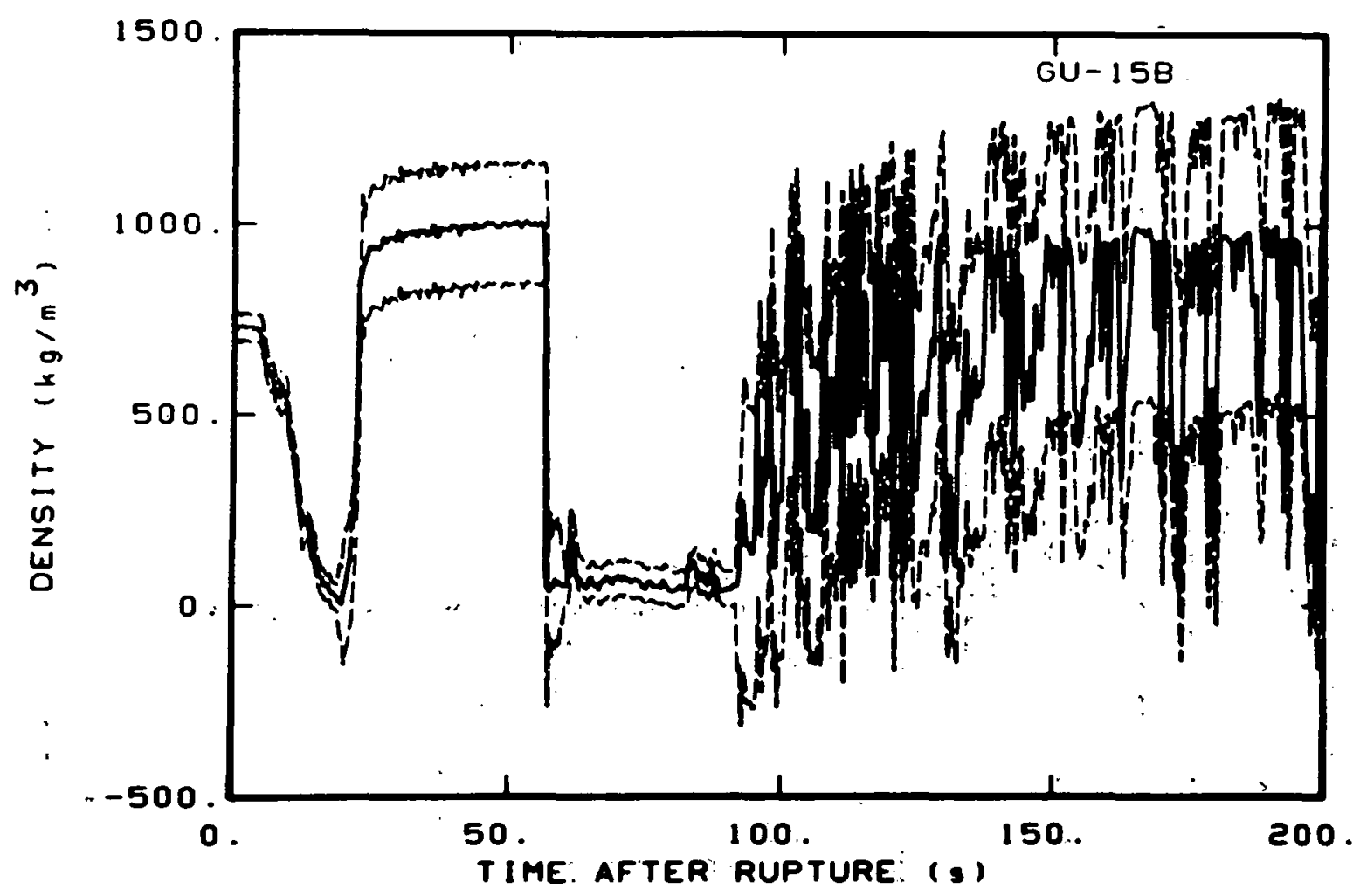

Fig. B-32 Density in intact loop (GU-15B).

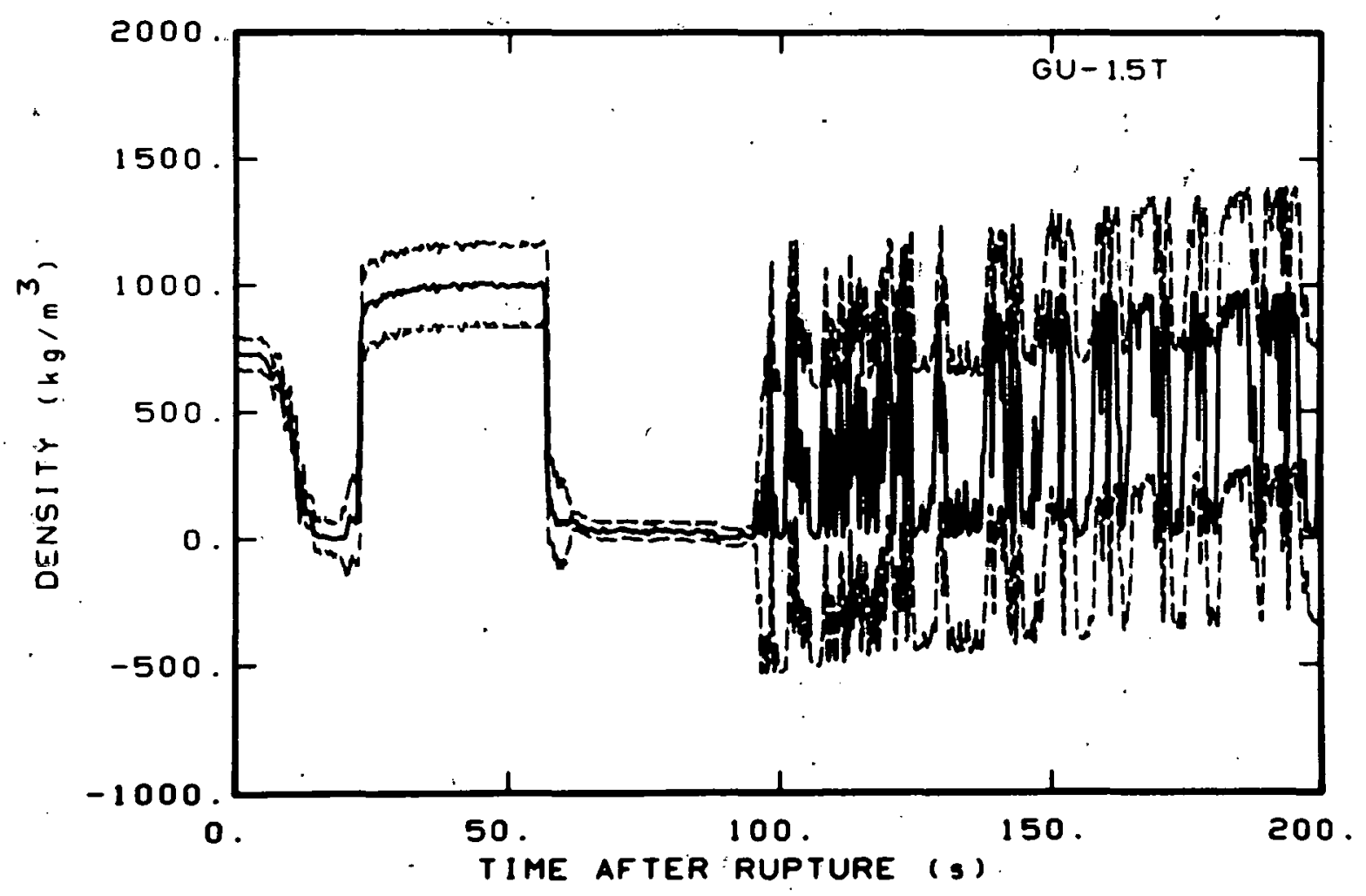

Fig. B-33 Density in intact 100p (GU-15T). 


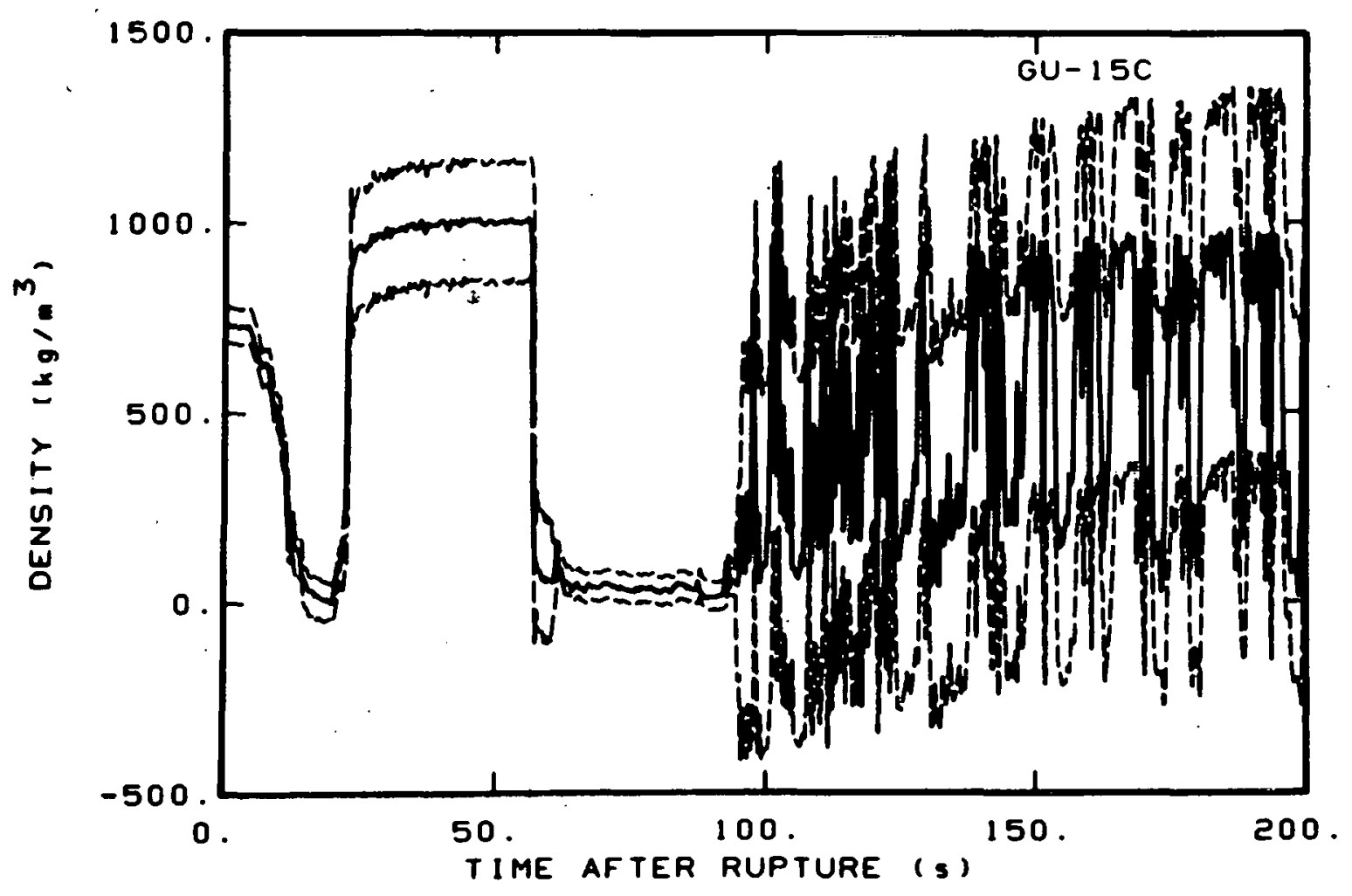

Fig. B-34 Density in intact loop (GU-15C).

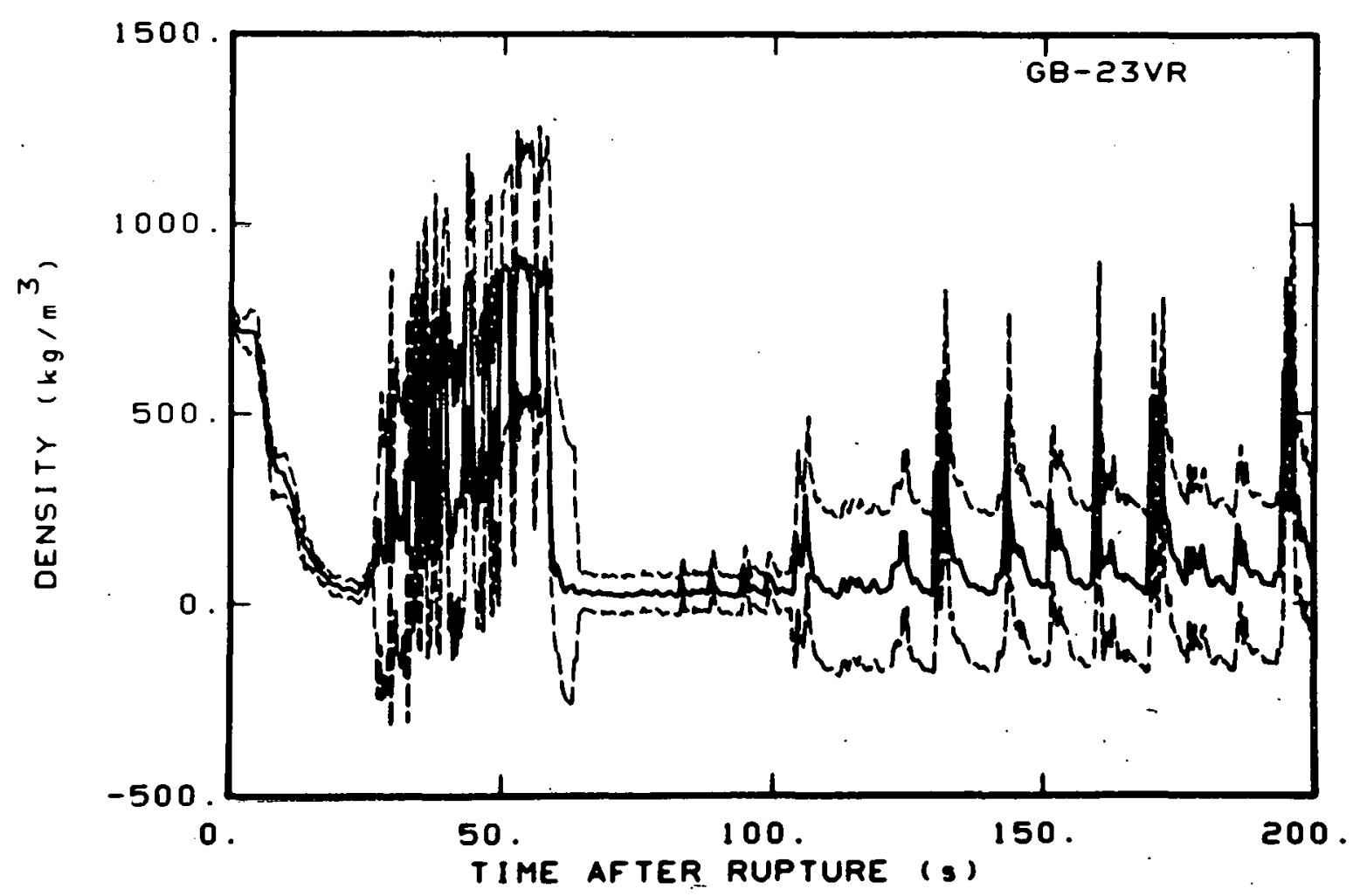

Fig. B-35 Density in broken loop (GV-23VR). 


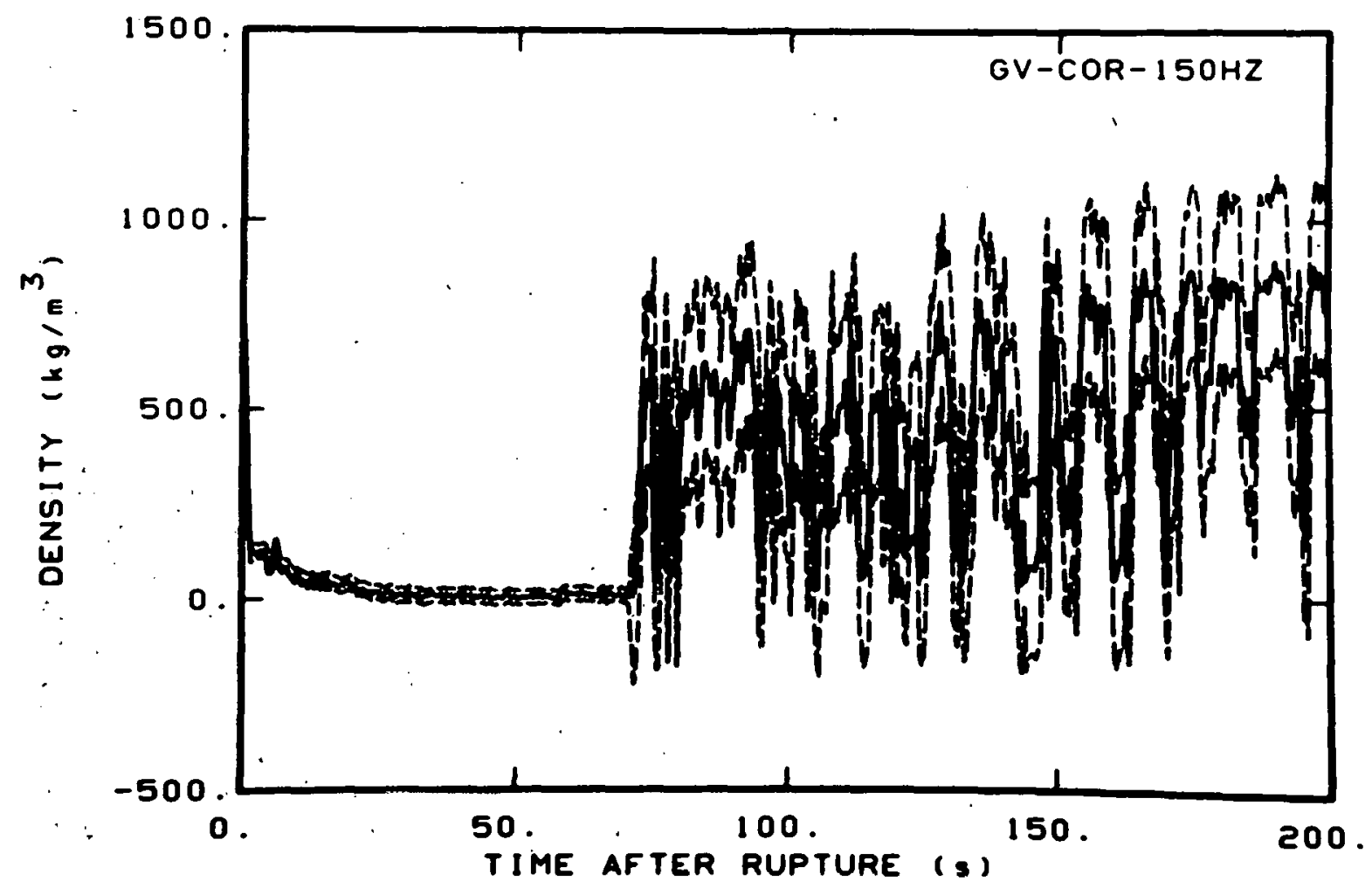

Fig. B-36 Density in vessel (GV-COR-150HZ).

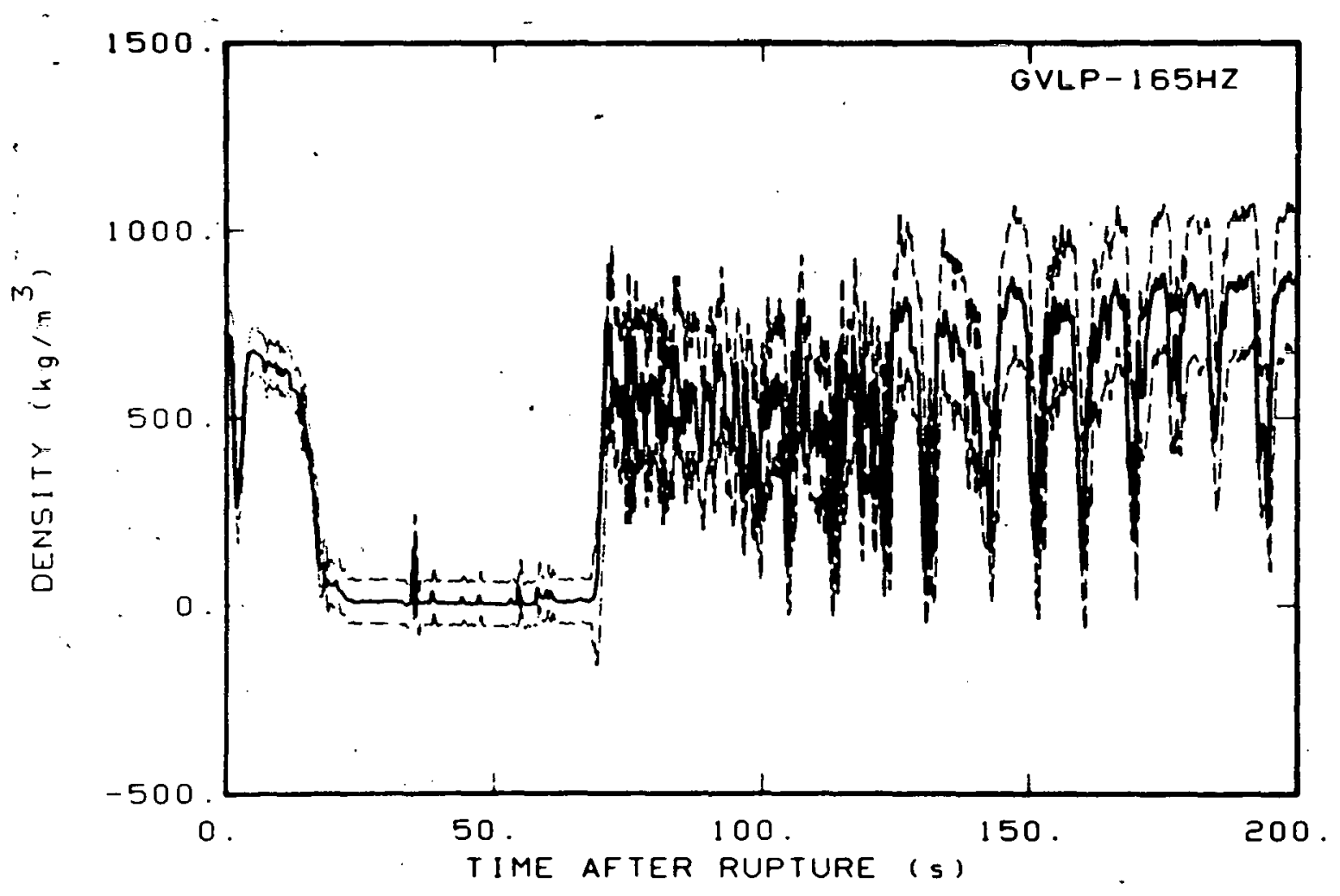

Fig. B-37 Density in vesset (GVLP-165HZ). 


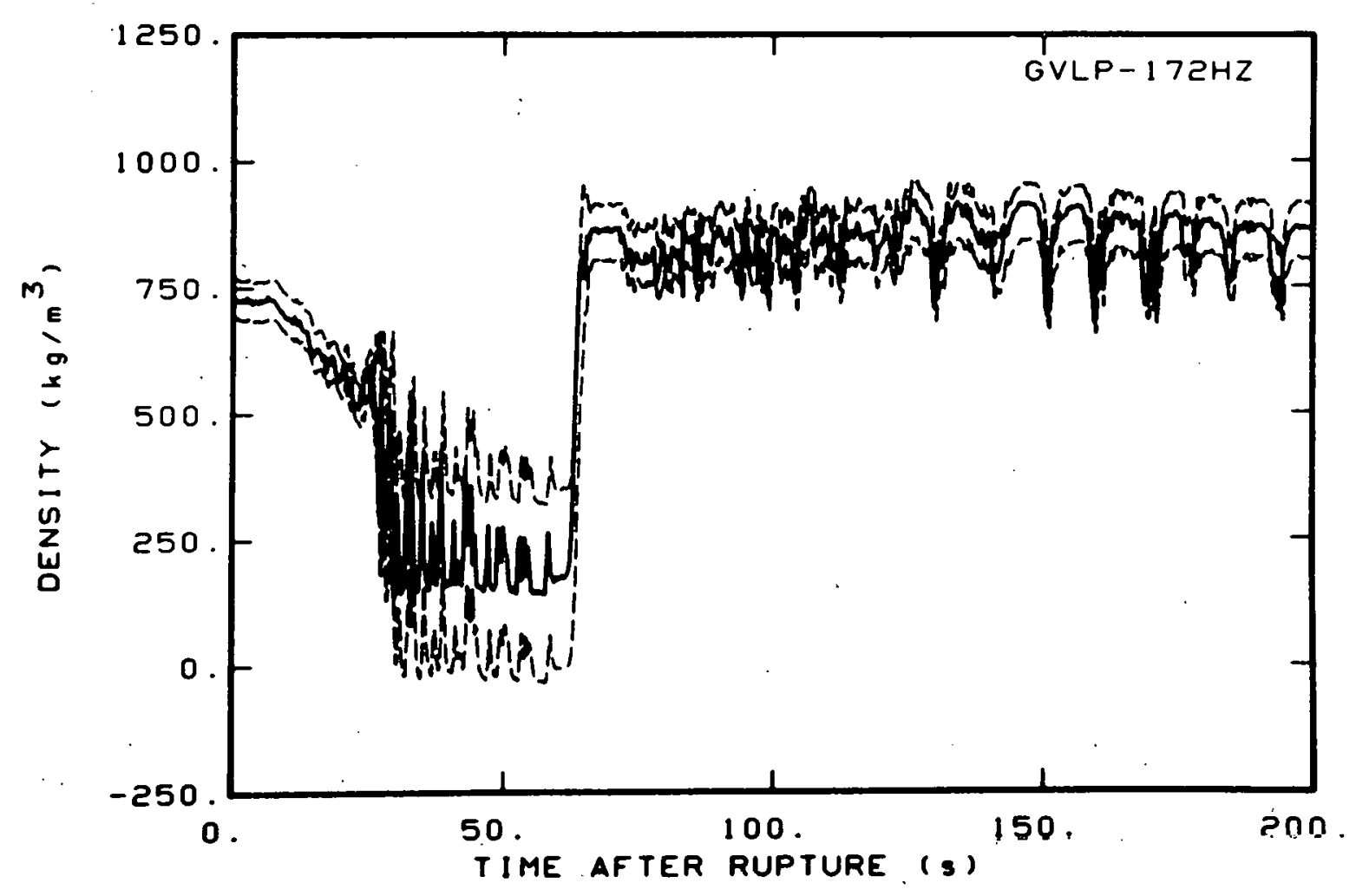

Fig. B-38 Density in vessel (GVLP-172HZ).

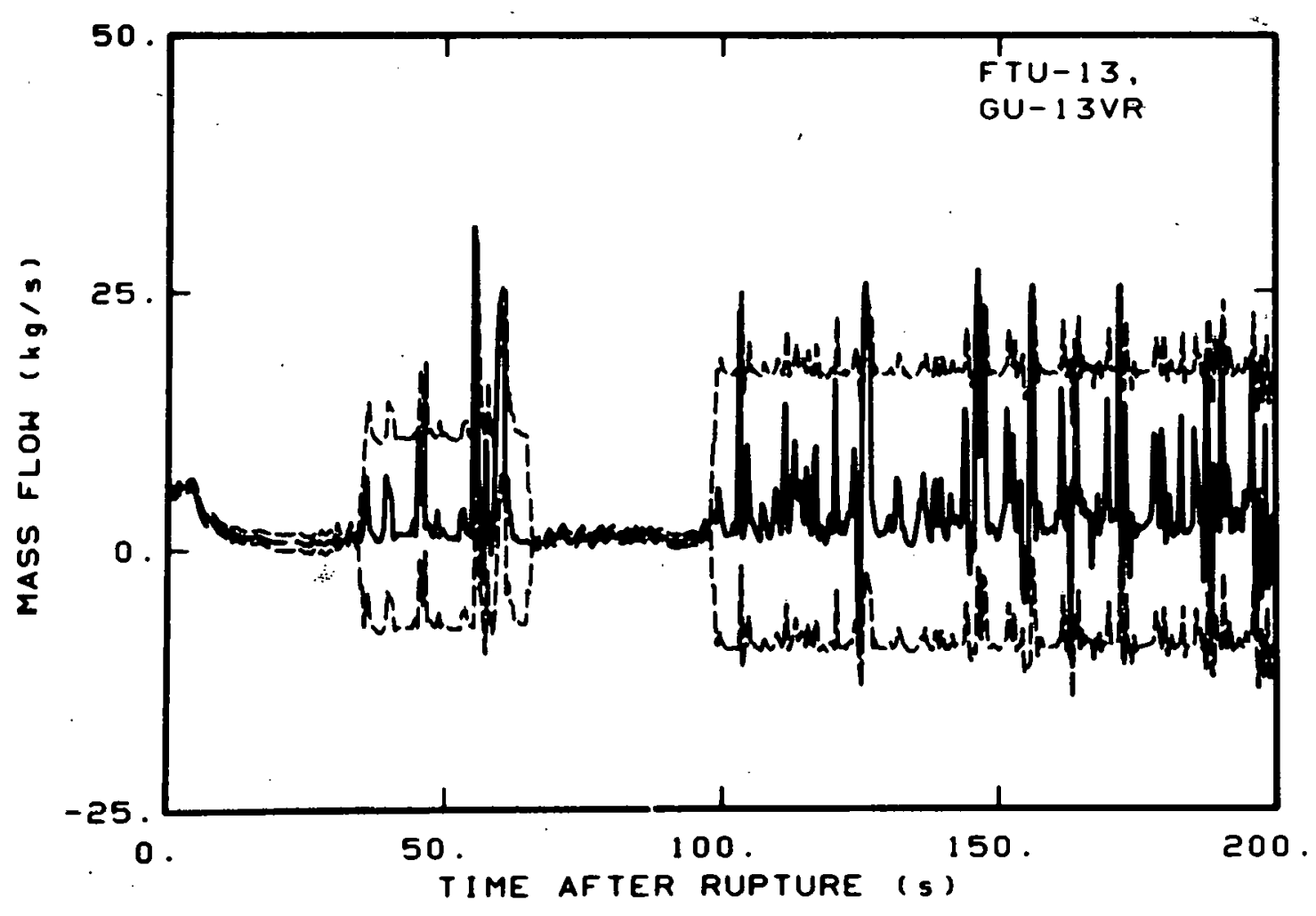

Fig. B-39 Mass flow in intact loop (FTU-13 and GU-13VR). 


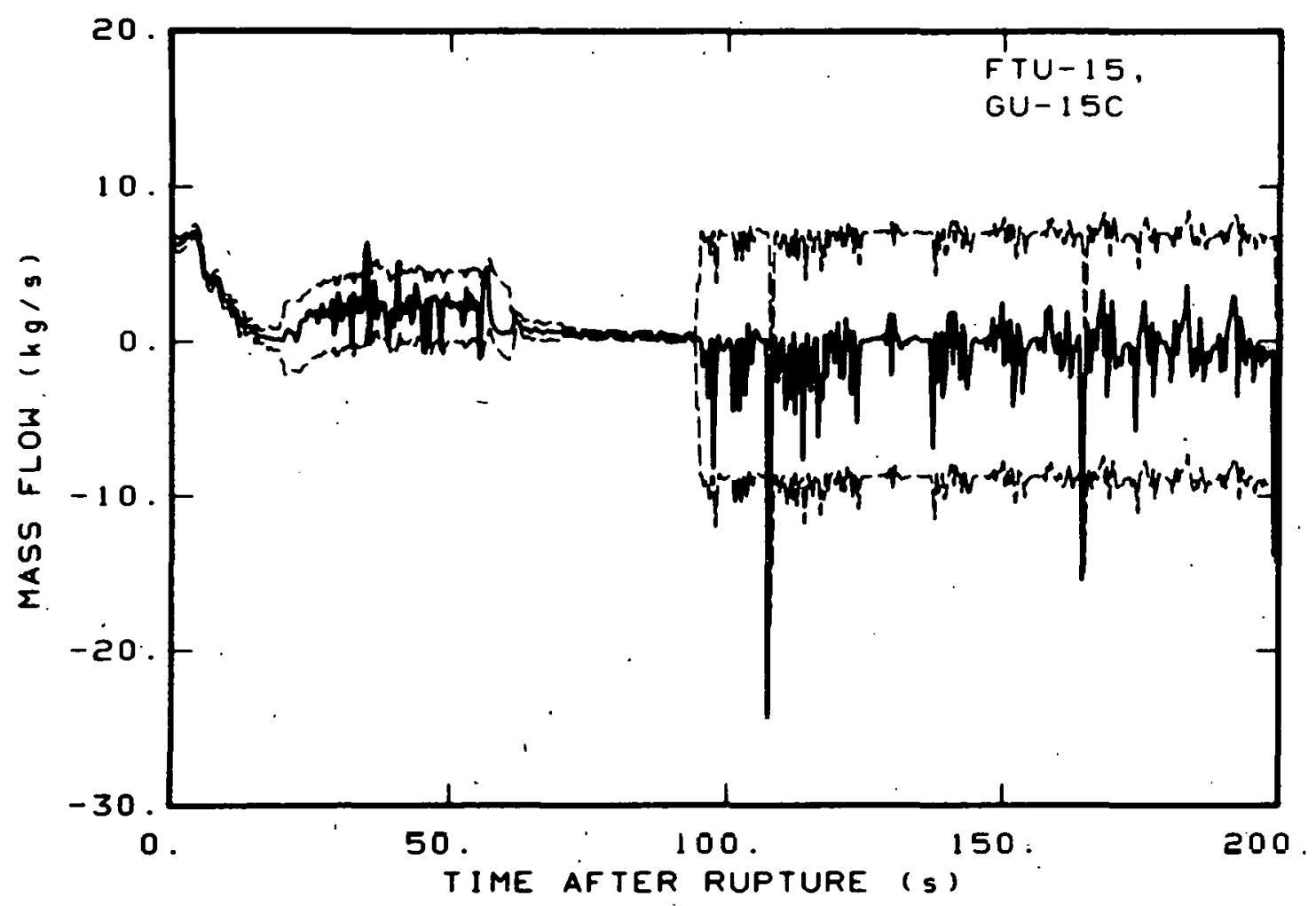

Fig. B-40 Mass flow in intact loop (FTU-15 and GU-15C).

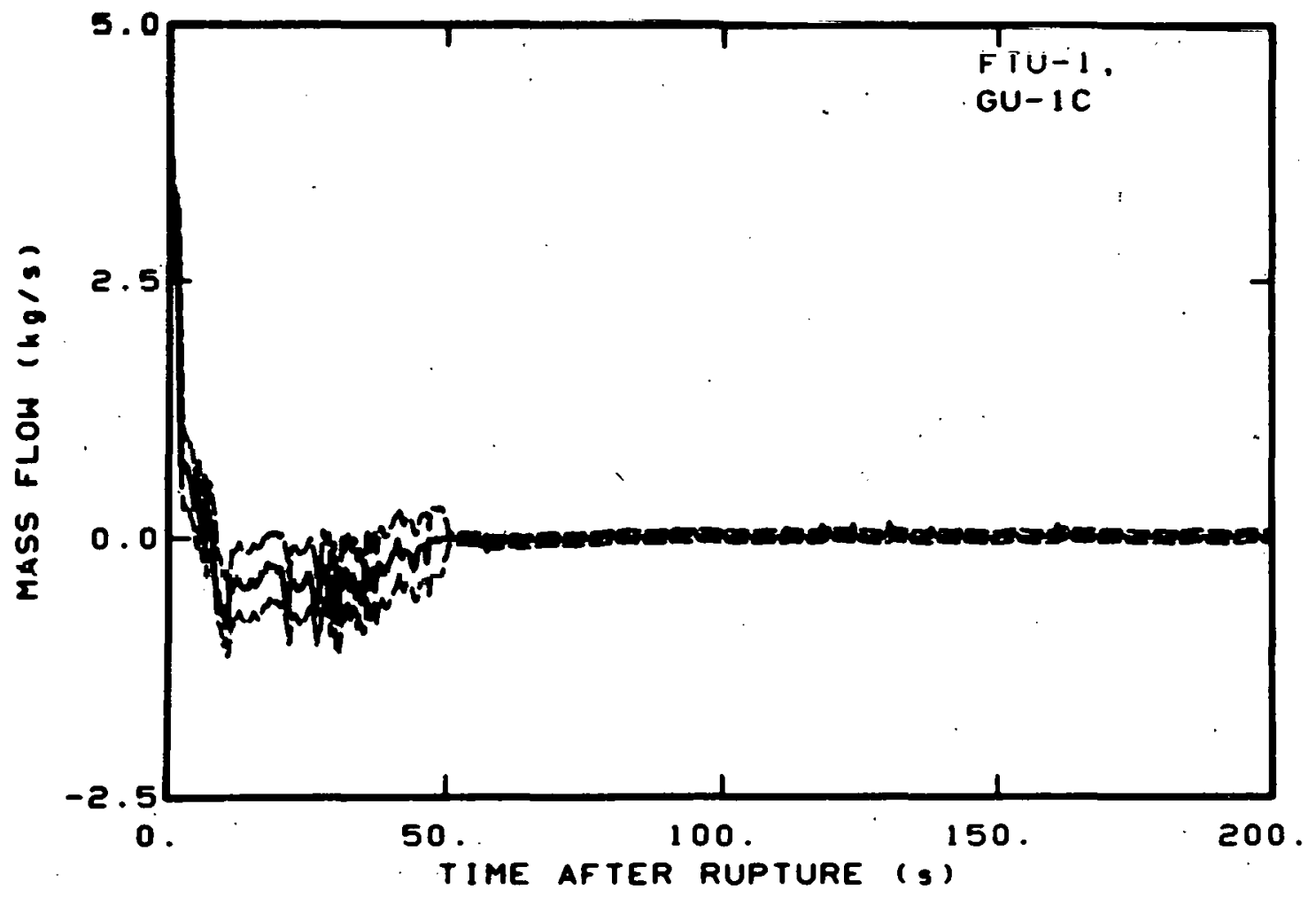

Fig. B-41. Mass flow in intact loop (FTU-1 and GU-IC). 


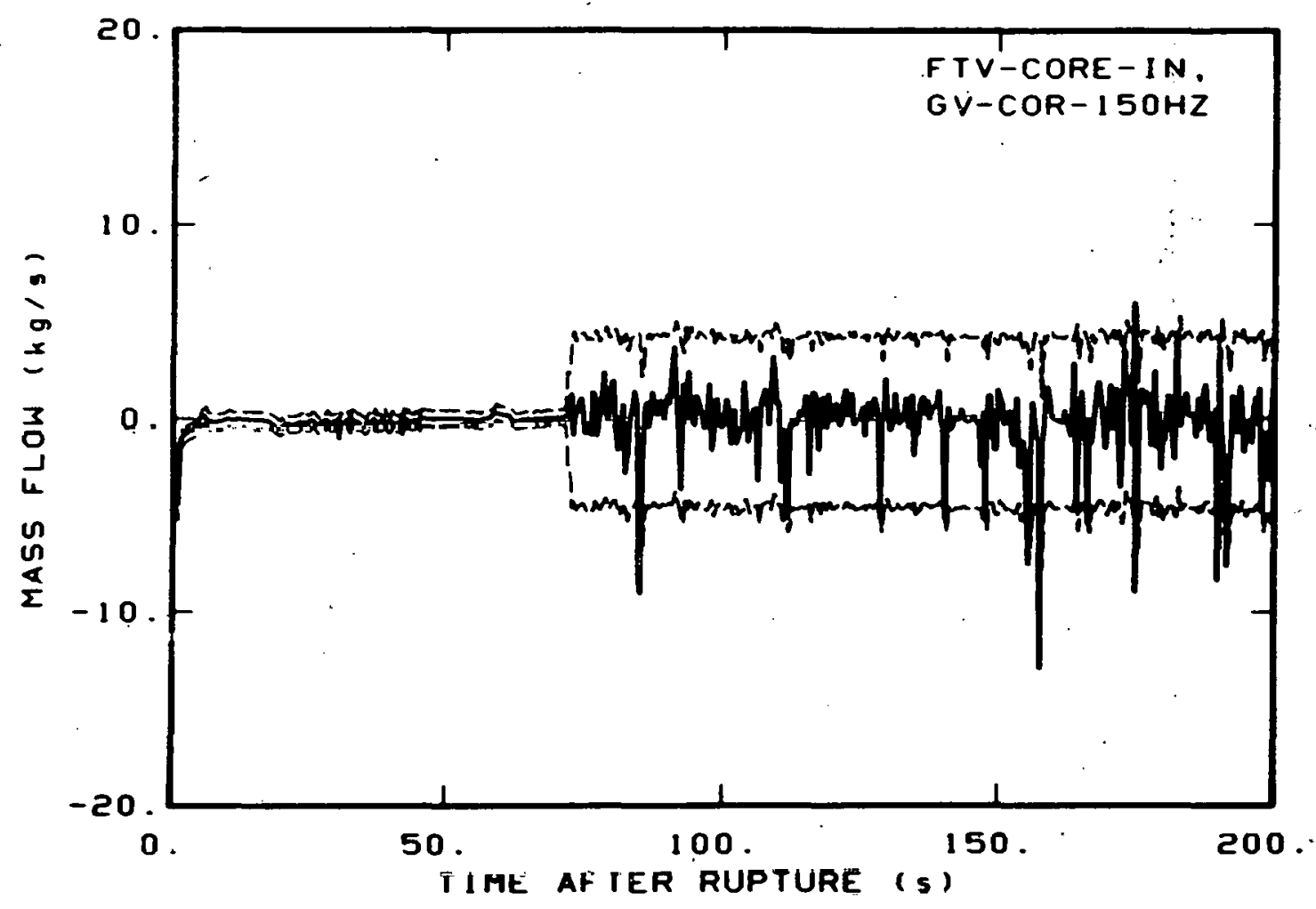

Fig. B-42 Mass flow in vessel (FTV-CORE-IN and GV-COR-150HZ).

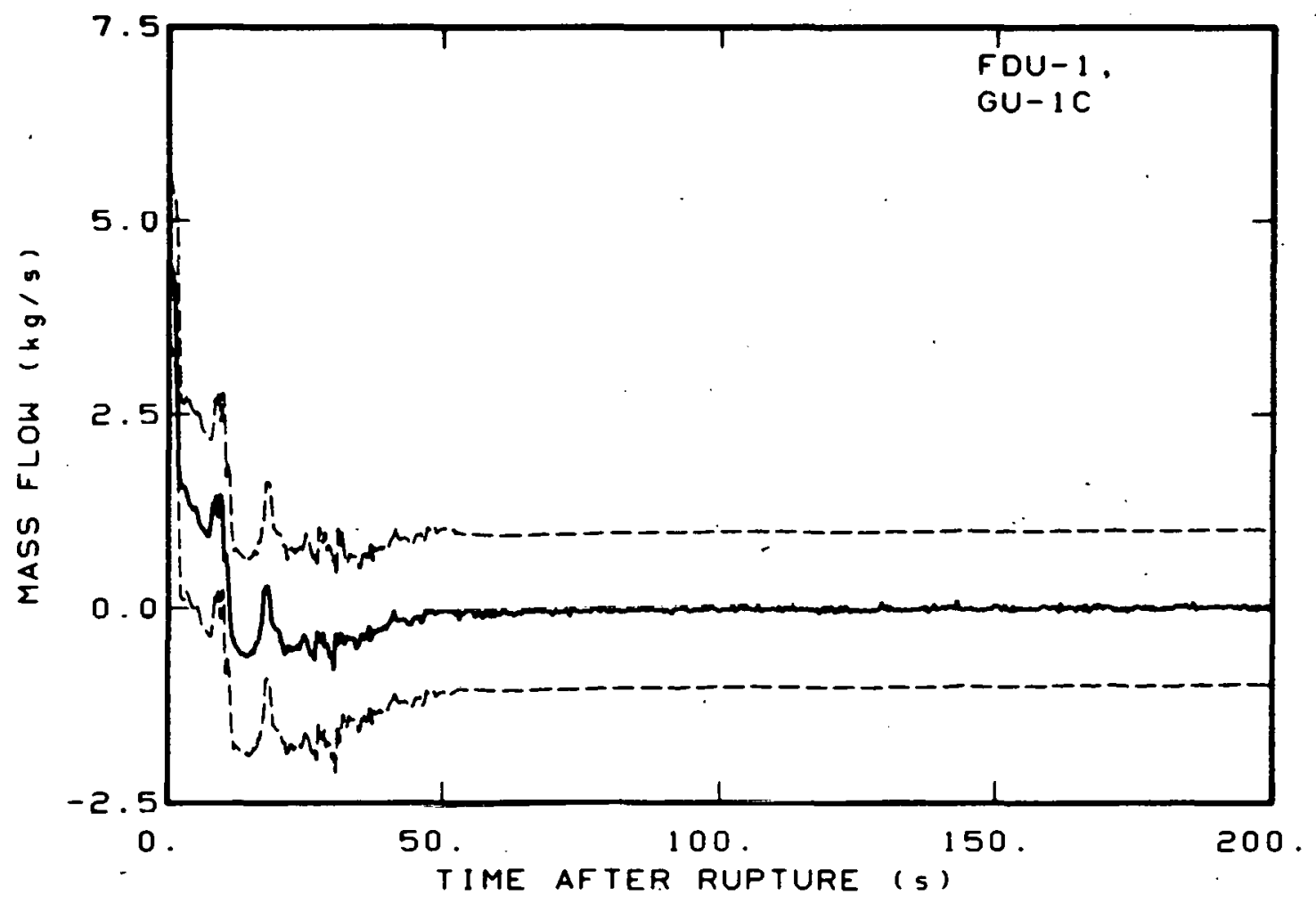

Fig. B-43 Mass flow in intact loop (FDU-1 and GU-1C). 


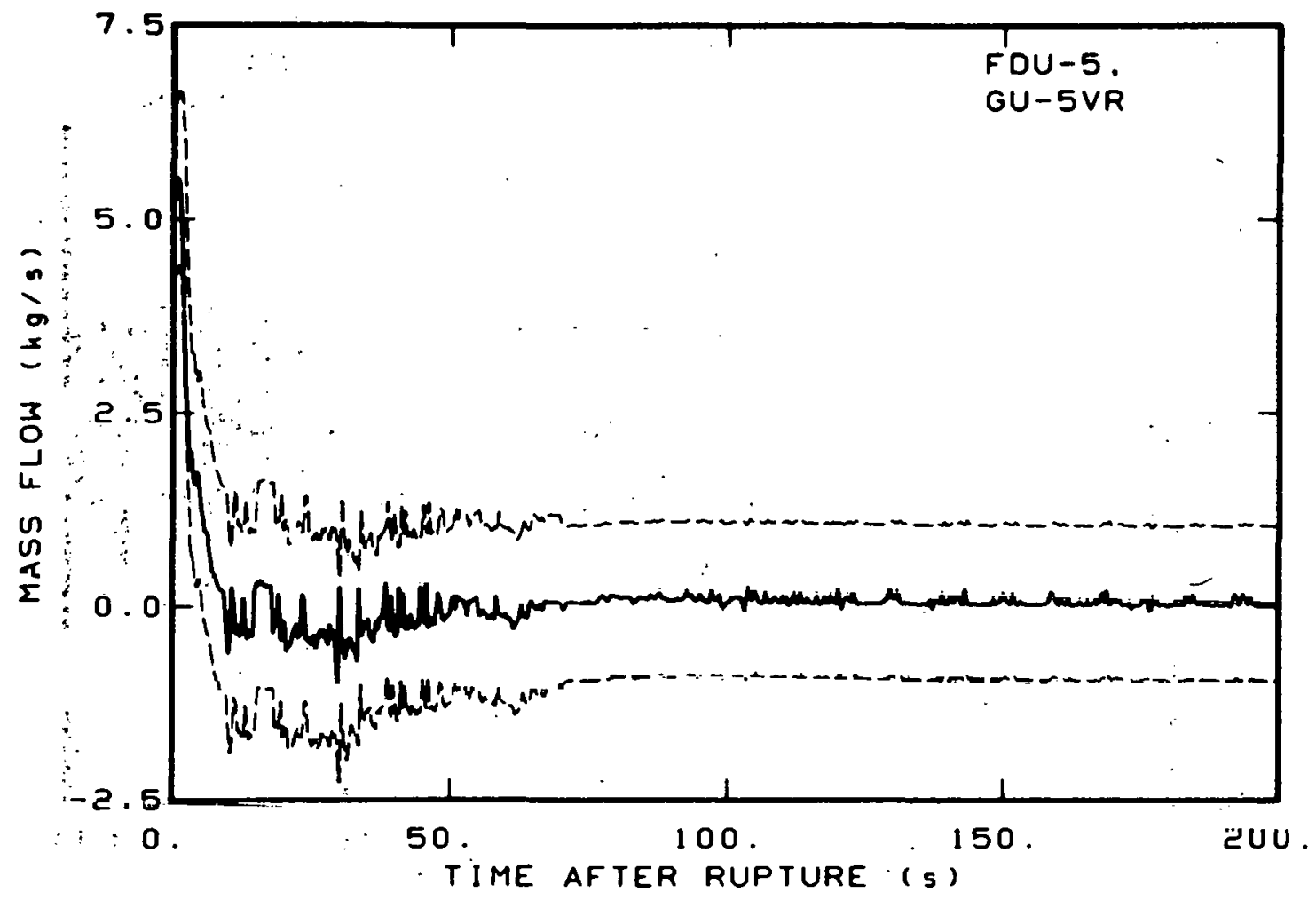

Fig. B-44 Mass flow in intact loop (FDU-5 and GU-5VR).

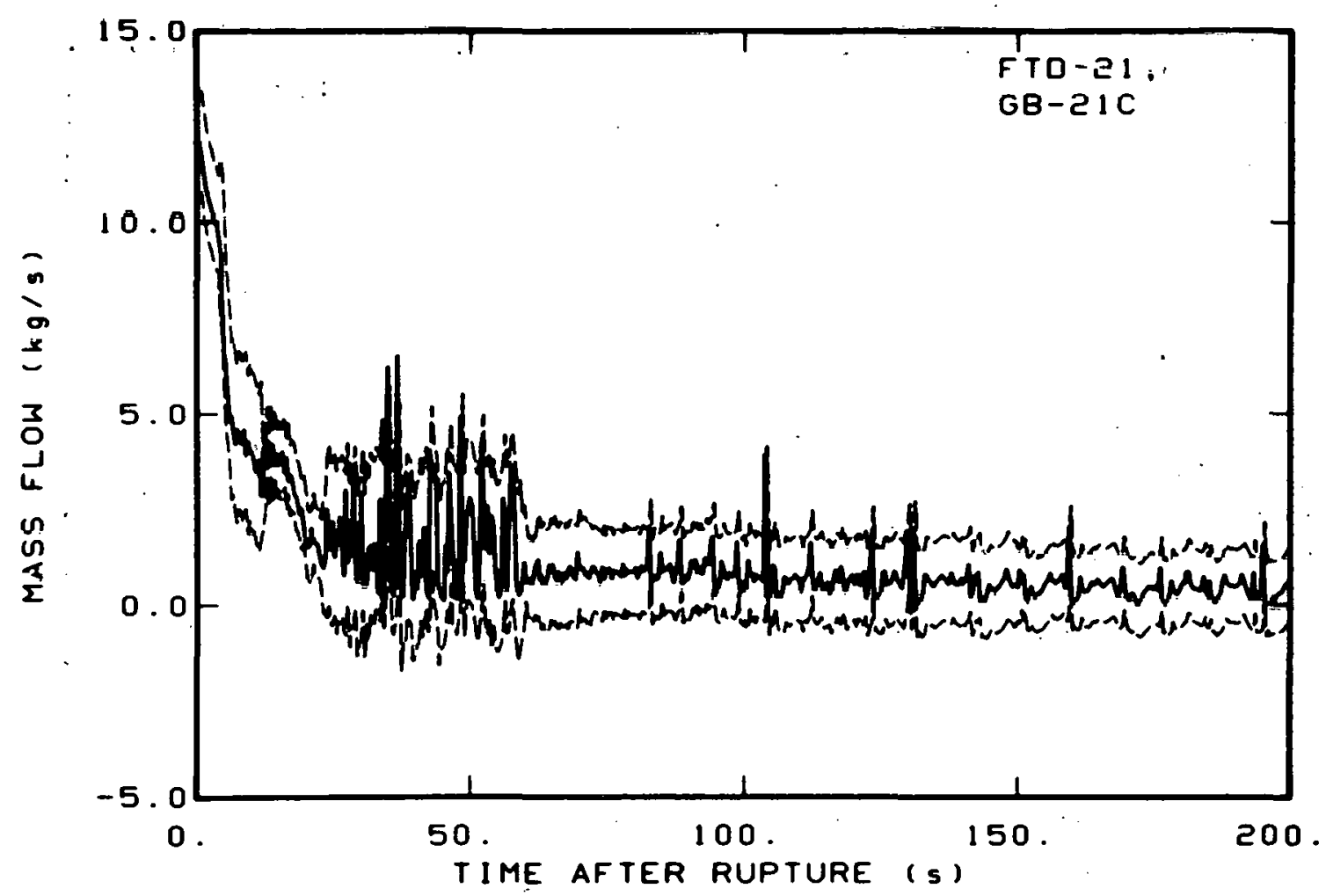

Fig. B-45 Mass flow in broken loop (FTB-21 and GB-21C). 
TABLE B-II

GENERAL MEASUREMENT ENGINEERING ERROR SCURCES AND ERROR VALUES

\begin{tabular}{|c|c|c|c|}
\hline $\begin{array}{c}\text { Measurement } \\
\text { Category }\end{array}$ & Errar Sources & Error Value & Expected Error Value \\
\hline \multirow[t]{4}{*}{$\begin{array}{l}\text { Fluid } \\
\text { Temperature }\end{array}$} & $\begin{array}{l}\text { Changes in homogeneity of the } \\
\text { thermocouple wire due to cold } \\
\text { working }\end{array}$ & $\pm 1.11 \mathrm{~K}$. & \\
\hline & $\begin{array}{l}\text { Data interpretation from } \\
\text { standard reference tables }\end{array}$ & $\pm 1.11 \mathrm{~K}$ & \\
\hline & $\begin{array}{l}\text { General data acquisition and } \\
\text { processing. }\end{array}$ & $\pm 2.50 \mathrm{~K}$ & \\
\hline & Thermal aging of the thermocouples & $\pm 0.28 \mathrm{~K}$ & \\
\hline \multirow[t]{4}{*}{$\begin{array}{l}\text { Material } \\
\text { Temperature }\end{array}$} & $\begin{array}{l}\text { Changes in homogeneity of the } \\
\text { thermocouple wire due to cold } \\
\text { working }\end{array}$ & $\pm 1.11 \mathrm{~K}$ & \\
\hline & Thermocouple radial position & $+2.78 k$ & \\
\hline & $\begin{array}{l}\text { Data interprejation from standard } \\
\text { reference tables }\end{array}$ & $\pm 1.11 \mathrm{~K}$ & $+3.9 \mathrm{~K}$ \\
\hline & $\begin{array}{l}\text { General data acquisition and } \\
\text { processing }\end{array}$ & $\pm 2.50 \mathrm{~K}$ & \\
\hline & Thermal aging of the thermocouples & $+0.28 \mathrm{~K}$ & \\
\hline
\end{tabular}


TAB $-E$ B-II (continued)

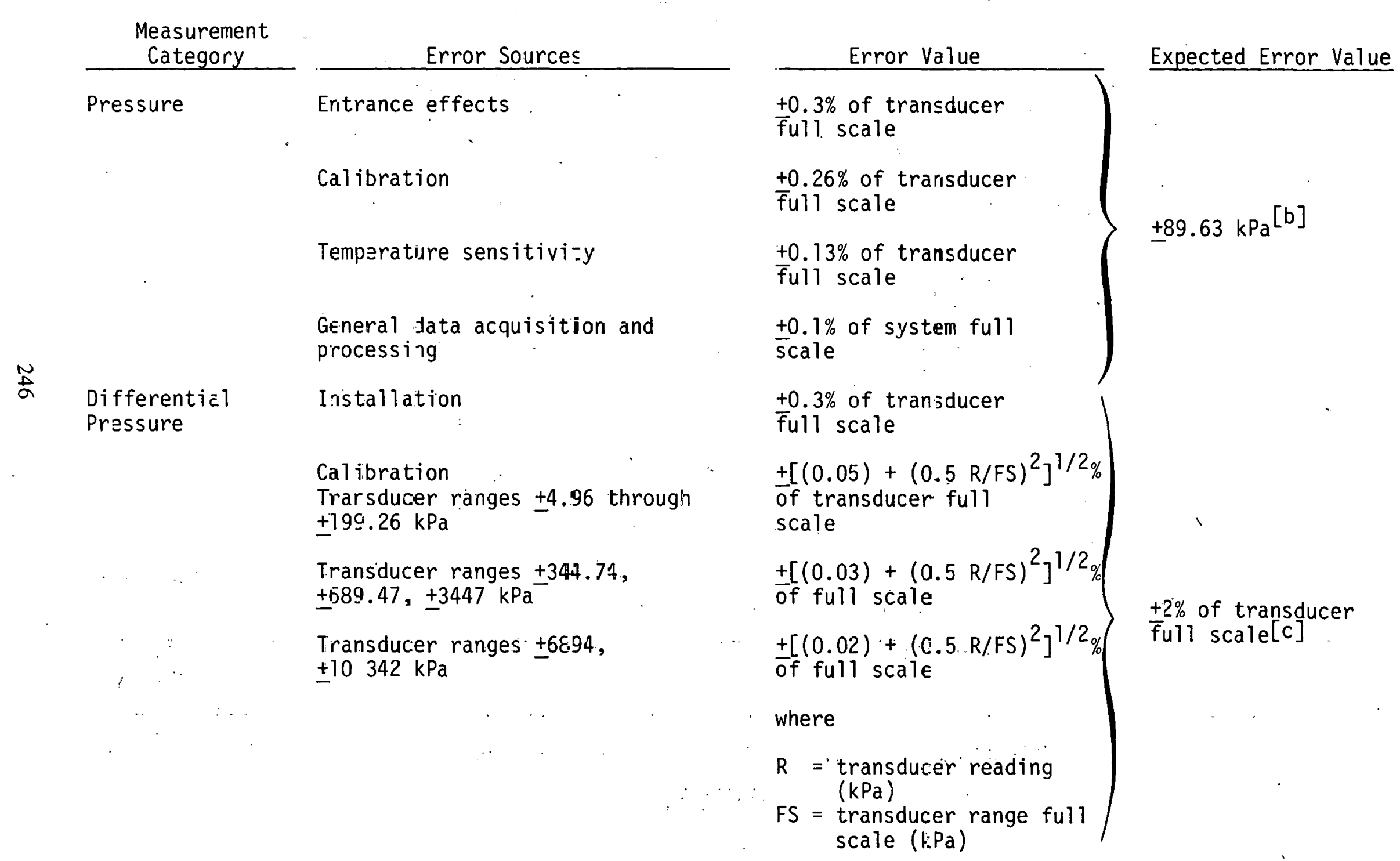


TABLE B-II (continued)

\begin{tabular}{|c|c|c|c|}
\hline $\begin{array}{l}\text { Measurement } \\
\text { Category }\end{array}$ & Error Sources & Error Value & Expected Error Value \\
\hline \multirow{3}{*}{$\begin{array}{l}\text { Differential } \\
\text { Pressure } \\
\text { (continued) }\end{array}$} & Temperature sensitivity & $\begin{array}{l}+0.5 \% \text { of transducer } \\
\text { full scale }\end{array}$ & \multirow{2}{*}{$\begin{array}{l}+2 \% \text { of trapsducer } \\
\text { full scale }[\mathrm{c}]\end{array}$} \\
\hline & $\begin{array}{l}\text { General data acquisition and } \\
\text { processing }\end{array}$ & $\begin{array}{l}+0.1 \% \text { of system full } \\
\text { scale }\end{array}$ & \\
\hline & Air entrapment & $\pm 0.069 \mathrm{kPa}$ & · \\
\hline \multirow{4}{*}{$\begin{array}{l}\text { Fluid Velocity } \\
\text { (point velocities } \\
\text { measured with } \\
\text { turboprobes) }\end{array}$} & Installation & $\begin{array}{l}+0.8 \% \text { of transducer } \\
\text { full scale }\end{array}$ & \multirow{2}{*}{$\stackrel{+[0.5825+}{\left.(0.008 R)^{2}\right]^{1 / 2}(\mathrm{~m} / \mathrm{s})}$} \\
\hline & Calibration & $\begin{array}{l}+5 \% \text { of transducer } \\
\text { full scale }\end{array}$ & \\
\hline & $\begin{array}{l}\text { Data acquisiticn and processing } \\
\text { frequency conversion }\end{array}$ & $\begin{array}{l}+0.25 \% \text { of transducer } \\
\text { full scale }\end{array}$ & \multirow{3}{*}{$\begin{array}{l}\text { where } \\
\mathrm{R}=\text { transducer read- } \\
\quad \text { ing }(\mathrm{m} / \mathrm{s})\end{array}$} \\
\hline & General & $\begin{array}{l}+0.1 \% \text { of system } \\
\text { full scale }\end{array}$ & \\
\hline \multirow[t]{3}{*}{ Density } & Calibration & $\pm .7 .0 \%$ of reading $\left(\mathrm{kg} / \mathrm{m}^{3}\right)$ & \\
\hline & Detector system error & $\pm 2.1 \mathrm{~kg} / \mathrm{m}^{3}$. & \multirow{2}{*}{ [d] } \\
\hline & $\begin{array}{l}\text { General data acquisition and } \\
\text { processing }\end{array}$ & $\pm 1.6 \mathrm{~kg} / \mathrm{m}^{3}$ & \\
\hline
\end{tabular}




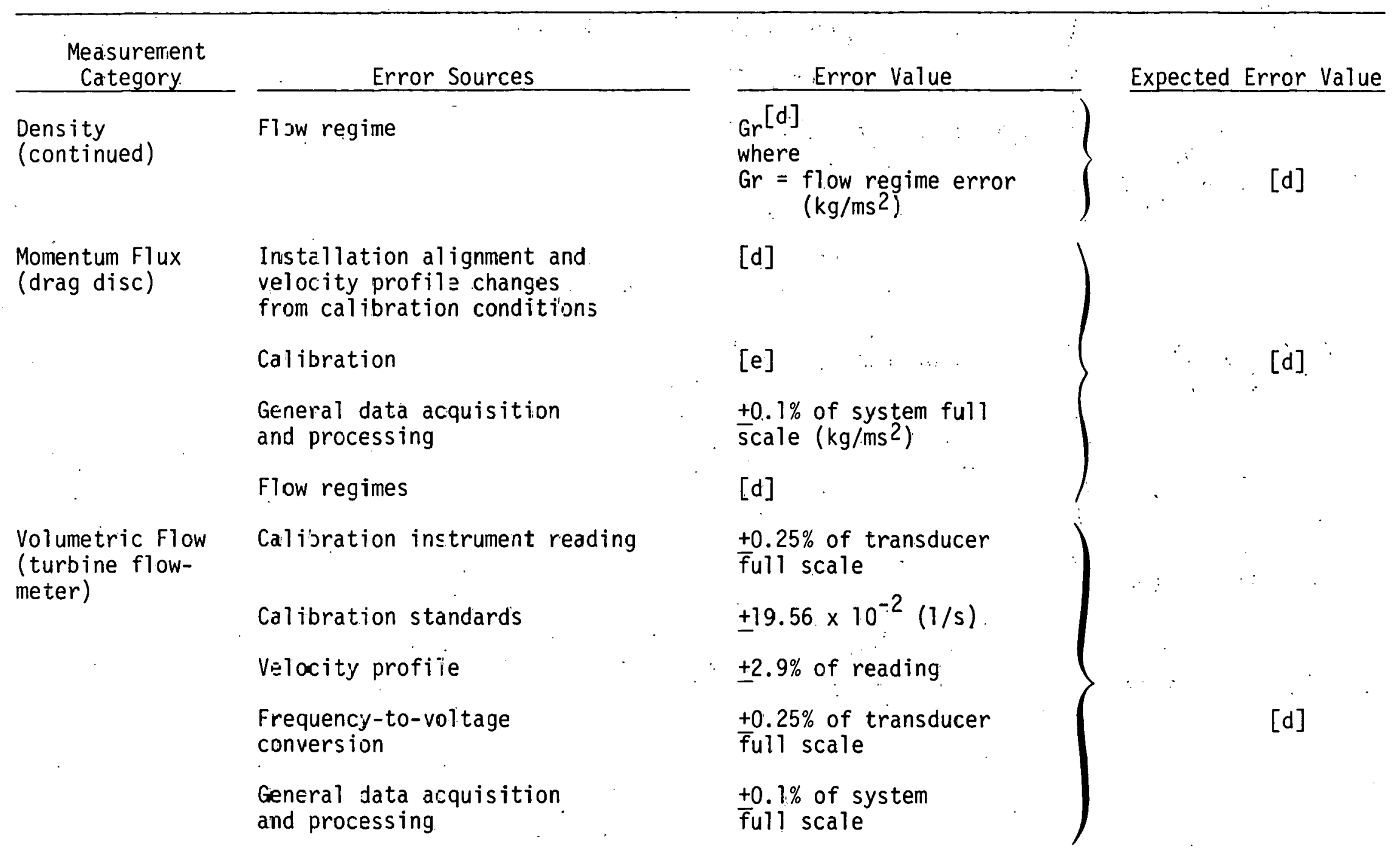




\section{TABLE B-II (continued)}

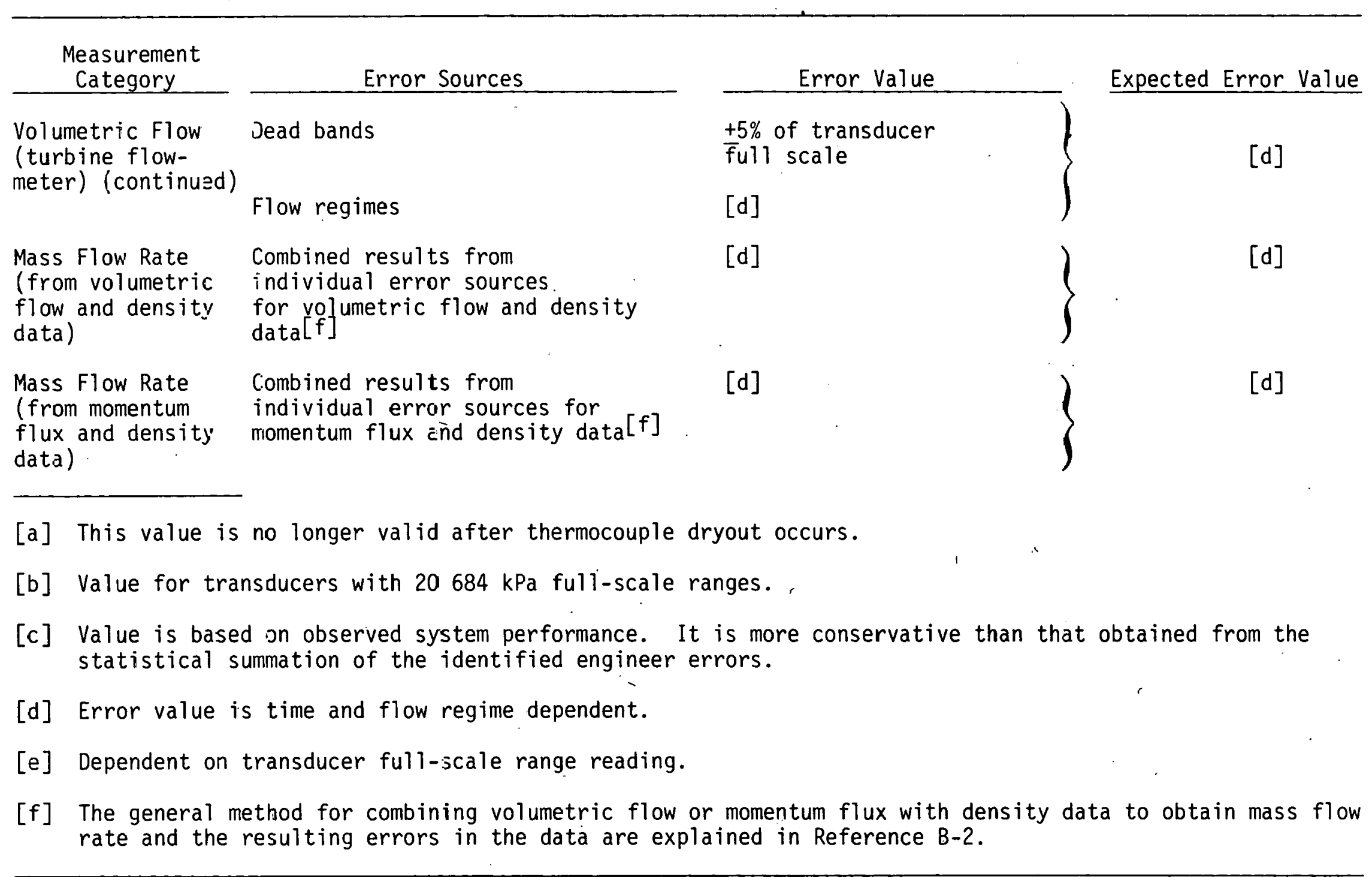


$\underline{\text { TABLE B-III }}$

TIME PERIODS WHEN FLOW REGIME ERRORS WERE APPLIED

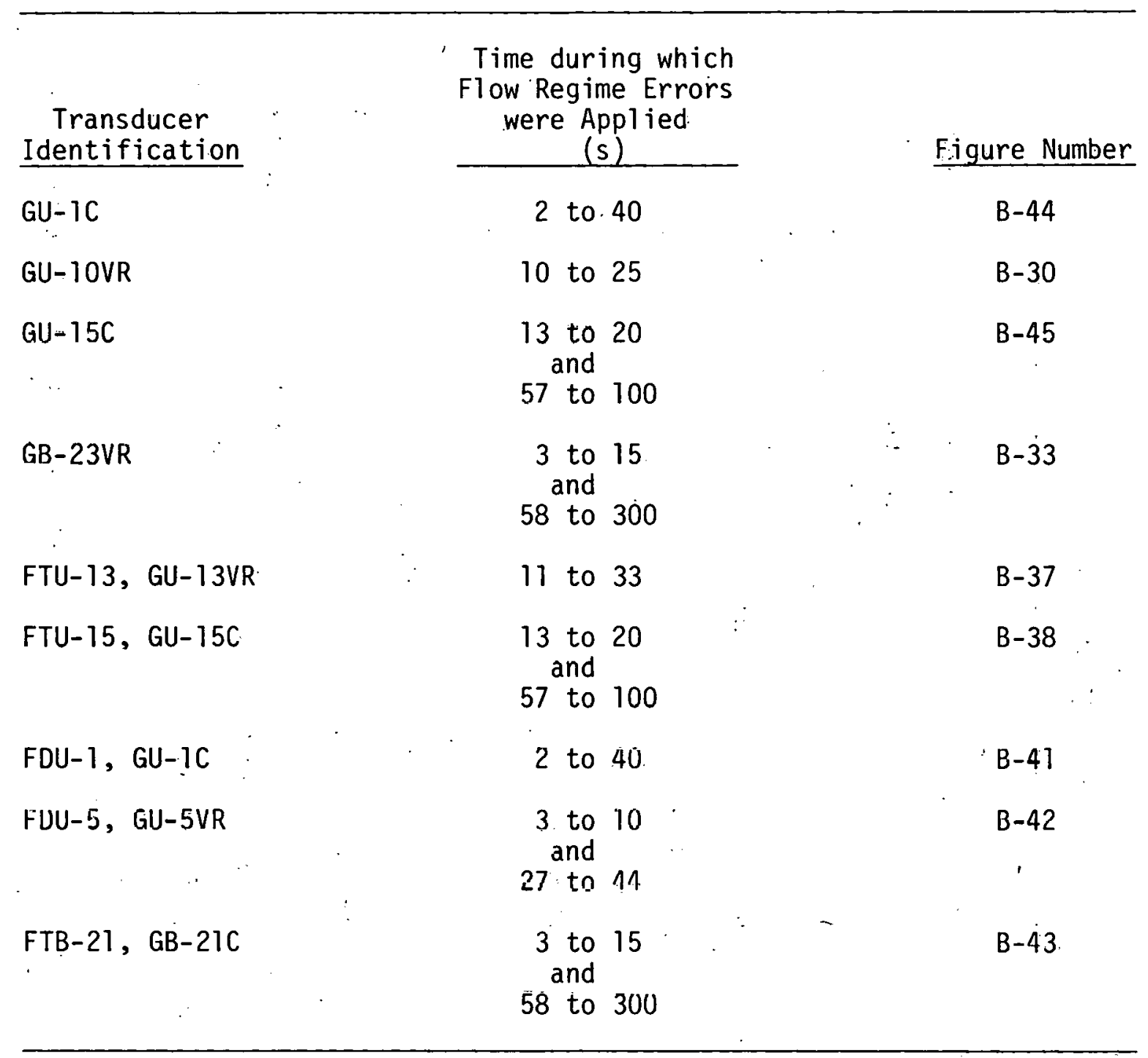

\section{REFERENCÉS}

B-1. G. E. P. Box and B. M. Jenkins, Time Series Analysis - Forecasting and Control, San Francisco: Holden-Day, 1970.

B-2. E. M. Feldman and S. A. Naff, Error Analysis for 1-1/2-Loop Semiscale System Isothermal Test Data, ANCR-1188 (May 1975). 


\section{DISTRIBUTION RECORD FOR TREE-NUREG 1121}

Internal Distribution

1 - Chicago Patent Group 9800 South Cass Avenue Argonne, Illino is 60439

2 - C.A. Benson Idaho Operations office-ERDA Idaho Falls, ID 83401

3 - R.J. Beers, ID

4 - P.E. Litteneker, ID

5 - R.E. Tiller, ID

6 - R.E. Wood, ID

7 - H.P. Pearson, Supervisor Technical Information

8-17 - INEL Technical Library

18-37 - Authors

3อ- 95 S Snerial Internal

\section{External Distribution}

96-97 - Saul Levine, Director Office of Nuclear Regulatory Research, NRC Washington, D.C. 20555

98-402 - Distribution under NRC-2, Water Reactor Safety Research Systems Engineering 